THOMAS BRÜSEMEISTER

Klaus-Dieter Eubel (Hg.)

\title{
Zur Modernisierung der Schule
}

Leitideen - Konzepte - Akteure

Ein Überblick 
Thomas Brüsemeister/Klaus-Dieter Eubel (Hg.)

Zur Modernisierung der Schule 
Thomas Brüsemeister, Dr., Diplom-Sozialwissenschaftler, geboren 1962, seit 1999 wissenschaftlicher Assistent im Lehrgebiet »Handeln und Strukturen « (Prof. Dr. Uwe Schimank) an der FernUniversität in Hagen.

Arbeitsschwerpunkte: Differenzierungstheorie, Inklusionsbedingungen im Bildungssystem, soziologische Gegenwartsdiagnosen, qualitative Methoden der Sozialforschung, Biographieforschung.

Klaus-Dieter Eubel, Dr., Erziehungswissenschaftler, geboren I943, seit 1976 wissenschaftlicher Mitarbeiter im Lehrgebiet »Theorie der Schule und des Unterrichts« des Instituts für Erziehungswissenschaft und Bildungsforschung der FernUniversität in Hagen.

Arbeitsschwerpunkte: Schulpädagogik, insbesondere Schultheorie und Schulgeschichte, vergleichende Erziehungswissenschaft. 
Thomas Brüsemeister/Klaus-Dieter Eubel (Hg.)

Zur Modernisierung der Schule

Leitideen - Konzepte - Akteure

Ein Überblick

[transcript] 
Die in diesem Band wiederveröffentlichten Beiträge wurden vom Verlag ungeprüft übernommen. Der Verlag bedankt sich bei den Autorinnen und Autoren sowie den Verlagen für die freundliche Genehmigung zum Wiederabdruck.

\section{Bibliografische Information der Deutschen Bibliothek}

Die Deutsche Bibliothek verzeichnet diese Publikation in der Deutschen Nationalbibliografie; detaillierte bibliografische Daten sind im Internet über http://dnb.ddb.de abrufbar.

(C) 2003 transcript Verlag, Bielefeld

Umschlaggestaltung: Kordula Röckenhaus, Bielefeld

Lektorat: Kai Reinhardt, Bielefeld

Satz: Thomas Brüsemeister, Klaus-Dieter Eubel

Druck: Majuskel Medienproduktion GmbH, Wetzlar ISBN 3-89942-I20-5 


\section{Inhalt}

Vorwort

Zum Aufbau des Buches

Einleitung

Facetten schulischer Modernisierung

\section{Theoretisch-methodische Zugänge}

\section{Soziologie}

Kommentar (Brüsemeister)

UWE SCHIMANK

Teilsysteminterdependenzen und Inklusionsverhältnisse.

Ein differenzierungstheoretisches Forschungsprogramm zur

System- und Sozialintegration der modernen Gesellschaft

\section{Pädagogik}

Kommentar (Eubel)

JÜRGEN OELKERS

Schulen in erweiterter Verantwortung -

Eine Positionsbestimmung aus erziehungswissenschaftlicher Sicht

JÜRGEN OELKERS

Wie lernt ein Bildungssystem?

\section{Zur Herkunft von schulischer Modernisierung}

Kommentar (Brüsemeister)

INGO RICHTER

Entscheidungsstrukturen für Bildungsfragen in offenen Gesellschaften 
HORST WEISHAUPT

Die Situation des Schulwesens im Kontext der veränderten

Wahrnehmung öffentlicher Aufgaben durch den Staat

PIERRE BOURDIEU

Die rechte und die linke Hand des Staates

Interview mit R. P. Droit und T. Ferenczi, erschienen in Le Monde

am 14. Januar 1992.

INGO RICHTER

Die Öffentliche Schule im Umbau des Sozialstaats

\section{Schulkultur}

Kommentar (Eubel)

HELMUT FEND

Schulkultur und Schulqualität

JÜRGEN OELKERS

Unterricht und Effizienz: Probleme der Schulentwicklung

\section{Markt}

Kommentar (Eubel)

WILLIAM LOWE BOYD

Die Politik der freien Schulwahl und marktorientierte Schulreform in Großbritannien und den Vereinigten Staaten

Wie erklären sich die Unterschiede?

\section{Schulautonomie}

Kommentar (Brüsemeister)

FRANK-OLAF RADTKE

Schulautonomie: Bildungspolitisches Ringen um Definitionsmacht

NORBERT MARITZEN

Schule zwischen Staat und Markt?

Für kritische Genauigkeit beim Reden über Schulautonomie eine Antwort auf Frank-Olaf Radtke 
Kommentar (Eubel)

HELMUT HEID

Chancengleichheit unter den Bedingungen sozialstruktureller Ungleichheit.

Zur gesellschaftlichen Funktion eines Legitimationsmusters

WULF HOPF

Chancengleichheit und Individualisierung.

Zur Revision eines bildungspolitischen Ziels

ANNEMARIE VON DER GROEBEN

Wo liegen die Wurzeln von Schulqualität?

Eine Antwort auf Hermann Lange

TIMSS- und PISA-Schock

Kommentar (Brüsemeister)

HERMANN LANGE

Qualitätssicherung in Schulen

THOMAS BETHGE

Zum Umgang mit den Ergebnissen von TIMSS

RUDOLF MESSNER

Das Bildungskonzept von PISA als Teil

einer globalen gesellschaftlichen Neuorientierung

\section{Was beinhaltet schulische Modernisierung?}

Einführungstexte

Kommentar (Eubel)

EWALD TERHART

Qualität und Qualitätssicherung im Schulsystem.

Hintergründe - Konzepte - Probleme

KONSTANTIN BÄHR

Die Rolle von Schulleistungstests für das Qualitätsmanagement

im Bildungswesen, in Schulen und Klassenzimmern 
Qualitätsarbeit als Schulentwicklung: Praxisfelder und Methoden

NORBERT MARITZEN

Schulprogramm und Rechenschaft - eine schwierige Beziehung

CHRISTOPH MAEDER

Brauchbare Artefakte. Statistiksoftware für das Pflegemanagement im Spital als das Produkt ethnographischer Arbeit

\section{Unterrichtsentwicklung}

Kommentar (Eubel)

JOHANNES BASTIAN

Pädagogische Schulentwicklung -

Von der Unterrichtsreform zur Entwicklung der Einzelschule

HEINZ KLIPPERT

Schule entwickeln - Unterricht neu gestalten

Plädoyer für ein konzentriertes Innovationsmanagement

\section{Beobachtung von Akteurkonstellationen}

Methodisches

Kommentar (Brüsemeister)

HELMUT FEND

Schulkultur als Zusammenspiel der Teilkulturen

von Lehrern, Schülern und Eltern - Schisma oder Partnerschaft? 
Kommentar (Brüsemeister)

JOCHEN WISSINGER

Rolle und Aufgaben der Schulleitung

bei der Qualitätssicherung und -entwicklung von Schulen

Lehrkräfte

Kommentar (Brüsemeister/Eubel)

Lehrkräfte und Innovation

FRITZ BOHNSACK

Widerstand von Lehrern gegen Innovationen in der Schule

THOMAS BRÜSEMEISTER

Zur Kopplung von Lehrkräften und Schulorganisation

Kommentar (Eubel)

ROLF-TORSTEN KRAMER, WERNER HELSPER

SchülerInnen zwischen Familie und Schule

- systematische Bestimmungen

HEIKE ACKERMANN

Eltern - Ratgeber für Schulqualität?

Über die Rolle der Eltern im Prozeß der Schulentwicklung

\section{Schüler}

Kommentar (Eubel)

THOMAS ZIEHE

Adieu 70er Jahre!

Jugendliche und Schule in der zweiten Modernisierung

WolfGang Melzer, Sabine AL-Diban

Vermittlung von Fachleistungs-, Sozial-

und Selbstkompetenzen als zentrale Bildungsaufgabe von Schule 


\section{Mögliche Effekte von schulischer Modernisierung}

Fallbeispiele

Kommentar (Eubel)

Sylvain Broccolichi, FrançoIse CEuVRard

Das Räderwerk

S. KARIN AMOS

Schulentwicklung und soziale Ungleichheit -

Was lässt sich am amerikanischen Beispiel beobachten?

KATRIN DÖRNER

Ethnische Minderheiten im niederländischen Schulwesen

THOMAS BRÜSEMEISTER

Lehrerbiographien in der Schulmodernisierung -

Modernisierungspfade - Steuerungsschwierigkeiten

\section{Anhang}




\section{Vorwort}

Dieses Buch geht aus der gemeinsamen Lehre und Forschung eines Pädagogen (Klaus-Dieter Eubel) und eines Soziologen (Thomas Brüsemeister) an der FernUniversität Hagen zum aktuellen Thema der schulischen Modernisierung hervor und versammelt Grundlagentexte aus beiden Disziplinen. Die überwiegend an anderen Orten veröffentlichten Beiträge der Autorinnen und Autoren wurden von uns auf ihre Kernaussagen hin gekürzt, um interessierte Leserinnen und Leser in die Lage zu versetzen, die gegenwärtig ablaufende Modernisierung von Schulen aus verschiedenen Perspektiven beleuchten zu können. Das Hauptaugenmerk liegt hierbei auf dem deutschen Schulsystem. Gegenüber anderen Aufsatzsammlungen geht der Anspruch dieses Buches weiter, insofern Beiträge nicht nur nebeneinander gestellt, sondern einleitend von den Herausgebern kommentiert werden. Die Auswahl der präsentierten Beiträge - fast 40 an der Zahl - ist bewusst weit angelegt, denn nicht zuletzt geht es uns in dem Buch darum, offene Forschungsfragen anzusprechen.

\section{Danksagungen}

Wir möchten an dieser Stelle dem Lehrerseminar in Kreuzlingen $(\mathrm{CH})$, in persona Erhard Eglin, danken, der mit uns zusammen im Juni 2001 ein Seminarkonzept zum gleichen Thema erprobte.

Autorinnen und Autoren sowie ihre Verlage haben den Mut gehabt, das Projekt in Ungewissheit seines Ausgangs außerordentlich zu unterstützen. Vielleicht ist auch diese Risikobereitschaft ein Zeichen von Modernisierung. Dem wohlwollenden Verhalten gebührt auf jeden Fall unser allergrößter Dank. Sie alle, sehr geehrte Kolleginnen und Kollegen, haben diesem Buch nicht nur Material, sondern Kontur gegeben - nicht zuletzt durch viele Hinweise auf weiterführende Literatur, die wir nach Möglichkeit aufgegriffen haben.

Ebenso gedankt sei dem Forschungspool zur Förderung des wissenschaftlichen Nachwuchses an der FernUniversität Hagen für eine großzügige Teilfinanzierung.

Der gezielte Zufall hat uns zu Karin Werner und der Mannschaft vom transcript Verlag geführt. Alle haben uns motiviert, das Projekt tatsächlich zu realisieren, und durch intensive Betreuung zu seinem Gelingen beigetragen. Ihnen, liebe Kolleginnen und insbesondere lieber Kai Reinhardt, als akribischer Lektor und Mitleser, verdanken wir viel, ohne dass wir dies hier gebührend zum Ausdruck bringen könnten.

Dank außerdem Hilke Ostendorf von der FernUniversität Hagen für das Scannen von Texten. Vor allem wäre durch die gewissenhafte redaktionelle Arbeit von Andrea Poppe das Buch nicht so geworden, wie es jetzt ist; Sie, liebe Frau Poppe, haben auch ohne einen Apple-Computer und trotz vieler 
unterschiedlicher Dateien penibel den Gesamttext dieses Buches erstellt Dank Ihnen!

Die Kollegen Michael Faust (Göttingen), Rainer Greshoff (Hagen), Frank Meier (Bielefeld) und Uwe Schimank (Hagen) haben uns durch umfassende Kommentierungen unseres Einleitungstextes sehr geholfen. Dafür möchten wir Ihnen an dieser Stelle ebenfalls herzlich danken.

\section{Zum Aufbau des Buches}

\section{Theoretisch-methodische Zugänge}

Als Auftakt zu den vier Kapiteln des Buches gehen wir in einem ersten Abschnitt auf die von uns gewählten theoretisch-methodischen Zugänge ein.

Um die schulische Modernisierung zu untersuchen, stützen wir uns auf einen soziologischen Ansatz, der zugleich differenzierungs- und akteurtheoretisch arbeitet (vgl. Schimank 2000). Obwohl dieser Ansatz nicht am Beispiel der Schule entwickelt wurde, lässt er sich besonders gut für die Beobachtung schulischer Modernisierung nutzen, da er auf die Integration des System- und des Akteurverständnisses zielt. Für unseren Anwendungsbereich scheint uns dieses Konzept auf Grund dieser Integrationsbemühungen vielversprechend.

Auch in der Pädagogik finden sich bereits dezidierte differenzierungsund akteurtheoretische Analysen. Jürgen Oelkers z.B. verwendet sie in seinen historisch orientierten Untersuchungen. Er beschreibt mit diesem Instrumentarium Widersprüche und eigensinnige Dynamiken und Potentiale des Schulsystems, die offensichtlich auch das aktuelle Geschehen der schulischen Modernisierung auszeichnen.

\section{Textblock I}

Nach den methodischen Beiträgen gehen wir im ersten Textblock auf Vordiskussionen der schulischen Modernisierung ein ( „I. Zur Herkunft schulischer Modernisierung"). Die hier versammelten Texte erörtern vor allem, welche semantischen Leitideen schulischer Modernisierung in der jüngeren Vergangenheit ausgemacht werden können. Die von den Autorinnen und Autoren diskutierten Leitideen stammen aus der Umwelt von Schule einerseits oder aus schulischen Kontexten andererseits. Die Texte aus diesem Themenblock verweisen auf beide Aspekte:

Modernisierung wird einerseits von exogenen Faktoren außerhalb des Bildungssystem mitbestimmt. Die externen Modernisierungsdiskurse zeichnen sich dabei durch eine stärkere Betonung von Management, Effizienz und Qualität aus. Andererseits diskutieren die Texte des ersten Themenblocks auch, inwiefern neue Leitbegriffe auch in pädagogischen Diskursen formuliert werden und so ebenfalls die gegenwärtige Modernisie- 
rung des Schulsystems mit vorbereiten. Konkreten Forschungen überantwortet bleibt die Frage - die von den hier versammelten Grundlagentexten nicht behandelt werden kann -, in welchem Verhältnis externe und interne Faktoren auf die schulische Modernisierung wirken. Hier soll mit den Texten ebenfalls nur ein Problemfeld markiert werden. ${ }^{1}$

\section{Textblöcke II und III}

Der zweite Beobachtungsfokus des Buches ist auf gegenwärtige Konturen der schulischen Modernisierung gerichtet (,II. Was beinhaltet schulische Modernisierung“, „III. Beobachtung von Akteurkonstellationen“). Im Abschnitt II geht es dabei um inhaltliche Konzepte von Schulmodernisierung (Organisations-, Personal- und Unterrichtsentwicklung; Qualitätsmanagements) und um Strategien der Modernisierung.

Es sind vor allem zwei Akteure, die Strategien der Governance vertreten, nämlich die Bildungsverwaltung auf der einen Seite sowie die Schulprofession auf der anderen Seite. In diesem Buch beschränken wir uns darauf, mögliche sachliche Inhalte der Modernisierung vorzustellen, wie sie entweder von Bildungsverwaltungen oder von der Profession formuliert werden, ohne dass diese beiden Akteure in ihren praktischen Handlungsdimensionen im Abschnitt III, in dem es um Akteurkonstellationen geht, nochmals angesprochen sind.

Mit Textblock III soll dann überlegt werden, welche Haltungen Akteure der Einzelschule zu Sachinhalten und Instrumenten der schulischen Modernisierung einnehmen. Interessen und Erwartungen der Akteure (Schulleitung, Lehrkräfte, Schüler, Eltern) motivieren solche Haltungen, führen dazu, dass Modernisierungsvorgänge unterstützt oder abgelehnt werden.

Abschnitt III konzentriert sich also auf Akteure ,innerhalb“ der Einzelschule, die das Schulgeschehen vor Ort, die Interaktionsebene des Schulsystems, beeinflussen. Wir gehen dabei davon aus, dass Akteure Leitideen und damit verbundene Programme - wie z.B. ein Qualitätsmanagement interpretieren und variieren. Grundsätzlich berücksichtigen wir in diesem Textblock einen zentralen Befund der pädagogischen und soziologischen Schulforschung, nämlich dass das Gelingen oder Misslingen einer Modernisierung von einem Konstellationsgefüge abhängt, wie man es in einer Einzelschule vorfindet. ${ }^{2}$ Mit den Texten, die auf einzelne Akteure verweisen, ist noch nicht konkret erklärt, wie eine Modernisierung in lokalen Kontexten abläuft, welche Akteure auftreten und welche Konstellationen sie ausbilden. Aber es gibt einen Beobachtungsrahmen dafür.

$1 \mathrm{Zu}$ einem Erklärungsversuch, wie Veränderungen in der Umwelt des Schulsystems sowie interne Sichtweisen der schulischen Profession zusammenhängen, vgl. Brüsemeister 2002b.

2 Für die Pädagogik halten dies etwa Fend (Auszüge hier im Lernbuch) sowie Posch/Altrichter 1996 fest, für die Soziologie vgl. exemplarisch Schimank $1995 \mathrm{zu}$ Hochschulen. 


\section{Textblock IV}

Schließlich gehen wir in einem weiteren Textblock möglichen Folgen von Schulmodernisierung nach („IV. Mögliche Effekte schulischer Modernisierung"). Da die konkreten Folgen einer Modernisierung u.a. von spezifischen Randbedingungen, sozialen Konfigurationen, Modernisierungspfaden und Akteurkonstellationen in lokalen Settings abhängen und von daher empirische Forschungen notwendig sind, um Genaueres anzugeben - wobei es nach unserem Kenntnisstand solche Forschungen noch nicht in ausreichendem Maße gibt -, kann und soll hier nur grundsätzlich auf die Problematik von Modernisierungsfolgen aufmerksam gemacht werden. $\mathrm{Zu}$ den positiven Folgen könnte etwa die erhöhte Binnenkommunikation zwischen Lehrkräften gehören. Im Rahmen möglicher negativer Folgen werden soziale Ungleichheiten erörtert. Ein wesentlicher Schwerpunkt liegt dabei auf der Frage, ob mit dem Umschwenken der Leitorientierung (von ,Chancengleichheit" hin zu „Management“, „Effizienz“ und „Qualität“) auch die Sensibilisierung des Schulsystems für soziale Ungleichheiten abnimmt.

\section{Editorisches}

Die Texte der Autorinnen und Autoren werden wie folgt wiedergegeben: Auslassungen werden mit eckigen Klammern [...] markiert. Wenn durch unsere Auslassungen die Lesbarkeit einzelner Beiträge beeinträchtigt sein sollte, geht dies zu unseren Lasten. Bibliographische Angaben wurden nicht verändert, außer bei der Zitation innerhalb der Texte. Hier haben wir einheitlich auf die amerikanische Zitierweise umgestellt. Hervorhebungen im Text wurden als Kursivsetzungen übernommen, die im Originaltext jeweils verwendete Rechtschreibung ebenfalls. Ort und Zeitpunkt der Erstveröffentlichung der Beiträge werden im Anhang des Buches (Quellennachweis) aufgeführt. Weiterführende Literatur, auf die wir in unseren Kommentierungen hinweisen, ist ebenfalls am Ende des Buches nachgewiesen. 


\section{Einleitung:}

\section{Facetten schulischer Modernisierung}

Die Schulsysteme werden derzeit modernisiert. In der Schule und in dem ihr zugehörigen Reflexions-System, der Erziehungswissenschaft, entsteht nach einer langen Phase der zwar durchaus kontroversen, aber doch auch kontinuierlichen Entwicklung und Expansion des Bildungswesens eine neue, ,unübersichtliche' Lage, in der sich vor allem die professionellen Akteure (Lehrer, Administratoren, Wissenschaftler) wiederfinden. Mit gängigen pädagogischen Theorien scheint sich diese Situation nicht befriedigend analysieren zu lassen. Zwar gibt es viele Ansätze, das angedeutete Dilemma zu bearbeiten, wie auch die Texte von Pädagogen im vorliegenden Band bezeugen. Dennoch erscheint es sinnvoll, bei einem systematisierenden Überblick über die vielfältigen Aspekte schulischer Modernisierung auch auf Importe aus anderen Wissenschaften zu setzen, da diese am ehesten geeignet erscheinen, die angesichts der langjährigen Entwicklungslinien verständliche ,Betriebsblindheit` im Teilsystem Bildung zu überwinden. In diesem einleitenden Kapitel wird insbesondere der ,fremde Blick' der Soziologie für die Diskussion fruchtbar gemacht und deren modernisierungstheoretische Impulse vorgestellt.

Ohne dass an dieser Stelle schon der Begriff „schulische Modernisierung" geklärt wäre, lassen sich für gegenwärtige Schulsysteme schlaglichtartig eine Reihe von Veränderungen angeben. „Zum ersten Mal seit Beginn des 19. Jahrhunderts", so exemplarisch Jürgen Oelkers (2000a: 2), seien Schulen „einem technischen Innovationsschub ausgesetzt“, der sie „nachhaltig verändern wird" - Bildungspolitik begnügt sich heute kaum mehr damit, Schulen mit Ressourcen auszustatten. Statt einer solchen Orientierung am Input werden die Schulen vielmehr auch hinsichtlich ihrer Leistungen auf den verschiedenen Ebenen ihres Outputs beobachtet. Obwohl mit PISA nicht direkt Leistungen von Schulen, sondern Basiskompetenzen von Schülerinnen und Schülern gemessen wurden (vgl. Deutsches PISAKonsortium 2001), macht die Öffentlichkeit Schulen für das schlechte Abschneiden Deutschlands bei diesem internationalen Leistungsvergleich verantwortlich. Nicht zuletzt in Reaktion darauf werden unter dem Stichwort der Governance neue Steuerungssysteme diskutiert. ${ }^{3}$ Es dominiert das

3 Governance-Strukturen lassen sich als „Regelungsstrukturen“ verstehen (Braun 2001: 247). Sie resultieren wesentlich aus dem Zusammenspiel mehrerer Akteure. In den Regelungsstrukturen sind „Verfügungsrechte zum Treffen von Entscheidungen" (ebd., 248) je spezifisch organisiert, je nach dem, ob ein mehr bürokratischoligarchisches Modell, mehr ein Staatsmodell oder mehr ein Markt- oder Konkurrenzmodell vorliegt (um nur einige Beispiele von Governance-Strukturen zu nennen). Vgl. auch König (2001). 
„Neue Steuerungsmodell“ und das „New Public Management“(NPM) (vgl. Schedler/Proeller 2000). Im Kern geht es hierbei darum, wie staatliche Dienstleistungen effizienter gemacht werden können.

Auch wenn konkretere Maßnahmen für das deutsche Schulsystem erst noch realisiert werden müssen, ist das zukünftige Szenario klar erkennbar: Der Staat wird sich teilweise aus den Organisationsaufgaben der Einzelschule zurückziehen. Es wird prinzipiell für zumutbar gehalten, dass die einzelne Schule über die Verwendung von Ressourcen entscheidet, Daten erhebt, Personal einstellt und Leistungen beurteilt. Der Staat engagiert sich dadurch, dass er für die Schulen allgemeine Rahmenziele festlegt, deren Umsetzung regelmäßig unter anderem im Rahmen nationaler Bildungsberichterstattung evaluiert wird. Wenn einzelne Einrichtungen in operativer Hinsicht mehr hervortreten sollen, wird dies auch technisch gesehen möglich, da den Schulen Quality Managements zur Verfügung stehen. Diese technischen Hilfsinstrumente erlauben den Akteuren der Einzelschule, operative Entscheidungen zu formulieren, umzusetzen und deren Wirkungen zu beobachten.

Die Schlaglichter verweisen darauf: Es gibt schulische Modernisierungen, die vor allem hinsichtlich der Änderung der Governance in eine relativ einheitliche Richtung gehen. Darauf werden wir weiter unten zurückkommen. Zunächst sind jedoch Theorien der schulischen Modernisierung anzusprechen.

In den Sozialwissenschaften wurde die Diskussion um Modernisierung nach dem Zweiten Weltkrieg vom Strukturfunktionalisten Talcott Parsons (1972) dominiert, dessen Focus auf dem Wandel und der Gestaltbarkeit „großer" Sozialsysteme lag. Nach dem in den 1970er Jahren einsetzenden Niedergang dieses Modernisierungsansatzes ist heute keine neue bereichsübergreifende Theorie der Modernisierung in Sicht. ${ }^{4}$ In der Pädagogik wur-

4 Vgl. exemplarisch die zusammenfassende Kritik von Geißler (1996: 358-59) am Strukturfunktionalismus. Zum gegenwärtigen Stand von Modernisierungstheorien, auf den hier nicht weiter eingegangen werden kann, vgl. aber Hill (2001). Zapf (2001: 14) resümiert die Abfolge von Modernisierungstheorien nach dem Zweiten Weltkrieg als permanente Enttäuschung: „Die frühe Modernisierungstheorie rekonstruierte die westliche Entwicklung und projizierte sie im liberalen Glauben an den garantierten Fortschritt und die Universalisierung amerikanischer Werte auf die ganze Welt, insbesondere die Entwicklungsländer. Dagegen formierte sich eine radikale marxistische Kapitalismuskritik, die insbesondere in der Dependenciatheorie und in der [...] World System Theory den bevorstehenden Übergang des Spätkapitalismus in den Sozialismus prophezeite und die die Unterentwicklung der Peripherieländer aus ihrer Abhängigkeit von den kapitalistischen Zentren erklärte. Als dieser Übergang nicht eintrat und als einige Entwicklungsländer überraschende Fortschritte machten, hatte sich diese Kontroverse erschöpft. Diverse Theorien der Postmoderne versuchten, sowohl die liberale Modernisierungstheorie als auch die marxistischen Alternativen zu dekonstruieren, als überholte ,große Erzählungen' zu ironisieren und durch multiple kulturalistische und konstruktivistische Kontingenztheorien zu ersetzen. Mit dem Zusammenbruch des Kommunismus und mit dem Er- 
de die Modernisierungsthematik schwerpunktmäßig vor allem auf (Unterrichts-)Inhalte bezogen (vgl. von Below 2002: 22). In dieser wissenschaftlichen ,Arbeitsteilung' geht offensichtlich vieles von dem verloren, was interessierte Zeitgenossen an Veränderungen in Schulen bemerken. Mit anderen Worten: Es lässt sich derzeit weder in der Pädagogik noch in den Sozialwissenschaften eine hinreichende Theorie schulischer Modernisierung ausmachen. ${ }^{5}$

Deshalb verbleibt für das vorliegende Buch nur eine pragmatische Vorgehensweise. Wir stellen nachfolgend Facetten der schulischen Modernisierung vor. Auch wenn diese nicht trennscharf und unterschiedlich weit theoretisch ausgearbeitet sind, bieten sie doch Hinweise auf eine noch zu schreibende Theorie der schulischen Modernisierung. Obwohl eine solche Theorie hier nicht entfaltet werden kann, wissen Pädagogen und Soziologen auch nicht ,Nichts' über schulische Modernisierung, wie die für das vorliegende Buch ausgewählten Beiträge zeigen. Im Vorgriff lässt sich resümieren, dass die neue Governance von Schulen als dominierende Facette der gegenwärtigen schulischen Modernisierung gesehen werden kann. Zur Hintergrundinformation fassen wir im Folgenden diesen Punkt und anschließend weitere, allgemeinere Facetten von schulischer Modernisierung zusammen.

\section{Neue Governance}

Der wichtigste Modernisierungsschwerpunkt, der in den Beiträgen der Autorinnen und Autoren des vorliegenden Buches angesprochen wird, beinhaltet eine neue Governance von Schule. Diese ist in einzelnen Ländern unterschiedlich weit entwickelt, lässt sich aber nachfolgend idealtypisch zusammenstellen. Dabei unterscheiden wir (mit Schimank 2002a: 3) drei Ebenen: die Makro-Ebene des schulischen Gesamtsystems, die MesoEbene von Einzelschulen sowie die Mikro-Ebene des Rollenhandelns von Lehrkräften sowie anderer Akteure der Einzelschule ${ }^{6}$ :

folg mehrerer asiatischer Länder richtete sich dann schließlich die Aufmerksamkeit wieder auf die Voraussetzungen und Leistungen von Demokratie und Marktwirtschaft."

5 Ähnliches stellen auch Baumgart/Lange (1999: 16-21) für eine Theorie der Schule fest. Wie wir selbst empfehlen die beiden Autoren daraufhin ein pragmatisches Vorgehen.

6 Im Schulsystem wirken eine Vielzahl von Akteuren, auf die hier nicht umfassend eingegangen werden kann. In jüngster Zeit wird das Schulsystem z.B. von „supranationalen" Akteuren wie der OECD beeinflusst, die den internationalen Schülerleistungsvergleich PISA initiierte, oder von der Europäischen Union, die durch die ,Erklärung von Bologna' auf eine Homogenisierung der verschiedenen nationalen Lehrerausbildungen drängt. Diese supranationalen Akteure bleiben im vorliegenden Buch weitgehend unberücksichtigt, weil ihre Untersuchung den Rahmen gesprengt hätte. Es fehlen sowohl Theorien zu solchen Akteuren, als auch theoretische Ver- 


\section{a) Makro-Ebene des schulischen Gesamtsystems}

Auf dieser Ebene findet sich eine veränderte Beziehung des Schulsystems zum Staat, d.h. eine vom Staat induzierte Diskussion über neue Governance-Strukturen, die mehr Elemente des Managements, des Wettbewerbs und der Eigenverantwortung für Schulsysteme beinhalten - der Staat zieht sich zurück und engagiert sich gleichzeitig mehr im Sinne strategischer Zielsetzungen. Der allgemeinere Kontext hierfür ist das neue Steuerungsmodell nach dem New Public Management (NPM), welches sich europaweit als das derzeit dominierende Muster der neuen Governance darstellt.7

\section{b) Meso-Ebene intraorganisationaler Entscheidungsprozesse der einzelnen Schule}

Auf dieser Ebene beinhaltet das neue Governance-Modell größere Entscheidungsbefugnisse der Einzelschule. Die einzelne Schule wird zum verlängerten Arm des Staates, sie soll staatliche Ziele in eigener operativer Autonomie durchsetzen. ${ }^{8}$ Eine wesentliche Funktion kommt dabei der Schulleitung zu, die in ihren Managementbefugnissen aufgewertet wird. Insgesamt soll die Einzelschule operative Fähigkeiten bei Personal-, Organisations- und Unterrichtsentscheidungen entfalten. Im Rahmen eines ,pädagogischen Qualitätsmanagements“ stehen der Schule zudem neue Methoden zur Verfügung, die Wirkung von Entscheidungen zu messen. Darüber hinaus werden Möglichkeiten der externen Evaluierung genutzt. Da-

knüpfungen bzw. Erörterungen von Strukturdynamiken, die sich zwischen den global und den lokal agierenden Akteuren ergeben. Vgl. aber zur OECD Messner (in diesem Buch) und Gruber (2002). Zu Wandlungsprozessen des Bildungssystems in der Globalisierung vgl. Amos u.a. (2002). Zum Einfluss wissenschaftlicher Beratungen auf Schulmodernisierungen vgl. Tillmann/Vollstädt (2001); zur Bedeutung politischer Berater für das Bildungssystem vgl. Weegen u.a. (2002); zur ,educational policy“ politischer Parteien in Deutschland vgl. Keiner u.a. (2000). Zu aus der Wirtschaft stammenden „Quality Movements“, die öffentliche Einrichtungen beeinflussen, vgl. Kaboolian (2000). Ebenfalls ausgeblendet bleiben Gewerkschaften (vgl. aber exemplarisch zu Aktivitäten der GEW Böttcher u.a. (1997) und Lehrerverbände. Die wichtigsten Verbände sind Deutscher Philologenverband (vorwiegend Gymnasiallehrer): http://www.dphv.de; Verband Bildung und Erziehung (Real-, Haupt- und Grundschullehrer): http://www.vbe.de; Deutscher Lehrerverband: http://www.lehrerverband.de.

7 In der Pädagogik und in der Bildungssoziologie wird der Umbau der Beziehung ,Staat-Schule' überwiegend so gesehen, dass sich der Staat unter Kostengesichtspunkten aus Teilen seines Engagements für Schulen zurückzieht (vgl. Lohmann/Rilling 2002) und sich „Quasi-Märkte“ als neue Steuerungsregimes verbreiteten (vgl. Weiß 2002). Dagegen lässt sich mit Schimank betonen, dass die entscheidende Stoßrichtung des NPM darin besteht, ,dass der Staat sich einerseits aus der Regulierung zurückzieht und andererseits stärker im Sinne von Zielvorgaben steuern soll“" (2002a: 4). An diesem Doppel geht vorbei, wer nur von einem Rückzug des Staates (auf Basis von Sparzwängen) spricht.

8 Dies ersetzt die bislang nur lose Kopplung lokaler Schulorganisationen an den Staat (vgl. Terhart 1986). 
mit wird es möglich, die auf verschiedenen Ebenen (von Schulleitung, Lehrkräften und Schülern) erbrachten Leistungen aufeinander zu beziehen. Es wird zunehmend auf den Output einzelner Systemebenen geachtet.

\section{c) Mikro-Ebene des Rollenhandelns einzelner Lehrkräfte und anderer Akteure der Einzelschule}

Auf der Mikro-Ebene des Rollenhandelns einzelner Lehrer werden neue Konzepte der Unterrichtsorganisation formuliert. Zudem verändern sich die Aushandlungsprozesse zwischen Lehrkräften auf der einen sowie zwischen Schulleitungen, Schülern und Eltern auf der anderen Seite. Diese verändern das professionelle Selbstverständnis des Lehrers. Dazu trägt auch bei, dass die Lehrerarbeit mit neuen Organisationsprinzipien im Rahmen von Qualitätsverfahren konfrontiert wird, die dazu führen, dass die Lehrkraft die Frequenz der Beobachtung von Schülern erhöht sowie die Zusammenarbeit mit Kollegen und Eltern intensiviert. Im Rahmen von Qualitätsmethoden kommt es zur strukturellen Aufwertung des Kollegiums, weg von einer „weichen“ Schulkultur, hin zu einer teambasierten kollektiven Entscheidungsinstanz einer als Qualitäts-Organisation erneuerten Schule. Die stärkere gemeinsame Beobachtung von Systemoutputs steht dabei mit der bisherigen Alleinzuständigkeit der einzelnen professionellen Lehrkraft in Konflikt - das Selbstverständnis der Profession ist herausgefordert.

Insgesamt fallen bei der neuen Governance erstens auf der Makro-Ebene des gesamten interorganisatorischen Schulsystems neue Managementmethoden auf, zweitens auf der Meso-Ebene der Einzelschule Techniken und Methoden, die Einzelschule als Organisation, als Instanz operativer Entscheidungen, stark zu machen. Und dies ist drittens gegen die bisherige pädagogische Alleinzuständigkeit der professionellen Lehrkraft gerichtet. Die neue Governance zeichnet sich insgesamt dadurch aus, dass die Makro-, die Meso- und die Mikro-Ebene des Schulsystems einheitlich reguliert und verstärkt integriert werden sollen.

\section{Struktur des Schulsystems}

Vergleicht man die oben unter a) genannte Makro-Ebene und die unter c) angeführte Mikro-Ebene, dann fällt auf, dass für das Schulsystem zwei sehr unterschiedliche institutionelle Kontexte mit unterschiedlichen sozialen Strukturdynamiken vorliegen. ${ }^{9}$

9 Soziale Strukturdynamiken ergeben sich aus dem handelnden Zusammenwirken von Akteuren. Hierbei lassen sich idealtypisch mit Schimank (2000) drei Arten von Konstellationsgefügen unterscheiden: Beobachtung, Beeinflussung und Verhandlung. Über solche formalen Kennzeichnungen von Strukturen hinaus lassen sich auch die inneren Wirkmechanismen des handelnden Zusammenwirkens in Model- 
Das angedeutete Governance-Modell wird auf der Makro-Ebene des Schulsystems zwischen einer überschaubaren Zahl von Akteuren wirksam. ${ }^{10}$ Es gibt eine geschlossene soziale Strukturdynamik, weil auf dieser Ebene des Schulsystems nur ganz bestimmte Akteure an der Governance mitwirken. ${ }^{11} \mathrm{Zu}$ diesen gehören der Staat selbst, die Bildungsverwaltung und die Profession der Lehrkräfte. Es kommunizieren hierbei überwiegend Organisationen miteinander; es bestehen vor allem von Seiten des Staates und der Bildungsverwaltungen dezidierte Steuerungsabsichten; und es gibt einen Zwang zu Verhandlungen, da schulpolitische Entscheidungen letztlich landesweit umgesetzt werden müssen - es bleibt oft nicht bei Beeinflussungsversuchen oder bloßen wechselseitigen Beobachtungen der Akteure.

Auf der Mikro-Ebene sieht das Schulsystem hingegen ganz anders aus: statt der Organisationen gibt es eine Vielzahl individueller Akteure. Einzelne Lehrer und nicht Organisationen kommunizieren mit vielen anderen Akteuren (Kollegen, Schülern, Schulleitung, Eltern, Öffentlichkeit) über angemessene Erziehungshandlungen. Diese Interaktionen führen unter dem Einfluss von je individuellen Identitätsansprüchen, Rollenfähigkeiten und Nutzenkalkülen zu höchst unterschiedlichen lokalen Konstellationsgefügen. Man kann für diese Ebene auch davon sprechen, dass das Schulsystem beständig einem sozialen Wandel unterworfen ist. In den Generationen der an Schule Beteiligten ändern sich sukzessive Wertvorstellungen, Erwartungen und Ansprüche (vgl. grundsätzlich Schimank 1998: 71-76), und dies beeinflusst auch die Vorstellungen von ,Erziehung. ${ }^{12}$

Neben diesen Elementen eines schwerpunktmäßig langfristigen, ungesteuerten sozialen Wandels und einer Vielfalt von Interaktionen ist das Schulsystem also gleichzeitig auf der Ebene der Governance aktuellen bildungspolitischen Steuerungsbemühungen unterworfen. Und damit ist das Schulsystem insgesamt ,von oben“ her eng durch Governance-Muster und

len mittlerer Reichweite festhalten. Diese Modelle sind zum Beispiel: Pattsituationen zwischen annähernd gleich starken Akteuren (wie man sie für die Kultusministerkonferenz annehmen kann); das „Prisoners dilemma“ (für das Hochschulsystem: Schimank 1995: 278); „Principal-agent“-Konstellationen (Schimank 2000: 318320), die darauf hinauslaufen, dass Vereinbarungen in Arbeitsorganisationen unterlaufen werden; der Matthäus-Effekt (,Wer hat, dem wird noch mehr gegeben“; Merton 1968).

10 Auch wenn sich von Zeit zu Zeit gravierende Änderungen durch das Auftreten eines neuen Akteurs wie die OECD einstellen.

11 So sind z.B. die Muster des handelnden Zusammenwirkens von institutionellen Gegebenheiten, von den role sets der pädagogischen Profession beeinflusst (so auch für Hochschulen, vgl. Schimank 2002b: 164).

12 Vgl. zum Wandel von Lehrer- und Schülergenerationen Ziehe (in diesem Band). Änderungen ergeben sich für den Nationalstaat z.B. dadurch, dass sich Migrationsströme und Kohortenzusammensetzungen verändern sowie neue Anspruchsgruppen auftauchen. Vgl. exemplarisch Lowe (1997) für die Entwicklung sozialer Gruppen im englischen Bildungssystem zwischen 1964 und 1990. 
geschlossene Strukturdynamiken gerahmt und gleichzeitig ,,von unten“ her, den Interaktionen, durch offene soziale Strukturdynamiken beeinflusst.

Diese Struktur macht es schwierig, wenn nicht unmöglich, eine einzige Theorie der schulischen Modernisierung zu entwickeln. Denn diese müsste die Integration völlig unterschiedlicher sozialer Strukturdynamiken nicht nur jeweils auf der Makro-, Meso- und Mikro-Ebene begrifflich durchdringen, sondern auch noch miteinander verbinden und zudem noch mit prognostizierbaren Ergebnissen ausstatten können.

\section{Grenzen einer Theorie der Modernisierung - soziale Mechanismen mittlerer Reichweite}

Es ist kein Zufall, dass Raymond Boudon als einer der wichtigsten Theoretiker, der sich mit sozialen Strukturdynamiken des handelnden Zusammenwirkens beschäftigt und dabei auch das Bildungssystem vor Augen hat, 25 Jahre Theorien zur Modernisierung und zu sozialem Wandel so resümiert: „No theory“ (Boudon 1983) - es gibt keine Theorie.

Als Ersatz für eine „große“ Theorie der Modernisierung und des sozialen Wandels sind in den Sozialwissenschaften theoretische Konzepte mittlerer Reichweite entwickelt worden (Merton 1967), mit denen auch die hier thematisierte aktuelle Modernisierung von Schulsystemen beobachtet werden kann. Anschließend an die von Boudon zum Ausdruck gebrachte Unmöglichkeit einer umfassenden Theorie der Modernisierung zielen die nachfolgenden Erörterungen im Prinzip darauf, für nationale Bildungssysteme fallspezifische Analysen mittlerer Reichweite immerhin vorzudenken, wenn schon nicht selbst durchzuführen.

\section{Vergessen von Reformen}

In der Gesellschaft geraten frühere Modernisierungen oftmals in Vergessenheit, so Niklas Luhmann (2002: 166-167; 179, Anm. 27). Bildungssysteme sind immer wieder mit einem Impuls zur Veränderung konfrontiert, ohne dass die Geschichte vergangener Reformen in einem Systemgedächtnis bewahrt würde. Vielmehr scheint mit einer neuen Reform gleichsam immer wieder bei Null begonnen zu werden. Reformen wollen in der Regel ein aktuelles Bestandsproblem mit Hilfe einer ganz anderen Lösungsvariante überspringen, die eben deshalb auch radikale Wirkungen versprechen mag, weil zurückliegende Reformen und ihr Scheitern nicht in den Kanon verfügbarer Alternativen einbezogen werden. So beginnen Reformen fast nie mit einer Evaluation dessen, was es an Reformen in der Vergangenheit bereits gab, und geben sich als neu und alternativlos aus. Deshalb ist es möglich, dass vergangene Reformideen bisweilen im neuen Gewand wieder auftauchen. 
Parallel zu Geschichten über die Wiederkehr von Reformen ließen sich Geschichten über das „ewige Scheitern“ von Reformen formulieren. Grund für dieses Scheitern ist in akteurtheoretischer Sicht unter anderem, dass in einer Modernisierung nicht nur Modernisierer auftreten, sondern auch Modernisierungsgegner. Zudem können Modernisierungsbefürworter in wesentlichen Punkten irren. Würden Reformen mehr Erfahrungen berücksichtigen, die frühere Auseinandersetzungen zwischen Befürwortern und Gegnern festhalten, würden Reformen vermutlich weniger transintentionale Folgen haben, d.h. Effekte, die über die Intentionen der Beteiligten hinausgehen. ${ }^{13}$ Die widersprüchliche Realität von Modernisierungen, eine $\mathrm{Zu}-$ kunft gestalten zu wollen und doch immer wieder unerwartete Konsequenzen zu produzieren, zwingt Modernisierer eigentlich dazu, von vornherein auf mögliche Folgen zu achten, die sich aus akteurtheoretischer Sicht unter anderem aus dem Verhalten der Gegner oder der Zögerlichen ergibt - mit dem Ziel, die Modernisierung gegenüber verschiedenen Akteuren flexibel zu machen. Nicht nur Modernisierer, auch Modernisierungstheorien lassen sich dahingehend befragen, inwieweit sie „,worst cases“, unerwünschte Nebenfolgen und mögliches Scheitern a priori mit überlegen. ${ }^{14}$

Würden in Schulen Qualitätsmaßnahmen greifen, die beinhalten, dass sich die Akteure der Schule regelmäßig untereinander beobachten, Daten erheben, auswerten und dokumentieren (vgl. Kempfert/Rolff in diesem Band), würde es schwieriger sein, Reformen zu vergessen. In der ,radikalen' Outputbeobachtung, die - neben dem Management der Ergebnisse den Kern der Qualitätsmethoden ausmacht, würden sich gewollte und ungewollte Wirkungen eingeführter Reformeffekte sofort an mehreren Stellen zeigen und wiederum als Daten festgehalten. Frühere Reformbegriffe postulierten dagegen Ziele, die mitunter schwierig operationalisierbar waren.

So konnte und musste bei Anzeichen des Scheiterns ein ,ideologisches“ Reformprogramm komplett gegen ein anderes ausgetauscht werden. In einer qualitätsorientierten - und das heißt: datenbasierten - Schule sind dagegen ideologische Programme reduziert zugunsten einer Vielzahl technischer, operativer Angaben, wie in der Schule beobachtet und Daten festgehalten werden sollen. Solche Techniken der Selbstbeobachtung stellen natürlich selbst wieder ein ideologisches Programm dar. Aber sie bieten den Akteuren der Schule eindeutig operative Hilfen an, mit denen „kleinschrittig“ sowie permanent Wirkungen von Leistungen auf verschiedenen Ebenen indiziert werden können. Würden diese Hilfen genutzt, könnte die Schule ebenso kleinschrittig entscheiden, welche einzelnen Elemente schulischen Prozessgeschehens vergessen und welche der Bearbeitung wieder zugeführt werden sollen. Es müsste nicht mehr zum Vergessen

13 Vgl. zu dem von Uwe Schimank stammenden Begriff Transintentionalität: Schimank in diesem Band; grundsätzlich Greshoff u.a. (2002); bezogen auf das Bildungssystem: Brüsemeister (2002a).

14 Im letzten Kapitel dieses Buches wird ein Teil der Folgeproblematik von Modernisierungen angesprochen. 
großer Reformideen kommen, wie es Luhmann (ebd.) für die bisherige Geschichte des Bildungssystems festgestellt hat.

\section{Wirksamkeit von Leitideen im Rahmen von Beobachtung, Beeinflussung, Verhandlung}

Ein zentrales Begriffspaar für das Verständnis von schulischer Modernisierung bezieht sich auf Akteure und soziale Systeme als Träger der Modernisierung. Den Systembegriff benötigt man unter anderem für die Beobachtung, dass in der Gesellschaft z.B. bestimmte Leitbegriffe - wie derzeit Management und Effizienz - in mehreren gesellschaftlichen Teilsystemen gleichzeitig bedeutsam werden, wobei man kaum davon ausgehen kann, dass diese von wenigen Akteuren gesteuert seien. Vielmehr dient als Ansatzpunkt die differenzierungstheoretische Überlegung, Gesellschaft sei in Teilsysteme funktional differenziert. ${ }^{15}$ Würde man nur systemtheoretisch denken, dann würde Modernisierung evolutionär vorkommen, nach Maßgabe der je eigenen Autopoiesis eines Teilsystems - Modernisierung kann dann in der Gesellschaft auch nicht zentral gesteuert werden. Damit verweisen Systemtheoretiker auf die Selbstläufigkeit des sozialen Wandels bzw. auf Grenzen ,gezielter' Modernisierung (vgl. Stichweh 1994).

Auch Akteurtheoretiker stützen sich auf differenzierungstheoretische Überlegungen und versuchen zu zeigen, wie Codes und Programme der Teilsysteme die Interessen von Akteuren anleiten (Schimank/Volkmann 1999: 17-19). Bei ihrer Interessenausübung können Akteure jedoch kaum davon ausgehen, dass sie allein agieren und ihre Ziele vollständig realisieren. Vielmehr werden ihre Mittel und Ziele durch soziale Mechanismen, in Konstellationen des handelnden Zusammenwirkens und in der Auseinandersetzung mit den Interessen anderer Akteure kontextuiert und abgeändert.

Das Zusammenwirken der Akteure spielt sich im Rahmen von Verhandlungen, Beeinflussungen oder auch nur in Form lockerer Beobachtungen ab (vgl. Schimank 2000): entweder gelangen Akteure in Verhandlungen zu einem verbindlichen Kompromiss in der Ausgestaltung einer Modernisierungsidee, oder eine Gruppe kann andere Gruppen mit eigenen Vorstellungen von Modernisierung stärker beeinflussen, oder die Gruppen irritieren sich durch lockere Beobachtungen wechselseitig. Die Ergebnisse von Verhandlungen, Beeinflussungen und Beobachtungen können dabei prinzipiell den Intentionen der Akteure oder Gruppen entsprechen. Das handelnde Zusammenwirken kann aber auch transintentionale

15 Jedes Teilsystem übernimmt nach Maßgabe einer eigenen Autopoiesis bestimmte Leistungsfunktionen für die Gesellschaft. Der Sinn dieser Leistungen ist jeweils systemspezifisch, nach eigenen Codes (Leitideen) und Programmen organisiert. Für die Wirtschaft z.B. lautet der Code ,zahlen/nicht zahlen“. Im Bildungssystem ist der Code „vermittelbar/nicht vermittelbar“, das Medium ist der Lebenslauf (vgl. Kade 1997). 
Effekte hervorbringen, die keiner der Beteiligten gewollt hat. Dies bedeutet für den hier diskutierten Zusammenhang: Modernisierungen erreichen unter Umständen nicht das, was mit ihnen beabsichtigt wird. Dies wirft die grundsätzliche Frage auf, unter welchen Bedingungen eine Modernisierungsidee Geltung beanspruchen kann. Diesem Aspekt wollen wir uns nun widmen.

\section{Leitideen und Geltungskontexte}

Gesellschaftliche Leitideen scheinen wichtige Faktoren für die Erklärung von Modernisierung darzustellen. Hier lässt sich eine differenzierungs- und akteurtheoretische Überlegung anführen: Es interessiert, wie die verschiedenen Akteure Codes (Leitideen) und Programme aufgreifen. ${ }^{16}$ Lepsius (1997: 59) geht hierbei von verschiedenen Geltungskontexten aus, die zum Beispiel von Interessenkoalitionen bestimmt werden (vgl. Faust 2002: 74). In diesen Geltungskontexten findet eine Leitidee ihre Konkretion.

Zum Beispiel zeigt Boyd (hier im Buch), dass in den Vereinigten Staaten und in England bestimmte Akteure als ,think tanks“ transnational in der Verbreitung von Modernisierungsideen aktiv sind, indem sie etwa internationale Konferenzen abhalten. Diese Modernisierungsideen werden aber nicht automatisch auf der Ebene der Einzelschule wirksam. Wie bei den transnationalen Akteuren gibt es auch hier besondere Interessen (vgl. generell Esser 2000: 367f.), welche den Zugriff und die Geltung einer Modernisierungsidee von vornherein spezifizieren. Kursierende Leitideen, über die man spricht, sind eine Sache, aber die Geltungskontexte der Leitideen eine zweite. Erst Geltungskontexte entscheiden über die Handlungswirksamkeit einer Leitidee, oder anders gesagt: Leitideen müssen im Handeln realisiert werden. Der wissenschaftliche Beobachter kann - z.B. mit der Diskursanalyse - zeigen, dass und welche Semantiken gesellschaftlich neu auftauchen, wie über sie gesprochen wird (talk), auf welche Semantik das Denken von Akteuren neu ausgerichtet werden soll. In welchem Ausmaß jedoch dieses Denken ein Handeln anleitet (action), lässt sich aus der Leitidee selbst nicht ableiten. ${ }^{17}$ Hierfür bedarf es der Analyse von Geltungskontexten.

Offensichtlich sind auch die drei von Schimank genannten Konstellationsarten des handelnden Zusammenwirkens - Beobachtung, Beeinflussung und Verhandlung - gleichzeitig Geltungskontexte für eine Modernisierungsidee. Kommt es zwischen Akteuren zu Verhandlungen, kann eine Modernisierungsidee am Ende vielleicht rechtlich institutionalisiert wer-

16 Nach Schimank/Volkmann (1999: 17) geben Codes gesellschaftlicher Teilsysteme „Akteuren die Möglichkeit, ihre Ziel- und Mittelwahl methodischer vorzunehmen, da der generelle Orientierungsrahmen für das Handeln bereits unzweideutig definiert ist“. Die Programme der Teilsysteme ,sind Spezifizierungen der hochabstrakten Codes, also Regeln, wie die Codes zu verstehen sind“" (ebd., 11).

17 Vgl. zur Unterscheidung von ,talk/action“ in Organisationen: Brunsson 1989. 
den, was dann die neuen, mit der Modernisierungsidee verbundenen Handlungsmaximen bei Nichterfüllung sanktionierbar macht. Beobachten und irritieren sich dagegen Akteure nur wechselseitig mit ihren Vorstellungen, gibt es einen Streit der Modernisierungsideen, ist der Geltungskontext offensichtlich schwächer.

Um Konstellationen der Beobachtung, der Beeinflussung oder der Verhandlung kenntlich zu machen, empfehlen Akteurtheoretiker zudem, nach bestimmten Akteuren Ausschau zu halten. Schimank/Volkmann (1999: 19) beziehen sich z.B. auf Colomy (1990), der vier Typen von Akteuren unterscheidet, „,institutional entrepreneurs', die an einem bestimmten Differenzierungsvorgang interessiert sind und ihn voranzutreiben versuchen; ,institutional followers', die sich ab einem bestimmten Punkt davon mitreißen lassen; ,institutional conservatives', die den Status quo aufrechterhalten wollen; und ,institutional accomodationists', die zwischen diesen beiden Lagern vermittelnd eingreifen können.“

Es kommt also bei einer Modernisierung darauf an, welche Akteure mit welchen Interessen an ihr beteiligt sind, und welche soziale Mechanismen die Akteure durch ihr Zusammenwirken gewollt sowie ungewollt konstituieren.

\section{Institutionalisierung}

Die sozialen Mechanismen der Beobachtung, Beeinflussung und Verhandlung sind wiederum von institutionellen Kontexten gerahmt, d.h. der Verkehrsweise, die in einem Teil des sozialen Feldes jeweils vorherrscht. So lässt sich in lockerer Anlehnung an Birnbaum (2000) sagen, dass die ,management fads", innerhalb derer sich Leitideen verbreiten, unterschiedlich konturiert sind, je nach dem, ob die sozialen Beziehungen vornehmlich hierarchisch (wie im Staat), eher über den Markt (wie in der Wirtschaft) oder eher netzwerkförmig (wie in der Profession des Schulsystems) organisiert sind. Während Staat und Wirtschaft Amtsautorität, rationale Verfahren und hierarchische Organisationen für die Verbreitung von Leitideen nutzen können, spielen im Schulsystem eher lose gekoppelte Beziehungen zwischen autonomen Professionellen eine Rolle, wobei die Akteure auf die Kraft des besseren pädagogischen Arguments setzen. Und dies bedeutet auch, dass sich Leitideen aus der Wirtschaft und dem Staat - wie die derzeitigen Semantiken des Managements oder der Effizienz - nicht einfach in das Schulsystem übertragen lassen (vgl. Brüsemeister 2002b).

Unter dem Begriff der Institutionalisierung und der institutionellen Kontexte wird ebenfalls diskutiert, wie Leitideen in verschiedenen Geltungskontexten wirken. So notiert Lepsius (1997: 58f.; vgl. ähnlich Esser 2000: 5f.): 
„Im Prozess der Institutionalisierung einer Wertvorstellung werden aus Ideen Handlungsmaximen mit Anspruch auf Gültigkeit gegenüber ganz verschiedenen Menschen mit je eigenen Motiven und Interessen. [...] Beispielsweise gilt für wirtschaftliches Handeln die Maxime der Einkommensmaximierung als rational. [...] Der Institutionalisierungsprozess umfasst nicht nur die Konkretisierung einer Leitidee, sondern stets auch eine Kontextbestimmung ihrer Gültigkeit. Erlaubt der Handlungskontext keine Verhaltensorientierung an den Rationalitätskriterien, so können diese nicht oder nur unvollkommen verfolgt werden.“

Faust (2002: 73f.) beschreibt im Anschluss an Lepsius den Kampf um Leitideen, wobei er zugleich mit Wagner (1995: 48) der Ansicht ist, dass Leitideen vor allem von „modernisierenden Eliten“ ausgehen. Folgt man dieser Überlegung von Faust (die für ein anderes Thema formuliert wurde), so nimmt dies Autoren im vorliegenden Buch vorweg, die auf das Schulsystem bezogen von einem Kampf bisheriger und neuer Leitideen sprechen (etwa „Chancengleichheit“ contra „Effizienz“):

„Die Leitidee selbst ist [...] vage und interpretationsoffen, aber auch -bedürftig. Ideen werden erst wirksam, wenn sie sich mit Interessen verbinden, wie Interessen einer Legitimation in der Ideenwelt bedürfen. In Institutionalisierungsprozessen einer Leitidee verbindet sich beides. Ferner beherrscht nie eine Leitidee das Feld unangefochten, wiewohl man manchmal den Eindruck hat, zu bestimmten Zeiten seien Alternativen sprachlos geworden. Aber allemal arbeitet sich eine neue Leitidee an den Leitideen der ,alten Ordnung $a b$, die sie herausfordert. Wenn die alten Leitideen hinreichend diskreditiert sind, verschwinden dennoch nicht die Interessen und Werte, die sich mit den früheren Leitideen verbanden.“ (Faust 2002: 75f.; Herv. i.O.)

Es ist also von einem „Wettstreit der Ideen“ (ebd., 76) auszugehen. Und dieser Wettstreit wird, wie oben angedeutet, offensichtlich von verschiedenen institutionellen Kontexten moderiert, die staatlich, marktlich oder netzwerkförmig organisiert sind. Es ist derzeit offenkundig (noch) nicht der Fall, dass sich im gesamten schulischen Feld Ideen des Managements, der Überprüfbarkeit und der Effizienz durchgesetzt haben. Aus dem vom Staat organisierten Teilfeld der Schule heraus werden zwar solche Leitideen mitsamt den Techniken des Qualitätsmanagements, basierend auf bestimmten Interessen, angeboten. Schulleiter, Lehrkräfte, Schüler und Eltern haben jedoch ebenfalls spezifische Interessen an der Aufnahme oder Ablehnung solcher Ideen und Techniken. Es kann zu subtilen Strategien des Unterlaufens kommen, d.h. eine neue Leitidee wird nicht unbedingt offensiv abgelehnt, sondern auf verschiedensten schulischen Ebenen umgangen.

Nach Faust (2000: 63-69) werden Leitideen erstens in nationalen Arenen interpretiert. Zweitens setzt sich der Interpretationsprozess vor Ort in einzelnen Organisationen fort (ebd., 79-81) - in unserem Fall in der einzelnen Schule. ${ }^{18}$ Neben der nationalen Arena gibt es also eine weitere Arena,

18 Wie sich Leitideen im Einzelnen in nationalen und lokalen Arenen gestalten, ist nach Faust (2000: 66) erst in Ansätzen theoretisch ausgearbeitet worden. 
in der die Leitideen einem Wettstreit ausgeliefert sind. Auch hier spielt aktive Uminterpretation eine Rolle, nun unter anderem motiviert von Karriereinteressen der Lehrkräfte sowie von Interessen anderer Akteure der Einzelschule. Diese Uminterpretation scheint besonders für die Modernisierung von Schulsystemen relevant, weil Schulsysteme - neben der ,,von oben“" steuernden staatlichen Governance - ,nach unten hin“ auf der lokalen Ebene interaktionsoffen sind. ${ }^{19}$

Die Fragen, welche Bedeutung die Arena der einzelnen Schule bezüglich der Annahme oder der Ablehnung einer Modernisierungsidee hat und welche Mechanismen des handelnden Zusammenwirkens dabei relevant werden, haben auch Untersuchungen zur Mikropolitik der Schulentwicklung behandelt. Sie beschäftigen sich mit Machtstrategien einzelner Akteure auf der ,Vorder- und Hinterbühne' einer Schule. ${ }^{20}$ Man kann also in Ergänzung zu Lepsius und Faust weitere Theoriebausteine anführen, die für den Interaktionsbereich der Schulen fragen, wie mit Modernisierungsideen umgegangen wird.

Insgesamt umschreibt das Modell von Lepsius und Faust Leitideen auf der Ebene nationaler Institutionenlandschaften, innerhalb derer es verschiedene Akteurkonstellationen gibt, welche sich um Vertreter der alten und der neuen Leitideen gruppieren. Neben dieser nationalen Arena gibt es lokale Arenen einzelner Schulen, in denen ebenfalls Akteure auf Basis ihrer Interessen und Werte eine Idee ,kontextualisieren“ und damit unter Umständen handlungsrelevant machen.

\section{Mediatisierung der Modernisierung durch das Bildungssystem}

In ähnlicher Weise führt Margaret S. Archer (1982) aus, dass ,ideas“ - im Sinne von Max Weber als ein System der Überzeugungen verstanden - in nationalen Erziehungssystemen ,become institutionalized as ,educational knowledge" at the systemic level“" (ebd., 254). Wie auch Lepsius ist Archer um eine Präzisierung des Verhältnisses ,,between interests and ideas“ bemüht, und auch sie geht von einem Wettstreit der Ideen aus, der von verschiedenen Interessengruppen geführt wird - mit dem Ziel, je eigene Vorstellungen von ,educational politics“ durchzusetzen). Hierbei liegen Ideen miteinander im Wettstreit:

„Even if we assume that a group in firm educational control is perfectly clear and correct about its objective interests, there is not just one set of ideas alone which can legitimate their educational domination nor only one kind of knowledge which is obviously going to serve them best by constituting the school curricula." (ebd., 255)

19 Letzteres gründet sich vor allem auf die für die Profession der Lehrer typische Autonomie.

20 Vgl. Altrichter/Posch (1996). Vgl. auch zur Macht und Ohnmacht von Akteuren in der Verwaltungsmodernisierung: Bogumil/Kißler (1998). 
Archer interessiert dabei auch, wie Ideen und Interessen in spezifische nationale Curricula münden (ebd.) und konstruiert ein Modell, das sowohl das Schulsystem als Ganzes erfasst, als auch bis hinunter zu schulischen „outputs" gelangt (ebd., 240).

Dabei geht es ihr um die Frage der Genese des Schulsystems (,origins"). Diesbezüglich geht sie davon aus, dass das Bildungssystem zum Teil abhängige Variable der Gesellschaft ist, insofern verschiedene gesellschaftliche Teilsysteme Einfluss auf das Bildungssystem nehmen. ${ }^{21}$ Beispiele für solche Abhängigkeitsbeziehungen werden z.B. in Argumenten angedeutet, dass wesentliche Schulleistungen von Kindern und Jugendlichen auf das Familiensystem zurückgehen, dass Rahmenbedingungen des Lehrerhandelns an das Rechtssystem gebunden sind (vgl. auch Richter hier im Buch), dass das Wirtschaftssystem über Inhalte der beruflichen Bildung mitbestimmt oder die Politik über die Steuerung des Bildungssystems entscheidet.

Neben diesem Modus der Abhängigkeit stellt Archer heraus, dass das Bildungssystem andere Teilsysteme der Gesellschaft mediatisiert (ebd., 238). Im Kern lautet das Argument, dass das Bildungssystem gesellschaftsweit handlungswirksame Maximen installiert hat, welche weitgehend selbstverständlich geworden und damit kaum thematisiert werden. Allerdings beweisen sie sich in Krisenzeiten: So lässt sich für die Gegenwart nach den Schulleistungsvergleichen PISA und dem schlechten Abschneiden Deutschlands zwar bemerken, dass Schulsysteme in erhebliche Kritik geraten. Aber dabei scheint öffentlich „nur“ über den Modus der Governance gestritten zu werden, d.h. wie Leistungen künftig organisiert werden sollen - dass es diese Leistungen geben soll, scheint hingegen unstrittig. Niemand fordert offensiv die Reduktion von Bildungsprogrammen. Auch wenn die Umstrukturierung des Bildungssystems im Rahmen eines neuen, am Management orientierten Governance-Modells von manchen deutschen Bundesländern im Hinblick auf mögliche Einsparungen diskutiert wird, so gilt doch das Ziel einer Verbesserung von Bildungsangeboten nach wie vor als Maxime - gerade insofern die OECD-Länder nach PISA strukturelle Verbesserungen ihrer Leistungsangebote anstreben, um in der Weltgesellschaft letztlich nationale Produktionsvorteile erzielen zu können (so Messner in diesem Band). ${ }^{22}$ Man kann die Idee fortlaufend verbesserter

21 Schimank diskutiert dies in seinem Beitrag für diesen Band auf einer grundsätzlichen Ebene unter dem Begriff der Teilsysteminterdependenzen.

22 Die Einsparungs-Strategien der Landesverwaltungen dürfen jedoch keinesfalls unterschätzt werden. Man könnte in den zum Teil seit Jahren spürbaren Bemühungen, die wöchentliche Arbeitszeit von Lehrkräften und Klassenfrequenzen zu erhöhen sowie die wöchentliche Unterrichtszeit der Lernenden zu verringern (Klemm 1997: 101), eine „konservative Transformation bzw. Modernisierung“ des Wohlfahrtsstaates im Bereich Schulbildung sehen (angenähert an die Einschätzung von Borchert 1995). Der Begriff der konservativen Transformation verweist darauf, dass zwar Leitlinien der Inklusion semantisch weiterhin vertreten, Finanzmittel jedoch fak- 
Bildungsangebote als gesellschaftliche Verankerung des Inklusionsgebots verstehen (vgl. schon Parsons 1972: 120; auch Schimank im vorliegenden Buch). Zwar wird, wie bereits erwähnt, über neue Governance-Modelle gestritten. Die Orientierung an Inklusion als solcher jedoch wird dabei weder von der Politik, noch von Familien, noch von der Wirtschaft oder einem anderen Teilsystem in Frage gestellt. In diesem Sinne hat die Vorstellung einer Inklusion via Bildung offensichtlich die Gesellschaft durchdrungen.

Es ist also nicht nur so, dass die Interdependenzverhältnisse zwischen gesellschaftlichen Teilsystemen zu Lasten des Bildungssystems gehen, sondern das Bildungssystem mischt sich gleichzeitig in die Belange anderer Teilsysteme ein - und mediatisiert sie stillschweigend.

\section{Modernisierungspfade}

Die Modernisierung der Gesellschaft ist von Pfadabhängigkeiten gekennzeichnet (vgl. Schimank 2000: 224-226). Dies meint, dass zunächst von institutionellen Gegebenheiten eines Landes ausgegangen werden muss. ${ }^{23}$ So wird z.B. in Überlegungen für eine Schule nach PISA die deutsche Kultusministerkonferenz nicht einfach abgeschafft - trotz vielfacher Kritik an dieser Einrichtung -, sondern in die Modernisierungsbestrebungen eingebunden. ${ }^{24}$ Diese institutionalisierten Gegebenheiten lassen sich auch in anderen Ländern finden - z.B. in der Schweiz. So muss die Bildungsdirektion im Kanton Zürich bei Modernisierungsabsichten zunächst die Macht der Bezirks- und der Gemeindeschulpflege zur Kenntnis nehmen. Beide Einrichtungen treffen bislang wesentliche Entscheidungen über die zur Gemeinde gehörenden Schulen. Wenn das Schulsystem auf ein zentrales Management umgestellt werden soll, dann muss die Modernisierung auf diesen Punkt eingehen - was sie im Kanton Zürich auch tatsächlich tut (vgl. Bildungsdirektion des Kantons Zürich 1999, Kap. 11).

tisch eingefroren werden, da sich die Politik einer Haushaltssanierung unterwirft, deren Notwendigkeit sie selbst erzeugt. Immerhin bliebe auch in diesem Fall die semantische Orientierung an Inklusion erhalten, sie wird aber auf die Ebene des „talk“ reduziert, wenn gleichzeitig auf der Ebene der ,action“ Mittel eingefroren werden. Ob dieser Verdacht - und wenn, für welche Landesregierungen und verwaltungen - zutrifft, ist nicht untersucht. Vgl. auch zum Druck der Sparpolitik, der die Gemeinden derzeit zum Verkauf von Schulgebäuden und Abwassernetzen drängt, grundsätzlich (aus politikwissenschaftlicher Sicht) Bogumil/Holtkamp 2002.

$23 \mathrm{Vgl}$. zu den rechtlichen Gegebenheiten den ersten Text von Richter in diesem Buch.

24 Zudem haben offensichtlich PISA bzw. die OECD die Kultusministerkonferenz dynamisiert. Das schlechte Abschneiden bei PISA sei ein „heilsamer Schock“ gewesen, so die Präsidentin der Kultusministerkonferenz, Dagmar Schipanski, insofern nun über gemeinsame Bildungsstandards sowie eine nationale Bildungsberichterstattung immerhin gesprochen werde (Süddeutsche Zeitung vom 7./8. Dezember 2002, S. 6). 
Modernisierungspfade beinhalten also Selbstfestlegungen durch frühere Entscheidungen, die immer auch Nichtentscheidungen für Alternativen waren, die dann in der Gegenwart nicht zur Verfügung stehen. Luhmann (1987: 403) zufolge kann aber gerade eine Entscheidung die Bedeutung der nichtgewählten Alternativen erhöhen, was heißt, dass die Gesellschaft unter Umständen einen Modernisierungspfad einschlägt, den sie vorher nicht gegangen ist. Die in Modernisierungspfaden verfestigten Praktiken scheinen nur von relativer Dauer, da in einer Gesellschaft fortlaufend andere Ideen und Interessen aufkommen.

Für das deutsche Schulsystem deutet dies eine Skizze zur Veränderung der Governance an. Die Bildungspolitik konzentriert sich in den 1960er Jahren nach der von Picht (1964) ausgerufenen „Bildungskatastrophe“ um den Ausbau von Bildungsprogrammen und die Beseitigung von Bildungsnachteilen. Das Gebot der Nicht-Diskriminierung zwingt das Bildungssystem, nach in punkto Bildung besonders benachteiligten Kollektiven Ausschau zu halten. In der Bundesrepublik dieser Zeit sind dies Arbeiterkinder, Mädchen, die katholische sowie die auf dem Land lebende Bevölkerung (vgl. Herrlitz u.a. 1998: 205). Im Rahmen eines bürokratischen Steuerungsmodells wird das Schulsystem gleichsam vom Kopf her ausgebaut (vgl. Übersicht 1, nach Fend 2001: 41):

\section{Übersicht 1: Historisch entstandenes und neues Steuerungsmodell von Schule}

\begin{tabular}{|c|c|c|}
\hline & $\begin{array}{l}\text { Historisch entstandenes } \\
\text { Steuerungsmodell }\end{array}$ & Neues Steuerungsmodell \\
\hline Systemebene & $\begin{array}{l}\text { - Festlegung von Prüfungsan- } \\
\text { forderungen über gesetzliche } \\
\text { Vorgaben } \\
\text { - inhaltliche Festlegungen über } \\
\text { Lehrpläne (Schaffung von } \\
\text { Zeitgefäßen) } \\
\text { - Präzisierung von Standards } \\
\text { über Lehrmittel und -bücher } \\
\text { - zentrale Mittelausstattung } \\
\text { - zentrale Lehrerzuordnung }\end{array}$ & $\begin{array}{l}\text { - Rahmenvorgaben, Leitlinien, Fä- } \\
\text { cherkombinationen, Anforderun- } \\
\text { gen bei Abschlüssen } \\
\text { - wirkungsorientierte Steuerung } \\
\text { über standardisierte Prüfungen } \\
\text { - Ranking von Schulen }\end{array}$ \\
\hline Schulebene & - schwach entwickelt & $\begin{array}{l}\text { - gebietsunabhängige Schulwahl der } \\
\text { Schüler } \\
\text { - Selbstwahl von Leitern und Zuwahl } \\
\text { neuer Lehrer durch das Kollegium } \\
\text { - Erwirtschaftung eigener Einkünfte }\end{array}$ \\
\hline Lehrerebene & $\begin{array}{l}\text { - Überprüfung der Lehrerer- } \\
\text { gebnisse und Lernerfolge über } \\
\text { eng curricular gebundene Prü- } \\
\text { fungen im schulischen Alltag } \\
\text { - Autonomie des Lehrers in me- } \\
\text { thodisch-didaktischen Fragen }\end{array}$ & $\begin{array}{l}\text { - lohnwirksame Leistungsbeurteilung } \\
\text { - formative Selbstevaluation }\end{array}$ \\
\hline Schülerebene & $\begin{array}{l}\text { - Bindung der schulischen und } \\
\text { beruflichen Aufstiegschancen } \\
\text { an die Abschlussprüfungen in } \\
\text { den Schulen }\end{array}$ & - Beurteilung der Lehrkräfte \\
\hline Elternebene & - schwach entwickelt & $\begin{array}{l}\text { - Wahl von Schulen } \\
\text { - Evaluation der Lehrkräfte } \\
\text { - Voucher-System }\end{array}$ \\
\hline
\end{tabular}


Um mit bildungspolitischer Planung auf Chancenungleichheiten zu reagieren, ist das bürokratische Steuerungsmodell auf der Seite des Inputs stark. Man nimmt an, dass zielgerichtet Effekte in der Umwelt erzeugt, d.h. Bildungsbenachteiligungen abgebaut werden können. Weil die internen Steuerungsebenen (die Ebenen der einzelnen Schule, Lehrer, Schüler und Eltern) als homolog zu den Inputzielen angesehen werden, können sie so gut wie vernachlässigt werden. Was für den Ausbau der Inklusion notwendig ist, lässt sich bürokratisch top-down festlegen - als Prüfungsanforderungen, als inhaltliche Ausgestaltung von Lehrplänen, als Präzisierung von Standards bei Lehrmitteln und -büchern, als zentrale Mittelausstattung und Lehrerzuordnung. Ergänzend zu Fend (ebd.) kann man sagen, dass das System auch „top-down“ über den Grad der Lehrer- und Elternmitsprache und die Art der Schülerbeteiligung entscheidet. Die Steuerungsebenen der einzelnen Schule, der Lehrer und der Eltern sind hier nur schwach entwickelt. Im Systemablauf muss das Publikum auf diesen Ebenen kaum vorkommen. Denn Schulen, Lehrkräfte, Schüler und Eltern, für die sich der Staat mit Leistungsprogrammen engagiert (wobei die Lehrkräfte Anwälte dieser Programme sind), müssen wenig entscheiden, wenn das System schon in ihrem Sinn optiert und Leistungserhöhungen für alle zu gewährleisten scheint.

Die Systemlogik, die sich am Input orientiert, stirbt etwa Mitte der 1970er Jahre bildlich gesprochen am eigenen Erfolg, wobei dieser ,Erfolg', wie PISA und andere Studien zeigen, vor allem auf der Ebene des talk anzusiedeln ist, da es dem deutschen Bildungssystem - anders als anderen Ländern - offensichtlich nicht gelungen ist, sozialstrukturelle Benachteiligungen zu verringern. Als Erbschaft der 1970er Jahre wird eine ,Verkümmerung ' von Steuerungsebenen unterhalb der Systemebene hinterlassen.

Anders stellt sich die Situation angesichts heutiger, am Management ansetzender Steuerungsmodelle dar: Der Systeminput ist auf eine strategische Führung zurückgezogen (Fend 2001: 42), den darunter liegenden Ebenen wird größere operative Autonomie gegeben. Die Ausformulierung und Umsetzung der Inklusion soll in stärkerer Beteiligung „,von unten“, von den Akteuren der Einzelschule (Lehrkräften, Schülern und Eltern) erfolgen. Es gibt Rückkoppelungsschleifen, die bottom-up (nach oben) wirken und von der strategischen Führung aufgegriffen werden. Von der Systemebene werden Leistungen auf den darunter liegenden Ebenen grundsätzlich für messbar gehalten. Mit der stärkeren operativen Beteiligung der unteren Ebenen ist der wesentliche Unterschied zum bürokratischen Steuerungsmodell markiert. Auf der Ebene der Einzelschule zum Beispiel soll sich das Kollegium neue Kräfte selbst zuwählen können; Lehrer sollen einen Teil ihrer Leistungen untereinander evaluieren; die Frequenz der Beobachtung von Schülerleistungen wird erhöht; und Eltern nehmen durch Schulwahl sowie durch ihre Beurteilung von Lehrkräften stärkeren Einfluss. Man kann diese am ,New Public Management" (NPM) angelehnte Steuerungsvorstellung als Intensivierung der Beobachtungs- und Beurteilungsmöglichkeiten derjenigen Akteure beschreiben, die in ihren Leistungs- und Publikumsrol- 
len an der schulischen Inklusion beteiligt sind. Während das bürokratische Steuerungsmodell top-down organisiert war, sollen die Schulakteure nun bottom-up an der Inklusion mitwirken.

\section{Forschungsskizze}

Das gerade skizzierte neue Steuerungsmodell wird im Schulsystem „topdown“ eingeführt. Diesbezüglich kann man vermuten - darauf verweisen die in diesem Buch versammelten Texte -, dass wir es mit einer Modernisierungsoffensive zu tun haben. Dies wirft gemäß Wagner (1995) die Frage auf, wer hierbei die „modernisierenden Eliten“ sind, inwieweit neue Leitideen - wie Management, Effizienz und Qualität - die Praktiken der an Schule Beteiligten schon durchdringen, welche Grenzen oder Unterstützung die neuen Leitideen in der Praxis der schulischen Felder finden. Diese Fragen sind für die deutschen Bundesländer, die Hoheitsträger des Schulsystems, noch kaum systematisch untersucht. Man kann jedoch für eine Forschungsskizze Grundsätzliches überlegen:

Erstens lässt sich bezüglich der modernisierenden Eliten sagen, dass sie auf der Makro-Ebene der Governance diejenigen Akteure sind, die das schulische Gesamtsystem in einem Bundesland am NPM-Modell ausrichten. Für welche Bundesländer dies gilt, ist derzeit noch nicht erhoben worden. ${ }^{25}$ Es gibt jedoch erste Hinweise, dass die deutschen Stadtstaaten in diesem Punkt vergleichsweise fortgeschritten sind - vermutlich auf Grund überschaubarerer Akteurkonstellationen, in denen eine am NPM ausgerichtete Schule leichter durchgesetzt werden kann. ${ }^{26}$

25 Es gibt derzeit nicht nur keine überblickende Literatur zu der Frage, inwieweit die Schulsysteme der einzelnen deutschen Bundesländer am New Public Management orientiert sind, sondern auch noch keine vergleichende Übersicht, inwieweit sich die Bundesländer im Punkt der Verwaltungsmodernisierung auf ein New Public Management zu bewegen. Diese Auffassung bestätigt Jörg Bogumil als einer der erfahrendsten politikwissenschaftlichen Forscher zum Bereich der Verwaltungsmodernisierung in Deutschland (private Mitteilung). Bogumil vermutet, dass die Landesverwaltungen skeptisch gegenüber Evaluationen sind, und nennt uns immerhin drei weiterführende Literaturtitel: Konzendorf 1998 (dort, beim Forschungsinstitut für öffentliche Verwaltung in Speyer, der aktuellste Überblick zu Verwaltungsmodernisierungen auf Landesebene, vgl. auch http://foev.dhv-speyer.de), Bogumil 1999, 2000. Vgl. auch grundsätzlich Bogumil 2002.

26 Vgl. zu den Stadtstaaten Bremen und Hamburg Maritzen (in diesem Buch); vgl. für Hamburg auch: Tillmann/Vollstädt 2001. Überschaubarer sind offensichtlich auch Akteurkonstellationen im Kanton Zürich. Die dortige Bildungsdirektion ist eindeutig am NPM orientiert, vgl. Buschor in diesem Band. Überschaubarkeit bedeutet jedoch nicht automatisch Langfristigkeit in der Orientierung am NPM. Gerade in Hamburg hat die Koalition aus CDU, Schill-Partei und FDP die Bemühungen der dortigen Bildungsverwaltung im Herbst 2002 zurückgestutzt, dies unter der Federführung eines Senators der FDP, die sich die Modernisierung im neoliberalen Gewand auf die Fahnen geschrieben hat. Im Kanton Zürich wurde eine Verallgemeine- 
Auf der Makro-Ebene des schulischen Gesamtsystems ist also das entscheidende Element der Modernisierung die Einführung von Managementmethoden der Governance im Rahmen von NPM, die dazu führen, dass die einzelne Schule eine hohe operative Autonomie erhält. Der Grad einer Modernisierung eines Bundeslandes ließe sich daran messen, inwiefern diese größere Autonomie der Einzelschule nicht nur punktuell - in ausgewählten und zeitlich begrenzten Schulversuchen -, sondern flächendeckend eingeführt wird. Eine solche Phase der Institutionalisierung, die über Versuchsstadien hinausgeht, ist unseres Wissens nur in Bremen und Hamburg begonnen worden.

Zweitens sind modernisierende Eliten auf der Meso-Ebene der Einzelschule diejenigen Akteure, die bereits mit Programmen der Qualitätsmanagements in Kontakt gekommen sind. Die Akteure müssen darüber nicht nur etwas gelesen oder gehört, sondern diese Programme in ihrem Handeln aufgegriffen und an lokale Bedingungen ihrer Schule angepasst haben.

Drittens sind auf der Mikro-Ebene des Rollenhandelns insbesondere Schulleiterinnen und Lehrkräfte als modernisierende Eliten zu sehen, nämlich dann, wenn sie ihre Handlungsmaximen an den größeren Entscheidungsbefugnissen der Einzelschule ausrichten und damit Leitideen und Programme realisieren, wie es sie auf der Governance-Ebene des NPM sowie auf der Meso-Ebene einer an Qualitätsmanagements neu ausgerichteten Schule gibt.

Wollte man also eine Forschungsskizze zu einer Theorie der schulischen Modernisierung entwerfen, ließe sich für jedes Bundesland untersuchen, erstens inwiefern auf allen drei Ebenen (Makro, Meso, Mikro) modernisierende Eliten mit Leitideen in Erscheinung getreten sind (talk), und zweitens, inwiefern die praktische Umsetzung der Leitideen auf der Handlungsebene (action) begonnen wurde. In beiden Dimensionen werden die Bundesländer vermutlich unterschiedlich weit entwickelt sein.

rung des Schulversuchs der „Teilautonomen Volksschule“ per Volksentscheid am 24. November 2002 verhindert. 



\section{Theoretisch-methodische}

\section{Zugänge}





\section{Soziologie}

\section{Kommentar (Brüsemeister)}

Aus soziologischer Sicht eröffnet eine kombinierte Akteur- und Differenzierungstheorie, wie sie Uwe Schimank (FernUniversität Hagen) in seinem Beitrag „Teilsysteminterdependenzen und Inklusionsverhältnisse“ darlegt, einen Zugang zum Thema Modernisierung von Schule und Gesellschaft. Wir gehen im Folgenden zunächst auf den Begriff der Teilsysteminterdependenzen, dann auf Inklusionsverhältnisse, und schließlich auf Schimanks Begriff der Transintentionalität ein. ${ }^{1}$

Theorieansätze der gesellschaftlichen Differenzierung (für einen Überblick vgl. Schimank/Volkmann 1999) gehen davon aus, dass die Gesellschaft eine ,polykontexturale“ Struktur hat, d.h. aus verschiedenen gesellschaftlichen Teilsystemen besteht, von denen jedes spezifische Leistungen für die Gesellschaft erbringt. ${ }^{2}$ So etwa die Politik durch das Organisieren kollektiv verbindlicher Entscheidungen, die Wissenschaft in der Produktion wissenschaftlich-wahrer Aussagen oder die Religion in der Bereitstellung von Glaubensorientierungen. Die Differenzierungstheorie versucht dabei nicht nur, Eigenarten einzelner Teilsysteme herauszuarbeiten, ${ }^{3}$ sondern vielmehr auch „Überschneidungsbereiche“ (Luhmann/Schorr 1979: 53-58) - oder mit der Begrifflichkeit von Schimank: die Interdependenzen - eines Teilsystems zu kennzeichnen, die es mit anderen Teilsystemen hat. In dieser Perspektive interessiert, wie sich gesellschaftliche Teilsysteme gegenseitig beeinflussen, und welche Folgen dies für einzelne Teilsysteme und die Gesellschaft auf der Ebene der Systemintegration hat (zu den Begriffen System- und Sozialintegration vgl. Lockwood 1979). ${ }^{4}$ Teilsysteminterdependenzen, die zur Makroebene gesellschaftlicher Betrachtungsweisen gehören, untersucht Schimank nicht am Beispiel von Schulsystemen, sondern um eine generelle Forschungsperspektive für die künftige Analyse beliebiger Teilsysteme zu entwerfen.

Der Focus auf Teilsysteminterdependenzen scheint interessant, wenn man an die derzeitige Veränderung der Governance von Schulsystemen denkt (vgl. dazu die Einleitung in diesem Buch). An der früheren Gover-

1 In seinem Beitrag legt Schimank zudem sein Interesse an soziologischen Gegenwartsdiagnosen dar. Dieser Aspekt bleibt hier unberücksichtigt.

2 Bis dato unterscheidet man: Wirtschaft, Politik, Recht, Wissenschaft, Religion, Militär, Kunst, Massenmedien, Bildung, Gesundheitswesen, Sport, Familie und Intimbeziehungen; vgl. Schimank/Volkmann (1999: 32-35).

3 Dies hat vor allem Luhmann als einer der wichtigsten Differenzierungstheoretiker getan, indem er zum Beispiel das „Recht der Gesellschaft“ oder die „Wirtschaft der Gesellschaft" betrachtet (Luhmann 1993, 1994b).

4 Die systemintegrative Frage nach Teilsysteminterdependenzen, und die sozialintegrative Frage nach Inklusionsverhältnissen werden auch behandelt in Schimank/Volkmann (1999: 31-43). 
nance des Schulsystems waren vor allem zwei Teilsysteme beteiligt: der Staat und das Schulsystem selbst. Heute scheinen weitere Teilsysteme die Governance-Strukturen mit eigenen Leitideen und Programmen zu beeinflussen - neben dem Staat zum Beispiel die Wirtschaft mit Forderungen nach einer höheren Effizienz des Schulsystems und der Bereitstellung von Qualitätsverfahren, oder die Wissenschaft, indem sie Entscheidern in Bildungspolitik und -verwaltung wissenschaftliche Daten und Beratungsmöglichkeiten bereitstellt. Zudem operieren am NPM orientierte Bildungsverwaltungen eigenständiger als früher auf Basis wissenschaftlicher Expertisen, d.h. die Wissenschaft scheint auch indirekt ebenfalls größeren Einfluss auf die Governance zu haben.

Bei den Interdependenzen zwischen Teilsystemen kommt es gemäß Schimank darauf an, positive Leistungsbeziehungen sowie negative Störungsbeziehungen auszumachen. Für unser Thema scheint es vor allem wichtig, ob man in der neuen Governance des Staates entweder einen ideellen und finanziellen Rückzug des Staates sieht, der darauf hinausläuft, dass der Staat Kosten an die Schulsysteme externalisiert bzw. sie allein auf sich gestellt den Marktkräften überantwortet, was dann eine negative Interdependenzbeziehung zum Staat wäre (vgl. in diesem Sinne Bourdieu in diesem Band); oder ob man eine neue verantwortliche Führungsrolle des Staates erkennt, insofern er verstärkt auf strategische Rahmenplanungen setzt dies wäre eine positive Interdependenzbeziehung. Für die Klärung der Sichtweisen käme es darauf an, gegenwärtige Leistungs- und Störungsbeziehungen insbesondere zwischen dem Staat und dem Schulsystem, aber auch zwischen anderen Teilsystemen und dem Schulsystem genauer zu betrachten, was in der Literatur noch nicht geschehen ist. ${ }^{5}$

Neben veränderten Teilsysteminterdependenzen und der Perspektive der Systemintegration interessiert sich Schimank mit dem Begriff der Inklusionsverhältnisse für die Perspektive der Sozialintegration. Hierbei geht es um die Frage, wie Individuen an einzelnen Teilsystemen partizipieren und welche Folgen sich daraus für die Lebenschancen der Individuen ergeben (vgl. Dahrendorf 1979). Für Teilsysteme lassen sich Inklusionsverhältnisse betrachten, d.h. Möglichkeiten von Individuen, über Funktionsrollen - zum Beispiel als Sportzuschauer im Sportsystem oder als Schüler im Bildungssystem - an der Gesellschaft teilzunehmen (vgl. Stichweh 1988). Für Schulsysteme gibt es hingegen noch keine systematische Betrachtung von Inklusionsverhältnissen. Es lässt sich aber zumindest skizzenhaft feststel-

5 Darüber hinaus lässt sich mit der Perspektive von Interdependenzverhältnissen daran erinnern, dass das Bildungssystem nicht das einzige Teilsystem ist, in dem das Thema Modernisierung derzeit eine vehemente Rolle spielt. Hierbei spielt für das Bildungssystem, das Gesundheitssystem und das System der Sozialen Arbeit die jeweilige Beziehung zum Staat eine zentrale Rolle, insofern in all diesen Teilsystemen eine mehr am Management orientierte Governance eingerichtet wird, welche zumindest für das Schulsystem - unter dem Stichwort „Modernisierung von Sozialstaaten“ diskutiert wird (vgl. Textblock I dieses Buches). 
len, dass die Schulsysteme der Wohlfahrtsstaaten nach dem Zweiten Weltkrieg zumindest diesbezüglich eine Erfolgsgeschichte aufweisen können (vgl. für Deutschland exemplarisch Herrlitz u.a. 1998, Kap. 9-11). Im Zuge der Bildungsexpansion wurden immer größere Teile der Bevölkerung über Publikumsrollen der Schüler und Studenten in das Bildungssystem inkludiert. Zum einen bedeutet diese Inklusion, dass über Organisationen und Programme gesellschaftlicher Teilsysteme die Rechte für Inklusion erweitert werden. Zum anderen werden Rechte und Teilhabemöglichkeiten aber auch von Akteuren eingefordert. Es geht hierbei um Inklusionsansprüche, die vor allem vom Postulat der Gleichheit angetrieben sind. Schimank berücksichtigt unter dem Stichwort der Inklusionsverhältnisse besonders diese zweite Seite, um die gesellschaftlichen Differenzierungsvorgänge ,von unten“, aus Sicht von Akteuren, zu betrachten (Schimank 2001: 118). Für das Thema „Modernisierung“ bedeutet dies, auf Akteure zu achten, die bottom-up an der Modernisierung beteiligt sind. Dieser Aspekt wird in Abschnitt III des Buches interessieren.

Eine weitere Forschungsfrage entlang des Textes lautet, wie sich die aktuelle Schulmodernisierung im Allgemeinen sowie die neue Governance im Besonderen auf Inklusionsverhältnisse auswirkt, d.h. ob durch sie mehr oder andere Teile der Bevölkerung an Bildungsleistungen partizipieren, ob als Folge neuer Leitideen wie Effizienz und Management mehr Selektion und die Zunahme sozialer Ungleichheiten, d.h. eine verminderte Inklusion in Schulsystemen zu beobachten ist (zu Letzterem vgl. Teil IV des Buches). Ein Teil der Beiträge in diesem Band greift diese Fragen auf, insofern erörtert wird, inwiefern bei der Schulmodernisierung die Orientierung an Chancengleichheit, die in den vorangehenden Jahrzehnten für eine schrittweise Ausweitung der Inklusion sorgte, gewahrt bleibt (vgl. z.B. Radtke hier im Buch).

Uwe Schimank erörtert in seinem Beitrag zudem den Begriff „Transintentionalität“. Dieser scheint ebenfalls für das Thema „Modernisierung von Schule und Gesellschaft" interessant, da er berücksichtigt, dass unter Umständen nicht das mit der Modernisierung Beabsichtigte, sondern etwas Anderes, „Transintentionales“ herauskommen kann. Dabei kann Transintentionalität in zwei Varianten auftreten: In der ersten entsteht sie als Folge eines beiläufigen Zusammenwirkens mehrerer Individuen, d.h. es gab zu Beginn keine Gestaltungsabsichten. ${ }^{6}$ In der zweiten Variante entwickelt sich Transintentionalität aus (intentionalen) Gestaltungsabsichten heraus. Ein Beispiel wäre, dass jemand eine Regalwand bauen will, jedoch die Wand falsch ausmisst (vgl. Schimank 2000: 181f.). Ähnlich sind für das Bildungssystem intentionale Gestaltungsabsichten, i.S. von pädagogischen

6 Beispiele dafür sind der Sprachwandel oder das Aufkommen von Modewörtern, die von niemandem maßgeblich gesteuert werden (Schimank 2000: 179f.). Für das Wirtschaftssystem spricht man bspw. von ,invisible hand effects“, bei denen z.B. „Gruppen von Akteuren durch ihre aggregierte Nachfrage [...] den Preis der Waren" bestimmen (ebd., 185). 
Interventionen in die Psyche einer, werdenden' Person, charakteristisch. Aber der Intervenierende kann sich verschätzen, unwissend sein oder irren (ebd., 184). Transintentionalität kann sich also zeigen ,als Scheitern von Intentionen auf Grund falsch eingeschätzter Kontextbedingungen“ (ebd.). $\mathrm{Zu}$ dieser Variante von Transintentionalität gehören auch Gestaltungsabsichten mehrer Individuen, die in einer Konstellation zusammenwirken, wobei dann das Ergebnis den Intentionen der Einzelnen widerspricht. Ein für unser Thema passendes Beispiel sind Gestaltungsabsichten von Lehrkräften innerhalb eines Modernisierungsprozesses, die vielleicht mit den Modernisierungsauffassungen des Staates und der Bildungsverwaltung nicht kompatibel sind. Insbesondere die Tatsache, dass Leistungen des Bildungssystems auf Interaktionen beruhen, führt dazu, dass im System viele Akteure beteiligt sind, die etwas wollen, was aber in Konstellationen des handelnden Zusammenwirkens dann vielleicht nicht zu den gewünschten Ergebnissen, sondern zu Transintentionalität führt. Aber auch für die erste Variante von Transintentionalität, die sich ohne ,gewollte“ Gestaltungsabsichten durch das Handeln Vieler einstellt, sind Beispiele in Schulsystemen zu finden, wenn man z.B. an veränderte Ansprüche von Jugendlichen, Familien und Lehrkräften denkt, die sich in der Bundesrepublik gewissermaBen beiläufig als kultureller Wandel nach dem Zweiten Weltkrieg ergeben haben (vgl. zu Lehrkräften Ziehe hier im Band sowie generell Gerhards 2001). Eine offene Frage ist, ob und wie sich Transintentionalität, die sich aus solchen beiläufigen Prozessen ergibt, mit derjenigen Transintentionalität zusammenwirkt, wie sie sich im Rahmen der gewollten Modernisierung von Schulsystemen einstellt.

\section{UWE SCHIMANK}

\section{Teilsysteminterdependenzen und Inklusionsverhältnisse}

Ein differenzierungstheoretisches Forschungsprogramm zur System- und Sozialintegration der modernen Gesellschaft

Die Soziologie braucht einen Perspektivenpluralismus, um der immensen Komplexität ihres Gegenstandes eine hinreichende „requisite variety“ (Ashby 1956) entgegen zu setzen. Auch dass es teilweise unüberbrückbare Widersprüche zwischen einzelnen soziologischen Perspektiven geben mag, gehört zu dieser „requisite variety“. Wir dürfen nicht hoffen, die Komplexität der sozialen Wirklichkeit in einem in sich völlig konsistenten Theoriegebäude einfangen zu können.

\section{$[\ldots]$}

Zwar birgt jeder Pluralismus die Gefahr einer entfesselten Differenzierungsdynamik à la Durkheim, bei der sich im Extremfall jeder neu als Theorieproduzent Hinzustoßende seine ganz eigene Nische sucht, in der er genau so gleichgültig gegenüber den anderen verharrt wie diese ihm gegen- 
über in ihren jeweiligen Nischen. Doch dergleichen steht in der soziologischen Theoriediskussion derzeit nicht zu befürchten. Vielmehr herrscht ein begrenzter und diskussionsbereiter Pluralismus vor, der in den letzten Jahren überdies durch zahlreiche Bemühungen der Perspektivensynthese, also der teils generellen, teils problembezogenen Verknüpfung zweier oder mehrerer Perspektiven, gekennzeichnet ist. Die Vertreter der verschiedenen Perspektiven bleiben somit im Gespräch miteinander und verlangen einander Begründungen $a b$. Mehr ist nicht nötig, um gleichermaßen Indifferenz wie Bekehrungseifer zu vermeiden.

[...]

Meine zukünftigen Forschungsinteressen hängen, wen wundert's, eng damit zusammen, was mich bislang soziologisch beschäftigt hat. Auf eine Kurzformel gebracht, geht es bei diesem Forschungsprogramm darum, mit akteurtheoretischen Mitteln wichtige differenzierungstheoretische Fragestellungen, die bislang noch stark vernachlässigt worden sind, anzugehen und die dazu gewonnenen Einsichten auch in gegenwartsdiagnostische Bemühungen der Soziologie einzubringen.

$$
[\ldots]
$$

\section{Gesellschaftliche Differenzierung: Die Integration der Teilsysteme und Individuen $[\ldots]$}

Die soziologische Gesellschaftstheorie hat seit den Klassikern des Fachs vor allem zwei Gruppen von analytischen Perspektiven auf ihren Gegenstand entfaltet. Dies sind die Theorien sozialer Ungleichheit auf der einen und die Theorien gesellschaftlicher Differenzierung auf der anderen Seite. ${ }^{7}$

Ungleichheitstheorien sehen das grundlegende Strukturmerkmal der modernen Gesellschaft darin, dass nicht alle Gesellschaftsmitglieder gleiche gesellschaftliche Einflussmöglicheiten und „Lebenschancen“ (Dahrendorf 1979) haben, sondern beides ungleich verteilt ist - ablesbar etwa an Ressourcen wie Einkommen, Bildung, Sozialprestige oder politischer Macht sowie an weiteren Merkmalen der sozialen Lage wie Geschlecht, Alter, Generationszugehörigkeit, ethnischer Zugehörigkeit oder Familienstand. Mit den jeweiligen Einflusspotentialen ausgetragene Kämpfe um „Lebenschancen“ stellen demzufolge die zentralen Triebkräfte gesellschaftlicher Dynamik dar.

Differenzierungstheorien betrachten die moderne Gesellschaft demgegenüber als ein Ensemble ausdifferenzierter Teilsysteme, in denen eine jeweils eigene Logik des Handelns herrscht. Jedes Teilsystem steuert dementsprechend einen besonderen, von keinem anderen Teilsystem geleisteten Beitrag zur Reproduktion des gesellschaftlichen Ganzen bei. Gesellschaftliche Dynamik verortet diese Sichtweise zum einen innerhalb jedes Teilsystems, etwa als immer weiter vorangetriebene Rationalisierung der Hand-

7 Zu ersteren siehe nur Kreckel (1992), zu letzteren Schimank (1996). 
lungslogiken, und zum anderen in den Interferenzen zwischen den Teilsystemen, etwa als Herausbildung und Engführung bestimmter struktureller Kopplungen.

Beide gesellschaftstheoretischen Perspektiven, die ungleichheits- und die differenzierungstheoretische Sichtweise, richten die Aufmerksamkeit auf äußerst wichtige Merkmale der modernen Gesellschaft. Man könnte allerdings einen analytischen Primat der Differenzierungstheorien damit begründen, dass sie das völlig Neue der Moderne gegenüber allen vormodernen Gesellschaftsformen akzentuieren. Soziale Ungleichheit hat es immer gegeben; nur ihre Arten und vielleicht ihr Ausmaß verändern sich je nach Gesellschaftsform (Lenski 1966). Hingegen weist allein die moderne Gesellschaft eine Differenzierungsform auf, die auf der selbstreferentiellen Geschlossenheit der Handlungszusammenhänge von etwa einem Dutzend Teilsystemen beruht. Das hat zuerst Max Weber deutlich gesehen, ${ }^{8}$ und Luhmann hat diesen Sachverhalt dann genauer durchdrungen.

[...] Weber (1919: 27f.) spricht vom „Polytheismus“ der „Wertsphären“, Luhmann von der polykontexturalen Gesellschaft. Die moderne Gesellschaft ist genau besehen eine Mehrzahl einander überlappender Gesellschaften: die Gesellschaft der Wirtschaft und die Gesellschaft der Wissenschaft und die Gesellschaft der Politik und die Gesellschaft der Kunst usw.

Diese Polykontexturalität ist nicht nur das eigentlich Neue an der modernen Gesellschaft, sondern auch das ihre Gestalt und Dynamik am stärksten prägende Moment. Jeffrey Alexander (1990: 11) behauptet: „... differentiation comes closer than any other contemporary conception to identifying the actual texture, the eminent dangers, and the real promises of modern life." $[\ldots]$

Ich will nun zu den beiden Fragekomplexen kommen, die mich im Rahmen einer differenzierungstheoretischen Betrachtung der modernen Gesellschaft besonders interessieren. [...] Zum einen will ich mich den Interdependenzgeflechten zwischen den verschiedenen gesellschaftlichen Teilsystemen und zum anderen der Inklusion der individuellen Gesellschaftsmitglieder in die verschiedenen Teilsysteme widmen. ${ }^{9}$

[...] Was nach wie vor erarbeitet werden muss, ist eine möglichst umfassende Darstellung der modernen Gesellschaft als eines Verflechtungszusammenhangs der Teilsysteme.

Dies ist erforderlich, um die Systemintegration der modernen Gesellschaft zu verstehen. Was hält die Teilsysteme zusammen, gerade weil sie keinen arbeitsteilig koordinierten Zusammenhang bilden, sondern einander aufgrund ihrer selbstreferentiellen Geschlossenheit fundamental indifferent gegenüberstehen? Zusammenhalt meint dabei nicht mehr als „... die Vermeidung des Umstands, daß die Operationen eines Teilsystems in einem anderen Teilsystem zu unlösbaren Problemen führen.“ (Luhmann 1977:

8 Auch Wilhelm Dilthey, worauf Hahn (1999) hinweist.

9 Siehe auch bereits Schimank/Volkmann (1999: 35-43). 
242) Es geht also bei der Betrachtung der Teilsysteminterdependenzen letztlich darum, sowohl systemintegrative Gefährdungen als auch systemintegrative Mechanismen einschätzen und begreifen zu können.

Dabei sind zwei Arten von Verflechtungen zwischen gesellschaftlichen Teilsystemen zu unterscheiden. Auf der einen Seite erbringt ein Teilsystem vielfältige Leistungen für eine Reihe anderer Teilsysteme und erhält seinerseits vielfältige Leistungen von anderen Teilsystemen - wobei Leistungsabgabe und Leistungsempfang keineswegs reziprok verlaufen müssen. So bezieht etwa die Politik Finanzmittel in der Form von Steuern aus der Wirtschaft; und nur ein kleiner Teil davon gelangt über wirtschaftspolitische Maßnahmen oder die Bereitstellung von Infrastruktur wieder als Leistungen der Politik an die Wirtschaft zurück. Zugleich erbringt die Politik aber auch andere Leistungen für die Wirtschaft - etwa die außenpolitische Erschließung von Absatzmärkten oder die Produktion von Gesetzen, die den Umgang mit Eigentum regeln. [...]

Neben Leistungsbeziehungen gibt es weiterhin Störungsbeziehungen zwischen gesellschaftlichen Teilsystemen. [...] Während man aus Untersuchungen zu den verschiedenen gesellschaftlichen Teilsystemen einiges über deren Leistungsverflechtungen mit den jeweils anderen Teilsystemen wei $\beta,{ }^{10}$ sind die Störungsverflechtungen noch relativ wenig erforscht.

$[\ldots]$

Der zweite mich interessierende differenzierungstheoretische Fragenkomplex sind [...] die gesellschaftlichen Inklusionsverhältnisse. Dabei geht es um die Intensitäten und Arten des Einbezugs der individuellen Gesellschaftsmitglieder in die verschiedenen Teilsysteme. ${ }^{11}$ Dies ist eine wichtige Facette der Sozialintegration der modernen Gesellschaft. Insbesondere über Rollen, also institutionalisierte normative Erwartungen an bestimmte soziale Positionen, werden Individuen in die Gesellschaft eingebunden - und in der polykontexturalen modernen Gesellschaft können dies nur teilsystemspezifische Rollenzusammenhänge sein. Waren die Personen in vormodernen Gesellschaften total in eine und nur eine der primären gesellschaftlichen Untereinheiten - z.B. Stände im Mittelalter - inkludiert, so liegen in der modernen Gesellschaft multiple Partialinklusionen vor (Hillebrand 1999). Niemand ist beispielsweise, so wie er im Feudalismus Bauer und dann nicht Adliger oder Geistlicher war, heute nur Konsument oder nur Mutter oder nur Patient; sondern jeder kombiniert in seiner Lebensführung vielfältige teilsystemspezifische Rollen.

$[\ldots]$

Auch bei den Inklusionsverhältnissen geht es zunächst einmal darum, sie hinsichtlich der verschiedenen Teilsysteme nach Art und Intensität zu katalogisieren. Als erstes ist in einigen Fällen interessant, ob überhaupt ein

10 Siehe beispielsweise Bette/Schimank (1995: 52-106) zum Spitzensport oder Blöbaum (1994: 4) zu den Massenmedien.

11 Grundlegend hierzu in systemtheoretischer Perspektive Stichweh (1988). 
Inklusionsverhältnis vorliegt oder nicht. Eine Reihe von Inklusionsverhältnissen sind, auf Grund normativer Regelungen oder existentieller Sachzwänge, obligatorisch. So kommt so gut wie kein erwachsenes Mitglied der modernen Gesellschaft, jedenfalls in der entwickelten westlichen Welt, an der Konsumentenrolle vorbei, weil das erforderte, ein völliger Selbstversorger zu sein. Und die gesetzlich geregelte Schulpflicht sorgt dafür, dass jemand zumindest in einer bestimmten Lebensspanne zwangsweise ins Bildungssystem inkludiert ist. Andere Inklusionsverhältnisse sind hingegen optional. Ob jemand sich für Sport interessiert, also die Rolle des Breitensportlers oder des Sportzuschauers einnimmt, obliegt seiner eigenen Entscheidung; und das gleiche gilt auch für die Inklusion ins Kunstsystem oder, schon eingeschränkter, ins System der Massenmedien. Es ist immerhin vorstellbar, dass sich jemand sein Leben lang konsequent weigert, eine Zeitung zu lesen, Radio zu hören oder fern zu sehen.

$[\ldots]$

Die soziale Modalität der Inklusion in ein bestimmtes Teilsystem läßt sich in mehreren Hinsichten näher bestimmen. Vier seien hier genannt. Erstens können die Rollen, die das Inklusionsverhältnis konstituieren, Mitgliedsrollen in formalen Organisationen sein oder nicht. Zweitens kann man kommerzielle und nichtkommerzielle Formen der Inklusion danach unterscheiden, ob man für die erhaltenen Leistungen des Teilsystems einen Marktpreis bezahlen muss oder nicht - was wiederum damit zusammenhängt, ob der Leistungsanbieter gewinnorientiert tätig ist oder nicht. Drittens kann man Inklusionsverhältnisse nach dem Grad der Asymmetrie der betreffenden Publikumsrollen zu den komplementären Leistungsrollen einstufen. Stark asymmetrisch ist etwa das Verhältnis des Schülers zum Lehrer, erhebliche Asymmetrien auf Grund hoher sachlicher Abhängigkeit enthält auch das Verhältnis des Patienten zum Arzt - wobei ersterer immerhin letzteren wechseln kann. Noch stärker nivelliert die Möglichkeit des Wechsels die Asymmetrie im Verhältnis der Konsumenten zu den Anbietern von Gütern und Dienstleistungen. Wenn die Inklusion optional ist, ist letztlich gar keine Asymmetrie gegeben - wie beim Verhältnis des Sportzuschauers zu den Akteuren des Spitzensports. Viertens schließlich sind neben den bisher angesprochenen direkten auch indirekte Inklusionen zu berücksichtigen. Jemand kann darüber in ein bestimmtes Teilsystem inkludiert sein, daß eine ihm nahestehende Person - meistens ein enger Familienangehöriger - inkludiert ist. Beispiele wären Eltern, die durch ihre Kinder mehr oder weniger intensive Kontakte zum Bildungssystem haben, oder eine Frau, die durch die chronische Krankheit ihres Mannes stark ins Gesundheitssystem eingebunden wird.

Mit den entwickelten Kategorien lässt sich ein Individuum daraufhin beschreiben, wie es rollenförmig Leistungen der verschiedenen gesellschaftlichen Teilsysteme erhält. Das Inklusionsprofil einer Person ist dann das Gesamtbild, das sich aus den einzelnen teilsystemischen Inklusionen ergibt. Im Profil bildet sich somit Inklusion in die moderne Gesellschaft als 
ganze ab. Dieses Profil ist in erheblichem Maße durch die soziale Lage einer Person determiniert - womit Anknüpfungspunkte der differenzierungstheoretischen an eine ungleichheitstheoretische Betrachtung sichtbar werden. Das Einkommens- und das Bildungsniveau, das Alter und das Geschlecht, der Familienstand und die ethnische Zugehörigkeit prägen auf vielfältige Weise, welche Inklusionsbezüge jemand wie zu realisieren vermag. [...]

Über die Inklusionsverhältnisse betrachtet man somit gesellschaftliche Differenzierung ,,von unten“, aus der Sicht der je einzelnen Individuen. Inklusionen, die teilsystemische Leistungen vermitteln, sind deshalb auch der Gegenstand von individuellen Ansprüchen. Die Gesellschaftsmitglieder beanspruchen Rechte zur Teilhabe an den verschiedenen Inklusionen; und zur tatsächlichen Nutzung dieser Rechte sind oftmals auch entsprechende finanzielle Ressourcen erforderlich. Inklusionsverhältnisse sind somit möglicher Gegenstand von gesellschaftlichen Konflikten über „Lebenschancen“ (Schimank 1998). Dabei ist stets der Zusammenhang zur modernen Gleichheits- und zur Fortschrittsidee im Blick zu behalten. Dass die Einen etwas haben, was den Anderen fehlt, wirft erhebliche Begründungspflichten auf; und dass es allen immer besser gehen soll, wird als selbstverständlich eingefordert. Sozialintegrativ problematisch wird es insbesondere dann, wenn Ansprüche kollektiv und mit politischen Mitteln durchzusetzen versucht werden - anstatt dass man versucht, die Ansprüche durch individuelle Aufwärtsmobilität oder Kriminalität zu realisieren. Auch hier ergibt sich, wie bei der Systemintegration, die Frage, welche Mechanismen im einzelnen dafür sorgen, dass die gesellschaftliche Sozialintegration gewahrt bleibt - unter welchen Umständen diese Mechanismen versagen müssen und wie die Mechanismen möglicherweise angesichts veränderter Inklusionsverhältnisse und gesellschaftlicher Rahmenbedingungen umgebaut werden müssen? Für letzteres stellt beispielsweise der „Umbau des Sozialstaats“ zur Zeit viel empirisches Anschauungsmaterial bereit.

\section{Handeln und Strukturen: Gestaltungsintentionen und transintentionale Dynamiken}

$[\ldots]$

Spezifiziert man, der allgemeinen Leitvorstellung des wechselseitigen Konstitutionsverhältnisses von sozialen Ereignissen und sozialen Strukturen folgend, die interessierenden Handlungsergebnisse auf Struktureffekte, läuft dies auf der Gesellschaftsebene auf einen bestimmten Typus von Analysen hinaus. Sie wollen gesellschaftliche Strukturdynamiken - etwa von Teilsysteminterdependenzen oder Inklusionsverhältnissen - daraus erklären, dass individuelle, kollektive oder korporative Akteure, die sich im Kontext der betreffenden Strukturen bewegen, diese in Konstellationen 
handelnden Zusammenwirkens schaffen, erhalten, verändern oder zerstören. ${ }^{12}$ Hierbei kommt Transintentionalität in zweierlei Gestalt vor:

- Zum einen sind an derartigen Strukturdynamiken immer auch mehr oder weniger viele Akteure beteiligt, deren Intentionen sich gar nicht auf die Gestaltung der betreffenden Strukturen richten, sondern auf etwas ganz anderes. Die Mitwirkung dieser Akteure an der Strukturdynamik ist transintentional im Sinne eines beiläufigen Nebeneffekts der Verfolgung andersartiger Intentionen. Ein Beispiel wären Passanten, die immer auch zur öffentlichen Sicherheit beitragen - durch ihre bloße Anwesenheit, die auf alle möglichen Absichten zurückgehen kann.

- Zum anderen gibt es nicht immer, aber doch häufig Akteure, die die betreffenden Strukturen gezielt gestalten wollen. Diese Akteure müssen oft genug realisieren, dass ihnen dies nur äußerst bruchstückhaft oder gar nicht gelungen ist und sie statt dessen ganz etwas anderes als erwartet und beabsichtigt bewirkt haben. Dies ist dann Transintentionalität als verfehlte Intentionalität.

Entscheidend ist: Selbst wenn man Transintentionalität in beiden Hinsichten für den weitaus häufigeren Fall hält als eine relativ ungebrochene Realisierung von Gestaltungsabsichten, kann man die Intentionalität von Akteuren nicht einfach analytisch ausblenden. Auch wenn sie nicht verwirklichen, was sie gewollt haben, ist ihr Wollen doch wichtig, weil es als so und nicht anders beschaffener Handlungsimpuls in die soziale Wirklichkeit hinein gewirkt hat. Bei der Vektoraddition muß man schließlich auch die Ausrichtungen aller zu addierenden Vektoren berücksichtigen. Selbst wenn der Summenvektor weit von jedem von ihnen abweicht, ergibt er sich doch in seiner Richtung und Stärke nur aus ihnen.

So erklärt sich, dass ich bei meinen differenzierungstheoretischen Forschungsinteressen weder Luhmanns kommunikationstheoretische Perspektive noch eine nicht-teleologische Handlungskonzeption zu Grunde legen kann. Es bietet sich vielmehr unter den schon genannten Akteurmodellen insbesondere der Homo Oeconomicus der Rational-Choice-Perspektive an, der auf eine gezielte Nutzenorientierung abstellt - was unter anderem ein Bemühen um strategische Strukturgestaltung sein kann. Zur Erklärung desjenigen Handelns, das ohne Gestaltungsabsichten an den betreffenden Strukturdynamiken beteiligt ist, kann man dann neben dem Homo Oeconomicus auch auf den normorientierten Homo Sociologicus, den ,emotional man" und den Identitätsbehaupter zurückgreifen (Schimank 2000: 19167).

Noch wichtiger sind freilich für meine Fragestellungen theoretische Modelle, die bestimmte Konstellationen handelnden Zusammenwirkens in

12 Dies ist auch die Leitvorstellung der Forschungen des Kölner Max-Planck-Instituts für Gesellschaftsforschung - siehe als eine Zwischenbilanz Mayntz/Scharpf 1995. 
ihren dynamischen Verläufen und strukturellen Effekten einfangen. Hierzu hat die allgemeine Soziologie leider bis heute notorisch wenig anzubieten. [...] Und erst recht hat die allgemeine Soziologie geflissentlich ignoriert, was andere Sozialwissenschaften diesbezüglich bereits vorgelegt haben von der Spieltheorie über die ökonomische Marktformenlehre und die „path dependency“ bis hin zu politikwissenschaftlichen ,governance“-Konzepten. All das und weiteres mehr versuche ich in meinem soziologischen Werkzeugkasten unterzubringen und richtig zu sortieren. [...]

Eine differenzierungstheoretische Perspektive mit der skizzierten Art von Akteurtheorie zu koppeln ist allerdings wenig verbreitet. ${ }^{13}$ Üblich ist nach wie vor die an Luhmann anschließende systemtheoretische Fundierung differenzierungstheoretischer Analysen. Es dürfte allerdings bereits deutlich geworden sein, daß sich für die mich interessierenden Fragen bezüglich der Teilsysteminterdependenzen und Inklusionsverhältnisse eine das zielorientierte Handeln akzentuierende akteurtheoretische Herangehensweise besonders eignet. Gesellschaftliche Differenzierungsstrukturen sind insgesamt Resultat eines Wechselspiels von „,naturwüchsigen“ Differenzierungsdynamiken und ,differenzierungspolitischen“ Bemühungen der gezielten Gestaltung. [...]

Gestaltungsbemühungen bringen freilich, wie gesagt, keineswegs immer die gewünschten Resultate. Nebenwirkungen können sich einstellen und stärker ins Gewicht fallen als die beabsichtigten Effekte; letztere können sogar gänzlich ausbleiben. [...]

\section{Literatur}

Alexander, Jeffrey, 1990: Introduction - Differentiation Theory: Problems and Prospects. In: Jeffrey Alexander/Paul Colomy (Hg.), Differentiation Theory and Social Change. Comparative and Historical Perspectives. New York: Columbia University Press, 1-15.

Ashby, W. Ross, 1956: Einführung in die Kybernetik. Frankfurt a.M. 1974: Suhrkamp.

Bette, Karl-Heinrich/Uwe Schimank, 1995: Doping im Hochleistungssport. Frankfurt/M.: Suhrkamp.

Blöbaum, Bernd, 1994: Journalismus als soziales System. Opladen: Westdeutscher Verlag.

Dahrendorf, Ralf, 1979: Lebenschancen. Anläufe zur sozialen und politischen Theorie. Frankfurt/M.: Suhrkamp.

Hahn, Alois, 1999: Die Systemtheorie Wilhelm Diltheys. In: Berliner Journal für Soziologie 9, 5-24.

Hillebrand, Frank, 1999: Exklusionsindividualität. Moderne Gesellschaftsstruktur und die soziale Konstruktion des Menschen. Opladen: Leske + Budrich.

Kreckel, Reinhard, 1992: Politische Soziologie der sozialen Ungleichheit. Frankfurt/M.: Campus.

13 Während die ungleichheitstheoretische Perspektive, etwa in Reinhard Kreckels (1992) „,politischer Soziologie sozialer Ungleichheit“, ganz selbstverständlich eine derartige akteurtheoretische Herangehensweise benutzt. 
Lenski, Gerhard, 1966: Macht und Privileg. Eine Theorie der sozialen Schichtung. Frankfurt/M., 1977: Suhrkamp.

Luhmann, Niklas, 1975: Interaktion, Organisation, Gesellschaft. Anwendungen der Systemtheorie. In: Niklas Luhmann, Soziologische Aufklärung 2. Aufsätze zur Theorie der Gesellschaft. Opladen: Westdeutscher Verlag, 9-19.

Luhmann, Niklas, 1977: Funktion der Religion. Frankfurt/M.: Suhrkamp.

Mayntz, Renate/Fritz Scharpf (Hg.), 1995: Gesellschaftliche Selbstregelung und politische Steuerung. Frankfurt/M.: Campus.

Münch, Richard, 1991: Dialektik der Kommunikationsgesellschaft. Frankfurt/M.: Suhrkamp.

Schimank, Uwe, 1996: Theorien gesellschaftlicher Differenzierung. Opladen 1996: Leske + Budrich (UTB).

Schimank, Uwe, 1998: Funktionale Differenzierung und soziale Ungleichheit: die zwei Gesellschaftstheorien und ihre konflikttheoretische Verknüpfung. In: Hans-Joachim Giegel (Hg.), Konflikt in modernen Gesellschaften. Frankfurt/M.: Suhrkamp, 61-88.

Schimank, Uwe, 2000: Handeln und Strukturen. Einführung in die akteurtheoretische Soziologie. Weinheim, München: Juventa.

Schimank, Uwe/Ute Volkmann, 1999: Gesellschaftliche Differenzierung. Bielefeld: Transcript.

Stichweh, Rudolf, 1988: Inklusion in Funktionssysteme der modernen Gesellschaft. In: Renate Mayntz, u.a. (Hg.): Differenzierung und Verselbständigung. Frankfurt a.M., 261-293.

Weber, Max, 1919: Wissenschaft als Beruf. Berlin, 1967: Duncker \& Humblot. 


\section{Pädagogik}

\section{Kommentar (Eubel)}

Die Beschäftigung mit sozialem Wandel, mit gesellschaftlichen Änderungsprozessen generell, ist für die Soziologie selbstverständlich. Richtet sie ihr Augenmerk also auf den Gegenstandsbereich dieses Buches, braucht sie nur ihren Werkzeugkasten aufzumachen und kann ans Werk gehen. Die einzige Schwierigkeit, die sich ergeben könnte, liegt in der Entscheidung darüber, welche Methoden und ,Werkzeuge' zum Einsatz kommen sollen. ${ }^{14}$

Im Falle der Pädagogik dürfte auffallen, dass zumindest in Teilbereichen der Erziehungswissenschaft die Erkenntnis, dass auch die Schule eine gesellschaftliche Einrichtung, eine soziale Tatsache ist, nicht unbedingt zu den ,Essentials' gehört. Bei genauerem Hinsehen gibt es jedoch eine Menge an theoretischen und empirischen Versuchen, die Verfasstheit der Schule als ,soziale Tatsache“ (Emile Durkheim 1984) ernst zu nehmen und gehaltvoll theoretisch zu fassen. ${ }^{15}$

Hier sind zunächst Ansätze der historischen Bildungsforschung zu nennen, die den Anteil der öffentlichen Schule an der Herausbildung der modernen Nationalstaaten (vgl. Wenning 1999) oder die Eigenentwicklung des Bildungssystems - einschließlich besonderer „Wachstumsschübe“ und Phasen relativer Stagnation (vgl. Nath 2003; Lundgreen 2003) - untersuchen. ${ }^{16}$ Die Schule wird als wesentlicher Motor der gesellschaftlichen Modernisierung gesehen: in den Vereinigten Staaten ist sie der Ort der „Amerikanisierung" einer heterogenen Zuwanderergesellschaft; die französischen Volksschullehrer erscheinen als die Husaren der Republik (Ozouf 1967); die preußische Schule ist das Instrument zur „Prussianisierung“ der Bevölkerung (Leschinsky/Roeder 1976) und zugleich die Institution zur ,Verfertigung' des preußischen Untertanen. Die Schule wurde zu einem universalisierten Modell, das sich weltweit durchsetzte (vgl. Adick 1992; Archer 1982a, 1984; Meyer u.a. 1977; Ringer 1979), einschließlich prob-

14 Dass dieser Entscheidungsprozess nicht beliebig ist, sondern dass es zum jetzigen Zeitpunkt gute Gründe für die Bevorzugung akteurtheoretisch orientierter Ansätze gibt, die in diesem Buch im Vordergrund stehen, wird - hoffentlich! - der Ertrag dieses Buches zeigen.

15 Um die ,ziemlich heterogene Menge von Literatur“" (Diederich/Tenorth 1997: 7) zu strukturieren, hier einige, in unseren Augen wichtige Publikationen. Dazu gehören in jedem Fall Fend (1980), Tilmann (1987), Apel (1995), besonders auch Diederich/Tenorth (1997), Grunder/Schweitzer (1999) und Baumgart/Lange (1999).

16 Vgl. dazu den Thementeil „Bildungssystem im Wandel - Zwischen Eigendynamik, Politik und Pädagogik“ in Heft 1/2003 der Zeitschrift für Pädagogik, der Beiträge eines Symposions (,Reformen in den regelmäßigen Wachstumsschüben des Bildungssystems im 19. und 20. Jahrhundert") vom 18. Kongress der Deutschen Gesellschaft für Erziehungswissenschaft im März 2002 in München versammelt. 
lematischer Konsequenzen, wie Erfahrungen aus Ländern der Dritten Welt zeigen.

Parallel zur Entstehung und Expansion der modernen Schulsysteme entwickelte sich Skepsis darüber, ob der eingeschlagene Weg der richtige sei. Die Kritik munitionierte sich dabei aus unterschiedlichen Quellen: Zum einen wurde bezweifelt, ob die ,richtige' Bildung an Kinder und Jugendliche vermittelt wurde, außerdem wurde danach gefragt, ob das wertvolle Gut ,Bildung' auch gerecht unter ihnen verteilt werde. In diesem Zusammenhang entsteht der Verdacht, dass sich die erstarkten Bildungssysteme relativ unabhängig gemacht hätten von ihrem gesellschaftlichen Auftrag, Chancengleichheit zu fördern, dass sie nur eine „Illusion der Chancengleichheit" vortäuschten (vgl. Bourdieu/Passeron 1971), um ihre eigenen Interessen verfolgen zu können. Zudem war von Anfang an fraglich, welche Rolle der Staat bei der Entwicklung und Steuerung von Schulsystemen einzunehmen habe. Skepsis gegenüber zu hoher staatlicher Steuerung finden wir bereits bei Humboldt, allerdings ohne große Konsequenzen für Preußen/Deutschland. Andernorts hingegen waren solche ,liberalen' Vorbehalte erfolgreicher.

Interessant ist nun aber auch, dass in der Retrospektive viele Intentionen und Argumente der Kritik an der ,modernen' Schule von der Forschung als Affekt - vor allem der Pädagogen - gegen die „Moderne“ selbst charakterisiert werden. Vor allem der Reformpädagogik werden idealistische Verkürzungen (vgl. Oelkers 1989) und eine Romantisierung der Vormoderne, eine reduktionistische Sicht der modernen Gesellschaft und eine unzureichende Verankerung von schulischen Bildungsangeboten in den ausdifferenzierten Gesellschaften der modernen Staaten vorgeworfen (vgl. Benner/Kemper 2002).

Der Erfolg der Schule einerseits und ihre durchaus ,eigensinnige' Eigendynamik andererseits weisen auf ein Dilemma hin. Retrospektiv lässt sich der Stellenwert der öffentlichen Schule im Prozess der Modernisierung recht gut beschreiben. Überspitzt gesagt könnte man formulieren: Die Schule, wie sie sich im Laufe des 19. und 20. Jahrhunderts entwickelte, hat sich, wenn auch zögerlich voranschreitend, ,zu Tode gesiegt ${ }^{\star}$. Da sich nun aber einige gesellschaftlichen Prämissen verändert haben, ist zu bezweifeln, ob die Weiterentwicklung der Schule nach dem althergebrachten Programm weiterhin ihren Erfolg sichert. Wie allerdings ein Umsteuern aussehen könnte, ob ein solches - vor allem im Schulsystem selbst - überhaupt als erforderlich angesehen wird, das ist auch in der pädagogischen Theoriebildung durchaus unklar. Es gibt aber vehemente Fürsprecher dafür, sich diesen Fragen aus erziehungswissenschaftlicher Sicht zu nähern und sie haben gute Argumente, die sich systematisieren und mit Reformvorschlägen vernetzen lassen.

Im ersten Beitrag des folgenden Buchabschnitts geht Jürgen Oelkers (Universität Zürich) der Frage nach, ob und wie sich die „Verantwortung“ der Schule aus erziehungswissenschaftlicher Sicht verändert, wenn sie sich 
mit „Schulautonomie“ auseinandersetzt, einem der zentralen Begriffe in den derzeitigen schulischen Modernisierungsdiskursen.

Nach Oelkers meint Autonomie, legt man die Tradition und die Entwicklung der öffentlichen Schule seit dem 19. Jahrhundert zugrunde, aus der Sicht des Schulsystems und vor allem der Lehrer: Der Staat unterhält öffentliche Schulen komplett, versieht sie mit Privilegien und lässt sie möglichst unbehelligt. Autonomie heute - Oelkers spricht auch von „erweiterter Verantwortung“ - dagegen bedeutet: „Formulierung und Überprüfung erreichbarer Ziele“, „Nachweis von Fehlern“, „,vorbehaltlose Analyse von Stärken und Schwächen“, also Herstellung ,innerer Transparenz“. Dies bedeutet eine radikale semantische Umcodierung des Autonomiebegriffs! Eine solchermaßen veränderte Schule handelt sich durch die Umcodierung auf diese Art von Autonomie erst einmal Unsicherheit ein, schafft sich zusätzlich Konkurrenz auf einem entstehenden Bildungsmarkt. So ist nicht verwunderlich, dass der Status quo durchaus attraktiv erscheint, dass Bürokratie, Beharrungsvermögen, Frontalunterricht sich plötzlich als Vorteil gegenüber den wechselnden und fehlbaren Moden der Veränderung von Schule darstellen, zumindest in der Binnenperspektive der einzelnen Schule. Die Pointe der Argumentation von Oelkers lautet aber: Ein ,bisschen Umcodierung und Programmwechsel geht nicht. Entweder die Schule lässt sich radikal auf die neue erweiterte Verantwortung ein oder sie tastet den Status quo erst gar nicht an. Da Oelkers viele, von ihm als Utopien bezeichnete Argumente für das „Umschwenken“ nennt, aber auch auf „Systemfallen" hinweist, die sich daraus ergeben könnten und darüber hinaus auch viele (gute) Gründe für das Beharrungsvermögen der Institution Schule angibt, bleibt zu fragen, was sich aus seiner Analyse ergibt. Auf keinen Fall neue Gewissheiten, außer der, dass weder Modernisierer noch Traditionalisten sich exklusiv auf ihn berufen können. Oder - auf einer höheren Abstraktionsebene: Die pädagogischen Begründungen für Modernisierung sind derzeit nicht systematisiert formulierbar, sie sind ein offener Katalog, sie bieten aber mehr Ansatzpunkte für empirische Bewährungsproben als dies in den stärker geschlossenen Argumentationszirkeln zur Legitimierung des Status quo vorgesehen ist. Und aus der Erfahrung mit der historischen Entwicklung des Bildungswesens mit seinen durchaus strukturerhaltenden und konservativen Tendenzen muss geschlossen werden, dass Modernisierung in keinem Falle ein sich von selbst erzeugendes Programm darstellt.

Das belegt auch der zweite Beitrag von Oelkers in diesem Buch, in dem er die Frage stellt: „Wie lernt ein Bildungssystem?“ Er zeigt auf, dass die historisch nachvollziehbare Erfolgsstory der öffentlichen Schule, bestimmt durch immer mehr Wachstum und Bildungsvertrauen, in einer „Monopolstellung des staatlichen Anbieters" endete, mit fatalen Folgen: Schwache öffentliche Kontrolle, die unprofessionelle Neigung zur Intransparenz und eine hohe persönliche Belastung aller Beteiligten. Deshalb muss sich das System nach außen „irrtumsfrei und hochgradig zielkonform“ darstellen. Das aber führt zu einem „,falschen Lernverhalten, das Konformität belohnt 
und die Fehlertoleranz bestraft". So wie Paul Watzlawick das paradoxe Verhalten von Individuen beschreibt, die sich Änderungen wünschen, sich diese aber durch die Strategie des ,more of the same“ systematisch verbauen (vgl. Watzlawick u.a. 2000), so lernt auch das Bildungssystem: Indem es „sich selbst fortsetzt.“ Marginaler Wandel, der in der Vergangenheit durchaus den Erfolg garantierte, könnte aber angesichts der dramatischen Veränderungen der schulischen Umwelt zum Überlebensrisiko werden: Vor allem der technologische Kern der Schule, der Mitte des 19. Jahrhunderts einen gewaltigen Modernisierungsschub brachte (verbindliche Lehrmittel, didaktisierte Schulbücher, standardisierte Methoden, starre Zeitschemata), wird heute - angesichts der Forderungen nach Individualisierung - zum Risiko, vor allem auch deshalb, weil außerhalb der Schule Lerntechnologien zur Verfügung stehen, mit denen diese Forderung erfüllbar erscheint.

Die in der Schule heute schon weitgehend akzeptierte und von den Schülern eingeforderte Veränderung der Lerngewohnheiten, weg vom ,trägen 'Wissen, das den schulischen Kanon reproduziert, hin zum ,Lernen des Lernens', das in der Wissensgesellschaft erforderlich sein wird, muss um einen weiteren, notwendigen Schritt ergänzt werden. Die Schule muss zu einer lernenden Organisation werden. Ohne genau auszuführen, was dies im Einzelnen impliziert ${ }^{17}$, dürfte klar sein, dass damit die Ebene des individuellen und personenbezogenen Lernens überschritten wird, dass so etwas wie ein Institutionsgedächtnis etabliert wird, was wiederum Auswirkungen auf die Arbeitsorganisation und Prozesssteuerung hat.

Transponiert man solche Aussagen auf die Ebene pädagogischer Theoriebildung, dann bedeutet dies, dass die Schule nicht mehr wie bisher als eine ,Lehrerschule' mit einseitig verteilten Verantwortlichkeiten und Privilegien beziehungsweise Pflichten konzipiert werden kann - Rechenschaft und Transparenz nach innen und außen müssen an deren Stelle treten.

Wie also nähert sich die Erziehungswissenschaft dem Problem der Modernisierung? Die Einlassungen von Oelkers belegen, dass es sich offensichtlich um ein sehr ambivalentes Phänomen handelt, ambivalent vor allem deshalb, weil sich das ,Neue' nicht problemlos in die Tradition integrieren lässt, also Entscheidungen gefordert sind, entweder die Vergangenheit in die Zukunft zu verlängern oder aber das Ruder herumzuwerfen, und die Schule ,neu zu denken', wenn die sprachliche Anleihe bei Hartmut von Hentig (1994) erlaubt ist. Das Dilemma, die Entscheidung zwischen, weiter so ' oder , umsteuern“ wird nun je nach Standpunkt von verschiedenen Akteuren eher defensiv oder offensiv angegangen.

Denkt man die durch Oelkers deutlich gemachten Widersprüche und Paradoxien eines Schulsystems zwischen Beharrung und Wandel weiter (vgl. Besag/Nelson 1984), dann stellt sich sehr schnell die weitergehende Frage nach dem Zusammenhang von Pädagogik und Politik, danach, wie

17 Beiträge in Textblock „Beobachtung von Akteurkonstellationen“ vertiefen diesen Aspekt. 
(1) pädagogische Theoriebildung als Produkt des pädagogischen Establishments (vgl. Luhmann/Schorr 1979), (2) eine eventuelle Eigendynamik des Bildungswesens und (3) Politik und Gesellschaft sich zueinander, verhalten'. Wie sich durch neueste bildungshistorische Forschungen andeutet, scheint sich retrospektiv eine starke Relativierung der Relevanz der gängigen Formen, in denen theoretische Aussagen über institutionalisierte Bildungsprozesse formuliert wurden, zu ergeben. Zwar scheint das Diktum des Bildungshistorikers Friedrich Paulsen vom Anfang des letzten Jahrhunderts, dass ,das Bildungswesen keine Eigenbewegung hat, sondern von dem großen Gang der allgemeinen Kulturbewegung bestimmt wird" (Paulsen 1906, zit. nach Link u.a. 2003: 1), durchaus widerlegbar zu sein. Wie aber der Stellenwert pädagogischer Reflexion zu bewerten ist, bleibt strittig. Radikale Kritiker, wie die konservative amerikanische Bildungshistorikerin und -beraterin Diane Ravitch $(1983,2000)$ sehen in pädagogischen Reformreflexionen das Grundübel, das ursächlich für die Irrwege der Entwicklung im Bildungswesen ist. Differenzierter analysierende Bildungshistoriker gehen eher von einer relativ geringen Wirkung solcher Reflexion aus, vor allem wenn es deren Wirkung für die alltägliche unterrichtliche Praxis zu bestimmen gilt (vgl. Cuban/Tyack 1995; Tenorth 2003).

Wenn die Pädagogik diese Diskurse - angesichts radikal veränderter Umwelten - mehr oder weniger unverändert fortsetzt, die tradierte Argumentationslogik weiter verfolgt, eine Option, die Oelkers für möglich hält, ist zu vermuten, dass der Grad der Irrelevanz solcher Diskurse zunimmt. Wenn aber - auch diese Option hält Oelkers für denkbar - die Inhalte und Begründungen pädagogischer Theorie sich durch ein umweltoffeneres Verhalten ändern, sprich: wenn Theorie vermehrt empirische Inputs zulässt, wenn das Bildungssystem sein Lernverhalten im Sinne einer lernenden Organisation ändert, muss es nicht bei dieser relativen Irrelevanz bleiben. Wie aber diese Theorie sich inhaltlich ausgestalten lässt, ist derzeit nur in Ansätzen erahnbar. Es handelt sich um eine ,Baustelle', an der von den unterschiedlichsten Ausgangspunkten her intensiv gearbeitet wird. Auch dafür sind die Beiträge unseres Buches Beleg. ${ }^{18}$

18 Das Thema ist auch nicht nur das Hobby einzelner Forscherinnen und Forscher, sondern hat einen hohen Stellenwert in den Diskursen der Profession. So befassten sich mehrere Kongresse der Deutschen Gesellschaft für Erziehungswissenschaft mit einschlägigen Themen. Vgl. Benner u.a. (1992); Achtenhagen/Gogolin (2002). 


\section{JÜRGEN OELKERS \\ Schulen in erweiterter Verantwortung \\ Eine Positionsbestimmung aus erziehungswissenschaftlicher Sicht}

[...] Ich werde im folgenden drei Thesen vertreten, die einander hoffentlich produktiv widersprechen: Versteht man unter "Schulautonomie“ Unbehelligtsein, dann spricht alles dafür, den Status quo zu bestärken (1). Wenn Effizienzfragen unvermeidlich werden, ist der Status quo gefährdet, das System tut gut daran, Freiheiten zu fordern (2). Jede neue Freiheit erhöht den Kontrollaufwand; das System verteuert sich mit der Autonomie; die erhöhte Leistungsfähigkeit ist nur zu haben, wenn neue Rechnungen möglich werden (3).

\section{Staatliche Schulautonomie}

Wer heute „Schulautonomie“ fordert, verwendet oft eine alte Professionsstrategie, die im 19. Jahrhundert ausprobiert wurde. „Autonom“ sind öffentliche Schulen dann, wenn der Staat sie komplett unterhält, mit exklusiven Privilegien versieht, sie nach den Forderungen der Schule ausbaut und dabei möglichst unbehelligt läßt. Die Investition soll ohne externe Produktkontrolle erfolgen, Aufsicht ist zulässig nur als Unterstützung, der Grad der Autonomie bemißt sich entsprechend am Grad der inneren Freiheit, die beurteilt wird, wie unbehelligt sich die Lehrkräfte fühlen. Je weniger der Staat, von dem alle Mittel kommen, eingreift, desto mehr "Autonomie“ scheint $\mathrm{zu}$ bestehen. An unabhängige und folgenreiche Kontrollen ist das System nach seiner langen Erfolgsgeschichte nicht gewöhnt.

In diesem Sinne schützt die ausgebaute Staatlichkeit die Schulautonomie, was paradoxerweise mit Forderungen nach mehr Autonomie verbunden werden kann. Die historische Autonomiediskussion geht einher mit einer sehr suggestiven Bürokratiekritik [...]. Amtliche Regelungen behindern den Lehrer, der ein öffentliches Amt eigener, nämlich pädagogischer Art versehen soll. Der fremdbestimmte Lehrer kann mangelnde Effektivität auf die einengenden Vorschriften zurückführen, jeder neue Erlaß bestätigt dann die These der Behinderung „von oben“. Die eher schwachen Reglemente zeigen dagegen, daß „oben“ und ,unten“ nicht wie militärische Befehlsebenen verstanden werden dürfen. Top-down, um das heutige Schlagwort zu gebrauchen, war nicht nur eine flache, sondern auch eine höchst vorteilhafte Verbindung, weil die staatliche Schulaufsicht immer systemsorgend war und Nachteile in Grenzen zu halten verstand. Das Feindbild ist also nur Rhetorik.

Die Bürokratiekritik übersieht zweierlei, zum einen kontrolliert die Schulaufsicht nicht wirklich und garantiert damit die Schulautonomie, zum anderen bringt sie tägliche und unverzichtbare Vorteile. Ich nenne nur: Schutz der Haushalte, annähernd gleiche Verteilung der Ressourcen, gere- 
gelte Personalanstellung, Ausgleich bei Konflikten und sogar Chancen für den Aufstieg. Die Kontrolle im Gegenzug zu diesen Leistungen ist vergleichsweise schwach oder unwirksam. Schulverwaltungen sorgen nicht für unabhängige Erhebungen, die die Effekte von Unterricht und Verschulung vergleichend und folgenreich beschreiben würden, es gibt keinen geregelten Wettbewerb, die einzelne Schule kann davon ausgehen, daß sie unbehelligt von den Effekten anderer Schulen betrachtet und verwaltet wird. Sie muß nicht einmal die eigenen Stärken und Schwächen unterscheiden, vermutlich das größte Privileg, das heute denkbar ist.

Schulen sind nicht nur staatlich geschützt, sie sind mit ihrer Bestandsgarantie in bestimmten, entscheidenden Fragen autonom. Sie geben Noten oder formelle Beurteilungen, ohne die tatsächlichen Leistungen nachweisen zu müssen; sie regeln die Zeitverteilung, den wichtigsten Faktor für das Produkt, ohne auf Effizienz achten zu müssen; sie garantieren mit dem Kollegialitätsideal den einzelnen Lehrkräften eine beispiellose Handlungsfreiheit, die gegenüber niemandem wirklich berichtspflichtig ist. Schulen dürfen sanktionieren, beurteilen, über Schicksale entscheiden, ohne ernsthafte und ständige Kontrolle fürchten zu müssen. Selbst gerichtliche Korrekturen von Schulentscheidungen sind verglichen mit anderen Bereichen des öffentlichen Lebens immer noch eher seltene Erscheinungen. Die Schulen bestimmen faktisch auch über den Wandel ihres Produkts, den nichtstaatliche Lehrplanarbeit erzeugt. Schulkulturen haben gelernt, sich vor Zumutungen zu schützen, also vor störenden Forderungen, die in die Autonomie des Inneren eingreifen könnten. Anders ließen sich die Tag-für-TagAnstrengungen der einzelnen Lehrkraft auch kaum bewältigen, sie nutzt gleichsam die Chancen des relativen Unbehelligtseins, während genau dadurch Transparenz behindert wird. Jede Lehrkraft braucht ein eigenes Königreich, Öffnungen sind immer riskant, weil dann andere Beurteilungen der je eigenen Leistung anfallen als lediglich die der Schüler. Die faktische Autonomie schützt daher auch intransparente Unfähigkeit, weil Leistungsvergleiche verpönt sind und auch tatsächlich das Ideal stillschweigender Kollegialität gefährden würden.

Das System nutzt den staatlichen Auftrag und verteilt seine Anstrengungen wesentlich nach innen. Lehrpersonen und ihre Tätigkeit sind die Grundlage aller Berechnungen, externe Einflüsse können unbeachtet bleiben, auch Schwankungen, die von außen verursacht werden, haben keinen Einfluß bei der Festlegung der Etats und so der Investitionen. Verschult wird das abstrakte Schulkind, das unfreiwillig anwesend sein muß, den Lehrplan des Lehrers (und so der Schule) zu lernen hat, kaum über Mitspracherecht verfügt und so der Schule nur motivational gefährlich werden kann. Die Machtverteilung ist zugunsten des Anbieters und einseitig festgelegt; das System bedient nicht Kunden mit einem marktfähigen Angebot, sondern vollzieht staatliche Autorität auf weitgehend unbehelligte Weise.

Eltern etwa müssen sich für die Schule engagieren, wenn sie Verbesserungen bewirken wollen - meistens solche, die der Schulverwaltung abver- 
langt werden und die heute nur Umverteilungen sein können. Gegen die Schule ist Widerstand nicht vorgesehen, Kritik muß sich auf ein autonomes System einstellen, das sich der Öffentlichkeit entziehen kann, ohne Nachteile zu erleben. Umgang mit der Öffentlichkeit gehört nur am Rande zu den Aufgaben der Schule, sie ist in einem sehr wörtlichen Sinne korporativ verfaßt oder verhält sich zumindest so, daß die politische Metapher des corpus bezeichnet, was die Schule charakterisiert. Die staatliche Anstalt kontrolliert selbst, was von außen wahrgenommen und aufgegriffen werden soll. Das System kennzeichnet ein vorsichtiger Konservativismus, der möglichst bleiben will, was er selbst als Erfolg definieren kann.

Dieses Verhalten wird gestützt durch die Privilegien des Systems, also Abschlüsse, Berechtigungen, Übergänge, die alle ohne Konkurrenz organisiert sind. Der Schuleintritt kennt nicht verschiedene Anbieter, sondern eine Grundschule; Wechsel in andere Teilsysteme setzen einen Abstimmungsprozeß zwischen Schule und Elternhaus voraus, nicht die Wahl zwischen verschiedenen Angeboten auf gleichem Niveau; die weiteren Karrieren verlaufen wesentlich dort, wo die Erstplazierung erfolgt ist, Korrekturen etwa durch Entscheide für alternative Anbieter sind nicht möglich, verlangen einen Ausstieg oder gefährden die Karriere. Das System lernt nicht negativ, für schlechte Erfahrungen gibt es keine sinnvolle Verwendung, während positive Erfahrungen immer wie Systembestätigungen verstanden werden müssen.

Neben den Abschlüssen verfügt die Schule über eine Reihe von internen Privilegien, die so selbstverständlich genutzt werden, daß sie kaum ins Auge fallen. Ich nenne drei: die Autonomie von Kausalitäten, das historische Recht der Beharrung und das Vorrecht, sich die Leistungen selbst bestätigen zu können. Was immer eine „Schulleistung“ sein mag, sie wird von der Schule und nur von ihr erzeugt. Alle Systeme der Beurteilung gehen von einer singulären, ungeteilten Kausalität aus, externe Faktoren werden vernachlässigt oder bleiben unberücksichtigt. Dabei profitiert die Schule unablässig von Vorteilen, die sie nicht erzeugt; ebenso wird sie durch Nachteile beeinträchtigt, für die sie nicht verantwortlich ist und die gleichwohl ihre Leistungen beeinflussen. Den Erwerb nützlicher Fremdsprachenkenntnisse muß man sich mit einer hohen Außenkausalität vorstellen, ähnlich Musikkenntnisse oder Fähigkeiten, die der Sportunterricht der Schule nutzt, aber nicht hervorbringt. Selbst Perfektionsgrade in den Kulturtechniken hängen vermutlich mehr von den Qualitätsansprüchen der Elternhäuser als von den tatsächlichen Erfolgen der Grundschule ab. Wer davon abstrahieren kann, muß über eine hohe Autonomie verfügen.

Das zweite interne Privileg ist das der Beharrung. David Tyack und Larry Cuban (1995) haben dafür den Ausdruck "grammar of schooling“" geprägt. Die grammatische Form sozusagen der Schule ist persistent, und es trifft sicher nicht nur auf die amerikanischen Reformerfahrungen dieses Jahrhunderts zu, was Tyack und Cuban schlußfolgern: „Little has changed in the ways that schools divide time and space, classify students and alloca- 
te them to classrooms, splinter knowledge into ,subjects' and award grades and ,credits" as evidence of learning." (ebd., 85) Mit diesen Vorgaben und aus diesen Vorgaben heraus lernt das System (Oelkers 1995). Lernen wäre so Bestätigung der Struktur, die wie ein historisches Recht gefaßt wird. Die Verteilung von Wochenstunden nach Fächern, also das organisatorische Zentrum der Schule, erlaubt Umschichtungen nur mit hysterischen Folgen. Niemand weiß, wie viele Stunden Englisch pro Woche in wieviel Jahren welche Kompetenz hervorbringt, aber eine Stunde weniger wäre eine nicht zu tolerierende Maßnahme, wesentlich weil andere Fächer profitieren, über die man ebensowenig weiß.

Das dritte Privileg erwächst aus der Praxis der Leistungsbeurteilung. Lehrerinnen und Lehrer beurteilen Schülerleistungen, wesentlich ohne dabei den Anteil der Lehrerleistung in Rechnung zu stellen. Die Note oder das Leistungsurteil faßt eine gemeinsame Erfahrung zusammen, die einseitig beschrieben wird. Wieviel und was genau dem Lehrer zugeschrieben wird, wie sich Leistungsunterschiede der Lehrer anrechnen lassen, welche Nachteile und welche Vorteile ein guter und ein schlechter Lehrer für die Leistungen der Schüler mit sich bringt, bleibt unberücksichtigt, aber Noten werden erteilt, die alle den gleichen symbolischen wie rechtlichen Status haben. Die Schule beurteilt sich damit selbst, ohne auch nur Vergleiche mit anderen Schulen anstreben zu müssen. Ein Vergleich gar, ob die BerlitzSchool effektiveren Englischunterricht gibt als die staatliche Volksschule, ist schon als Idee eine Provokation.

Aus diesen Beobachtungen schließe ich, daß Gründe gar nicht gut genug sein können, eine Systemkorrektur mit Unterstützung des Systems zu veranlassen. Auch sehr überzeugende Gründe, etwa solche, die darauf hinweisen daß allgemeine Steuern nicht allgemein genutzt werden, wenn öffentliche Schulen Abschlüsse ungleich verteilen, sind kein Anlaß zur Veränderung, lange die staatlich geschützte Autonomie bestehen bleibt. Wie also gelangt man zu größeren Freiheiten, wenn jeder einzelne Schritt Unsicherheit erzeugt und so den Status quo bestätigt? Schulen in erweiterter Verantwortung können nur Schulen sein, die mehr Risiken eingehen müssen, mehr Entscheidung zu verantworten haben und diesen Wandel nicht nur als Vorteil erleben werden. Warum sollten sie den Wandel eingehen?

\section{Wege zum Wandel}

Faktoren für die Trägheit des Schulsystems sind nicht nur solche, die aus inneren Privilegien erwachsen, die niemand gern preisgeben möchte. „Trägheit“" kann auch als Vorsicht gedeutet werden und als Stil, wie angesichts unerfüllbarer Erwartungen Überleben in einer historisch erfolgreichen Form mit möglichst geringen Risiken zu gewährleisten ist. Die Geschichte der Schule beschreibt auch einen starken Effekt der Gewöhnung an Schule, also an eine Organisationsform, die für ihr Publikum über einen 
längeren Zeitraum wiedererkennbar ist, zwischen den Generationen oft den einzigen Erfahrungszusammenhang herstellt und wie eine wohltuend ungewandelte Institution erlebt wird. [...]

Reformen des Systems sind staatliche Maßnahmen, die politisch entschieden werden, ohne öffentlich abgestimmt zu sein. Das Beispiel Schweiz zeigt, daß Schulen gute Chancen haben, Abstimmungen auch gegen die staatlichen Schulreformer zu gewinnen, wenn sie ihre lokale Öffentlichkeit mobilisieren, die die bestehende Form bestätigt oder nur geringfügig verändert sehen will. Beharrung ist dann auch ein Mittel gegen übertriebene Schulideologien, mit denen Entscheide getroffen werden, die langfristig wirksam sind, ohne Verantwortung oder gar Haftung zu verlangen. Die Wünsche sind der Wirklichkeit immer voraus, aber pädagogische Wünsche sind auf seltsame Weise ungetestete Größen, die immer auf die gesamte Wirklichkeit projiziert werden und immer alle Schulen umfassen. Flops wie das ,programmierte Lernen“ werden nicht auf ihre Kosten untersucht, für Fehlinvestitionen wird niemand bestraft, während neue Methoden auf unsicherem Grund ständig ausprobiert werden.

Spätestens hier greift das Effizienzargument. Innovationen sind teuer, aber sie werden noch teurer, wenn niemand weiß, ob und wann sie scheitern. Das erklärt vermutlich auch den ständigen Rückgriff auf das Bewährte, mit dem sich Erfahrungen des Gelingens verbinden, auch wenn man sich für Frontalunterricht sozusagen entschuldigen muß. Aber der Frontalunterricht organisiert Zeit, verteilt die Rollen, erlaubt halbwegs verläßliche Kontrollen und entspricht mehr schulischen Erwartungen als eine flüchtige Projektwoche, die für Wechsel sorgt, aber ihren Effekt für das Schulschema nur mühsam nachweisen kann. Reformen tragen dabei eine Beweislast, die sie unmöglich erfüllen können, wenn die konventionelle Form diktiert, was effizient ist und was nicht (Cuban 1993). [...]

Lehrerinnen und Lehrer wissen im allgemeinen nicht, was eine Zwei in Englisch vor fünf Jahren bedeutet hat, weil sie verläßliche Daten gar nicht erheben müssen. Aber sie verteilen mit ihren Noten oder Urteilen Berechtigungen, die auf Leistungen gegenüber schulischen Aufgaben reagieren. Sie beschreiben nicht oder wenigstens nicht systematisch, ob bestimmte Standards oder Qualitätsziele erreicht wurden oder nicht. Sie sind nicht einmal an solchen Zielen orientiert, weil Lehrpläne fast jeden Spielraum lassen, Ziele nicht danach unterschieden werden, ob und wie sie in welcher Zeit erreichbar sind, und gemeinsame Standards oft nur sprachlich vorhanden sind. Man kommuniziert über Ziele, aber berechnet schon nicht mehr die konkrete Arbeitszeit des Lehrers. Ein Jahrespensum ist in vielen Fächern ein lockeres Vorhaben, das mit jeder Schulwoche fortgeschrieben wird, oft so, daß ad-hoc-Berechnungen der Arbeitszeit und die erwarteten Effekte das Programm bestimmen. Schulen legen keine Gesamterwartungen ihres Zeitverbrauchs vor. Entsprechend leicht ist es, von Effizienzargumenten Abstand zu nehmen und sich den großen Bildungszielen anzuvertrauen, 
deren Rückübersetzung im Unterricht der Systemautonomie anvertraut wird.

Die Kernfrage lautet dann, wieviel Zeit in welcher Qualität Schulen benötigen, um Ziele zu erreichen, die auf staatliche Aufträge reagieren, ohne diese pauschal abgelten zu können. Die Stichworte der heutigen Diskussion - „Qualitätssicherung“, Leistungsnachweise, Flexibilisierung - verweisen auf diese Richtung, die von der Schule ohne Wandel des Systems unmöglich eingeschlagen werden kann. Jede wirkliche Produktorientierung verlangt ein autonomes Zeitbudget, die Einrichtung von lernenden Lehrplänen, die Formlierung und Überprüfung erreichbarer Ziele, den Nachweis von Fehlern, also die vorbehaltlose Analyse von Stärken und Schwächen, ohne die innere Transparenz unmöglich erreicht werden kann. Auf einen solchen Wandel sind staatliche Schulen in Deutschland nicht vorbereitet, man muß also auch fragen, ob die Einführung von mehr Autonomie nicht zugleich das System schwächt, weil in viel zu kurzer Zeit viel zu viel Innovation gelernt werden muß.

Letztlich ist das eine Frage, wieviel Kontrolle die vermehrte Autonomie weniger erträgt als erzeugt. Autonomie - Schulen in erweiterter Selbstverantwortung - setzt Unterschiede frei, nicht nur solche der lokalen Schulkulturen, sondern solche der Systemsteuerung. Schulen mit einem flexiblen Zeitbudget können selbst entscheiden, wieviel Zeit sie in Mathematik, Sport oder Religion investieren, um bestimmte gegenüber anderen Zielen zu erreichen. Weil es keine klare Kausalität zwischen Zeitaufwand und Leistung gibt, werden gerade die lokalen Verhältnisse - Milieuvorteile oder -nachteile, Schulakzeptanz, Elternengagement - für ungleiche Zeitverteilungen und besondere Angebotsprofile sorgen, die nur mühsam vergleichbar gehalten werden können. Verabschiedet man sich also von der Fiktion, Lehrerinnen und Lehrer, nur weil sie zwei Staatsexamen und Praxis nachweisen können, gäben überall gleichen Unterricht, da sie überall eine gleich definierte Stelle innehätten, dann lassen sich flexible Lösungen für alle Probleme denken, aber mit dem Preis, wirksame Kontrollen einzuführen und das System vermutlich insgesamt zu verteuern. Die Chance besteht darin, die Produktivität zu verbessern, weil starre Zuordnungen von Fächern, Stunden und Lehrplänen preisgegeben werden; die Risiken ergeben sich aus dieser neuen Form von Autonomie, die Schulen werden aus dem staatlichen Schutz entlassen und müssen zugleich, was sie nie wirklich haben tun müssen, effektive Kontrollen auf sich nehmen.

Das bringt mich auf meinen letzten Punkt: Welche neuen Rechnungen sind möglich, wenn es vorbei sein soll mit der alten Gemütlichkeit?

\section{Neue Rechnungen}

Konkrete Wege des Wandels, die auf Flexibilisierungen reagieren können oder müssen, sind vielfach beschrieben worden. Das Spektrum reicht von 
der Autonomie der Haushalte über die Organisationsentwicklung bis zur Gleichsetzung von Schulleitern mit „Managern“, wo von Unternehmern noch nicht gesprochen werden soll. Gegenrechnungen sind bereits heute möglich. Angelsächsische Daten verweisen auf erhöhte Streßfaktoren bei schärferen Kontrollen und unsicheren Anstellungen (Travers/Cooper 1996), auf die Entwicklung von Eigennutz bei Etablierung von Marktverhältnissen (Ball 1994), auf die Verlagerung von Lehrerarbeitskraft in Imagepflege und public relation, wobei sich Faktoren sozialer Ungleichheit verstärken und edukative Aufgaben vernachlässigt werden (Fuller/Elmore 1996; Gewirtz u.a. 1995). Die Entstaatlichung hat ihren Preis, so daß neue Rechnungen nur mit grundsätzlichen Systementscheidungen aufzustellen sind.

Der Markt ist kein Messias, ist in einer jüngeren amerikanischen Kritik der freigesetzten Schulwahl zu lesen (Cookson Jr. 1994: 99ff.). Ein Marktprinzip würde die innengeleitete Schulreform, die öffentlichen Zielsetzungen folgt, gefährden oder unmöglich machen (ebd., 121ff.), weil Elternwahlen sich an konservativen Schulformen ausrichten und von diesen wesentlich nur erwarten, daß sie für akademische Exzellenz des je eigenen Kindes sorgen. Soziale Integration sei dann weder ein Ziel noch ein Bedürfnis, die culture of education, Jerome Bruners (1996) Term, wäre dann ein durch Wahl und Wahlentscheide beliebig auftrennbarer Zusammenhang. Die Berlitz-School wäre ein Wettbewerber, den Wettbewerb gewinnt der leistungsfähigste Anbieter, es ist nicht mehr die Schulerfahrung, die prägt (ebd., 36ff.), die Erfahrung einer einzigartigen Institution (,community of learners", ebd., 38), sondern der Erfolg in einem Wettbewerb, der definiert wird durch Kundennachfrage.

Dagegen spricht die Idee und das Konzept der öffentlichen Bildung, die sich auf das bezieht, was Joseph Priestley (1793, Bd. I: 6) „the business of civil life" genannt hat und das mit „staatsbürgerlicher Erziehung“ falsch übersetzt wäre. Wer am öffentlichen Leben aktiv teilnehmen will und soll (ebd., 9), muß über minimal gleichverteilte Kenntnisse und Lernformen verfügen, das Ziel sind kritische und loyale Bürgerinnen und Bürger, die sich für die öffentlichen Geschäfte interessieren, weil sie Teil dessen sind. Demokratische Politik wäre anders nicht möglich, wer mit Wahlen über die Regierung entscheidet, kann nicht, so John Stuart Mill (1974: 173), die Wahl haben, über seine Bildung völlig frei zu entscheiden und auch völlige Ignoranz zu wählen, Obskuranz oder Arroganz. [...] Nach Mill sollte es gerade wegen der öffentlichen Bedeutung der Bildung kein staatliches Schulmonopol geben (ebd., 176f.), allenfalls wäre der Staat ein Anbieter unter anderen. Er wäre keine „moralische Polizei“ (ebd., 152) und sollte nur den Rahmen bestimmen, den Lehrplan „be confined to facts and positive science exclusively“ (ebd., 178). Offenbar ist aber mehr erforderlich, nicht nur mehr an Inhalten, sondern ein Zusammenhang von Knowledge and Teaching, das, wie Lee Shulman 1987 schrieb, die Inhalte ernst nimmt und sie nicht hinter der Diskussion von Methoden und Organisationsreformen zum Verschwinden bringt. Das beschränkt automatisch die Schulauto- 
nomie. Schulen können nicht alles anbieten und müssen sich auf Inhalte beziehen, die nicht von einem Kanon abzulösen sind. Soll von cultural capital die Rede sein, dann wesentlich in dieser Hinsicht (Guillory 1993). Wenn es verschiedene Anbieter neben dem Staat gibt, dann nur unter der Voraussetzung definierter kultureller Standards, sonst definiert der Markt, was Bildung ist, und man könnte nicht mehr unterscheiden, ob schulische Lernzeit für Hip-Hop-Training einer sozialpädagogischen Maßnahme oder einem Bildungsziel gilt.

So weit geht mein konservativer Schluß: Schulkulturen können Angebotstraditionen nicht beliebig unterschreiten und alles mögliche für relevant erklären, nur weil zufällig Nachfrage besteht. Sie kann privat abgedeckt werden, während Schulen öffentlich definiert und finanziert sind, also auch öffentliche Bildungserwartungen erfüllen müssen. Mein liberales Argument erwächst aus Vermutungen der Ineffizienz oder der steigerbaren Effizienz der jetzigen Organisationsform: Wenn Schulen sich auf bestimmte Aufgaben und Profile konzentrieren, verlangt dies keine staatliche Einheitsform. Im Gegenteil sollte gerade die inhaltliche Profilierung mit Effizienzgewinnen verbunden sein, die sich klar oder möglichst klar der Schule zuschreiben lassen. Das gelingt nur dann, wenn gleichsam die inhaltliche Leistungsfähigkeit mit der sozialen verknüpft wird, was grundlegenden Wandel in der Zeitplanung, im Mitteleinsatz und in der Investitionsbereitschaft voraussetzt.

Mit solchen Forderungen haben Schulen keine oder keine zureichende Erfahrung. Sie können Stunden nach Fächern verteilen, aber sie sind nicht gewohnt zu entscheiden, ob für den Sprachunterricht in Lehrkräfte oder in Auslandsaufenthalte investiert werden soll (oder wenn in beides, in welchen Verteilungen). Sie können nicht Vorteile, die Schüler aus privatem Musikunterricht für ihren Schulerfolg verwenden, berechnen, sie können nicht in Rechnung stellen, daß Ausländerkinder höhere Lernleistungen für den muttersprachlichen Standard erbringen müssen, sie können sich selbst keinen Malus zuschreiben, wenn der Perfektionsgrad der Kulturtechniken so weit unterschritten wird, daß Anschlußschulen davon Nachteile haben usw.

Neue Rechnungen sind also notwendig, auch wenn der Systementscheid konservativ ist, also den Staat nicht von der öffentlichen Bildung entbindet. Jede Verantwortungserweiterung verlangt andere als die bisherigen Rechnungen, nämlich neue und radikal andere Verteilungen von Zeit, mit den neuen Medien auch von Anwesenheit, so von Lernen und Schulerfolg. Die Lernzeit wird individualisiert werden, damit erhöht sich die Verantwortung für den Lernerfolg nicht etwa nur der Schüler, sondern der Schule, die Lernaufträge vergibt und sie überwacht. Die Präzisierung der Ziele muß den Aufwand und die Erfolgschancen sichtbar machen, anders ist schulische Selbsttätigkeit nicht möglich. Schüler und Lehrer müssen sich an definierte Arbeitszeit gewöhnen, was Freiräume schließt und Lehren wie Lernen unter Effizienzdruck setzt. Erfolge sind dann nicht mehr Noten oder 
Notendurchschnitte, sondern Leistungen im Blick auf Standards, die von innen und außen kontrolliert werden. Schulen, die nicht für eine solche Qualitätssicherung sorgen, müssen mit Sanktionen rechnen, auch die öffentliche Bildungsversorgung kann nicht länger die Fiktion aufrechterhalten, alle Schulen seien gut, nur weil sie stattfinden.

Genug der Utopie - ich schließe mit einer Gegenrechnung, die auf Systemfallen aufmerksam macht, welche in der Veränderungsrhetorik - auch meiner eigenen - oft nicht thematisiert werden. Erweiterte Verantwortung impliziert Verengung oder besser Verlagerung, die eine Seite gibt ab, die andere nimmt auf. Schulleitungen etwa erhalten erweiterte Entscheidungsbefugnisse, die aber fast immer nicht einhergehen mit erhöhter Mittelzuweisung. Schulverwaltungen erfinden für sich neue Aufgaben, solche im Management der erweiterten Verantwortung, also geben nicht etwa einen Abbau an die Schulen weiter. Oft erweitern sich für die Schulen die unangenehmen Aufgaben, die unklaren Verantwortlichkeiten, die unfairen $\mathrm{Zu}-$ mutungen, solche, die den Effekt vor dem Versuch erwarten oder die keine Zeit lassen, Innovationen auszuprobieren, weil möglichst sofort das Image der guten, erweiterten Schule entstehen soll.

Die Reaktion darauf sind oft Potemkinsche Dörfer; eine gute Gegenwehr gegen zu hohen Innovationsdruck; andererseits ist pädagogischer Schein eine rasch verblassende Größe, wenn und soweit Mittel verstärkt nach Leistungen verteilt, Unterschiede toleriert und entsprechend Kontrollen erhöht werden. Man kann jedoch nicht das Angenehme des Status quo mit dem Nützlichen der Reform verbinden, wenn die Reform dem Status quo gilt. Paradoxien dieser Art sind allerdings im pädagogischen Bewußtsein eine dominante Größe, nur wirkliche Erfolge sorgen für Entparadoxierung, und der Witz wäre, daß autonome, halbautonome oder Schulen mit erweiterter Verantwortung nicht mehr allein bestimmen können, was ihre Erfolge sind. Wer das bewahren will, sollte den Status quo nicht antasten.

\section{Literatur}

Ball. S. J. (1994). Education reform. A critical und post-structural approach. Buckingham: Open University Press.

Bruner. J. (1996). The culture of education. Cambridge, MA: Harvard University Press.

Cookson Jr., P. W. (1994). School choice. The struggle for the soul of American education. New Haven: Yale University Press.

Cuban, L. (1993). How teachers taught. Constancy and change in American classrooms 1890-1990. 2nd ed., New York: Teachers College Press.

Fuller. B. \& Elmore R. F. (Eds.). (1996). Who chooses? Who loses? Culture, institutions, und the unequal effects of school choice. New York: Teachers College Press.

Gewirtz. S., Ball, S. J. \& Bowe, R. (1995). Markets, choice und equity in education. Buckingham: Open University Press.

Guillory, J. (1993). Cultural capital. The problem of literary canon formation. Chicago: The University of Chicago Press.

Mill, J. S. (1974). On liberty. Harmondsworth: Penguin Books (I. Aufl. 1859). 
Oelkers, J. (1995). Schulreform und Schulkritik. Würzburg: Ergon-Verlag (Erziehung, Schule, Gesellschaft, 1).

Priestley, J. (1793). An essay on a course of liberal education für civil and active life (1764). In J. Priestley, Lectures on history and general policy (Vol. I, pp. 1-38). London: J. Johnson.

Travers, C. J. \& Cooper, C. L. (1996). Teachers under pressure. Stress in the teaching profession. London: Routledge.

\section{JÜRGEN OELKERS \\ Wie lernt ein Bildungssystem?}

[...] Staatliche Investitionen haben im 19. Jahrhundert für einen Qualitätsschub im gesamten Bildungsbereich, vor allem aber im Primarbereich (Kuhlemann 1992) gesorgt; die Verstaatlichung des Systems erhöhte das gesellschaftliche Ansehen; die Konkurrenz privater Anbieter wurde durch Subventionspolitik und so durch Preisverfall marginalisiert. Das Bildungssystem konnte sich ungestört und mit rasch wachsendem Zuspruch entwickeln, ohne je etwas anderes als Wachstum zu erleben. Zwischen den Generationen stabilisierte sich nicht bloß Kontinuität, sondern Fortschritt. Am Ende des 19. Jahrhunderts - schon stabil in den Städten, noch fragil auf dem Lande - konnte jede nachwachsende Generation damit rechnen, bessere Bildungssysteme als die vorhergehenden Generationen zur Verfügung zu haben. Damit wuchs zugleich das Bildungsvertrauen: Immer mehr Aufgaben wurden einem immer mächtigeren System übertragen, dem es doch auf allen Entwicklungsstufen gelang, so defizitär zu erscheinen, daß unablässig neue Investitionen als notwendig angesehen wurden und öffentlichen $\mathrm{Zu}$ spruch erhielten.

[...] Der Preis war die Monopolstellung des staatlichen Anbieters, der seine eigene Form, eben eine Verwaltungseinheit, auf Dauer stellte. Anders wäre im 19. Jahrhundert eine flächendeckende, an Intensität zunehmende Verschulung der Gesellschaft kaum möglich gewesen, zumal dann nicht, wenn annähernd gleiche Schulverhältnisse, damit auch annähernd gleiche Steigerungsraten, angestrebt werden sollten. Dieses Ziel wurde erreicht: Das Schulsystem in der Bundesrepublik Deutschland ist wohl different, aber nicht ungleich (vgl. Zedler 1992; Hansen 1993). Abweichungen sind systemverträglich, sehr große Devianzen kommen nicht vor, an keiner Stelle entsteht Anomie.

Das hängt mit drei zentralen Überlebensgarantien zusammen, die das System schützen und sein Lernverhalten maßgeblich bestimmen: (i) Die Finanzierung erfolgt extern und belastet das System nicht oder nur marginal. Stärkere Beschränkungen sind zumindest in den letzten Jahrzehnten nahezu ausgeschlossen gewesen, Verteilungskämpfe waren extrem selten; die Zuständigkeit ist hierarchisch geregelt und die Zuteilung der Mittel erfolgt innerhalb derselben Kategorien nach den gleichen Maßstäben. (ii) Die 
Klientel wird entweder automatisch zugeführt, unterteilt nach dem einfachsten Prinzip der Jahrgangskohorte, oder aber ist durch Zugehörigkeit $\mathrm{zu}$ Verwaltungsräumen weitgehend garantiert. (iii) Die Ausstattung ist normiert, einschließlich der Besoldung des Personals, der Bedingungen seiner Anstellung und der im System möglichen Karrieren.

[...] Aber, was wäre die öffentliche Schule ohne eine automatische Garantie ihres Unterhalts, ihres Personals und ihrer Ausstattung? Weniger abstrakt gefragt: Wie würden sich Schulen bei ungleicher Finanzierung, die Risiken und Anreize kennt, verhalten? Was würden sie tun, wenn die Klientel - Schülerinnen und Schüler - nicht durch gesetzlichen Zwang ihnen einfach zugeführt wird? Und wie kämen sie mit einem uneinheitlichen Personal zurecht, das auch unabhängig von staatlichen Patenten rekrutiert werden könnte und für dessen Anstellung einzig die berufliche Bewährung maßgeblich wäre?

[...] An dieser Stelle will ich zunächst drei Nachteile des Systems analysieren, die weniger offensichtlich sind, aber ebenfalls das Lernverhalten massiv beeinflussen, nämlich die schwache öffentliche Kontrolle, die unprofessionelle Neigung zur Intransparenz sowie die hohe persönliche Belastung aller Beteiligten.

(i) Die öffentliche Bildung in Deutschland findet fast ausschließlich in staatlichen Schulen statt. Diese Gleichsetzung ist keineswegs selbstverständlich und wird in der Literatur auch erst mit Beginn des 19. Jahrhunderts massiv gefordert. Was nach 1806 als „Staatspädagogik“ (Krug 1810) konfigurierte und allmählich konsensfähig wurde, war zuvor eine durchaus umstrittene Größe. Mindestens sollte die „öffentliche Schule“ zu Staat und Kirche gleichermaßen in Distanz gehalten werden (Trapp 1792). Die staatliche Finanzierung sollte keineswegs ein staatliches Monopol begründen, dem die Aufsicht durch Dritte - öffentliche Kontrolle - weitgehend fehlt. Genau das aber trat ein; staatliche Schulaufsicht bedeutet wesentlich, daß der Staat sich selbst kontrolliert, auf einem Feld, das die Bürger existentiell betrifft. Der Staat verfügt über ihre Bildung, eine nennenswerte Beteiligung der Betroffenen und so der Öffentlichkeit gibt es nicht. Die Staatspädagogik ist in Deutschland die bis heute dominante Form der Erziehungsreflexion; sie gilt einem Monopolisten, der sich weitgehend paternal verhalten kann, ohne Einbußen befürchten zu müssen. Die dafür notwendige Einflußnahme der Bürger ist an fast allen Stellen strukturell ausgeschlossen. Sie sind weder bei der Auswahl und Anstellung der Lehrer noch bei der Gestaltung der Curricula oder der Evaluation der Systemleistungen wirksam beteiligt.

(ii) Auf diese Struktur ist die Lehrerprofession mental wie habituell eingestellt. Sie setzt Intransparenz voraus und bemüht sich nur gelegentlich um die Erhöhung von Durchsichtigkeit. Es gibt keinen öffentlichen Leistungsnachweis von Schulen, keinen Bilanzierungswettbewerb oder gar Versuche, die eigenen Fehler verständlich zu machen. Das System muß sich nach außen irrtumsfrei und hochgradig zielkonform darstellen, ob- 
gleich genügend Einzelerfahrungen dieser Darstellung widersprechen. Daraus resultieren nicht nur Imageprobleme, sondern zugleich ein falsches Lernverhalten, das Konformität belohnt und die Fehlertoleranz bestraft. Entsprechend schwach ist die Neigung zur Dienstleistung und so zur bewußt gesuchten Transparenz aller Vorgänge. Schulen sind, strukturell gesehen, immer noch hoheitliche Räume des Staates, die die - verglichen mit dem 19. Jahrhundert - ästhetische Lässigkeit des Personals nicht etwa aufhebt, sondern lediglich den Wahrnehmungsbedingungen anpaßt.

(iii) Erscheinungsbild, Mentalität und Habitus sind kein Spiegel der gestiegenen Belastungen, die intern wie extern allenfalls in seltenen Krisensituationen überhaupt artikuliert werden. Sie sind kein Lernthema, weil die Risiken negativer Zuschreibungen zu groß erscheinen. Andererseits beeinträchtigen sie die Leistungsfähigkeit des Systems gerade dadurch, daß sie schwach sichtbar sind. Sie erwachsen aus Hauptproblemen der Schule, diffusen Rollen, überzogenen Ansprüchen und immer neuen Versuchen, sich auf unklare Erwartungen überzeugend einzustellen. [...] In dieser Situation kann man alles auf sich beziehen oder alles abwehren, ohne daß starkes Engagement eindeutig von Vorteil und starkes Nichtengagement eindeutig von Nachteil wäre. [...]

Alle drei genannten Nachteile entstehen durch Außenbeobachtung; die Wahrnehmung von innen kann davon abweichen: „Zunehmende Belastung" ist eine individuelle Größe, die mit existentieller Absicherung verrechnet wird; die Intransparenz mag unprofessionell sein, aber sie schützt; und „öffentliche Kontrolle“ ist eine Forderung, die auf jedem Elternabend widerlegt werden kann. Systemindikatoren für Zufriedenheit jenseits individueller Befindlichkeiten wären etwa die schwache Thematisierung von Basisproblemen in der Professionsliteratur ${ }^{19}$, die fehlende Reklamierung von Alternativen außerhalb der typischen Lehrerutopien ${ }^{20}$ und das Übersehen anderer Lernfelder. Weil die Schule, und nur sie, über das staatliche Privileg verfügt, Allgemeinbildung zu besorgen, ist das System überzeugt, lediglich sich selbst die entsprechenden Lernprogramme zuzutrauen. Daß außerhalb des Bildungssystems „Bildung“ möglich ist und daß diese Möglichkeit zu einer bedrohlichen Alternative anwachsen könnte, gehört zu den Fragen, die die Schule, zu ihrem Nachteil, nicht stellen muß.

$[\ldots]$

Die Schwächen der Schule sind Thema der Kritik seit Beginn der Verstaatlichung. Die Schulkritik hat dabei ihr Objekt immer unterschätzt, nicht

19 Die Lehrerliteratur - Zeitschriften, Handbücher, bevorzugte Pädagogen - spart Themen der Effizienz aus, behandelt technologischen Wandel wie ein Problem für Spezialisten, pflegt bestimmte Krisensymptome wie Gewalt oder Belastung, ohne Strategien der Systementwicklung wirklich voranzutreiben. Nicht zufällig entstammt die diesbezügliche Literatur Sektoren außerhalb der Schulpädagogik.

20 Formeln wie „Ganzheit“ oder „,vom Kinde aus“ sind typischerweise nicht an eine Organisationsform zurückgebunden. Die Bilder der Utopie sind daher nur schwach enttäuschungsresistent, obwohl oder weil sie ständig erneuert werden. 
nur weil sie die Stärken verkannte, sondern auch weil sie die Veränderung an der falschen Stelle erwartete. Sie setzt auf die richtige pädagogische Einsicht und deren massenhafte Verbreitung, während die langjährige Alltagserfahrung weit mehr die Stärken des Systems - Existenzsicherung, staatliche Wohlfahrt, Professionsgewinne - unter Beweis stellte. Aus welchem Grund auch sollte sich ein gesellschaftlich akzeptiertes System verändern, das moralisch hoch gesichert ist, gerade weil es über den sensiblen Bereich der Erziehung verfügen kann? Denkbare Substitute, die über ein ähnliches Vertrauen verfügten, sind gar nicht absehbar, so daß dann in der Schulkritik nicht zufällig immer die Schule die Alternative zur Schule darstellt.

Aber die Schulkritik hat auch die Schwachstellen falsch analysiert: „Schwach“ ist oder wird die Schule nicht aufgrund fehlenden pädagogischen Bewußtseins, sondern dann, wenn ihr Monopol in Gefahr gerät. Gesellschaftliche Akzeptanz hat sie nur so lange, wie ihr exklusive Modernisierungen zugetraut werden, die andere Systeme nicht und vor allem nicht besser erfüllen können. Daß es diese Wahl derzeit nicht gibt, schafft nicht schon Beruhigung, wenn man noch einmal das charakteristische Lernverhalten in Rechnung stellt. Es könnte nämlich sein, daß Schulen erfolgreich, aber letztlich falsch lernen, insofern sie nichts an ihrer zurückgebliebenen Technologie verändern, nichts am unökonomischen Zeitverbrauch, an der schwerfälligen didaktischen Organisation und der Behandlung ihres Personals, die allein jede Innovation ausschließen muß. Was also den Erfolg bisher gesichert hat, der marginale Wandel in zentralen Bereichen, könnte gerade das sein, was künftiges Überleben gefährdet.

$[\ldots]$

Ökonomische Fragen sind staatlichen Bildungssystemen in gewisser Hinsicht ebenso fremd wie technologische, obwohl beide Fragen sie zentral berühren. Schulen verbrauchen Zeit, setzen Arbeitskraft ein und müssen Aufwand und Ertrag kalkulieren. Das geschieht nicht unter dem Gesichtspunkt der Konkurrenz verschiedener Angebote, sondern durch schematische Zuteilung von Zeit für Lerneinheiten, die nach einem imaginären Durchschnitt bemessen sind. Leistungsunterschiede bei Lehrern wie bei Schülern schlagen weder auf die ökonomische noch auf die technologische Kalkulation durch. Im Prinzip wird jede Einheit gleich unterrichtet. Die Variation der Methoden und der Kosten ist denkbar gering.

Schulen sind weitgehend Lehrerschulen. Was sie an hausgemachten Technologien verwenden - Tafel, Kreide, Schwamm; Lehrbücher, ersatzweise Fotokopien; Folien, ersatzweise lose Blätter; Anschauungsmittel, Standardmethoden, Zensuren -, ist auf die unterrichtende Person zugeschnitten. Sie soll Lehren und Lernen gleichermaßen steuern und zu einem Ziel bringen. Entsprechend schwach und störanfällig sind die Technologien; ihre Wirksamkeit ist gebunden an fragile soziale Situationen, in denen die Aufmerksamkeit rasch wechselt, das Verhalten ständig neu abgestimmt werden muß, Interessen und Bedürfnisse nur im Durchschnitt vorausgesetzt 
werden können, zugleich Anfang und Ende rigide determiniert sind und doch limitlose Erwartungen bestehen, die den vorhandenen Möglichkeiten mehr oder weniger dramatisch widersprechen.

$[\ldots]$

Gemessen an den Erfahrungen der Freizeitindustrie und der Medienkultur bieten Schulen zu wenig Wechsel und zu wenig Erleben. Sie brauchen zu lange, um Erfolg oder Können zu vermitteln, benötigen zuviel Routinen und nehmen so ein $\mathrm{Ma}$ an Langeweile in Kauf, das sich kaum mit Aktivierungs- oder gar Modernisierungsprogrammen vereinbaren läßt. Auch über die Kosten der Langeweile oder der Zeiten relativer Beschäftigungslosigkeit ist nichts bekannt. Andererseits liegt eine Beruhigungsstrategie nahe: Es gibt historische Quellen genug, um hier keine allzu große Systemgefahr zu vermuten, denn sehr viel anders ist die Meinung der Abnehmer, soweit sie dokumentiert ist, nie gewesen, ohne daß dem Bildungssystem daraus ein Schaden erwachsen wäre. Ein Feedback der Abnehmer oder die Erfahrungen ihrer Kunden sind nie zur Kontrolle des Verhaltens von Schulen eingesetzt worden. Sie war nie konsumentenorientiert, warum sollte da ausgerechnet die Konsumkultur gefährlich werden?

Eine grundlegend andere Risikobestimmung drängt sich auf, wenn der technologische Kern der Schule herausgefordert und die Technologieschwäche mit Kosten-Nutzen-Analysen konfrontiert wird. Die Lernmedien der Zukunft sind nicht hausgemacht; sie werden schneller und effektiver arbeiten, keine unbedingte Anwesenheit verlangen und zugleich das Verhältnis von Zeitaufwand und Leistung dramatisch individualisieren. Man muß kein Prophet sein, sondern lediglich in Rechnung stellen, mit welch groben und streuenden Methoden die Schule operiert, um den Vorteil interaktiver Lernsysteme wenigstens für den Bereich der Wissensvermittlung zu erkennen. Sie erlauben erstmalig die Versorgung der Gesellschaft mit Bildungsprogrammen, die nicht an den Ort und die Zeit der Schule gebunden sind. [...]

Ich sage damit nicht, die pädagogische Institution wird überflüssig; aber sie wird ihre Konvention, die Grundform ihrer Organisation von Lehren und Lernen, grundlegend verändern müssen, wenn sie überleben will. Große technologische Schübe hat die westliche Schule zuletzt Mitte des 19. Jahrhunderts erlebt, mit der Einführung verbindlicher Lehrmittel, vor allem didaktisierter Schulbücher, der standardisierten Unterrichtsmethode sowie der dazu passenden Zeitstruktur. Was vor einhundertfünfzig Jahren eine zwingende Modernisierung war, ist es heute nicht mehr, weil eine nivellierende Unterrichtsorganisation mit individualisierenden Erwartungen nicht verträglich ist und aber für diese Erwartungen neue Lerntechnologien zur Verfügung stehen.

$[\ldots]$

Mich interessiert an dieser Stelle nicht, ob und wann sich diese Prognose erfüllt, sondern nur, daß sie technisch möglich ist und daß sich mit dieser Möglichkeit ökonomische Berechnungen verbinden lassen, die das staatli- 
che Bildungssystem unter Druck setzen. Auf diese Situation ist das System schlecht vorbereitet, einfach weil es weitgehend gemäß der eigenen Vorgaben hat wachsen können und ihm starke Beschränkungen erspart blieben. Es hat, anders gesagt, weder mit raschem Wandel noch mit Prozessen der Schrumpfung eine sehr intime Erfahrung. Die Frage stellt sich aber, ob das System einfach weiterwachsen kann oder soll, wenn die Systemleistungen allmählich problematisch werden und sich der Verdacht aufdrängt, die Leistungen entsprechen weder den Standards heutiger Lerneffektivität noch den Erwartungen an einen kostengünstigen Einsatz der zur Verfügung stehenden Mittel.

$$
[\ldots]
$$

\section{Literatur}

Hansen, R.: Quantitative und strukturelle Veränderungen der Schule in der BRD. Dortmund 1993.

Krug, W. T.: Der Staat und die Schule. Oder Politik und Pädagogik in ihrem gegenseitigen Verhältnisse zur Begründung einer Staatspädagogik dargestellt. Leipzig 1810 .

Kuhlemann, F.-M.: Modernisierung und Disziplinierung. Sozialgeschichte des preußischen Volksschulwesens 1794-1872. Göttingen 1992.

Trapp, E. Chr.: Von der Nothwendigkeit öffentlicher Schulen und von ihrem Verhältnisse zu Staat und Kirche. In: J. H. Campe (Hg.): Allgemeine Revision des gesammten Schul- und Erziehungswesens von einer Gesellschaft practischer Erzieher. Sechzehnter Theil. Wien/Braunschweig 1792, S. 1-43.

Zedler, P. (Hg.): Strukturprobleme, Disparitäten, Grundbildung in der Sekundarstufe I. Weinheim 1992. 


\section{Zur Herkunft schulischer}

Modernisierung

I. 



\section{Vorbemerkung}

Der folgende Abschnitt „Zur Herkunft schulischer Modernisierung“ folgt der Überlegung, dass sich die aktuelle Modernisierungsdebatte nicht über Nacht eingestellt hat. Die Texte erörtern, welche semantischen Leitideen schulischer Modernisierung in der (jüngeren) Vergangenheit ausgemacht werden können und geben dabei zuerst Diskussionen älteren Datums wieder. Zur Modernisierung von Sozialstaaten, Schulkultur, Markt und Schulautonomie gab es diese schon in den 1980er Jahren. Gegen Ende des Textblockes finden sich Diskussionen jüngeren Datums, die sich auf Wertediskussionen, TIMSS und PISA beziehen.

Neben der Tatsache, dass dem Schulsystem - etwa im Rahmen von Auseinandersetzungen über die Leistungsfähigkeit des Wohlfahrtsstaates Debatten extern aufgelegt werden, ist es plausibel, dass auch Diskussionen innerhalb des Schulsystems heutige Modernisierungen mit vorbereiten. Dies wirft die schwierige Frage nach dem Verhältnis von exogener und endogener Modernisierung auf. Texte dieses Themenblocks konkretisieren hier immerhin zweierlei: erstens, dass Modernisierung von exogenen Faktoren außerhalb des Bildungssystem mitbestimmt wird, insofern insbesondere veränderte Governance-Modelle zu erkennen sind. Unter dem Stichwort „Umbau des Sozialstaates“ z.B. lassen sich von der Politik initiierte Änderungen der Steuerung von Schulsystemen erkennen - im Zuge der Betonung von Management, Effizienz und Qualität verändern sich Leitideen.

Zweitens diskutieren die Texte, inwiefern neue Leitbegriffe auch durch verschiedene pädagogische Diskurse aufgegriffen und formuliert werden und so ebenfalls die gegenwärtige Modernisierung des Schulsystems mit vorbereiten. Die Liste der pädagogischen Diskurse beansprucht nicht, vollständig zu sein, und sie beantwortet auch nicht die Frage - was nur empirische Forschungen tun können -, in welcher Gewichtung sich die verschiedenen Vordiskussionen auf die schulische Modernisierung ausgewirkt haben. Jedoch erfüllt die Liste der Diskurse ihre Funktion darin, überhaupt auf Vordiskussionen als Faktoren für die Modernisierung des Schulsystems aufmerksam zu machen. Konkreten Forschungen überantwortet wird auch die Frage - die von den hier versammelten Grundlagentexten ebenfalls nicht behandelt werden kann -, in welchem Verhältnis externe und interne Diskussionen auf die schulische Modernisierung einwirken. Der Anspruch dieses Bandes ist, mit den Texten ebenfalls nur - aber immerhin - ein Problemfeld zu markieren. ${ }^{1}$

$1 \mathrm{Zu}$ einem Erklärungsversuch zu Zusammenhängen zwischen Schulumwelt und schulischer Profession vgl. Brüsemeister (2002b). 


\section{Modernisierung von Sozialstaaten}

\section{Kommentar (Brüsemeister)}

Ein Thema, dass die gegenwärtige Schulmodernisierung offensichtlich mit vorbereitet hat, ist die Modernisierung von Sozialstaaten. Hierzu haben wir vier Texte ausgewählt.

Ingo Richter, ehemals Direktor des Deutschen Jugendinstituts München, eröffnet den Themenblock „Modernisierung von Sozialstaaten“. Sein Text dient weniger dazu, die Herkunft von Diskussionen über schulische Modernisierung schon konkret zu erörtern, als vielmehr eine der möglichen Grundlagen für solche Debatten anzugeben. Richter weist hier auf rechtliche Rahmenbedingungen der jeweiligen Nationalstaaten hin, welche bei den Debatten über die Modernisierung von Schulsystemen selten berücksichtigt werden - obwohl sie die eingeschlagenen Modernisierungspfade wesentlich beeinflussen.

Mit dem Titel seines Beitrages „Entscheidungsstrukturen für Bildungsfragen in offenen Gesellschaften" legt der Autor dar, dass im Gegensatz zu früheren theokratischen oder aus anderen Gründen geschlossenen Gesellschaften die Gegenwartsgesellschaften als offene zu bezeichnen sind. Es lässt sich für moderne Gesellschaften unterstellen, dass sie in der Vergangenheit darüber entschieden haben, wie das Verhältnis zwischen Staat, Recht und Bildung aussehen soll. Gesellschaften tun dies nach Richter auch gegenwärtig, insofern neue Modelle des Sozialstaates und der sozialstaatlichen Verankerung von Bildungssystemen, man kann sagen: neue Governance-Modelle, überlegt werden. Stichworte einer Umorientierung sind nach seiner Auffassung „,De-Institutionalisierung, Effizienzerwartung, Multikulturalität, Wahlfreiheit, Beteiligung“. Wie also, fragt der Autor, soll gegenwärtig angesichts einer Krise des Sozialstaates das Verhältnis zwischen Recht, Staat und Erziehung aussehen?

Diese Frage behandelt Richter, indem er drei historische Verhältnisse zwischen Recht, Staat und Schulsystem anspricht, wie sie sich in einzelnen Ländern herausgebildet haben, nämlich das Verwaltungsmodell, das Verfassungsmodell und das Vertragsmodell. Wie immer auch die drei Modelle für sich genommen oder in einem Mischungsverhältnis die Realität einzelner Länder abbilden, Richters Beitrag hält dazu an, über die Verhältnisse zwischen Recht, Staat und Schulsystem nachzudenken. Es ist zu vermuten, dass sich allein aus rechtlichen Kontextbedingungen der einzelnen Länder unterschiedliche Möglichkeiten und Grenzen für Modernisierungen des schulischen Systems ergeben. Zum Beispiel benötigt ein Schulmodell, welches in das Verwaltungsmodell eingebettet ist, zuerst eine Verwaltungsmodernisierung, damit sich auch die Schulorganisation ändern kann. Es würde 
bei einem Teil der Modernisierung also gar nicht primär um Schulen, sondern um die staatliche Verwaltung gehen, die verändert werden soll. ${ }^{2}$

Mit Richter kann man zudem vermuten, dass in einem Vertragsmodell die Bürger ganz andere Möglichkeiten haben, über Modernisierungen der Schule mitzuentscheiden, denn in diesem Modell werden Bildungsorganisationen im Prinzip als von Bürgern und nicht als vom Staat gegründete gedacht. Wenn dann Staat und Politik Bildungseinrichtungen verändern wollen, müssen sie mit größeren Einflussnahmen, alternativen Vorschlägen, Widerständen der Bürger rechnen.

Hieran anschließend lassen sich zwei grundverschiedene Prozessverläufe von Modernisierung unterscheiden, zum einen eine top-downModernisierung, die von Staat und Politik ausgeht und den am Bildungsprozess Beteiligten selbst wenig Mitsprachemöglichkeit bei der Modernisierung gibt - etwa wenn Politik und Bildungsverwaltung beschließen, dass alle Schulen ein Schulprogramm haben sollen, ohne schulische Akteure vorher einzubeziehen. Die andere Prozessvariante verläuft bottom-up, in der das Neue von den Beteiligten selbst ,an der Basis“ initiiert wird, etwa wenn sich Lehrer und Eltern an einer Schule zu einem Förderprogramm entschließen und dieses Modell dann landesweit übernommen wird.

Grundsätzlich, so kann man in Anlehnung an Richter vermuten, beinhaltet ein Vertragsmodell relativ große Einflussmöglichkeiten innerhalb lokaler Schulkulturen, eine Modernisierung bottom-up selbst zu beginnen. Dagegen scheinen in Verwaltungs- und Verfassungsmodellen viele Akteure, insbesondere Lehrkräfte (vgl. Arnold u.a. 1999: 119ff.), auf Modernisierungen ,,von oben“ zu warten. Traditionell wird ein regulierender Staat für Bildungspolitik und -struktur verantwortlich gemacht, Wohingegen die Logik des Vertragsmodells besagt, dass Akteure (Bürger) bei der Modernisierung selbst aktiv werden. Aus den verschiedenen rechtlichen Verankerungen von Schule ließen sich also unterschiedliche Szenarien und Pfade der Modernisierung extrapolieren. ${ }^{3}$

Der zweite Text stammt von Horst Weishaupt (Universität Erfurt) und behandelt das Themenfeld „Modernisierung von Sozialstaaten“ im engeren Sinne. Ähnlich wie Richter und auch viele weitere Beiträge dieses Bandes bemerkt der Autor ein Umschwenken, weg von einer rein staatlichen Steuerung von Schulsystemen hin zu mehr Selbstbestimmung, Autonomie, Profilierung der einzelnen Schule und mehr Wettbewerb zwischen Schulen. Dabei geht es um Veränderungen der politische Steuerung bzw. der Governance. Eine der zentralen Thesen von Weishaupt ist, dass die gegenwärtige

2 Siehe die zusammenfassenden Bemerkungen zur neuen Governance zu Beginn unserer Einleitung.

3 Wollte man den Einfluss des Rechtssystems auf Schulsysteme konkreter untersuchen, müssten für ein Land eine Vielzahl rechtlicher Institutionalisierungen betrachtet werden. In Deutschland wäre insbesondere das Dienstrecht einzubeziehen, das bei einer Modernisierung umgestaltet werden muss, und über das Akteure ihre Interessen wahren können. 
„Entkoppelung von Administration und öffentlicher Willensbildung“ durch „Aktivierung eines nicht-staatlichen Steuerungspotentials“ und die „Verschiebung von parlamentarischen Zuständigkeiten auf Verhandlungssysteme" zu beobachten sei. Legitimiert wird ein solches Vorgehen, so Weishaupt, mit der Behauptung, dass sich zielorientiertere Maßnahmen für Schulen im bisherigen staatlichen System nicht durchsetzen ließen. Die Kritik des Autors setzt daran an, dass eine solche gravierende Änderung des Verhältnisses zwischen Staat und Schule stillschweigend - an Gesetzgebung und Öffentlichkeit vorbei - als interne Verwaltungsmodernisierung durchgeführt wird. Man muss also fragen, ob die Schulmodernisierung nur die Spitze des Eisbergs einer viel tiefer gehenden Umgestaltung des Politischen ist, welche die Administration und die politisch-demokratische Willensbildung in ein neues Verhältnis setzt. Es taucht die Frage auf, inwieweit der Umbau des Verhältnisses von Politik, Verwaltung und Schule überhaupt öffentlich diskutiert wird, oder inwieweit Politik und Bildungsverwaltung die Öffentlichkeit vor vollendete Tatsachen stellen, in dem sie eine neue Governance einfach einführen.

Am Ende seines Beitrages, den wir hier nicht abdrucken, sondern lediglich zusammenfassen wollen, verweist Weishaupt auch darauf, welche konkreten Auswirkungen die neue Governance auf den Ebenen der Landesund Kommunalverwaltungen schon jetzt hat (z.B. mehr Kostenorientierung, Einführung von Leistungsvergleichen, restriktive Ausgabenpolitik, Überlegungen zur Auslagerung von Aufgaben). Weishaupt sieht die einzelnen Verwaltungen weitgehend isoliert handeln; es fehle „eine länder- und bildungsbereichsübergreifende Diskussion und Abstimmung der Entwicklungsprobleme im Bildungswesen“. An dieser im Jahr 1998 formulierten Auffassung hat sich bis heute wenig geändert - Landes- und Kommunalverwaltungen scheinen sogar angesichts angespannter Haushalte noch stärker zu inkrementalistischen, nur von Fall zu Fall reflektierten Strategien der Bildungsfinanzierung zu greifen. Gleichzeitig wird nach Weishaupt Kritik „an der inneren Leistungsfähigkeit des Schulsystems geübt“. Insgesamt sieht der Autordie sozialstaatliche Verankerung des Schulsystems in Frage gestellt, insofern es Überlegungen gibt, welche schulische Aufgaben sich auslagern und nicht-staatlich finanzieren lassen.

Der dritte für diesen Buchabschnitt ausgewählte Text, der das Schulsystem im Kontext einer Modernisierung des Sozialstaats sieht, stammt vom französischen Soziologen Pierre Bourdieu. Dieser hat schon in den 1970er Jahren Bildungsanalysen verfasst (Bourdieu/Passeron 1971). Mit der 1998 in Deutschland erschienenen politischen Streitschrift „Gegenfeuer“, aus der wir eine knappe Interviewpassage wiedergeben, will Bourdieu die Öffentlichkeit darauf aufmerksam machen, dass man eine neoliberale Anpassung des Sozialstaates keineswegs hinnehmen müsse und den Umbau der Governance nicht allein der Politik überlassen muss.

Der Textabschnitt „Die rechte und die linke Hand des Staates“ verweist indirekt auf Bourdieus soziologische Gegenwartsdiagnose „Das Elend der 
Welt"“. In diesem Werk, das in Frankreich fachübergreifend Beachtung fand, kommen Menschen in Interviews zu Wort, die zu Beginn der 1990er Jahre von der neoliberalen Modernisierung betroffen wurden. Als Opfer fühlen sich auch Beschäftigte des Bildungssystems. Bourdieu verstärkt implizit die These von Weishaupt, insofern er nicht nur von veränderten Aufgaben des Staates spricht, sondern provokant einen Rückzug des Staates aus den Bildungs- und Sozialbereichen anklagt. Der Autor macht hierbei einen Machtkampf zwischen der am Neoliberalismus orientierten Verwaltungselite auf der einen Seite aus, die er die „rechte Hand des Staates“ nennt. Nach Bourdieu sieht diese Fraktion des Staates Bildung und Soziales nur als Kostenverursacher bzw. als Störenfriede freier Markkräfte. Dagegen richtet sich auf der anderen Seite die ,linke Hand des Staates“, die ausführenden kleinen Beamten und Angestellten vor Ort, z.B. Lehrer, Richter, Polizisten und Sozialarbeiter. Sie versuchen, sich dabei von ihren Vorgesetzten im Stich gelassen fühlend, mit den verbliebenen Mitteln ihre Arbeit aufrechtzuerhalten. ${ }^{5}$

Bourdieus Schilderungen für Frankreich lesen sich als Kritik einer radikalen top-down-Modernisierung, in welcher dem Bildungs- und Sozialbereich nur noch eine Verwaltung ,des Elends“, aber keine aktive Bildungsund Sozialpolitik mehr bleibt. Grund dafür, dass die bisherige Inklusion nicht mehr fortgesetzt werden soll, ist hier der fehlende politische Wille einer am Neoliberalismus ausgerichteten Staatselite. Für Bourdieu ist ausgemacht, dass im neoliberalen Umbau das Bildungssystem sich selbst überlassen bleibt. Wie auch Richter sieht, werden die Beziehungen zwischen Staat und Bildungssystem neu gestaltet. In Bourdieus Sicht geht dies zu Lasten der Abnehmer von Leistungen und insbesondere auch der im Schulsystem Beschäftigten. Zudem vermutet Bourdieu, dass sich durch den Rückzug des Staates Spannungen zwischen der Mehrheitsklasse auf der einen Seite sowie den ohnehin schon Benachteiligten auf der anderen Seite, insbesondere ausländischen Familien, vergrößern. ${ }^{6}$

Bezieht man Richters Ausführungen bezüglich der rechtlichen Verankerung von Schulsystemen auf Bourdieus Text, wäre zu prüfen, inwiefern sich die skizzierten französischen Verhältnisse auf andere Länder übertragen lassen. Zum Beispiel gibt es im (deutschen) Verfassungsmodell andere Möglichkeiten, auf die Modernisierung von Schule Einfluss zu nehmen als in Frankreich, wo der Schulbereich Teil eines Verwaltungsmodells ist und entsprechend leichter allein von Politik und Bildungsverwaltung umgestaltet werden kann.

In einem weiteren Text (,Die öffentliche Schule im Umbau des Sozialstaats“) fasst Ingo Richter noch einmal die historischen Aufgaben zusam-

4 Vgl. Bourdieu u.a. (1997). Zum Bildungssystem siehe die Seiten 527-679.

5 Vgl. dazu auch Brüsemeister (2002a).

6 Auf die durch die Modernisierung unter Umständen entstehenden sozialen Ungleichheiten wird im Textblock IV eingegangen. 
men, die sich der Staat hinsichtlich des Schulsystems gegeben hat. Anhand der Sozialstaatsklausel in Deutschland stellt Richter fest, dass der Staat sich zwar auf ein öffentliches Schulangebot verpflichtet habe, nicht jedoch auf Details der organisatorischen Ausgestaltung. Der Autor ist der Überzeugung, dass Aufgaben aus dem Staat ausgegliedert und ohne zusätzliche Kosten „effektiver" realisiert werden könnten, da die Aufsichtspflicht des Staates gegenüber Schulen nach wie vor bestehen bleibe. Da vom Gesetz her keine feste Trägerschaft - also Staat, Markt oder Mischvarianten festgelegt sei, regt der Autor dazu an, eine Gesellschaft möge sich die beste Träger-Variante überlegen. Richter selbst spricht sich für einen „dritten Sektor" aus, in dem jenseits von Staat oder Markt private, gemeinnützige und öffentliche Organisationen gemeinsam öffentliche Aufgaben wahrnehmen sollten.

Unabhängig davon, ob man diesem Punkt folgt, belegt der Text das gegenwärtig zu beobachtende - zum Teil radikale - Umdenken des Sozialstaates und seiner Bildungsorganisationen. Und Richters im Prinzip idealtypische Unterstellung, Gesellschaften könnten sich hierbei einen „best way" aussuchen, erscheint als eine der brauchbaren Folien, vor deren Hintergrund man die tatsächlichen, oftmals inkrementalistischen, kleinschrittigen, nicht immer durchgeplanten Modernisierungsentscheidungen in einzelnen Ländern beobachten kann. Wichtig ist außerdem, dass die Überlegungen zu einem ,best way“ von Richter nicht im Sinne einer maximalen Kosteneffizienz für das Schulsystem formuliert sind, sondern auf Fortsetzung und Ausbau der schulischen Inklusion zielen - ein Gesichtspunkt, der nach Ansicht des Autors unter die Wertentscheidung einer Gesellschaft fällt. ${ }^{7}$

\section{INGO RICHTER \\ Entscheidungsstrukturen für Bildungsfragen in offenen Gesellschaften}

[...] Können offene Gesellschaften, die über eine bestimmte Staatsideologie nicht verfügen, sondern unterschiedliche Interessen organisieren, Ziele für ein öffentliches Bildungssystem überhaupt begründen? Nachdem die fraglose Eingliederung des Bildungswesens in die Staatsverwaltung nicht mehr legitim erscheint und nachdem sich eine Organisation nach dem Demokratieprinzip als fragwürdig erwiesen hat, ist zunehmend von vertraglichen Regelungen auch im Bildungswesen die Rede, von Marktmechanismen oder korporativistischen Prinzipien. Privatisierung ist dafür das falsche Stichwort, es scheint eher um die vertragliche Organisation öffentlichen Handelns zu gehen. Die neuere bildungspolitische Entwicklung geht in die-

7 Ein Punkt, der in diesem Buch unter „Wertediskussionen“ fortgesetzt wird. 
se Richtung: De-Institutionalisierung, Effizienzerwartung, Multikulturalität, Wahlfreiheit, Beteiligung.

[...]

\section{Drei Modelle zu Recht und Erziehung}

Ich werde drei Modelle zum Verhältnis von Recht und Erziehung bilden. Dabei interessieren mich drei Fragen:

1. Folgt die Organisation des Bildungswesens den Organisationsprinzipien der Gesellschaft oder ist das Bildungswesen ganz anders organisiert als die Gesamtgesellschaft?

2. Soll Organisation erziehen? D.h. steht die Organisation des Bildungswesens selber im Dienste der Erziehungsziele?

3. Hat das Recht eine große oder eine kleine Bedeutung bei der Organisation des Bildungswesens und entspricht das Recht dem jeweiligen Organisationsmodell?

Ich werde diese drei Modelle kurz vorstellen und mich mit einigen historischen Erscheinungsformen und mit den rechtlichen Ausprägungen beschäftigen.

\section{Das Verwaltungsmodell}

Im Verwaltungsmodell ist das Bildungswesen Teil der Staatsverwaltung. Die Organisationsprinzipien der Staatsverwaltung finden sich auch im Bildungswesen wieder. Durch die Abbildung der gesellschaftlichen Organisationsprinzipien im Bildungswesen sollen die Lernenden frühzeitig mit den Verhältnissen der Gesellschaft vertraut werden, sich in sie einleben, sie mehr und mehr übernehmen. Einer rechtlichen Regelung bedarf es hierzu nicht und schon gar nicht einer juristischen Konfliktregelung. Das Verwaltungsmodell ist juristisch unterdeterminiert.

\section{Das Verfassungsmodell}

Im Verfassungsmodell gehört das Bildungswesen zwar auch in den Bereich der öffentlichen Organisation; es ist jedoch nicht in die Verwaltung integriert, sondern hat einen eigenständigen Ort, der durch Verfassungsprinzipien geregelt wird. Diese Prinzipien entsprechen den Verfassungsprinzipien der Staatsorganisation. Zwar soll dies auch einen erzieherischen Wert haben; doch die erzieherische Kraft einer Verfassung ist problematisch. Die Ansprüche an die rechtliche Regelung sind dagegen deutlich: Die Rechte und Pflichten aller Beteiligten sind gesetzlich geregelt und ebenso die Verfahren der Entscheidungsbildung, und Konflikte werden vor unabhängigen Gerichten ausgetragen und von ihnen gelöst. 


\section{Das Vertragsmodell}

Im Vertragsmodell ist die Organisation des Bildungswesens weder durch die Staatsverwaltung noch durch die Staatsverfassung vorgegeben, sondern die Bürger und die gesellschaftlichen Gruppen schaffen sie selber. Die staatlichen Gesetze legen allenfalls bestimmte Bedingungen und Grenzen fest. Das Vertragsmodell setzt die individuelle Freiheit der Bürger (Wahlfreiheit) und die gesellschaftliche Autonomie der Gruppen (Selbstverwaltung) voraus. Die durch Verträge geschaffene Organisation des Bildungswesens kann gesellschaftlichen Organisationsformen entsprechen, sie muß es aber nicht. Über den erzieherischen Wert solcher Organisationsformen ist wenig bekannt; auch er wird unterschiedlich sein. Der Bedarf an einer allgemeinen gesetzlichen Regelung ist eher gering; die Organisationen schaffen ihr eigenes Recht. Dieses zu schaffende Recht entspricht wiederum den organisatorischen Besonderheiten. Es muß allerdings erst geschaffen werden.

\section{Recht und Erziehung in geschlossenen Gesellschaftssystemen}

Nehmen wir als Beispiel theokratische, nationalsozialistische oder sozialistische Gesellschaften. Ohne sie im übrigen miteinander vergleichen zu wollen, alle drei verbindet die Vorstellung, durch die Organisation des Bildungswesens die Gesellschaft zu formen.

In theokratischen Gesellschaften werden Glauben und Lernen nicht getrennt, der Priester ist der Lehrer, die Kirche ist die Schule, die Bibel ist das Lehrbuch und dies gilt gleichermaßen für nicht-christliche theokratische Gesellschaften. Eines Schulgesetzes bedarf es nicht, denn der Priester ist gleichzeitig der Richter. [...]

Auch der Nationalsozialismus wollte das Bildungswesen nach nationalsozialistischen Prinzipien organisieren: Kämpfen und Lernen sollten nicht getrennt werden; die Schule als Volksgemeinschaft und der Lehrer als Führer, das Parteiprogramm als Gesetz und die Partei als Richter. Doch das Bildungswesen als große differenzierte herkömmliche und bürokratische Organisation erwies sich als sperrig. [...]

Ähnliche Beobachtungen lassen sich auch für die sozialistischen Gesellschaften dieses Jahrhunderts machen: Arbeiten und Lernen sollte eins sein; das Bildungssystem sollte den sozialistischen Menschen schaffen. Doch die Integration des Lernens in die Produktion wollte nicht so recht gelingen, die Schule blieb Schule, und ihre Formung nach sozialistischen Prinzipien hielt sich in Grenzen.

$[\ldots]$

Halten wir also für das ,,Verwaltungsmodell“ einstweilen fest:

1. Institutionalisierte Bildung ist ein Staatsmonopol.

2. Es gibt eine zentrale Leitung, die durch die Regierung ausgeübt wird. 
3. Die Lehrenden sind Staatsdiener mit einer mehr oder weniger starken professionellen Prägung.

4. Die Lernziele werden durch die Regierung bestimmt; sie können einer einheitlichen Staats- und Erziehungsideologie entspringen, sie können aber auch den pragmatischen Bedürfnissen jeweiliger Mehrheiten entsprechen.

5. Die staatlichen Lernziele werden durch die weisungsabhängigen Staatsdiener in den Bildungsinstitutionen durchgesetzt; gesetzlicher Regelungen repräsentativer Körperschaften bedarf es nicht; die Lernenden und die Lehrenden können sich auf Individualrechte im Bildungswesen nicht berufen; eine gerichtliche Kontrolle findet nicht statt.

\section{Freiheit und Gleichheit in einem rechtsstaatlich verfaßten Bildungssystem}

Art. 1 der Französischen Erklärung der Menschen- und Bürgerrechte von 1789 stellte fest, daß die Menschen vor dem Gesetz frei und gleich geboren seien und es blieben und daß soziale Unterschiede nur auf das Gemeinwohl gegründet werden könnten, und Titel I der Verfassung von 1791 versprach den Franzosen ein allgemeines kostenloses öffentliches Unterrichtswesen. Ein solches Unterrichtswesen schloß jede partikulare Prägung durch religiöse oder politische Interessen aus; es sollte allein unter dem allgemeinen Gesetz stehen, das Ausdruck der ,volonté genérale“ ist.

Ein solches Bildungswesen folgt dem „Verfassungsmodell“. Freiheit und Gleichheit im Rahmen der für alle geltenden Gesetze sind die Prinzipien der Staatsorganisation, sie sollen auch für das Bildungswesen gelten. Dies muß notwendig öffentlich sein, denn nur ein öffentliches und kostenloses Bildungswesen kann die gleiche Freiheit aller Bürger gewährleisten; private Bildungseinrichtungen dienen partikularen Interessen und sind daher nicht zuzulassen. Dies bedeutet vor allem eine deutliche Trennung von Kirche und Staat. Diese Verfassung des Bildungssystems bedarf der gesetzlichen Regelung, denn die Freiheit der Bürger darf nur durch Gesetze eingeschränkt werden, und die Gleichheit der Bürger muß durch Gesetze konkretisiert werden. Über die Gewährleistung der Freiheit und die Durchsetzung der Gleichheit wachen die Gerichte, die nur dem Gesetz verpflichtet sind. Doch welchen Zielen diente diese sehr abstrakte Organisationsstruktur des Bildungssystems? Zur Zeit der Französischen Revolution sollte sie sicher den Zielen der Revolution dienen, der Schaffung der Gesellschaft der Freien und Gleichen. ,Wenn man nicht von Kindheit an lernt, republikanisch oder monarchisch, katholisch oder atheistisch zu sein, wird der Staat nie Nation werden“, sagte Napoleon bald darauf. Auch die republikanische Bildungsverfassung stand also im Dienst der republikanischen Staatsform - ebenso wie in den theokratischen, monarchischen oder anderen geschlossenen Systemen.

Doch das französische Modell eines konstitutionellen Bildungssystems setzte sich trotz des fortwirkenden Pathos der Französischen Revolution 
selbst im eigenen Land nicht durch. Die Freiheit wurde bald nicht allein als Freiheit, das öffentliche Bildungssystem besuchen zu dürfen, verstanden, sondern auch als Freiheit, freie Schulen i.S. von staatsfreien, meist kirchlichen Schulen zu gründen, zu unterhalten und zu besuchen. „L'enseignement libre" wurde - in einer Verkehrung des revolutionären Freiheitsbegriffes - das Schlagwort im Kampf für die religiösen Schulen, die im 19. Jhd. nach und nach staatlich genehmigt und schließlich seit der Mitte des 20. Jhd. auch staatlich finanziert wurden. Aus der Gleichheit aller wurde in einem äußerst differenzierten Bildungssystem sehr schnell eine Chancengleichheit zu Beginn und eine äußerst starke Ergebnisungleichheit am Ende der Bildungsbiographien. Das Gesetz, das Freiheit und Gleichheit doch nur nach Maßgabe des Gemeinwohls einschränken sollte, regelte schließlich ein duales System staatlicher und privater Schulen und ein Bildungssystem, das die gesellschaftliche Ungleichheit aufgrund einer scheinbaren Gleichheit im Bildungssystem nur um so besser reproduzierte (Bourdieu/Passeron 1971). Von einer gerichtlichen Korrektur dieser Ergebnisse aufgrund von verfassungsrechtlichen Freiheits- und Gleichheitsrechten konnte in der französischen Entwicklung überhaupt keine Rede sein.

Doch die Entwicklung des französischen Bildungssystems sollte uns nicht daran hindern, das Verfassungsmodell des Bildungswesens in seiner ursprünglichen Radikalität noch einmal nachzuzeichnen:

1. Institutionalisierte Bildung ist ein Staatsmonopol, private Schulen sind verboten; es besteht eine strikte Trennung von Staat und Kirche; ein Religionsunterricht findet in der Schule nicht statt.

2. Alle Kinder bzw. ihre Eltern haben ein gleiches Recht auf Bildung nach Maßgabe von Interesse und Qualifikation; es besteht Chancengleichheit auf allen Ebenen.

3. Die Lehrenden sind Staatsdiener mit einer mehr oder weniger starken professionellen Prägung.

4. Die Schulorganisation, die Anstellung der Lehrer und die Lehrpläne beruhen auf dem Prinzip der demokratischen Wahl, an der alle Staatsbürger zu beteiligen sind.

5. Das Gesetz regelt Rechte und Pflichten aller Beteiligten einschließlich der Wahlverfahren; alle Entscheidungen unterliegen der gerichtlichen Kontrolle.

Es ist verblüffend, daß das Verfassungsmodell des Bildungssystems, das mit seinen Elementen der Öffentlichkeit, Repräsentation, Gesetzlichkeit, Grundrechtsgewährung und Gerichtskontrolle doch in so hohem Maße den Staatsverfassungen der westlichen Industrienationen entspricht, sich im Bildungssystem so wenig durchgesetzt hat. 


\section{Markt oder Korporationen}

Das Vertragsmodell kann in zwei völlig unterschiedlichen Formen auftreten, und zwar

1. als Marktmodell, wenn private Anbieter auf einem Markt für Bildung privaten Nachfragern die Dienstleistungen des Bildungswesens anbieten und wenn eine freie Preisbildung grundsätzlich zulässig ist und

2. als Korporationsmodell, wenn öffentliche Organisationen mit dem Staat und untereinander die Bedingungen aushandeln, $\mathrm{zu}$ denen sie die Dienstleistungen des Bildungswesens den Bürgern anbieten.

Beiden Modellen ist gemeinsam, daß die Bürger die Wahl zwischen verschiedenen Angeboten haben. Der Unterschied besteht darin, daß es sich im ersten Fall um eine privatwirtschaftliche Organisationsform handelt, daß im ersten Fall die Konditionen frei ausgehandelt werden, während sie im zweiten Fall bestimmten Beschränkungen unterworfen sind. Beide Modelle können auch in einem gemischtwirtschaftlichen Modell vereint werden.

Das Marktmodell ist im Bereich der institutionalisierten Bildung großen Beschränkungen unterworfen, denn Schule und Hochschule sind in Westeuropa grundsätzlich staatlich. Soweit private Schulen und Hochschulen überhaupt vorgesehen sind, müssen sie bestimmte Zulassungsvoraussetzungen erfüllen, die sie zu einem Annex des staatlichen Schulwesens machen, und da sie in ihrer Preisgestaltung frei sind, hängen sie alle mehr oder weniger von staatlichen Subventionen und/oder privaten Spenden ab. Das ist kein privatwirtschaftlicher Markt, sondern ein öffentlich geregeltes Verwaltungssystem mit gewissen Spielräumen. Anders ist es jedoch im Bereich der beruflichen Bildung, soweit sie in Betrieben und nicht in Schulen organisiert ist, und ebenso in der Weiterbildung, wo es einen Markt privater Anbieter gibt. Hier hat sich also das Marktmodell weitgehend durchsetzen können, wenn es auch bestimmte staatliche Reglementierungen bei der $\mathrm{Zu}$ lassung und der Preisgestaltung gibt.

$[\ldots]$

Für ,reine Korporationsmodelle“ gibt es weder in Westeuropa noch sonst irgendwo auf der Welt Beispiele; es handelt sich immer um Mischformen zwischen verschiedenen Modellen. Am nächsten kommt dem Korporationsmodell das niederländische Bildungssystem (vgl. Liket 1993). In den Niederlanden hat sich aus den Auseinandersetzungen über die religiöse Prägung des Schulwesens ein Viersäulen-Modell des Schulwesens entwickelt, in dem neben einem öffentlichen Schulwesen, das nur etwa 30 Prozent der Schüler umfaßt, ein katholischer und evangelischer Sektor sowie ein weltlicher Bereich stehen, in dem Schulen unterschiedlichster Prägung zusammengefaßt sind. Das Besondere der niederländischen Organisationsform ist nun, daß im Prinzip jede gesellschaftliche Gruppe ein eigenes Schulwesen unterhalten kann (Art. 23 der Verfassung), in dem sie über 
Gründung und Schließung von Schulen, über Beschäftigung von Lehrern und Leitern, den Zugang und Abgang von Schülern sowie über das Curriculum entscheidet, - allerdings unter der Aufsicht der staatlichen Schulbehörden. Dieses Bildungssystem ist in gewisser Weise ein parzelliertes „Verwaltungsmodell“, wie ich es oben gekennzeichnet habe, nur daß nicht eine herrschende Ideologie das System dominiert, sondern daß es jede gesellschaftliche Gruppe auf ihre eigene Art und Weise tun kann. Das System entspricht deshalb in besonderem Maße den Strukturprinzipien der pluralistischen Gesellschaft. Da es jedoch auch einen Sektor der öffentlichen Schulen gibt, handelt es sich auch hier um ein „gemischtes System“.

In allen westeuropäischen Bildungssystemen finden sich korporationsrechtliche Elemente, d.h. daß das Bildungssystem nicht allein auf dem Gegensatz zwischen der staatlichen und der privaten Sphäre beruht, auf der Unterscheidung von staatlichen und privaten Schulen. Es lassen sich die folgenden korporationsrechtlichen Elemente feststellen:

1. die sogenannten Privatschulen werden in der Regel nicht von privaten Unternehmern oder von interessierten Bürgern bzw. Eltern unterhalten, sondern von den Kirchen, die in gewisser Weise auch öffentliche Korporationen sind.

2. In vielen westeuropäischen Ländern haben die Kommunen großen Einfluß auf die Schulen, und zwar insbesondere auf die Standorte, den Bau und die Unterhaltung sowie z. T. auch auf das Personal, und die Kommunen sind ebenfalls besondere öffentliche Korporationen.

3. Einige Länder räumen den Arbeitgeber- und Arbeitnehmerverbänden Einfluß auf die Berufsausbildung ein, einige Länder sogar auf das allgemeinbildende Schulwesen, den sie vertraglich regeln können, wodurch auch eine korporationsähnliche Lösung entsteht.

4. Es kommt hinzu, daß - insbesondere im Bereich der Hochschulen manche Bildungsinstitutionen selber Korporationen sind, denken wir nur an die ehrwürdige Geschichte von Oxford und Cambridge.

Es versteht sich, daß das ,gemischte“ System einen hohen Bedarf an rechtlichen Regelungen hat, und zwar sowohl gesetzlicher wie vertraglicher Art. Eine besondere Erziehungsfunktion wird man diesem Bildungssystem nicht zusprechen können; in ihm kommt vielmehr der für das Bildungssystem typische Interessenkonflikt zum Ausdruck.

\section{Bildungsverfassungen in Westeuropa}

Wenn man die derzeitigen Bildungssysteme Westeuropas betrachtet, so läßt sich nicht sagen, daß sie alle oder auch nur einzelne einem bestimmten der drei gekennzeichneten Modelle folgen, sondern in allen Ländern haben sich im Laufe der historischen Entwicklung verschiedene Modellelemente überlagert. Vielleicht lassen sich drei Gruppen von Ländern bilden: 
A. Frankreich und die Länder des romanischen Rechtskreises wird man noch am ehesten dem ,Verwaltungsmodell“" zuordnen können (Halls 1976). Die verfassungsrechtliche Prägung ist - sieht man von der Privatschulfreiheit ab - schwach; gesetzliche Regelungen konkretisieren nicht Grundrechte und gewähren keine Verfahrensrechte, sondern legalisieren im Grunde nur administrative Regelungen. Die gerichtliche Kontrolle ist nur schwach ausgeprägt.

B. Deutschland, Österreich und die Schweiz könnte man noch am ehesten dem „Verfassungsmodell“" zuordnen. Es bestehen umfangreiche gesetzliche Regelungen des Bildungswesens, begleitet von einer weitreichenden gerichtlichen Kontrolle bildungspolitischer und pädagogischer Entscheidungen. Bildung wird als Ausübung eines Grundrechts verstanden, wenn auch das Gleichheitspostulat nicht stärker verwirklicht ist als in anderen Ländern. Die Bildungseinrichtungen besitzen Selbstverwaltungsgremien, die gewählt werden. $\mathrm{Zu}$ diesen Elementen des Verfassungsmodells kommen jedoch korporative Elemente hinzu, und zwar durch die starke Stellung der Kirchen und Kommunen und gewisse marktwirtschaftliche Elemente durch die Organisation der Berufsausbildung.

C. In Skandinavien, in den Niederlanden und Großbritannien findet man gemischte Bildungsverfassungen, jedenfalls scheinen hier Elemente des „Vertragsmodells“ eine größere Rolle zu spielen als in anderen Ländern. Großbritannien fällt durch die starke Stellung der Kommunen auf, die jedoch neuerdings durch marktwirtschaftliche und korporativistische Elemente relativiert wird (Mann 1979); jedenfalls ist die Ausprägung des Verwaltungs- wie des Verfassungsmodells gering. Skandinavien ist durch die Kooperation von Arbeitgeber- und Arbeitnehmerorganisationen stark korporativistisch geprägt; doch bestehen starke Elemente des Verwaltungsmodells fort (Willmann 1980). Die Niederlande wurden bereits als stark korporativistisch gekennzeichnet.

Doch diese Gruppierungen können nur mit großem Vorbehalt vorgenommen werden; neuere Entwicklungen könnten sie sowieso obsolet werden lassen.

\section{Bildungsverfassungen in der Zukunft}

Die Zukunft wird m.E. eine Abkehr von den drei Annahmen bringen, die ich der Modellbildung zugrunde gelegt habe:

1. Die Sozialisationskraft von Institutionen wird abnehmen; da Bildung nicht in einer Institution allein erfolgt, sondern in einer Vielzahl von Verfahren und Einrichtungen, werden wir nicht mehr auf die prägende Kraft einer einzigen Einrichtung vertrauen (Hentig 1993).

2. Die Organisation von Bildungsinstitutionen folgt nicht mehr dem Modell der Staatsorganisation; Schulen und Universitäten sind nicht Kör- 
perschaften wie der Staat, sondern Körperschaften eigener Art (Fauser 1986).

3. Die Grenzen der rechtsstaatlichen Verfassung des Bildungswesen scheinen erreicht; Gesetzgebung und Rechtsprechung werden im Bildungswesen in Zukunft vermutlich eher eine geringere Rolle spielen als in einigen Ländern in der unmittelbaren Vergangenheit (Staupe 1986).

Die Zukunft könnte möglicherweise eine Hinwendung zum „Vertragsmodell" bringen. Mit dem Verschwinden einheitlicher Ideologien und mit der zunehmenden Differenzierung der gesellschaftlichen Ansprüche an das Bildungswesen verliert das „Verwaltungsmodell“" zunehmend seine Legitimation. Das „Verfassungsmodell“ hat sich mit seinen egalitären und demokratischen Ansprüchen nicht durchgesetzt, seine rechtsstaatlichen Ausprägungen scheinen auf Grenzen gestoßen zu sein, und seine freiheitlichen Aspekte begründen eine Pluralisierung, die dem unitaristischen und zentralistischen Ansatz des Verfassungsmodells widerstrebt. So stellt sich die Frage, ob denn das ,Vertragsmodell“ mit seiner marktwirtschaftlichen und korporativistischen Struktur die derzeitigen bildungspolitischen Probleme Westeuropas lösen kann.

$[\ldots]$

\section{Literatur}

Bourdieu, Pierre/Passeron, Jean-Claude: Die Illusion der Chancengleichheit. Stuttgart 1971.

Fauser, Peter: Pädagogische Freiheit in Schule und Recht. Frankfurt/M. 1986.

Halls, W.D.: Education, Culture and Politics in Modern France. Oxford 1976.

Hentig, Hartmut von: Die Schule neu denken. München 1993.

Liket, Theo: Freiheit und Verantwortung. Gütersloh 1993.

Mann, John: Education. London 1979.

Staupe, Jürgen: Parlamentsvorbehalt und Delegationsbefugnis. Berlin 1986.

Willmann, Bodo: Bildungswesen, Chancengleichheit und Beschäftigungssystem. Vergleichende Daten und Analysen zur Bildungspolitik in Schweden. München 1980.

\section{HORST WEISHAUPT \\ Die Situation des Schulwesens im Kontext der veränderten Wahrnehmung öffentlicher Aufgaben durch den Staat}

\section{Von der zentralen Steuerung des Schulwesens zur dezentralen Gestaltung}

Seit Anfang der 90er Jahre gibt es in mehreren Ländern - über Änderungen der Schulgesetze oder Versuchsprogramme - Ansätze, den Spielraum der einzelnen Schulen zur Selbstgestaltung zu erhöhen. Den Hintergrund dieser Entwicklung bildet eine Neubewertung der zentralen Steuerungsfähigkeit 
des Schulsystems. Die Kultusminister mußten erkennen, daß die zentral geplanten Schulstrukturreformen weitgehend gescheitert sind. Beispielhaft dafür ist die geplante Einführung der Gesamtschule, die sich aus politischen und rechtlichen Gründen nicht als Alternative zum dreigliedrigen Schulsystem verwirklichen ließ (Heckel/Avenarius 1986: 305). Im viergliedrigen Schulsystem wurde sie zur Schule für Schüler mit „spezifischer Indikation" (Baumert). Auch das sozialpolitische Ziel verbesserter Chancengleichheit wurde durch sie nicht erreicht. Gegen den Willen der Eltern und der unmittelbar Beteiligten lassen sich offensichtlich keine schulpolitischen Absichten durchsetzen.

Dies löste einen Umdenkungsprozeß aus, der zusätzlich von internationalen Tendenzen unterstützt wurde. An die Stelle zentraler Steuerung der Schulen tritt zunehmend die Bereitschaft, den Schulen eine begrenzte Selbstbestimmung zur Profilierung der einzelnen Schule und für den Wettbewerb zwischen den Schulen einzuräumen. Nicht mehr vom Kultusministerium wahrgenommene Regelungskompetenzen werden an die Schulträger und die einzelnen Schulen delegiert (vgl. Zedler/Fickermann 1997). Die naturwüchsige Herausbildung eines „Bildungsmarktes“ wird nicht mehr als Versagen der Politik verstanden, sondern zum Programm erhoben. Es wird so versucht, die Legitimation des politisch-administrativen Systems zu erhalten, indem auf die fehlende Durchsetzbarkeit zielorientierter Maßnahmen mit der Politik einer stärkeren Entkoppelung von Administration und öffentlicher Willensbildung geantwortet wird. Die Aktivierung eines nichtstaatlichen Steuerungspotentials führt aber zur Verschiebung von parlamentarischen Zuständigkeiten auf Verhandlungssysteme. Damit werden schulpolitische Fragen einem durch Verfassungsnormen festgelegten Entscheidungsmodus entzogen, der darauf verpflichtet ist, alle jeweils berührten Interessen gleichmäßig zu berücksichtigen (s. Habermas 1985: 154). Es ist bemerkenswert, daß gerade rot-grüne Landesregierungen (Leschinsky 1992: 30) sich dieser international dem Neokonservativismus zuzurechnenden Politik verpflichtet fühlen (Boyd 1993).

Dieses gewandelte Verständnis von Schulentwicklung, die nicht mehr von zentralen politischen Vorgaben ausgehen soll, sondern von den Entwicklungszielen der einzelnen Schule, formuliert auch die Bildungskommission Nordrhein-Westfalen:

„Im Mittelpunkt eines an Selbstgestaltung und Selbstverantwortung orientierten Steuerungskonzepts für den Schulbereich soll die Einzelschule stehen. Sie muß als relativ eigenständige Handlungseinheit gestärkt und rechtlich anerkannt werden. ... Größere Selbständigkeit der Einzelschule und erweiterte Gestaltungsmöglichkeiten der Träger und regionalen Gremien müssen aber in einem definierten Rahmen zum Tragen kommen, durch den eine Balance zwischen eigenverantworteten Entscheidungen vor Ort und weiterhin bestehender staatlicher Gesamtverantwortung hergestellt wird" (Bildungskommission NRW 1995: XXIV). 
Die in dem zweiten Satzes des Zitates zum Ausdruck kommende Einschränkung zeigt aber recht deutlich, daß der Umfang und die Bereiche der Selbstgestaltung nicht von den einzelnen Schulen gewählt werden sollen, sondern sich nach staatlichen Vorgaben bestimmen. So bleibt die einzelne Schule weiterhin abhängig von den Vorgaben des Kultusministeriums; der Handlungsrahmen wird nur rechtlich klarer abgesteckt als in der Vergangenheit. Schulorganisatorische Varianten, die in der Vergangenheit als Schulversuche beantragt werden mußten, werden nun schulgesetzlich ermöglicht.

Während der Deutsche Bildungsrat Möglichkeiten und Grenzen der Eigenverantwortung der Schule bei der Organisation von Lernprozessen von Rahmenrichtlinien neuer Art abhängig machte, die von den Kultusministerien erlassen werden und die herkömmlichen Lehr- und Rahmenpläne ersetzen sollten (Deutscher Bildungsrat 1973: 18), bleibt das Verhältnis von zentralen curricularen Vorgaben und dem Gestaltungsraum der Schule in dem Empfehlungstext der Bildungskommission NRW unbestimmt. Schulqualität soll nach diesen Überlegungen über eine situationsangemessene Gestaltung des Lehr- und Lernprozesses erreicht werden (Schule als „Lebens- und Erfahrungsraum"). Gesehen wird jedoch die Möglichkeit, daß sich dadurch Schulen unterschiedlich profilieren können und die Einheitlichkeit des Schulwesens und die Chancengleichheit der Schüler gefährdet ist (Magotsiu-Schweizerhof 1996).

Sowohl die politischen als auch die wissenschaftlichen Bestrebungen zur Verstärkung der Eigenverantwortlichkeit der einzelnen Schulen stehen vor dem Problem, daß sich die einzelnen Lehrer und Schulen diese Überlegungen zu eigen machen müssen, um wirksam werden zu können, denn Autonomie läßt sich nicht verordnen (s. Döbert 1997). Schon in einer Protokollerklärung zur Empfehlung des Bildungsrates von 1973 bemerkte Theodor Dams, daß die Empfehlung ohne eine Analyse und Diagnose der Situation an den Schulen beschlossen wurde und es offensichtlich ,nicht unerhebliche Kompetenzen auf Schulebene zu geben scheint, die entweder nicht ausgenützt bzw. zu stark beansprucht oder aber auszudehnen sind.“ (Deutscher Bildungsrat 1973: A-149, s. auch: Bessoth 1974) Auch die gegenwärtigen politischen Bestrebungen beruhen nicht auf einer Situationsanalyse an den Schulen. Für die Lehrer bedeutet der Koordinationsaufwand, der mit Projekten der Schulgestaltung verbunden ist, in jedem Fall Mehrarbeit. Die Autonomie, die die Schule darüber gewinnt, geht mit einem Verlust an individueller Autonomie des Lehrers bei der Unterrichtsgestaltung einher (zu möglichen rechtlichen Konsequenzen für die Lehrer s. Stock 1997). Insofern ist für Lehrer der Nutzen schulgestalterischen Engagements nicht eindeutig. Zu denken sollte auch geben, daß Untersuchungen zu Lehrerbiographien zum Ergebnis hatten, daß die älteren Lehrer, die sich für Reformprojekte engagiert hatten, oft verbittert und resigniert waren, während die „Herumbastler“, die sich immer wieder Neues für ihren Unterricht vornahmen und sich ,sehr konstant um klassenrauminterne Un- 
terrichtsexperimente bemühten“, auch nach über 20 Unterrichtsjahren noch mit Spaß ihren Beruf ausübten (Huberman 1993: 262). [...]

\section{Schule und neue Steuerungsmodelle in der Kommunalverwaltung}

Durch die zwischen Land und Schulträger geteilte Verantwortung für die Schulen ist mit der Dezentralisierung von Verantwortung durch das Kultusministerium auch eine Stärkung des Handlungsspielraums der Schulträger verbunden.

Von ihnen gehen ebenfalls neue Anforderungen an die Schulen aus, die aber völlig andere Ursachen haben. Die seit mehr als zehn Jahren zunehmende Finanznot der Städte und Gemeinden zwang sie zu immer weitreichenderen Leistungseinschränkungen, zugleich aber auch zu Überlegungen, wie die verfügbaren Mittel effizienter eingesetzt werden können. Ausgehend von einem Konzept der Kommunalen Gemeinschaftsstelle für Verwaltungsvereinfachung (KGSt) für ein neues Steuerungsmodell der Kommunalverwaltungen bemühen sich die Städte und Gemeinden in den letzten Jahren zunehmend, wieder Gestaltungsspielraum zu gewinnen. Drei Prinzipien sind mit der Neuorientierung der Kommunalverwaltungen verbunden:

„Voraussetzung für die neue Steuerung ist die Kundenorientierung. Dem Bürger werden nur noch die Leistungen angeboten, die er von der Verwaltung tatsächlich erwartet. Die Verwaltung sucht eine vertrauensvolle Zusammenarbeit, die alte Kontrollfunktion wird deutlich eingeschränkt. Wichtig ist die Leistungsorientierung. Die als Produkte beschriebenen Leistungen werden dazu genau beschrieben. ,Alte Zöpfe' werden abgeschnitten, und es werden nur die Leistungen erbracht, die kein anderer besser oder billiger erbringen kann. Deshalb gehört hierzu auch eine Kostenorientierung. Sie stellt sicher, daß die Leistungen wirtschaftlich erbracht werden. Durch Kostenermittlung lassen sich Leistungsumfang und Mittelbereitstellung koordinieren. Sie ermöglicht auch einen internen und externen Leistungsvergleich.“ (Stotz 1996: 134)

Mit der neuen Steuerung der Kommunalverwaltungen ist eine Dezentralisierung der Verantwortung für die Verwaltung der Haushaltsmittel verbunden. Die früher zentrale Verwaltung wird nun den einzelnen Fachressorts übertragen, die ihrerseits die Verantwortung über die Mittelverwendung und teilweise auch deren Verwaltung an einzelne Einrichtungen weitergeben. Dadurch sollen die Mittel zweck- und bedarfsorientiert ausgegeben werden. Im Rahmen dieser Bestrebungen gehen immer mehr Schulträger dazu über, den Schulen die eigenverantwortliche Bewirtschaftung einzelner Budgets zuzubilligen. Durch den Bericht der KGSt „Neue Steuerung im Schulbereich“ vom Herbst 1996 wird diese Tendenz in nächster Zeit weitere Impulse erhalten. Für die Schulen ist mit diesem Steuerungs- und Budgetierungsmodell der Vorteil verbunden, daß die Haushaltstitel zu gegenseitig deckungsfähigen Sammelpositionen zusammengefaßt werden, und sie die Mittel entsprechend ihren Prioritäten ausgeben können. Eingesparte Mittel werden nicht in den folgenden Jahren gekürzt und Mittelübertragun- 
gen in das folgende Jahr sind möglich, um für größere Ausgaben Mittel anzusparen. Dadurch können die Schulen pädagogische Programme gezielter finanziell unterstützen. Insofern ist die eigenverantwortliche Verwaltung der Haushaltsmittel durch die Schulen ein wirkungsvoller Ansatzpunkt zur Verbesserung der Effizienz des Mitteleinsatzes, der zugleich aber auch auf die pädagogische Programmentwicklung ausstrahlen kann. Allerdings sind damit auch zusätzliche Belastungen und ein spezifischer Qualifizierungsbedarf für die Schulen verbunden. Wenn diese Bedingungen nicht ausreichend berücksichtigt werden, kann dies die Akzeptanz dieses Ansatzes durch die Schulen stark beinträchtigen. [...]

\section{Literatur}

Bessoth, R.: Schulaufsicht und Partizipation. Eine pragmatische Kritik der Bildungsratsempfehlungen ,Verstärkte Selbständigkeit der Schule und Partizipation der Lehrer, Schüler und Eltern“. In: Zeitschrift für Pädagogik 20 (1974), H. 6, S. 865-886.

Bildungskommission NRW: Zukunft der Bildung - Schule der Zukunft. Denkschrift der Kommission „Zukunft der Bildung - Schule der Zukunft“ beim Ministerpräsidenten des Landes Nordrhein-Westfalen. Neuwied 1995.

Boyd, W. L.: Die Politik der freien Schulwahl und marktorientierte Schulreform in Großbritannien und den Vereinigten Staaten. Wie erklären sich die Unterschiede? In: Zeitschrift für Pädagogik 39 (1993) H. 1, S.53-69.

Deutscher Bildungsrat: Zur Reform von Organisation und Verwaltung im Bildungswesen. Teil I. Bonn 1973.

Döbert, H.: „Schulen in erweiterter Verantwortung.“ Bericht über einen Modellversuch in Berlin. In: Zedler, P./ Fickermann, D. (Hg.): Pädagogik und Recht. Rechtliche Rahmenbedingungen und Handlungsspielräume für eine erweiterte Selbständigkeit von Einzelschulen. Erfurt 1997, S. 59-74.

Habermas, J.: Die Krise des Wohlfahrtsstaates und die Erschöpfung utopischer Energien. In: Ders.: Die Neue Unübersichtlichkeit. Kleine politische Schriften V, Frankfurt/Main 1985, S. 141-163.

Heckel, H./Avenarius, H.: Schulrechtskunde. Neuwied 1986.

Huberman, M.: Der berufliche Lebenszyklus von Lehrern: Ergebnisse einer empirischen Untersuchung. In: Terhart, E. (Hrsg.): Unterrichten als Beruf. Neuere amerikanische und englische Arbeiten zur Berufskultur und Berufsbiographie von Lehrern und Lehrerinnen. Köln 1991, S. 249-267.

Leschinsky, A.: Dezentralisierung im Schulsystem der Bundesrepublik Deutschland. In: Arbeitsgruppe Entwicklung des Bildungswesens der Deutschen Gesellschaft für Erziehungswissenschaft: Strukturprobleme, Disparitäten, Grundbildung in der Sekundarstufe I, Weinheim 1992, S. 21-40.

Magotsiu-Schweizerhof, E.: Die Debatte um die Schulautonomie und die Folgen für die Chancengleichheit von Migrantenkindern. Eine Literatursynopse. (Beiträge zur erziehungswissenschaftlichen Migrations- und Minderheitenforschung 4). Frankfurt/Main 1996.

Stock, M.: Autonomie von Schule und ihre Bedeutung für die rechtliche Stellung des Lehrers. In: Zedler, P./ Fickermann, D. (Hg.): Pädagogik und Recht. Rechtliche Rahmenbedingungen und Handlungsspielräume für eine erweiterte Selbständigkeit von Einzelschulen. Erfurt 1997, S. 75-108.

Stotz, H.: Dezentrale Ressourcenverantwortung und Eigenverantwortung der Schule zwei Seiten einer Medaille. In: Pädagogische Führung 7 (1996) H. 3, S. 132-137. 
Zedler, P./Fickermann, D. (Hg.): Pädagogik und Recht. Rechtliche Rahmenbedingungen und Handlungsspielräume für eine erweiterte Selbständigkeit von Einzelschulen. Erfurt 1997

\section{PIERRE BOURDIEU \\ Die rechte und die linke Hand des Staates \\ Interview mit R. P. Droit und T. Ferenczi, erschienen in Le Monde am 14. Januar 1992. Aus dem Französischen von Jörg Ohnacker}

Frage - Eine der letzten Nummern von Actes de la Recherche, der Zeitschrift, die Sie herausgeben, hatte das Leiden zum Thema. ${ }^{8}$ Es finden sich dort mehrere Gespräche mit Menschen, die in den Medien nicht zu Wort kommen: Jugendliche aus benachteiligten Vorstädten, Kleinbauern, Sozialarbeiter. Der Direktor einer weiterführenden Schule berichtet zum Beispiel über seine bitteren persönlichen Erfahrungen: anstatt für die Vermittlung von Wissen zu sorgen, ist er gegen seinen Willen zu einer Art Polizeikommissar geworden. Glauben Sie, daß solch individuelle und anekdotenhafte Zeugnisse das Verständnis eines kollektiven Unbehagens ermöglichen?

P. B. - Bei unserer Untersuchung über das Leiden an der Gesellschaft treffen wir auf viele Menschen, die, wie dieser Schuldirektor, den Widersprüchen der gesellschaftlichen Welt ausgesetzt sind, die sie als persönliche Dramen erleben. Ich könnte ebenso den Projektleiter zitieren, der mit der Koordination aller Maßnahmen in einem ,schwierigen Viertel“ einer nordfranzösischen Kleinstadt beauftragt ist. Er ist mit Widersprüchen konfrontiert, die das Extrem derer darstellen, denen momentan all diejenigen ausgesetzt sind, die man als „Sozialarbeiter“ bezeichnet: Familienhelfer, Erzieher, kleine Beamte und auch, in steigendem Maße, die Lehrer der verschiedenen Schultypen. Sie stellen das dar, was ich als die linke Hand des Staates bezeichne, die Gesamtheit der Bediensteten der sogenannten kostenverursachenden Ministerien, die innerhalb des Staates aus den gesellschaftlichen Auseinandersetzungen der Vergangenheit hervorgegangen sind. Sie stehen in Opposition zum Staat der rechten Hand, zu den Absolventen der Kaderschulen im Finanzministerium, in den öffentlichen oder privaten Banken und den ministeriellen Kabinetten. In vielen sozialen Bewegungen, die wir miterleben (und miterleben werden), kommt die Revolte des niederen Staatsadels gegen den hohen Staatsadel ${ }^{9}$ zum Ausdruck.

Frage - Wie erklären Sie diese Erbitterung, diese Formen von Hoffnungslosigkeit und diese Auflehnung?

8 „La souffrance“, Actes de la recherche en sciences sociale, 90, Dezember 1991. Vgl. auch P. Bourdieu u.a., Das Elend der Welt, Konstanz, UVK Universitätsverlag Konstanz, 1997.

9 Anspielung auf Pierre Bourdieus Buch The State Nobility. Elite Schools in the Field of Power. Cambridge, Polity Press, 1996. 
P. B. - Ich denke, daß die linke Hand des Staates das Gefühl hat, daß die rechte Hand nicht mehr weiß, oder schlimmer, nicht wirklich wissen will, was die linke Hand tut. Auf jeden Fall will sie den Preis dafür nicht bezahlen. Ein Hauptgrund für die Verzweiflung all dieser Menschen ist die Tatsache, daß der Staat sich aus einer Anzahl von Bereichen des gesellschaftlichen Lebens, die ihm oblagen und für die er verantwortlich war, zurückgezogen hat oder im Begriff ist, dies zu tun: der öffentliche Wohnungsbau, das öffentliche Fernsehen und Radio, die öffentlichen Schulen, die öffentlichen Krankenhäuser usw. Dieses Verhalten ist, wenigstens für einige, umso schockierender bzw. skandalöser, als es sich um einen Staat unter sozialistischer Regierung handelt, von dem man mindestens erwarten könnte, daß er als Garant dafür auftritt, daß öffentliche Dienstleistungen unterschiedslos für alle offen zur Verfügung stehen ... Das, was als Krise der Politik, als Antiparlamentarismus bezeichnet wird, ist in Wirklichkeit ein Verzweifeln am Staat als Verantwortlichem für das öffentliche Interesse.

An dem Umstand, daß die Sozialisten nicht so sozialistisch waren, wie sie vorgaben, hat niemand Anstoß genommen: die Zeiten sind hart, und es gibt kaum Spielraum zum Manövrieren. Überraschend ist jedoch, in welchem $\mathrm{Ma} ß$ sie am Abbau der öffentlichen Aufgaben mitgewirkt haben: zunächst durch Tatsachen, d.h. alle möglichen Maßnahmen und politischen Schritte (ich nenne hier nur die Medien) zur Aufhebung der Errungenschaften des welfare state und, vielleicht vor allem, durch den öffentlichen Diskurs mit den Lobreden auf die Privatunternehmen (als ob Unternehmergeist nur in Unternehmen aktiv werden könnte) und der Ermutigung zur Durchsetzung von Privatinteressen. All dies überrascht vor allem diejenigen, die man in die vordersten Linien schickt, um die sogenannten ,sozialen“ Funktionen auszuüben und Abhilfe bei der gröbsten Mängeln der Logik des Marktes zu schaffen, ohne daß ihnen die Mittel zur Verfügung gestellt werden, ihrer Aufgabe wirklich gerecht zu werden. Müssen sie sich nicht zwangsläufig permanent angeschmiert und im Stich gelassen fühlen?

Man hätte längst begreifen müssen, daß die Ursachen ihrer Auflehnung weit über Gehaltsfragen hinausgehen, auch wenn das jeweils zugestandene Salär ein hervorragendes Indiz für den der Arbeit und den entsprechenden Arbeitskräften zugebilligten Wert ist. Die Geringschätzung einer Tätigkeit zeigt sich in erster Linie an der mehr oder minder lächerlichen Entlohnung, die ihr zuteil wird.

$[\ldots]$

Man müßte die kollektive Arbeit der ,neuen Intellektuellen“ analysieren, durch die ein Klima geschaffen wurde, das den Rückzug des Staates und, in noch größerem Maße, die Unterordnung unter die Werte der Ökonomie begünstigt hat. Ich denke auch an das, was allgemein als ,die Wiederkehr des Individualismus" bezeichnet wird; dabei handelt es sich um eine Art sich selbst verwirklichender Prophezeiung, die darauf abzielt, die philosophischen Fundamente des welfare state und, vor allem, den Begriff 
von kollektiver Verantwortung (im Fall eines Arbeitsunfalls, bei Krankheit oder Not) zu zerstören, der eine grundlegende Errungenschaft gesellschaftlichen (und soziologischen) Denkens ist. Es ist auch die Rückkehr zum Individuum, die es ermöglicht, „das Opfer zu tadeln“, das für sein Unglück allein verantwortlich ist, und ihm die selfhelp zu predigen, und dies alles unter dem Deckmantel der endlos beschworenen Notwendigkeit, die Unternehmenskosten zu senken. [...]

\section{INGO RICHTER \\ Die Öffentliche Schule im Umbau des Sozialstaates}

$\S 155$ Frankfurter Reichsverfassung lautete: „Für die Bildung der deutschen Jugend soll durch öffentliche Schulen überall genügend gesorgt werden“".

Nun ist die Frankfurter Reichsverfassung nie in Kraft getreten; doch Art. 143 Abs. 1 S. 1 Weimarer Reichsverfassung (WRV) nahm das Thema wieder auf: „Für die Bildung der Jugend ist durch öffentliche Anstalten zu sorgen". [...]

Das Grundgesetz hat die Regelungen des $\S 155$ FRV bzw. des Art. 143 Abs. 1 S. 1 WRV nicht wiederholt. Dennoch gilt auch unter der Herrschaft des Grundgesetzes der Satz, daß „für die Bildung der Jugend durch öffentliche Schulen genügend gesorgt" werden soll. Die Privatschulfreiheit des Grundgesetzes setzt diesen Satz voraus, denn Art. 7 Abs. 4 und 5 handeln von privaten Schulen „als Ersatz für öffentliche Schulen“. Verfassungsrechtlich begründet wird der Satz durch die sog. Sozialstaatsklausel des Grundgesetzes, die in diesem Sinne ausgelegt wird (Oppermann 1976: 23ff.). Die Wirklichkeit der Bundesrepublik bestätigt darüber hinaus diesen Satz: In der Bundesrepublik ist für die Bildung der Jugend in öffentlichen Schulen genügend gesorgt. Nur etwa $5 \%$ der Schüler an allgemeinbildenden Schulen besuchen zur Zeit in der Bundesrepublik private Schulen. Selbst wenn in einzelnen Bereichen der Anteil der Schüler in privaten Schulen deutlich höher ausfällt, so hat doch die Expansion des höheren Bildungswesens in den 1970er Jahren dazu geführt, daß die öffentlichen Schulen aller Arten heute für jedermann räumlich erreichbar sind. Die bildungspolitische Forderung der Frankfurter und der Weimarer Reichsverfassung nach der allgemeinen öffentlichen Schule ist in der Bundesrepublik heute im wesentlichen erfüllt.

\section{Die Krise des Sozialstaats und die Schulen}

Bestand und Bedeutung des öffentlichen Schulwesens beruhen in der Bundesrepublik also nicht auf einer verfassungsrechtlichen institutionellen Gewährleistung und auch nicht auf individuellen Grundrechten, die nur in öf- 
fentlichen Schulen erfüllt werden können, sondern auf der der sogenannten Sozialstaatsklausel, der verfassungsrechtlichen Aussage des Artikels 20 Abs. 1 GG, daß die Bundesrepublik ein „sozialer Staat“ ist. Die verfassungsrechtliche Sozialstaatsklausel jedoch garantiert keine bestimmte gesellschaftliche Organisationsform; sie ist eine bloße „Staatszielbestimmung", deren inhaltliche Ausgestaltung dem Gesetzgeber überlassen bleibt.

$[\ldots]$

Der Sozialstaat stellt die Schule also in den Dienst der Daseinsvorsorge und der Sozialplanung; er will individuelle und familiäre Defizite ausgleichen und durch die Schule soziale Gerechtigkeit gewährleisten. [...] Der Sozialstaat der Bundesrepublik, der alle diese Aufgaben zu erfüllen suchte und weitgehend auch erfüllt hat, befindet sich nun in einer Krise, von der allenthalben die Rede ist. Von einem „Umbau des Sozialstaats“ wird gesprochen, dessen Ansätze und Auswirkungen überall spürbar seien, insbesondere bei den öffentlichen Unternehmen, die ihre Preise und Leistungen sowie ihre Personalpolitik nach „Marktgesetzen“ ausrichten wollen, auch wenn sie (noch) gar nicht privatisiert sind. Das öffentliche Schulwesen, das zu allererst auch ein öffentliches Unternehmen des Sozialstaats ist, steht dagegen in der gesellschaftlichen Landschaft wie ein erratischer Block, der die Jahrhunderte überdauert hat und unverrückbar erscheint. Festhalten läßt sich angesichts dieser Tatsache jedoch, daß die Sozialstaatsklausel den Staat zwar dazu verpflichtet, die Öffentlichkeit des Schulwesens zu gewährleisten, nicht aber seine derzeitige Ausprägung in staatlichen, kommunalen und privaten Schulen.

Worin besteht nun diese vielberufene Krise des Sozialstaats? [...]

(1) Der Sozialstaat erreicht seine Ziele nicht bzw. nicht mehr. Die Sozialversicherungssysteme für die Versicherungsfälle Alter, Krankheit, Unfall und Arbeitslosigkeit können den Eintritt des Versicherungsfalles nicht verhindern und seine Folgen nicht ausreichend ausgleichen. [...] Die Hilfesysteme, die Chancengleichheit in der Gesellschaft gewährleisten (z.B. Ausbildungshilfe) und Gefahren für die Bürger beseitigen sollten (z.B. Sozialhilfe), vermochten weder soziale Ungleichheit zu verhindern, noch die Gefahren wirksam zu bekämpfen (Heinze u.a. 1988: 13ff.).

(2) Die zur Finanzierung des Sozialstaates aufgewandten Mittel werden als zu hoch eingeschätzt. Ihre Aufbringung über Beiträge der Versicherten erhöht die Stückkosten bei der Produktion von Gütern und beeinflußt damit die Wettbewerbsfähigkeit der Wirtschaft; ihre Deckung aus dem allgemeinen Steueraufkommen erhöht die Staatsquote am Sozialprodukt und beeinträchtigt die Belastbarkeit der Steuerzahler. [...]

(3) Der Sozialstaat war einmal die Antwort des Staates auf die Soziale Frage, und die Soziale Frage entstand aus der sozialen Lage der Arbeiterklasse. Durch die Entwicklung von Wirtschaft und Gesellschaft, nicht zuletzt auch durch die Entwicklung des Sozialstaates selbst hat sich diese Lage jedoch verändert. Die ehemalige Arbeiterklasse wurde in eine „Mittelstandsgesellschaft" integriert, und es entstand eine sog. Neue Soziale 
Frage, die sich aus der sozialen Lage derjenigen ableitete, die in die „Mittelstandsgesellschaft" und ihre soziale Sicherung nicht einbezogen waren, die zunächst als „Randgruppen“ bezeichnet wurden, nun aber eine neue soziale Gruppierung darstellen, die mit dem Begriff „neue Armut" beschrieben wird. Es geht um kinderreiche Familien und Alleinerziehende, um Ausländer und Obdachlose, alte Frauen, chronisch Kranke, Langzeitarbeitslose. Der Sozialstaat begünstigt, so die Kritik, die ohnehin Begünstigten und benachteiligt die ohnehin Benachteiligten (Geißler 1976). [...]

Die Kritik am Sozialstaat trifft durchaus auch die oben benannten sozialstaatlichen Funktionen der Schule:

1. Auch dem Schulwesen wird vorgeworfen, daß es seine sozialstaatlichen Ziele nicht erreicht. Die Kritik mag pauschal und unberechtigt sein; doch sie besteht und findet Gehör:

Die (Halbtags-)Schule betreut die Kinder nur einen Teil des Tages und leistet nicht (mehr) Schutz vor den Gefahren der Gesellschaft; sie ist vielmehr selbst ein Gefahrenherd geworden, wie es die derzeitige Gewaltdebatte verdeutlicht (Tillmann 1994). [...]

Die Aufgabe der Familie wird immer noch weitgehend darin gesehen, die Erziehung in der Schule zu unterstützen, anstatt umgekehrt die Aufgabe der Schule darin zu sehen, die Erziehung in der Familie zu unterstützen. Die „kopernikanische Wende“, die in diesem Bereich das Kinder- und Jugendhilfegesetz von 1990 vollzogen hat, steht der Schule noch bevor.

Die Politik der Chancengleichheit im Bildungswesen, die das „Jahrzehnt der Bildungspolitik“, d.h. die 70er Jahre beherrschte, hat zwar die Dauer der Bildungsgänge verlängert und das allgemeine Bildungsniveau angehoben; die Reproduktion der gesellschaftlichen Ungleichheit im und durch das Bildungswesen hat sie jedoch nicht beseitigt. [...]

2. Die Ausgaben der öffentlichen Hand und der Privatwirtschaft für das Schulwesen haben sich in den alten Bundesländern von $17 \mathrm{Mrd}$. DM im Jahre 1970 auf 56 Mrd. DM im Jahre 1991 erhöht, also in zwanzig Jahren mehr als verdreifacht; dabei betrug der Anteil der Personalausgaben jeweils rund zwei Drittel. Der Anteil der Ausgaben für das Schulwesen am öffentlichen Gesamthaushalt ging ebenso wie der Anteil am Bruttosozialprodukt in dieser Zeit [...] zurück (von 8,4 \% auf 7,1 \% bzw. von 2,5\% auf 2,1\%). [...] Angesichts der allgemeinen Einsparungen in den öffentlichen Haushalten und angesichts der Kritik an der sozialstaatlichen Aufgabenerfüllung des Schulwesens (siehe oben unter 1), erscheint es ausgeschlossen, daß das Schulwesen in der Diskussion um die Finanzkrise des Sozialstaates ausgespart bleibt. Erste Anzeichen, wie z.B. die Erhöhung der Pflichtstundenzahl der Lehrer, sprechen bereits eine deutliche Sprache. Die wieder ansteigenden Schülerzahlen scheinen andererseits zur vermehrten Neueinstellung von Lehrern zu führen.

3. Fragt man, ob die Schule einen Beitrag zur Lösung der „Neuen Sozialen Frage “ [...] leistet, so fällt die Antwort [...] leicht; sie ist negativ. Die 
Schule bietet für die besonders Benachteiligten keinen besonderen Schutz vor Gefahren; sie behandelt grundsätzlich alle Schüler gleich. [...]

Die Schulpolitik der letzten zwanzig Jahre war darauf gerichtet, entweder die organisatorische Differenzierung der Bildungsgänge zu beseitigen (Gesamtschule) oder durch eine curriculare Integration Übergänge zwischen den Bildungsgängen zu ermöglichen, was zur „Anpassung nach oben“ und zum „Ausbluten“ der Hauptschule führte. Die Zahl der Hauptschüler hat sich seit $1970 \mathrm{mehr}$ als halbiert (BMBW 1992/93). Von einer Förderung besonders benachteiligter Kinder kann jedenfalls tendenziell nicht die Rede sein.

Es ist ein altbekanntes Phänomen, daß in der Schule Mittelstandseltern das Sagen haben; sie treffen in der Schule auf Lehrerinnen und Lehrer, die ebenfalls weitgehend aus der Mittelschicht stammen. Für die Familienprobleme, die die Neue Soziale Frage aufgeworfen hat, gibt es in der Schule zwar viel Verständnis, jedoch kaum Lösungen.

Da die Schule nicht einmal einen Beitrag zur Angleichung der Bildungsbeteiligung der traditionalen sozialen Schichten leistet (s. o.), ist schon die Erwartung eines entsprechenden Beitrags zur Lösung der Neuen Sozialen Frage verfehlt. Das gilt allerdings nicht für die ausländischen Kinder, deren Bildungsbeteiligung sich deutlich erhöht hat. So hat sich die Zahl ausländischer Gymnasiasten in den alten Bundesländern von 1960 bis 1970 verachtfacht, von 1970 bis 1980 nochmals verdreifacht und von 1980 bis 1990 nochmals verdoppelt (BMBW 1992/93). [...]

Wenn also hiernach die Krise des Sozialstaates auch die sozialstaatlichen Funktionen der Schule betrifft, so wäre zu fragen, ob auch die Vorschläge zum Umbau des Sozialstaats auf die Schule angewandt werden können und sollen. [...]

\section{Der Umbau des Sozialstaats und die Schule \\ $[\ldots]$}

(1) Die Sozialbürokratie ist nicht weniger der Kritik ausgesetzt als die Staatsbürokratie. Die AOK und die Berufsgenossenschaft, die BfA und die Bundesanstalt der Arbeit gelten nicht als Selbstverwaltungseinrichtungen der Versicherten, sondern werden von ihnen als staatliche Behörden wahrgenommen. Im Sozialamt und im Jugendamt, im Ausbildungsförderungsamt und in der Erziehungsberatungsstelle sehen die Bürger nicht ihre eigenen kommunalen Einrichtungen, sondern die unterste Stufe einer Staatsbürokratie. [...] Alle diese Einrichtungen sind demokratisch-pluralistisch strukturiert; doch angesichts ihres starken Bürokratisierungsgrades können die Bürger dies oft nicht wahrnehmen. Es wurden deshalb auch kaum Versuche einer weiteren Stärkung der Bürgerbeteiligung unternommen, sondern man beschränkte sich darauf, den demokratisch-pluralistischen Charakter wieder stärker herzustellen. 
Anders dagegen in der staatlich-kommunalen Schule. Diese war und ist wirklich die unterste Stufe der Verwaltungshierarchie, wie Hellmut Becker (1954) dies bereits 1954 betonte. Sie ist eine unselbständige Anstalt des öffentlichen Rechts, ohne Rechte der Selbstverwaltung und ohne eine mitgliedschaftliche Struktur, d.h. sie hat im Rechtssinne keine eigenen Aufgaben, und ihre Organe werden nicht durch Mitglieder gewählt. Nun gab es zwar in den 70er Jahren eine breite Bewegung zur „Demokratisierung der Schule“, die zur Einführung von Repräsentativverfassungen (Mitbestimmung) führte; doch eine spürbare Veränderung des Charakters der Schule läßt sich nicht feststellen. Zwar gibt es in den 90er Jahren nun wieder ein Aufleben dieser alten Debatte unter etwas veränderten Vorzeichen (Autonomiedebatte); doch stammt die Schubkraft dieser Entwicklung weniger aus politisch-demokratischen, sondern aus ökonomisch-funktionalen Motiven (Richter 1994). Insofern paßt diese Entwicklung in die Diskussion über den „Umbau des Sozialstaates“.

(2) Die Wirtschaftlichkeit des sozialen Leistungssystems ist seit langer Zeit Gegenstand von Kritik und von Untersuchungen. Es gibt vermutlich keinen Bereich der öffentlichen Verwaltung, der so eingehend untersucht wurde. $\mathrm{Ob}$ es sich um die Wirtschaftlichkeit des Krankenhauses oder des kassenärztlichen Abrechnungssystems, des Arbeitsschutzes oder der Fortbildung und Umschulung handelt, nichts blieb ununtersucht [...]. Das Schulwesen blieb dagegen lange Zeit von derartigen Untersuchungen verschont. [...]

(3) Mehr aus Gründen der Sparsamkeit als der Effizienz der eingesetzten Mittel haben die Träger der sozialen Leistungssysteme damit begonnen, die Ausgaben für soziale Leistungen einzufrieren oder sogar zu senken. Dies geschieht auf zweierlei Weise, nämlich entweder durch den Abbau sozialer Leistungen oder durch die Kostenbeteiligung der Empfänger an der Finanzierung der Leistungen. Der erste Weg hat zur Folge, daß die Leistungen entweder gänzlich entfallen, so daß sie die Empfänger auf den „Markt" einkaufen müssen, oder daß sie durch andere soziale Systeme, z.B. die Familie, die Nachbarschaft, erbracht werden zu müssen. Beide Wege begrenzen den Umverteilungseffekt der sozialen Versicherungssysteme, indem sie die Beitragsbelastung aller Versicherten zu Lasten von Zahlungsverpflichtungen der Leistungsempfänger oder Dritter senken. Aus diesem Grunde gelten ,,beide Wege“" als ein Mittel zur Wirksamkeitssteigerung.

Im Schulwesen werden die beiden Wege zwar auch beschritten, jedoch eher zögerlich und unsystematisch. Der Leistungsabbau geschah insbesondere durch den Unterrichtsausfall, durch Kürzung des Unterrichts in der Stundentafel oder durch Verkürzung der Bildungsgänge (beispielsweise zur Zeit in der Auseinandersetzung um das 13. Schuljahr); wirklich einschneidende Leistungskürzungen wurden jedoch vermieden. [...] Eine Kostenbeteiligung, z.B. durch die Wiedereinführung des Schulgeldes, wurde bisher nicht ins Auge gefaßt; vollzogen wurde jedoch ein Leistungsab- 
bau durch die weitgehende Beseitigung des Schüler-BAföG, was zu einer stärkeren Selbstkostenbeteiligung der Eltern führte. Die Finanzpolitiker vermuten, daß hier noch große Reserven stecken, die beim „Umbau des Sozialstaates" mobilisiert werden können. [...]

(4) [...] Auch die Privatisierung einzelner schulischer Funktionen wird nur sehr zögerlich und nicht ganz ernsthaft ins Auge gefaßt. So wäre es zwar denkbar, daß die Schule den Sport- und Musikunterricht kommunalen, verbandlichen oder kommerziellen Anbietern überläßt, die dafür nach Ausschreibung - bestimmte Preise verlangen dürfen. Die Überlassung des Fremdsprachenunterrichts an kommerzielle Anbieter scheidet vermutlich von vornherein wegen der hohen Kosten der langen Lehrgänge aus. Die amerikanischen Versuche in den 70er Jahren, die in diese Richtung gingen, haben sich allerdings als nicht sehr erfolgreich herausgestellt (Richter 1975). Die Privatisierung scheint danach kein geeigneter Weg zum „Umbau des Sozialstaates“ im Bildungswesen zu sein.

(5) Was bleibt - nimmt man die begrenzten Möglichkeiten zu einem „Umbau des Sozialstaates“ im Bereich des Schulwesens zur Kenntnis - ist die Begründung des „Third Sector“, ist der „Welfare Mix“.

Als ,, Third Sector “ bezeichnet man in der Organisationstheorie den Bereich zwischen oder jenseits von Staat und Markt, in dem gemeinnützige, private und öffentliche Organisationen, insbesondere Stiftungen und Körperschaften öffentliche Aufgaben wahrnehmen, die vom Staat wirksam nicht erfüllt werden können, die man aber auch nicht dem Markt privater Anbieter überlassen will. [...]

Ein „Dritter Sektor“ läßt sich im Schulwesen leicht begründen: Der Staat schreibt einen bestimmten Teil des Schulwesens öffentlich aus und gewährt Leistungen, die unter den Pro-Kopf-Ausgaben für das staatliche Schulwesen liegen. Bewerben können sich kommunale, verbandliche und private Interessenten, die die Ausschreibungsbedingungen erfüllen und den Status der Gemeinnützigkeit erlangt haben. Dies hätte vermutlich zur Folge, daß zwischen dem staatlichen und dem kommerziellen Schulwesen ein breiter Bereich öffentlich-privater Schulträger entstünde, die um den $\mathrm{Zu}-$ schlag konkurrieren. Das niederländische Schulwesen wird häufig als Modell genannt, auch wenn es dort Ausschreibungen nicht gibt (Liket 1993). Diese Schulträger konkurrieren jedoch nicht nur im Rahmen der Ausschreibung miteinander, sondern sie konkurrieren mit den staatlichen und mit den kommerziellen Schulen wie auch untereinander um die Schüler, so daß für die Schüler und Eltern echte Wahlmöglichkeiten entstehen.

Man kann davon ausgehen, daß es in einem solchen System zu Formen begrenzter Zusammenarbeit zwischen den Trägern kommt, nämlich immer dann, wenn die Zusammenarbeit allen Beteiligten Vorteile bringt. Die Träger des Dritten Sektors werden insbesondere versuchen, durch die Beteiligung ehrenamtlicher Kräfte Personalkosten einzusparen, so daß im Zusammenhang mit dem Dritten Sektor ein breiter Selbsthilfebereich entstehen wird. Eine Zusammenarbeit ist jedoch nicht nur innerhalb des Dritten 
Sektors denkbar; auch die kommerziellen Schulen könnten sich bestimmter Leistungen, die im Dritten Sektor erbracht werden, bedienen, um ihre Marktchancen zu erhöhen. Der Staat könnte bestimmte Ausbildungsgänge $\mathrm{zu}$ besonderen Bedingungen ausschreiben und insoweit besondere Formen der Zusammenarbeit mit dem Dritten Sektor entwickeln, wofür das englische „Opting-Out“ ein Modell wäre. Auf diese Art und Weise entstünde zwischen den drei Sektoren etwas, das in Anlehnung an den „Welfare-Mix“ „Education-Mix“ "genannt werden könnte. Ein solcher „Education-Mix“ würde ein vielfältiges Schulwesen schaffen, dessen Funktionsfähigkeit nur durch einheitliche Prüfungen und Berechtigungsanforderungen gewährleistet werden kann. [...]

Geht man davon aus, daß die Kosten für das Schulwesen in einem solchen System gesenkt würden, so kann man annehmen, daß die Wirksamkeit des Schulwesens durch eine bessere Erfüllung der gesellschaftlichen Anforderungen erhöht würde. Die Schaffung eines „Dritten Sektors“ oder die Einführung eines „Education-Mix“ würde also die ersten beiden Ziele der Weimarer Reichsverfassung, die Öffnung der Schule für alle sozialen Schichten und aller Bekenntnisse, erfüllen können und damit ihren Beitrag zur Lösung der „Krise des Sozialstaates“ leisten. Einen Beitrag zur Lösung der Neuen sozialen Frage wird man sich allerdings von einem solchen System nicht erhoffen können.

Als Ergebnis läßt sich deshalb feststellen, daß die Schaffung eines „öffentlichen Schulwesens“ im Sinne von „Drittem Sektor“ und „EducationMix" die Effektivität des Schulwesens zu erhöhen verspricht, die soziale Gerechtigkeit jedoch eher vermindert. Es müßte also eine Wertentscheidung gefällt werden, wenn man dem „Umbau des Sozialstaates“ im Schulwesen nähertreten will.

\section{Literatur}

Becker, H.: Die verwaltete Schule. 1954, jetzt wieder abgedruckt in: Recht der Jugend und des Bildungswesens 1993.

Bildungsministerium für Bildung und Wissenschaft: Grund- und Strukturdaten 1992/93.

Geißler, H.: Die Neue soziale Frage. Freiburg i.Br. 1976.

Heinze, R.G./Olk, T./Hilbert, J.: Der neue Sozialstaat. Freiburg i.Br. 1988, S. 13 ff.

Liket, T.M.: Freiheit und Verantwortung. Das niederländische Modell des Bildungswesens. München 1993.

Oppermann, T.: Nach welchen rechtlichen Grundsätzen sind das öffentliche Schulwesen und die Stellung der an ihm Beteiligten zu ordnen? Gutachten C zum 51. DJT. München 1976.

Richter, I.: Die unorganisierte Bildungsreform. München 1975.

Richter, I.: Theorie der Schulautonomie. In: Recht der Jugend und des Bildungswesens (1994), S. 5 ff.

Tillmann, K-J.: Gewalt in der Schule. Was sagt die erziehungswissenschaftliche Forschung dazu? In: Recht der Jugend und des Bildungswesens (1994), S. 163 ff. 


\section{Schulkultur}

\section{Kommentar (Eubel)}

Ein weiterer Diskussionspunkt, der mit der gegenwärtigen Modernisierung von Schule einher geht, bezieht sich auf Schulkulturen. Hierzu wurden zwei Texte für den vorliegenden Band ausgewählt.

Die Fokussierung auf Helmut Fend (Universität Zürich) geschieht nicht in erster Linie, um ihn aus der Reihe all derer, die in diesem Feld arbeiten, besonders hervorzuheben - seine Meriten sind ohnehin unumstritten -, sondern weil seine Karriere als Forscher sich mit dem Begriff „Wandel aus Erfahrung" beschreiben lässt. Bekannt wurde Fend mit seiner Konstanzer Forschergruppe, die in großem Stil das herkömmliche deutsche Schulsystem vergleichen sollte mit einem aus Gründen der Verbesserung der Bildungschancen zu schaffenden Gesamtschulsystem. Der Auftrag dazu kam aus der Bildungspolitik.

Eine der wesentlichen methodischen Erkenntnisse dieser Forschungen: Der Systemvergleich alleine reicht nicht aus. $\mathrm{Zu}$ viele andere Faktoren spielen ebenfalls eine Rolle, wenn nicht sogar eine größere. Von daher die zunehmende Betonung komplexerer, integrierter Analysen. Anregungen dazu fand Fend in der angelsächsischen Bildungsforschung. Er orientierte sich weg von den Systemanalysen und richtete den Fokus eindeutig auf die Einzelschule. Dort galt es zu entdecken und zu beobachten, was es an gelungenen Beispielen für Schulqualität gibt. ${ }^{10}$ Neben solchen ,guten Schulen“ wurden auch Bedingungen für „schlechte Schulen“ sichtbar (vgl. Fend 1987). Die pädagogische Forschung deckte damit insgesamt auf, dass die Schullandschaft hinsichtlich der Schulkulturen von Einzellschulen sehr heterogen ist. Fend selbst arbeitet deshalb an einer perspektivischen Weiterentwicklung seines Forschungsprogramms, das Bedingungen für gelungene Schulreformen erkennen will, in der Absicht, Schulen nicht nur zu verändern, sondern sie überprüfbar zu verbessern.

Fend geht dabei vor allem von zwei Ressourcen aus, die eine Schulkultur beeinflussen können. Erstens die inneren Verpflichtungen der im Schulsystem Beschäftigten, d.h. ein Ethos des Engagements und der „inneren Entschlossenheit, etwas zu tun“ (Fend). Zweitens die Ressource der ,incentives“, der Anreize. Hierbei ist Fend stark von der US-amerikanischen Erforschung von Schulkulturen beeindruckt. Sie kann zeigen, dass sich durch konkrete soziale Mechanismen gezielt auf eine Schulkultur einwirken lässt.

10 Vgl. auch einen weiteren Text von Fend (in Auszügen) zu Beginn von Textblock „III. Beobachtung von Akteurkonstellationen“. Zwar gibt es in der Schulpädagogik unzählige Publikationen, die sich ausschließlich mit unterschiedlichen Ansätzen zur Erzeugung ,guten' Unterrichts und einer ,guten' Schule beschäftigen, oft aber nicht den Bezug zu den theoretischen und auch methodischen Voraussetzungen einer Modernisierung offen thematisieren. Diesen Brückenschlag liefert Fend. 
Fend notiert z.B. „[...] eine starke unterrichtsbezogene Führung (leadership), hohe Erwartungen, Konzentration auf Leistungsstandards, Überprüfung und Symbolisierung der Lernerfolge (award-system), die Formulierung einer Zielperspektive und eine klare, konsistente Entscheidungsstruktur gelten als empirisch belegte Indikatoren einer effektiven Schule“.

Im Prinzip ist damit eine der Positionen der wissenschaftlichen Pädagogik gegenüber der Schulmodernisierung benannt, die uns auch an vielen weiteren Stellen des Lernbuches noch begegnen wird. Da ist zum einen ein hoher Kenntnisstand über Bedingungen von guten und schlechten Schulen, der durch pädagogische Forschung - zu der Fend selbst wesentlich beigetragen hat - vermehrt wird. Zum anderen fehlen aber offensichtlich operative Konzepte der Umsetzung der „guten“ wissenschaftlichen Erkenntnisse. In diese Lücke stoßen Managementkonzepte der Steuerung, wie sie vor allem in angelsächsischen Ländern entwickelt wurden. Diese Konzepte versuchen vereinfacht gesagt unter Obergriffen wie leadership und Managements die verschiedenen Kräfte einer Schulkultur, auf die die pädagogische Forschung hinweist, zu bündeln. Die große Hoffnung der Modernisierer entlang von New Public Management besteht darin, dass mit leadership, Management und Eigenverantwortung der Einzelschule entscheidungsfähige Mechanismen gefunden sind, die es erlauben, qualitätsbasierte Schulkulturen stetiger und konsequenter, als es in den bisherigen Schulkulturen ohne Führung und Eigenverantwortung der Fall ist, fortzuentwickeln. Wie wir auch in weiteren Teilen des Lernbuches formulieren, geht es darum, die vielfältigen, aber oft nur locker miteinander verbundenen Interaktionszusammenhänge derzeitiger Schulkulturen umzustellen auf harte überprüfbare Fakten einer (zu schaffenden) Organisation Schule. Damit soll insgesamt auch eine Homogenisierung der Schullandschaft, die Angleichung schlechter an gute Schulen erreicht werden. Die Umstellung der Schulkultur auf Qualitätsarbeit und Effizienz ist mit einem hohen Rationalitätsversprechen verbunden.

Die Umstellung einer Schulkultur auf Effizienz ist auch explizit Thema eines weiteren Textes, von Jürgen Oelkers („Unterricht und Effizienz“). In seiner Analyse verlässt Oelkers für einige Momente die von ihm als Historiker oft bevorzugte Globalperspektive und operationalisiert an einem konkreten Beispiel die Fallstricke, in die man sich mit der Forderung nach effizientem Unterricht verfangen könnte. Offensichtlich wird das Thema Effizienz zu einer neuen, die Schulkultur prägende Modernisierungssemantik.

Oelkers beobachtet zunächst, welche Effizienzvorstellungen es in der jetzigen Schule schon gibt, z.B. hinsichtlich der Fächerverteilung mit Hilfe der Stundentafel. Soll die Effizienz im Fach A erhöht werden, könnte das zur Folge haben, dass im Fach B Zeit eingespart, also die Effizienz gesenkt werden müsste. Oelkers weist aber darauf hin, dass die Logik „,mehr Zeit ergibt erhöhte Effizienz" ohne empirische Evaluation kaum haltbar ist. Die Stundentafel sei folglich von „naiven Effizienztheorien“ geprägt. 
Naiv sind allerdings auch die aufwändigen Verfahren der Schulentwicklung, die alles mögliche zum Thema machen (vgl. die Aufzählung von Oelkers in seinem Textabschnitt „Nachteile der starren Zeiteinteilung“), sich aber um das Faktum drücken, dass über ,Erfolg und Misserfolg schulischer Bildung im Unterricht entschieden wird." Und das heißt vor allem: Durch die ,Fachlichkeit" des Fachunterrichts. Und auch da liegen unsere Kenntnisse sehr im argen.

Oelkers' Vorschlag, aus dieser unbefriedigenden Lage herauszukommen, ist mehrschrittig. Zuerst schlägt er vor, genauer zu klären, was Effizienz in schulischen Kontexten meint. Wegen der Verpflichtung auf „öffentliche Bildung“, die eine allgemeine und gleiche Bildungsversorgung impliziert, lehnt er einen ökonomischen Effizienzbegriff (maximaler Ertrag bei minimalen Kosten) ab, da (1) Bildung kein Produkt sei, da sie (2) wesentlich „Niveausicherung für anschließendes Lernen“ ist und dadurch (3) „prinzipiell unabschließbar" wird. Damit wird aber die Forderung nach Effizienz nicht prinzipiell zurückgewiesen ${ }^{11}$, sondern festgestellt, dass sie entkoppelt von einem „,diffusen Gesamtprozess ,Bildung ““ auf abgrenzbare und unterscheidbare schulische Prozesse bezogen werden sollte. Die Fachlichkeit des Unterrichts bietet sich dafür an, denn sie ist gekennzeichnet durch ,überprüfbare Ziele, dazu passende Zeitressourcen sowie fortlaufende Evaluationen ". Der Präzisierungsvorschlag, der hier unterbreitet wird, hat den Vorteil, dass er einen zentralen Bereich von Schule, den Unterricht und seine Qualität, dadurch diskutierbar und damit prinzipiell messbar macht, dass er die im Selbstverständnis der Profession zentralen Bereiche (,Bildung“) draußen vor lässt. Womit aber noch lange nicht geklärt ist, wie genau sich die Fachlichkeit mit einem dann nicht mehr ,naiven 'Verständnis von Effizienz verbindet. Das macht den Anspruch, dass Schulen sich entwickeln sollen, nicht einfacher. Aber auch wenn offensichtliche Aporien nicht in solcher Deutlichkeit angesprochen sind, stehen sie der Intention, die Schule zu modernisieren, dennoch im Wege. Hindernisse, über die man stolpert, weil man sie nicht sieht, sind möglicherweise gefährlicher, als Widerstände, auf die man gefasst ist, denn mit ihnen kann man rechnen. Die traditionelle Kultur der Reflexion über Schule bevorzugte das Wegschauen und hat die Schule auch nicht wesentlich weiter gebracht.

11 Diese Zurückweisung kann unterschiedliche Gründe haben: Prinzipielle Zweifel an der Transferierbarkeit neoliberaler Effizienzforderungen ins Bildungssystem, wie bei Bourdieu (siehe oben im Textblock I „Modernisierung von Sozialstaaten“) und seinen Mitstreiterinnen Sylvain Broccholichi und Françoise Euvrard (in Textblock „IV. Mögliche Effekte schulischer Modernisierung“; vgl. auch Lohmann/Rilling 2002), oder die Skepsis von reformorientierten Lehrerinnen und Lehrern, die befürchten, dass die Verpflichtung auf messbare ,outputs' die nicht oder nur schwer messbaren Bildungs- und Erziehungsziele der Schule zum Verschwinden bringen (siehe z.B. von der Groeben im Textblock „Wertediskussionen“ aber auch Melzer/Al-Diban im Textblock III „Akteurkonstellationen“, „Schüler“). 


\section{HELMUT FEND \\ Schulkultur und Schulqualität}

\section{Wissenschaftsgeschichtliche und geistesgeschichtliche Vorbemerkungen}

Um die Besonderheit der Schulqualitäts-Forschung sichtbar zu machen (siehe auch Specht 1994, Leschinsky 1992), ist ein Rückgriff auf die Geschichte der Schulreform seit den 1950er Jahren hilfreich. Erst die Kenntnis der Umbrüche in den pädagogischen Basisorientierungen von den 1950er zu den 1960er Jahren bzw. von den 1960er Jahren bis heute macht sichtbar, warum die Erforschung der Qualität der einzelnen Schule den heutigen hohen Stellenwert bekommen konnte.

Geistesgeschichtlich fällt für die 1950er Jahre die Orientierung an der „Person“, am „Geist“, an der „Existenz“ des Menschen auf. [...] In Anknüpfung an die Pädagogik vor dem Dritten Reich, in Anknüpfung an die sogenannte Reformpädagogik und an die humanistischen Erziehungstraditionen stand die personale Entwicklung des einzelnen Menschen sowie die Person des Lehrers als „Entwicklungshelfer“ - in oft geradezu intimen pädagogischen Bezügen sich bewegend - im Vordergrund. Die Weckung der kulturellen und geistigen Interessen in jungen Menschen durch die Begegnung mit den kanonisierten Gehalten der Kultur [...], verbunden mit Anklängen an religiöse Erleuchtungserlebnisse, und die personale Begegnung mit der Lehrerpersönlichkeit bewegten das pädagogische Ethos dieser Jahre, in denen über eine Rekonstruktion des Humanismus auch eine Wiedereingliederung in die lange abendländische Tradition versucht wurde.

Der Wandel in den 1960er Jahren war in der Tat dramatisch. [...] Die Aufmerksamkeit richtete sich jetzt fast ausschließlich auf die Lebensumstände des Menschen, insbesondere auf die sozialen und politischen Systeme, in denen er lebt und leidet. So traten sozialpolitische Zielsetzungen im Rahmen des Bildungswesens, wie zum Beispiel Chancengleichheit, in den Vordergrund. Dies geschah jetzt aber nicht mehr in einem existentialistisch-leidenden, pessimistischen und reduktionistischen Gestus, sondern in einer Attitüde der Kritik, der manchmal fast aggressiven Veränderungsforderung, in einer Attitüde der Machbarkeit und der Verantwortung für die Veränderung der Verhältnisse. Pädagogisch trat die Perspektive in den Vordergrund, daß der Mensch ein Produkt der Gesellschaft ist; die Kontexte, in denen er lebt, prägen seine Gestalt und sein Handeln. Defizite sind somit immer Defizite der Umwelt, insbesondere der gesellschaftlichen Rahmenbedingungen.

In diesem häufig selbstanklägerischen Geist der Erwachsenen gegenüber den Heranwachsenden, der Lehrenden gegenüber den Lernenden entwickelte sich ein heute unvorstellbarer Eifer der Systemveränderung, der sich insbesondere im Bildungswesen entfaltete. Durch die Veränderung der Systembedingungen sollte die ideale Schule entstehen, die Chancengleichheit für alle und Solidarität aller mit allen schafft. Aus ihr sollte der eman- 
zipierte, handlungsfähige und handlungswillige Mensch erwachsen, der selber wieder zur Veränderung der gesellschaftlichen Bedingungen bereit ist. Zumindest von den Konzepten her blieb im Bildungswesen damals kein Stein auf dem anderen. Bald haben sich aber die Bemühungen um Systemveränderung auf die Veränderung der Sekundarstufe I, insbesondere im Rahmen der Gesamtschulkonzepte, verengt. [...]

Die faktischen Ergebnisse dieser Veränderungsbemühungen sind bekannt (siehe z.B. Fend 1982). Im Rückblick nicht gerade überraschend hat sich gezeigt, daß Systemmerkmale des Bildungssystems in der in den 1960er Jahren definierten Gestalt nur eine begrenzte Bedeutung bei der Beförderung wünschenswerter humaner und pädagogischer Verhältnisse haben. Sie determinieren das alltägliche pädagogische Geschehen nicht in der vorgestellten Weise. Dies zur Kenntnis zu nehmen und neue Perspektiven aufzubauen, bedurfte einer längeren Trauerphase und führte zuweilen zu einem pädagogischen Defaitismus, hinter dem nicht selten eine massive Identitätsgefährdung stand.

Neue Sichtweisen mit neuen Hoffnungen und Handlungsperspektiven näherten sich auf verschiedenen Wegen. Ein wichtiges Ergebnis aus meinem Umkreis der Schulevaluation war die auch durch persönliche Anschauung untermauerte Tatsache, daß es Gesamtschulen gab, in denen sich aufzuhalten belastend bis quälend war, während in anderen tatsächlich eine Annäherung an Ideale erlebt wurde. Auch herkömmliche Schulen repräsentierten sich in völlig unterschiedlicher Attraktivität. Diese Varianz mußte ihre Gründe haben, die nicht im „System“ zu suchen waren. [...]

Ein zweiter Entwicklungsstrang entsprang dem wachsenden Mut, der Alltagserfahrung und der pädagogischen Intuition wieder zu trauen und sie nicht dem „Systemdenken“ zu opfern. Damit gewann die konkrete Erfahrung in und mit einzelnen Schulen wieder an Bedeutung; Schulbesuche, Fallstudien, Studienreisen begleiteten diesen Prozeß.

Entwicklungen der Bildungspolitik und Bildungsforschung in englischsprachigen Ländern stützten diese neuen, erst zaghaft auftauchenden Erfahrungen. Sie alle begannen die Bedeutung der gemeinschaftlichen Anstrengung eines Lehrerkollegiums an einer Schule zu würdigen und zu betonen. Die Arbeit von Rutter und Mitarbeitern (1979) ist besonders bekannt geworden, aber auch die amerikanischen Studien zu „school effectiveness“ untermauerten diese Einschätzung (Linney/Seidelmann 1989, United States Department of Education 1986, Edmonds 1979, Purkey/Smith 1983). [...]

\section{Zielbilder: Neue Sicherheiten im Gelungenen}

Ein Hauptergebnis [all] dieser Arbeiten [zur Theorie und Phänomenologie der Schule als pädagogischer Handlungsebene, vgl. z.B. Fend 1981] sehe ich darin, daß es gelungen ist, neue - wie sich allerdings zeigen sollte, oft gar nicht so neue, sondern aus der Reformpädagogik schon bekannte - 
Leitbilder gelungener schulischer Umwelt für Aufwachsen in unserer Zeit zu beschreiben, zu illustrieren, zu entwickeln und zu demonstrieren.

Nicht zuletzt die Anschauung und das lebendige Vorbild, das das für jedes Handeln so wichtige Zielbild enthält, haben eine neue Sicherheit im Gelungenen geschaffen.

So würde ich auch heute jedem, der erfahren möchte, wie man möglichst gute Schulen als Lebensräume des Aufwachsens gestalten sollte, empfehlen, herumzureisen und sich anzuschauen, wie Schulen aussehen, die einen guten Ruf haben [...]. Für eine solche Reise stünde ihm eine reiche Palette von Schulangeboten zur Verfügung: Er könnte die Erben der Reformpädagogik der ersten 20 Jahre dieses Jahrhunderts besichtigen [...].

Unser Sucher nach Visionen und Verwirklichungen einer guten Schule könnte aber auch die große Palette der Freien Schulen und Alternativschulen in den Blick nehmen, von Waldorfschulen bis Montessorischulen. [...]

Reisen ins Ausland, Besuche in Schulen anderer Länder würden das Vorstellungsvermögen, was Schule sein kann, gewiß noch zusätzlich bereichern. Doch jemand mag von diesen hier nur angedeuteten Erfahrungen genügend beeindruckt sein, um in eine tiefe Depression über das Erscheinungsbild der normalen staatlichen Schule zu verfallen, um die Kahlheit, Zerstörung und Trostlosigkeit vieler Schulräume und Schulhäuser zu bejammern, um die Langeweile eines sturen, lehrbuchgesteuerten Unterrichts zu betrauern, um die unwirschen, nur auf Vortrag und Prüfung beschränkten Interaktionen zwischen Lehrern und Schülern als Karikaturen des Möglichen zu erkennen und die pädagogisch „toten“, wenn nicht gar fraktionierten Lehrkörper zu bedauern und um sie als Zerrbilder von lebendigen, kooperierenden, pädagogisch engagierten und in einer Kultur des immer wieder neu Lernens lebenden Lehrergemeinschaften zu erkennen.

[...] Mir ist bei diesem kurzen, ja allzu kurzen Überblick die Vermittlung der Erfahrung wichtig, daß sich in den letzten Jahren unsere Vorstellungen, was Schule als Lebensraum und Entwicklungsraum für heranwachsende Menschenkinder sein kann, unübersehbar verfeinert und differenziert haben. Es gibt unzählige kreative pädagogische Erfindungen, die unsere Visionen guter Schulen in hohem Maße bereichern, so daß wir von diesen Leitbildern her nicht so orientierungslos sind, wie die Schulkritik in den Medien gelegentlich suggeriert.

\section{Von der Anschauung zur wissenschaftlichen Systematik: Die Präzisierung des Begriffs Schulkultur}

Die Forschung zur Schulqualität und Schulkultur lebt ohne Zweifel von der lebendigen Anschauung und der gelungenen Beschreibung von Einzelfällen. Derjenige, der meint, daß die Vielfalt der Bedingungen und Sonderkonstellationen, die zusammenkommen müssen, damit eine qualitativ hochwertige Schulumwelt entsteht, so groß ist, daß eine Generalisierung über Schulen hinweg unproduktiv sei, hat sicher gute Gründe für eine sol- 
che Position. Nichtsdestoweniger finden wir auch hier das Bemühen um Systematisierung.

Sie sind einmal auf der Ebene der Beschreibung angesiedelt. Sowohl die ethnomethodologische Fallstudienarbeit als auch die Survey-Ansätze haben klären geholfen, worin sich Schulen unterscheiden. Die ethnomethodologische Forschung ist um den Begriff der Kultur zentriert. Ohne auf die umfassende Diskussion zu diesem Begriff eingehen zu können, sei hier dasjenige, was ich als dessen Kern empfinde, kurz expliziert.

In drei Weisen kommt das zum Ausdruck, was man Schulkultur nennen könnte: in Symbolisierungen (Objektivationen), in Ereignissen und in Sprache. Das Verbindende dieser drei Äußerungsformen ist, daß jeweils etwas sichtbar gemacht wird - zum Beispiel pädagogische Haltungen und Denkweisen -, das dadurch zu einem Verbindenden einer Mehrzahl von Menschen wird. Über die „Objektivationen“ wird das gemeinsame Denken, Empfinden und werden die gemeinsamen Werte zum Ausdruck gebracht (Bürgi 1990). Was eine Gemeinschaft von Menschen als zu sich passend, als ihr Eigentliches in verschiedenen Objektivationen immer wieder zum Ausdruck bringt und damit auf ein gemeinsames Verständnis und gemeinsam Sein-Sollendes verweist, macht ihre „Kultur“ aus.

Am Beispiel der Schulkultur kann dies in drei Negativausprägungen kulturarmer Schulen verdeutlicht werden:

(1) Die Symbolisierungsarmut verweist auf ein spezifisch kulturelles Phänomen, die mangelnde Darstellung, ja das Fehlen einer Konzeption, so daß wir als Folge die äußerst dürftigen räumlichen Arrangements finden, die kahlen Klassen und kühlen Wände, nur gelegentlich verschönert von aus Langeweile geborener künstlerischer Notdurft in der Form von zerkratzten Bänken und beschmierten Wänden.

(2) Die Ereignisarmut ist dann ein Problem, wenn sie auf ein Minimum an Gemeinsamkeit, auf eine Gleichgültigkeit gegenüber dem Lauf des Lebens und seiner Phrasierung in Eintritte, Krisen, Erfolge, Rückschläge, Abschlüsse und Ziele verweist. Es fehlen dann sowohl Riten, die eine Phrasierung erlauben, als auch Gemeinsamkeiten, was etwa in dem an der Oberfläche kurios anmutenden Ergebnis vieler Schulvergleiche zum Ausdruck kam, daß gemeinsame Tanzveranstaltungen im Lehrerkollegium der beste Indikator für ein gutes Schulklima waren.

(3) Schulkultur ist auch ein Ergebnis der gemeinsamen Bedeutungen, die ihrerseits sprachlich zum Ausdruck kommen müssen und dann sich in der Weise des Redens über die Kollegen, die Schüler, die heutigen Zeiten insgesamt manifestieren. Diese symbolischen Welten können völlig außerschulisch besetzt sein, durch Reden über Urlaube, Hausbau, Versicherungen, Einkaufsmöglichkeiten, sie können sich in Diskursen über die Schüler erstrecken, die man am liebsten aus der Schule weg hätte, und sie können sich um das eigentliche des gemeinsam Schule-Gebens drehen.

Die kulturelle Innenausstattung der Schule moderiert in der Gestalt eines Schulethos in bedeutsamer Weise die Alltagsarbeit an einer Schule, die 
betriebswirtschaftlich oder organisationssoziologisch häufig beschrieben wurde. Ihr Kern gruppiert sie sich um die Lösung von Sachfragen, um die Bewältigung von Rechtsproblemen, um die Art und Weise der Bewältigung von Alltagsaufgaben, der Lösung von Konflikten, der Erfüllung von Sachansprüchen. Auch auf dieser Dimension können die Unterschiede zwischen einzelnen Schulen nicht extrem genug gedacht werden. Völlige Konfliktunfähigkeit und aggressive Fraktionierungen haben wir ebenso gefunden wie effiziente Koordination, Information und Entscheidungsfindung. Nirgends hat jedoch eine chaotische Organisation viel Positives zu einer kooperativen Schulkultur beigetragen.

Schon diese wenigen Dimensionen führen fast von selbst auf die Frage, welche Bedeutung der Schulleiter in einer solchen Betriebsstruktur wie der Schule hat (Baumert 1992), eine Frage, die hier nicht weiter bearbeitet werden kann.

Zumindest erwähnt werden müssen aber die fruchtbaren Versuche der großflächigen Survey-Studien, einzelne Faktoren guter und effizienter Schulen zu systematisieren, zu messen und in ihrer faktischen Wirksamkeit zu überprüfen. Wie unschwer ersichtlich ist, nähern sich diese Listen stärker dem ,guten Normalfall“ von Schule, den Standardbedingungen für ordentliche Schulen. So faßt Coleman seine Arbeiten darin zusammen, daß er in zwei - uns sehr bekannten - Merkmalen effiziente Schulen, gemessen an den Leistungsergebnissen, sieht: in einer ordentlichen, disziplinierten und für Amerika besonders wichtig - sicheren Lernumwelt und in einem ungebrochenen Ethos, Leistungen zu verlangen, zu überprüfen und zu belohnen.

[...] Eine starke unterrichtsbezogene Führung (leadership), hohe Erwartungen, Konzentration auf Leistungsstandards, Überprüfung und Symbolisierung der Lernerfolge (award-system), die Formulierung einer Zielperspektive und eine klare, konsistente Entscheidungsstruktur gelten als empirisch belegte Indikatoren einer effektiven Schule. Sie werden - auch dies ist für den amerikanischen Kulturkreis charakteristisch - ausbalanciert durch eine Kultur der Kooperation und vertrauensvollen Kollegialität, der Fairneß, der Wertschätzung des einzelnen Schülers und der Unterstellung von hoher Lernbereitschaft (siehe zusammenfassend Steffens/Bargel 1993: $71 \mathrm{ff}$.$) . [\ldots]$

\section{Die Mehr-Ebenen-Perspektive}

Neben den inhaltlichen Visionen guter Schulen hat sich für mich ein wichtiges methodisches Resultat der Forschung zu Qualitätsmerkmalen im Bildungswesen seit den 1950er Jahren herauskristallisiert: die Systematisierung der Ergebnisse zu einer mehrebenenanalytischen Betrachtungsweise. Die personenorientierte Pädagogik der 1950er Jahre hatte sich sehr auf die Person des Lehrers als Qualitätsgaranten des Bildungswesens konzentriert. In einer unterrichtstechnologischen Zwischenphase wurde die kleinere Einheit einzelner Unterrichtsstrategien zum Hoffnungsträger für die Qualität 
des Bildungsprozesses. Die gesellschaftstheoretische Ausrichtung sah in System- und Strukturmerkmalen, die sich in Organisationsformen niederschlugen, die primäre Quelle für ein akzeptierbares Schulsystem. Im Gefolge vieler Enttäuschungen ist dann die einzelne Schule als pädagogische Handlungseinheit zum Hoffnungsträger avanciert.

Die Vermutung liegt auf der Hand, daß es pädagogisch unsinnig wäre, die verschiedenen Ebenen gegeneinander auszuspielen. Aufschlußreich könnte aber die Frage werden, in welcher Weise die verschiedenen Ebenen interagieren. [...]

\section{Von der Beschreibung der inneren Konfigurationen zur Bedingungsanalyse und zur Suche nach Veränderungsmöglichkeiten}

[...] Wir müssen zur Suche nach Bedingungsfaktoren der Qualität von Bildungssystemen übergehen. Wenn wir über sie Bescheid wüßten, dann wären wir auch in einer guten Situation, um Schulen auf einen erwünschten Zustand hin zu entwickeln, denn über Forschungsprozesse entdeckte Entstehungsbedingungen und bei Veränderungsinteressen zu beachtende Entwicklungsbedingungen sind im Kern identisch. Praktische Veränderungsbemühungen und theoretisch-empirische Untersuchungen inspirieren sich dabei gegenseitig. Jenseits des Paradigmenstreites um Aktionsforschung oder analytisch-empirische Forschung leuchtet ein, daß sowohl aus Handlungsbemühungen und ihren Folgen gelernt werden kann als auch aus nüchtern-distanzierter Beobachtung und Untersuchung. In beiden Fällen muß aber der Erkenntnisprozeß systematisiert und organisiert werden. [...]

Pädagogen neigen dazu, in der ersten Ressource der Schulgestaltung die zentrale und auch die einzige zu sehen: in der kulturell-ideologischen. Man nennt sie Ethos, Moral, Engagement, Überzeugung, Verpflichtungsgefühl, Kultur, Weltanschauung, Ideologie. Ihnen gemeinsam ist eine innere Entschlossenheit, etwas zu tun, die Welt nach einem positiven Modell zu gestalten. Ihr Fehlen dokumentiert sich vor allem in Gleichgültigkeit, Verantwortungslosigkeit, Indifferenz. Doch woher kommt diese Ressource heute? Unzweifelhaft hat sie religiöse Wurzeln oder säkulare sozialethische Wurzeln. Beide sind heute in „,short supply“. Die Studentenbewegung und der in ihr enthaltene sozialethische Gestaltungswille war noch mit säkularisierten theologisch-religiösen moralischen Ansprüchen gesättigt; im modernen Individualisierungsschub hat sich die ethische Orientierung klar auf die Realisierung des eigenen Lebensprojekts verschoben. [...]

Vielleicht können wir mehr auf die zweite Ressource setzen, der marktwirtschaftliche Organisationsprinzipien zugrunde liegen: auf Incentives. Daß sich Engagement und Einsatz lohnen müssen, wäre hier also vor allem zu beachten, wenn Schulsysteme und Schulen gestaltet werden. So wären Anreize zu schaffen, daß sich Schulleiter an der pädagogischen und leistungsbezogenen Qualität der Schule orientieren, daß sich kollegiales Verhalten ,auszahlt“, daß ein effizienter und kollegialer Führungsstil be- 
lohnt wird. Gleiches gilt für Lehrer, ein Prinzip, das zum Beispiel in die neue Mitarbeiterbeurteilung und Lehrerbeurteilung im Kanton Zürich Einzug halten soll.

Wenn von Incentives als Ressource gesprochen wird, dann ist auch klar, daß gute Schulen und gute Lehrer nicht umsonst zu haben sind. Ideologie scheint dagegen als Ressource kostenlos zu sein, weshalb sie in Wirtschaftskreisen verständlicherweise immer als suspekt betrachtet wird.

Kostenneutral erscheint vielen auch die dritte Ressource zur Wirklichkeitsgestaltung: der Rekurs auf Aufsicht, Kontrolle und Sanktion. Kein soziales System kommt ohne sie aus. Der Rückgang auf formal-rechtliche Rahmenbedingungen bleibt als soziales Sicherheitsnetz unentbehrlich. Seine Exekution hat in den letzten Jahrzehnten deutlich an Popularität verloren, so daß auch sie in ,short supply“ geraten ist. [...]

Eine Bestandsaufnahme der Qualitätskriterien und ihrer Realisierung im Bildungswesen muß somit, wenn sie in Gestaltungsdenken führt, auch zu einer Bestandsaufnahme der obigen Handlungsressourcen führen. Auf diesem Wege kämen wir nicht nur zu einem neuen Leitbild guter Schulen, das uns in Umrissen heute so präzise wie schon lange nicht mehr vor Augen steht, sondern auch $\mathrm{zu}$ einer realistischen Konzeption, wie BildungsSystem-Gestaltung in Zukunft zu organisieren wäre.

Ohne Zweifel würde sich dann zeigen, daß die Verpflichtung auf Qualitätsstandards als eines ,normativen Geschäfts“ das Ergebnis eines gesellschaftlichen Diskurses und Einigungsprozesses sein muß, in den die Eltern, Lehrer, Administratoren, Interessenvertreter und Politiker jeweils ihre Vorstellungen über Qualitätsmerkmale einzubringen hätten. Die pädagogische Forschung könnte hier hilfreich sein, da die Forschungsbemühungen der letzten Jahre - wie hier zu zeigen versucht wurde - klare Hinweise auf qualitativ hochwertige Umwelten schulischen Lebens und Lernens erarbeitet haben.

\section{Literatur}

Baumert, J.: Schulleitung in der empirischen Forschung. In: Rosenbusch, H. W./Wissinger, J. (Hrsg.): Schulleiter zwischen Administration und Innovation. Braunschweig 1992, S. 52-63.

Bürgi, R.: Organisationskultur in Schulsystemen. Lizentiatsarbeit, Universität Zürich 1990.

Edmonds R. R.: Making public schools effective. In: Social Policy 12 (1979), S. 56-60.

Fend, H.: Theorie der Schule. München 1981

Fend, H.: Gesamtschule im Vergleich. Weinheim 1982.

Leschinsky, A.: Dezentralisierung im Schulsystem der Bundesrepublik Deutschland. In: Posch, P/Altrichter, H. (Hrsg.): Schulautonomie in Österreich. Wien 1992, S. $227-$ 239.

Linney, J. A./Seidmannn, E.: The future of schooling. In: American Psychologist 44 (1989), 2, pp. 336-340.

Purkey, S. C./Smith, M. S.: Effective schools: A review. In: The Elementary School Journal 83 (1983), 4, S. 426-452. 
Rutter, M./Maughan, B./Mortimer, P./Ouston, J.: Fünfzehntausend Stunden. Schulen und ihre Wirkungen auf Kinder. Weinheim 1979.

Specht, W.: Die vier Fallstudien im Kontext der Debatte um die Qualität von Schulen.

In: Altrichter, H./Radnitzky, E./Specht, W. (Hrsg.): Innenansichten guter Schulen.

Wien 1994, S. 18-42.

Steffens, U./Bargel, T.: Erkundungen zur Qualität von Schule. Neuwied 1993.

United States Department of Education: What works. Washington 1986.

\section{JÜRGEN OELKERS \\ Unterricht und Effizienz: Probleme der Schulentwicklung}

Im letzten Drittel des 19. Jahrhunderts gerieten die altphilologisch ausgerichteten Gymnasien im deutschen Sprachraum unter starken Legitimationsdruck. Ihr Angebot erhielt nur noch, wie Ernst Mach (1886) sich ausdrückte, relativen Bildungswert, die Fortschritte in den Naturwissenschaften würden zur Revision des Curriculums zwingen, also zur Reduktion von Griechisch und Latein zugunsten von Physik, Chemie und Mathematik. [...] Schmid (1878) sagt dies so: Wer sechs bis acht, ,wöchentliche Stunden für Mathematik" fordert, um Integral- und Differentialrechnung unterrichten zu können, analytische Geometrie und Funktionsgleichungen, könne das nur, wenn andere, „nicht entbehrliche Unterrichtsfächer“ reduziert werden. Entbehrlich sind immer die anderen Fächer. [...]

\section{Vorteile der Stundentafel}

$[\ldots]$

Die Stundentafel sorgt für Realismus, nämlich beschränkt die Zeit, die sich im Blick auf die fachlichen Notwendigkeiten immer nur erhöhen könnte. Der sinnvolle Stoff hat kein oberes Limit, daher ist immer $z u$ wenig Zeit vorhanden, während es nie gelingen würde, den Unterrichtsstoff allgemein so zu organisieren, dass er aus sich heraus die notwendige Zeit angeben könnte. [...]

Die Stundentafel hat noch einen weiteren Vorteil, sie sorgt für inneren Frieden. Erfahrungsberichte aus Gymnasien etwa zeigen, wie aufwendig Anstrengungen auch nur einer geringen Umverteilung organisiert werden müssen, mit wieviel fachbezogenen Emotionen sie verbunden sind und wie gering der Effekt tatsächlich ist (Graven 1999). Wenn man zwei Jahre braucht, um eine einzige Lektion zu verschieben, und wenn sicher ist, dass diese Revision bei der ersten günstigen Gelegenheit revidiert werden wird, dann ist kaum damit zu rechnen, dass Besitzstände nach einem Gesamtbedarf verteilt werden. Die feste Hierarchie der Fächer verhindert, dass Verteilungskämpfe zur permanenten Erscheinung werden, während man immer 
fragen kann, ob nicht eine Stunde mehr Musik zulasten der Mathematik einen besseren Gesamtertrag der Allgemeinbildung ergeben würde. Ich nenne das eine naive Effizienztheorie. [...] Auch sechs Stunden Mathematik statt fünf garantiert für sich genommen keinen besseren Effekt, einfach weil der durch „Lektionen“ bestimmte Zeitaufwand mit vielen anderen Wirkungsfaktoren kombiniert wird.

Ich nenne nur: die Qualität der Lehrkräfte, den Rang des Faches, die Motivation der Schüler für das Fach, die inhaltliche Organisation des Unterrichts, die Gestaltung des Unterrichtsprozesses, die soziale Kohäsion der Klasse, die Unterstützung durch das Umfeld. Die naive Effizienztheorie abstrahiert von diesen Faktoren und setzt allein auf Erhöhung oder Absenkung der Stundenzahl. Die zur Verfügung stehende Zeit wird nicht gesamthaft betrachtet, sondern von der eifersüchtig beobachteten Verteilung her.

[...]

Schüler wählen sehr gerne das Fach Pädagogik, obwohl oder weil es intellektuell weniger bietet als Mathematik. In diesem Zusammenhang wirkt die Stundentafel, also die zugeteilte und starre Zeit, geradezu wie ein Garant der Bildung, mit dem sich die falschen Wahlen verhindern lassen. [...] Es gibt unter den Schülern informelle Gesamteinschätzungen von Fächern, in denen die Physik, schon bevor überhaupt Unterrichtserfahrungen vorliegen, abqualifiziert wird. Schüler „wissen“, dass das Fach strapaziös, langweilig und für ihr Leben bedeutungslos ist. Das Interesse ist ein zentraler Faktor für den Erfolg. Wenn, wie im Falle der Physik - aus welchen Gründen auch immer -, das Interesse der Schüler anhaltend gering ist (Shamos 1995), muss auch der beste Unterricht mit hohen Behinderungen rechnen. Andererseits erzeugt der Unterricht das Interesse, für Physik, Chemie oder auch Geschichte interessieren sich die meisten Schüler nicht von sich aus. Die Alltagsunterstützung ist gering, historische Interessen bestehen nicht einfach und müssten dann entwickelt werden, vielmehr ist die Schule die einzige Agentur, die für geordnete historische Bildung zur Verfügung steht, mit allen Belastungen, wenn etwa Schüler schon den Ausdruck „Geschichte" für ein Signum des Veralteten halten, das keinerlei Aufmerksamkeit verdient.

Hier schützt nun die Stundentafel nicht mehr. Der Garant des inneren Friedens und der Organisationsruhe sichert nicht schon Motivation und Aufmerksamkeit für das Fach.

$[\ldots]$

Die amerikanische Ethnologin Jean Lave (1988) hat gezeigt, dass elementare Rechenoperationen, die im Alltag genutzt werden, vor allem durch die fortlaufenden Verwendungssituationen des Alltags und nicht etwa durch Unterricht stabilisiert werden. Auf der anderen Seite liegen kaum Studien vor, die Gegenrechnungen aufmachen, also die Effizienz des Mathematikunterrichts im Blick auf einen dauerhaften Bildungsgebrauch nachweisen (Helmke 1992, Sammons u.a. 1993, Lytton/Pyryt 1998). Generell scheint es schwierig zu sein, den Lebensnutzen von Fachunterricht 
nachzuweisen (Malaguerra 1999 für die Schweiz), auch weil langfristige Erhebungsdaten mit Sinn für biographische Feinheiten gar nicht vorliegen.

[...] Wir können nichts über ,die“ Effizienz „des“ Unterrichts aussagen, schon weil es zwischen den einzelnen Schulfächern einen einheitlichen Typus „Unterricht“ nur in einem sehr abstrakten und hochgradig formalisierten Sinne geben kann. [...]

\section{Nachteile der starren Zeitverteilung}

Über Erfolg und Misserfolg schulischer Bildung wird im Unterricht entschieden, und dies im Blick auf das Angebot und die Qualität einzelner Fächer. Zwei neuere Studien aus Zürich, die Leistungen im Mathematik- und Deutschunterricht erheben (Moser/Rhyn 1999, 2000), zeigen eindrücklich, dass nicht Variablen der Schulorganisation, sondern die Sequenzen des täglichen Unterrichts entscheidend sind. Das ist weniger trivial als es klingt, wenn man sich vor Augen führt, wie aufwendig heute Schulentwicklung betrieben wird, ohne den Fokus des Unterrichts zu berühren. Ich nenne nur Reformthemen wie:

1. Entwicklung der Schulleitung.

2. Schulleitbild und individuelle Profilierung der Schule.

3. Schulmanagement und Öffentlichkeitsarbeit.

4. Pädagogische Konferenzen.

5. Schulklima und Schulgemeinschaft.

6. Entwicklungs- und Leistungsverträge.

7. Interne Evaluationen.

Das ist für sich genommen alles gut begründet, aber als Organisationsreform nur dann sinnvoll, wenn der tägliche Unterricht davon profitiert. Diese Bedingung wird oft nicht erfüllt, vielfach auch gar nicht gesehen [...]. Der Fachunterricht ist weder ein thematischer Fokus noch ein Thema der Entwicklungsstrategie, wenigstens ist auffällig, dass die Inhalte, der Schulstoff oder die fachdidaktischen Arrangements, kein Problembereich sind, der von Organisationsentwicklung berührt werden würde (Oelkers 2000: 233ff.). [...] Evaluationen etwa sind Alibiübungen, wenn sie nicht echte Bilanzen offenlegen, die den Kern der Schule, den Unterricht, tangieren und Szenerien beschreiben, wie er verbessert werden kann.

Die Stundentafel und die Zeitverteilung sind nicht zufällig kein Thema in solchen Reformprojekten, wie überhaupt davon ausgegangen werden muss, dass Schulreformen unterstellen, es stünde beliebig viel Zeit gerade für sie zur Verfügung, während die Grundzeit der Schule verteilt ist. Das gilt allerdings nur im Sinne der Rangfestlegung, die sich danach bestimmt, wieviel Lektionen ein Fach erhält. Nicht ohne Grund werden Haupt- und Nebenfächer unterschieden und mit der Unterscheidung im Bewusstsein 
von Lehrkräften und Schülern verankert. Dieses Ranking sagt aber nichts über realen Zeitverbrauch aus, weder ist damit der Aufwand für Unterrichtsvorbereitung oder Hausaufgaben erfasst noch kann daraus auf die tatsächliche Lernzeit einzelner Schüler oder Lehrer geschlossen werden. Eine nicht-naive Effizienztheorie müsste diese Faktoren berücksichtigen, während Schulen mit vagen Kalkulationen auskommen, wieviel Zeit zum Erreichen welcher Ziele notwendig ist.

$[\ldots]$

Das Effizienz- ist also wesentlich ein Zeitproblem [...]. Wie schwierig sich die Zeitgestaltung ausnimmt, lässt sich gerade am Unterricht zeigen [...]. In 45 oder 50 Minuten müssen fast immer mehr als 25 Wahrnehmungshorizonte koordiniert werden, ohne dass bei allen eine einheitliche Aufmerksamkeitsschwelle gegeben wäre. Die Koordination von Wahrnehmung und Aufmerksamkeit ist in jeder Stunde eines neues Problem, das sich auf überraschende Weise verändern kann.

$[\ldots]$

Die gesamte Ordnung wäre gefährdet, würden sich alle Schüler auch nur annähernd gleich beteiligen. Das Nacheinander des Unterrichts lässt nur ungleiche Beteiligungen $\mathrm{zu}$, wenn aber fortlaufende Beteiligung ein Faktor für stabile Motivation ist, dann kann auch das Resultat nur ungleich sein. Individualisierung ist demgegenüber immer nur beschränkt möglich, die zugeteilte Zeit verhindert, dass sich Lehrkräfte um viele Schüler einzeln kümmern, weil die Zeit für alle gleich bemessen ist. Unterrichtet werden nicht Schüler, sondern Gruppen von Schülern, also soziale Verteilungen, die mit einer Standardsituation erfasst werden.

$[\ldots]$

Es ist nicht möglich, eine hochmotivierte Lernsituation, in der viele Schüler gute Problemlösungen entwickeln, solange fortzusetzen, wie sie andauert. Sie wird abgebrochen, selbst wenn klar ist, dass anschliessend Weitsprung geübt wird, bei dem die meisten Schüler nichts lernen. Zumeist ist das aber gar nicht klar, weil reale Programmabsprachen zwischen Fächern gar nicht bestehen. [...]

Stressstudien zeigen, dass ein wesentlicher Belastungsfaktor im Unterricht der diffuse Ertrag ist (Travers/Cooper 1996 und diverse andere). Lehrkräfte wissen oft nicht genau, was die Schüler gelernt haben und dies bei hohem Eigenaufwand und grossen Anstrengungen. Dafür ist die starr sequenzierte Zeit mitverantwortlich. Sie reagiert auf den Stundenplan, nicht auf die tatsächlichen oder mutmaßlichen Lernfortschritte einzelner Schüler.

$[\ldots]$

\section{Alternativen}

Über schulische Effizienz, also bessere Leistungen bei gleichen oder steigenden Mitteln, ist seit dem 19. Jahrhundert immer wieder nachgedacht worden (Cuban 1995), allerdings kaum in einem ökonomischen Verständ- 
nis. Bessere Leistungen wurden wesentlich von besserer Ausstattung erwartet, also von Zuwachs möglichst in allen Bereichen. Eine ökonomische „output efficiency“, die mit Erfahrungswerten festlegte, was ,the most desirable effect at mimum cost ${ }^{\text {‘12 }}$ wäre, ist schulischem Unterricht fremd. Er fragt nicht danach, was bei gegebenen Ressourcen die bessere Alternative sein kann, also sich gegenüber anderen durchsetzt, weil am besten Verluste vermieden worden sind. Schulen nehmen Verluste in Kauf, auch weil sie in keiner Rechung erscheinen müssen, und so ganz unklar ist, was als „Verlust“" geführt werden muss und was als „Gewinn“.

$[\ldots]$

Radikale Bildungsmärkte sind nicht zufällig nirgendwo entstanden, und die eher wenigen Experimente mit Quasi-Märkten ${ }^{13}$ haben vor allem unvorgesehene und unerwünschte soziale Nebenfolgen. Das begrenzt zugleich die Effizienzvorstellung: Wenn der Markt ausfällt, muss die Effizienz auf das Verhältnis von Bildungsauftrag und Schulorganisation bezogen werden, und das ist nicht leicht, weil beide Seiten komplex sind und das Regulativ von Gewinn oder Verlust ausfällt. Über den Auftrag lässt sich mindestens das folgende sagen:

1. Grundlegend ist ein Konzept öffentlicher Bildung, mit dem eine allgemeine und gleiche Bildungsversorgung definiert wird.

2. Erfolg und Misserfolg werden einzig durch persönliche Leistungen bestimmt, unabhängig von Geschlecht, sozialer oder ethnischer Zugehörigkeit.

3. Die öffentliche Schule übernimmt Bildungsverantwortung, in dem Sinne, dass ein bestimmter Kenntnisstand sowie ein Qualitätsausbau garantiert sein müssen.

4. Jede neue Generation muss sich darauf verlassen können, dass der Bildungsstand nicht sinkt, sondern gleichbleibendes oder verbessertes $\mathrm{Ni}$ veau erhält.

5. Die Versorgung muss unabhängig von politischen Interessen oder sozialen Schwankungen garantiert sein, also setzt gesellschaftlichen Konsens voraus.

6. Im Gegenzug muss die tatsächliche Qualität der öffentlichen Schulen fortlaufend evaluiert und folgenreichen Bewertungen unterzogen werden.

Das könnte man einen pädagogischen Gesellschaftsvertrag ${ }^{14}$ nennen, der in der Schweiz seit den dreißiger Jahren des 19. Jahrhunderts Kontur angenommen hat und dann eine nahezu selbstverständliche Geltung gefunden

12 Ich folge einem Vortrag von François Grin (2000).

13 Ich folge Weiß (2000) und Whitty (2000).

14 Genauer: einen Generationenvertrag; die verantwortliche Erwachsenengeneration sichert der nachwachsenden eine in der Qualität nicht nachlassende Bildungsversorgung, über die die nachwachsende Generation nicht selbst entscheiden kann. 
hat. Der Vertrag hat ein so komplexes Gefüge, dass es ausgeschlossen ist, ihn mit naiven Vorstellungen von Effizienz zu erfassen. Trotzdem stellt sich das Thema „Effizienz“, und zwar gerade weil ein öffentliches Gut betroffen ist (Winch 1996). [...] Unbestritten in der Relevanz, sperrt sich das Thema zugleich seiner Bearbeitung, und dies aus mindestens drei Gründen: Bildung ist kein Produkt, das sich mit einer Berechnung von Input und Output erfassen ließe. Es gibt ständig Blackbox-Phänomene, es ist zudem unabsehbar, wieviel externe Verstärkungen im Spiel sind, und ein abgeschlossenes Gesamtresultat ist nicht vorhanden. Zweitens nämlich ist Bildung wesentlich Niveausicherung für anschließendes Lernen, hat also ihren Effekt in der Akzeptanz von fachlichen Standards, die nicht unterlaufen werden dürfen, wenn Lernprozesse fortgesetzt werden sollen. Drittens ist Bildung damit unabschließbar und so immer die Fortsetzung ihrer selbst. Es ist daher zu erwarten, dass mit diesen Prozessen immer ein großer Rest Unverständlichkeit verbunden sein muss.

Gleichwohl lässt sich über „Effizienz“ in sinnvoller Weise sprechen, wenn nicht ein biographischer und diffuser Gesamtprozess „Bildung“ betrachtet wird, sondern abgrenzbare und unterscheidbare schulische Prozesse, für die Fachlichkeit bestimmend ist. Sie kennzeichnet dreierlei, überprüfbare Ziele, dazu passende Zeitressourcen sowie fortlaufende Evaluationen. Das ist wiederum nicht selbstverständlich, weil schulische „Ziele“ oft reine Wunschvorstellungen sind, die sich an keiner denkbaren Erfahrungswirklichkeit überprüfen lassen; die Ressourcen sind dann nicht auf Ziele eingestellt, sondern auf Zeitverbrauch. Das erste also wäre die Formulierung von überprüfbaren Zielen in einem transparent gehaltenen Programm, das verständlich kommuniziert werden kann. Schulen würden zu Beginn eines Jahrgangs oder einer Stufe darlegen, welche Ziele sie verfolgen, mit welchen Mitteln diese Ziele erreicht werden sollen und wieviel dafür erforderlich ist.

[...] Schulen verfolgen derartige Strategien kaum ansatzweise, vor allem weil Fächer Unterrichtsautonomie pflegen, also je nur für das eigene Angebot sorgen. Zudem ist das Angebot in vielen Fächern sehr stark von Vorlieben der einzelnen Lehrkraft abhängig, was umso mehr gilt, je liberaler die curricularen Verhältnisse beschaffen sind.

[...] Nochmals und in aller Deutlichkeit gesagt: Schulerfolg ist wesentlich abhängig von der Qualität des Fachunterrichts. Daraus sollte folgen, dass der Fachunterricht im Mittelpunkt der Reformbemühungen steht, während in vielen Diskussionen alles andere wichtiger erscheint. Mein Plädoyer geht dahin, die Schulreformdiskussion von läppischen oder marginalen Themen abzubringen und Probleme des Fachunterrichts stark zu machen, wohl wissend, wie schwach entwickelt die fachdidaktische Forschung ${ }^{15}$ ist, wie gering unser Kenntnisstand über die historische Entwicklung der Schulfächer und wie übermächtig die Reformillusionen. Schulreformen

15 Vgl. die Übersicht von Mangold/Oelkers (2000). 
sind immer wieder an der Schulstruktur gescheitert, an dem, was der amerikanische Historiker David Tyack The Grammar of Schooling nennt (Tyack/Tobin 1994), also an den ehernen Größen der Stundentafel, der Hierarchie der Fächer, der Gruppierung der Schüler in Jahrgängen, dem Einlehrer-Prinzip, dem Belohnungs- und Bestrafungssystem, der Anordnung von Stoff auf Prüfungen hin und ähnliches mehr.

$$
[\ldots]
$$

\section{Literatur}

Cuban, L.: History of the Concept of ,Effectiveness' As Applied to U.S. Public Schools. In: U.P. Trier (Hrsg.): Wirksamkeitsanalyse von Bildungssystemen. Aarau/Bern 1995, S. 205-217.

Graven, D.: Schulrealität: Wie mühsam und wie unmöglich ist „Effizienz“? Ms. Bern 1999.

Grin, F.: Effectiveness and Efficiency in Education. In: J. Oelkers (Ed.): Futures of Education. Bern 2000.

Helmke, A.: Unterrichtsqualität und Unterrichtseffekte - Ergebnisse der Münchner Studie. In: Der Mathematikunterricht 38 (1992), S. 40-58.

Lave, J.: Cognition in Practive. Mind, Mathematics and Culture in Everyday Life. Cambridge: Cambridge University Press 1988.

Lytton, H./Pyryt, M.: Predictors of Achievement in Basic Skills. A Canadian Effective School Study. In: Canadian Journal of Education 23 (1998), S. 281-301.

Mach, E.: Ueber den relativen Bildungswert der philologischen und der mathematischnaturwissenschaftlichen Unterrichtsfächer der höheren Schulen. (1886) In: E. Mach: Populär-wissenschaftliche Vorlesungen. M. e. Einl. v. A. Hohenester u. e. Vorw. v. F. Herneck. Neudr. der 5. Aufl. Leipzig 1923. Wien/Köln/Graz 1987, S. 313-355.

Malaguerra, C.: Préparé pour la vie? Evaluation des compétences en Suisse. In: La Vie économique 1 (1999), S. 42-47.

Mangold, M./Oelkers, J.: Fachdidaktik: Eine Bilanz. Ms. Bern/Zürich 2000.

Moser, U./Rhyn, H.: Evaluation der sechsten Klassen im Kanton Zürich. Aarau 2000.

Moser, U./Rhyn, H.: Schulmodelle im Vergleich. Eine Evaluation der Leistungen in zwei Schulmodellen der Sekundarstufe I. Aarau 1999.

Oelkers, J.: Schulreform und Schulkritik. 2., vollst. überarb. Aufl. Würzburg 2000 (erste Aufl. 1995) (= Erziehung, Schule, Gesellschaft, hrsg. v. W. Böhm, Bd. 1).

Sammons, P./Nuttall, D.L./Cuttence, P.F.: Differential School Effectiveness. Results from a Reanalysis of the Inner London Education Authority's Junior School Project Data. In: British Educational Research Journal 19 (1993), S. 381-405.

Schmid, K.A.: Gymnasiale Bildung. Stuttgart 1878.

Shamos, M.: The Myth of Scientific Literacy. New Brunswick, N.J.: Rutgers University Press 1995.

Travers, C.J./Cooper, C.L.: Teachers Under Pressure. Stress in the Teaching Profession. London/New York: Routledge 1996.

Tyack, D./Tobin, W.: The ,Grammar' of Schooling: Why Has It Been So Hard To Change? In: American Educational Research Vol. 31, No. 3 (1994), S. 453-479.

Weiß, M.: Entwicklung und Evaluation von Quasi-Märkten. In: J. Oelkers (Hrsg.): Futures of Education. Bern 2000.

Whitty, G.: Devolution and Choice in Education. In: J. Oelkers (Hrsg.): Futures of Education. Bern 2000.

Winch, C.: Quality and Education. Oxford/Cambridge: Blackwell Publishers 1996 (= Journal of Philosophy of Education Monograph Series, Vol. 2). 


\section{Markt}

\section{Kommentar (Eubel)}

Es gibt praktisch keinen modernen Industriestaat, der nicht ein öffentliches, staatlich finanziertes allgemeinbildendes Schulwesen für seine Bürger vorhält. Mit der Modernisierung des Sozialstaats geht allerdings oft die Forderung nach seinem Rückzug aus diesem Sektor einher. Wenn also über das Verhältnis von Staat und Markt diskutiert wird, ,lassen sich folgende Schwerpunkte herausdestillieren:

- die freie Schulwahl durch Eltern und Schüler anstelle der weithin praktizierten Schulzuweisung durch Behörden;

- die Förderung privater Bildungseinrichtungen, welche gegenüber öffentlichen Schulen Ansprüchen größerer Effektivität und Effizienz entsprechen sollen;

- der Rückzug des Staates aus seiner dominierenden, wenn nicht sogar monopolartigen Steuerungsfunktion.“"(Mitter 1996: 125f.)

Spricht man im deutschen Kontext von einem Bildungsmarkt ${ }^{16}$, dann wird der Begriff eher metaphorisch gebraucht und nicht im enger ökonomischen Sinn, mit dem die - dem Ausgleich von Angebot und Nachfrage dienende Institution der Preisbildung gemeint ist. Von mehr Markt wird schon gesprochen, wenn etwa der Rückzug des Staates aus der direkten Steuerung des Bildungssystems gefordert wird (Schulautonomie). Die Analogie zur Marktwirtschaft wird in diesem Fall bemüht, weil man annimmt, dass autonome Schulen besser auf Bedürfnisse der Adressaten, d.h.: Kunden, eingehen zu können. Nach „,mehr Markt" rufen vor allem aber auch die Lobbyisten der nichtstaatlichen Schulen, die gängigerweise als Privatschulen bezeichnet werden. ${ }^{17}$ Sie fordern mehr Freiräume, um konkurrenzfähiger gegenüber dem staatlichen Angebot zu werden. ${ }^{18}$

16 Bei Verwendung des Marktbegriffs im Kontext des deutschen Bildungssystems muss deutlich gemacht werden, welches Segment des Systems man im Auge hat. Allgemeinbildende Schulen und auch die Hochschulen sind derzeit noch weitgehend vor Marktkonkurrenz geschützt. Anders sieht es im Sektor der Weiterbildung aus. Dort wirken die Kräfte eines freien Marktes. Betriebswirtschaftliche Kalkulation des Kursangebots, Einwerbung von Kunden, Abgabe von Angeboten zu öffentlich ausgeschriebenen Bildungsmaßnahmen sind für alle privatwirtschaftlich organisierten Anbieter Alltag, bestimmen aber auch zunehmend die Arbeitsbedingungen der Anbieter, die derzeit noch unter dem ,Dach“ öffentlicher oder gemeinnütziger Organisationen agieren.

17 Zur neueren Debatte um Privatisierungstendenzen im deutschen Schulsystem finden sich kritisch-konservative Hinweise bei Hurrelmann (1996) und Preuss-Lausitz (1995, 1997), positive Argumente vor allem bei den Vertretern dieses Sektors (vgl. Vogel 1991 und 1995; Maas 1998; Arbeitsgemeinschaft Freier Schulen 1999; Bun- 
Als exemplarischen Text für diesen Themenblock haben wir einen Aufsatz von William Lowe Boyd (Pennsylvania State University) gewählt. Sein Text illustriert die Probleme freier Schulwahl und marktorientierter Schulreform an amerikanischen und englischen Erfahrungen. In den angelsächsischen Ländern wurden Forderungen nach marktförmigen schulischen Abgeboten früh und vehement formuliert ${ }^{19}$ und konsequent gefördert.

Interessant sind dabei die Unterschiede zwischen den USA und Großbritannien, weil sie uns darauf verweisen, dass jegliche Reform einer Institution immer auch mit den jeweiligen kulturellen, gesellschaftlichen und politischen Bedingungen des konkreten Kontextesrechnen muss. Bemerkenswert ist aber auch, dass es transnationale Austauschbeziehungen zwischen Bildungssystemen gibt, die beinhalten, dass Strategien der Modernisierung aneinander angeglichen werden. ${ }^{20}$ Das ist insbesondere dann der Fall, wenn es Übereinstimmung im Bereich der Grundüberzeugungen gibt. Boyd macht beispielsweise die vorherrschende neokonservative Kritik des Wohlfahrtstaates im England der Margret Thatcher und im Amerika des George Bush senior für die marktorientierte Politik im Schulwesen verantwortlich.

Bemerkenswert ist zudem, dass in beiden Ländern trotz zwischenzeitlicher Wechsel der politischen Führung - in England mit der Ablösung der Konservativen durch New Labour, in den USA mit dem Interim der demokratischen Administration von Bill Clinton - kein prinzipieller Richtungswechsel der Bildungspolitik verbunden war. So verbreiteten sich in den

desverband der Freien Alternativschulen in der BRD (o.J.)); fachlich differenzierte Analysen bei Weiß (2000).

18 Sie können sich dabei auf das Grundgesetz berufen, das ausdrücklich die Errichtung nichtstaatlicher Schulen garantiert.

19 In der Zwischenzeit gibt es auch im deutschsprachigen Raum vielfältige Publikationen zu den Stichworten „Bildung“, „Staat“ und „Markt“. Viele davon begnügen sich mit einer pauschalen Ablehnung einer Übernahme dieses Begriffs aus dem Bereich der Wirtschaft. Eine kleinere Gruppe von Bildungsökonomen und Bildungsforschern sichert, vor allem durch Auseinandersetzung mit der internationalen Literatur, die Anschlussfähigkeit der deutschen Forschung, indem sie die Konzepte und vor allem auch die empirischen Befunde zu diesem Thema analysieren. Für das Gros der erziehungswissenschaftlichen Zunft bleibt diese Debatte eher ein böhmisches Dorf. Als ein Beleg dafür mag der Hauptdokumentationsband zum 15. Kongress der Deutschen Gesellschaft für Erziehungswissenschaft gelten, der unter dem thematischen Titel „Bildung zwischen Staat und Markt“ (vgl. Krüger/Olbertz 1997) stand. Der größte Teil der dort versammelten Beiträge aus den verschiedenen Subdisziplinen ignoriert den Generaltitel oder streift ihn höchstens ,pflichtgemäß‘.

20 Akteure, die solche Konvergenzen fördern, sind beispielsweise ,think tanks“, die Politikberatung unter Nutzung wissenschaftlicher Methoden betreiben, aber auch internationale Organisationen, wie etwa die OECD. Diese ist seit Errichtung des Center for Educational Research and Innovation (CERI) zu einer wichtigen internationalen Bildungsforschungs- und Innovationsagentur geworden (vgl. Gruber 2002), was sich jüngst wieder bei der PISA-Studie zeigte (vgl. dazu das Kapitel „TIMSSund PISA-Schock“"im vorliegenden Buch). 
1990er Jahren in den USA die Charter Schools (vgl. Sarason 1998; Lorenzen 2002), die von nichtstaatlichen Betreibern im Auftrag des Staates (beziehungsweise der Kommune) als öffentliche Schulen angeboten werden. ${ }^{21}$ Der Grund für die Beibehaltung des bildungspolitischen Kurses mag darin liegen, dass die Semantik des Marktes, wenn man sie auf Schulen bezieht, eine höhere Effizienz verspricht. Boyd verweist dagegen auf widersprüchliche Ergebnisse der Marktorientierung ${ }^{22}$ : (1) Durch die Ausrichtung von Schulstrukturen auf Bildungsmärkte wird zwar die Autonomie von Einzelschulen erhöht, aber auch der Grad der Zentralisierung. Denn größere Entscheidungsspielräume für die einzelne Schule müssen unter Umständen erst gegen Widerstände vor Ort implementiert werden. (2) Eltern, die Möglichkeiten der freien Schulwahl haben, nutzen dies mehr oder weniger ,inkrementalistisch“, nach nächstliegenden „bequemen“ Rationalitätsfiktionen, setzen z.B. auf den Ruf einer Schule, orientieren sich an Entscheidungen anderer Eltern oder entscheiden nach der Länge des Schulweges - also weder orientiert am Markt noch an pädagogischen Kriterien. (3) ,Verlierer auf dem Bildungsmarkt scheinen vor allem solche Schulen zu sein, die in sozialstrukturschwachen Sozialräumen liegen und für die eigentlich Schulund Inklusionsprogramme verstärkt werden müssten. Boyd verweist also auf erhebliche Widersprüche zwischen den neuen, am Markt orientierten Zielsetzungen und deren faktischen Realisierungen.

Für den deutschen Kontext sind Forschungsergebnisse interessant, die zeigen, dass es anscheinend wenig empirische Evidenz dafür gibt, dass ,private " Angebote effizienter sind als das staatliche ,Regelschulwesen“ (vgl. Weiß/Steinert 1994). ${ }^{23}$ Dem Staat, der sich von seinen angestammten Aufgaben verabschiedet, wird von Kritikern deshalb vorgeworfen, dass er diese ,neoliberale' Strategie vor allem aus Gründen der Kostenersparnis einschlägt, was als Verrat an seinen moralischen Pflichten angesehen wird (vgl. dazu Molnar 1996; Lohmann/Rilling 2002; Böttcher 2002).

Angesichts der faktischen Kräfteverteilung im deutschen Bildungswesen ist allerdings auch zu konstatieren, dass das Marktargument derzeit ebenfalls eher als ein strategisches Instrument eingesetzt wird, als dass sich damit eine konkrete Politik verbände ${ }^{24}$ : Marktgegner versuchen, gestützt

21 Oft ist übrigens die zumindest teilweise Befreiung von den Regelungen, die für öffentliche Schulen gelten, Teil des Vertrags, der geschlossen wird.

22 Vgl. auch Chubb/Moe (1990); Weiß (1993, 2002); Friedman (1955, 1995); als einer der ,Urväter' der neoliberalen Kritik am Staat. Einen Überblick über den Zustand privater Bildungsangebote in Europa liefert die europäische Bildungsdatenbank Eurydice (2000; vgl. dazu auch Weiß/Steinert 1994).

23 Wobei daran zu erinnern ist, was über die Problematik von System- und Strukturvergleichen gesagt wurde; vgl. dazu Fend (in diesem Band).

24 Einen ganz speziellen Bildungsmarkt, mit großen Freiheiten für private Anbieter und wenig direkten Einflussmöglichkeiten des Staates, beschreibt Katrin Dörner (im vorliegenden Buch) am Beispiel der niederländischen Schule. Sie analysiert also Effekte eines ,modernisierten“ Schulsystems (vgl. dazu auch Dronkers 1996). Die 
auf stark moralisch aufgeladene Argumente, den Status quo zu sichern. Während faktisch die neueren Steuerungsansätze im deutschen Schulsystem im Kontext des New Public Managements in Richtung einer stärkeren staatlichen Steuerung durch Rahmenplanungen gehen, dienen offensichtlich die damit einhergehenden Semantiken des Marktes als argumentatives ,Einfallstor' für solche Akteure, die an der bisherigen staatlichen Steuerung unseres Erachtens zu sehr festhalten.

Darüber hinaus lässt sich in kritischer Absicht bemerken:

„Was fehlt, aber Not tut, ist ein Abwägen des Marktversagens gegen das Staatsversagen in einer umfassenden Nutzen-Kostenanalyse beider Steuerungssysteme, in die nicht nur die ökonomischen, sondern auch die nichtökonomischen direkten und indirekten privaten und sozialen Costs and Benefits einzugehen hätten." (Timmermann 1987: 137; Herv. i.O.)

\section{WILLIAM LOWE BOYD \\ Die Politik der freien Schulwahl und marktorientierte Schulreform in Großbritannien und den Vereinigten Staaten \\ Wie erklären sich die Unterschiede?}

\section{Einleitung}

Seit 1980 hat die Einstellung der Bevölkerung gegenüber der Bildungspolitik und der Verwaltung von Schulen in fast allen englischsprachigen Ländern einen erstaunlichen Wandel erfahren (Ball 1990; Clark/Astuto 1986; Harman u.a. 1991; Wirt/Harman 1986). Trotz erheblicher Unterschiede in den jeweiligen politischen Traditionen und sozialen Kontexten zeigen sich zwischen diesen Ländern (insbesondere zwischen Australien, Neuseeland, Großbritannien und den Vereinigten Staaten) auffallende Parallelen in den jeweils eingeschlagenen schulpolitischen Wegen und Reformen (Beare 1991, Beare/Boyd 1993). Natürlich sind diese Entwicklungen Teil eines umfassenderen, internationalen Musters. Weltweite soziale, wirtschaftliche und technologische Tendenzen haben zu Zwängen (vor allem hinsichtlich der wirtschaftlichen Wettbewerbsfähigkeit und des Arbeitskräftepotentials) geführt, auf die kaum eins der existierenden Schulsysteme eingestellt ist (Coombs 1985; Plank/Adams 1989). Folglich ist die Reform und Umstrukturierung der Schulsysteme zu einem internationalen Phänomen geworden (Beare/Boyd 1993).

In vielen Ländern, vor allem der englischsprachigen Welt, wird die Bildungsreform von der Überzeugung gelenkt, marktorientierte Reformen

Struktur dieser ,modernen“ Schule allerdings existiert in Grundzügen seit fast hundert Jahren. 
(d. h. Maßnahmen, die Marktkräfte innerhalb des Bildungssektors freisetzen, im Gegensatz zu Bildungssystemen, die als zentralistisch kontrollierte Regierungsmonopole geführt werden) seien der Schlüssel zu effektiveren und effizienteren Bildungssystemen. Diese Überzeugung ist Zeichen des Triumphs der neokonservativen Kritik des Wohlfahrtsstaates. [...]

\section{Transatlantischer Austausch?}

Die Parallelen zwischen den schulreformatorischen Bemühungen der Regierung Thatcher bzw. Major einerseits und der Regierung Reagan bzw. Bush andererseits sind tatsächlich weitreichend und nehmen sogar noch zu aufgrund der Stoßrichtung von Bushs Bildungsstrategie „Amerika 2000“, die er im April 1991 bekannt gab. Einige dieser Ähnlichkeiten sind auf bewußte transatlantische Anleihen in der Bildungspolitik zurückzuführen. So kam etwa Kenneth Baker [der englische Bildungsminister] zu einem Blitzbesuch in die Vereinigten Staaten, wo er einige der dortigen Magnetschulen besichtigte, was zur Idee der Gründung von City Technology Colleges (CTCs; Städtische Technische Fachschulen) führte. Ebenso wurde der Idee der Partnerschaften oder Verträge zwischen Schulen und Unternehmen, vor allem dem Beispiel des „Boston Compact“, große Aufmerksamkeit in Großbritannien zuteil. Und, um ein jüngeres Beispiel zu nennen, Aspekte des britischen Education Reform Act von 1988 werden in dem Programm „Amerika 2000“ aufgegriffen.

Im Gegensatz zu dem unsystematischen, dezentralisierten Reformansatz in den Vereinigten Staaten wurde und wird die Bildungsreform in Großbritannien zentral gesteuert und mit dem Erlaß des Education Reform Act (ERA) umfassend und systematisch gestaltet. [...] Die beiden Hauptkomponenten, die vor allem die Konkurrenz fördern, sind zum einen das, was Hywel Thomas (1993) den „Schüler-als-Gutschein-Plan“ nennt (freie Schulwahl, wobei die Gelder den Schülern an die jeweilige Schule folgen) und zum anderen Vorkehrungen dafür, daß Schulen sich, sollte die Elternschaft dafür stimmen, von ihrer lokalen Schulbehörde (Local Education Authority, LEA) lösen und zu „Grant Maintained Schools“, zu subventionierten Schulen, werden können, die ihre Gelder direkt von der Landesregierung erhalten. Beide Komponenten setzen die lokalen Schulbehörden einem starken Konkurrenzdruck aus.

In folgenden Punkten zeigen sich inzwischen besonders deutliche Parallelen zwischen Großbritannien und den USA:

- In beiden Ländern werden Reformbemühungen mit der Behauptung vorangetrieben und weitestgehend auch gerechtfertigt, daß besser gebildete Arbeitskräfte benötigt werden, um die wirtschaftliche Wettbewerbsfähigkeit zu steigern. 
- In beiden Ländern verstärken die Reformen gleichzeitig sowohl den Grad der Zentralisierung als auch den Grad der Dezentralisierung der Schulkontrolle. So wird den Schulen selbst in beiden Ländern mehr Entscheidungsgewalt zugesprochen (in den USA spricht man von „School Based Management“ [SBM], in GB von „Local Management of Schools“ [LMS]. Doch gleichzeitig sind neue Zentralisierungskräfte entstanden: das Nationale Curriculum in Großbritannien und die neuen Nationalen Bildungsziele in den USA (eine überraschende und absolut beispiellose Entwicklung, denkt man an die in den Staaten so ausgeprägte Tradition der lokalen Kontrolle des Bildungssektors).

- Beide Länder haben Magnetschulen, Programme zur Förderung der freien Schulwahl sowie Partnerschaften zwischen Schulen und Unternehmen $[\ldots]$.

- Desgleichen fand das britische Projekt der „Assisted Places“ (Geförderte Ausbildungsplätze) sein weniger erfolgreiches Gegenstück in Vorschlägen für bundesstaatliche Gutscheine für benachteiligte Jugendliche aus den Städten in den USA, die diesen den Besuch von Privatschulen ermöglichen sollten.

$[\ldots]$

\section{Getrennt durch eine gemeinsame Sprache?}

Trotz der vielen Parallelen und der gemeinsamen Sprache haben einige der Schlüsselbegriffe und -konzepte der marktorientierten Bildungsreform für „Tommies“ und „Amis“ nicht die genau gleiche Bedeutung. Beide Nationen sind, wie Winston Churchill zu sagen pflegte, ,getrennt durch eine gemeinsame Sprache“. Die wichtigsten der übergreifenden Faktoren, die eine Reform prägen und die sich von Nation zu Nation unterscheiden, sind wohl (1) der sozialgeschichtliche Kontext, (2) die politische Kultur, (3) Ideologie und Paradigmen und (4) Herrschaftsstrukturen. Offensichtlich unterscheiden sich trotz eines (gewissen) gemeinsamen Erbes Großbritannien und die Vereinigten Staaten erheblich in diesen Dimensionen. Und wegen dieser Differenzen, insbesondere in den ersten drei Bereichen, verweisen freie Schulwahl und marktorientierte Reformen in den beiden Ländern auf recht unterschiedliche Bedeutungen und Implikationen. Daraus ergibt sich, daß einer der auffallendsten Unterschiede zwischen den beiden Ländern darin besteht, daß diese Reformen in Großbritannien sehr viel stärker politisch und ideologisch betrachtet waren und sind. Im Gegensatz dazu haben sie in den USA große Unterstützung von allen Parteien erhalten, insbesondere seitens der demokratischen und der republikanischen Gouverneure. Interessant daran ist u.a. auch, daß genau der Punkt, der in Großbritannien den Kern der ideologischen Auseinandersetzung ausmacht - die Verlagerung auf Marktkräfte und Konsumentenkontrolle -, auch in den USA präsent ist, dort bisher jedoch kaum Groll heraufbeschworen hat. [...] 
In seinen Ausführungen zu den Wurzeln und Implikationen des Educational Reform Act von 1988 schließt Brian Simon (1989: 29) mit einer Betonung ,der ideologischen Auseinandersetzungen, die die gesamte Initiative begleiteten. Diese bezogen sich darauf, daß die Regierung sich auf Marktkräfte und Wettbewerbsmechanismen als Hauptmotivationen für einen Wandel stützte [...] und nicht auf das Konzept der gleichen Versorgung aller mit einem öffentlichen Gut (Bildung) -, ein Konzept, das notwendig die Einrichtung örtlicher Behörden vorantreiben wird und das daher nach Kooperation verlangt. Diese beiden Prinzipien stehen sich nun gegenüber, und je nach dem, welches von ihnen sich durchsetzt, wird mit sehr unterschiedlichen Ergebnissen zu rechnen sein.“

$[\ldots]$

Warum gibt es also in diesem Bereich so erhebliche Unterschiede? Zunächst einmal wird in Großbritannien die Neigung, Dinge zu politisieren ein Trend, der durch die von Thatcher vertretene schroffe Politik der „Überzeugung“ (im Gegensatz zu „Konsens") auf ein Höchstmaß gesteigert wurde - durch die dort (anders als in den USA) vorherrschenden größeren Klassenunterschiede und ein ausgeprägteres Klassenbewußtsein gefördert. So betont der britische Politologe David McKay in seiner Bewertung des Kontextes amerikanischer Politik das Fehlen einer sozialistischen oder proletarischen politischen Tradition in den USA. Dies ist wiederum im Zusammenhang mit dem amerikanischen Glauben an Gleichheit und soziale Mobilität sowie mit dem „Fehlen einer feudalen und aristokratischen Vergangenheit, einschließlich aller durch solche Strukturen implizierten, tief verwurzelten sozialen Spaltungen“" zu sehen (McKay 1989: 20).

In Großbritannien neigt man dazu, marktgerechte freie Auswahl im Bildungsbereich mit Privilegien zu assoziieren; mit privaten, unabhängigen Schulen; mit der Tradition der selektiven Grammar Schools; sowie mit Abschaffung des Gesamtschulcharakters der staatlichen Sekundarschulen und einer Wiedereinführung selektiver Schulen. [...] Im Gegensatz dazu hat in den USA, die auf keine aristokratische Vergangenheit zurückblicken, sondern vielmehr auf eine lange Geschichte nichtselektiver Gesamtschulen, neben denen nur wenige private Eliteschulen existieren, das Konzept der freien Wahl der Schule weniger elitäre Konnotationen. [...]

Neben dem Klassenbewußtsein liegt ein weiterer wichtiger Unterschied zwischen den beiden Nationen in ihrer Ausrichtung auf kollektivistische bzw. individualistische Ansätze. McKay (ebd., 27) vertritt die These, daß „der Amerikanismus sich in nichts deutlicher zeigt als in der Betonung individueller gegenüber kollektiven Handlungen“. Im allgemeinen ist in den Augen der Amerikaner die geringste Kontrolle die beste Kontrolle und „krasser Individualismus“ eine große Tugend. Dieser Individualismus wiederum verbindet sich mit Kapitalismus und Unternehmertum. Der amerikanische Politologe Walter Dean Burnham stellt fest: „In einer Gesellschaft und politischen Kultur, die von den Werten des freien Unternehmertums durchtränkt sind, nimmt die Wohlfahrtspolitik einen ungewissen Platz ein. 
Politische Maßnahmen, die im Grunde eine ,Sozialhilfe für Unternehmen sind, werden selten als solche von der Öffentlichkeit erkannt, geschweige denn zum Gegenstand weitreichender politischer Auseinandersetzungen. Sozialhilfe für die Armen dagegen hat immer einen gänzlich anderen Stellenwert gehabt" (Burnham 1983: 480). [...]

Zusammengenommen helfen diese Überlegungen zu erklären, warum die Akzeptanz von Marktkräften und Wettbewerb innerhalb der Bildungspolitik in den Vereinigten Staaten sehr viel höher ist. So etwas wie Thatchers Kampagne zur „Schaffung einer Unternehmenskultur“ wäre in den USA völlig überflüssig. [...]

Ein weiterer wichtiger Unterschied, der mit der zentralisierten und gesamtschulorientierten Bildungsreform in Großbritannien einerseits und den dezentralisierten und diffusen Ansätzen einer Reform in den USA andererseits zusammenhängt, hat zu tun mit dem Regierungssystem und der Regierungsstruktur. Das britische parlamentarische System erlaubt einer Regierung, die eine starke Mehrheit besitzt, Dinge durchzusetzen, die in dem stärker unterteilten politischen System der Vereinigten Staaten in der Regel erheblicher Kompromisse bedürften. Offensichtlich waren eine ausgeprägte Ideologie und eine „Überzeugungspolitik“ treibende Kräfte der in das Reformgesetz aufgenommenen umfassenden Reformen. Doch das parlamentarische System wie auch zentralistische Tendenzen (besonders ausgeprägt unter der Regierung Thatcher) stehen in scharfem Kontrast zu dem betont föderativen System der USA, zu ihrem konstitutionellen und komplizierten staatlichen System der Kontrolle und Gegenkontrolle sowie zu ihrer Tradition der einzelstaatlichen und lokalen Kontrolle des Bildungswesens. Anstatt auf eine umfassende Bildungsreformakte stützt sich die amerikanische Reform auf eine Mischung aus Kommissionsberichten, unterschiedlichen bundesstaatlichen Gesetzen und einheimischen Initiativen und Innovationen in (einigen) lokalen Schulbezirken. [...]

Wie Bruce Cooper (1990) bemerkt, hat die Dezentralisierung in den Vereinigten Staaten eine durchgreifende Anordnung marktorientierter Reformen behindert, während diese im extrem zentralisierten politischen System Großbritanniens sehr viel schneller durchgesetzt wurden. Doch andererseits hat eben diese Dezentralisierung des amerikanischen Systems ein Experimentieren mit Wahlfreiheit im Bildungsbereich ermöglicht. Wären die Entscheidungen auf nationaler Ebene zentralisiert worden, wäre nichts passiert aufgrund der häufigen Pattsituationen zwischen der von den Republikanern kontrollierten Exekutive und dem von den Demokraten kontrollierten Kongreß. Dies ist die Realität, die eine Verabschiedung der von Bush in seinem Projekt „Amerika 2000“ geforderten Gesetze vereitelt hat. Dennoch lebt dieser Plan weiter. [...]

Ein letzter wichtiger Unterschied zwischen den beiden Nationen besteht darin, daß - obwohl die Lehrer und Schulen in den USA fast genausoviel Kritik über sich ergehen lassen mußten wie in Großbritannien - die Amerikaner sich seit 1986 sehr stark darum bemüht haben, das Lehrergehalt und 
den Grad der Professionalisierung des Lehrerberufs erheblich zu erhöhen. In Großbritannien fehlen solche Bestrebungen gänzlich. Wenn der Zeitpunkt kommt, sich anzuschauen, wie Reformen durchgesetzt werden, wird diese Abweichung in der Behandlung der Lehrer wohl von großer Bedeutung sein. Guthrie und Pierce stellen fest:

„Die Thatcher-Regierung hofft nicht nur, Veränderungen im Bildungswesen mit erstaunlich wenig zusätzlichen finanziellen Ressourcen herbeizuführen; sie versucht auch, diese radikalen Ziele ohne große professionelle Unterstützung zu erreichen. Angesichts der geringen zusätzlichen Mittel wird der langfristige Erfolg des Thatcher-Programms im Bildungssektor wesentlich von der Kooperation professioneller Pädagogen abhängen. Es ist jedoch von der politischen Seite her kaum etwas systematisch unternommen worden, um ihr Wohlwollen und ihre Unterstützung zu gewinnen. [...]“ (1990: 202).

Ganz anders, so Guthrie und Pierce, wurde in den USA, „wo die Reformen sehr viel weiter verbreitet, aber weit weniger grundsätzlich sind“, die Kooperation der Lehrer wiederholt gesucht, und viele der Reformer der ,zweiten Phase“ „zielen bewußt darauf ab, den professionellen Status der Lehrer zu heben“" (ebd.).

\section{Keine Renaissance ohne Revolution? - Die Entwicklungen seit 1990}

$[\ldots]$

Eine Reihe von Entwicklungen legte die Vermutung nahe, daß wir uns einer Zeit umfassenderer und radikalerer Reformen nähern. Die Ernennung eines neuen Bildungsministers, Lamar Alexander, durch Präsident Bush gab der nationalen Bildungspolitik eine sehr viel dynamischere Stoßrichtung (Gigot 1991). [...]

Alexander stellte fest: „Eine der Lehren, die wir aus der Bildungsreform der achtziger Jahre ziehen können, ist die, daß wir zu langsam und zu zaghaft waren. Was wir brauchen, ist ein Volksaufstand" (zitiert nach Gigot 1991: 6). In Einklang mit dieser Ansicht sagte Präsident Bush anläßlich der Bekanntgabe des von Alexander entwickelten Bildungsplanes „America 2000“: „All denen, die eine wirkliche Verbesserung im amerikanischen Bildungswesen sehen wollen, sage ich: ,Es wird keine Renaissance ohne eine Revolution geben““ (zitiert nach Norris 1991: 11). [...]

Der neue Plan sah 550 Millionen Dollar für den Bau von 535 neuen Schulen vor - vermutlich eine Schule pro Wahlbezirk der Kongreßabgeordneten -, die zu ,rationalen Modellen an Vortrefflichkeit“" bestimmt waren. In einem Vorschlag, der an die City Technology Colleges in Großbritannien erinnert, wurde die amerikanische Industrie aufgefordert, 150 Millionen Dollar zum Bau dieser Schulen beizusteuern, wofür sie ihrerseits ein Mitspracherecht bei der Gestaltung und dem Lehrplan der Schulen erhalten 
würde. Norris (1991) vermutet, daß dieses neue Schulprojekt eine Art „Bestechung" sei, um die Zustimmung zu den begleitenden Vorschlägen für größere Freiheit in der Wahl der Schule seitens der Eltern zu gewinnen. (Wie sich herausstellte, lehnte der Kongreß beide Vorschläge ab.) Präsident Bush schlug vor, in diesem Bereich 230 Millionen Dollar auszugeben, um die Schuldistrikte zu ermutigen, größere Freiheit in der Schulwahl zuzulassen, und er machte erneut den umstrittenen Vorschlag, Bundesgelder für benachteiligte Schüler auch dann auszuzahlen, wenn diese auf private oder gar kirchliche Schulen gingen.

Republikanische Politiker hatten diesen Vorschlag schon zuvor gemacht, er wurde jedoch immer wieder von liberalen Demokraten im Kongreß abgewehrt, die - wie viele städtische Pädagogen auch - befürchten, daß dies einen Exodus in Richtung Privatschulen zur Folge haben könnte, der die ohnehin schon bedenklichen Finanzen und den Status der umstrittenen städtischen Schulen weiter gefährden würde. Tatsächlich war eine der überraschendsten Entwicklungen zu Beginn des Jahres 1991 das Wiederaufleben des Interesses an der Bereitstellung öffentlicher Gelder für den Besuch einer Privatschule. [...] Zusammen [...] verwiesen diese Entwicklungen auf einen unerwarteten Zusammenbruch des noch vor kurzem bestehenden Konsenses darüber, daß staatlich geförderte Pläne für eine freie Schulwahl auf öffentliche Schulen beschränkt sein sollten.

$[\ldots]$

Da jedoch kirchliche Schulen bei weitem den größten Teil der Privatschulen in den USA ausmachen, hängt die Zukunft des Konzeptes der freien Wahl auch privater Schulen in erster Linie von der Haltung des Obersten Bundesgerichts gegenüber dem First Amendment, dem ersten Zusatz zur amerikanischen Verfassung ab. (In diesem Zusatz ist die rigorose Trennung von Kirche und Staat verfügt.) In der Vergangenheit hat das Gericht immer die Ansicht vertreten, daß das First Amendment es verbiete, öffentliche Gelder für mit der Kirche zusammenhängende Aktivitäten einzusetzen. Doch herrscht im Obersten Bundesgericht heute aufgrund der Ernennungen zu Reagans Regierungszeit eine konservative Mehrheit. So könnte [...] das Gericht in Zukunft das First Amendment so auslegen, daß öffentliche Gelder an religiöse Organisationen gezahlt werden dürfen, sofern alle Glaubensrichtungen gleich behandelt werden und keine bevorzugt wird. Sollte dies schließlich eintreten, müßte man wirklich von einem grundlegenden Wandel in der Bildungspolitik sprechen. Bislang aber sind die organisierte politische Opposition gegen das Konzept der freien Wahl auch privater Schulen wie auch die rechtlichen Barrieren bei weitem nicht aus dem Weg. Folglich ist die Zukunft noch sehr ungewiß. 


\section{5. „Seid mutig, seid britisch"}

Der Economist veröffentlichte (23. März 1991) zu dem Zeitpunkt, als der Bildungsminister Lamar Alexander sich anschickte, die neue amerikanische Bildungspolitik vorzustellen, einen Leitartikel, in dem sie ihn aufforderte, aus der englischen Erfahrung zu lernen: „Sei mutig, sei britisch.“ Sicherlich ist die Schulreform der konservativen britischen Regierung mutig. Doch von einem typisch amerikanischen Standpunkt aus scheint sie auch unausgewogen zu sein. Der Durchschnittsamerikaner muß sowohl um Gleichheit bemüht sein als auch um Vortrefflichkeit und Effizienz. Die Frage der Gleichheit ist Bestandteil des amerikanischen Systems, festgehalten in den rechtlichen Garantien der Bill of Rights und im vierzehnten Verfassungszusatz (Fourteenth Amendment), der allen amerikanischen Staatsbürgern „gleichen Rechtsschutz“ und „rechtliches Gehör“ zusichert. Die amerikanischen Politiker müssen sich dieser Aspekte bewußt sein, wenn sie neue Gesetze machen. In Großbritannien werden konservative Politiker nicht durch ähnliche Vorkehrungen von ihrem Ziel der Effizienz abgebracht. Aufgrund einer starken Mehrheit im Parlament können ToryMinister ihre Ziele mit einem solch ungehinderten Eifer verfolgen, daß die amerikanischen Kongreßabgeordneten sie darum nur beneiden können.

Obwohl die konservative Regierung unter John Major moderater ist als unter Margaret Thatcher, folgt sie doch weiterhin einer marktorientierten, von Thatcher geprägten Bildungspolitik, die nur wenig von Fragen der Gleichheit beeinträchtigt wird. In den Vereinigten Staaten neigen sogar Befürworter von Systemen freier Schulwahl wie etwa Coons und Sugarman (1978) oder Chubb und Moe (1992) dazu, sich mit Sicherheitsvorkehrungen gegen die offensichtlich Ungleichheit verursachenden Folgen von vö1lig ungesteuerten Systemen abzumühen und sie in ihre Konzepte einzubauen. Dies scheint in England nicht der Fall zu sein.

Wir haben bereits darauf hingewiesen, daß das britische Reformgesetz von 1988 (ERA) den marktorientierten Wettstreit zwischen Schulen betont. Die beiden Hauptkomponenten, die vor allem die Konkurrenz fördern, seien hier noch einmal genannt: (1) der „Schüler-als-Gutschein-Plan“ (freie Schulwahl, wobei die Gelder den Schülern an die jeweilige Schule folgen) und (2) Vorkehrungen dafür, daß Schulen sich, sollte die Elternschaft dafür stimmen, von ihrer lokalen Schulbehörde (Local Education Authority, LEA) lösen und zu „Grant Maintained Schools“, zu subventionierten Schulen, werden können, die ihre Gelder direkt von der Landesregierung erhalten.

Obgleich die Vereinigten Staaten keinen Plan entwickelt haben, der dem Projekt staatlich subventionierter Schulen gleicht, setzen sich Chubb und Moe (1990) tatsächlich doch für ein großangelegtes Vorhaben ein, das es auch amerikanischen Schulen ermöglichen soll, ,,auszusteigen“. Aber im Gegensatz zur britischen Strategie würde ihr Vorschlag darauf abzielen, daß die Politiker auf Bundesstaatenebene ihre Schulen aus gegebenen staat- 
lichen Systemen einer demokratisch kontrollierten Leitung von Schulbezirken lösen, zugunsten eines marktgetriebenen Systems von staatlich unterstützten öffentlichen und privaten Schulen. Die voraussichtlichen Folgen sowohl des von Chubb und Moe vertretenen Planes wie auch des britischen Subventionsprojektes allerdings werden vergleichbar sein. In beiden Fällen werden die Schulen einer kommunalen demokratischen Leitung entzogen, und gemeindeweite Planung wird durch die ,unsichtbare Hand“ des Marktes ersetzt. Beunruhigend insbesondere im Hinblick auf die britische Entwicklung ist das mögliche Wiederaufleben des ungleichen, zweigleisigen Systems der selektiven Grammar Schools und der Secondary Modern Schools (einer Kombination von Real- und Hauptschule). [...] Die Vertreter des Egalitarismus befürchten, daß dies eine schleichende Privatisierung staatlicher Schulen bedeute sowie eine mögliche Wiedereinführung von Selektion und Elitedenken. Die Verfechter der Regierungspolitik antworten darauf, daß die Möglichkeit des Aussteigens der Schlüssel zur Befreiung der Schulen sei und sie effizienter, effektiver und handlungsfähiger machen würde.

Politiker auf beiden Seiten des Atlantik täten gut daran, die sich in Großbritannien langsam ansammelnden empirischen Untersuchungen zur freien Schulwahl genau zu studieren. Diese bieten zum ersten Mal systematische und umfangreiche Daten darüber, was passiert, wenn auf dem Prinzip der freien Schulwahl basierende Projekte mit bestimmten Charakteristika eingeführt werden. In Schottland wird seit 1982 eine Politik der freien Schulwahl seitens der Eltern verfolgt, die der mit der ERA für England und Wales vorgesehenen Regelung gleicht. Dort durchgeführte Studien (Adler u.a. 1989; Echols u.a. 1990) bieten einen wichtigen Prüfstein für die der ERA zugrundeliegenden Annahmen. Einige der von Adler, Petch und Tweedie veröffentlichten Ergebnisse stellen diese Annahmen in Frage:

- Für die Mehrzahl der Eltern bedeutete die freie Schulwahl, eine zufriedenstellende Alternative zur Bezirksschule zu finden, nicht aber eine optimale Auswahl aus einer großen Zahl möglicher Schulen zu treffen.

- In der Suche nach Schulen für ihre Kinder lassen sich Eltern sehr viel mehr von geographischen und sozialen Faktoren, wie z.B. Länge des Schulwegs und Schuldisziplin, sowie vom allgemeinen Ruf einer Schule beeinflussen als von pädagogischen Überlegungen.

- Insgesamt waren die Schulen, die die meisten Schüler für sich gewannen, jene, die ehemals zu den selektiven Schulen in mittelständischen Gegenden zählten, während die Schulen, die die meisten Schüler verloren, jene waren, deren Einzugsbereich in Wohnungsprojekten der Kommunalbehörden in unterprivilegierten Randbezirken lagen.

- Es gibt zahlreiche Belege für herdentriebartige Mechanismen und nur wenige Hinweise darauf, daß der Markt als sich selbst korrigierender Mechanismus funktioniert. (Adler 1990: 4f.) 
Obwohl Adler (1990) zu dem Schluß kommt, daß zu den Folgen der freien Schulwahl durch die Eltern in Schottland auch ein weniger effizienter Einsatz der Mittel zählt sowie eine Zunahme der Ungleichheiten zwischen Schulen und das Wiederauftauchen eines zweigleisigen Systems von Sekundarschulen in den Großstädten, ist er dennoch der Ansicht, daß man nicht völlig auf ein solches System verzichten solle, sondern vielmehr die Politik so ändern müsse, daß diese unerwünschten Konsequenzen vermieden würden.

\section{Schlußbetrachtung}

Trotz der erheblichen Unterschiede experimentieren die Vereinigten Staaten und Großbritannien doch mit vergleichbaren marktorientierten Taktiken, um ihre Schulen grundlegend umzustrukturieren und zu verbessern. In den USA wächst die Unterstützung für mutige, ja sogar revolutionäre Maßnahmen zur Verbesserung des Schulsystems; doch durch die im politischen System Amerikas verankerte Machtverteilung und ihre Kontrollinstanzen werden eher allmähliche als radikale Veränderungen gefördert. Allerdings hat das Oberste Bundesgericht den Joker in der Hand, denn ihm ist die Möglichkeit gegeben, den ersten Verfassungszusatz (First Amendment) bezüglich der Trennung von Staat und Kirche neu auszulegen. Sollte diese Karte jemals gespielt werden, wird sie neue Spielregeln setzen, und die amerikanische Bildungspolitik könnte ein „mutiges und britisches“ Gesicht annehmen.

\section{Literatur}

Adler, M.: Parental choice and the enhancement of children's interests. Paper presented at Seminar on Public and Private Choice in Education, Centre for Educational Sociology, University of Edinburgh, March 4, 1990.

Adler, M./Petch, A./Tweedie, J.: Parental choice and educational policy. Edinburgh: Edinburgh University Press 1989.

Ball, S.J.: Politics and policy making in education: Explorations in policy sociology. London: Routledge 1990.

Beare, H.: Chapter 1. In: G. Harman/H. Bear/G.F. Berkeley (Eds.): Restructuring school management: Administrative Reorganization of public school governance in Australia. Canberra: Australian College of Education Press 1991.

Beare, H./Boyd, W.L. (Eds.): Restructuring Schools: An International Perspective on the Movement to Transform the Control and Performance of Schools. London: Falmer Press 1993.

Burnham, W.D.: Democracy in the Making. Englewood Cliffs, NU: Prentice-Hall 1983. Caldwell, B. J.: Paradox and uncertainty in the governance of education. Paper presented at the annual meeting of the American Educational Research Association, San Francisco, March 29, 1989.

Chubb, J.E./Moe, T.M.: Politics, markets, and America's schools. Washington, D.C.: The Brookings Institution 1990. 
Chubb, J.E./Moe, T.M.: A lesson in school reform from Great Britain. Washington, D.C.: The brookings Institution 1992.

Clark, D.L./Astuto, T.A.: The significance and permanence of changes in federal education policy. Educational Researcher (October 1986), S. 4-13.

Coombs, P.H.: The world crisis in education: The view from the eighties. New York: Oxford University Press 1985.

Coons, J.E./Sugarman, S.D.: Education by choice: The case for family control. Berkeley, CA: University of California Press 1978.

Cooper, B.: Local school reform in Great Britain and the United States: Points of comparison - points of departure. Education Review 42 (1990), 2, S. 133-149.

Echols, F./McPherson, A./Willms, J.D.: Parental choice in Scotland. Journal of Education Policy 5 (1990), 3, S. 207-222.

Economist (March 23, 1991): „Be bold, be British: A lesson for America's Schools.“ Vol. 318, N. 7699, S. 19-20.

Gigot, P.A.: School reform now turns to revolution. Wall Street Journal, April 8 (1991), S. 6.

Guthrie, J.W./Pierce, L.C.: The International Economy and National Education Reform: A Comparison of Education Reforms in the United States and Great Britain. Oxford Review of Education, vol. 16 (1990), no.2, S. 179-205.

Harman, G./Beare, H./Berkeley, G.F. (Eds.): Restructuring school management: Administrative reorganization of public school governance in Australia. Canberra: Australian College of Education Press 1991. San Francisco: Institute for Contemporary Studies 1988.

McKay, D.: American Politics \& Society 2nd edition. Oxford: Basil Blackwell1989.

Norris, B.: A revolution starts with small change. Times Educational Supplement (1991), May 3, S. 11.

Plank, D./Adams, D.: Death, taxes, and school reform, Administrator's Notebook. 1989.

Simon, B.: The Education Act, 1988: Origins and Implementation. The Welsh Journal of Education, vol. 1 (1989), no.1, S. 24-29.

Thomas, H.: The Education Reform Movement in England and Wales. In H. Beare/W. Boyd (Eds.): Restructuring Schools: An International Perspective on the Movement to nansform the Control and Performance of Schools. London and New York: Falmer Press 1993.

Wirt, F./Harman, G. (Eds.): Education recession and the world village. London: Falmer Press 1986. 


\section{Schulautonomie}

\section{Kommentar (Brüsemeister)}

Neben den Debatten über den Umbau des Sozialstaats sowie Diskussionen über Schulkultur und Markt wurde die heute zu beobachtende schulische Modernisierung offensichtlich auch von Diskussionen über die Autonomie der Einzelschule innerhalb der Pädagogik geprägt. Debatten über Schulautonomie kommen in den 1980er Jahren insbesondere in den USA und England auf (vgl. Boyd im vorliegenden Buch) und erreichen ungefähr zu Beginn der 1990er Jahre den deutschsprachigen Raum. Eine stärkere Konjunktur haben sie etwa seit Mitte der 1990er Jahre (vgl. MagotsiuSchweizerhof 2000). Die Vorstellung, der einzelnen Schule eine größere Autonomie zu geben, ihre Entscheidungskompetenzen im organisatorischen und pädagogischen Bereich zu verbessern, bedingt eine neue Relation zwischen Staat - dem bisherigen Entscheidungsträger - und der Einzelschule. Darauf gehen in diesem Abschnitt des Buches zwei Autoren ein, Frank-Olaf Radtke (Universität Frankfurt) und Norbert Maritzen (Hamburger Behörde für Schule, Jugend und Berufsbildung).

Frank-Olaf Radtke stellt in seinem Beitrag heraus, dass die Debatte über Schulautonomie von unterschiedlichen Lagern geführt wird sowie mit unterschiedlichen Zielsetzungen verbunden ist. ${ }^{25}$ Als einer der ersten weist der Autor schon Mitte der 1990er Jahre darauf hin, dass ein gesellschaftlicher Kampf über die richtige Lesart, ein „Ringen um Definitionsmacht“ hinsichtlich der Probleme und Aufgaben des Bildungssystems zu beobachten ist (was zudem implizit einer Vorstellung Bourdieus folgt). Des Weiteren ist das zentrale Anliegen des Aufsatzes, auf die Gefahren für die bisherige an Inklusion und Chancengleichheit orientierte Bildungspolitik hinzuweisen, welche bei den Diskussionen um Schulautonomie , auf der Strecke zu bleiben droht.

Radtke führt mehrfache semantische Umcodierungen an, die aufverschiedene Akteurgruppen zurück gehen. ${ }^{26}$ Es soll uns für dieses Buch aber zunächst darum gehen, mit dem Autor eine Vielzahl semantischer Veränderungen zu beobachten. Radtke fragt, warum überhaupt Debatten über eine neue Bildungspolitik - mit der Schulautonomie im Zentrum - zu einem bestimmten Zeitpunkt aufkommen. Um das Rätsel zu lösen, schaut er sich genauer die Akteure an, die in die Debatte eingreifen. Zum einen lässt sich vermuten, dass Reformer der 1970er Jahre mit der Autonomiediskussion die frühere Chancengleichheits- und Inklusionspolitik fortsetzen wollen.

25 Eine spätere Version des Beitrages ist in dem von Radtke/Weiß (2000) herausgegebenen Band „Schulautonomie, Wohlfahrtsstaat und Chancengleichheit“ erschienen, der für den Focus des vorliegenden Buches generell informativ ist.

26 Dies wird insbesondere im Textblock „Beobachtung von Akteurkonstellationen“ thematisiert. 
Um Bildungsreformversprechen weiter verfolgen zu können, ist daran gedacht, sich bewährter Methoden der Wirtschaft zu bedienen: man entlässt kleinere Einheiten - Schulen - in Märkte, auf denen sie ,autonom“ operieren sollen. Zum anderen lässt sich umgekehrt annehmen, dass Schulautonomie auf eine Nach-unten-Regulierung, also einen Abbau von Chancengleichheit und Inklusion zielt. Hier weist Radtke insbesondere auf internationale Organisationen als Akteure (OECD, Weltbank) hin, die sich mit einer größeren Schulautonomie Kostenreduktionen im Bildungsbereich versprechen könnten. Reformer der 1970er Jahre und internationale Organisationen sind Beispiele für konträre bildungspolitische Positionen, die im Kern darüber streiten, ob das Bildungsangebot weiterhin ein öffentliches Gut sein soll - wie in der bisherigen Inklusions- und Chancengleichheitspolitik -, oder ob man es privaten Konsumentenentscheidungen frei gibt, wobei dann sozial schwache Schichten benachteiligt würden.

Letzteres wird von den an Chancengleichheit orientierten Akteuren des Schulsystems natürlich nicht akzeptiert. Und in diesem Zusammenhang verweist Radtke auf merkwürdige semantische Umpolungen in der $\mathrm{Ge}-$ schichte der Debatte um Schulautonomie. Während die an Chancengleichheit orientierten Akteure in den 1970er Jahren die Autonomie der Einzelschule gegen die Bildungsverwaltung und eine in ihren Augen zu große Bildungsbürokratie erstreiten mussten, um die Chancengleichheitspolitik zu realisieren, geht heute umgekehrt der Impuls zu mehr Schulautonomie von den Bildungsbehörden aus. Dies bedeutet, dass die semantische Positionen gleichsam die Akteur-Lager gewechselt haben.

In seiner Antwort auf Radtke richtet Norbert Maritzen sein Hauptaugenmerk darauf, der in seinen Augen von Radtke zu pauschalisiert geführten Kritik an neoliberalen Deregulierungsprogrammen konkrete Erfahrungen mit neuen Steuerungsmodellen entgegenzuhalten, wie sie in lokalen Entwicklungsprojekten bereits realisiert wurden. Es entspricht nach Maritzen nicht mehr der bildungspolitischen Realität, Modernisierungen entweder als rein staatliche oder als reine Markt-Steuerung zu sehen. Qualitätssicherung sei immer weniger als klassische „Durchgriffsaufsicht“ von oben möglich, da Schulen bereits im hohen Maße dezentral seien und selbständig arbeiten. Deshalb müssten neue Steuerungsmodelle entwickelt werden (wie etwa in Bremen), die die bestehende Autonomie von Schulen berücksichtigen.

Implizit berühren beide Autoren einen wichtigen Punkt, der uns für das gesamte Thema der Schulmodernisierung zentral erscheint. Dieser Punkt bezieht sich auf die Frage, ob die Governance- und Steuerungsmodelle, wie sie Maritzen hervorhebt - also Organisationsmodelle, die eine größere Autonomie der Einzelschule technisch möglich machen -, unabhängig von bildungspolitischen Zielen - wie sie Radtke hervorhebt - gesehen werden können oder nicht. Es handelt sich hierbei um einen Unterschied zwischen den kognitiven oder technischen Dimensionen einer Modernisierung auf der einen Seite, d.h. dem technisch Machbaren und dem kognitiv Vorstell- 
baren. Auf der anderen Seite sind evaluative Dimensionen der Modernisierung angesprochen, also das, was als erstrebens- und wünschenswert angesehen wird (zur Unterscheidung von kognitiven und evaluativen Orientierungen vgl. Schimank 2000: 177). Dieser Bereich betrifft die Wertentscheidungen einer Gesellschaft. In unseren Textbeispielen bezieht sich dies auf die Frage, ob die Inklusions- und Chancengleichheitspolitik fortgesetzt werden soll oder nicht. Diese Frage ist unabhängig von technischen Realisierungsmöglichkeit im Rahmen einer neuen Governance (die z.B. auf Schulautonomie zielt) zu sehen, da Fragen der technischen Realisierung und Wertentscheidungen auf unterschiedlichen Ebenen liegen.

Radtkes Befürchtung, mit mehr Markt und Autonomie als Zielvorgaben könne die Orientierung an Chancengleichheit verloren gehen, besagt implizit, dass die neuen Steuerungs- und Governancemodelle, die um Autonomie kreisen, nicht getrennt gesehen werden können von den gesellschaftlichen Wertentscheidungen. Konkreter: die neuen Modelle lassen sich nicht mit einer Bildungspolitik, die auf Inklusion und Chancengleichheit setzt, vereinbaren. Maritzen vertritt dagegen die Ansicht, dass die neuen Steuerungsmodelle auch mit der bildungspolitischen Diskussion um Chancengleichheit kombiniert werden können. Bei den neuen GovernanceModellen, wie man sie z.B. in Bremen erprobt, bleibe Chancengleichheit als normativer Referenzrahmen ausdrücklich erhalten, so Maritzen.

\section{FRANK-OLAF RADTKE \\ Schulautonomie: Bildungspolitisches Ringen um Definitionsmacht}

In einem Beitrag zur Debatte um die „Autonomie“ der Schulen hat einer ihrer Protagonisten, Norbert Maritzen, [...] von der „eminenten Gefahr der Entpolitisierung" der Bildungsdiskussion gesprochen, die darin bestehe, daß eine ,gestaltende Bildungspolitik mit Blick auf das Ganze“ abgelöst werde von einer „Provinzialisierung“, bei der es nur noch um die „Mikropolitik von Schulen oder Gremien“" gehe (Maritzen 1996: 34). Er fordert einen ,inhaltlichen Bildungsdialog“, der verloren zu gehen drohe in dem von ihm selbst vorgetragenen - merkwürdig abstrakt bleibenden Ansinnen an die Schulen, ,in lose verkoppelten, vernetzten Beziehungen, die als diskursive Verhandlungssysteme zu begreifen sind, ihre widersprüchlichen Teillogiken aneinander ab(zu)arbeiten“ (ebd., 30). „Dieser inhaltliche Bildungsdialog ist m. E.“, so schreibt Maritzen weiter, „,noch gar nicht richtig aufgenommen worden; er droht eher zu verschwinden im blinden Fleck der Autonomie-Diskussion" (ebd., 34).

„Blinde Flecken“ sind am ehesten durch Beobachtung von außen aufzudecken. Insofern die Diskussion um erweiterte Schulautonomie sich selbst als bildungspolitisches Programm für die Zukunft präsentiert (Bil- 
dungskommission NRW 1995), ginge es - zur Eröffnung eines ,inhaltlichen Dialogs" - darum, die Debatte zu repolitisieren und ihr eine bildungsund gesellschaftspolitische Einordnung nachzuliefern, die - anders als in der anglo-amerikanischen Diskussion - in Deutschland bisher zu kurz gekommen ist. Dazu wollen die folgenden Überlegungen einen Beitrag liefern. [...]

Was wir in der Diskussion um eine erweiterte „Autonomie“ oder „Selbständigkeit" der einzelnen Schulen [...] gegenwärtig beobachten können, ist ein gigantisches semantisches Ringen um die immer gleiche Frage, wer die Definitionsmacht über die Probleme und Aufgaben erlangt oder behält, die sich dem Bildungssystem heute und in der absehbaren Zukunft stellen. Wie soll der Zustand unserer Schulen und Hochschulen angesichts einer neuen Welt(un)ordnung beschrieben, wie die Qualität der Bildung angesichts vermeintlich neuer sozialer, ökonomischer und politischer Herausforderungen bestimmt, welche Prioritäten sollen gesetzt, wie nötigenfalls Anpassung veranlaßt oder Abhilfe geschaffen werden?

Die wieder einmal erhitzte Auseinandersetzung über die weitere Entwicklung der Schulen findet statt zwischen dem ,pädagogisch-kurativen Komplex" auf der einen Seite, der bislang ein beinahe hegemoniales Deutungsmonopol in Bildungsfragen besessen hat. Seine Repräsentanten fordern die Einlösung der unerfüllten Reformversprechen der letzten, gerade deprimierend gescheiteren Reform. Mehr Autonomie im Bildungswesen, mehr Demokratie und Partizipation sollen die Antwort sein auf das Versagen traditioneller, bürokratisch von oben nach unten organisierter Bildungsplanung. Das Programm soll die Chance eröffnen, auch für das Schulsystem neue, auf den „Managementebenen großer Konzerne“ abgeguckten Steuerungsmodelle zu entwickeln, deren Stärke in der ErschlieBung eines ,dezentralen Gestaltungspotentials“ zu sehen wäre (vgl. zuletzt Maritzen 1996).

Auf der anderen Seite melden sich verstärkt neo-konservative und neoliberale Finanz- und Wirtschaftspolitiker zu Wort, die mit der „Globalisierungs- bzw. Standortdebatte“ auch in Deutschland auf den Um- oder gar Abbau des Sozialstaates zielen und davon das Bildungssystem nicht länger ausgespart sehen wollen. Auch sie haben durchaus Sympathien für die neuen Managementtechniken. Zwischen den Fronten irren ein paar grün-rote Bildungsstrategen (vgl. z.B. Daschner u.a. 1995) herum, die sich gegenseitig auf die Notwendigkeit zu „neuem Denken“ eingeschworen und dazu gelernt haben, ihre Rhetorik mit harten betriebswirtschaftlichen Begriffen wie „Budgetierung“, ,re-engineering“, ,controlling“ oder „,out-sourcing“ anzureichern.

Der „pädagogisch-kurative Komplex“ rekrutiert sich aus Lehrern in den Schulen, ihren Verbandsfunktionären sowie aus solchen Erziehungswissenschaftlern, die unter der disziplinär auferlegten Theorie-Praxis-Verpflichtung voller Engagement dazu neigen, die pädagogischen Selbstbeschreibungen der (Lehrerinnen in den) Schulen, was das Problem sei, zu verdop- 
peln und mit wissenschaftlicher „Wahrheit“ anzureichern. Auf der anderen Seite stehen Finanzexperten, zunehmend aber auch Administratoren, Verbands- und Bildungspolitiker, die in der Not knapper Haushaltsmittel Unternehmensberater und Organisationsentwickler zu Hilfe gerufen haben, damit sie mit dem ihnen eigenen, der Pädagogik aber ungewohnt fremden Blick der Zweck-Mittel-Rationalität die Probleme der modernen Schulen neu definieren und sie anschließend reorganisieren.

\section{Warum „Autonomie" jetzt?}

[...] Die Erfahrung, daß man dabei etwas Neues sieht, eingefahrene Gewohnheiten, Wahrnehmungs- und Erfahrungsmuster auf ihre Gültigkeit befragen und unter Umständen viel Geld sparen kann, liegt aus vielen Organisationen und Berufsfeldern vor. Man könnte sich also durchaus auf eine Evaluation der Organisation Schule einlassen, zumal zu erwarten steht, daß dort viel Leerlauf zu vermeiden wäre und sich vieles verbessern ließe.

$\mathrm{Zu}$ fragen bleibt aber in der gegenwärtigen Situation, wer die Initiative ergriffen hat? Warum soll das Bildungssystem gerade jetzt autonomisiert, rationalisiert und evaluiert werden? [...] Man kann zur Beantwortung der Frage, worum es sich bei der „Autonomisierung“ im Bildungssystem handelt, drei Hypothesen nachgehen:

(A) Es handelt sich um allfällige Reformforderung auf einem neuem Ticket: Dann wären die unermüdlichen Reformer der siebziger Jahre aus eigenem Antrieb dabei, einen neuen Anlauf zu nehmen. Sie könnten versucht sein, Reformnotwendigkeiten, die heute in erster Linie finanzpolitisch motiviert sind, umzufunktionieren: für immer schon verfolgte bildungspolitische Utopien. Dann machte es Sinn, in der „Autonomiediskussion“ ein neues „Steuerungsparadigma“ zu entdecken, die „Einzelschule im Zentrum von Entwicklungs- und Veränderungsprozessen" zu sehen und dabei eine stärkere „Klienten- und Marktorientierung“ in Kauf zu nehmen (Rolff 1995: 377), bei der Probleme mit der Chancengleichheit eingeräumt werden müssen. Die Optimisten könnten sich übernehmen. Schon einmal - in den siebziger Jahren - ist der Versuch gescheitert, den Stier der Rationalisierung des Bildungssystems zu reiten und der Reform eine emanzipatorische Wende zu geben. Davon legt der innere Zustand vieler Gesamtschulen Zeugnis ab.

(B) Man beginnt, eine Neubestimmung der Rentabilität von Bildungsinvestitionen vorzunehmen: Wird „Autonomie“ weltweit ein Thema, weil die OECD über Deregulierung im Bildungssektor zur Kostenreduktion diskutiert (vgl. OECD 1992, 1994)? Oder weil Weltbank und Internationaler Währungsfonds die Überprüfung der bisherigen Bildungspolitiken begonnen und allererst die Kürzung der Bildungsausgaben in der sogenannten Dritten Welt gefordert haben (vgl. Carnoy 1995)? Mag sein. Der Einfluß internationaler Organisationen auf die politische Problemwahrnehmung in den Mitgliedsstaaten und die Formulierung von Politiken wäre jedenfalls 
zu untersuchen. Man käme vielleicht dahinter, wo die bildungspolitischen Moden gemacht werden.

[...]

Daß Bildungsinvestitionen Zukunftsinvestitionen und Bildungsverlängerung und -verbreiterung die gebotenen Strategien seien, galt bislang unangefochten in allen Industrieländern (vgl. Weiß 1996). Die Überzeugung wird nun in Gesellschaften Zug um Zug infrage gezogen, die sich selbst unter neo-liberalen Sparzwang setzten und dabei gelernt haben, die Produktivität ihrer Wirtschaft ohne Rücksicht auf das Beschäftigungssystem exponentiell zu steigern. Nicht mehr Bildungsexpansion und die Inklusion aller in ein umfassendes Bildungsangebot, sondern Konzentration auf einen Teil der Bevölkerung und die Förderung von Eliten könnten sich in den Zentren als neues bildungspolitisches Kalkül durchsetzen. Das wagt im (noch) bestehenden Sozialstaat nach all den Jahren der Bildungswerbung (noch) niemand offen auszusprechen, aber man fängt an zu rechnen: Wieviel Schuljahre, wieviel Stunden pro Woche sind zu unterrichten? Kostet die Schulzeitverlängerung durch Vorschule oder Sitzenbleiben - gemessen an den Effekten dieser Einrichtungen - nicht zuviel? Gibt es zuviele Gymnasiasten und Studenten? Wird zu lange studiert? In solchen ständig wiederholten Fragen wird die Rolle des „Humankapitals“ und das Verhältnis des Bildungssystems zum Beschäftigungssystem unter der Hand neu bestimmt. Genau in diesen gesellschaftspolitischen Kontext gehört die „AutonomieDebatte“. Wo über Investitionen und ihre Rentabilität nachgedacht wird, kommt die Deregulierungsmode im Gewand einer Verwaltungsreform, die Aufgabenverlagerung und Ressourceneffizienz verspricht, gerade recht. Zumindest gerät das Autonomieversprechen der siebziger Jahre in einen neuen Kontext. Marktsteuerung könnte dem Sozialstaat erlauben, sich nicht nur von der Müllabfuhr und den Schwimmbädern usw., sondern nun unausgesprochen auch von Garantieverpflichtungen im Bildungsbereich zu verabschieden.

(C) Bleibt als weitere Hypothese über das Motiv, das die AutonomieDiskussion in Deutschland anfacht, die Überwälzung der Kosten der Bildung unter den Bedingungen einer rabiaten Austerity-Politik, in deren Zug es der Zentralregierung gelungen ist, immer mehr Kosten der sozialen Sicherung auf die Länder und Kommunen zu überwälzen. Deren prekäre Finanzlage stimuliert neue Überlegungen über die Frage, wieviel sie für ihren größten Teilhaushalt Bildung sinnvoller, das meint politisch vertretbarer Weise aufwenden wollen. Es zeichnet sich - wie schon im Gesundheitsund nun auch im Rentenbereich - eine Umstellung der Aufgaben öffentlicher Erziehung auf eine „Grundversorgung“ ab: Für den individuellen, karriereförderlichen Nutzen der Bildung soll in Zukunft ein jeder selbst bezahlen.

[...] Bisher gibt es in Deutschland keinen „Bildungsmarkt“, dessen Sogwirkung man für die Umgestaltung der Schullandschaft nutzen könnte. Und so leicht wird niemand das preußische oder bayrische, auch nicht das 
bremische Staatsschulwesen deregulieren. Aber die Diskussion um mehr „Autonomie der Schulen“ bereitet genau die beklagte Entpolitisierung der Bildungsdiskussion vor, wenn Bildung als „öffentliches Gut" abgelöst und als Gegenstand privater Konsumentenentscheidungen gedacht werden soll. Bildungspolitik und Gesellschaftspolitik werden voneinander getrennt. Dabei handelt es sich nicht um eine Entpolitisierung, sondern objektiv um eine andere, neo-liberale Politik, auch wenn die Intentionen der Reformer andere wären. Die Langzeitwirkung dieser Umstellung ist nicht zu unterschätzen.

[...] Für die Neo-Konservativen eröffnet die Diskussion über die Qualität der Schulen [...] die Möglichkeit, offensiv Standards anzumahnen, welche die mit der Bildungsexpansion vermeintlich verlorengegangene Selektivität des Schulsystems wiederherstellen sollen. Der Druck auf die Schulen wächst.

\section{,Sei autonom!}

Um zu verstehen, wie das pädagogische Establishment derart in die Defensive geraten konnte, ist es hilfreich, zunächst die gängigen (Selbst-)Beschreibungen der Schule für den unbefriedigenden Zustand des Bildungssystems bzw. für Schulmißerfolge (von Schülern), die (soziale) Ungleichheit bei der Verteilung des begehrten Gutes Schulerfolg und die hohen Kosten seiner Produktion zu rekonstruieren. Argumentiert wurde (und wird) mit Hilfe von zwei Annahmen, die in der Profession bislang fast unbestritten galten:

(1) Schulerfolge bzw. die Ausschöpfung der individuellen Bildungsreserven seien - neben der kognitiven Ausstattung - abhängig von dem sozio-kulturellen Kapital, über das ein Kind (und seine Eltern) beim Eintritt in die Schule verfüge und das ihm den Umgang mit der Organisation und ihren Anforderungen erleichtere oder erschwere. Defizite sind nur begrenzt auszugleichen. Zum Beleg dieser These wird im wesentlichen auf zum common sense abgesunkene Ergebnisse aus Untersuchungen von Bourdieu/Passeron (1971) verwiesen. Im Falle von Migrantenkindern komme als Ursache für Schulmißerfolg zusätzlich die Kulturdifferenz bzw. der immer wieder beschworene Kulturkonflikt hinzu, der sich beim täglichen „Leben zwischen zwei Welten“ unvermeidbar als Belastung der Kinder einstelle. [...]

Pädagogen konnten mit Verweis auf den erziehungsfeindlichen Zustand der Welt nicht nur immer wieder neue Reformen, mehr Mittel und Personal fordern, sondern die Ursachen für unbefriedigende Ergebnisse der Arbeit der Schule zugleich auch erfolgreich externalisieren, und dies in doppelter Weise. Wenn Schüler - gemessen in qualifizierten Abschlüssen - keinen Erfolg hatten, oder wenn Hochschulen und Arbeitgeber die Qualität der Ausbildung bemängelten, dann ließ sich erstens verweisen auf die „wachsenden Schwierigkeiten“ außerhalb der Schule. [...] 
(2) Ergänzt wurde die gängige Externalisierung von Ursachen zweitens durch ein weiteres Standardargument, das die Ursachen für unbefriedigende Ergebnisse pädagogischer Arbeit ebenfalls in der Umwelt der Schule suchte: die Schulbürokratie behindere die pädagogische Arbeit in der Schule durch allzu viele Vorgaben und Vorschriften. Bürokratische Verkrustungen, praxisferne Entscheidungen einer zentralistischen Schulverwaltung erstickten die Motivationen und die Kreativität einzelner Lehrer und ganzer Kollegien. Die Schule werde ,administrativ verstört“ (Rumpf 1966, nun als Steuerungskritik Maritzen 1996: 23-26) und so an einer raschen situativen Anpassung an neue Herausforderungen und einer darauf antwortenden pädagogischen Profilierung gehindert.

Wenn es also in der Schule nicht so lief, wie es laufen sollte, dann konnte bisher - unter selektiver Verwendung sozialwissenschaftlicher Befunde, denen man nur einen kleinen organisationsverträglichen Dreh geben mußte - auf die Familie und/oder die Bürokratie als Chiffren für die eigenen Beschränkungen verwiesen werden. Als Gegenforderung wurde schon seit den zwanziger Jahren [...] und dann noch einmal im Bildungsratsgutachten von 1973 (vgl. Deutscher Bildungsrat 1973) nach mehr Mitarbeit der Eltern (die damit selbst zum Objekt pädagogischer Anstrengungen werden konnten) und mehr Autonomie der einzelnen Schulen gegenüber der Schulaufsicht gerufen. Die sollten über ihr Budget, über ihre Arbeitspläne, den Einsatz ihres Personals und ihr pädagogisches Profil selbst bestimmen. $\mathrm{Zu}$ solcher Autonomie gehörte in einer demokratisch verfaßten Gesellschaft die Mitbestimmung und Partizipation der Lehrerinnen und Lehrer, der Eltern und sogar der Schüler bei Entscheidungsprozessen, die auch die Rekrutierung von Personal und Schülern, bis zur Wahl der Schulleitung einschließen sollten. Autonomisierung wurde begriffen als ein Schritt in Richtung auf mehr schulinterne Demokratie, als Vorbereitung auf eine aktive Staatsbürgerrolle in der Zivilgesellschaft. Das entsprach dem auf Demokratisierung gerichteten Geist der Zeit in den siebziger Jahren. Die Forderung nach Autonomie und Partizipation ging aus von der Basis der unruhigen Lehrer, sie war gegen die Bildungsadministration gerichtet und wurde seinerzeit - wie selbstverständlich - von der Verwaltung ,nicht gewährt", aber auch nicht erkämpft.

In der neuen volks- und betriebswirtschaftlichen Logik wird vorausgesetzt, da $\beta$ auch unter anerkannt schwierigen Bedingungen bedarfsgerecht und effektiv erzogen werden kann. Sofort haben die Argumente die Seite gewechselt. Nun sinnt die Bildungsverwaltung den einzelnen Schulen die früher verweigerte Autonomie an, damit sie sich im parteipolitischen Gezänk nicht länger selbst den Zustand der Schulen zurechnen lassen muß. Selbstbestimmung der Schule (nicht in der Schule) kann das Argument der „administrativen Störung“ aushebeln. Die Schulaufsicht erwartet - nachdem sie bislang immer mit mehr Regulierung auf Probleme geantwortet hat - nun mehr Selbstverantwortlichkeit für zu treffende Entscheidungen und mahnt von den Schulen einen Qualitätsnachweis und mehr Effizienz an, die 
durch externe Evaluation der Organisation des Bildungsprozesses nachgewiesen werden soll. Davor fürchten sich die Schulen. ${ }^{27}$ Nun sind es die Verbände der Lehrerinnen und Lehrer, die darin nicht die Chancen zu mehr Partizipation und Demokratisierung ihrer Einrichtung sehen, sondern verschärfte Kontrolle und eine Überwälzung von Arbeitslasten und Verantwortlichkeiten. Die wollen sie nicht übernehmen, ohne wirkliche Entscheidungsbefugnisse hinzu zu gewinnen.

Mit der publikumswirksamen Durchsetzung einer inhaltsleeren Qualitäts- und Effizienzforderung (Woran bemißt sich Qualitäts- oder Effizienzsteigerung?), die sich letztlich auf ein Kostenargument reduzieren läßt, und einem paradoxen Autonomieansinnen (,Sei autonom!'), das den Schulen politisch aufgenötigt werden soll, hat die bisher erfolgreiche Immunisierungsstrategie der Pädagogik gegen Kritik von außen ein nachhaltiges Ende gefunden. „Niemand hört uns mehr zu, wenn wir mehr Lehrer fordern“, klagt der GEW-Vorsitzende, und fordert nun seinerseits dazu auf, Schule „,neu zu denken“. Daß es mit der derzeitigen Autonomie-Diskussion gelungen ist, das Dauerlamento des pädagogischen Establishments zu durchkreuzen, mag man mit bildungsreformerischer Erleichterung registrieren. Die ausgelöste Bewegung, die man damit ins Schulsystem gebracht hat, könnte sich als Pyrrhussieg erweisen.

[...]

Wer also daran geht, die erweiterte Autonomie und erhöhte Selbständigkeit der einzelnen Schulen zu propagieren, muß sich der Gefahr bewußt sein, daß der Versuch, Marktkräfte und Wettbewerbsmechanismen in das System einzuführen, mit dem Wert der Chancengleichheit und Gerechtigkeit kollidieren kann und, wie erste empirische Befunde aus den ,avancierten Deregulierungsländern“" zeigen (vgl. OECD 1994, Ball u.a. 1996), zu neuen Formen der Ungerechtigkeit gerade auch für Migranten und Minderheiten führen wird. Der Versuch, den viele der Autonomie-Befürworter machen wollen (vgl. z.B. Holzapfel 1994), die beiden Prinzipien „Wettbewerb" und „Chancengleichheit" in einer Autonomisierungsstrategie zu verbinden, um positive (Synergie-)Effekte zu erzielen, würde also zumindest voraussetzen, daß systematisch über Sicherungsvorkehrungen nachgedacht würde, die notwendig wären, um offensichtlich Ungleichheit verursachende Folgen von ungesteuerten bzw. marktförmig gesteuerten Systemen zu vermeiden. [...]

\section{Literatur}

Bildungskommission NRW (1995): Zukunft der Bildung - Zukunft der Schule, Neuwied.

27 Die Bildungskommission NRW bietet den Schulen deshalb in gedrechselten Formulierungen die „Selbstevaluation“ an (1995: 67), die ihnen am Ende gesetzlich auferlegt werden wird (vgl. Rolff 1995: 381). 
Ball, S. J./Bowe, R./Gewirtz, S. (1996): School choice, social class and the realisation of social advantage in education, in: J. of Education Policy 11 (1996) 1, S. 75-88

Bourdieu, P./Passeron, J. C. (1971): Die Illusion der Chancengleichheit, Stuttgart.

Carnoy, M. (1995): Structural adjustment and the changing face of education, in: International Labour Review, Vol. 134, No. 6, S. 653-673.

Daschner, P./Rolff, H.-G./Stryk, T. (Hg.) (1995): Schulautonomie - Chancen und Grenzen, Weinheim.

Deutscher Bildungsrat (1973): Empfehlungen der Bildungskommission: Zur Reform von Organisation und Verwaltung im Bildungswesen, Teil 1: Verstärkte Selbständigkeit der Schule und Partizipation der Lehrer, Schüler und Eltern, Bonn.

Holzapfel, H. (1994): Autonomie verändert die Schule schneller als erwartet, in: Pädagogik 46 (1994) 9, S. 46-48.

Maritzen, N. (1996): Im Spagat zwischen Hierarchie und Autonomie. Steuerungsprobleme in der Bildungsplanung, in: Die Deutsche Schule 88 (1996) 1, S. 22-36.

OECD (1992): High-quality education and training for all, Paris.

OECD (1994): School: a matter of choice, Centre for Educational Research and innovation, Paris.

Rolff, H.-G. (1995): Steuerung, Entwicklung und Qualitätssicherung von Schulen durch Evaluation, in: Ders. (Hg.): Zukunftsfelder von Schulforschung, Weinheim, S. 375392.

Rumpf, H. (1966): Die administrative Verstörung der Schule, Essen

Weiß, M. (1996): Bildung ist Zukunftsinvestition!, In: Die Deutsche Schule 88, Heft 2, S. 132-134.

\section{NORBERT MARITZEN}

Schule zwischen Staat und Markt?

Für kritische Genauigkeit beim Reden über Schulautonomie eine Antwort auf Frank-Olaf Radtke

Nicht nur die bildungspolitische Diskussion, sondern auch die konkrete Entwicklung der Schulsysteme ist in vielen Ländern seit einigen Jahren geprägt durch einen oft beschworenen Paradigmenwechsel (manche sagen eine „Modeerscheinung") die mit Begriffen wie „Schul-Autonomie“, „teilautonome Schule“, „selbständige Schule“, „erweiterte Gestaltungsautonomie“ oder "Schule in erweiterter Verantwortung" eher schlagwortartig als deskriptiv-korrekt gekennzeichnet wird. Kennzeichnend für den Tenor der Debatte ist einerseits, daß das Schlagwort „Autonomie“ offenbar als Gegenbegriff gegen tradierte Vorstellungen von der Stellung der Schule im Gesamtgefüge des Bildungssystems mehr provokatives denn erklärendes Potential entfalten soll. Andererseits indizieren die umschreibend-relativierenden Begrifflichkeiten eine krampfhafte Vermeidungshaltung, als gelte es, etwas Unaussprechliches, nämlich die Gestaltungskompetenz der Schule und der in ihr arbeitend-lernenden Menschen, verbal zu kaschieren.

$[\ldots]$

Tillmann hat mit Recht auf eine erstaunliche Paradoxie in der aktuellen Diskussion aufmerksam gemacht, nämlich auf das Phänomen, daß die Ak- 
teure der Autonomie-Debatte offensichtlich jeweils ,aus Versehen die Texte ihrer Gegner aufsagen" (Tillmann 1993: 6). Kultusminister fordern zu mehr Autonomie auf wie in den 60er/70er Jahren fortschrittliche Lehrer und Erziehungswissenschaftler, während besonders gewerkschaftliche Lehrer-Vertreter heute vor den Folgen einer solchen Reform warnen. Bildungsverwaltungen gewähren erweiterte Handlungsspielräume, die lange vergeblich eingeklagt wurden von denen, die nun solche Freiheiten beargwöhnen.

$[\ldots]$

Die diskursive Gemengelage ist die keineswegs nur ein Ringen von Bildungspolitikern um rhetorische Hegemonialstellungen, sondern ein Ausdruck der Verstörung und zugleich des Suchens angesichts des Verlustes alter Zukunftsgewißheiten. Deshalb ist es zu begrüßen, wenn Olaf Radtke die bildungspolitische Autonomiediskussion kritisch analysiert und als „ein gigantisches semantische Ringen um die immergleiche Frage“ interpretiert, ,wer die Definitionsmacht über die Probleme und Aufgaben erlangt oder behält, die sich dem Bildungssystem heute und in absehbarer Zukunft stellen“. [...] Ein solcher Erklärungsansatz richtet die Aufmerksamkeit darauf, daß es in bildungspolitischen Gestaltungsfragen, hier in der Diskussion um schulische Autonomie, immer auch um Machtfragen, also um die Spannung zwischen politischer Defintionshegemonie einerseits und gerechter Teilhabe an Gestaltung ebenso wie an Nutznießung gesellschaftlicher Einrichtungen anderseits geht.

Problematisch, fragwürdig und exemplarisch ist allerdings die Art und Weise, wie Radtke seine Argumentation entfaltet. [...]

Radtkes verschenkt gewissermaßen das kritisch anregende Potential, das seiner Fragestellung zugrundeliegt, da er sich in seiner Gegenstandskonstituierung nicht auf die konkrete Entwicklung in den deutschen Bundesländern, auf ihre durchaus unterschiedlichen legislativen, strukturellen und inhaltlichen Entwicklungen einläßt. Diese entscheidende Unterlassung hat zur paradoxen Konsequenz, daß man durchaus geneigt ist, vielen seiner diagnostischen Befunde zuzustimmen, sie aber nur schwer - wenn überhaupt - mit der Realität im eigenen Lande zusammenkriegt.

[...]

Ich argumentiere aus dem konzeptionellen Horizont des bremischen Entwicklungsprojektes ${ }^{28}$, weil Radtke sich auf dieses mehrfach explizit bezieht und weil es darüber hinaus geeignet ist, die Steuerungsvorstellungen zu präzisieren und zu exemplifizieren, denen Radtke zu Unrecht vorwirft, sie hätten „die Reduzierung sozialer Ungleichheit ... gar nicht mehr im Blick“ $[\ldots]$.

$28 \mathrm{Zu}$ Ansatz und Entwicklung der Systemreform in Bremen seit 1991 siehe z.B. Senator für Bildung, Wissenschaft, Kunst und Sport 1995, Fleischer-Bickmann 1993, Hoffmann 1995, Rolff 1996. 
Radtke deutet - das ist seine zentrale These - die internationale und bundesdeutsche Autonomiediskussion als „Triumph der Kritik des Sozialbzw. Wohlfahrtsstaates" [...]. Entweder explizit angestrebt oder eher implizit auf den Weg gebracht, setze sich angesichts des Versagens etatistischer Reformmodelle und des Erstarkens neokonservativer Politikkonzepte eine „Marktorientierung“ als Steuerungsvorstellung auch im Bildungsbereich durch zu Lasten der staatlichen Gewährleistung von Chancengleichheit und Bildungsgerechtigkeit. ${ }^{29}$ „Profilbildung“" oder Verstärkung des Elterneinflusses z.B. durch Freigabe der Schulwahl seien Ausdruck einer gefährlichen Rücknahme der staatlichen, auf die Einlösung egalitärer demokratischer Postulate verpflichteten Gestaltungshoheit, die lange Zeit Kern eines bildungspolitischen Konsens bildete. Zentrale Denkfigur in Radtkes Argumentation ist also die Polarität von „Staat" und „Markt", die derzeit im Bildungsbereich zu letzterem hin aufgelöst zu werden drohe mit allen bekannten, vor allem in den USA und Großbritannien bereits nachweisbaren Folgen für die Durchsetzung von Bildungsansprüchen gerade benachteiligter gesellschaftlicher Gruppen.

Vieles in der konkreten Entwicklung der Bildungsbereiche ebenso wie in - das ist etwas anderes - den aktuellen Reformdiskursen scheint dafür zu sprechen, daß die Rede von der Schlagseite in Richtung „Markt“ die aktuellen Tendenzen begrifflich faßt und damit verbundene Gefahren auf den Punkt bringt. Dennoch - so ist zu zeigen - greift dieses polare Denkmodell zu kurz, da es die Konzeptionierung möglicher Integrationsmodelle oder „Dritter Wege“, die immer existierten oder in einigen Autonomievorhaben gerade neu formuliert werden, grob versimpelt. Dies wird deutlich, wenn man sich komplexe systemische Reformvorhaben wie das bremische im Detail anschaut.

$[\ldots]$

Kennzeichnend für Autonomieansätze, die als Systemreform angelegt sind, muß nämlich keineswegs notwendig ein Rückzug staatlicher Verantwortung und Gestaltungsmacht sein, sondern im Gegenteil deren Wiedergewinnung dadurch, daß staatliche Instanzen ihre veränderten Handlungsbedingungen in breit angelegten Prozessen reflektieren und ihre Handlungsmöglichkeiten durch Entwurf veränderter Beziehungsstrukturen zwischen „Zentrale“ und „Peripherie“ neu bestimmen. Dabei wird vor allem deutlich: Die Komplexität systemisch angelegter Gestaltungsautonomie und ihre in der Tat komplizierter gewordene Rückbindung an demokratische Normen und Zielsetzungen wird mit Kategorien wie „Öffnung zum Markt" völlig verkannt. Die verantwortliche Implementation des Programms schulischer Gestaltungsautonomie ist vielmehr ein komplizierter

29 Ich gehe hier nicht näher auf historische oder begriffsanalytische Aspekte der politischen Forderung nach Chancengleichheit oder Bildungsgerechtigkeit ein. Siehe dazu z.B. Bayer u.a. 1983, Flitner 1985, Klemm u.a. 1986, Heid 1988, von Friedeburg 1989. 
Mehr-Ebenen-Prozeß, der den Bereich der einzelnen Schule bei weitem überschreitet (vgl. zu folgendem ausführlicher Maritzen 1997a). Die gängig gewordene Rede von der Schule als Handlungseinheit verdeckt nur allzu leicht, daß Gestaltungsautonomie der Einzelschule bildungspolitisch nur zu legitimieren ist in einem Gesamtpaket von Systemveränderung, das auch Bildungsverwaltungen und Unterstützungssysteme einschließt, und zwar nicht etwa im Sinne eines effizienzsteigernden und kostensenkenden Reengineering, sondern im Sinne einer Reformulierung der rechtlichen, strukturellen und steuerungsrelevanten Voraussetzungen für das Wirksamwerden der weiterhin aktuell bleibenden Aufgabenbestimmung des Sozialstaates.

Aus diesem Grunde wurde die Reformstrategie in Bremen in verschiedenen Handlungssträngen und auf unterschiedlichen Ebenen initiiert, die eng miteinander verküpft sind: Auf einer ersten Ebene erfolgte eine systematische Bestandsaufnahme des qualitativen Zusammenhangs von innerer und äußerer Reform des Schulsystems, und zwar in einer Form, die nicht auf die reine Effizienzanalysen des Ressourceneinsatzes fokussiert war (Senator für Bildung und Wissenschaft 1993). Eine zweite Ebene ist die Ebene der Schulgesetze. Selbst wenn Schulen auch im gesetzlichen Status quo vorhandene Spielräume nicht konsequent genug nutzen, ist doch deutlich geworden, daß durch eine Weiterentwicklung des inhaltlichen, organisatorischen und formalen Rechtsrahmens die intendierte Entwicklung der Schule im Gesamtsystem abgesichert werden muß, und zwar explizit unter Rückbezug auf einen normativen Referenzrahmen, der dem Chancengleichheitspostulat ausdrücklich verpflichtet ist (vgl. $\S \S 3$ bis 9 BremSchulG). Eine dritte Ebene der Reform ließe sich kennzeichnen als umfassender Organisationsentwicklungsprozeß. Ein solcher Proze $\beta$, der in der Bildlungsverwaltung, zwischen Bildungsverwaltung und Schule und in einzelnen Schulen ansetzt, wurde begonnen eingedenk der Annahme, daß Gestaltungsautonomie von Schulen nur sinnvoll ist, wenn sich die Schulbehörden sowohl in ihrer Aufbau- als auch in ihrer Ablauforganisation ziemlich radikal ändern, wenn sie aus ihrer starken Orientierung nach innen ausbrechen und zu qualitativ anderen Beziehungen zu Schulen kommen. Sie ist andererseits auch nur dann vernünftig, wenn auch Schulen lernen, systemische Entwicklungsprozesse professioneller zu planen und umzusetzen.

$[\ldots]$

Bereits im innerschulischen Bereich [...] erfaßt die Autonomie unterschiedliche Handlungsfelder:

- innere Schulverfassung: z.B. Struktur, Zusammensetzung und Aufgabenbestimmung schulischer Beratungs- und Entscheidungsgremien; veränderte Zusammensetzung und Aufgabenbestimmung für die Schulleitung usw. In der bremischen Gesetzesnovellierung werden hier einschneidende Veränderungen vorgenommen mit der Tendenz, die traditionell dominierende Rolle der Lehrer zurückzunehmen zugunsten einer 
Stärkung der innerschulischen demokratischen Teilhabe aller Beteiligter.

- schuleigene Curricula: Lehrplanarbeit, die aus einem neuen, diskursiv anzulegenden Verhältnis zwischen zentraler Rahmenregelung und schulinterner Curriculumarbeit zu entwickeln ist (Fleischer-Bickmann 1994).

- Schulorganisation: Ausgestaltung der Stundentafeln (z.B. Ablösung der Wochen- durch Jahresstundentafeln), Veränderung der Unterrichtsorganisation und der Zeitstrukturen usw., so daß auf spezifische Standortgegebenheiten und Einsichten in Bedingungen des Lernens adäquater eingegangen werden kann.

- Haushalt: Globalbudget für Schulen, wirtschaftliche Eigenständigkeit, Aufhebung des kameralistischen Annuitätsprinzips usw. (Isermann 1994 und 1995; Hinrichs 1994).

Wenn nun von „Autonomie als Paket“ die Rede ist, sind drei grundsätzliche Zusammenhänge gemeint: Erstens zeigt sich überall dort, wo ernsthaft erweiterte Handlungsspielräume für Einzelschulen erprobt werden, die Gefahr, daß einzelne Bereiche aus dem Gesamtmenü herausgelöst werden. Demgegenüber ist festzuhalten: Gestaltungsautonomie setzt voraus, daß die oben genannten Gestaltungsbereiche von Schulentwicklung in einen planvollen und zielorientierten Gesamtzusammenhang eingebunden werden. Dies ist durch innere und äußere Vorkehrungen sicherzustellen. Zweiter grundsätzlicher Aspekt: Das Paket bedarf auf der Ebene der Einzelschule der Rückbindung an ein Schulprogramm und der regelmäßigen Evaluation (Fleischer-Bickmann/Maritzen 1996, Maritzen 1996b und c). Die Bremer Schulgesetze verpflichten deshalb die Schulen, Prozesse der Programmerstellung zu initiieren und die schulische Arbeit insgesamt kontinuierlich zu evaluieren. Dritter grundsätzlicher Aspekt: Innerschulische Gestaltungsautonomie bedarf völlig veränderter Vorgaben und neuer Instrumente der Qualitätssicherung.

$[\ldots]$

Neue Verfahren der Qualitätssicherung sind in Bremen und anderswo in Erarbeitung und Erprobung. Keineswegs gibt also der Staat seine Gestaltungsprärogative einfach auf, sondern er entwirft sie neu, indem er die Verantwortungswahrnehmung im System in ein neues Beziehungsgeflecht setzt, demokratisiert und professionalisiert, also gerade nicht auflöst, wie Radtke behauptet. Dies sei am Beispiel Schulprogramm und Evaluation angedeutet, zwei Konzepte, für die Radtke allenfalls verständnislose $\mathrm{Ne}-$ benbemerkungen reserviert (vgl. z.B. S. 11).

Die Qualitätsentwicklung und -sicherung für selbständigere Schulen wird in Zukunft immer weniger wirksam geleistet werden können mittels der Instrumentarien klassischer Durchgriffsaufsicht, die sich in die Ablauforganisation der Schule qua höherer, d. h. allgemeine Interessen inkarnierender Einsicht maßregelnd einmischt. Gegenüber selbstbewußteren Schu- 
len verfangen eben zentralistisch vorformulierte Detailregulierungen nicht mehr; sie werden im Gegenteil kontraproduktiv, indem sie erfolgreiche Steuerungsleistungen der Zentrale suggerieren, wo die Selbständigkeit der dezentralen Einrichtungen im Alltag längst ein Ausmaß angenommen hat, von dem die meisten Ministerialen kaum etwas ahnen. Wenn diese Diagnose richtig ist, wenn die Frage der externen Beeindruckbarkeit von Schulen als Organisationen sich immer radikaler stellt, dann müssen einerseits Steuerungsleistungen in neuer Form und effektiver als bisher von den Schulen selbst erbracht werden. [...]

[...] Der Regelkreis von Schulprogramm, interner und externer Evaluation versucht also einem neuen schulpolitischen Steuerungsparadigma Rechnung zu tragen. Die Schulen entwickeln ihre standortspezifischen Profile $^{30}$, indem sie auf der Grundlage interner Konsensbildung in Schulprogrammen Ziele und Bereiche der inhaltlichen Entwicklung von Unterricht und Schulleben strategisch festschreiben, Schwerpunkte setzen, curriculare Vorgaben spezifizieren, Handlungsperspektiven zeitlich festlegen, Verantwortlichkeiten personell zuordnen und Erfolgskriterien festlegen. Schulprogramme sind also nicht Texte, die auf Nimmerwiedersehen in einer behördlichen Berichtesammlung verschwinden. [...]

Bis hierher liegt die Verantwortung für die Qualitätssicherung bei der Einzelschule, konkreter bei den schulischen Entscheidungsträgern, auf die das Schulgesetz die Kompetenzen für die Programmentwicklung und die interne Evaluation verteilt. Interne Evaluation bleibt aber vermutlich wenig wirksam, wenn sie nicht gespiegelt wird durch den Blick externer Schulund Evaluationsexperten. Die externe Evaluation wird in Bremen die wichtigste Aufgabe der Schulinspektion ${ }^{31}$ sein, die in Kenntnis des inneren Entwicklungszustands der Einzelschulen in neuer Form die Mitverantwortung für Steuerung des Gesamtsystems wahrnehmen soll. Dies soll auf vor allem zweierlei Weise geschehen. Erstens vereinbart die Schulinspektion mit den Schulen die Gegenstände und Kriterien für eine Validierung der innerschulischen Evaluation, die dann auf der Grundlage eines Evaluationsberichtes der Schulen und vereinbarter zusätzlicher Daten einer kritischen Prüfung unterzogen wird. Das Ergebnis dieser Prüfung einschließlich bestimmter Empfehlungen wird in vorher verabredeten Verfahren mit den Schulen zurückgekoppelt und anschließend in einem Inspektionsbericht veröffentlicht. Aus der vergleichenden Analyse schulinterner Evaluationen und übergreifenden Untersuchungen zu ausgewählten Fragestellungen (z.B. hinsichtlich der sozialen Selektivität von „Profilbildungen“) gewinnt die Schulinspektion zweitens Erkenntnisse über den qualitativen Zustand des

30 Also gerade nicht „Profil““ im Radtkeschen Verständnis einer Konkurrenzorientierung.

31 Die Aufgaben dieser neuen Einrichtung werden umrissen im $\S 13$ BremSchVwG. Genaueres siehe in Maritzen 1997, auf die Steuerungsfunktion von Evaluation bezogen Rolff 1995. 
Gesamtsystems, die sie sowohl an die Schulen als auch an die administrativen und politischen Entscheidungsträger weitergibt.

Vor diesem Hintergrund mag auch evident werden, daß die Qualitätsdebatte in ganz besonderer Weise Virulenz gewinnt, also alles andere als ,inhaltsleer" (S. 11) sich gestalten wird, wie Radtke behaupten muß, da er das Risiko von Standarddiskussionen aufgrund seines Ansatzes einseitig im neokonservativen Versuch einer Wiederherstellung der Selektivität des Systems sieht (S. 8). Wer den inneren Zustand von Schule kennt, weiß: Die Präzisierung von Qualitätsmerkmalen und Standards bzw. der Kriterien ihrer Einlösung ist als Ausweis der Professionalität von Lehrern ebenso wie als Gegenstand der Verständigung aller schulischer Akteure dringend notwendig. Wer kein differenziertes Bild von der Qualität des Lehrens, des Lernens, der Strukturen und Prozesse hat, gibt das Feld erst recht neokonservativen Restrukturierern preis, die Unternehmensberatungen definieren lassen, was das Produkt der Schule sei (vgl. kritisch Flitner/Klemm 1995).

$[\ldots]$

\section{Literatur}

Bayer, M./Muth, J./Otten, D./Rolff, H.-G./Uhe, E.: Chancenungleichheit und Strukturkrise. Ein Memorandum zur Schulentwicklung für den Landesverband NordrheinWestfalen der Gewerkschaft Erziehung und Wissenschaft. Essen 1983.

Fleischer-Bickmann, W.: Projekt Autonomie. Schule und Schulverwaltung. Erfahrungen aus Bremen. In: Pädagogik 45 (1993) 11, S. 21-25.

Fleischer-Bickmann, W.: Rahmenplan und Schulcurriculum. In: Buchen, H./Horster, L./Rolff, H.-G. (Hg.): Handbuch Schulleitung und Schulentwicklung. Berlin: Raabe, 1994

Fleischer-Bickmann, W./Maritzen, N.: Schulprogramm. Anspruch und Wirklichkeit eines Instruments der Schulentwicklung. In: Pädagogik 48 (1996) 1, S. 12-17.

Flitner, A.: Gerechtigkeit als Problem der Schule und als Thema der Bildungsreform. In: Zeitschrift für Pädagogik 31 (1985) 1, S. 1-26.

Flitner, A./Klemm, K.: Unternehmensberater machen Schulpolitik. In: Die Deutsche Schule 87 (1995) 4, S. 404-407.

v. Friedeburg, L.: Bildungsreform in Deutschland. Geschichte und gesellschaftlicher Widerspruch. Frankfurt/M. 1989.

Heid, H.: Zur Paradoxie der bildungspolitischen Forderung nach Chancengleichheit. In: Zeitschrift für Pädagogik 34 (1988) 1, S. 1-17.

Hinrichs, T.: Budgetautonomie. Ein Modell für die erweiterte finanzielle Autonomie. In: Buchen, H./Horster, L./Rolff, H.-G. (Hg.): Schulleitung und Schulentwicklung. Erfahrungen, Konzepte, Strategien. Berlin: 1994

Hoffmann, R.: Autonomie und Systementwicklung. Erfahrungen aus Bremen. In: Daschner, P./Rolff, H.-G./Stryck, T. (Hg.): Schulautonomie - Chancen und Grenzen. Impulse für die Schulentwicklung. Weinheim/München 1995, S. 227-252.

Isermann, M.: Wirtschaftliche Autonomie für Bremer Schulen. In: Schulmanagement 25 (1994) 4, S. 41-42.

Isermann, M.: Ein Budget für die Schule - Praxisprobleme am Pilotprojekt „Wirtschaftliche Autonomie von Schulen“ in Bremen. In: Schulmanagement (1995) 5, S. 4042. 
Klemm, K./Rolff, H.-G./Tilllmann, K.-J.: Bildung für das Jahr 2000. Bilanz der Reform, Zukunft der Schule. Reinbek bei Hamburg 1986.

Maritzen, N.: Sich selbst und anderen Rechenschaft geben. Qualitätssicherung durch Evaluation. In: Pädagogik 48 (1996b) 1, S. 25-29.

Maritzen, N.: Etwas besseres als ein Profil finden wir allemal. Suchbewegungen zum Schulprogramm. Der bremische Kontext. In: Hamburg macht Schule 8 (1996c) 5, S. 22-23.

Maritzen, N.: Autonomie der Schule. Schulentwicklung zwischen Selbst- und Systemsteuerung. In: Altrichter, H./Schley, W./Schratz, M. (Hg.): Handbuch für Schulentwicklung. Innsbruck/Wien (1997a).

Rolff, H.-G.: Steuerung, Entwicklung und Qualitätssicherung durch Evaluation? In: Rolff, H.-G. (Hg.): Zukunftsfelder von Schulforschung. Weinheim: Juventa, 1995, S. 375-392.

Rolff, H.-G.: Verwaltungsreform im Schulbereich: Schlanker und pädagogischer zugleich? Ein Fallbeispiel aus Bremen. In: Organisationsentwicklung 15 (1996) 2, S. 30-40.

Senator für Bildung und Wissenschaft: Innovation und Kontinuität. Empfehlungen zur Schulentwicklung in Bremen. Bericht der Kommission zur Weiterführung der Schulreform in Bremen. Bremen 1993.

Senator für Bildung, Wissenschaft, Kunst und Sport: ISP/OE. Organisationsentwicklungsprogramm für Schulen und Schulverwaltung. Bremen 1995.

Tillmann, K.-J.: Autonomie der Schule oder: Wollen Schulen verwaltet werden? In: Pädagogik 45 (1993) 11, S. 6-8. 


\section{Wertediskussionen}

\section{Kommentar (Eubel)}

Generalthema der drei hier unter dem Stichwort „Wertediskussionen“ versammelten Aufsätze ${ }^{32}$ ist die „Chancengleichheit“. $\mathrm{Zu}$ diesem Problembereich wird offensichtlich publiziert, weil die vormalig dominierende Ausrichtung des Bildungssystems an diesem Begriff durch das Aufkommen von Konzepten wie „Effizienz" und „Qualität" in Frage gestellt scheint. ${ }^{33}$ Allem Anschein nach hat eine Umwertung der Werte begonnen und die Modernisierungen von Schule und Unterricht folgen dem neuen Muster.

Helmut Heid (Universität Regensburg) interessiert zum einen die ,innere Logik' der Forderung nach Chancengleichheit. Außerdem fragt er nach den legitimatorischen Implikationen dieses Konzepts. Klar wird dabei vor allem, dass ,Gleichheit', aber auch ,Gerechtigkeit' sehr voraussetzungsvolle Konstrukte sind, die vorab gesellschaftlich definiert werden müssen. Auch wenn das Postulat der Chancengleichheit nicht dazu geeignet scheint, Ungleichheit aufzuheben, so doch dazu, diese „Ungleichheiten zu reorganisieren und dadurch zu ihrer Legitimation beizutragen."

Die Argumentation von Wulf Hopf (Universität Göttingen) zielt in eine andere Richtung. Angesichts der Deregulierungstendenzen im aktuellen Bildungssystem fragt er danach, wie Chancengleichheit in den 1960er und 1970er Jahren konzipiert wurde, ob und gegebenenfalls welche Veränderungen der Begriff zwischenzeitlich erfahren hat - dies von der Absicht geleitet, zu prüfen, ob man ihn beibehalten sollte oder nicht. Ein Fazit seiner Analyse: Es zeigt sich, dass die damalige Operationalisierung des Chancengleichheitsbegriffs sehr differenziert und präzise war. Hopf analysiert kritische Einwände und exemplarische Weiterentwicklungen des Chancengleichheitspostulats, die unternommen wurden, weil man dem Konzept vorwarf, zu eng und ungerecht zu sein, da es mehr der ,Egalisierung ' vorhandener Unterschiede diene, als der tatsächlichen Förderung der Individuen, die doch alle unterschiedlich seien (so bei Andreas Flitner 1985), oder weil kritisiert wurde, dass das Recht auf Bildung nach wie vor zu stark idealistisch und zu wenig durch egalitäre Momente geprägt sei (so bei Jörg Schlömerkemper 1986). Er kommt zu dem Schluss, dass diese Modifikationen in aller Regel nicht zu einer besseren Klärung der Forderung nach „Gleichheit der Wettbewerbsbedingungen und nach Gleichheit der Bildungsteilhabe" geführt haben, sondern diesen doppelten Zusammenhang

32 Vgl. jedoch auch Terhart (im Textblock „Was beinhaltet schulische Modernisierung?" des vorliegenden Bandes).

33 Ganz andere Wertedimensionen, die sich zumindest nicht ohne weiteres mit ,höheren" Zielen wie Chancengleichheit oder Effizienz verbinden lassen, finden sich in der Praxis des Lehrerhandelns, zum Beispiel im Zusammenhang mit Selektionsentscheidungen bzw. der alltäglichen Beurteilungspraxis (vgl. Terhart 2001c). 
eher verunklaren. Man sollte den Begriff folglich in der damals erreichten Präzision beibehalten, vor allem weil er die durchaus widersprüchlichen Effekte und unerwünschten Nebenfolgen, die sich aus der Gültigkeit des Leistungsprinzips ergeben, erklärbar macht.

Man kann vielen Verfechtern der Chancengleichheit aber den Vorwurf nicht ersparen, dass sie sich zu wenig für die Frage interessierten, ob die Orientierung an diesem Wert erfolgreich war. ${ }^{34}$ Nach der derzeitigen Forschungslage muss man ganz nüchtern eingestehen, dass dieses Programm zumindest partiell gescheitert ist. Es ist nicht gelungen, sozialstrukturelle Ungleichheiten substantiell zu verringern. Das gilt in unterschiedlichem Ausmaß für die meisten Bildungssysteme (vgl. Blossfeld/Shavit 1993; von Below 2002), das gilt besonders augenfällig aber vor allem für die deutsche Schule, der durch die PISA-Studie bestätigt wurde, dass gerade im deutschen Schulsystem die Unterschiede im schulischen Leistungsvermögen der Schülerinnen und Schüler in besonders hohem Ausmaß auf den Faktor ,soziale Benachteiligung' zurückgeführt werden können (vgl. Deutsches PISA-Konsortium 2001).

Der Ansatzpunkt Annemarie von der Groebens (Didaktische Leiterin der Laborschule Bielefeld) ist wieder ein anderer als bei Heid und Hopf. Explizit kommt der Begriff der Chancengleichheit bei ihr gar nicht vor, sondern ihre Argumentation kreist um das Schlüsselwort „Qualität“. Auf die Forderung der Modernisierer, dass zur Sicherstellung der Qualität in Schulen externe Evaluationen erforderlich seien, um ihnen Daten über den Grad der Zielerreichung zur Verfügung stellen und gegebenenfalls ,gegensteuern' zu können, antwortet sie, dass das wichtigste Kriterium, an dem ,guter' Unterricht bemessen werden könnte, mit der Frage zusammenhänge, ,ob und wie er auf die Unterschiedlichkeit der Kinder eingeht." Gut wäre er vor allem dann, ,wenn er den je individuellen Stand [der Schülerinnen und Schüler] prinzipiell positiv bewertet und alle Hilfen bereitstellt für ihre weitere Entwicklung.“ Sie äußert die Sorge, dass das „Neue Steuerungsmodell"', das jetzt auch in Schulen zur Anwendung kommen soll ${ }^{35}$, guten“ Unterricht in ihrem Sinne geradezu verhindert, weil die Qualität, die nach ihren Vorstellungen erzeugt werden soll (optimale individuelle Förderung eines jeden Schülers) nur schwer oder überhaupt nicht nach außen kommunizierbar ist, vor allem dann, wenn die optimale Förderung den Schülern gilt, deren Bildungschancen schlecht sind. Also steht zu befürchten, dass der Wert ,Chancengleichheit' nicht mehr hinreichend beachtet wird, weil dieser in externen Evaluationen keine Rolle spielt. Von der Groeben postuliert, dass Qualitätsmessungen der neuen Art prinzipiell ungeeignet sind,

34 Die von uns ausgewählten Autoren seien ausdrücklich von diesem Vorwurf ausgenommen!

35 Dieses „Neue Steuerungsmodell“ beruht im wesentlichen darauf, lediglich die ,outputs‘ einer Schule zu kontrollieren und nicht wie bisher üblich über die präzise Definition der ,inputs“ (Festlegung der zugewiesenen Mittel, detaillierte Festlegung der Lehrpläne etc.) Qualität und Gleichheit (!) sicherzustellen. 
qualitativ wertvolle Informationen über den Einzelfall zu erheben. Eine möglicherweise unbeabsichtigte Nebenfolge besteht dann darin, dass sich der Unterricht an den Anforderungen der Tests orientiert ${ }^{36}$, indem er zum Beispiel Fakten oder abfragbares, ,träges Wissen' eintrainiert. Genau das macht nach den Wertvorstellungen engagierter Lehrerinnen und Lehrer ,schlechten' Unterricht aus und ist auch nicht unbedingt kompatibel mit den Erfordernissen einer modernen Wissensgesellschaft, für deren Erfordernisse die Modernisierer die traditionelle Schule ja gerade umkrempeln wollen.

Zwei Maximalpositionen zeichnen sich ab: Die Anhänger der ,alten“ Chancengleichheit-Werte geraten in die Defensive, weil sie keine Outputdaten vorlegen können. Und Anhänger von Effizienzforderungen müssen sich ,Wertlosigkeit' vorwerfen lassen, da sie ihre Outputergebnisse nicht an (gesellschaftliche) Zielfragen anbinden. Beide Positionen, diejenigen der Chancengleichheitsorientierung sowie die neue Effizienzausrichtung, bilden Realitäten gesellschaftlicher Schuldiskussionen. Das erlaubt, noch einen Schritt weiter zu gehen und zu fragen, ob die Polarität oder Unvereinbarkeit von Gleichheit und Qualität, die von vielen Diskutanten als gegeben vorausgesetzt wird, zwingend ist. Es gibt Schulsysteme, die sich beide Ziele gleichzeitig ins offizielle Programm geschrieben haben, zum Beispiel die Vereinigten Staaten. ${ }^{37}$ Auch wenn es in anderen Bildungssystemen nicht unbedingt diesen explizierten Kodex geben sollte, so ist doch zu konstatieren, dass viele von ihnen erfolgreicher sind in der gleichzeitigen Verfolgung von Gleichheit und Qualität als die deutsche Schule (vgl. Deutsches PISA-Konsortium 2001). ${ }^{38}$

36 Die Frage danach, was - und auch: von wem - gemessen werden soll, hat viele Dimensionen. Das Bildungskonzept zum Beispiel, von dem ausgehend die Testfragen der PISA-Studie entwickelt wurden, charakterisiert Messner als „konstruktiven Pragmatismus" (vgl. seinen Text im vorliegenden Buch), eine Bildungstheorie, die im deutschen Kontext bislang keine bedeutende Rolle spielte. Benner (2002) weist auf weitere bildungstheoretische Probleme der Internationalisierung hin. Die Rolle der OECD als ,global educational player' zeigt Gruber (2002). Aber auch die ,Enteignung der einzelnen Lehrperson, die nicht mehr nach ihren Methoden den Lernstand der Schüler erhebt, sondern diesen von außen, vorgesetzt ${ }^{\star}$ bekommt, versehen mit Hinweisen auf lokale/regionale/nationale Standards, dürfte tiefgreifende, vermutlich auch transintentionale Wirkungen nach sich ziehen. Also gibt es genügend Anlass, die Euphorie über die plötzlich möglich scheinende Technologisierung des Schulwesens ein wenig zu dämpfen.

37 „Equality and excellence“ sind dort im gesellschaftlichen Diskurs um Schule kaum voneinander trennbar (vgl. Boyd hier im Buch).

38 Aus solchen Befunden könnten sich Forschungsprogramme entwickeln, in denen vertiefende Analysen über die erfolgreiche Erreichung auch anspruchsvoller und werthaltiger Bildungsziele angestellt werden. Solche Vergleichsstudien bedienten nicht nur oberflächliche Interpretationen, die den ,Wettbewerb“ der Bildungssysteme auf eine Art „olympische Spiele, bei denen um schulische Leistungen gerungen wird“, reduzieren (Inkeles 1979: 366; Übersetzung - d. Hg.). Diese werden aber im öffentlichen Diskurs dominieren, wenn es die anderen Stimmen nicht gibt. 
Somit beinhalten die Wertediskussionen eine Chance: Sie könnten zur Klärung und Konkretisierung bildungspolitischer Vorstellungen beitragen. ${ }^{39}$ Gerade die Friktionen, die sich aus der Konfrontation eines Begriffs wie Chancengleichheit, der auf den Abbau sozialer Ungleichheiten im Bildungswesen zielt, und dem Qualitäts-Begriff ergeben, der nicht Ungleichheiten, sondern Leistungsmöglichkeiten des Bildungssystems in den Blick nimmt, die empirisch nachgewiesen werden müssen, könnten dafür genutzt werden und zu neuen Zielwerten führen. Nachzudenken wäre allerdings auch über neue Wege zu den Zielen.

\section{HELMUT HEID \\ Chancengleichheit unter den Bedingungen sozialstruktureller Ungleichheit Zur gesellschaftlichen Funktion eines Legitimationsmusters}

$\mathrm{Zu}$ den verbreitetsten Maximen bildungspolitischer Programme gehört die Forderung nach Chancengleichheit. Wie grob die Missverständnisse dieser Forderung sein können, zeigt sich beispielhaft dort, wo die Forderung nach Chancengleichheit unter Bezugnahme auf die Feststellung kritisiert wird, die Menschen seien nun einmal ungleich, und es sei völlig utopisch, daran etwas ändern zu wollen. Nicht nur der informierte, sondern auch der ambitionierte Autor der kritisierten Forderung wird diese Feststellung nicht bestreiten. Mehr noch: als kritisches Argument gegen seine Forderung ist die reklamierte Feststellung schlicht irrelevant. Denn gefordert wird nicht Gleichheit an sich, sondern eben Chancengleichheit in freilich präzisierungsbedürftiger Hinsicht.

39 Annemarie von der Groeben, sie ist Lehrerin, reagiert mit ihrer Analyse der wahren Wurzeln von Schulqualität auf einen Artikel, in dem ein Vertreter der Schulverwaltung, der damalige hamburgische Staatsrat für das Schulwesen, Hermann Lange, vehement für die neue Form der Qualitätssicherung plädiert (in diesem Band auszugsweise abgedruckt im Textblock „TIMSS- und PISA-Schock“) und dabei zu dem Schluss kommt, dass ein Paradigmenwechsel unvermeidlich sei. Lange reagiert übrigens seinerseits auf von der Groeben (vgl. Lange 2000), indem er zu bedenken gibt, dass die Gefahren, die sie sieht, vor allem dann gebannt werden können, wenn Lehrerinnen und Lehrer sich aktiv an dem anstehenden Veränderungsprozess beteiligen. Außerdem gibt er zu bedenken, dass die Methodenskepsis, die sie den neuen Evaluationsverfahren entgegenbringt, nicht schlüssig ist, weil nach seinem Dafürhalten all das, was von der Groeben als guten Unterricht bezeichnet, prinzipiell zumindest in Ansätzen evaluierbar ist (zu den differenzierten Methoden der Schulqualitätsforschung vgl. auch Fend im Textblock „Schulkultur“ dieses Bandes). Diese Kontroverse, wie übrigens auch die Diskussion Radtke - Maritzen (im Textblock „Autonomie“ dieses Buches), könnte ein anregendes Beispiel für die angesprochene Klärung und Konkretisierung sein. 
Die wie auch immer motivierte Fixierung der erwähnten Kritiker auf das Grundwort „Gleichheit“ zeigt sich auch in dem Vorschlag, den Begriff Chancengleichheit, wenn man nicht ganz auf Forderungen dieser Art verzichten wolle, doch wenigstens durch den Begriff Chancengerechtigkeit zu ersetzen. Mit der Einführung des formalen Hochwertbegriffs „Gerechtigkeit" (vgl. dazu u.a. Kelsen 1933 [1964]: 217ff.) wird in vermutlich strategischer Unbestimmtheit der Gesichtspunkt jener Selektivität bildungspraktischer Förderung ins Spiel gebracht, die erst Anlass für die bildungspolitische Forderung nach Chancengleichheit war und ist. Wo Befürworter der Gerechtigkeit in abendländischer Denktradition (vgl. Loos u.a. 1974) empfehlen, jedem „das Seinige“ zuzumessen, wird die Idee der Legitimierung bestehender Ungleichheit und der Anwendung des so genannten MatthäusPrinzips bereits in die Konzeption der Chancengerechtigkeit und nicht erst in deren praktische Umsetzung aufgenommen.

So verräterisch die Beanspruchung der Vokabel „Gerechtigkeit“ in hier thematischen Kontexten auch oft sein mag, die Verwendung des Grundwortes „Gleichheit“ ist ebenfalls alles andere als unmissverständlich. Die Forderung nach Gleichheit sowohl der Menschen als aber auch der Chancen hat Voraussetzungen, die nicht immer hinreichend beachtet werden.

Gleichheit oder Ungleichheit kann es nicht an sich oder als solche geben. Gleich oder ungleich können immer nur konkrete Menschen oder Sachverhalte, physische oder psychische Gegebenheiten (Inhalte) unter Bezugnahme auf ein bestimmtes Vergleichskriterium sein. Das für den Vergleich unentbehrliche Kriterium ergibt sich nicht aus der verglichenen Sache (i.w.S.) selbst, sondern ist Resultat einer Entscheidung, an der die Entscheidungssubjekte in genau jener Ungleichheit partizipieren, deren Kritik Voraussetzung für die Gleichheitsforderung ist. Ob Menschen beispielsweise nach ihrer Körpergröße, nach ihrer Körperkraft, nach ihrem Lebensalter, nach dem Geschlecht oder nach den Noten in einem Schulfach verglichen werden, das ergibt sich aus dem expliziten oder impliziten Vergleichszweck dessen, der den Vergleich anstellt.

Damit ist bereits eine zweite Voraussetzung angedeutet. Die Forderung nach Gleichheit gleich welcher Art ist nur sinnvoll, wo diesbezügliche Ungleichheit besteht. Damit aber nicht genug: diese Ungleichheit muss negativ - als zu überwindend - bewertet werden, sie muss überdies verhinderbar bzw. revidierbar sein, und die Revision - das ist im Zeitalter der Genmanipulation besonders zu betonen - muss mit geltenden Normen vereinbar sein. Es gibt nicht nur unvermeidbare, sondern zweifellos auch erwünschte Realisierungsformen von Unterschied und Ungleichheit mannigfacher Art - beispielsweise als Kennzeichen von Komplexität oder Reichhaltigkeit. Nun wäre es eine nicht nur grobe, sondern auch unzulässige Vereinfachung, von den beiden folgenden Unterstellungen auszugehen, nämlich erstens davon, dass über die Bewertung bestimmter Konkretisierungsformen von Ungleichheit Einigkeit leicht herbeizuführen sei, und 
zweitens davon, dass es an der Revidierbarkeit kritikwürdiger Ungleichheit kaum etwas zu deuteln gebe.

So nahe es liegen mag, (analytisch) zwischen der vermeintlich wertneutralen Ungleichartigkeit einerseits und der Ungleichwertigkeit interpersonaler Differenzen andererseits zu unterscheiden, so wenig lässt sich diese Unterscheidung in der gesellschaftlichen Praxis faktisch durchhalten. Das zentrale Argument zur Begründung dieser Unmöglichkeit besteht darin, dass Wertungen außer einem normativen Kriterium stets einen konkreten Gegenstand haben (müssen). Wertvoll kann immer nur eine konkrete Eigenschaft (i. w. S.) eines Menschen sein (bezogen auf ein bestimmtes sportliches Leistungskriterium beispielsweise die dafür besonders relevante körperliche Konstitution). Man kann also die Wertung real nicht von ihrem Gegenstand trennen. Ein weiterer wichtiger, wenn auch häufig vernachlässigter Grund für die unterschiedliche Bewertung bestimmter Konkretisierungsformen sozialer Ungleichheit besteht in der Wahl eines Vergleichsund Bewertungskriteriums. Das für eine Bewertung unentbehrliche Kriterium ist Resultat eines Entscheidungsprozesses, an dem von sozialer Ungleichheit stets selbst Betroffene mit sehr unterschiedlichen Einwirkungsund Durchsetzungschancen, also ungleich partizipieren (Heid 1996). Offensichtlicher scheinen individuelle Bewertungsdifferenzen sozialer Ungleichheit schließlich dort zu sein, wo Konkretisierungsformen dieser Ungleichheit in einer bereits werthaltigen sozialen Privilegierungskontrastierung bestehen, beispielsweise (stark vereinfacht): zwischen Arm und Reich, zwischen sozialem oder politischem Oben und Unten, zwischen Qualifizierten und Unqualifizierten. In der gesellschaftlichen Wirklichkeit sind die Dinge allerdings wesentlich komplizierter. Geht man davon aus, dass soziale Ungleichheiten, und zwar auch solche sozial strittiger Art einerseits und Konflikte über die gerechte Güterverteilung andererseits „normal“" oder gar unvermeidlich sind (Rawls 1988: 20ff.), dann wird deutlich, dass es von interindividuell höchst ungleicher sozialer Definitionsund Sanktionsmacht abhängt, welche Be-Wertungen verschiedener Sachverhalte sich in diesen Konflikten durchsetzen. Wer entscheidet beispielsweise darüber, welcher Krieg, welcher Widerstand, welcher Ungehorsam, welche soziale Herrschaft jeweils gerecht, also wünschenswert sind (Rawls 1988: 25)? [...]

Vordergründig hängt die Chancenrealisierung von mindestens zwei Voraussetzungen ab, und zwar erstens von den externalen Realisierungsbedingungen und zweitens von den internalen, insbesondere durch Bildungsmaßnahmen beeinflussbaren Voraussetzungen, die erfüllt sein müssen, damit jemand (unter gegebenen externalen Realisierungsbedingungen) ein Anrecht darauf geltend machen kann, zu erreichen, was er für erstrebenswert hält. Insofern sind die bildungsabhängigen internalen Voraussetzungen notwendige, aber keineswegs auch schon hinreichende Voraussetzungen der Chancenrealisierung. 
Bei der weiteren Erörterung spielt es theoretisch keine, dafür praktisch aber eine umso größere Rolle, ob es sich bei einer jeweils zur Diskussion stehenden Chance um die Aspiration dessen handelt, der seine eigene Chance sucht, erwirbt oder nutzt, oder ob es sich (nur) um das Konstrukt jenes externalen Beobachters handelt, der die Wahrscheinlichkeit thematisiert oder postuliert, mit der der Beobachtete zu realisieren vermöchte, was (zunächst nur) der Beobachter (gleichsam hypothetisch) für erstrebenswert hält. Dieser Hinweis erscheint mir wichtig, weil „Chancengleichheit“ mindestens ebenso oft Thema „teilnahmsloser" wissenschaftlicher Analysen wie Forderung bildungspolitischen oder bildungspraktischen Handelns Betroffener ist, und weil der eine Diskurs relativ unabhängig von dem anderen geführt werden kann und geführt wird.

Die thematisch bedeutsamen Besonderheiten der externalen Realisierungsbedingungen einer Chance bestehen nun darin, dass sie von Einzelnen nur überaus begrenzt, wenn überhaupt beeinflussbar sind, und zum anderen darin, dass sie sich aus noch zu erörternden Gründen nicht als Ungleichheit relativierend oder gar reduzierend, sondern eher verschärfend und - das kommt hinzu und ist überaus wichtig: - als Ungleichheit legitimierend auswirken.

Diesem Befund scheint zu widersprechen, dass bereits die Bestimmung des Unterscheidungskriteriums von (revidierbaren) Entscheidungen abhängt, und dass diese Entscheidungen von wiederum handlungsabhängigen und beeinflussbaren Interessen gesteuert werden. Insofern scheint sowohl die Ungleichheit unter den Menschen als auch die Chancenungleichheit leicht revidierbar, obwohl das keineswegs so sein muss. Denn dabei darf zweierlei nicht übersehen werden, und zwar zum einen, dass in den sozialen Prozessen der Definition und Durchsetzung herrschender Kriterien zur Unterscheidung der Menschen gleichsam zirkulär jene Ungleichheit zur Geltung kommt, die durch das Postulat der Chancengleichheit revidiert werden soll, dass also die Diagnose der Ungleichheit unter den Menschen in besonderem $\mathrm{Ma} \beta$ von den Interessen derer bestimmt wird, denen diese Ungleichheit durchaus nutzt (vgl. dazu Mattern/Weißhuhn 1980: 157ff.; Herrlitz u.a. 1981: 20f., 47ff., 63ff., 174). Zum anderen gelingt es den sozial definitions- und sanktionsmächtigen Teilnehmern an Diskursen zur „Erklärung" bestehender (und durchaus erwünschter) Ungleichheit, dafür solche Faktoren verantwortlich zu machen, die als objektiv revisionsresistent erscheinen (z.B. „die“ natürliche Begabungsverteilung), die gesellschaftlich (beispielsweise durch die faktische soziale Definitionsmacht) aus der Sicht Benachteiligter aber auch tatsächlich revisionsresistent sind. $\mathrm{Zu}$ dieser Revisionsresistenz und deren Legitimierung tragen die dadurch Benachteiligten bei, indem sie die Überwindung der kritisierten Ungleichheit unter genau jenen Bedingungen erstreben, unter denen es erst begründbar erscheint, Chancengleichheit zu fordern. Denn wer die Realisierungsbedingungen individueller Chancen nicht beachtet und respektiert, reduziert damit die Aussicht, seine individuelle Chance auch tatsächlich zu nutzen. 
Wer jedoch seine Aufmerksamkeit auf die Schaffung nur der internalen Voraussetzungen der Wahrung seiner Chance konzentriert und reduziert beispielsweise durch Qualifizierung im Hinblick auf vorfindliche Verwertungsbedingungen -, der reproduziert und legitimiert die realen Bedingungen der Notwendigkeit, Chancengleichheit zu fordern. Ein Mittel zur Realisierung individueller Chancen sind Qualifikationen also nur in der Hand dessen, der die Bedingungen der Qualifikationsverwertung bereitzustellen vermag. Er entscheidet auch darüber, ob der Träger einer Chance un- oder fehlqualifiziert und insofern real chancenlos „ist“, und zwar unabhängig davon, welche Kompetenz dieser ,im Übrigen“ besitzt.

Adressat der Forderung, seine Chance zu wahren, und in diesem Sinn Subjekt einer Chance ist aber nicht, wer über die externalen Bedingungen der Chancenrealisierung verfügt, sondern der, von dem diese Bedingungen am wenigsten abhängen, dem es nicht einmal möglich ist, die Entwicklung dieser Bedingungen längerfristig vorherzusehen. Auf diese Weise wird ein objektives Strukturproblem in ein subjektives Qualifizierungsproblem verwandelt, das aber als ein solches unlösbar ist.

In dem Maß, in dem es gesellschafts- und bildungspolitisch gelingt, wie auch immer begründete Behinderungen individueller Qualifizierung abzubauen und die so verstandene Chancengleichheit zu vergrößern, wird die Zahl derer, die um erstrebenswerte Güter oder Positionen konkurrieren, größer, ohne dass sich dadurch an der Anzahl dieser Güter oder Positionen etwas ändert. Für den Einzelnen wird die Chancenrealisierung rein quantitativ immer unwahrscheinlicher, allerdings in der Regel auch immer attraktiver. Hinzu kommt, dass der Zwang, seine Chance durch Qualifizierung zu wahren, sich in dem Maße vergrößert, in dem Behinderungen des Bildungszugangs und des Bildungserfolgs für möglichst viele oder gar alle Wettbewerber verringert werden.

Die Ungleichheit der Chancenrealisierung ist nicht nur mit der Gleichheit der Chancen vereinbar, die Ungleichheit der Chancenrealisierung ist auch Zweck der Forderung nach Gleichheit jener Chancen, die durch keine gesellschaftliche Praxis dementiert zu werden vermögen. Selbst dort, wo hunderte und mehr Bewerber unbehindert (also „,chancengleich“) um eine erstrebenswerte Position konkurrieren, bleibt das mit dem Chancenbegriff verbundene Versprechen gewahrt: Alle haben eine Chance und obendrein die Verantwortung, sich um die internalen Voraussetzungen der Realisierung dieser Chance zu kümmern. Chancengleichheit ist nicht geeignet, jene Ungleichheit unter den Menschen aufzuheben, der das Postulat allererst seine Bedeutung verlangt. Sie ist aber sehr wohl geeignet, diese Ungleichheit zu reorganisieren und dadurch zu ihrer Legitimation beizutragen.

\section{Literatur}

Heid, H. 1996: Förderung Benachteiligter in der Berufsausbildung. In: Seyd, W.; R. Witt (Hg.): Situation Handlung Persönlichkeit. Hamburg: Feldbaus, S. 45-56 
Herrlitz, Hans-Georg; Wulf Hopf, Hartmut Titze 1981: Deutsche Schulgeschichte von 1800 bis zur Gegenwart. Königstein: Athenäum

Kelsen, H. 1964: Die platonische Gerechtigkeit (1933). In: Derselbe. Aufsätze zur Ideologiekritik. Hg. v. Topitsch, E., Neuwied/Berlin: Luchterhand, S. 198-231

Loos, F.; H.-L. Schreiber, H. Welzel 1974: Gerechtigkeit. In: Historisches Wörterbuch der Philosophie. Hg. v. Ritter, J., Bd. 3. Darmstadt: Wissenschaftliche Buchgesellschaft, Sp. 329-338

Mattern,C.; G. Weißhuhn 1980: Einführung in die ökonomische Theorie von Bildung, Arbeit und Produktion. Frankfurt a. M.: Diesterweg/Aarau: Sauerländer

Rawls, J. 1988: Eine Theorie der Gerechtigkeit. Frankfurt a.M.: Suhrkamp

\section{WULF HOPF}

\section{Chancengleichheit und Individualisierung} Zur Revision eines bildungspolitischen Ziels

Die gegenwärtigen Reformansätze von Schule und Hochschule - die Deregulierung des staatlichen Bildungssystems, die Autonomisierung und Profilierung der Einzelinstitution, die Einführung von Globalhaushalten, die Verschärfung der Konkurrenz unter den Bildungsinstitutionen um Personen und Mittel, die Evaluation - sind sehr umstritten und nähren bei ihren Kritikern den Verdacht, neoliberale Prinzipien einer entfesselten Marktwirtschaft auf Kosten der Verantwortung von Schule und Hochschule für sozial und bildungsmäßig Schwächere zu forcieren. In diesem Konflikt zwischen „Modernisierern“ und „Traditionalisten“ wird auch das Ziel der Bildungschancengleichheit, das die Reformen der 60er und 70er Jahre wenn nicht beherrschte, so doch stark beeinflusste, auf dem Prüfstand stehen. Dieses Ziel, das in der öffentlichen Diskussion häufig genannt und auch abgeändert wurde (z.B. in der Forderung nach „Bildungsgerechtigkeit“), ist notorisch vage. Dadurch erscheinen unterschiedliche bildungspolitische Positionen unter einer gemeinsamen Leitformel integrierbar. Sieht man aber genauer hin, werden Konflikte und Widersprüche sichtbar. Genauer hinsehen muss man vor allem auf den Begriff von „Chancengleichheit" und auf die Methode, mit der ihr Vorhandensein oder Nicht-Vorhandensein empirisch bestimmt wird. Die folgenden Ausführungen beziehen sich auf die erste Frage der begrifflichen Bestimmung von „Chancengleichheit“. Dabei wird in einem ersten Schritt noch einmal derjenige Begriff rekonstruiert, der die Diskussionen um „Chancengleichheit“ in der Zeit der Bildungsreformen in den 60er Jahre bestimmte. In einem zweiten Schritt werden theoretische und begriffliche Erweiterungen diskutiert, die auf Probleme der Umsetzung der Bildungsreformen reagierten und ein aufgeklärteres Konzept von „Bildungschancengleichheit" $\mathrm{zu}$ versprechen scheinen. 


\section{Chancengleichheit in den 60er Jahren}

„Chancengleichheit“ als bildungspolitisches Ziel kann als Konkretisierung der „zuteilenden Gerechtigkeit“ begriffen werden. Deren Wertprinzipien regeln die Zuteilung knapper gesellschaftlicher Güter, die für die individuelle Lebenserfüllung wie für das Gemeinwohl begehrenswert erscheinen (Heckhausen 1981: 55). Dabei müssen drei Wertprinzipien miteinander abgewogen werden:

- das Bedürftigkeitsprinzip

- das Billigkeitsprinzip (bei Heckhausen: die Aufteilung von Erträgen und Verlusten nach Verdienst)

- das Gleichheitsprinzip.

Heckhausens Modell gilt zunächst für die Verteilung materieller Güter in einer Gruppe oder Gesellschaft. Betrachtet man eine lange und aufwendige, spezialisierte oder allgemeine Ausbildung als ein knappes Gut, dann sind seine Überlegungen jedoch auch auf das Bildungssystem übertragbar. Dabei spielt die Unterscheidung von Chancen in Wettbewerben und in Nicht-Wettbewerben eine wichtige Rolle. [...]

Das moderne öffentliche Bildungssystem integriert zwei Organisationsformen: den Markt und die staatliche Bürokratie. Aus beiden ergeben sich jeweils unterschiedliche Folgerungen für das Konzept von Bildungschancen. Über das Berechtigungssystem, das ungleiche Bildungsleistungen und ihre Zertifizierung (,Abschlüsse“) mit ungleichen Berufszugängen verkoppelt, ist das öffentliche Bildungssystem mit dem Arbeitsmarkt verbunden, und es kann jeder Bildungsprozess ,konkurrenzthematisch“ werden. Selbst wenn die Lehrerschaft oder die Schule dieses nicht oder nur abgeschwächt wünschen sollten, werden dies die Schüler und ihre Eltern so wahrnehmen und sich entsprechend verhalten (vgl. Arbeitsgruppe Schulforschung 1980; Hurrelmann 1983). Ein Leistungswettbewerb integriert im Idealfall Gleichheit und Ungleichheit ohne inneren Widerspruch. Vorausgesetzt, die TeilnehmerInnen haben zu Beginn des Wettbewerbs die gleichen Chancen im Sinne eines zukunftsoffenen Resultats und halten sich an die vereinbarten, niemanden einseitig bevorzugenden Regeln, dann entwickelt sich intern im Verlauf ein ungleiches Ergebnis, das die Grundlage für die Vergabe begehrter, knapper Anschlusschancen darstellt. [...]

Wenn man so das Modell eines Leistungswettbewerbs auf Bildungsprozesse überträgt (und damit das entsprechende Konzept von Chancengleichheit), dann handelt man sich zwei grundlegende Probleme ein: Erstens können Bildungsprozesse zeitlich, sachlich und sozial nicht so leicht wie Wettbewerbsspiele aus ihrem Umfeld herausgelöst werden, so dass ungleiche Ergebnisse nicht allein als Folge des internen Wettbewerbsprozesses verstanden werden können. Vielmehr wirkt die Ungleichheit der externen Bildungsressourcen dauernd in das Wettbewerbsgeschehen hinein. Zwei- 
tens stellt die Bildungslaufbahn eine Kette von Leistungswettbewerben und nicht bloß einen einzigen dar. Bildung ist ein „Aufbauphänomen“ (Titze 1999). Zusammen genommen führen beide Merkmale dazu, dass es mit der einmaligen Schaffung von Startchancengleichheit nicht getan ist, nach der sich „das Spiel entwickeln“ kann, sondern dass mehr oder weniger permanent zugleich mit dem Leistungswettbewerb seine personalen, extern bestimmten Voraussetzungen egalisiert werden müssten. Dies ist ein tiefer, unaufhebbarer Widerspruch einer an Wettbewerbs-Chancengleichheit während der Bildungslaufbahn orientierten Pädagogik und Bildungspolitik, der nur pragmatisch, nicht prinzipiell gelöst werden kann. [...]

Bildungsprozesse werden aber nicht nur deshalb staatlich organisiert, um Qualifikationen für den Arbeitsmarkt bereitzustellen und nach dem Leistungsprinzip zuzuordnen, sondern auch auf Grund anderer, allgemeiner Aufgaben oder Funktionen von Bildung, insbesondere der soziokulturellen und politischen „Integration“ der jüngeren Generation in die Gesellschaft (vgl. Herrlitz 1984). Für sie müssen Gerechtigkeitsprinzipien definiert werden, die nicht dem Billigkeitsprinzip folgen. Es sind dies - in Heckhausens Schema - die Prinzipien von „Bedürftigkeit" und von „Gleichheit“. Dabei ist entscheidend, dass diese Prinzipien außerhalb von Leistungswettbewerben definiert sind. Wenn der Staat eine gleiche Bildung für alle garantiert, dann tut er dies nicht, weil er gleiche Rahmenbedingungen für eine auf den Arbeitsmarkt und die ungleiche Berufsstruktur bezogene Konkurrenz sichern will, sondern er tut dies „aus Prinzip“ - weil alle Staatsbürger jenseits der Konkurrenz in den Genuss einer grundlegenden, gleichen Bildung gelangen sollen, die sie zur Rolle des Bürgers in einem sehr allgemeinen Sinne befähigt. Wenn besondere Anstrengungen für besonders bedürftige Kinder und Jugendliche unternommen werden, dann nicht, um Startunterschiede für einen Leistungswettbewerb zu kompensieren, sondern aus einem sozialen, der Gerechtigkeit verbundenen Prinzip heraus. Eine begriffliche und empirische Schwierigkeit beim Konzept der Chancengleichheit liegt also darin, dass der Staat sowohl die Rahmenbedingungen für marktvermittelte Leistungskonkurrenz zu sichern als auch - darüber hinaus - für die Geltung des nicht-marktförmig vermittelten Gleichheits- und Bedürftigkeitsprinzips zu sorgen hat. In der langfristigen historischen Entwicklung des Prinzips der Bildungs-Chancengleichheit (vgl. dazu auch Titze 1975) können zwei große Abschnitte unterschieden werden:

A) Zunächst heißt „Chancengleichheit“ Nicht-Diskriminierung. Alle sollen das gleiche Teilhaberecht an Bildung haben. Keine Gruppe soll allein aufgrund eines zugeschriebenen Status von Bildung ausgeschlossen sein. Das Prinzip der Nicht-Diskriminierung reguliert damit die Inklusion oder Exklusion von Teilnehmern an Bildungsprozessen. [...]

B) Erst wenn die Inklusion möglichst aller an Bildung politisch und rechtlich gesichert ist, kann nach faktisch gleichen Bildungsbedingungen gefragt werden. Erst dann werden faktische „Benachteiligungen“ und „Privilegierungen" sichtbar und politisch beeinflussbar. Das sind zunächst öko- 
nomische Ungleichheiten, die die Forderung einer gleichen und unentgeltlichen Bildung nach sich ziehen. Erst wenn sie realisiert ist, geraten unterschiedliche personale Voraussetzungen (Fähigkeiten und Orientierungen) ins Blickfeld [...].

Beeinträchtigungen der „Start-Chancengleichheit“ und der „ErgebnisGleichheit" können sich vor allem auf der Grundlage zugeschriebener Merkmale ergeben, d.h. die mit der Geburt in eine bestimmte Familie, Geschlechterrolle, Region, Schicht, Ethnie und Religion verbunden sind und nicht durch Eigenleistung oder eigene freie Entscheidung „erworben“ wurden. [...] Alle Konzepte, die diesen Tatbestand leugnen, brauchen keine Politik der Chancengleichheit mehr, weil nach ihrer Auffassung das Individuum selbst dafür sorgt, dass askriptive Merkmale in ihrer Wirkung oder Bedeutung zurücktreten. Wenn z.B. Preuss-Lausitz (1997) meint, dass bereits Kinder (erst recht: Jugendliche) ihre Geschlechtsidentität aus unterschiedlichen Vorlagen aktiv ,zusammenbasteln“ (patchwork identity), dann braucht man keine Politik mehr, die Chancengleichheit der Geschlechter herzustellen sich bemüht. Die Geschlechtsidentität hört bei dieser Vorstellung von „patchwork identity“ auf, zugeschriebenes Schicksal zu sein, vielmehr entscheidet das Individuum selbst, welche Geschlechtsidentität es ,hat". [...]

\section{Gerechtigkeit, Allgemeinbildung und Chancengleichheit}

[...] Den Bildungsreformen der „sozial-liberalen Ära“ wurde unterstellt, einem verengten Konzept von Schule als Vorbereitungs- und Zuteilungsinstanz für Berufe gefolgt zu sein und damit lediglich einen „missratenen Fortschritt" (Flitner 1977) hervorgebracht zu haben. Mit dieser Kritik war der Versuch verbunden, einen Begriff von Gerechtigkeit im Bildungssystem zu entwickeln, der die unerwünschte Kehrseite der Leistungskonkurrenz - vor allem ein eindimensionaler, öder Leistungsbegriff; fehlende Erfahrungen mit Kooperation und Solidarität; schematische Behandlung von Unterschieden unter den Schülern und Schülerinnen - auszuschalten oder zu vermindern trachtete. Im Rahmen der drei Prinzipien, die nach Heckhausen zu balancieren sind, lag der Akzent bei diesen Versuchen auf dem Prinzip der Gleichheit und der Bedürftigkeit, weniger beim Billigkeits- oder Leistungsprinzip. Im Folgenden sollen zwei Exponenten dieser Kritik Flitner und Schlömerkemper - unter der Frage diskutiert werden, zu welchen Lösungsvorschlägen sie kommen. [...]

Flitner fragt sich, ob die Reformen der 60er und 70er Jahre das Bildungssystem gerechter gemacht bzw. dem „Bürgerrecht auf Bildung“ mehr Geltung verschafft haben. Er meint, dass die Schulreform vor allem eine von zwei regulativen Ideen von Gerechtigkeit, nämlich die „egalisierende“ zu Ungunsten der „unterscheidenden“, gefördert habe. Das Prinzip der egalisierenden Gerechtigkeit lautet: „Allen das Gleiche“. Diese Forderung wird für Flitner aber erst sinnvoll, wenn sie mit dem Prinzip der unter- 
scheidenden Gerechtigkeit „verbunden und abgewogen“ wird. „Jedem muss das Seine werden, auch in der Erziehung. Erst die unterscheidende Gerechtigkeit gibt allen im höheren Sinne das Gleiche, nämlich etwas gleich Wichtiges, Hilfreiches" (1985, S. 2). Es ist Flitners Verdienst, das Zusammenspiel der beiden Prinzipien auf unterschiedlichen Ebenen zu erörtern: Auf der Ebene der Rechte der einzelnen Schüler, der Klasse und Schule als Institution sowie auf der Ebene des Gesamtsystems. Dabei ergeben sich charakteristische Gewichtungen der beiden Prinzipien, die im Schulalltag in einem Spannungsverhältnis zueinander stehen. Den Rechten der einzelnen Schüler wird am ehesten durch die unterscheidende Gerechtigkeit entsprochen. Auf der Ebene der Schule als Institution dagegen obwaltet die gleichsetzende Gerechtigkeit - der Lehrer soll alle Schüler ohne Ansehen der Person fördern, er soll gerecht zensieren usw. Allerdings steht diese gleichsetzende Gerechtigkeit auch auf der institutionellen Ebene in Spannung zur unterscheidenden Gerechtigkeit. Auf der Ebene des Schulsystems insgesamt und der Schulpolitik herrschte nach Flitners Ansicht ebenfalls die gleichsetzende Gerechtigkeit vor. Er schließt dies daraus, dass die Bildungsreformen der 60er und 70er Jahre auf Chancenprobleme von Arbeiterkindern, Mädchen, Landkindern, Kindern katholischen Glaubens fixiert waren und solche Differenzen vernachlässigten, die sich erst in der Perspektive der unterscheidenden Gerechtigkeit eröffnen, also z.B. die Probleme von Hochbegabten, Ausländerkindern, sozial schwierigen und gefährdeten Kindern (1985: 7) [...]. Flitner fragt sich, ob der Begriff der gleichsetzenden Gerechtigkeit überhaupt noch brauchbar sei. Er favorisiert andere Bedeutungen von Chancengleichheit: die allgemeine und vielseitige Förderung für alle Kinder, das Erreichen eines gewissen Basis- oder Sockelniveaus an grundlegender Bildung, das von allen Kindern erreicht werden kann, sowie die Eröffnung von Chancen für das „Leben und Gedeihen innerhalb der Schule“ (ebd., 15). Am liebsten würde Flitner die so verstandene "Gerechtigkeit in der Schule“ an die Stelle des Ziels der Chancengleichheit setzen. Aber am Ende überlebt die egalisierende Gerechtigkeit auf der Ebene der Schuladministration, während die unterscheidende Gerechtigkeit mehr von den Lehrern und der einzelnen Schule wahrzunehmen ist (ebd., 20).

Flitners Versuch, egalisierende und unterscheidende Gerechtigkeit zu differenzieren und an unterschiedliche Ebenen des pädagogischen, schulorganisatorischen und bildungspolitischen Handeins zu koppeln, vermag nicht zu überzeugen. Er dient eher der Konfliktvermeidung und der Erhaltung eines guten pädagogischen Gewissens als dass er zur Klärung der Chancengleichheitsproblematik beitrüge. Indem man ,jedem das Seine gibt", gibt man angeblich allen etwas Gleiches, nämlich gleich Wichtiges und Hilfreiches (vgl. das Zitat weiter oben). Man könnte dies als „Verinnerlichung äußerer Ansprüche“ bezeichnen: Man gibt jedem „das Seine“ und dies kann sehr unterschiedlich sein -, aber das Gleiche und Gemeinsame ist die innere Bedeutsamkeit. $\mathrm{Zu}$ einer Spannung zwischen unter- 
scheidender und egalisierender Gerechtigkeit kann es auf dieser Ebene nicht kommen. Die unterscheidende Gerechtigkeit ist per se schon egalisierend. Mit einer solchen Subjektivierung und Verinnerlichung von Ansprüchen, die auf äußerliche Gleichbehandlung oder Gleichstellung pochen könnten, sind schon immer sogenannte überzogene Forderungen abgewehrt worden. [...] Der entscheidende Konflikt bei Flitners Vorstellung von Chancengleichheit liegt nicht - wie es die Gegenüberstellung von gleichsetzender und unterscheidender Gerechtigkeit fälschlich suggeriert - zwischen dem Gleichheits- und dem Bedürftigkeitsprinzip, sondern er liegt zwischen diesen beiden auf der einen Seite und dem Billigkeits- oder Leistungsprinzip auf der andern Seite. Dieses wird aus der Vorstellung von „Gerechtigkeit in der Schule“ weitgehend verbannt. Flitner betrachtet es insbesondere in der Form der vermeintlich objektiven Leistungsmessung als überaus schädlich. Indem er das Leistungsprinzip und die mit ihm verbundene Bildungskonkurrenz vom pädagogischen Alltag fern zu halten versucht, lässt er einen zentralen Konflikt im Chancengleichheitsprinzip gar nicht erst zu: den Konflikt zwischen nicht-konkurrentiell bestimmter Gleichheit und Bedürftigkeit einerseits und der Schaffung von gleichen Chancen für einen Leistungswettbewerb andererseits. Flitner gelangt demgegenüber zu der etwas weltfremden Vorstellung, dass das Leistungsprinzip „allenfalls“ den Abschluss der Schullaufbahn bestimmen dürfte und dass zum Übergang in das Berufsleben die Fähigkeit gehöre, fremdbestimmte oder objektive Leistungsmaßstäbe anzuerkennen und sie an die eigenen Leistungen anlegen zu lassen (ebd., 7). [...]

Indem Flitner Front gegen die - in seinen Augen: perversen - Folgen einer allein an Objektivität, Vergleichbarkeit, gleichsetzender Gerechtigkeit orientierten Schule macht, redet er letztlich einer Herauslösung der Schule aus umfassenderen Bezügen gesellschaftlicher Ungleichheit und der gegen sie gerichteten Sozialpolitik im weitesten Sinn - auch auf dem Feld der Schule - das Wort. Sein nach innen gerichteter pädagogischer Begriff von „Gerechtigkeit in der Schule“ mag zwar den alltäglichen Handlungsproblemen und Sichtweisen von Lehrenden und Schülern gut zu entsprechen, aber er besitzt keine diagnostische Kraft und keinen gesellschaftspolitischen Bezug mehr.

Schlömerkempers Diskussion von „Chancengleichheit“ setzt grundsätzlicher an als Flitners Lösungsversuch. Er teilt mit Flitner die Auffassung, dass das Recht auf Bildung mehr bedeute, als ,gleichberechtigt um ,Bildungsabschlüsse“ rivalisieren zu dürfen“ (1986: 409). Dieses „Mehr“ gewinnt er aus einer Neubestimmung des Inhalts von Allgemeinbildung. Er geht auf W. von Humboldts Erörterung von „Idealität" und „Gleichheit“ der Bildung zurück und stellt fest, dass die darin angelegte Spannung bei Humboldt einseitig zugunsten der Idealität verkürzt worden sei. Demgegenüber will Schlömerkemper das egalitäre Moment stärken; er möchte es ,so definieren, dass es auch dann eingelöst werden kann, wenn das Ideal (noch) nicht erreicht ist" (ebd.). 
Dazu gehört, dass es nicht genügt, den Heranwachsenden das Recht auf gleiche Bildungschancen einzuräumen, ,sondern dass alle Kinder unabhängig von ihrer jeweiligen Nähe oder Distanz zum Ideal entfalteter ,Bildung“ einen Anspruch darauf haben, dass das, was Erwachsene mit ihnen tun (ihnen ,zumuten'), für die Entfaltung ihrer Persönlichkeit [...] bedeutsam ist oder zumindest bedeutsam sein kann - und zwar nicht bedeutsam in Hinblick auf einen irgendwann möglicherweise erreichbaren Zustand, sondern in der jetzigen Lebenssituation, für die bisherigen Erfahrungen und die überschaubare Zukunft.“ (ebd., 409f.)

Indem Schlömerkemper die Bedeutsamkeit des Gelernten für die aktuelle Lebenssituation der Kinder betont, verschärft er das Problem der Vermittlung von Egalität und Idealität der Bildung. Nicht bloß ein Recht auf gleiche Bildung soll garantiert sein, nicht nur sollen in fernerer Zukunft jetzige Kompetenzunterschiede im Sinne einer Ergebnis-Gleichheit angenähert werden, sondern der egalitäre Anspruch soll in kürzerfristiger Perspektive, für die überschaubare Zukunft der Kinder realisiert werden. Was kann das für ein Begriff von „Bildung“ sein, der zwar die faktisch gegebenen Kompetenzunterschiede voraussetzt, zugleich aber von allen Menschen gleichermaßen erreicht werden kann? Die Antwort hierauf sieht Schlömerkemper in der Art und Weise, wie die Menschen mit einer jeweils verfügbaren, durchaus verschiedenen Kompetenz umgehen. Es geht damit um etwas, was Schlömerkemper eine „Haltung“ nennt. Darunter versteht er eine bestimmte Art des Umgangs mit den vielfältigen Lebensaufgaben, mit Natur und Kultur. [...] Insbesondere ist für Schlömerkemper eine auf Egalität gerichtete ,gebildete Haltung“ die Fähigkeit, mit unterschiedlicher kultureller Kompetenz umzugehen. „Gebildet wäre demnach eine Person, die in der ihr verfügbaren Kompetenz eine soziale Verpflichtung und eine besondere Verantwortlichkeit sieht, ohne daraus den Anspruch auf Privilegierungen abzuleiten.“ (ebd., 412) [...]

Daraus ergeben sich auch bildungspolitische Folgen:

„Diese Entkoppelung von Bildung und Kompetenz macht es in neuer Weise möglich, mit bildungstheoretischen Zielen für das Moment der Integration zu argumentieren: Integration wäre nicht nur wichtig, weil alle Kinder die gleiche Chance haben müssen, sich einem für alle verbindlichen Leistungs- und „Bildungs“-maßstab anzunähern, sondern weil Bildung in dem egalitären Sinn die Fähigkeit beinhaltet, mit der Unterschiedlichkeit von Kompetenzen konstruktiv und sozial umzugehen. Das Argument der ,sozialen Integration', wie es der Deutsche Bildungsrat formuliert hatte und wie es zum ,sozialen Lernen' weiterentwickelt worden ist, hätte einen zentralen Platz im Konzept der Bildung selbst.“ (ebd., 413)

[Dann aber stellt sich] die Frage, inwiefern der Konflikt von Egalität und Idealität lösbar erscheint und damit das Konzept von Bildungschancengleichheit neu positioniert wird. Die Antwort fällt differenziert aus: Bildungstheoretisch - und dies ist Schlömerkempers maßgeblicher Bezugspunkt - halte ich die Position für begründet; in Bezug auf das Problem der 
Ermöglichung gleicher Lernchancen dagegen nicht. [...] Das Problem der Spannung bzw. des Widerspruchs zwischen Egalität und Idealität, von dem Schlömerkemper ausging, ist mit der Einführung einer primär sozialen Kompetenz (konstruktiver und verantwortlicher Umgang mit Fähigkeitsunterschieden) nicht gelöst. Diese „Kompetenz-Kompetenz" ist nur eine weitere, zusätzliche Qualifikation. [...] Im Zweifelsfall werden der (Humboldtsche) Tagelöhner und der Gebildete sich eben auch noch in der Sozialkompetenz unterscheiden. Und wenn man dem ,egalitären Moment“ wirklich ein größeres Gewicht einräumen will, dann muss man die Konsequenz ziehen, für alle gleiche soziale Fähigkeiten des konstruktiven und verantwortlichen Umgangs mit Kompetenzunterschieden zu fordern. Darin liegt zweifellos ein Moment der „Nivellierung“, um das man nicht herumkommt. Damit ist man wieder auf den Begriff von „Ergebnisgleichheit“ bzw. von Fähigkeiten verwiesen, die alle Mitglieder einer Gruppe, Gesellschaft usw. gleichermaßen entwickelt haben sollen.

\section{Bilanz}

Das heuristische Schema Heckhausens diente uns dazu, unterschiedliche, zum Teil widersprüchliche Dimensionen im Konzept von Chancengleichheit herauszuarbeiten. Damit gewannen wir einen Rahmen, um Weiterentwicklungen und Revisionen des Begriffs seit der Zeit der Bildungsreformen von 1965 bis 1975 beurteilen zu können. Unseres Erachtens können all diese Versuche, auch wenn sie zu individuelleren Vorstellungen von Gerechtigkeit führen und herkömmliche sozial zugeschriebene Merkmale durch andere, ebenfalls zugeschriebene ersetzen, an der Logik des ursprünglichen Begriffs nichts ändern. Diese schärft sogar den Blick für Gerechtigkeitsprobleme, die einzelne Revisionen verdunkeln. Das gilt insbesondere für die Notwendigkeit, das Billigkeits- oder Leistungsprinzip als Bestandteil des Chancengleichheits-Postulats zu erhalten.

Solange es ungleiche, mit unterschiedlichen Privilegien und Belastungen verbundene Berufe gibt und solange anspruchsvollere Ausbildungsgänge in Schule und Hochschule knapp sind, solange wird das Leistungsprinzip die Zugänge zu knappen Positionen regulieren müssen und damit seine - pädagogisch zum Teil unerwünschten - Nebenfolgen zeitigen. In einer Phase zunehmender privater Finanzierung höherer Bildung wird man sich des emanzipatorischen Gehaltes des Leistungsprinzips vielleicht wieder stärker bewusst. Wenn das Leistungsprinzip unter den genannten Bedingungen (trotz aller Verkehrungen und negativen Folgen) alternativlos ist, dann gibt es wettbewerbliche und nicht-wettbewerbliche Komponenten von Gleichheit und Gerechtigkeit im Bildungssystem, die sich zudem widersprechen werden.

Ein zentraler Konflikt liegt dabei in der wettbewerbsorientierten Herstellung einer Start-Chancengleichheit und einer nicht-wettbewerblichen Gleichheit von Bildungsergebnissen als Folge eines Bürgerrechts auf Bil- 
dung. Beide Erscheinungsformen von Bildungschancen - Wettbewerbschancen und Teilhabechancen - unterliegen sich historisch wandelnden sozialen Einschränkungen (,Zuschreibungen“). Diese können sich im Zuge von historischen Individualisierungsprozessen differenzieren oder auch abschwächen; zudem ist ihr Einfluss zu Beginn der Bildungsbiographie stärker als am Ende. Aber sie bleiben Kristallisationspunkte für politische Forderungen nach Gleichheit der Wettbewerbsbedingungen und nach Gleichheit der Bildungsteilhabe.

\section{Literatur}

Arbeitsgruppe Schulforschung 1980: Leistung und Versagen. Alltagstheorien von Schülern und Lehrern. München: Juventa.

Flitner, Andreas 1977: Mißratener Fortschritt. Pädagogische Anmerkungen zur Bildungspolitik. München: Piper.

Flitner, Andreas 1985: Gerechtigkeit als Problem der Schule und als Thema der Bildungsreform. In: Zeitschrift für Pädagogik. 31, I, S. 1-26.

Heckhausen, Heinz 1981: Chancengleichheit. In: Schiefele, H. und Andreas Krapp (Hg.): Handlexikon zur Pädagogischen Psychologie. München: Ehrenwirth, S. 5461.

Herrlitz, Hans-Georg 1984: Art. Schule - Schultheorie. In: Wulf, Christoph (Hg.): Wörterbuch der Erziehung. Neuausgabe, 6. Aufl. München: Piper, S. 506-509 (zuerst 1974).

Hurrelmann, Klaus 1983: Kinder der Bildungsexpansion. Die Interpretation der eigenen Bildungs- und Berufschancen durch Angehörige der Jahrgänge 1962-1964. In: Zeitschrift für Sozialisationsforschung und Erziehungssoziologie. 3, S. 263-283.

Preuss-Lausitz, Ulf 1997: Geschlechtersozialisation und Schulpädagogik in der Nachmoderne. In: Die Deutsche Schule. 89, 4, S. 429-445.

Schlömerkemper, Jörg 1986: Bildung für alle. Über das Verhältnis von Egalität und Bildung. In: Die Deutsche Schule. 78, S. 405-416.

Titze, Hartmut 1975: Erziehung, Selektion und Berechtigung. In: Die Deutsche Schule 67, 6, S. 378-392.

Titze, Hartmut 1999: Wie wächst das Bildungssystem? In: Zeitschrift für Pädagogik. 45, 1, S. 103-120.

\section{ANNEMARIE VON DER GROEBEN Wo liegen die Wurzeln von Schulqualität? Eine Antwort auf Hermann Lange}

„Es ist immer gut, die Realitäten so in den Blick zu nehmen, wie sie wirklich sind.“ So beginnt ein Beitrag von Hermann Lange über „Qualitätssicherung in Schulen“. Er plädiert dafür, ,die empirische Wendung der pädagogischen Wissenschaften ... endlich zu vollziehen“ (1999: 144). ${ }^{40}[\ldots]$

40 [In: Die Deutsche Schule, 2/1999. In diesem Band auszugsweise abgedruckt im Textblock „TIMSS- und PISA-Schock“.] 
Mit meiner Antwort möchte ich zeigen, dass man aus der gleichen Intention heraus, eben die Realitäten in den Blick zu nehmen, wie sie wirklich sind, auch zu ganz anderen Einschätzungen der gegenwärtigen Qualitätsdebatte und Bildungspolitik kommen kann. [...] In vielen Punkten gibt es keinen Dissens. Die Rechenschaftspflicht von Schulen scheint mir ebenso selbstverständlich zu sein wie die Tatsache, dass der Staat als „Investor“ nach den Erträgen dieser seiner Investition fragt und sich dazu empirischer Methoden bedient. Die Unterschiede liegen darin, was unter „Erträgen“ verstanden werden soll, allgemeiner, welches Verständnis von Qualität welche Maßnahmen der Qualitätssicherung nach sich zieht, mit welchem Erkenntnisinteresse und welchen Methoden folglich welche Fragen empirisch zu klären sind. [...] Meine Position sei kurz vorab skizziert: Qualität entsteht (oder entsteht nicht) in der einzelnen Schule und der einzelnen Unterrichtsstunde. Quantitative Vergleichsuntersuchungen sind nicht geeignet, diese zu ermitteln. [...]

\section{Wo liegen die Wurzeln von Unterrichtsqualität?}

[...] [Das wichtigste Kriterium], nach dem sich Unterricht bewerten lässt, ergibt sich [aus der] Frage, ob und wie er auf die Unterschiedlichkeit der Kinder eingeht. Guter Unterricht wäre demnach daran zu erkennen, dass er deren je individuellen Stand prinzipiell positiv bewertet und alle Hilfen bereitstellt für ihre weitere Entwicklung. Demnach geht es gerade nicht darum, alle ,auf einen Stand zu bringen“, sondern umgekehrt darum, die unterschiedlichen „Stände“ als gegeben und normal anzusehen und daraus weiterführende Lernwege abzuleiten.

Das „,neue Steuerungsmodell“, für das Lange in seinem Beitrag plädiert, geht jedoch von einem ganz anderen Ansatz aus. Es versteht unter Qualitätssicherung vor allem ,die Suche nach Mißerfolgen und nach Schwächen, die es zu beseitigen gilt"“ (ebd., 147). Es geht von Standards aus, die zu erfüllen sind. Ein niedriges Ergebnis wird prinzipiell als Defizit interpretiert, das es zu beheben gilt.

Ein niedriges Ergebnis kann aber ganz unterschiedliche Ursachen haben. Es kann darauf zurückzuführen sein, dass der Fachunterricht im Sinne der oben genannten Kriterien schlecht ist, also nicht genügend individualisiert und differenziert. Es kann natürlich auch schlicht an mangelnder Kompetenz oder mangelndem Einsatz der Lehrkräfte liegen. Oder daran, dass diese sich zwar alle Mühe geben, aber gegen ungünstige Bedingungen wie beispielsweise Disziplinprobleme nicht ankommen. Oder schließlich daran, dass die je individuellen Lernstände auf Grund außerschulischer Faktoren - welcher auch immer - in ihrer Gesamtheit hinter der erwarteten Norm zurückbleiben. Die Ursachen können, mit einem Wort, auf ganz unterschiedlichen Ebenen liegen, die in der Praxis nicht säuberlich getrennt auftauchen, sondern oft eine schwierige Gemengelage ergeben [...]. Und alle diese Aspekte sind in sich wiederum äußerst komplex und von ver- 
schiedenen Faktoren bedingt. Um herauszufinden, ,wie die Realitäten wirklich sind“, muss man also sehr genau hinsehen. Dafür aber sind quantitative Vergleichsuntersuchungen nicht das geeignete Instrument, weil sie die Komplexität des Gesamtgefüges „Unterricht“ nicht erfassen, nicht an die Wurzeln reichen können. Um zu ihnen vorzudringen, bedarf es weiterführender qualitativer Studien.

\section{Zur Qualität sozialer Prozesse}

[...] Aus empirischen Befunden ergibt sich folgendes Bild: Die real existierende Unterschiedlichkeit unserer Schülerinnen und Schüler scheint nicht nur zuzunehmen, sondern hat äußerst komplexe Ursachen: das soziale Umfeld und die individuellen genetischen Anlagen und unterschiedlich verlaufende neuronale Prozesse und die unterschiedliche Verweildauer auf den Entwicklungsstufen und die Ausbildung je eigener Lernmuster und deren subjektive Bedingtheit, die sich keineswegs allein aus dem sozialen Umfeld ergibt.

Die Einflussmöglichkeiten der Schule scheinen von daher geringer zu sein als wir uns das wünschen mögen. Als zwingende Konsequenz ergibt sich für ihre Arbeit, dass sie diese umso besser nutzen kann, je bewusster und je didaktisch reflektierter sie die Gestaltung sozialer Lernprozesse in den Blick nimmt, und das in allen Fächern. [...]

Lange weist auf die Wichtigkeit sozialen Lernens ausdrücklich hin und betont, es sei „unsinnig, fachliche gegen soziale Ziele aufzurechnen“ (ebd., 151). Das ist ganz im Sinne der genannten didaktischen Prinzipien: Soziale Ziele sind fachliche Ziele. Aber als Argument gegen die Kritiker von quantitativen Vergleichstests überzeugt es mich nicht. Gerade diese Dimension des Unterrichts ist durch quantitative Vergleichsuntersuchungen nicht $\mathrm{zu}$ erheben, aus dem bereits genannten Grund: Sie können das Gelingen oder Nicht-Gelingen von sozialen Lernprozessen nicht auf der Ebene erfassen, wo sie ablaufen. [...]

Gerade angesichts dieser Übereinstimmung in einer so grundsätzlichen Frage habe ich Mühe, Langes Argumentation nicht als widersprüchlich zu seinen eigenen Überzeugungen zu verstehen. [...] Ausgehend von der Prämisse ,zu messen ist, was wichtig ist" kommt er zu der Einschätzung, die Behauptung mangelnder Messbarkeit sei „... oft nichts anderes als ein Beleg für unklare Zielsetzung“ (ebd., 150). Da nicht alles zugleich messbar sei, müsse man sich entscheiden, welchem „Ausschnitt des Zielbündels“ (ebd., 151) man sich zunächst zuwenden wolle.

Wie will man denn aber ,messen“, was Religions- oder Literaturunterricht in den Köpfen und Seelen bewirkt? [...] In Bildungsbiographien und Interviews, in Gruppengesprächen und natürlich auch auf Grund schriftlicher Äußerungen ließe sich sehr wohl empirisch belegen und interpretieren, ob Unterricht in diesem Sinne „bildend“ ist oder nicht. Aber ganz gewiss 
nicht mit quantitativen Vergleichsuntersuchungen. Bildungserlebnisse (ich stehe zu diesem Wort!) sind nicht messbar. [...]

\section{Mündigkeit und Verantwortung - zur Qualität überfachlicher Lernprozesse}

[...] Lese- und Schreibfertigkeiten, Textverständnis und -produktion lassen sich operationalisieren. Aber wie sollte das gehen für allgemeinere Fähigkeiten? Den eigenen Standpunkt vertreten und den anderer achten; sich in andere eindenken und einfühlen; Kritik ertragen können und andere so kritisieren, dass dies als Hilfe erfahren werden kann; den Mut haben, eigene Gefühle zu äußern, und den Takt, die anderer zu achten; neugierig sein auf Fremdes, am Fremden das Eigene verstehen; Freude am Sprachspiel haben, Freude an Gedichten und Geschichten, am eigenen Experimentieren und Phantasieren; der eigenen Überzeugung treu bleiben und für sie einstehen, sich nicht beirren lassen von Mehrheitsmeinungen, den Mut haben, widerständig zu reden und dies, wenn nötig, öffentlich, Täuschung und Verführung erkennen und ihr widerstehen; redlich mit sich selbst und der Sprache umgehen, andere beharrlich zu überzeugen versuchen oder sich selbst überzeugen lassen; sich der eigenen Grenzen bewusst sein, Fehler eingestehen können - dies alles und noch mehr will Deutschunterricht bewirken, das ist sein allgemeiner Bildungsanspruch. [...] Messbar und quantitativ evaluierbar ist er gewiss nicht. Soll er darum nicht gelten? Oder, noch schlimmer: Soll er als allgemein-appellativer Anspruch allenfalls in Richtlinien stehen, während das, was zu tun ist, um ihn zu erfüllen, nicht ,zählt" bei der Beurteilung von Qualität? [...]

\section{Ethos und „output" - zur Rückwirkung der Methode auf ihren Gegenstand}

[...] Befürworter des eingeschlagenen Weges zur „Qualitätssicherung“ würden auf die hier vorgetragenen Argumente vermutlich antworten, ein Deutschunterricht, der nach den genannten Kriterien ,gut“ ist, werde durch Vergleichsstudien keineswegs bedroht, sondern im Gegenteil bestärkt. Sie verweisen auf die PISA-Studie, die gerade nicht auf angepasstes, abfragbares Wissen angelegt sei, sondern auf flexibles, eigenständiges Denken. [...] Zum gegenwärtigen Zeitpunkt [...] ließe sich ein interessantes Experiment durchführen, das wenig kostet und die genannte Frage pragmatisch klären könnte: Man bilde eine Experten-Kommission, bestehend aus Vertreterinnen und Vertretern der Fachdidaktik sowie der verschiedenen Schularten, und lasse sie Empfehlungen zum wirksamen Lernen von Sprach- und Lesefähigkeiten erarbeiten. Diese können dann später mit den PISAErgebnissen verglichen werden. Ich wage eine Vermutung: Gute Ideen gibt es zur Genüge, sie sind weltweit verbreitet, so dass Schulen voneinander lernen können. Es kommt darauf an, dass sie das auch tun. Und um das zu befördern, muss man „unten“ ansetzen, auf der Ebene der einzelnen Schu- 
len. Wie auf der Ebene des Fachunterrichts scheint auch hier Individualisierung und Vielfalt der bessere Weg zu sein als „,verordneter Gleichschritt“.

Die gegenwärtig in der Öffentlichkeit geführte Bildungs-Debatte gibt jedoch wenig Anlass zu der Hoffnung, die Entwicklung könne in diese Richtung gehen. Vielmehr scheint es so zu sein, dass wir uns in einem Prozess der „Umwertung aller Werte“ befinden, in dessen Verlauf sich nicht nur das Verständnis von Leistung verändert, sondern auch ein genereller Paradigmenwechsel stattfindet in der Frage, was guten Unterricht, was eine gute Schule ausmache. [...]

Wolfgang Klafki hat kürzlich noch einmal die Grundgedanken seines pädagogischen Leistungsbegriffs referiert, um daran seine Besorgnis über diesen Paradigmenwechsel zum Ausdruck zu bringen:

„Es (kommt) darauf an, das vorwiegend individualistisch-wettbewerbsorientierte Leistungsverständnis in unseren Schulen durch einen Leistungsbegriff zu ersetzen, der an der Lösung gemeinsamer Aufgaben und am Prinzip der Solidarität einer lernenden Gruppe orientiert ist. ... Eine Schule, die sich konsequent an solchen Kriterien orientiert, würde an ihre Schüler höhere Anforderungen stellen als die bisherige Schule. Sie wäre allerdings zugleich eine Schule, die sich kritisch auf gegenläufige Trends bezöge, die seit einigen Jahren wieder von einflussreichen gesellschaftlichen Gruppen und leider auch weiten Teilen der offiziellen Politik nachdrücklich propagiert werden." (Klafki 1999: 58)

[...]

Und die Lehrerinnen und Lehrer? Wenn sie wissen, dass die Qualität beispielsweise ihres Deutschunterrichts allein danach bemessen wird, wieviel Wissen in welcher Zeit in welche Köpfe gelangt, werden sie ihren Unterricht - auch wider besseres Wissen und entgegen der eigenen Überzeugung - nach diesen Kriterien planen müssen. Nicht nur die Schulaufsicht und die bevorstehende Vergleichsarbeit fordern das von ihnen ein, sondern auch und in erster Linie die Eltern und die Schülerinnen und Schüler selbst. Sie wollen wissen, was ,zählt“. Und da dies die messbaren Leistungen sind, muss der Unterricht darauf ausgerichtet sein, diesen seinen „output“ zu „maximieren“. Und dabei drohen alle oben genannten Qualitätsmerkmale auf der Strecke zu bleiben: die der individuellen, sozialen und überfachlichen Lernprozesse, vor allem aber die Bildung. Wenn alle die beschriebenen Tätigkeiten nicht ,zählen“, wird es sie nicht mehr geben. [...]

Vermutlich ist dieses generelle Umdenken mit all seinen Folgen so von niemandem gewollt, weder von den Forschern noch von den Bildungspolitikern. Geforscht wird „am lebenden Objekt“. Die Methode wirkt zurück auf ihren „Gegenstand“", sie verändert das Denken über Schule, Unterricht und Bildung. Letztere, angeblich das „Mega-Thema“ des neuen Jahrhunderts, wird umdefiniert zum Wissenserwerb. Das Problem entsteht also auf der Ebene der Interpretation und Bewertung und der Konsequenzen, die daraus zu ziehen sind. [...] 
Um Qualitätsmerkmale wie die [von mir] genannten zu evaluieren, bedarf es andere Instrumente: solcher, die die Prozesse in den Blick nehmen, die individuellen Lernwege, das Unterrichtsklima, die je unterschiedlichen Formen subjektiver Aneignung, und die Produkte im Kontext ihrer Entstehung interpretieren. Was für die Bewertung von Schülerleistungen längst bekannt ist, gilt erst recht für ein so komplexes Gebilde wie Unterricht: Beide sind ist mit quantitativen Messlatten (wie Noten von 1-6) nicht angemessen zu bestimmen. Das Instrument passt nicht zu seinem Gegenstand.

\section{Was ist eine gute Schule?}

\section{Antinomien der gegenwärtigen Qualitätsdikussion}

[...] Die Widersprüchlichkeit der gegenwärtigen Bildungsdiskussion versuche ich durch die nachstehende Liste von Antinomien auf den Punkt zu bringen, die zwei gedachten ,gegnerischen Lagern“ zugeordnet werden. [...] Sie sollen den Prioritätenwechsel im Streit um Schulqualität illustrieren. $[\ldots]$

\begin{tabular}{|c|c|}
\hline Position A & Position B \\
\hline Der Sinn von Schule ist Wissensmaximierung. & $\begin{array}{l}\text { Der Sinn von Schule ist Erziehung und Bil- } \\
\text { dung. }\end{array}$ \\
\hline $\begin{array}{l}\text { Die Schule muss sich auf ihr Kerngeschäft, } \\
\text { den Unterricht, konzentrieren. Mit weiterge- } \\
\text { henden Aufgaben hat sie sich nicht zu be- } \\
\text { lasten. Werte- und Demokratieerziehung sind } \\
\text { im Unterricht der dafür zuständigen Fächer } \\
\text { zu verankern. Das Konzept einer Schule als } \\
\text { Lebensraum ist eine Überforderung. }\end{array}$ & $\begin{array}{l}\text { Die Schule muss sich an den Leitwerten unse- } \\
\text { rer Gesellschaft orientieren. Die Erfahrung } \\
\text { von einem guten Leben nach diesem Maßstab } \\
\text { muss in der Schule gemacht werden können, } \\
\text { weil viele Kinder sie sonst nicht machen kön- } \\
\text { nen. Werte und demokratisches Verhalten } \\
\text { müssen gelebt werden. Leben und Lernen } \\
\text { gehören zusammen. }\end{array}$ \\
\hline $\begin{array}{l}\text { Wir leben in einer Leistungsgesellschaft. Das } \\
\text { Wettbewerbs- und Konkurrenzprinzip muss in } \\
\text { jedem Unterricht gelten. Leistung muss nach } \\
\text { objektiven Normen bewerten werden. }\end{array}$ & $\begin{array}{l}\text { Leistung ist ein Prozess. In den Entwicklungs- } \\
\text { jahren muss er individuell gefördert werden. } \\
\text { Dies ist zugleich der beste Weg zu objektiv } \\
\text { guten Leistungen. }\end{array}$ \\
\hline $\begin{array}{l}\text { Schulen sind Teil im weltweiten Wissenswett- } \\
\text { bewerb. Mit zunehmender Globalisierung } \\
\text { müssen alle Schulen sich ihm stellen. Lernen } \\
\text { gleicht einer ständigen Olympiade, bei der es } \\
\text { um Bestleistungen geht. Das Wettbewerbs- } \\
\text { Prinzip muss zwischen den Schulen ebenso } \\
\text { gelten wie im Fachunterricht. [...] }\end{array}$ & $\begin{array}{l}\text { Im Schulsport wird nicht für Olympia trai- } \\
\text { niert. Jedes Individuum soll seine Bestleis- } \\
\text { tungen zu erbringen lernen, in Kooperation } \\
\text { mit anderen und nicht gegen sie. Ein Ranking } \\
\text { zwischen den Schulen gefährdet deren all- } \\
\text { gemeinen Bildungsauftrag. [...] }\end{array}$ \\
\hline $\begin{array}{l}\text { Wir müssen unsere Schulen einem weltweiten } \\
\text { Vergleich unterziehen. Der Orientierungsrah- } \\
\text { men ist ein aus dem Ländervergleich zu kon- } \\
\text { struierendes globales Curriculum. Aus den Er- } \\
\text { gebnissen sind die Maßnahmen zur Optimie- } \\
\text { rung der Wissensvermittlung abzuleiten. }\end{array}$ & $\begin{array}{l}\text { Wir müssen alle Schulen nach den Erkennt- } \\
\text { nissen der Fachdidaktik weiter entwickeln. } \\
\text { Dazu muss man ",unten" ansetzen, bei der } \\
\text { einzelnen Schule mit ihren konkreten Bedin- } \\
\text { gungen und ihre gesamte Arbeit in den Blick } \\
\text { nehmen. }\end{array}$ \\
\hline $\begin{array}{l}\text { Erkenntnis von einer besseren Pädagogik er- } \\
\text { wächst aus externer Evaluation nach vorge- } \\
\text { gebenen Kriterien: empirischen quantitativen } \\
\text { Vergleichsstudien. }\end{array}$ & $\begin{array}{l}\text { Erkenntnis von einer besseren Pädagogik er- } \\
\text { wächst aus Beobachtung und Entwicklung der } \\
\text { Praxis, die durch geeignete empirische Ver- } \\
\text { fahren zu sichern sind. }\end{array}$ \\
\hline Der output von Schule ist messbares Wissen. & Der output von Schule sind Menschen. \\
\hline $\begin{array}{l}\text { Niedrige Testergebnisse bedeuten schlechte } \\
\text { Schulen. }\end{array}$ & $\begin{array}{l}\text { Schulen mit niedrigen Werten können } \\
\text { gleichwohl sehr gute Arbeit leisten. }\end{array}$ \\
\hline
\end{tabular}




\begin{tabular}{|c|c|}
\hline $\begin{array}{l}\text { Gute Testergebnisse lassen auf ein gutes } \\
\text { Schulsystem schließen. Wir müssen die „Er- } \\
\text { folgssysteme" anderer Länder studieren und } \\
\text { auf unsere Schulen übertragen. }\end{array}$ & $\begin{array}{l}\text { Die DDR hat bei TIMSS } 1 \text { sehr gut abgeschnit- } \\
\text { ten. Fremde Vorbilder sind nicht ohne weite- } \\
\text { res übertragbar, da u.U. mit unserer Kultur } \\
\text { nicht vereinbar. }\end{array}$ \\
\hline $\begin{array}{l}\text { Die Qualität von Unterricht bemisst sich an } \\
\text { den Durchschnittsleistungen einer Kohorte. }\end{array}$ & $\begin{array}{l}\text { Die Qualität von Unterricht bemisst sich an } \\
\text { der der individuellen und sozialen Lern- und } \\
\text { Bildungsprozesse. }\end{array}$ \\
\hline $\begin{array}{l}\text { Schulen müssen dafür sorgen, dass in allen } \\
\text { Jahrgängen einer Schulart jeweils gleiche } \\
\text { Standards erreicht werden. }\end{array}$ & $\begin{array}{l}\text { Schulen müssen die Unterschiedlichkeit der } \\
\text { Kinder sehen und darauf mit geeigneten } \\
\text { Maßnahmen antworten. }\end{array}$ \\
\hline $\begin{array}{l}\text { Der Staat muss die Einhaltung von Standards } \\
\text { schärfer kontrollieren und schlechte Schulen } \\
\text { bestrafen. }\end{array}$ & $\begin{array}{l}\text { Der Staat muss Schulentwicklung „von unten“ } \\
\text { fördern und mit den Schulen die Art der Re- } \\
\text { chenschaftslegung vereinbaren. }\end{array}$ \\
\hline $\begin{array}{l}\text { „Die Reformpädagogik" ist schuld am schlech- } \\
\text { ten Abschneiden deutscher Schulen. }\end{array}$ & $\begin{array}{l}\text { Der Stand heutiger Didaktik bestätigt die } \\
\text { Richtigkeit fast aller reformpädagogischen } \\
\text { Ansätze. }\end{array}$ \\
\hline $\begin{array}{l}\text { Die Schulzeit kann und muss verkürzt werden. } \\
\text { In den Schulen muss schneller mehr gelernt } \\
\text { werden. }\end{array}$ & $\begin{array}{l}\text { Verstehen braucht Zeit. Ruhe und Gelassen- } \\
\text { heit sind lernförderlich, nicht Hektik und } \\
\text { Zeitdruck. }\end{array}$ \\
\hline
\end{tabular}

[...] Dabei, so scheint mir, haben sich die Prioritäten in kurzer Zeit von B nach A verlagert, ohne dass dies je explizit diskutiert worden wäre. Sehr verkürzt und in bewusster Zuspitzung gesagt: Die Richtlinien spiegeln eher die Position B wider, die Maßnahmen zur Qualitätssicherung hingegen folgen eher der Position A. So kann die eine Intention die andere lahm legen.

Die Reformbewegung der 70er Jahre orientierte sich vorrangig an der Position B. [...] Nach dem Stand heutiger Didaktik (s.o.) dürfte das schlechte Abschneiden deutscher Schulen eher darauf zurückzuführen sein, dass die Position B nicht konsequent genug verwirklicht wurde. Das aber steht nicht zur Diskussion. Stattdessen werden die unter B genannten Orientierungen stillschweigend abgesagt. Oder aber man geht davon aus, dass sie von den Schulen selbstverständlich ,mitbedient“" werden. [...]

\section{Die Rolle der Lehrerinnen und Lehrer}

Schulen sollen ermutigt werden, ihre Entwicklung selbst in die Hand zu nehmen, neue Wege zu erproben. Das ist der Kern des Konzepts verstärkter Schulautonomie. Dazu bedarf es autonomer Menschen

Schulen sollen ein Vorbild dessen sein, wozu sie erziehen: das ist die pädagogische Variante des gleichen Grundgedankens. Kinder lernen Selbständigkeit und Verantwortung, indem man sie zunehmend selbständig und verantwortlich arbeiten lässt. An diesen Werten muss sich nicht nur die Erziehungs- und Bildungsarbeit der Schule orientieren, sondern auch ihre eigene Weiterentwicklung. Andernfalls würde sie unglaubwürdig.

Aus verstärkter Autonomie ergibt sich eine verstärkte Rechenschaftspflicht dem Staat gegenüber. Lange vertritt mit Nachdruck die Position, externe Evaluation sei dazu notwendig. [...]

Lange [sagt auch]: „Veränderungen lassen sich nur mit, nicht gegen wesentlich Beteiligte erreichen“ (1999: 146). Zugleich übt er scharfe Kritik an Lehrerinnen und Lehrern, die Autonomie missverstehen als „Unterneh- 
men zur Steigerung der eigenen Selbstzufriedenheit“ (ebd., 150), als „Möglichkeit sich in eine selbstbestimmte Welt des Traums von einer unbegrenzten pädagogischen Freiheit zu flüchten" (ebd., 147) und darum externe Evaluation als „Sünde wider den heiligen Geist pädagogischer Unschuld“ (ebd., 150) ablehnen.

[...] Es ist sicher richtig, dass es in unserem Berufsstand, wie in jedem anderen, realitätsferne Träumer gibt oder auch solche, die mehr ihr persönliches Wohl als gute Arbeit im Sinn haben. Daraus eine kollektive Schelte zu machen, erscheint mir jedoch wenig hilfreich, weil dies nur die Entstehung neuer „Feindbilder“ begünstigt. Viele Lehrerinnen und Lehrer fühlen sich von der gegenwärtigen Entwicklung überrollt, von den Verantwortlichen „,verraten und verkauft“. [...] Sie sehen eine neue Allianz von Bildungspolitik, Wirtschaft und Wissenschaft als feindliche Macht, die mit einem gewaltigen Apparat und mit entsprechendem Imponiergehabe in der Art eines Panzergeschwaders einherkommt - eingehüllt in eine Staubwolke von Management-Jargon - und ihre pädagogische Arbeit bedroht. Es erübrigt sich hinzuzufügen, dass ich dieses Feindbild ebenfalls für wenig hilfreich halte.

$\mathrm{Zu}$ lockern sind solche festgefahrenen Positionen, wie ich meine, nur durch Überzeugungsprozesse, nicht durch administrative Maßnahmen. Da$\mathrm{zu}$ aber muss die Erfahrung und das Wissen der Lehrerinnen und Lehrer gehört und ernst genommen werden. Eine Forschung, die gegen ihren Willen und gegen ihre Überzeugung administrativ erzwungen wird, unter methodischer Ausblendung ihrer Professionalität und ihrer Erfahrung und ausgehend von Erkenntnisinteressen, die ihnen nicht einleuchten, eine solche Forschung - so meine Überzeugung - kann nichts Gutes bringen. Damit sollen nicht Defizite „schön geredet" und Probleme verschleiert werden. Schon gar nicht geht es darum, Kritik abzuwehren, sondern vielmehr darum, dass sie als hilfreich erfahren und umgesetzt werden kann. Das aber setzt voraus, dass diejenigen, die das tun sollen, nicht „Objekte“ der Forschung sind, sondern handelnde Subjekte, deren Wissen zählt. [...]

\section{Fazit: Die Blickrichtung ändern}

Hermann Lange fordert, die „empirische Wende“ endgültig zu vollziehen. Meine Antwort: Der gegenwärtige Trend erfordert seinerseits eine empirische Wende, eine Korrektur mit Hilfe qualitativer empirischer Methoden und Studien, die „unten“ ansetzen, auf der Ebene der Schulwirklichkeit, und das in den Blick nehmen, was quantitative Vergleichsstudien nicht ermitteln können.

Das Fundament solcher Empirie ist die Arbeit der Schulen selbst. Die Erfahrung der letzten Jahrzehnte zeigt: Weiterführende pädagogische und didaktische Impulse sind immer wieder von einzelnen Schulen ausgegangen, die selbstbewusst und tatkräftig daran gegangen sind, neuartige Lösungen zu entwickeln. [...] Immer hat die empirische Erziehungswissen- 
schaft ihre Beispiele dort gesucht und gefunden, wo Schulen eigene, neue Wege gegangen sind. Sie gilt es zu ermutigen. Mehr Autonomie, die die Bildungspolitiker darum den Schulen zugestehen wollen, macht jedoch keinen Mut, wenn sie zugleich mit geschwungener Anpassungs-Keule einherkommt. Diesen Widerspruch gilt es aufzuheben. Das geht nur, wenn es gelingt, die Verantwortlichen in der Bildungspolitik von der Notwendigkeit einer solchen Korrektur zu überzeugen. [...]

Die Schülerinnen und Schüler und deren Eltern sind gegenwärtig wohl am meisten verunsichert und können damit indirekt dazu beitragen, der Schulentwicklung eine Richtung zu geben, der sie im Grunde selbst nicht zustimmen würden. Sie wollen - natürlich! - das Beste für ihre Kinder. Da nun vorrangig oder ausschließlich messbare Leistungen „zählen“, sind sie bemüht, alles zu tun, um diese zu fördern - vom pränatalen Training bis zur Anmeldung im Gymnasium, auch wenn die Lehrer abraten und das Kind mit Nachhilfestunden regelrecht gequält werden muss. Sie fordern „Schnellzug-Klassen“ und Eliteschulen. Man muss nicht lange fragen, in welchen Stadtteilen diese liegen werden. Die Daten sind bekannt.

Die neue Zweiteilung in „Modernisierungsgewinner“ und „Modernisierungsverlierer“ ist demnach bereits „unten“ angelegt. Sie könnte, so der Alptraum, zu einer „Billigbeschulung“ der einen und einer Konzentration der Mittel in den „guten“ Schulen, somit zu einer vorrangigen Förderung der anderen führen. Hermann Lange wird mir in dem Urteil zustimmen, dass dies eine zutiefst inhumane Bildungspolitik wäre. Auch wenn das Ziel der Chancengleichheit zur Zeit gänzlich unerreichbar scheint, bedürfen wir seiner doch als Korrektiv. Real und erreichbar ist das Ziel von mehr Bildungsgerechtigkeit in unseren Schulen: dann, wenn wir den Menschen gerecht zu werden versuchen, wie sie sind (und nicht, wie wir sie uns wünschen mögen).

\section{Literatur}

Klafki, Wolfgang: Gesellschaftliche, bildungspolitische und pädagogische Implikationen zum Problembereich Leistung und Leistungsanspruch. In: Preuß, Eckhardt/Itz, Ulrike/Ulonska, Herbert (Hg.): Lernen und Leistung in der Grundschule. Bad Heilbrunn 1999, S. 45-66.

Lange, Hermann: Qualitätssicherung in Schulen. In: Die Deutsche Schule 91(2), S. 144159. 


\section{TIMSS- und PISA-Schock}

\section{Kommentar (Brüsemeister)}

$\mathrm{Zu}$ den Ausgangspunkten der jüngeren Diskussionen über Schulmodernisierung gehören die internationalen Leistungsmessungen TIMSS und PISA. Deutschland und andere Länder haben in jüngster Zeit an solchen Tests teilgenommen ${ }^{41}$; weil das deutsche Bildungssystem schlecht abgeschnitten hat, spricht man vom „TIMSS- und PISA-Schock“".

PISA wirft die auch schon in unserer Einleitung erwähnte schwierige Frage auf, ob es sich hierbei überhaupt um pädagogische Vordiskussionen handelt - immerhin wurde der Leistungstest ja maßgeblich von einer internationalen Wirtschaftsorganisation (OECD) initiiert. ${ }^{42}$ Die deutsche Kultusministerkonferenz hatte jedoch 1997 die Beteiligung an PISA beschlossen (vgl. Deutsches PISA-Konsortium 2001: 11) und sie damit erst möglich gemacht. Zudem hat PISA eine Flut von Diskussionen ausgelöst - nicht nur innerhalb der Pädagogik. Vom Gegenteil zeugen allein die Diskussionen in den Tageszeitungen (vgl. Adam 2002). Der Einfachheit halber beschränken wir uns hier jedoch auf pädagogische Diskussion (vgl. auch Terhart 2002), die es erlauben, PISA auch internen Vordiskussionen zuzurechnen, welche sich auf die aktuelle Schulmodernisierung auswirken. ${ }^{43}$

41 Vgl. zu TIMSS (,The Third International Mathematics and Science Study“): Baumert u.a. (2000). Zu PISA („Programme for International Student Assessment“) sowie zum Abschneiden der einzelnen deutschen Bundesländer vgl. Deutsches PISA-Konsortium $(2001,2002)$.

42 TIMSS dagegen wurde von einem Akteur des Schulsystems durchgeführt. Nach Köller u.a. (2001: 271) steht TIMSS in Tradition der IEA (,International Association for the Evaluation of Educational Achievement", eine Forschungsorganisation, der in der Mehrzahl Regierungseinrichtungen der Mitgliedsstaaten angehören). In Deutschland wurde TIMSS ,als Forschungsvorhaben des Instituts für Pädagogik der Naturwissenschaften (IPN) und der Universität Hamburg in Zusammenarbeit mit dem Deutschen Institut für internationale pädagogische Forschung in Frankfurt begonnen“ (ebd.). In einer zweiten Projektphase haben das Max-Planck-Institut für Bildungsforschung und die Humboldt-Universität zu Berlin Arbeitsschwerpunkte gebildet; das Bundesministerium für Bildung, Wissenschaft, Forschung und Technologie förderte TIMSS (vgl. ebd.).

43 Wie einleitend zu Textblock I bemerkt, kann hier die Frage, wie externe und interne Diskussionen im Einzelnen auf die Schulmodernisierung wirken, nicht geklärt werden. Dies liegt daran, dass sich nationale Akteure (Profession, Bildungsverwaltung, Politik) zunehmend weltgesellschaftlich orientieren (vgl. nachfolgend den Beitrag von Messner). Was dies für einzelne nationale Akteure konkret bedeutet, ist kaum untersucht. Es wäre zu berücksichtigen, in welcher Weise sich nationale und internationale Akteure (wie die OECD) wechselseitig beeinflussen und welche Akteurkonstellationen sie ausbilden. $\mathrm{Zu}$ diesem Punkt stellt sich die Literaturlage etwas umfangreicher dar. Gruber (2002) z.B. vermutet in seiner Übersicht zum „global player" OECD, dass sich die skandinavischen Länder, die Niederlande, Australien und Neuseeland offen und lernbereit gegenüber der OECD zeigen, während dies die 
Die drei nachfolgenden Texte zu den internationalen Leistungsmessungen verweisen auf die grundsätzliche Bedeutung erstens der Beobachtung von Bildungssystemen vom Output her, wie sie den Tests innewohnen, zweitens auf die zunehmende Internationalisierung solcher Beobachtungen. Die Autoren erörtern damit gesellschaftliche Bedeutungen der Leistungsvergleiche, die für das Thema der Modernisierung von Schule interessant sind. Wir beschränken uns damit auf einen schmalen, wenngleich wichtigen Bereich pädagogischer Diskussion um TIMSS und PISA. Einzelne Testmethoden und -ergebnisse bleiben ausgeblendet. Zudem erlauben wir uns in Kommentaren jetzt schon, die veränderten und teilweise neu aufkommenden Diskussionen mit Hinweisen auf veränderte Konstellationen zwischen den an Schule beteiligten Akteuren in Verbindung zu bringen, auch wenn Akteurkonstellationen als solche erst im Textblock III des vorliegenden Buches zur Sprache kommen.

Hermann Lange (Staatsrat a.D., Behörde für Schule, Jugend und Berufsbildung, Hamburg) verweist auf die Zunahme internationaler Leistungsmessungen, die von nationalen Schulsystemen aufgegriffen werden und sieht mit TIMSS und PISA den „Übergang von input-orientierten zu output-orientierten Steuerungsverfahren“. Sodann problematisiert er, dass zwar mitunter ein großer Aufwand bei der empirischen Messung von Schülerleistungen betrieben werde, aber im Verhältnis dazu z.T. der Aufwand für eine „strategische Nutzung der Ergebnisse solcher Untersuchungen“ gering sei. Man kann im Anschluss an diese Aussage zum Beispiel überlegen, inwiefern sich nationale Bildungsverwaltungen und die Schulprofession durchaus „modern“ geben, wenn sie Leistungsmessungen durchführen aber vielleicht bei der Interpretation der Ergebnisse weniger engagiert sind, insofern sie es dem bisherigen ,Spiel' der Politik überlassen, Ergebnisse zu deuten. Genauer gesagt müsste man solche Bildungssysteme unterscheiden, bei denen Leistungsmessungen von vornherein in Reformen des Bildungswesens münden sollen und solche Bildungssysteme, die an Leistungsmessungen vielleicht nur teilnehmen, um sich damit vor Beobachtern zu legitimieren. Die Leistungsmessungen wären dann zwar immer noch Impulse für eine Modernisierung - diese würde aber zunächst nur auf der Ebene des „talk“ stattfinden und nicht zu einer ,action“ der Schulsysteme führen, d.h. zu faktischen Änderungen der Schulstruktur. Vieles an der Diskussion in Deutschland deutet auf ein bloßes semantisches Bearbeiten der Ergebnisse von PISA hin, da strukturelle Änderungen größeren Ausmaßes bislang aus-

USA nicht seien (ebd., 74). Andere Länder scheinen nach Gruber nur dann auf OECD-Positionen zurückzugreifen, ,wenn sie sich zur Legitimierung und Bekräftigung nationaler Prioritäten eignen“"(ebd.). Offensichtlich kommt es bei der Nutzung von Vorschlägen der OECD wiederum auf Geltungskontexte, nationale Arenen und Interessen der nationalen Akteure an. 
geblieben sind. Immerhin ist die Semantik ein wichtiger Teil der Modernisierung, in deren Folge sich Strukturänderungen anbahnen. ${ }^{44}$

Darüber hinaus verweist Lange darauf, dass zwar Leistungsmessungen wie TIMSS und PISA den Zustand des Bildungssystems insbesondere bei Leistungsabnehmern, den Schülern, erkennen sollten, darüber hinaus jedoch regelmäßig Faktoren, die außerhalb des Systems liegen - die „sozialen Bedingungen, unter denen Schüler aufwachsen“ - als zentrale Ursachen für Unterschiede bei den Lernleistungen ausmachen. Dies wirft dann die gesellschaftliche Frage auf, ob man diese Ungleichheiten beseitigen will oder nicht. Es ist also so, dass gerade die „exakten“ Messungen des Systeminneren auf Umweltbedingungen des Schulsystems verweisen. Und auf diese einzugehen, liegt dann nicht mehr allein in der Hand des Schulsystems, sondern fordert gesellschaftliche Werte und Ressourcen heraus.

Thomas Bethge (Landesinstitut für Schule in Bremen) stellt dar, dass durch die TIMS-Studie ,der mathematische und naturwissenschaftliche Unterricht zum Gegenstand der öffentlichen Debatte" wird. Das Schulsystem steht offensichtlich, wenn man sich die von Bethge aufgelisteten Reaktionen anschaut, unter Generalverdacht, schlechte Schulleistungen hervorzubringen (,Das deutsche Bildungssystem muss einen Mittelplatz verlassen und einen Spitzenplatz im Nationen-Ranking einnehmen"). Vor diesem Hintergrund sind Reaktionen von Pädagogen und der Bildungsverwaltungen in den jeweiligen Ländern bedeutsam. Diese Reaktionen beinhalten nach Bethge entweder Zweifel an der ,Seriösität und Wissenschaftlichkeit der Studie" (gemeint ist TIMSS), oder Akzeptanz der Ergebnisse und den Versuch, Schule und Unterricht zu verändern. Unterrichtsprobleme sollten dabei nicht punktuell, sondern in Zusammenhang mit einer zu verändernden Lehrerarbeit, einer neuen Zusammenarbeit von Fachkollegien gesehen werden, so Bethge. In diesem Zusammenhang ist die zuvor vom Autor erwähnte Bemerkung wichtig, dass es eine pädagogische Kritik an bestimmten Dimensionen des mathematischen und naturwissenschaftlichen Unterrichts immer schon gegeben habe, aber daraus keine bildungspolitischen Folgerungen abgeleitet wurden. Beides scheint erst durch den Druck der internationalen Leistungsmessungen möglich, so ließe sich der Autor ergänzen. Brachliegende Reformkonzepte können offensichtlich im Rahmen einer neuen Situation, nämlich eine durch internationale Leistungsmessungen

44 Dazu gehört zum Beispiel in Deutschland, dass zwar einerseits der Streit darum, ob der Bund und/oder die Länder für eine nachhaltige Bildungspolitik zuständig seien, neu aufflammt, die alte Akteurkonstellation innerhalb des gegebenen Modernisierungspfades also wieder relevant wird. Es entwickelt sich bei diesem Streit aber auf Basis der neuen Semantik, die zum Beispiel die Notwendigkeit weiterer Datenerhebungen nahe legt, auch eine Dynamisierung der jeweiligen Akteure. Denn durch die neuen Themen werden andere Unterscheidungslinien in eine Akteurkonstellationen eingeführt, d.h. die Akteure positionieren sich zueinander auf Grund der veränderten Semantik neu und sind deshalb auch zu anderen bildungspolitischen Entscheidungen in der Lage. 
,aufgeschreckte' Öffentlichkeit, offensiver angegangen werden. Neu ist jedoch, dass die Akteure nun empirische Befunde aus den Leistungsvergleichsstudien aufgreifen müssen, was den Vertretern bisheriger Konzepte nicht in gleichem Maße gelingt. Es ist also nicht so, dass in der Folge von TIMSS und PISA einfach alte Ideologien und Programme wieder, aufgewärmt' werden können, denn es ist eine grundlegend neue Situation entstanden, insofern Daten über das Schulsystem - zudem öffentlich - vorhanden sind. An diese müssen die Reformvorschläge angeschlossen werden, was wiederum potentiell von der Öffentlichkeit überprüft werden kann.

Der dritte Beitrag dieses Textabschnitts stammt von Rudolf Messner (Universität Kassel), der die internationalen Leistungsvergleiche in noch größeren Zusammenhängen betrachtet. Ausgangspunkt ist die Feststellung des Autors, dass bei den PISA-Studien der OECD, welche die Basiskompetenzen von 15-jährigen Schülern untersuchen, ,ein verändertes Konzept von grundlegender Bildung“ vorliegt. PISA zielt auf „basale Kulturwerkzeuge, die ein Bürger benötigt, um sich in einer Welt, im gesellschaftlichen Leben nicht nur zu behaupten, sondern eine aktive Rolle spielen zu können. PISA setzt also den Akzent auf fächerübergreifende, alltags-, schul- und berufsbezogene Grundfähigkeiten [...]. Man kann dies als bildungstheoretisch höchst relevante Neubestimmung schulischer Zielsetzungen verstehen" (Herv. i.O.). Die PISA zu Grunde gelegten Kriterien sind also nicht ein Verschnitt von Lerninhalten der verschiedenen Länder, die an der OECD-Untersuchung teilgenommen haben, sondern führen selbst ein neues, nämlich pragmatisches Verständnis von zu erlernenden Grundfähigkeiten ein.

Messner sieht dieses Bildungsziel in Zusammenhang mit dem neuen Paradigma einer Wissensgesellschaft, in der ,dynamisch einsetzbares Wissen zur zentralen gesellschaftlichen Produktivkraft geworden ist". Insbesondere die OECD-Staaten, die 28 der insgesamt 34 an PISA beteiligten Staaten ausmachen, versuchen nach Messner, eine moderne Bildungskonzeption zu entwickeln, um sich selbst für den Übergang von der Industriezur Wissensgesellschaft zu rüsten. ${ }^{45}$ Mit den Leistungsmessungen setzen die Industrieländer offensichtlich einen einheitlichen Vergleichsmaßstab und erzeugen damit einen Veränderungsdruck für sich selbst, sich auf das Ziel einer Wissensgesellschaft hin zu bewegen.

\section{Folgerungen}

Aus dieser These folgt eine Perspektivenverschiebung. Während zuvor Länder, die in den Tests schlecht abschneiden, als benachteiligt erscheinen, so sind nun jene Länder benachteiligt, die an den OECD-Untersuchungen gar nicht teilnehmen können - und dies ist immerhin die Mehrheit der Staa-

45 Vgl. ausführlicher Messner (1998 sowie 2002); Letzteres ist eine erweiterte Fassung des im Folgenden abgedruckten Beitrages. 
tengemeinschaft. Leistungsmessungen erscheinen nun im Weltmaßstab als Angelegenheit eines, exklusiven Clubs' reicher Industrienationen. Solche Messungen wären dann von den OECD-Staaten entweder explizit oder stillschweigend als selektive Instrumente eingesetzt, um sich in der Weltgesellschaft bildungsbezogene sowie letztlich wirtschaftliche Vorteile zu erobern.

Diese Perspektive stellt die vermeintlich neutralen Leistungsmessungen als semantische Konstrukte der Industrienationen dar, welche zudem handlungswirksame Konsequenzen haben. Erstens werden sich innerhalb einer nationalen Arena, auf der die Konstrukte als Leitideen verbreitet werden, entsprechende Modernisierungseliten ausmachen lassen, die sich selbst durch das Konstrukt dynamisieren - und außerdem auch die Akteurkonstellation in der nationalen Arena, insofern sich bezüglich der Tests Befürworter, Gegner, Zögerliche und Konservative werden unterscheiden lassen. Zweitens bewirkt die Semantik eine Dynamisierung von Nationen als Akteuren der Weltgesellschaft. Auf dieser supranationalen Arena lassen sich OECD-Staaten und gleichsam „der Rest der Welt" unterscheiden, und auch hier lässt eine der möglichen Forschungsperspektiven nach der Dynamisierung der Akteurkonstellation fragen, die zweifelsohne mit den internationalen Leistungsmessungen gegeben ist. ${ }^{46}$

\section{HERMANN LANGE Qualitätssicherung in Schulen}

Es ist immer gut, die Realitäten so in den Blick zu nehmen, wie sie wirklich sind. In der Bildungspolitik besteht dazu heute mehr denn je Anlaß. Vor ungefähr 30 Jahren hatte Heinrich Roth die empirische Wendung der pädagogischen Wissenschaften gefordert. Sie gilt es, so könnte man auch sagen, endlich zu vollziehen, und zwar auch in der Bildungspolitik und im Schulalltag. $[\ldots]$

\section{Was ist neu an der "empirischen Wende"?}

Methoden und Instrumente, die zur Klärung des Erreichens der jeweils verfolgten Ziele eingesetzt werden, sind nicht neu. Neu ist indessen, daß diese Instrumente und Methoden in breiter Form genutzt werden sollen, um die Ergebnisse des konkreten Handelns systematisch zu überprüfen. Dies wird große Anstrengungen erfordern, und zwar nicht nur weil es immer schwer

46 Für einzelne Nationen wäre zu erforschen, inwieweit sich eine solche Dynamisierung und Modernisierung nur auf die Ebene des ,talk“ bezieht, insofern vielleicht an Leistungsmessungen teilgenommen und über Testergebnisse auch gesprochen wird, das Schulsystem von der Struktur her aber belassen bleibt. Diesen Verdacht gibt es, wie bereits erwähnt, für den Akteur Deutschland. 
ist, einen vielfältigen Einflüssen und Interessen unterliegenden Großbereich überhaupt in Bewegung zu bringen. Vielmehr sprechen auch verbreitete Gewohnheiten des gegenwärtigen Wissenschaftsbetriebes dagegen. Zwar ist die Wendung der Erziehungswissenschaften zu einer (auch) empirisch-sozialwissenschaftlichen Orientierung seit langem verkündet, insgesamt aber noch kaum vollzogen. Die Frontlinie der Auseinandersetzung um Eignung und Nebenwirkungen der Instrumente verläuft deshalb heute bemerkenswerterweise nicht zwischen „A-Ländern“ (SPD-regiert) und „BLändern" (CDU-regiert), sondern quer durch die Profession selbst. Insofern geht es nicht nur um die empirische Wende in der Bildungspolitik, sondern noch immer auch um die empirische Wende der pädagogischen Wissenschaften. Das Bemühen, Folgerungen daraus zu ziehen, stößt freilich auch auf die Schwierigkeit, dass die erziehungswissenschaftlichen Fakultäten vielfach nicht über die Stellen (Lehrstühle, Institute) verfügen, die sich kompetent mit den quantitativen Methoden empirischer Forschung befassen könnten. Daraus resultieren Defizite in der Lehre, die die Rezeption der Ergebnisse empirischer Untersuchungen durch die schulische Praxis erschweren.

Neu ist auch eine Haltung, die das Dogma von der Unfehlbarkeit des Pädagogen aufhebt, solange er nur im rechten Geist handelt. Man muß zuzugeben lernen und zugeben können, daß auch gute Absichten fehlschlagen können, daß nicht jedes gute Ziel auch erreicht wird und daß die Gründe hierfür nicht bereits mit der heute vielfach üblichen pädagogischen Verelendungstheorie (gesellschaftliche Entwicklungen, fehlende Mittel etc.) abschließend beschrieben sind. Das Nichterreichen von Zielen, das bisher als Folge nicht veränderbarer Umstände allzu leicht aus dem Verantwortungsbereich der handelnden Personen herausgeschoben wird, als individuelles Scheitern hinter verschlossenen Türen verborgen bleibt, von der einzelnen Lehrkraft als persönlich belastendes Schicksal verarbeitet werden muß oder durch Gelingensgemeinschaften und Verbrüderungen (der Lehrer mit den Schülern, der Kollegen untereinander und mit den Schulleitungen) verschleiert wird, kann offen kommuniziert werden. Ehrlichkeit gegen sich selbst kann freilich schmerzlich sein. Sie ist ohne Frage risikoreich. Die Veränderungen werden Ängste und Widerstand auslösen. Sie können aber auch als Chance der (individuellen wie gemeinsamen) Befreiung und Erleichterung begriffen und als Möglichkeit genutzt werden, das Bildungswesen wieder in das Zentrum öffentlicher Aufmerksamkeit und öffentlichen Interesses zu rücken.

\section{Leistungsmessung und Leistungsvergleiche, national und international: TIMSS, LAU und PISA}

Gegenwärtig haben auf nationaler wie auf internationaler Ebene insbesondere vergleichende Untersuchungen zum Leistungsstand von Schülerinnen und Schülern Konjunktur. Das bekannteste und derzeit viel diskutierte Bei- 
spiel einer internationalen Vergleichsuntersuchung ist die „Dritte Internationale Mathematik- und Naturwissenschaftsstudie" (The Third International Mathematics and Science Study - TIMSS), die unter dem Dach der International Association for the Evaluation of Educational Achievement (IEA) durchgeführt wurde. Die Ergebnisse dieser Untersuchung dürfen als bekannt vorausgesetzt werden, so daß sie hier nicht im einzelnen referiert werden müssen (vgl. Baumert/Lehmann 1997; Baumert u.a. 1998).

Als ein wichtiges Beispiel für derartige Untersuchungen in Deutschland ist ferner die „Lernausgangslagenuntersuchung“ (LAU) zu nennen, mit deren Hilfe in Hamburg flächendeckend der Leistungsstand der Schülerinnen und Schüler am Beginn der Sekundarstufe I, d.h. letztlich am Ende der Grundschule, erfaßt wurde. Untersucht wurden dabei Kenntnisse, Fertigkeiten und Fähigkeiten in den Bereichen Sprachverständnis, Leseverständnis, Rechtschreibung, Mathematik und Informationsentnahme aus Karten, Tabellen und Diagrammen, die Fähigkeit zu freier und kreativer Text- und Bildgestaltung unabhängig von der Rechtschreibkompetenz, die Fähigkeit zu schlußfolgerndem Denken, insbesondere auch die Fähigkeit, komplexe Beziehungen in neuartigen Situationen wahrzunehmen, und zwar weitgehend unabhängig von dem Grad der Beherrschung der deutschen Sprache. Erfaßt wurden zugleich die unterschiedlichen familiären Hintergründe und Schülermerkmale wie Staatsangehörigkeit, Schullaufbahn, Besuch einer Vorschulklasse etc. sowie die Einstellungen der Kinder zum schulischen Lernen.

Die Ergebnisse der Untersuchung lassen sich - sehr vereinfacht - in folgenden Thesen zusammenfassen (vgl. Lehmann u.a. 1996):

(1.) Es gibt deutliche regionale Unterschiede im Leistungsniveau der Grundschulen. Ein großer Teil der beobachteten Varianz erklärt sich noch immer aus soziostrukturellen Merkmalen (insbesondere dem durchschnittlichen Buchbestand in den Elternhäusern, dem Schulabschluß der Eltern und dem Ausländeranteil), die das Umfeld einer Schule bestimmen. Dies gilt nicht in gleicher Weise für die Fähigkeit zum nicht sprachgebundenen schlußfolgernden Denken und schulbezogene Einstellungen von Schülerinnen und Schülern.

(2.) Vor diesem Hintergrund gibt es Schulen, die - gemessen an den Bedingungen ihres sozialen Umfeldes - erwartungswidrig gut, und solche, die erwartungswidrig schlecht abschneiden.

(3.) Bildet man Durchschnittswerte für alle Hamburger Schulen, so deuten sich möglicherweise auch für deren Leistungsniveau insgesamt Probleme im Verhältnis zu dem Niveau der Schulen in anderen Ländern (auch in anderen Großstädten) an.

Inzwischen werden im Rahmen der OECD unter dem Kürzel PISA (, Programme for International Student Assessment") weitere Vergleichsuntersuchungen vorbereitet, an denen sich ungefähr 30 Staaten, darunter auch die Bundesrepublik Deutschland, beteiligen werden. Projektnehmer auf internationaler Ebene ist das Australian Council of Educational Re- 
search (ACER $)^{47}$. Die Durchführung der Untersuchungen in Deutschland ist einem Konsortium unter Führung des Max-Planck-Instituts für Bildungsforschung in Berlin übertragen worden. Gegenstand der Untersuchung ist ein Vergleich der Leistungen von 15-jährigen Schülerinnen und Schülern in den Bereichen Leseverständnis, Mathematik, Naturwissenschaften, wobei neben international vereinbarten Untersuchungsansätzen ${ }^{48}$ bestimmte Ergänzungen in den einzelnen beteiligten Ländern (nationale Optionen) vorgesehen sind. Im Rahmen der nationalen Optionen soll in Deutschland z.B. geklärt werden, welche aussichtsreichen pädagogischen Interventionsmöglichkeiten zur Verbesserung von Leseverständnis und Lesekompetenz sich identifizieren lassen.

Dabei geht es sowohl um die pädagogisch-psychologische Basis von Fördermaßnahmen (bereichsspezifisches Vorwissen, motivationale Faktoren wie Aufmerksamkeit und thematisches Interesse, Arbeitsgedächtnis und Verfügbarkeit von Lese- und Lernstrategien) als auch um die Situation von Risikogruppen (,schwache Leser“ und Leser nicht-deutscher Muttersprache), um außerschulische Stützsysteme beim Erwerb der Lesekompetenz (Leseanlässe und Lesegelegenheiten, häusliche Lesekultur und Regeln der Mediennutzung, Wertschätzung des Lesens in den jeweiligen peergroups), um die Rolle des Lesens im Sprach- und Literaturunterricht sowie seine Bedeutung und Nutzung als Instrument selbständigen Wissenserwerbs. Untersucht werden sollen ferner fächerübergreifende Kompetenzen (cross curricular competencies), so z.B. die Fähigkeit, extracurriculare Projekte zu planen und zu steuern, allein oder gemeinsam mit anderen technische Probleme zu lösen oder Lösungsstrategien durch Analogiebildung auf neue Aufgabenstellungen zu übertragen. Unter dem Aspekt „soziale Kompetenz" soll die Fähigkeit untersucht werden, soziale Informationen zu dekodieren und zu interpretieren sowie ein Repertoire variabler Handlungsentwürfe für gängige Interaktionssituationen zu entwickeln. Die Untersuchungen sollen sowohl die sozialen Kontexte wie auch Aspekte der Schulqualität etc. einschließen.

Die Felderprobung der erforderlichen Tests wird bis zum Sommer 1999 durchgeführt werden. Die Hauptuntersuchung soll im Jahre 2000 erfolgen, der Bericht im Jahre 2001 vorliegen. Inzwischen hat die Kultusministerkonferenz beschlossen, die Untersuchungen über die für den internationalen Vergleich erforderliche begrenzte Stichprobe hinaus so anzulegen, daß auch Leistungsvergleiche innerhalb der Bundesrepublik möglich werden ${ }^{49}$. Ebenfalls beschlossen wurde von der Kultusministerkonferenz, eine weitere Vergleichsuntersuchung zur Fremdsprachenkompetenz der Schülerinnen

47 Beteiligt sind ferner das Netherlands Institute of Educational Management (Cito), der Service de Pedagogie Experimentale, Universite de Liege (SPE), und Westat Inc., Rockville (USA), als Datenverarbeitungszentrum.

48 Die „Frameworks“ der geplanten Untersuchungen sind nach dem jeweils aktuellen Stand im Internet verfügbar (http://www.pisa.oecd.org).

49 Beschluß der Amtschefskonferenz der KMK vom 17./18. September 1998. 
und Schüler an deutschen Schulen durchzuführen. Diese Untersuchung ist inzwischen ausgeschrieben worden. ${ }^{50}$

\section{Was weiß man und was tut man, wenn man untersucht hat?}

Vorbereitung und Durchsetzung von empirischen Untersuchungen zum Leistungsstand von Schulen erfordern einen hohen Aufwand. Dieser steht in einem eigenartigen Gegensatz zu dem vergleichsweise geringen Aufwand, den man sich bisher noch leistet, um eine tragfähige Konzeption für die strategische Nutzung der Ergebnisse solcher Untersuchungen zu entwickeln. Zwar hat die Rückmeldung der Untersuchungsergebnisse der Lernausgangslagenuntersuchung in Hamburg an die Grundschulen und an die weiterführenden Schulen einen intensiven Diskussionsprozeß in Gang gesetzt. Er bezieht sich auf die Klassenbildung, die pädagogische Arbeit innerhalb der Klassen und die Entwicklung von spezifischen Fördermaßnahmen, die Zusammenarbeit der Lehrkräfte innerhalb einer Schule ebenso wie auf die Zusammenarbeit von Grundschule und weiterführenden Schulen, Aktivitäten der Schulberatung, der Lehrerfortbildung und der Standardsicherung durch Vergleichsarbeiten (vgl. Behörde für Schule, Jugend und Berufsbildung Hamburg 1998). Insgesamt wäre es jedoch falsch zu glauben, daß auf diese Weise allein bereits alle notwendigen Impulse zur Veränderung der Situation ausgelöst werden können. Jedes der oben mitgeteilten Ergebnisse dieser Untersuchung muß Folgerungen und weitere Klärungen auf unterschiedlichen Ebenen nach sich ziehen, die vielfach nicht von einer einzelnen Schule allein bewirkt werden können.

Die Aussagen in These (2) legen den Schluß auf Ursachenfaktoren im Lehrerhandeln und im Konzept der einzelnen Schule nahe. Um herauszufinden, was man tun sollte, wäre es vor allem interessant zu klären, was die erwartungswidrig guten Schulen anders machen als andere und ob bzw. unter welchen Bedingungen ihre Vorgehensweisen auf andere Schulen übertragbar sind.

Die Aussagen zu These (3) legen Vermutungen nahe, die sich in gleicher Weise auf die Situation aller Hamburger Schulen beziehen. Wenn man auf dieser Ebene handeln will, muß man klären, was andere Länder in gleicher Situation anders machen als Hamburg (curriculare Vorgaben? Struktur, Einstellungen und Qualifikation der Lehrerschaft? Steuerungsverfahren? oder ... ?).

Der Umgang mit den Folgerungen aus These (1) ist fraglos am schwierigsten. Sie bestätigt, was längst bekannt ist, aber zeitweilig im Glauben an die Wirksamkeit vielfältiger Förderprogramme und den mit ihnen verbundenen finanziellen input zu sehr verdrängt wurde: Unterschiedliche Lernleistungen haben ihre Ursache auch in den sozialen Bedingungen, unter denen Schüler aufwachsen. Soweit sich dies daraus erklärt, daß Lernen eben nicht nur in der Schule stattfindet, sondern in starkem Maße auch von au-

50 Beschluß der Amtschefskonferenz der KMK vom 4./5. Februar 1999. 
ßerschulischen Stützsystemen abhängt, drängt sich die Frage auf, ob man dies resignierend auf sich beruhen lassen darf oder ob es nicht doch außerschulisch ansetzende wirksame Strategien gibt, soziale Unterschiede besser als bisher zu kompensieren. Entzaubert ist freilich der Glaube, daß man bereits durch eine Addition vielfältiger Förderprogramme ohne weiteres Probleme löst.

Bei alledem lassen sich viele der damit aufgeworfenen Fragen zuverlässig anhand von Querschnittsuntersuchungen noch nicht beantworten. Deshalb plant Hamburg Folgeuntersuchungen für die Klassenstufen 7 und 9. Sie werden gleichfalls flächendeckend angelegt sein. Die Tests für die Klassenstufe 7 sind abgeschlossen, aber noch nicht ausgewertet. Die Untersuchungen werden von der Frage geleitet, ob sich die Unterschiede in den Leistungen am Ende der Grundschule im weiteren Verlauf ausgleichen, ob sie unverändert bleiben oder ob sie sich vielleicht sogar verstärken. Erst auf dieser Basis ließen sich z.B. Entscheidungen über die weitere Entwicklung der Grundschulkonzeption treffen. Denn immerhin ist denkbar, daß auch bei schwächeren Leistungen zu einem bestimmten Zeitpunkt die Basis für positive Entwicklungen in der Folgezeit bereits gelegt ist.

Es zeigt sich mithin: Leistungsvergleiche erlauben eine allgemeine Standortbestimmung (,bench-marking“) und geben erste Hinweise auf Handlungsnotwendigkeiten. Sie liefern jedoch nur begrenzt Aufschluß über mögliche Ursachenzusammenhänge und erst recht nicht bereits didaktische Konzepte zur Beseitigung erkannter Defizite. Dabei sind Aussagen stets nur in den Grenzen des gewählten Untersuchungsansatzes möglich. Dies darf indessen keine Rechtfertigung dafür sein, unbequeme Untersuchungsergebnisse mit dem Argument der begrenzten Reichweite von Untersuchungen vorschnell zu relativieren oder Untersuchungen nur dort anzusetzen, wo man sich für unangreifbar hält.

Vergleichsuntersuchungen sind nach alle dem nur der Einstieg in ein Feld, dem weitere Schritte in Form gezielter Untersuchungen folgen müssen. Je nachdem, auf welcher Ebene man ansetzen will und welche Fragestellungen dabei leitend sein sollen, wird auch die Frage unterschiedlich zu beantworten sein, wie breit (flächendeckend oder stichprobenartig, bestimmte Gruppen), in welcher Zeitabfolge (einmalig, regelmäßig, anlaßbezogen) und auf welchen Veranlassungsebenen (Einzelschule zum Zwecke der Selbstevaluation, Steuerungswissen der Schuladministration) weitere Untersuchungen anzulegen sind. Dabei ist es eine offene Frage, ob gelegentliche Untersuchungen zu unterschiedlichen Fragestellungen ausreichen oder ob es einer regelmäßigen Berichterstattung über die Leistungsstände von Schülerinnen und Schülern bedarf. Auch wenn hinter dieser Frage ein erhebliches Maß an Sprengstoff stecken könnte, wird sie in absehbarer Zeit zu beantworten sein.

Die Folgerungen aus bereits gewonnen Erkenntnissen und aus weiteren Untersuchungen werden das Handeln vieler Akteure erfordern. Sie beziehen sich auf Änderungen in der Lehrerausbildung ebenso wie auf verstärkte 
Anstrengungen der Lehrerfortbildung, auf curriculare Entwicklungen und die Entwicklung didaktischer Konzepte ${ }^{51}$ wie auf Bemühungen im Rahmen der Schulentwicklung und des Schulmanagements.

\section{Risiken und Nebenwirkungen ausgeschlossen?}

Untersuchungen, wie sie derzeit durchgeführt werden, sollen Steuerungswissen erzeugen. Sie dienen nicht einer Überprüfung der individuellen Leistung einzelner Schüler oder einzelner Lehrer. Zentrale Tests sollen weder die geltenden Formen der Leistungsbewertung von Schülerinnen und Schülern (Noten, Zeugnisse) noch der Beurteilung des einzelnen Lehrers ersetzen. Sie sind weder die Grundlage der individuellen Entscheidung über Berechtigungen zum Besuch weiterführender Bildungseinrichtungen noch ein Element der Personalbeurteilung und Karriereplanung. Insofern ist die Situation in Deutschland der Situation in England oder in den Vereinigten Staaten nicht vergleichbar, wo Tests bereits in großer Breite zur regelmäßigen Leistungsbewertung im Vergleich einzelner Schulen untereinander (,Ranking") wie auf der individuellen Ebene der Schülerinnen und Schüler Verwendung finden. Eine solche Entwicklung zuzulassen, kann auch kein vernünftiges schulpolitisches Ziel sein. Trotzdem muß man sich darüber klar sein, daß auch die in Deutschland eingeleiteten Entwicklungen nicht frei von Risiken und Nebenwirkungen sind:

(1) Es können sich Rückwirkungen für Curricula und Unterrichtsmaterialien ergeben, die Ziel und Mittel umdrehen. Statt zu testen, ob man erreicht, was man erreichen will, versucht man zu erreichen, was sich auf eine einfache Weise testen läßt.

(2) Eine zunehmende Bedeutung von Testergebnissen für die Wertschätzung der einzelnen Schule im Urteil der Eltern kann Schulen zu unsinnigen Reaktionen veranlassen, z.B. Tests in extensiver Weise zu trainieren oder Schüler, von denen ein negativen Einfluß auf das Testergebnis erwartet wird, vom Test fernzuhalten.

(3) Die Funktion der Rechenschaftslegung (,accountability“) kann die der Verbesserung (,improvement") auf Dauer überlagern und statt zu einer Qualitätssteigerung zum Festhalten am (scheinbar) Bewährten verleiten. Diese Gefahr wäre insbesondere dann gegeben, wenn sich die Meßverfahren in der Fixierung auf einmal gewählte Parameter gegenüber der kritischen Reflexion komplexer Zusammenhänge unterschiedlicher Dimensionen von Leistung und Qualität verselbständigen.

(4) Standardisierung und Vereinheitlichung können die Reduzierung von Vielfalt bewirken, die gerade das Kennzeichen eines föderalen Systems

51 Vgl. in diesem Zusammenhang als Reaktion auf die Ergebnisse von TIMSS etwa die Erklärung der Fachverbände DMV, GDM und MNU vom 21. Mai 1998, die die Notwendigkeit einer konzeptionellen Veränderung des Mathematikunterrichts in Deutschland unterstreicht, sowie das Gutachten von Baumert et. al. für die BundLänder-Kommission für Bildungsplanung und Forschungsförderung (BLK 1997). 
sein soll. Auch wenn es unsinnig ist, unterschiedliche Bildungsziele gegeneinander auszuspielen, so kommt man doch nicht daran vorbei, daß sich nicht alle Ziele (zumal angesichts der Restriktionen im Zeitbudget von Schülerinnen und Schülern) gleichzeitig optimal realisieren lassen. Man muß sich also entscheiden. Diese Entscheidung kann unterschiedlich ausfallen. Man muß sie in ihrer Unterschiedlichkeit gelten lassen, solange sie sich innerhalb einer Bandbreite hält, die Durchlässigkeit und Vergleichbarkeit nicht ernstlich gefährdet.

(5) Das Leistungsniveau der Schülerinnen und Schüler einer Schule hängt stark von deren sozialen Kontextbedingungen ab. Ein ,,ranking "von Schulen, das diesen Aspekt vernachlässigt, ist nicht zulässig. Dennoch kann niemand garantieren, daß es angesichts der zu erwartenden plakativen Darstellung von Untersuchungsergebnissen zu hinreichend differenzierten Urteilen kommt. Eine Schule in objektiv ungünstiger Situation wird vermutlich auf Dauer eine ungünstige Wettbewerbssituation haben. Demotivation von Lehrkräften und Schülern könnte die Folge sein. Es ist offen, ob sich dieser Gefahr bereits dadurch ausreichend begegnen ließe, daß Gegenstand von Untersuchungen nicht der Leistungsstand zu einem bestimmten Zeitpunkt, sondern der Leistungszuwachs innerhalb eines bestimmten Zeitraums (value added approach) wird.

Die Gefahr von Fehlentwicklungen in dem damit angedeuteten Sinne ist durchaus real. Sie darf dennoch kein Grund sein, den Kopf in den Sand zu stecken und darauf zu verzichten, Urteilsmaßstäbe auch aus den Vergleichen mit anderen abzuleiten. Aber man muß sich der Möglichkeit einer mißbräuchlichen oder unkundigen Verwendung von Untersuchungsergebnissen sehr bewußt sein. Auch wenn niemand daran denkt, derartigen Entwicklungen Vorschub zu leisten, kann man nicht sicher sein, daß alle den Versuchungen auf Dauer widerstehen können. Die Faszination einer scheinbaren Objektivität, die sich ergibt, wenn man in einem allzu simplen Urteil die vielfältigen Aspekte vernachlässigt, die bei der Interpretation von Untersuchungsergebnissen bedacht sein wollen, ist nicht gering. Welche Dynamik den eingeleiteten Entwicklungen innewohnt, läßt sich deshalb derzeit kaum abschätzen. Wachsamkeit ist unerläßlich.

\section{Literatur}

Baumert, J./Bos, W./Watermann, R.: TIMSS/III - Schülerleistungen in Mathematik und den Naturwissenschaften am Ende der Sekundarstufe 11 im internationalen Vergleich. Zusammenfassung deskriptiver Ergebnisse, Berlin, 1998.

Baumert, J./Lehmann, R./Lehrke, M./Schmitz, B./Clausen, M./Hosenfeld, I./Köller, O./Neubrand, J.: TIMSS - Mathematisch-naturwissenschaftlicher Unterricht im Vergleich. Deskriptive Befunde, Opladen, 1997.

Behörde für Schule, Jugend und Berufsbildung Hamburg: Standardisierte Leistungsmessung als Instrument der Qualitätssicherung im Bildungswesen. Materialien für die Referendarinnen und Referendare, Hamburg, 1998. 
BLK: Gutachten zur Vorbereitung des Programms „Steigerung der Effizienz des mathematisch-naturwissenschaftlichen Unterrichts" der Bund-Länder-Kommission für Bildungsplanung und Forschungsförderung, Materialien zur Bildungsforschung, Heft 60, Bonn, 1997.

Lehmann, R/Peek, R./Gänsfuß, R.: Aspekte der Lernausgangslage von Schülerinnen und Schülern der fünften Klassen an Hamburger Schulen. Bericht über die Untersuchung im September 1996, Hamburg, 1997.

\section{THOMAS BETHGE Zum Umgang mit den Ergebnissen von TIMSS}

Durch die TIMS-Studie (Baumert u.a. 1997) wird der mathematische und naturwissenschaftliche Unterricht zum Gegenstand der öffentlichen Debatte. Seine Leistungsfähigkeit wird angezweifelt, das Selbstbild der Fachkolleginnen und -kollegen wird infrage gestellt. Es werden von der Öffentlichkeit Rezepte zur schnellen Veränderungen der Situation gefordert. Das deutsche Bildungssystem muß seinen Mittelplatz verlassen und einen Spitzenplatz im Nationenranking einnehmen. Die öffentliche Debatte ist nicht bei der Kritik der mathematischen und naturwissenschaftlichen Fachleistungen stehengeblieben, sie bezieht sich auf das gesamte Bildungssystem. Die große Bedeutung, die die TIMS-Studie durch die Verallgemeinerung ihrer Ergebnisse über die Naturwissenschaften hinaus erlangt hat, macht es nicht einfacher, die notwendige Weiterentwicklung des mathematischen und naturwissenschaftlichen Unterrichts zu diskutieren.

Die Kritik an Mathematik und Naturwissenschaften in der Schule ist nicht neu. Fachdidaktiker, Lehrer und Fachverbände haben die Kritik vorgetragen, sie erreichte nicht die Öffentlichkeit und erforderte damit keine bildungspolitischen Reaktionen.

Folgende Kritikpunkte wurden vorgetragen:

- Unterricht erlangt nur eine begrenzte Wirksamkeit für den Aufbau naturwissenschaftlichen Wissens und Könnens bei den Schülerinnen und Schülern. Ein kontinuierlicher Kompetenzzuwachs über die Schuljahre ist für sie nicht erfahrbar.

- Das Interesse am naturwissenschaftlichen Unterricht wird im Verlauf der Schulzeit geringer (s. Hoffmann/Lehrke 1986).

- Im Mathematikunterricht bestehen Defizite im Umgang mit der mathematischen Symbolsprache und bei der mathematischen Modellbildung (s. Heymann 1996). 


\section{Unterschiedliche Sichtweisen}

Die Ergebnisse der Studie, obwohl seit fast 2 Jahren in der Diskussion, werden noch immer sehr unterschiedlich wahrgenommen. Nicht nur die Bedeutung von schulübergreifenden Leistungstests für das Bildungssystem löst Kontroversen aus, auch die Bedeutung von TIMSS für den mathematischen und naturwissenschaftlichen Unterricht - den eigentlichen Gegenstand der Studie - wird unterschiedlich eingeschätzt:

- Die Seriosität und Wissenschaftlichkeit der Studie selbst wird infrage gestellt. Damit sind auch ihre Ergebnisse fragwürdig und die Notwendigkeit der Veränderung des Unterrichts gerät aus dem Blick. In dem Aufsatz von Hagemeister (1999) [...] wird dieser Weg der Auseinandersetzung mit TIMSS gewählt.

- Die Ergebnisse von TIMSS und ihre Interpretationen werden als eine Grundlage der Veränderung des Unterrichts genommen. Die Expertise „Steigerung der Effizienz des mathematisch-naturwissenschaftlichen Unterrichts“ (BLK 1997) legt diesen Weg nahe; sie ist Grundlage des entsprechenden Modellversuchsprogramm. ${ }^{52}$

Die beiden Positionen kennzeichnen sehr unterschiedliche Umgehensweisen mit den Ergebnissen der TIMS-Studie. Einem prinzipiellen Infragestellen steht eine instrumentelle Nutzung der Ergebnisse zur Weiterentwicklung des mathematischen und naturwissenschaftlichen Unterrichts in Schule gegenüber.

Die Kritik von Hagemeister (1999) - auch wenn sie für einzelne Items berechtigt erscheint - führt nicht von der Notwendigkeit ab, die Ausrichtung und die Ergebnisse des mathematischen und naturwissenschaftlichen Unterrichts kritisch zu hinterfragen. Die Kritik an der Formulierung einzelner Items stellt die Aussagekraft der gesamten Untersuchung nicht in Frage, zumal die Grundtendenz durch fachdidaktische Untersuchungen von Schülerkonzepten - allerdings nicht in dieser Breite - auch „vor TIMSS“ bereits erhoben und diskutiert worden ist.

Mit der Kritik an den Items will ich mich nicht auseinandersetzen, dies bleibt ihren Konstrukteuren vorbehalten. Einige Bemerkungen kann ich aber nicht unterlassen:

- Die Formulierungen der Items werden von Hagemeister (1999) analysiert ohne einen Bezug zum empirischen Antwortverhalten der Schülerinnen und Schüler herzustellen. So wird einem Item (I 10) ein besonderer Bezug zur US-typischen Ernährungslehre unterstellt, womit gleichzeitig eine „Bevorteilung“ des Landes unterstellt wird. Diese Einschät-

52 An dem Modellversuchsprogramm der Bund-Länder-Kommission für Bildungsplanung und Forschungsförderung (BLK) nehmen 15 Bundesländer mit insgesamt 180 Schulen teil. 
zung läßt sich aus dem Antwortverhalten nicht bestätigen. Deutsche Schülerinnen und Schüler antworten - im Sinne der Testkonstrukteure zu einem höheren Anteil richtig als die in den USA - bei etwa gleicher Lösungshäufigkeit in dem gesamten Teiltest (Life-Science).

- Die Vermutung von Hagemeister, daß physikalisches Wissen die Beantwortung eines Items (M12) zum Verhältnis von Stromstärke und Spannung in einem Stromkreis mit einer Glühbirne erschwert, erscheint mir kaum nachvollziehbar, auch wenn die Aufgabe von ihren physikalischen Inhalten her Schwächen hat. Die Lösungshäufigkeit liegt in Deutschland deutlich über der dem internationalen Mittelwert. Die zusammenfassende Aussage der TIMS-Studie über die mangelnde Fähigkeit bei deutschen Schülerinnen und Schülern zur Lösung komplexerer Aufgaben macht die vorgebrachte Deutung des Items unwahrscheinlich.

Die Diskussion der Test-Items in Bezug auf länderspezifische Besonderheiten, wie sie von Hagemeister durchgeführt wird, ist ein Einlassen auf ein Nationen-Ranking mit dem Versuch, den Rangplatz zu verschieben.

Für die Weiterentwicklung des naturwissenschaftlichen Unterrichts ist hingegen von Bedeutung, welche spezifischen Schwierigkeiten und Defizite der Unterricht ausweist und welche Richtungen der Veränderungen unter einer fachdidaktischen Perspektive bestehen. Die Ergebnisse der TIMSStudie bieten dabei die Möglichkeit, die Ergebnisse der Schülerleistung und die Unterrichtspraxis anderer Länder als Außensicht in die Reflexion über die eigene Unterrichtspraxis einzubringen.

\section{Veränderung des Unterrichts als Schulentwicklung}

In Bremen arbeitet ein Set von sechs Schulen im Rahmen des BLKModellversuchsprogramm ${ }^{53}$ an der Weiterentwicklung des mathematischen und naturwissenschaftlichen Unterrichts. Zwei Bereiche stehen im Mittelpunkt der inhaltlichen Arbeit im Schulset:

- Eine Veränderung der Struktur der Aufgabenstellung im Unterricht.

- Ein stärkerer Bezug zwischen der Einzelfächern des mathematischen und naturwissenschaftlichen Bereichs in einem Jahrgang und auch über die Jahrgänge hinweg durch ein verändertes schuleigenes Curriculum.

Die inhaltliche Arbeit greift Vorarbeiten der beteiligten Schulen auf und richtet sich an den Vorschlägen der Expertise (BLK 1997) aus.

Ein für die Arbeit an den Schulen des Sets unverzichtbarer Aspekt, der deutlich über die Veränderung der inhaltlichen Unterrichtsgestaltung hinausweist, ist die Veränderung des Verständnisses von Lehrerarbeit. In dem Aufbau und der Wiederbelebung kollegialer Zusammenarbeit, der ge-

53 Steigerung der Effizienz des mathematisch-naturwissenschaftlichen Unterrichts (SINUS). 
meinsamen Reflexion über Unterricht - auch durch gegenseitiges Hospitieren angeregt, liegt ein wichtiger Schlüssel für die Veränderung von Unterricht.

In der Zusammenarbeit des Fachkollegiums werden z.B. positive Erfahrungen mit einzelnen mathematischen Aufgabenstellungen eines Kollegen für die ganze Schule genutzt, aber auch hinterfragt und in ihrer Wirkung für den Lernprozeß der Schülerinnen und Schüler reflektiert. In diesem kollegialen Diskurs werden die von Hagemeister (1999) diskreditierten TIMSVideo-Studien als weiterer Bezugspunkt der Reflexion genutzt. Die Typik nationaler Unterrichtsskripte bei aller individuellen Verschiedenheit des Unterrichts schärft den Blick für tradierte Eigenheiten des diskutierten Unterrichts und bietet Möglichkeiten der vorsichtigen Veränderung.

Der Teil der TIMS-Studie, die sich auf das Ende der Sekundarstufe II (Population III) bezieht und keinen Leistungszuwachs in Mathematik zwischen dem 12. und 13. Jahrgang in 13jährigen Schulsystemen feststellt (Baumert u.a. 1998: 125ff.) ist von erheblicher Brisanz für die Gestaltung des Mathematikunterrichts in der gymnasialen Oberstufe.

Dieses Ergebnis wird von Hagemeister ohne nähere Begründung in $\mathrm{Ab}-$ rede gestellt, weil er nicht zwischen additiven und kumulativen Lernzuwachs unterscheidet. In der Darstellung von Baumert u.a. (1998: 126) ist auf die Sensitivität der Test-Items für einen kumulativen Lernzuwachs ausdrücklich hingewiesen worden. Dieses Ergebnis stellt einen wichtigen Hinweis für die Gestaltung und Überarbeitung von schulischen Sequenzen im Mathematikunterricht dar, er wird in der Diskussion im Schul-Set auch versucht aufzunehmen. Auch die Veränderung der curricularen Rahmenvorgaben in diesem Zusammenhang diskutiert werden.

Der in der BLK-Expertise (BLK 1997) zum Modellversuchsprogramm „SINUS“ angelegt Umgang mit den Ergebnissen der Messung der Leistungen der Schülerinnen und Schüler durch die TIMS-Studie macht deutlich, daß die Leistungsmessung sehr wohl einen fruchtbaren Beitrag zur Entwicklung von Schulen leisten kann. Die TIMS-Studie steht damit nicht im Gegensatz zur pädagogischen Entwicklung von Schule. Die Ergebnisse der Studie und ihre Interpretationen müssen den Schulen zur Verfügung gestellt werden. Schulen müssen Gestaltungsraum und -zeit für eine offene Debatte der TIMSS-Ergebnisse haben um sie vor dem Hintergrund ihrer jeweiligen Situation auswerten zu können.

\section{Literatur}

Baumert, Jürgen u.a.: TIMSS - Mathematisch-naturwissenschaftlicher Unterricht im interdisziplinären Vergleich. Deskriptive Befunde. Opladen: Leske + Budrich 1997.

Baumert, Jürgen / Bos, Wilfried / Watermann, Rainer: TIMSS/III - Schülerleistungen in Mathematik und den Naturwissenschaften am Ende der Sekundarstufe II im internationalen Vergleich. Berlin: Max-Planck-Institut für Bildungsforschung 1998. 
BLK-Gutachten: Steigerung der Effizienz des mathematisch-naturwissenschaftlichen Unterrichts. Bonn: Bund-Länder-Kommission für Bildungsplanung und Forschungsförderung 1997.

Hagemeister, Volker: Was lehrt uns TIMSS über Bildung und Leistungsmessung. In: Die Deutsche Schule, 91, 1999.

Heymann, Hans Werner: Mathematikunterricht in der Gymnasialen Oberstufe. In: Zeitschrift für Pädagogik. 42, 1996, S. 541-556.

Hoffmann, Lore / Lehrke, Manfred: Eine Untersuchung über Schülerinteressen an Physik und Technik. In: Zeitschrift für Pädagogik. 32, 1986, S. 189-204.

\section{RUDOLF MESSNER \\ Das Bildungskonzept von PISA als Teil einer globalen gesellschaftlichen Neuorientierung}

[...] Dem von PISA vertretenen Begriff von Basiskompetenzen ist ein verändertes Konzept von grundlegender Bildung zu eigen, das gegenüber dem herkömmlichen Verständnis deutlich Reformcharakter besitzt. Dies zeigt sich schon darin, dass für die Bezeichnung des neuen Konzepts auch der neue Begriff „Literacy“ eingeführt und mit den Inhaltsbereichen verbunden wird: Reading Literacy, Mathematical Literacy, Scientific Literacy (vgl. Baumert u.a. 2001: 17ff.).

Die literale Grundbildung wird in der PISA-Studie, um den Kernpunkt vorwegzunehmen, aus pragmatisch-funktionaler Sicht interpretiert. Sie umfasst jene Basisfähigkeiten, durch die einzelne Fachgebiete in produktiver Weise erschlossen werden können. Die einzelnen Literacy-Bereiche sind dabei allerdings nicht nebengeordnet. Lesekompetenz (Reading Literacy) besitzt insofern universelleren Charakter, als im Medium von Texten (vgl. Barton 1994) der Zugang zu allen übrigen Gegenstandsbereichen geschaffen wird.

Das Literacy-Konzept von Grundbildung lässt sich an der Lösung einer PISA-typischen Testaufgabe illustrieren. ${ }^{54}$ Die Aufgabe lautet (die als Reaktion darauf entstandene Lösungsskizze eines Studenten ist angefügt): „Martin und Maria gehen beide in dieselbe Schule. Martin wohnt fünf Kilometer von der Schule entfernt, Maria zwei Kilometer: - Wie weit wohnen Martin und Maria voneinander entfernt?"

Lehrerstudenten, denen die Aufgabe vorgelegt wurde, machten sich zunächst auf die Suche nach einer, ,eindeutigen“"Lösung. Als sich diese nicht finden ließ, vermuteten Einige, dass die Aufgabe eine Art „Falle“ darstelle, um Voreilige zu desavouieren. Auf die Versicherung, dass niemand hereingelegt werden solle und die Aufgabe tatsächlich Lösungen zulasse, stellte schließlich ein Nicht-Mathematiker, ausgehend von der von ihm selbst entworfenen [...] Skizze, folgende Überlegungen vor:

54 Für Hinweise sei Prof. Werner Blum, Universität Kassel, gedankt. 
„Ich habe um das Schulhaus zwei Kreise gezogen. Im Abstand von 2 Kilometern, das ist der Maria-Kreis. Im Abstand von 5 Kilometern, das ist der Martin-Kreis. Jetzt kann ich sagen: Martin und Maria wohnen maximal 7 und mindestens 3 Kilometer voneinander entfernt.“

Angeregt durch ihren Kommilitonen, trugen andere Studentinnen und Studenten weitere Ideen zur räumlichen Relation der Wohnorte von Martin und Maria bei unterschiedlicher Lage auf den beiden Kreisbahnen vor (darunter auch topografische Überlegungen für den Fall nicht geradlinig verlaufender Wege).

Was ist bei diesen Lösungsversuchen bemerkenswert? Offensichtlich wird, so einfach sich die Zahlenverhältnisse darstellen, die Erwartung einer eindeutigen, gar einer schematischen Lösung enttäuscht. Martin und Maria wohnen nicht auf derselben, geradlinig zur Schule führenden Wegstrecke. Um dennoch etwas aussagen zu können, muss ein Konzept der gegebenen Situation entworfen, ist - wie sich im Sinne von PISA sagen ließe - eine innere Aktivität des „Modellierens“ vonnöten. Das bedeutet nicht, dass rechentechnische Fähigkeiten keine Rolle spielen. Es muss auch addiert und subtrahiert werden. Den Kern des Lösungsverhaltens bildet aber eine der Aufgabe angemessene Modellbildung.

Als gebildet im Sinne der Aufgabe erweist sich also, wer nicht nach der bloßen Anwendung von Routinen strebt, sondern zur , konstruktiven “ Leistung einer eigenständigen Konzeptualisierung fähig ist (die Denkschule des „Konstruktivismus“ lässt grüßen!). Bildung besteht demnach im Lebendigmachen von Wissen in Anwendungssituationen. Überhaupt zielt PISA, entsprechend dem Literacy-Konzept, auf das Tüchtigsein in Verwendungsund Lebenssituationen. Allgemeiner gesagt, die in PISA getesteten Kompetenzen verstehen sich als basale Kulturwerkzeuge, die ein Bürger benötigt, um sich in seiner Welt, im gesellschaftlichen Leben nicht nur zu behaupten, sondern eine aktive Rolle spielen zu können.

PISA setzt also den Akzent auf fächerübergreifende, alltags-, schulund berufsbezogene Grundfähigkeiten (auf solider wissenschaftlich-pragmatischer Grundlage). Man kann dies als bildungstheoretisch höchst relevante Neubestimmung schulischer Zielsetzungen verstehen. Ein Bildungsverständnis, das sich nach Boenicke durch die fünffache Orientierung an Verständnis, Problemen, Anwendung, Kommunikation und Methoden kennzeichnen lässt (vgl. Boenicke 2000: 4). Ein solches Verständnis kann auch als neue Version von „Schlüsselqualifikationen“ betrachtet werden. Die Suche nach derartigen fachübergreifenden Fähigkeiten hat sich angesichts der Bereichsspezifität menschlicher Fähigkeiten oft genug als Illusion erwiesen. Mit der Literacy-Idee ist man jedoch solchen allgemeineren Qualifikationen auf der Spur. [...]

Aus soziologischer Sicht ist unverkennbar, dass sich die beschriebene Revision des Bildungsbegriffs in zentralen Schulfächern im Kontext dessen abspielt, was „Globalisierung“ genannt wird. Unter diesem schillernden Begriff kann das Aufsprengen nationaler oder staatlicher Ordnungen und 
Konzepte verstanden werden, wie sie sich aufgrund der weltweiten Vernetzung von Lebensbereichen gegenwärtig mit bisher nicht dagewesener Intensität vollzieht. An die Stelle vertrauter und oft lange Zeit tradierter Institutionen treten neue, teilweise noch diffuse übergreifende Einrichtungen (vgl. Beck 1997). Wir haben eine solche, im Zuge der Globalisierung erfolgende Neukonstitution scheinbar unverrückbarer Lebensformen und gesellschaftlichen Handlungsmuster im Bereich der Wirtschaft erlebt, auch im Wandel der Berufe oder in der Umstrukturierung der Landwirtschaft. Zuletzt hat sie uns die vor kurzem noch kaum vorstellbare Aufgabe der DM-Währung zugunsten des supranationalen Euro beschert.

In diesem Sinne sind auch PISA und seine Folgen ein Globalisierungsphänomen. Wir erleben nun im Bereich der Schule das vorher Undenkbare. Das deutsche Schulwesen wird in einen weltweiten Zusammenhang gestellt, und deutsche Lehrerinnen und Lehrer, Schülerinnen und Schüler müssen sich unmittelbar mit den Schulleistungen ihrer Kolleginnen und Kollegen oder Mitschüler in Japan, Finnland, Neuseeland und Luxemburg vergleichen lassen. $\mathrm{Zu}$ akzeptieren ist auch, dass die Leistungen der Schule nun für messbar gehalten werden. Regelmäßige empirische Leistungskontrollen an Schulen, wie sie im anglo-amerikanischern Bereich schon lange gang und gäbe sind, werden gegenwärtig in allen Bundesländern entweder schon durchgeführt oder vorbereitet.

Die eigentliche Pointe von PISA besteht darin, dass es sich bei 28 der 32 an der Vergleichsstudie beteiligten Länder um OECD-Staaten handelt. Deutschland tritt insofern mit der PISA-Studie im Hinblick auf zentrale Bereiche seiner Schulleistungen in Weltkonkurrenz mit den am meisten entwickelten Industriestaaten. Anders gesagt: Die entwickeltsten Industrieländer versuchen, mit PISA eine moderne, für den Übergang von der Industrie- zur Wissensgesellschaft angemessene moderne Bildungskonzeption zu entwickeln. Deutschland erhält damit die Gelegenheit, die auch als Chance begriffen werden kann, sich in diese Entwicklung zu integrieren.

In PISA 2000 wird der komplexe Zusammenhang des PISA-Bildungskonzepts mit der Entwicklung zur Wissensgesellschaft in internationaler Konkurrenz ausdrücklich thematisiert:

„Der Gedanke der notwendigen Universalisierung von Basisqualifikationen wird in der angelsächsischen Literacy-Diskussion mit dem Argument neuer und infolge des sich beschleunigenden Wandels von der Industrie- zur Wissensgesellschaft steigender Qualifikationsanforderungen verknüpft. Die Messlatte für muttersprachliche, mathematische und naturwissenschaftliche Literalität wird sichtbar höher gelegt; schlichte Alphabetisierung genügt diesem Anspruch nicht“" (Baumert u.a. 2001: 20).

Die Kernüberlegung lautet, dass seit Ende des 20. Jahrhunderts anstelle des Faktors Arbeit dynamisch einsetzbares Wissen zur zentralen gesellschaftlichen Produktivkraft geworden ist (vgl. Brödel 1998: 2ff.). Demzufolge muss der Entwicklung solcher Wissensgrundlagen und -formen höchste Priorität eingeräumt werden, wenn eine Gesellschaft im globalen Wettbe- 
werb nicht nur ihren Bildungsstandard, sondern ihr ökonomisches Potenzial und ihren Wohlstand behaupten will. Die weitere Konsequenz besteht darin, die Förderung problem-, anwendungs- und lebensbezogenen Wissens sowie individueller und kooperativer Arbeitsweisen, welche das Denken und selbständige Handeln der Lernenden aktivieren, in den Mittelpunkt von Schule zu rücken.

Wie ist die beschriebene Revision des Bildungsverständnisses durch PISA aus erziehungswissenschaftlich-pädagogischer Sicht einzuschätzen? Kein Zweifel, das PISA-Bildungskonzept bedeutet in vieler Hinsicht einen Gewinn. Es gibt den Anstoß, eine Reihe von Einseitigkeiten und Ausblendungen im bisherigen Bildungsverständnis zu überwinden. Dies gilt vor allem für die in der einheimischen Tradition durchgängig zu gering geschätzte pragmatische Dimension von Bildung oder für die oft übersteigerten Berührungsängste gegenüber der objektivierenden Überprüfung von Schulleistungen. Das PISA-Bildungskonzept betont auch, angesichts der aktuellen Bildungssituation ein dringliches Anliegen, die Bedeutung von Wissen, vor allem im Hinblick auf dessen dynamischen Aspekt zur aktiven Fortentwicklung individueller Kompetenz (was das PISA-Konzept in eine, von den Kritikern zu wenig beachtete Nähe zu klassischen Bildungskonzepten bringt).

Es deutet sich allerdings auch an, dass das PISA-Bildungskonzept zumindest die Gefahr birgt, Anlass von nicht unproblematischen Akzentverschiebungen und möglichen neuen Einseitigkeiten zu werden. Auch wenn man die Leistungen der Lehrer- und Schülerarbeit in wesentlichen Aspekten für objektivier- und messbar halten und insofern externe Evaluation für ein unverzichtbares Korrektiv gegenüber schulischem Wunschdenken und Selbsttäuschung halten muss, bleibt doch das Bedenken, dass aufgrund von PISA die Messbarkeit von Bildungsprozessen überschätzt werden könnte. Menschenbildung ist in vieler Hinsicht, gerade in zentralen Aspekten, aber nur schwer oder überhaupt nicht in Testsituationen „,messbar“, und die persönliche Erfahrung und das individuelle Urteil von Beteiligten sind nicht so unzuverlässig, wie oft glauben gemacht wird.

$\mathrm{Zu}$ fragen ist auch, ob im funktional-pragmatischen Bildungskonzept von PISA nicht eine Reihe zentraler Aspekte ausgeblendet werden, nämlich sinnliche, handelnd-emotionale, ästhetische und kritisch-reflexive Momente, die auch in der Moderne für ein Bildungsverständnis, in dem wir unsere Geschichte und Identität wiederfinden und in zeitgemäßer Form bewahrt wissen können, unaufgebbar sind.

Hinweise auf solche Einschränkungen finden sich in PISA 2000 selbst, etwa wenn im Hinblick auf den Lesekompetenz-Tests gegenüber Zielsetzungen literarischer Bildung formuliert wird: „Dies bedeutet gleichzeitig, dass Leseverständnis Voraussetzung und Teil sprachlichliterarischer Grundbildung ist, mit dieser aber selbstverständlich nicht deckungsgleich ist. Insofern gibt PISA auch keine annähernd erschöpfende Auskunft über diesen zentralen Bereich der Allgemeinbildung" (Baumert u.a. 2001: 21). 
Die PISA-Autoren werden gegenüber diesem Vorbehalt einwenden, dass sich PISA notwendigerweise auf die Basisqualifikationen konzentriere - und eben nicht auf alle Ziele des darauf aufbauenden weiteren, gleichsam höheren literarischen Bildungsprozesses. Zudem liefern die PISA-Daten eine gute Prognose auch für die in der literarischen Bildung geforderten und dort besonders wichtigen sprachlich-kognitiven Kompetenzen. Dagegen ist allerdings wiederum zu sagen, dass eine umfassend verstandene literarische Bildung - nach allen vorliegenden Erfahrungen - auch schon Ziel und Inhalt des Lernens von Kindern, also des Konzepts der Basiskompetenzen zu sein hätte.

Diese Fragen sollten m.E. keineswegs dramatisiert werden. PISA besitzt gerade im Bereich der Lesekompetenz das Verdienst, auf die grundlegenden Qualifikationen aufmerksam zu machen, auf die auch jede Bildung in einem höheren Sinne notwendig aufbaut. Gerade die Konzentration und der Verweis auf die unerlässlichen Basiskompetenzen sind für die Entwicklung unseres Schulwesens von hoher Bedeutung. Andererseits sind noch nicht alle Fragen geklärt, etwa die, ob das PISA-Bildungskonzept mit seiner notwendigen Akzentsetzung nicht selbst dazu beitragen könnte, die Vorstellungen von Bildung im materialen Sinne zu verengen. Solche Fragen zu diskutieren, ist vor allem im Hinblick auf die aus PISA zu ziehenden praktischen Konsequenzen wichtig. Eine solche grundlegende Bildungs-Diskussion in Gang gebracht zu haben, kann übrigens auch als Verdienst von PISA 2000 angesehen werden.

\section{Literatur}

Barton, David 1994: Literacy. An Introduction to the Ecology of Written Language. Oxford: Blackwell.

Baumert, Jürgen u.a. 2001: PISA 2000. Basiskompetenzen von Schülerinnen und Schülern im internationalen Vergleich. Opladen: Leske + Budrich (auch zitiert als: Deutsches PISA-Konsortium (Hg.) 2001).

Beck, Ulrich 1997: Was ist Globalisierung? Edition Zweite Moderne. Frankfurt am Main: Suhrkamp.

Boenicke, Rose 2000: PISA und die Suche nach einem internationalen Kerncurriculum. Neue Maßstäbe für Grundbildung? In: Die Deutsche Schule, 92, Heft 4, S. 394-406.

Brödel, Rainer (Hg.) 1998: Lebenslanges Lernen - lebensbegleitende Bildung. Neuwied: Luchterhand. 

Was beinhaltet schulische Modernisierung?

II. 



\section{Vorbemerkung}

Im folgenden Textblock werden die Instrumente und Methoden von Schulmodernisierung genauer vorgestellt. Diese Konzepte sind nicht mehr lediglich Semantiken, sondern Organisationskonzepte und -instrumente, mit der Schulen hinsichtlich ihrer Personal-, Organisations- und Unterrichtsdimensionen umgestaltet werden können. Wesentliche Bedeutung haben dabei Instrumente der Qualitätsentwicklung, die auch in anderen gesellschaftlichen Teilsystemen auf der Organisationsebene für Modernisierungsbestrebungen Verwendung finden. Wir wechseln damit von der gesellschaftlichen Makroebene hin zur Mesoebene der einzelnen Schule, d.h. vor allem: ihrer Organisationsdimensionen. Die neue Governance sieht vor, dass zwischen strategischer Führung und operativer Umsetzung unterschieden wird, was die Einzelschule als eine qualitätsbasierte Organisation aufwertet.

Bei der Auswahl der Texte sprechen wir zuerst Probleme der Qualitätssicherung in genereller Perspektive an (Terhart und Bähr) und wechseln dann zu Organisationsfragen, die eine schulische Organisation als Ganze betreffen (Buschor und Kempfert/Rolff als Beispiele für die top-downSicht; Maritzen und Mäder als Beispiele für die bottom-up-Perspektive). Weitere zwei Texte beschäftigen sich mit dem Interaktionszusammenhang Schule (Bastian, Klippert). Alle Texte gehen im Prinzip sowohl auf die Dimensionen Organisation wie auch Unterricht ein, aber es lassen sich unterschiedliche Schwerpunkte, entweder mit Blick auf die Organisationsoder auf die Unterrichtsdimension erkennen. Dies deutet schon an, dass es keine einheitliche Sicht darüber gibt, was in einem Modernisierungsprozess schwerpunktmäßig verändert werden soll.

Wir beschränken uns hier darauf, Sachinhalte der Schulmodernisierung aus Sicht der Bildungsverwaltung (siehe die Texte von Buschor; Maritzen; ebenfalls Bähr) sowie der Profession (Kempfert/Rolff; Terhart sowie potentiell Maeder) vorzustellen. Anschließend lässt sich dann im darauffolgenden Textblock überlegen, wie Akteure der Einzelschule diese Sachinhalte aufgreifen und interpretieren. ${ }^{1}$

1 Es dürfte deutlich werden, dass die Textblöcke II und III in enger Verbindung stehen, da in beiden Akteure und Akteurkonstellationen angesprochen werden. Die beiden Akteure, die in Textblock II im Mittelpunkt des Interesses stehen, die Bildungsverwaltung und die Profession des Schulsystems, müssten eigentlich auch im Textblock III gesondert behandelt werden. Wesentlicher Grund für ihr dortiges Fehlen ist, dass die Bildungsverwaltung und die Profession des Schulsystems als Akteure schwieriger zu bestimmen sind, da sie nicht wie die anderen Akteure vornehmlich lokal an einer Einzelschule agieren, sondern auch national und international. Wir haben folglich die Sachverhalte, die mit den beiden Gruppen verbunden sind (nämlich ,top-down“ bestimmte Modernisierungsinhalte vorzuschlagen oder solche ,bottom-up“ zu entwickeln), auf den folgenden Buchabschnitt konzentriert, ohne in Textblock III nochmals auf die sozialen Konturen dieser Akteure zu verweisen. 
Bevor wir auf die einzelnen Texte eingehen, ist die grundsätzliche Richtung anzugeben, auf die die derzeitige organisationale Umgestaltung der Schule hinzielt. Dazu muss kurz die bisherige Organisation Schule angesprochen $\operatorname{sein}^{2}$, was im Folgenden nur ausschnittartig und begrenzt auf Deutschland geschehen soll.

Die bisherige Schulorganisation zerfällt in zwei Bereiche: erstens in eine Ablaufbürokratie des Staates, die wichtige Rahmen für die unterrichtliche Interaktion setzt, aber in diese selbst nicht hineinsteuert; und zweitens die unterrichtliche Interaktion selbst, in der sich professionelle Lehrkräfte um unterrichtsbezogene Standards kümmern. Entsprechend diesem Doppel sind die Rollenstrukturen der Lehrkräfte einerseits formal auf die staatliche Arbeitsorganisation Schule gerichtet, insofern es individuelle Arbeitsverträge gibt, die auf einem Tausch von Leistung gegen Lohn basieren. Andererseits orientieren sich Lehrkräfte an inhaltlichen Standards der Unterrichtsinteraktion, d.h. in ihrem eigentlichen Leistungsbereich an der schulischen Profession.

Die bürokratische Organisation Schule ist nur lose an die unterrichtliche Interaktion gekoppelt - sie bildet nur den äußerlichen Rahmen. Der Bearbeitung von Unterrichtsaufgaben fehlt also jegliche Organisationsperspektive.

Das Unterrichtsgeschehen wird nicht kollektiv nach festen Mitgliedschaftsregeln einer Organisation strukturiert, sondern nach Standards einzelner Professioneller. In der ,neuen Schule ${ }^{6}$ als einer qualitätsbasierten Organisation (vgl. z.B. Kempfert/Rolff in diesem Textblock) sind gerade nicht einzelne Lehrer, sondern Teams für Unterrichtsbelange vorgesehen.

Generell wurde der Unterricht in der Pädagogik bislang so gesehen, dass er aus hochgradig variierenden Interaktionssituationen besteht, der sich nicht mit formalisierten Organisationstechniken bzw. Technologien bearbeiten lässt (vgl. zu diesem sog. „Technologiedefizit“ des Bildungssystems: Luhmann/Schorr 1982). Bei den Qualitätsmanagements wird dagegen gerade von der Technisierbarkeit nicht nur von Organisations- und Personalfragen, sondern auch von Unterrichtsaspekten ausgegangen. In der neuen qualitätsbasierten Schule können alle drei Bereiche „organisational“ bearbeitet werden - die neue Technik basiert auf den Teams.

Es ist für die neuere Diskussion um die schulische Organisation entscheidend, dass die bisherige bürokratische Organisation kaum Möglichkeiten hatte, von der Makroebene des Schulsystems ausgehend - der Bildungsverwaltung und der Politik - auf Unterricht zuzugreifen. In der ,alten' Governance ist die bürokratische Organisation Schule nur lose an Unterricht gekoppelt. Im vom Staat und der Bildungsverwaltung ausgehenden

2 Bis auf wenige Ausnahmen (vgl. Lenhardt 1984; Terhart 1986) ist in der Pädagogik die Organisationsdimension der Schule stiefmütterlich behandelt, vgl. aber neuerdings Oelkers (2000b: 110-133); Gomolla/Radtke (2002: 54-77); Kuper (2003). Für die Soziologie vgl. Luhmann/Schorr (1979) sowie Luhmann (2002: 142-167). 
neuen Governance-Modell, das sich am NPM und Qualitätsmanagements ausrichtet, soll dagegen die Schulpraxis nicht mehr wie bislang lose an die Organisation Schule gekoppelt sein; vielmehr soll es eine Organisation mit echten Zugriffsmöglichkeiten auf den Unterricht geben, die zugleich mit der Bildungsverwaltung und dem Staat kommunizieren kann. Damit würden - vermittelt über die qualitätsbasierte Schule - Staat und Bildungsverwaltung Zugriff auf den Unterricht haben. Es würde also erstmals eine systematische Verbindung zwischen der Makroebene (den Entscheidungsträgern in Politik und Bildungsverwaltung) und der Mikroebene des Unterrichts geben; die Verbindung würde über die Mesoebene der Einzelschule mit Hilfe von Qualitätsmanagements hergestellt. Eine qualitätsbasierte Schule würde gemäß dem neuen Governance-Modell des NPM operative Entscheidungsfreiheiten haben, aber auch innerhalb dieser operativen Freiheit stärker an die neue Governance gebunden sein, insofern es Staat und Bildungsverwaltung sind, die die Trennung zwischen strategischen Rahmenplanungen (für die sich die beiden Akteure selbst vorsehen) und operativer Ausführung durch die Einzelschule regulieren. Allerdings gibt es eine qualitätsbasierte Schule als eigenständige Mitgliedschaftsorganisation bislang nicht. Sie herzustellen hat sich insbesondere die pädagogische Qualitätsentwicklung zur Aufgabe gemacht, welche als untrennbarer Teil der neuen Governance zu sehen ist. 


\section{Einführungstexte}

\section{Kommentar (Eubel)}

Zwei Akteure sind besonders aktiv im Umgang mit dem Thema „Modernisierung der Schule“: die Bildungsverwaltung und eine Teilgruppe der Profession - die Wissenschaft. Das wesentliche Unterscheidungsmerkmal der beiden Akteurgruppen ergibt sich aus ihrem ,Auftrag'. Während die Wissenschaft abwägend das Für und Wider erörtert, steht die Bildungsverwaltung unter Handlungszwang. Sie will ,machen', auch wenn die Signale aus der Wissenschaft noch nicht auf ,grün' stehen. ${ }^{3}$

Ein Merkmal vieler Publikationen, aber auch vieler Reforminitiativen besteht nun darin, dass sie sich mit Detailaspekten befassen, beziehungsweise partielle Reforminitiativen anstoßen, die es dem Beobachter und auch den Betroffenen schwer machen, diese einordnen zu können. Aus diesem Grund haben wir an den Anfang dieses Textblockes zwei Texte gestellt, die äußerst differenziert und präzise versuchen, einen systematischen Überblick zu liefern.

Ewald Terhart (Universität Münster) beleuchtet die Hintergründe der Qualitätsdebatte, untersucht ihre Konzepte und fragt danach, wie die Maximen von Qualität und Qualitätssicherung und die Schule als Organisation und Handlungsfeld zusammenpassen. Er kommt zu relativ skeptischen Einschätzungen, die sich aus der abwägenden Konfrontation einer neuen Programmatik und den besonderen Bedingungen der Schule ergeben. ${ }^{4}$

Konstantin Bähr (Bildungsdirektion des Kantons Zürich, Abteilung Bildungsplanung) weist in seinem Beitrag am Beispiel standardisierter Testverfahren die große Bedeutung von Input-Steuerung und den begrenzten Stellenwert der Output-Steuerung für die Qualität des Unterrichts nach. Der systematische Ertrag seiner Darstellung wird noch dadurch gesteigert, dass er zeigt, wie die Systemebenen (Makro-, Meso- und Mikroebene) des Bildungssystems miteinander verknüpft sind, wenn es gilt, ,Qualität‘ im Unterricht herzustellen.

3 Es lässt sich jedoch keine trennscharfe Unterscheidung der beiden Akteurgruppen (in die ,abwägenden' Wissenschaftler auf der einen und die ,ungeduldigen " und möglicherweise ,voreiligen Macher' auf der anderen Seite) leisten. Viele Wissenschaftler agieren in beiden ,Kulturen' gleichzeitig, als ,fragende“ Forscher und als Berater der Bildungspolitik, die aktiv an der Entwicklung von Programmen mitwirken oder diese sogar initiieren. So wie auch das Bild der hyperaktiven Administration, die ständig etwas Neues ausprobiert, ohne sich auf Daten und Befunde der Wissenschaft zu stützen, ebenfalls nicht stimmt (vgl. dazu Maritzen 2001). Dennoch sind die Beziehungen zwischen beiden Gruppen nicht ganz problemlos (vgl. grundsätzlich: Terhart 2001a; Tillmann/Vollstädt 2001; Weegen u.a. 2002).

4 Aufgrund seines Informationsgehalts und wegen seiner Systematik kann dieser Text als ein zentraler Bezugspunkt dieses Buches gelten. 


\section{EWALD TERHART \\ Qualität und Qualitätssicherung im Schulsystem: Hintergründe - Konzepte - Probleme}

\section{Einleitung}

Qualität ist zu einem der leitenden Begriffe innerhalb des allgemeinen Bildungsdiskurses geworden und hat mittlerweile eine Prominenz erreicht, die durchaus derjenigen früherer Leitkonzepte wie etwa Kindgemäßheit, Chancengleichheit, Emanzipation oder Wissenschaftsorientierung entspricht. Nun sind derartige Leitkonzepte nie als präzise definierte, empirisch operationalisierte oder auch nur operationalisierbare Landmarken innerhalb des Diskursfeldes „Bildung“ zu betrachten, sondern viel eher als begriffliche Verdichtungen breit gefächerter Bündel von Argumenten, Zielsetzungen, Überzeugungen und Verfahrensvorschlägen.

$$
[\ldots]
$$

\section{Hintergründe des Qualitätsdiskurses im Schulbereich}

Es ist eine komplexe Gemengelage von wissenschaftsinternen und -externen Faktoren, die dazu geführt haben, daß der Begriff der "Qualität“ sowie daran angeknüpfte Wortverbindungen seit einigen Jahren einen zentralen Stellenwert im Bildungsdiskurs erhalten haben. ${ }^{5}$

\subsection{Forschungs- und Innovationserfahrungen}

Zunächst einmal ist auf Forschungs- und Innovationserfahrungen innerhalb des Schulbereichs hinzuweisen: Die Steigerung von Quantitäten allein (mehr Schulen, mehr Lehrer etc.) führt zwar zu massiven Expansionen im Bildungsbereich und ändert ebenso das Verhältnis zwischen nichtinstitutionalisierter Lebenswelt und institutionalisierten Formen von Lehren und Lernen, Bildung und Erziehung - die tatsächlichen Ergebnisse der Teilhabe an Bildungs- und Ausbildungsprozessen werden damit jedoch nicht unbedingt und in gleichem Maße besser bzw. bleiben davon unberührt oder verschlechtern sich gar. [...] Die Schulforschung hat die Unfruchtbarkeit von pauschalen Systemvergleichen erkennen müssen, denn die Differenzen zwischen Schulen ein und derselben Form können größer sein als diejenigen zwischen verschiedenen, konkurrierenden Systemen.

5 Auf einer gesellschaftspolitischen Ebene ist es die Umstellung der in den 1960er und 1970er Jahren dominierenden vier Leitkonzepte Quantität, Egalität, Staat und Wissenschaft auf Qualität, Exzellenz, Markt und Evaluation (vgl. die Einleitung der Herausgeber zu Helmke/Hornstein/Terhart 2000). 
Die Erfahrung der Betroffenen (Schüler) wird strukturiert durch die innerhalb der einzelnen Arbeitseinheiten erbrachten Leistungen.

Mit dem Wechsel von der am Vergleich von Schulsystemen ansetzenden Forschung zur differenzierten Analyse innerhalb und zwischen Schulen derselben Art wird die Aufmerksamkeit von den großen quantitativen Systemparametern auf die Qualität der Erfahrung der Betroffenen vor Ort umgestellt. Schulforschung hat überzeugend zeigen können, daß einzelne Institutionen gleichen Typs, gleichen Umfelds und gleicher Ressourcenversorgung eine sehr unterschiedliche Qualität ihrer Prozesse sowie einen divergierenden Wirkungsgrad erreichen können. Die Bedeutung quantitativer Indices (Finanz- und Personalversorgung etc.) wird damit nicht reduziert, denn auf der unteren Ebene kann man Qualität auch anhand quantitativer Kenngrößen sichtbar machen. Es handelt sich im Grunde um eine Ausweitung der Optik bzw. Fragehaltung: die Auswirkungen aller Maßnahmen und Entscheidungen - der makroskopischen wie der mikroskopischen werden an ihrem Beitrag für erfahrbare, empirisch bestimmbare Qualität der institutionellen Leistungen bemessen.

\subsection{Enger werdender Finanzrahmen}

Als zweiter Faktor ist auf die immer drängender und wichtiger werdende Finanzierungsproblematik hinzuweisen. Bildungs- und Schulsysteme sind nicht zum Nulltarif zu haben, sondern kosten viel Geld. Dies gilt in gleichem Maße für private wie öffentliche Finanzierung. In dem Maße, wie die politischen Entscheidungsträger aufgrund des auf den öffentlichen Haushalten lastenden Spardrucks weder bereit noch in der Lage sind, Änderungen, Verbesserungen und Ausweitungen von Bildungseinrichtungen durch erhöhte finanzielle Zuwendungen seitens des Staates zu finanzieren, wächst der Druck auf die genannten Bereiche, Änderungen, Umstellungen und Verbesserungen durch interne Mittelumschichtung, durch Einwerbung von Drittmitteln aller Art sowie generell durch klügeren Mitteleinsatz zustande zu bringen. Diejenigen Elemente einer Institution, die zu diesen Wirkungen nichts beitragen, stehen zur Disposition, denn es widerspräche dem für alles rationale Handeln grundlegenden Prinzip der Mittelökonomie, wenn man mit den zur Verfügung stehenden Ressourcen nicht den optimalen Wirkungsgrad in Richtung auf die vorgestellten Ziele anstreben würde. Umgekehrt bedeutet dies, daß man ebenso nicht auf die Chance verzichten sollte, gleiche Wirkungen mit weniger Ressourceneinsatz zu erzielen. Der kluge Einsatz grundsätzlich limitierter Mittel wird zur zentralen Aufgabe, denn auf absehbare Zeit wird es vermutlich keine durchschlagenden finanziellen Zuwächse geben - wohl aber einen Zuwachs an Rechtfertigungsdruck auf den Bildungsbereich insgesamt sowie auf die einzelnen Einrichtungen innerhalb dieses Bereichs. Letztere werden sich untereinander daraufhin vergleichen lassen müssen, wie produktiv sie unter Berücksichtigung jeweiliger Ausgangs- und Umfeldbedingungen ihre Mittel einsetzen. 
Qualität kann nicht länger als selbstverständlich behauptet werden - sie muß auf empirischer Basis vergleichend und öffentlich dokumentiert werden. Dies gilt auch und gerade für ,moralische“ Zwecke bzw. Einrichtungen, die an sich weitgehend unstrittig sind.

So befremdlich, unangemessen oder gar empörend es vielleicht erscheinen mag, Bildungs- und Erziehungsprozesse sowie Lehr- und Lernaufgaben unter betriebswirtschaftlichen Gesichtspunkten zu betrachten bzw. aus dieser Sicht heraus Druck auf die entsprechenden Organisationen und ihr Personal auszuüben - geht es doch um grundsätzlich positive und notwendige Dinge wie individuelle Bildung, zeitgemäße Qualifizierung, soziale Solidarität und allgemeine Humanität -, so ist gleichwohl festzuhalten, daß aus der Bildungsadministration heraus schon immer besorgte und mehr oder weniger vorsichtige Fragen nach Effektivität und Effizienz gegeben hat. Solche Fragen konnten in Zeiten von Zuwächsen und Expansionen und anderer politischer Prioritäten vergleichsweise leicht stillgestellt werden. Das Insistieren auf Effizienz (Verhältnis von Aufwand und Ertrag oder: Werden die tatsächlich erreichten Ziele kostengünstig erreicht?) und Effektivität (Verhältnis von Absicht und Wirkung oder: Werden tatsächlich die Ziele erreicht, die erreicht werden sollen?) sowie die dahinterliegenden allgemeinen Denkmuster haben seit gut einem Jahrzehnt allerdings eine immer größere Dringlichkeit erhalten: Auch im Bildungswesen wird Qualität eben nicht mehr allein an guten Absichten, sondern an den erzielten Wirkungen sowie schließlich am Verhältnis von Aufwand und Ertrag bemessen.

\section{3 Übertragung ökonomischer Denkmodelle auf den Bildungsbereich}

Im Zusammenhang mit dem Hinweis auf die Grenzen der Finanzierbarkeit werden ökonomische Denkmodelle auf den Bildungsbereich übertragen. [...] Im „Total Quality Management (TQM)“ (vgl. Frehr 1994; Zemke 1993) werden Arbeitseinsatz, Präzision, Verantwortungsbewußtsein sowie das rastlose Bemühen um Verbesserungen, die ganzheitliche Hingabe des einzelnen an den Betriebszweck, kurzum: die fast schon religiös zu nennende ,totale“ Ausrichtung aller Betriebsabläufe auf Qualität im Dienste der Kundenzufriedenheit propagiert.

Aus dem privatwirtschaftlichen Bereich sind solche Denkmodelle auf den Bildungsbereich übertragen bzw. von hier aus übernommen worden und haben dort mittlerweile Fuß gefaßt, wobei allerdings nicht die Wirtschaftswissenschaften selbst den Bildungsbereich für sich entdeckt haben. Es waren vielmehr Politik und Administration, die verstärkt die Anwendung ökonomischer Denkmodelle aus der privatwirtschaftlichen Sphäre der Güterproduktion und des Dienstleistungssektors auf Schule übertragen haben bzw. übertragen sehen wollten. Dies führt solange und insofern zu großen Schwierigkeiten, als das Schulwesen als dominierend öffentlichstaatlich-steuerfinanziert, also nicht privatwirtschaftlich organisierter Sek- 
tor keine wirkliche Marktkonkurrenz der einzelnen Anbieter kennt, eine marktgesteuerte Preisbildung nicht stattfinden kann und insofern ein aus Marktkonkurrenz erwachsender Rationalisierungsdruck nicht besteht. ${ }^{6}$

\subsection{Nicht überzeugender Wirkungsgrad der Institutionen}

[...] Die ungewöhnlich intensiven politischen und öffentlichen Reaktionen auf TIMSS (s.u.) sowie auch auf andere, betriebs- und arbeitswissenschaftlich ansetzende Studien (Kienbaum in NRW und Bremen; Mummert \& Partner in NRW) sind ein Indikator dafür, daß das Bildungssystem und seine Einrichtungen nicht mehr gleichsam automatisch der Wirkungskontrolle entzogen sind, sondern sich der Frage nach dem Verhältnis von Aufwand und Ertrag stellen müssen.

Durch diese Sicht wird auf einer allgemeineren Ebene in der Öffentlichkeit an latent bereits vorhandene negative Einstellungen zu Institutionen sowie Personal im Bildungs- (und auch Sozialbereich) angeknüpft; durch mediengerechte Darstellung (Vereinfachung, Skandalisierung, Moralisierung) wird die negative Einstellung noch weiter verstärkt. In schöner Regelmäßigkeit wird in den Medien Lehrer- bzw. generell Pädagogenschelte praktiziert - wobei Hochschullehrer hierin immer eingeschlossen sind. Berichte über Vorfälle innerhalb sozialpädagogischer Einrichtungen, über ebenso teure wie wirkungslose sozialpädagogische Fallarbeit, über „Deutschlands faulsten Lehrer“ etc. rücken öffentlichkeitswirksam letztlich alle Institutionen und Professionen im Bildungs- und Sozialbereich in ein trübes Licht. In manchen (gerade auch akademischen) Milieus schlagen Lehrern, vor allem aber Sozialpädagogen und Sozialarbeitern Spott und Ironie, ja Verachtung entgegen. [...] Romantisch-anarchistische Apparateund Professionenkritik trifft sich mit ökonomisch motivierten Spar-, Deregulierungs- und Rationalisierungsinteressen und führt im Ergebnis zur gemeinsam praktizierten Strategie der Verlagerung von Risiken und Kosten auf die einzelnen: Die einen feiern dies emphatisch als „Wiedererstarken des Subjekts“, die anderen sprechen kühl von „Mehr consumer“s choice!“”und machen Kasse.

\section{Konzepte von Qualität}

\subsection{Normative Bestimmungsversuche}

[...] Im Blick auf Qualität, die ja in unterschiedlichen Abstufungen auftreten kann, interessiert zunächst immer die höchste Stufe von Qualität: Es

6 Ganz anders sind die Verhältnisse im Bereich der Erwachsenenbildung bzw. Weiterbildung. Hier existiert eine große Zahl von öffentlichen und privaten Anbietern, die um Kunden konkurrieren und insofern den Marktmechanismen unterliegen. Insbesondere in der (beruflichen) Weiterbildung sind die Qualitätsdiskussion sowie das konkrete Qualitätsmanagement sehr viel weiter fortgeschritten als im Schulbereich. 
geht um die „gute Schule“. Dies ist durch Rückgang auf empirisch zu ermittelnde Sachverhalte in Schulen oder Wirkungen von Schulen allein nicht zu bestimmen, denn es muß eine Entscheidung darüber gefällt werden, welche Sachverhalte und Wirkungen man als Ausdruck hoher Qualität betrachten will. In diese Entscheidungen fließen unausweichlich und massiv normative Vorstellungen über pädagogische, bildungspolitische Ziele und Absichten ein. Eine „gute Schule“ ist dann eine solche, die sich zu diesen normativen Setzungen bekennt bzw. diese übernimmt, innerhalb ihres Programms sowie in ihrer täglichen Arbeit möglichst umsetzt und die vorgestellten Ziele als tatsächliche Wirkungen auch möglichst weitgehend erreicht. Die Quellen für solche normativen Setzungen können Traditionen, allgemein- und sozialpolitische Überzeugungen, sozial- und bildungstheoretische Erwägungen und Entscheidungen, können normative Menschenbildannahmen sowie globale Zielvorstellungen über Personen-, Gesellschafts- oder gar Menschheitsentwicklung generell sein.

Wichtig und kennzeichnend für normative Bestimmungsversuche ist der Sachverhalt, daß die Zielvorstellungen als Kriterien hoher und höchster Qualität vielfach und zunächst einmal nicht im Blick auf empirische oder sonstige Restriktionen, auf alltägliche Umsetzungsprobleme oder ökonomische Kosten/Nutzen-Kalküle, auch nicht auf der Basis empirischer Zweck/Mittel-Erprobungen entwickelt werden, sondern sich im normativen Raum der Setzung von übergeordneten, „letzten“ Zwecken sowie der Ableitung von daraus resultierenden Konsequenzen bewegen. Normative Bestimmungs- und Begründungsversuche von Qualität jedoch, die sich allein auf Setzungen und deren immanent-systematische Begründung beziehen, nicht aber zugleich den historisch-gesellschaftlichen Wert- und Problemwandel sowie ebenso die je gegebenen empirischen Verhältnisse sowie institutionellen und personalen Möglichkeiten berücksichtigen, sind im schlechten Sinne als normativistisch zu bezeichnen.

Es soll an dieser Stelle einem möglichen Mißverständnis entgegengewirkt werden: Solche normativen Bestimmungsversuche von Bildungsqualität, die Zielsetzungen und Aufgabenbeschreibungen unter Berücksichtigung von (nicht: durch Vermengung mit) historischer und empirischer Argumentation vollziehen, sind notwendiger Bestandteil der öffentlichen wie auch der fachinternen Diskussion um die Qualität und Qualitätssicherung von Sozial- und Bildungsinstitutionen. Ohne die Bezugnahme auf diesen normativen Diskurs verliefe die Diskussion um Qualität (im doppelten Sinne) ziellos; Strategien und Instrumente der Qualitätskontrolle und Qualitätssicherung blieben inhaltsleer und würden im schlechten Sinne technokratisch. Die Auseinandersetzung um den gesellschaftlichen Auftrag von Bildungs- und Sozialinstitutionen sowie um die inhaltlichen Qualitätskriterien der dort geleisteten Arbeit muß öffentlich und im politischen Raum geführt werden; die Bildungswissenschaften haben hierbei ihre Informationspflichten zu erfüllen sowie auch ihre kritisch-analytische Funktion wahrzunehmen. 


\subsection{Analytische Bestimmungsversuche}

[...] Harvey/Green (2000) kommen zu dem Ergebnis, daß es keine einheitliche inhaltliche Bestimmung von Qualität im Bildungsbereich geben kann, da die verschiedenen beteiligten Gruppierungen ganz unterschiedliche Interessen verfolgen und insofern Qualität immer nur aus ihrer jeweiligen Perspektive definieren.

Dieses Ergebnis ist nicht weiter erstaunlich: Analytische Bestimmungsversuche von Qualität können letztendlich keinen inhaltlich-substanziellen Beitrag zur Qualitätsdebatte leisten, sondern haben demgegenüber eine eher formale, „disziplinierende“ Aufgabe, deren Wert allerdings nicht unterschätzt werden sollte: Sie klären den Begriffsgebrauch, machen auf nicht oder selten gesehene Implikationen aufmerksam, identifizieren mögliche Mißverständnisse und warnen vor sprachlich bedingten Denkfallen und Schein-Begründungen. Damit werden analytische Bestimmungsversuche zu einem wichtigen und leider viel zu wenig beachteten qualitätssichernden Element im Diskurs über Qualität.

\subsection{Empirische Bestimmungsversuche}

Empirische Bestimmungsversuche von Qualität zielen darauf ab, die tatsächliche Wirkung von Bildungs- und Sozialeinrichtungen zu erfassen und diese eingetretene Wirkung in Beziehung zu setzen zu dem offiziellen Zweck oder Auftrag dieser Einrichtungen. Empirische Bestimmungsversuche erfassen die angestrebten Ziele, die eingesetzten Ressourcen, die verwendeten Programme und die eingetretenen Wirkungen und versuchen dann, auf der Basis des Vergleichs von Absicht, Ressourcenverbrauch und Wirkung das Verhältnis von Aufwand und Ertrag zu bestimmen. Es handelt sich also um eine Wirkungskontrolle mit dem Ziel, wirkungsstarke von wirkungsarmen Einrichtungen und Prozessen zu unterscheiden, wobei die jeweils unterschiedliche Ausgangslage sowie auch der jeweils unterschiedliche Aufwand mit berücksichtigt werden.

Damit ist ein Arbeitsprogramm beschrieben, daß in dieser Weise bislang noch von keiner empirischen Studie vollständig erfüllt worden ist. Die TIMS-Studie beinhaltet den Leistungsvergleich von Schülern bestimmter Jahrgangsstufen in einem bestimmten schulischen Lernfeld - weder werden alle Schüler, alle Lernfelder noch systemspezifischer Ressourcenverbrauch vollständig erfaßt. Gleichwohl bietet eine solche einerseits ungemein breit (weil international vergleichend) angesetzte, andererseits nur einen bestimmten schmalen Ausschnitt möglicher Voraussetzungs-, Prozeß- und Wirkungsvariablen erfassende Studie einen äußerst wichtigen und folgenreichen Einblick in die Situation des Schulwesens. Die BIJU-Studie (Bildungsverläufe und psychosoziale Entwicklung im Jugendalter) ist demgegenüber sehr viel differenzierter angelegt und vermittelt einen komplexeren Einblick in die Hintergründe und Auswirkungen schulischer und außerschulischer Erfahrungsräume von Jugendlichen. Die Vergleichsuntersu- 
chungen im Zusammenhang mit PISA und PISA-E werden ein breiteres Fächerspektrum sowie auch fächerübergreifende Kompetenzen mit umfassen.

Empirische Bestimmungsversuche von Qualität haben sich mit folgenden Problemen auseinanderzusetzen:

- Gerade anspruchsvolle und weitreichende Zielsetzungen von Sozialund Bildungsinstitutionen lassen sich nicht ohne weiteres in irgendeiner kontrollierbaren und konsensfähigen Form überprüfen. So besteht immer die Gefahr, daß schließlich nur noch das überprüft wird, was vergleichsweise leicht bestimmbar oder meßbar ist. Auf diese Weise würde ein Mittel (Effektkontrolle) zum Selbstzweck werden: Das System selbst würde sich nur noch diejenigen Zwecke setzen, deren Erreichen leicht überprüfbar ist. Diese Gefahr vor Augen muß man sich grundsätzlich über den Ausschnittcharakter vieler Evaluationen und Vergleichsuntersuchungen im klaren sein.

- Die Wirkung (der Teilnahme an) Bildungsinstitutionen ist in sachlicher und in zeitlicher Hinsicht nur sehr schwer, z.T. gar nicht punktgenau zu erfassen: Die tatsächlichen Effekte von Bildungsmaßnahmen sind innerhalb des breiten Bandes aller möglichen Sozialisationswirkungen nicht präzise zu isolieren. Darüber hinaus ist es immer eine Sache der Entscheidung, wann man welche Effekte überprüfen will. Manche Wirkungen von Bildungsmaßnahmen zeigen sich erst verzögert - und sind dann womöglich noch sehr viel stärker mit anderen, nicht-kontrollierten Sozialisationsbedingungen konfudiert. Eine Art Gesamtrechnung der Bildungs- und Sozialausgaben, die dann auch die möglichen Folgekosten ausbleibender oder fehlgesteuerter Investitionen mit zu umfassen hätte, wird aufgrund der Unsicherheiten von Zurechnung, der Konfundierung von Variablen sowie der unterschiedlichen Zeithorizonte bei der Suche nach Effekten wohl nie zu erstellen sein.

- Grundsätzlich entsteht das Problem, inwieweit man die Unterschiedlichkeit der Ausgangslagen miteinbeziehen soll und kann und ob trotz aller Unterschiedlichkeit der Ausgangslagen eine für alle gleichartigen Einrichtungen gleiche Zieldefinition gelten soll. In einem schwierigen Umfeld kontinuierlich durchschnittliche Leistungen zu erzeugen dokumentiert womöglich höhere Qualität als in einem sehr begünstigenden Umfeld kontinuierlich gute Leistungen zu erbringen. Für den Vergleich der Wirksamkeit zwischen Institutionen gleicher Art ist der angesichts der Ausgangsbedingungen erreichte Wert (value added) eine aussagekräftigere Größe als der Vergleich der Leistungsindices einzelner Institutionen mit einem pauschalen Durchschnitts- oder Idealwert. ${ }^{7}$

7 Im Blick auf die vergleichende Bewertung von Institutionen gleicher Art treten alle die Probleme der Auswahl des Bezugssystems bzw. der Vergleichsbasis auf, die man aus der Beurteilung von Schülerleistungen kennt: Man kann jede einzelne 


\subsection{Qualität als operatives Problem}

Ein operatives Problem ist Qualität dort, wo es um die Frage geht, wie man ein möglichst hohes Maß an Qualität erreichen kann. Diese Frage kann das Personal einer einzelnen Einrichtung umtreiben, kann zu einem Problem für die administrativ verantwortlichen Stellen einer Region werden, und kann schließlich die Spitze des gesamten „Unternehmens“, d. h. also ein Kultusministerium beschäftigen. Wo ist welches Instrument anzusetzen? Wie wirken sich welche Strategien der Qualitätsverbesserung aus? Welche „Erfolge" kommen leichter, welche schwerer zustande?

Mit Blick auf Qualität als operatives Problem stellt sich die Frage, welche allgemeine Strategie man verfolgen will und welche Instrumente zum Zuge kommen sollen. So ist zwischen einer Strategie zu unterscheiden, die auf die Identifikation und Behebung der "schlimmsten Fälle“ konzentriert (kompensatorisch), und einer Strategie, die die besonders positiven Fälle identifiziert und diese zur Vorlage für die Qualitätssteigerung aller anderen Einheiten werden läßt. Beide Strategien (die übrigens kombiniert werden können) zielen darauf ab, die Gesamtqualität des (jeweiligen) Systems zu erhöhen, wobei es eine empirisch zu beantwortende Frage ist, bei welcher dieser beiden Strategien das Verhältnis von Aufwand (Innovationskosten) und Ertrag (Steigerung der Gesamtleistung) am günstigsten ist. Dabei ist es nicht hinreichend, nur eine Steigerung der durchschnittlichen Qualitätsniveaus anzustreben; zugleich muß es das Ziel sein, die Leistungsstreuung zwischen den einzelnen Einheiten gleicher Art zu reduzieren, zumindest aber nicht zu erhöhen. Die doppelte Aufgabenstellung muß darauf gerichtet sein, das durchschnittliche Qualitätsniveau zu steigern bei gleichzeitiger Reduktion der Streubreite der Einzelleistungen. Es ist eine empirisch zu entscheidende Frage, ob sich dieses Ziel - Erhöhung der Gesamtqualität des Systems bei Reduktion der Streubreite - eher durch ein Ansetzen an den negativen Ausfällen (dort dann intensive Förderung), durch Übernahme von positiven Vorbildern durch alle anderen Einheiten und gleichmäßige Förderung aller, oder aber umgekehrt durch Schließung ineffektiver Einheiten sowie durch verstärkte Förderung nur der starken Einrichtungen erreichen läßt.

Im Bereich der Instrumente zur Steuerung und Kontrolle von Qualität wird im öffentlichen Sektor die traditionelle Input-Steuerung durch die Kontrolle von Outputs bzw. Outcomes ersetzt. Das erstgenannte Modell

Schule an einem errechneten Durchschnittswert aller Schulen dieser Art bemessen, dabei ggf. eine „normale“ Verteilung zugrundelegen und auf diese Weise eine rangbezogene Einstufung vornehmen (analog zum klasseninternen Bezugssystem), man kann jede einzelne Schule an vorab definierten, für alle Schulen dieser Art verbindlichen Leistungskriterien messen und den Abstand zum Zielkriterium zur Grundlage von Beurteilungen machen (analog zum lernzielorientierten Bezugssystem), oder man kann schließlich jeden Vergleich über Institutionen hinweg vermeiden, indem man sich allein auf Beobachtung und Förderung des immanenten Entwicklungsprozesses einer Schule konzentriert (analog zum personeninternen Bezugssystem). 
klassischer Verwaltungssteuerung spezifiziert und standardisiert die Vorgaben, Ressourcen und Prozeßmerkmale. Die Standardisierung der Inputs gilt dann als Garant für die Gleichförmigkeit und Vergleichbarkeit der administrativen (innerbehördlichen) Abläufe und Ergebnisse; damit wird ein formales Gerechtigkeitsideal verwaltungsintern in Form von Gleichmäßigkeit und Gleichbehandlung umgesetzt: Ressourcen werden gleichmäßig verteilt. Eine Kontrolle der tatsächlich am Ende zustandekommenden Wirkungen und Folgen unterbleibt weithin; bei entsprechenden Zweifeln wird der Grad an Input-Standardisierung erhöht, das Verteilungssystem feiner ausdifferenziert oder schließlich - sofern vorhanden - mehr Geld ausgegeben. Dieses klassisch-administrative Steuerungsmodell wird zunehmend herausgefordert durch die Vorstellung einer Steuerung, die lediglich allgemeine Zielsetzungen und Aufgaben definiert, und den nachgeordneten Ebenen sehr viel Entscheidungsfreiheit bei der Programmentwicklung und -gestaltung zur Erreichung dieser Aufgaben beläßt. Im Bildungskontext wird nun aber nicht selten übersehen, daß diese erweiterte Autonomie und Eigenverantwortung nachgeordneter Ebenen zugleich und notwendig verbunden ist mit einer empirischen Effektkontrolle, die wiederum von übergeordneten Ebenen durchgeführt wird und Folgen haben kann. Erweiterte Autonomie und intensivierte externe Wirkungskontrolle gehören in diesem Steuerungsmodell unauflöslich zusammen.

Im Rahmen der verschiedenen Bemühungen um Qualitätssicherung im Bildungsbereich werden alle diejenigen Instrumentarien übernommen und adaptiert, die aus dem privatwirtschaftlichen Sektor bekannt sind: Organisations- und Personalentwicklung, innerbetriebliche Leistungsvergleiche, Benchmarking, Zielvereinbarungen, Ausbreitung von Qualitätsbewußtsein, Identifikation von spezifischen Problemstellen und Engpässen, Qualitätszirkel, Verlagerung von Entscheidungskompetenzen ,nach unten“, emotionale Einstimmung und Ausrichtung des Personals auf den Betrieb, materielle oder symbolische Anreize, Abbau von überflüssigen und umständlichen Verfahren, Prozeßelementen oder Wartezeiten, Auslagerung von bestimmten Aufgaben, Einbindung der "Zulieferbetriebe“ in die eigene Betriebskultur, Vorschlagswesen etc.

\section{Qualität und Qualitätssicherung in der Schule}

Neben dem Hochschulsystem, der Erwachsenenbildung bzw. Weiterbildung und den sozialen Sicherungssystemen und -einrichtungen ist insbesondere das Schulsystem in seinen verschiedenen Ebenen, Institutionen und Personengruppen Gegenstand von Qualitätsforschung, -entwicklung und -kontrolle. ${ }^{8}$

8 Vgl. z.B. OECD (1989/1991); Johnston (1992); Aurin (1990);. Rolff (1995); Steffens/Bargel (1993); Cuttance (1994a; 1994b); De Jong/Prins (1995); Specht/Thon- 


\subsection{Anlässe für den schulbezogenen Qualitätsdiskurs}

Der Qualitätsdiskurs im Blick auf das Schulsystem ist zunächst durch ein Ergebnis der Schulsystemvergleiche aus den siebziger Jahren ausgelöst worden: Innerhalb der Diskussion um gegliederte versus integrierte Systeme kristallisierte sich als ein Ergebnis u.a. die Erfahrung heraus, daß unabhängig von der Systemzugehörigkeit bzw. auch unabhängig von der Zugehörigkeit zu einer bestimmten Schulform die Differenzen zwischen einzelnen Schulen beträchtlich sein können. Unter gleichen systemischen (ökonomischen, sozialen, administrativen) Rahmenbedingungen können einzelne Schulen sehr unterschiedliche Eigenarten entwickeln. Die daraus resultierende Konzentration des analytischen Blicks auf die Einzelschule befreite von der ebenso festgefahrenen wie frustrierenden Auseinandersetzung um die Systemfrage. Die Frage nach der Qualität wurde nicht mehr auf der Systemebene, sondern auf der Ebene der Einzelschule gestellt - und beantwortet. Die Schulforschung konzentrierte sich auf die Herausarbeitung der Kennzeichen guter Schulen (welchen Typs auch immer) - und die Schulreformdebatte entledigte sich der Systemperspektive und konzentrierte sich auf die Einzelschule als Handlungseinheit. Damit war eine klare Bezugnahme auf innere Schulreform verbunden.

Für diese Diskussion von großer Bedeutung waren die Arbeiten des Arbeitskreises „Qualität von Schule“, der seit 1985 Schulforscher und - z. T. in Personalunion - Schulreformer (aus der Epoche der Systemreform) des Hessischen Institut für Bildungsplanung und Schulentwicklung (HIBS) sowie der Konstanzer Forschungsgruppe Gesellschaft und Region (FGR) zusammenbrachte und die schulbezogene Forschungs- und Reformdiskussion auf die Ebene der Einzelschule heruntertransformierte. In der Konsequenz dieser Umstellung der Perspektive wurde Schulreform nicht länger als Systemwandel (,äußere Schulreform"), sondern als Entwicklung der Einzelschule verstanden. ${ }^{9}$ Betrachtet man auf diese Weise die einzelne Schule als

hauser (1996); Hopkins/Stern (1996); Posch/Altrichter (1997); Weibel (1997); Ackermann/Wissinger (1998); Fend (1998); Posch (1999). Als Themenhefte von Zeitschriften vgl. z.B. „Qualität im Bildungswesen“ in Bildung und Erziehung 49 (1996) H.2; „Qualitätsmanagement“ in Pädagogische Führung 9 (1998) H. 4 und die Sonderausgabe der Zeitschrift Schulverwaltung zum Thema „Evaluation - Befürchtungen und Hoffnungen“ (1999) H. 2. Für eine sehr kritische Sicht des Verhältnisses von Schulforschung und den daraus gezogenen Konsequenzen für die Schulentwicklung vgl. Coe/Fitz-Gibbon (1998) sowie Koch (1999).

9 In doppelter Hinsicht schulebildend war der 1986 in der Zeitschrift Die deutsche Schule erschienene Aufsatz von H. Fend über „Gute Schulen - schlechte Schulen. Die einzelne Schule als pädagogische Handlungseinheit“" (Fend 1986). Von Bedeutung war weiterhin der Bericht der OECD über "Schulen und Qualität" (1989/1991). Eine der ersten größeren Arbeiten zur Übertragung moderner arbeitswissenschaftlicher Konzepte auf Schule war das von der GEW in Auftrag gegebene Gutachten von Lehner/Widmaier (1992). Als wichtiges bildungspolitisches Dokument der Integration von Managementwissenschaften, neuen Lernphilosophien und alter wie neuer Reformpädagogik in einer Schule als „Haus des Lernens“ vgl. den 
analytische Einheit der Reform, so läßt sich diese Strategie sehr leicht mit traditionellen Denkmodellen aus der reformpädagogischen Bewegung verknüpfen (,,innere Schulreform“); dies erklärt vielleicht die ebenso erleichterte wie begeisterte Rezeption des einzelschulischen Reformansatzes in weiten Teilen der Pädagogik, da Reform nunmehr (,wieder") als überzeugungsgetragenes Handlungs- und Gestaltungsproblem vor Ort betrachtet werden konnte. Zugleich aber ergab sich eine direkte Verbindung zu den Denkmodellen und Strategien der Betriebs- und Arbeitswissenschaften sowie des Qualitätsmanagements. So wurde etwa „Organisationsentwicklung“" als Management-Technik zur Vorlage für die Gestaltung innerschulischer Entwicklungsprozesse; romantische Reformpädagogik verbindet sich zwanglos mit der gänzlich anders motivierten Perspektive von Unternehmensberatung. Beide Seiten sind dabei aufeinander zugegangen, denn auch für das Management einer Firma sind „weiche“ Elemente wie Qualitätskultur, Mitarbeitermotivation, Personalentwicklung, corporate identity etc. zu Problem- und Handlungsfeldern geworden, die man nicht mehr mechanisch (durch eine Kombination von Anordnungen und materiellen Anreizen), sondern nur noch i.w.S. pädagogisch gestalten kann. Während unter ökonomischer Perspektive Schule als Betrieb erscheint - und dies für Pädagogen ungewöhnlich ist -, ist es umgekehrt so, daß Betriebe nicht mehr als profitorientierte Zwecksysteme, sondern als Sinngemeinschaften bezeichnet werden (vgl. Lietz 1994) - für Ökonomen ebenfalls ungewöhnlich. Im Bild von der "lernenden Organisation“ kommen Managementdenken und pädagogisches Denken zusammen (vgl. Fullan 1999; Dalin 1999; zur Kritik übersteigerter Hoffnungen vgl. Kühl 2000), wobei die angestrebten Ziele inhaltlich zwar unterschiedlich sind - im wirtschaftlichen Bereich: Effizienz und Profit, im Schulbereich: Lernen und Bildung -, sich in formaler Hinsicht aber durchaus ähneln: beide Ziele können ,endlos“ angestrebt werden und kennen keine definierbare oder natürliche obere Grenze.

Ein weiterer und zugleich aktuellerer, weiter oben bereits kurz gestreifter Auslöser für die Qualitätsdebatte im Schulbereich waren und sind die internationalen Leistungsvergleichuntersuchungen zum mathematischnaturwissenschaftlichen Unterricht TIMSS (vgl. Baumert/Lehmann u.a. 1997; Baumert/Köller 1998), die schulbezogenen, innerhalb Deutschlands vergleichenden Ergebnisse der Studie des Max-Planck-Instituts für Bildungsforschung über ,Bildungsverläufe und psychosoziale Entwicklung im Jugendalter" (BIJU 1996; Köller/Baumert/Schnabel 1999) sowie die Studie zur Lernausgangslage und zur Leistungsentwicklung von Grundschülern am Ende der Grundschulzeit bzw. auf ihrem weiteren Weg durch die Sekundarschulen (vgl. Lehmann u.a. 1997, 1999). Das nur durchschnittliche

Bericht der Bildungskommission NRW (1995). Zum Verhältnis von eigendynamischem Wandel und (politisch oder pädagogisch) motivierter Steuerung im Schulsystem vgl. Terhart (2000). 
Abschneiden deutscher Schüler im internationalen Vergleich der mathematisch-naturwissenschaftlichen Leistungen, die Differenzen zwischen Bundesländern sowie die Hamburger Ergebnisse über die starken Zusammenhänge zwischen Milieu und Schulerfolg, über Leistungsdifferenzen innerhalb von Schulen auf Klassenebene etc. haben eine ungewöhnlich hohe Resonanz innerhalb der Fach- und allgemeinen Öffentlichkeit gefunden. Nicht selten war jedoch eine verkürzte Rezeption der Ergebnisse festzustellen, falsche Fronten wurden aufgebaut und schließlich durch TIMSS nun gerade nicht begründete Konsequenzen gezogen oder angekündigt (vgl. die intensive Diskussion um TIMSS, PISA etc. in der Zeitschrift Die deutsche Schule sowie auch Brügelmann 1999). Gleichwohl ist durch diese Diskussion die (Doppel-)Frage nach der tatsächlichen, empirisch zu kontrollierenden Leistungsfähigkeit der Schule sowie nach dem ökonomischen Einsatz der Mittel drängend geworden - der Druck auf das Schulwesen, auf Schulen, Lehrer und Fächer hinsichtlich der Rechtfertigung ihres Mitteleinsatzes und ihres Vorgehens bei der Erzielung ihrer Ergebnisse ist enorm gestiegen. Qualität und Qualitätssicherung werden zu den Leitbegriffen einer an Produkten bzw. an Wirkungen festgemachten vergleichenden Überprüfung der Leistungsfähigkeit, während die (noch nicht abgeschlossenen) Ursachenanalysen zu den Gründen der Entstehung der TIMSS-Resultate dominierend in eine prozeßbezogene Richtung weisen (curricularer Aufbau, fachdidaktische Handlungstraditionen der Lehrer, didaktisch-methodisches Vorgehen). ${ }^{10}$ Damit verweisen die Ergebnisse von Leistungsvergleichen sowie die ersten Studien zu den Ursachen für die erhaltenen Differenzen auf die schul- und klassenzimmerinterne Ebene des Lehrens und Lernens, des Interagierens und Kommunizierens zurück. Für empirische Wirkungskontrollen sowie für die Weiterentwicklung der Schulen und des Unterrichts auf dieser Ebene heißt das, den Gedanken der selbstgetragenen pädagogischen Entwicklung mit dem der Wirkungskontrolle zu verbinden (vgl. dazu z.B. Rolff 1995; Buhren u.a. 1998; Burkart 1999). Hierbei handelt es sich um den Versuch, die in der Diskussion immer wieder aufgebaute Alternative zwischen proving quality oder improving quality, zwischen dem Vermessen oder Entwickeln von Schulen, zwischen dem control paradigm und dem enhancement paradigm in der Qualitätssicherungsdiskussion (vgl. Withers 1995) zu überwinden.

10 Die Serie der internationalen Vergleichsstudien wird durch das laufende PISAProjekt der OECD weitergeführt. Die veröffentlichten Statements zum Für und Wider von TIMSS, BIJU, LAU, PISA etc. sind unübersehbar. Für eine abgewogene Erörterung der Problematik solcher Studien sowie ihrer Voraussetzungen und möglichen Konsequenzen vgl. Lange (1999) und Tillmann (1999). 


\subsection{Privatwirtschaftlich-ökonomisches Denken und Schule: Grenzen der Übertragbarkeit}

Wenn man die Implikationen und Konsequenzen aus den genannten Anlässen - Schulforschung, Schulleistungsvergleiche und Schulentwicklung berücksichtigt, so fällt eine bestimmte Gemeinsamkeit auf: Es wird in unterschiedlicher Weise und an verschiedenen Stellen auf Qualitätssicherungs- und Qualitätsmanagementkonzepte aus dem privatwirtschaftlichen Sektor zurückgegriffen - in der Schulentwicklungsliteratur noch sehr viel massiver als in der Schuleffekteliteratur. Nun kann es nicht illegitim sein, tatsächliche Erträge empirisch zu ermitteln und dabei auch nach dem Verhältnis von Aufwand und Ertrag zu fragen. Jede Form der Schulgestaltung und Schulentwicklung sollte dies tun. Die Übernahme der im privatwirtschaftlichen Sektor geltenden ökonomischen Begrifflichkeit und Modellrechnungen sowie die Übertragung von arbeitswissenschaftlichen und qualitätssichernden Instrumenten auf Prozesse und Produkte der Schule muß jedoch gravierende Kontextdifferenzen beachten. Um dies zu verdeutlichen, sollen noch einmal wichtige Differenzen zwischen dem staatlich regulierten steuerfinanzierten öffentlichen Schulwesen in Deutschland und privaten Wirtschaftsunternehmen markiert werden:

- Keine Preisbildung: Für den einzelnen hat der Schulbesuch keinen individuell spürbaren bzw. zu zahlenden Preis. Ebenso besteht kein $\mathrm{Zu}-$ sammentreffen von freiem Angebot und freier Nachfrage, das preisgestaltend und -regulierend wirken könnte. Darüber hinaus kennt das Bildungswesen kein universales Medium (Geld), auf dessen Basis sich Preise, Leistungen und Effekte berechnen sowie zurechnen lassen. Aus diesem Grunde sind Geldströme und ihre Wirkung, ihre Erträge nicht präzise zu bestimmen und zuzuordnen sowie schließlich in eine die individualbiographische (Schüler), betriebsinterne (Schule), systembezogene (Schulsystem) sowie schließlich makroökonomische (Bildungssystem und Gesellschaft) Ebene einbeziehende Gesamtrechnung einzubringen. Damit aber fehlt eine elementare Voraussetzung für die sinnvolle und wirksame Anwendung privatwirtschaftlich-ökonomischen Denkens auf den Schulbereich.

- Keine Marktkonkurrenz: Das Schulwesen insgesamt ist nicht durch Marktkonkurrenz bestimmt, da der Staat eine Monopolstellung innehat (auch Privatschulen müssen staatlich anerkannt sein). Die einzelne Schule steht nur dann unter schwachen Konkurrenzbedingungen, wenn es keine festgelegten und verpflichtenden Schuleinzugsbereiche gibt und das Schulangebot so breit ausgebaut ist, daß den Eltern bzw. Schülern praktikable Alternativen zur Verfügung stehen. Im Sinne des Vertrauens auf die vereinheitlichende Wirkung einheitlicher Inputs ist die Schulaufsicht bislang von der Gleichheit aller Schulen gleicher Form ausgegangen und hat insofern Marktkonkurrenz grundsätzlich ausge- 
schlossen. Durch Profilbildung u.ä. werden allerdings erste Differenzen und Konkurrenzen innerhalb des staatlich regulierten Schulwesens zugelassen.

- Stark eingeschränkte Kundenautonomie: Beim staatlichen Pflichtschulsystem ist die Position des Kunden nicht klar auszumachen; in weiten Teilen des Weiterbildungsbereichs sieht dies anders aus. Wer sind eigentlich die Kunden(gruppen) einer Schule bzw. des Schulsystems: die Schüler, die Eltern, die Abnehmer (Betriebe, Behörden, andere Bildungseinrichtungen), die allgemeine Öffentlichkeit? Die Schüler (im schulpflichtigen Alter) können insofern keine Kunden sein, als sie in das Pflichtschulsystem hineingezwungen werden; umgekehrt ist das Pflichtschulsystem gezwungen, jede schulpflichtige Person in sich aufzunehmen. Der „Kunde“ kann durch sein Wegbleiben das Schulsystem insgesamt nicht bestrafen - er wird in diesem Fall vielmehr selbst bestraft.

- Kein Konkurs: Einzelne Schulen sowie auch das gesamte Schulsystem können nicht im unmittelbaren Sinne, in Konkurs gehen' und dann vom (nicht vorhandenen) Markt verschwinden. Insofern fehlt das Risiko des Untergangs, hervorgerufen durch Mißmanagement, Innovationsschwäche o.ä. Weil es keine Marktabhängigkeit, kein klares Kundenverhältnis und insofern kein Risiko des Unterganges gibt, entfällt eine zentrale Triebfeder, die in privatwirtschaftlichen Kontexten (Güterproduktion oder Dienstleistungen) zu kontinuierlichen Anstrengungen um Qualitätssicherung führt. Das einfache Schließen ineffektiver und ineffizienter staatlicher Einrichtungen im Bildungs- und Sozialbereich verbietet sich angesichts elementarer sozialstaatlicher Versorgungspflichten.

- Kein einheitliches, überprüfbares Ziel: Während Gewinn das „,schlichte" Ziel ökonomischen Handelns ist, welches durch eine konsequente Markt- bzw. Kundenorientierung angestrebt wird, sind die Zielvorstellungen für das Schulsystem durchaus komplex, in sich widersprüchlich und öffentlich vielfach strittig. Eine Konkretisierung allgemeiner Ziele macht diese in der Regel noch strittiger. Das Fehlen einheitlicher und überprüfbarer Zielsetzungen macht dann auch eine Ergebniskontrolle (,Jahresabschluß“) entsprechend schwierig.

- Eigenart des Prozesses: Der Ablauf der innerschulischen bzw. unterrichtlichen Erzeugung von Lernen und Bildung kann nicht auf der Basis klarer Kausalitäten und beherrschbarer Prozesse gesteuert und optimiert werden. Darüber hinaus kommen die Ergebnisse des Schulwesens nicht allein durch die Arbeit des Lehrpersonals sowie durch die bereitgestellten Strukturen zustande, sondern immer nur in Kooperation mit den Schülern; Schüler und Lehrer erarbeiten gemeinsam ein Produkt (Lernund Sozialisationsergebnis). Schließlich kann das Eintreffen von beabsichtigten Wirkungen und deren Bewertung zu sehr unterschiedlichen Zeitpunkten, anhand unterschiedlicher Bewertungskriterien und insofern mit stark divergierenden Ergebnissen erfolgen. 
- Keine Haftung: Weil die Kausalitäten zwischen der Einrichtung Schule bzw. der Arbeit der Lehrer und den Effekten dieser Einrichtung bzw. Arbeit nicht eindeutig sind und die Resultate bzw. Produkte der Teilhabe an Schule unter hoher Eigenbeteiligung der Schüler entstehen, können Schulen bzw. Lehrer keine Gewährleistung für ihre Erzeugnisse geben und sind auch für einen evtl. Fehler ihrer Produkte nicht haftbar zu machen. Die didaktische Arbeit des Lehrers ist nicht justiziabel; auf unterrichtliches Handeln bezogene Kunstfehlerprozesse sind in diesem Kontext bislang noch nicht geführt worden. Im privatwirtschaftlichen Sektor ist die Haftungsfrage ein ganz wichtiger Antrieb für Qualitätssicherung. 11

- Keine Personalflexibilität: Das Personal des Schulsystems ist faktisch unkündbar, die Laufbahnen (noch) streng vorgegeben, Zurückstufungen nicht möglich. In sehr großen Teilen ist der Lehrerberuf ein Beruf ohne Karriere. Kompetenz- und Leistungsunterschiede zahlen sich nicht aus. Ungenügende Berufsleistung allein kann nicht zum Ausschluß führen. Die relative Unbeweglichkeit der Personalsituation engt sowohl die Schuladministration wie auch die einzelnen Lehrerinnen und Lehrer ein. $^{12}$

Hält man sich diese Punkte vor Augen, so wird deutlich, daß mit der Übernahme von Konzepten des Qualitätsmanagements aus dem wirtschaftlichen Sektor in das Schulsystem insgesamt bzw. in die einzelne Schule große kategoriale und reale Probleme verbunden sind (vgl. ausführlicher und detail-

11 Es ist bemerkenswert, dass das öffentliche Bildungswesen keine Garantie oder Gewährleistung für seine „Produkte“ gibt - und insofern auf dieser Basis auch nicht verklagt werden kann. Prozesse (über Noten, Versetzungsentscheidungen etc.) beziehen sich immer nur auf die Einhaltung formaler Regeln (,Blauer Brief rechtzeitig versandt?"“), nicht aber auf die Frage, ob die Unterrichtsleistung vom Lehrer nicht fachgerecht erbracht und deshalb dann der Lernerfolg des Schülers ausgeblieben ist. Zu Kunstfehlern beim Unterrichten vgl. Memmert (1997). Dies wirft noch einmal ein Licht auf den Sachverhalt, daß Schüler bzw. Eltern nicht die Kunden eines Anbieters sind, die auf Vertragsbasis eine Leistung gegen Geld einkaufen - und bei Problemen auf Wandlung, Minderung oder Haftung klagen können. In den USA wie auch in England ist dies anders. Dort wurde und wird von Eltern immer wieder versucht, Schulen, Schulträger oder Lehrer - in Analogie zu Kunstfehlerprozessen bei Ärzten - zu verklagen, wenn der Lernerfolg eines Schülers ausblieb und/oder pädagogische Probleme nicht fachgerecht behandelt wurden (vgl. für England die beeindruckenden und unglaublichen Fälle bei Harris 1999; für die USA Westbury 1999). In Deutschland treten solche Streitfälle im Privatschulwesen auf; innerhalb des Bereichs privat finanzierter Weiterbildung, Fernlehrkursen etc. ist das „Unterrichtsrecht" zuständig (vgl. Gilles/Heinbuch/Gounalakis 1988).

12 Insofern ist es (noch) äußerst schwierig, Elemente einer differenzierten Personalplanung v. a. Personalentwicklung in die Lehrerbildung (Erstausbildung und kontinuierliches Weiterlernen im Beruf) sowie in die Struktur (vgl. Laufbahnrecht etc.) und Kultur (vgl. Mentalität) des Lehrerberufs einzubringen. Zum Problem vgl. Lange (1995); KMK-Kommission (2000); Smolka (2000). 
lierter Maeck 1999: Kap. 6). In vielen Fällen handelt es sich denn auch lediglich um eine analogisierende Adaption, die unter Absehung unverträglicher und direkt widerständiger Elemente Denkweisen, Modelle und Handlungskonzepte aus dem privatwirtschaftlichen Bereich auf den Schulbereich überträgt. Dies führt wie jeder Wechsel der Perspektive, der Denkweise und der Semantik zunächst einmal zu überraschenden und neuen Einsichten. Eine genaue und systematische Prüfung der Frage, ob eigentlich die sachlichen Voraussetzungen für die Übertragung dieser Denkweise gegeben sind, zeigt im vorliegenden Fall eher die Problematik dieser Übertragung, als da $\beta$ es zur weiteren Ausgestaltung und Forcierung der Anwendung von Qualitätsmanagement auf Schule ermuntert. ${ }^{13}$

$[\ldots]$

\section{Literatur}

Ackermann, H./Wissinger, J. (Hg.): Schulqualität managen. Von der Verwaltung der Schule zur Entwicklung von Schulqualität. Neuwied 1998.

Aurin, K. (Hg.): Gute Schulen - worauf beruht ihre Wirksamkeit? Bad Heilbrunn 1990.

Baumert, J./Köller, O.: Nationale und Internationale Schulleistungsstudien. Was können sie leisten, wo sind ihre Grenzen? In: Pädagogik 50 (1998), S. 12-18.

Baumert, J./Lehmann, R. u.a.: TIMSS - Mathematisch-naturwissenschaftlicher Unterricht im internationalen Vergleich. Deskriptive Befunde. Opladen 1997.

BIJU: Bildungsverläufe und psychosoziale Entwicklung im Jugendalter. 2. Bericht für die Schulen. Max-Planck-Institut für Bildungsforschung. Berlin 1996.

Bildung und Erziehung: Themenheft „Qualität im Bildungswesen“, 49 (1996).

Bildungskommission NRW: Zukunft der Bildung - Schule der Zukunft. Neuwied 1995.

Brügelmann, H. (Hg.): Was leisten unsere Schulen? Zur Qualität und Evaluation von Unterricht. Seelze 1999.

Buhren, C.G./Killus, D./Müller, S.: Wege und Methoden der Selbstevaluation. Ein praktischer Leitfaden für Schulen. Dortmund 1999.

Burkart, Chr.: Wie Selbstevaluation gelingen kann. In: Jahrbuch für Lehrerforschung. Bd. 2. Weinheim 1999, S. 175-190.

Coe, R./Fitz-Gibbon, C.T.: School Effectiveness Research: Criticisms and Recommendations. In: Oxford Review of Education 24 (1998), S. 421-438.

Cuttance, P.: Quality Assurance in Education Systems. In: Studies in Educational Evaluation 20 (1994a), S. 99-112.

13 Die wissenssoziologisch interessante Anschlussfrage drängt sich sofort auf: Wie erklärt sich angesichts dieser kategorial und real beträchtlichen Übertragungsprobleme ökonomischen auf pädagogischen Qualitätsdenkens die gleichwohl massive Rezeption - zumindest auf den Ebenen von Bildungs- und Sozialverwaltung? Ist es das blanke Sparinteresse, das es zu verdecken gilt? Ist es die Idee von der Unvermeidlichkeit einer Ökonomisierung aller Lebensbereiche - und will man deshalb ganz vorne dabei sein? Ist es nur eine semantisch- symbolische Drohgebärde, die die Instrumente zeigt - wohl wissend, dass sie nicht greifen? Auf pädagogischer Seite ist hier und da sogar eine gewisse Angstlust im Umgang mit dem Thema festzustellen. 
Cuttance, P.: Monitoring Educational Quality through Performance Indicatiors for School Practice. In: School Effectiveness and School Improvement 5 (1994b), S. 101-126.

Dalin, P.: Theorie und Praxis der Schulentwicklung. Neuwied 1999.

De Jong, R./Prins, J.: No Silence after the Storm: From Quality Assessment to Quality Improvement. In: European Journal of Teacher Education 18 (1995), S. 37-45.

Fend, H.: Gute Schulen - schlechte Schulen. Die einzelne Schule als pädagogische Handlungseinheit. In: Die deutsche Schule 82 (1986), S. 275-293.

Fend, H.: Qualität im Bildungswesen. Schulforschung zu Systembedingungen, Schulprofilen und Lehrerleistungen. Weinheim 1998.

Fullan, M: Die Schule als lernendes Unternehmen. Konzepte für eine neue Kultur in der Pädagogik. Stuttgart 1999.

Frehr, H.-U.: Total-Quality-Management. In: Handbuch Qualitätsmanagement, hrsg. Von M. Masing. München ${ }^{3} 1994$, S. 31-48

Gilles, P./Heinbuch, H./Gounalakis, G.: Handbuch des Unterrichtsrechts. Schulung, Bildung und Freizeitgestaltung durch kommerziellen Direktunterricht und Fernunterricht privater Dienstleistungsunternehmen in Recht und Praxis. München 1988.

Harris, N.: Ausbilder auf der Anklagebank: Vom Aufstieg und Fall der Prozesse wegen Ausbildungsmängeln vor den englischen Gerichten. In: Recht der Jugend und des Bildungswesens 47 (1999), S. 202-215.

Harvey, L./Green, D.: Qualität definieren. Fünf unterschiedliche Ansätze. In: A. Helmke/W. Hornstein/E. Terhart (Hg.): Qualität und Qualitätssicherung im Bildungsbereich: Schule, Sozialpädagogik, Hochschule. In: Zeitschrift Pädagogik, 41. Beiheft (2000), S. 17-39.

Helmke, A./Hornstein, W./Terhart, E. (Hg.): Qualität und Qualitätssicherung im Bildungsbereich: Schule, Sozialpädagogik, Hochschule. In: Zeitschrift für Pädagogik, 41. Beiheft (2000), S. 7-14.

Hopkins, D./Stern, D.: Quality Teachers, Quality Schools: International Perspectives and Policy Implications. In: Teachers and Teacher Education 12 (1996), S. 501-517.

Johnston, J.: Quality Assurance, Schools Self-Management and the Contradictions of Control. In: European Journal of Education 27 (1992), S. 165-175.

KMK-Kommission: Perspektiven der Lehrerbildung in Deutschland. Abschlußbericht der von der Kultusministerkonferenz eingesetzten Kommission. Im Auftrag der Kommission herausgegeben von E. Terhart. Weinheim 2000.

Koch, S.: Wenn Schulforscher von Schulreform träumen. Theorie und Praxis in der „Schulqualitätsforschung“. In: Die Deutsche Schule 91 (1999), S. 411-423.

Köller, O./Baumert, J./Schnabel, K.: Wege zur Hochschulreife: Offenheit des Systems und Sicherung vergleichbarer Standards. In: Zeitschrift für Erziehungswissenschaft 2 (1999), S. 385-422.

Kühl, St.: Das Regenmacher-Phänomen. Widersprüche und Aberglaube im Konzept der lernenden Organisation. Frankfurt a. M. 2000.

Lange, H.: Schulautonomie und Personalentwicklung für Schulen. In: P. Daschner/H.G. Rolff/T. Stryck (Hg.): Schulautonomie - Chancen und Grenzen. Weinheim 1995, S. 207-226.

Lange, H.: Qualitätssicherung in Schulen. In: Die Deutsche Schule 91 (1999), S. 144159.

Lehmann, R.H./Peek, R./Gänsfuß, R.: Aspekte der Lernausgangslage von Schülerinnen und Schülern der fünften Klassen an Hamburger Schulen. Bericht über eine Untersuchung im September 1996. Herausgegeben von der Behörde für Schule, Jugend und Berufsbildung. Hamburg 1997. 
Lehmann, R.H./Gänsfuß, R./Peek, R.: Aspekte der Lernausgangslage und der Lernentwicklung von Schülerinnen und Schülern an Hamburger Schulen. Klassenstufe 7. Bericht über eine Untersuchung im September 1998. herausgegeben von der Behörde für Schule, Jugend und Berufsbildung. Hamburg 1999.

Lehner, F./Widmaier, U.: Eine Schule für eine moderne Industriegesellschaft. Essen 1992.

Lietz, H: Von der Zweck-Gemeinschaft zur Sinn-Gemeinschaft. In: G. Kamiske (Hg.): Die Hohe Schule des Total Quality Management. Berlin 1994, S. 111-130.

Maeck, H.: Managementvergleich zwischen öffentlichem Schulwesen und privater Wirtschaft. Konsequenzen für eine schulische Systemevolution. Neuwied 1999.

Memmert, W.: Kunstfehler beim Unterrichten. In: B. Schwarz/K. Prange (Hg.): Schlechte Lehrer/innen. $\mathrm{Zu}$ einem vernachlässigten Aspekt des Berufslebens. Weinheim 1997, S. 248-274.

OECD (Hg.): Schulen und Qualität. Ein internationaler OECD-Bericht (1989). Frankfurt a.M. 1991.

Pädagogische Führung: Themenheft „Qualitätsmanagement“, 9 (1998).

Posch, P.: Qualitätsevaluation und Qualitätsentwicklung im Schulwesen. In: Erziehung und Unterricht 5-6 (1999), S. 326-337.

Posch, P./Altrichter, H.: Möglichkeiten und Grenzen der Qualitätsevaluation und Qualitätsentwicklung im Schulwesen. Innsbruck 1997.

Rolff, H.-G.: Steuerung, Entwicklung und Qualitätssicherung von Schulen durch Evaluation. In: Landesinstitut für Schule und Weiterbildung (Hg.): Evaluation und Schulentwicklung. Bönen 1995, S. 293-310.

Schulverwaltung: Themenheft „Evaluation - Befürchtungen und Hoffnungen“, Sonderausgabe (1999).

Smolka, D. (Hg.): Motivation und Mitarbeiterführung in der Schule. Empfehlungen für die Schulpraxis. Neuwied 2000.

Specht, W./Thonhauser, J. (Hg.): Schulqualität. Entwicklungen - Befunde - Perspektiven. Innsbruck 1996.

Steffens, U./Bargel, T.: Erkundungen zur Qualität von Schule. Neuwied 1993.

Terhart, E.: Zwischen Aufsicht und Autonomie: Geplanter und ungeplanter Wandel im Bildungsbereich. In: Neue Sammlung 40 (2000), S. 123-140.

Tillmann, K.-J.: Deutsche Schulen unter „ferner liefen“. Was leisten (internationale) Leistungsvergleiche? In: Leistung. Jahresheft Schüler '99. Seelze 1999, S. 84-87.

Weibel, W.: Qualitätssicherung durch Qualitätsentwicklung in der Schule. In: Pädagogische Führung 8 (1997), S. 58-65.

Westbury, I.: Educational Malpractice and the Professionalization Project around Teaching: A Commentary on the „Jurisdiction” of Teachers. Unveröff. Manuskript 1999.

Withers, R.: Quality Assessment: Two Traditions. A Review Article. In: Quality Assurance in Education 3 (1995), S. 39-46.

Zemke, R.: A Bluffer's Guide to TQM. In Training 30 (1993), S. 48-55. 


\section{KONSTANTIN BÄHR \\ Die Rolle von Schulleistungstests für das Qualitätsmanagement im Bildungswesen, in Schulen und Klassenzimmern}

\section{Einleitung}

Der Standard der im Unterricht erzeugten Qualität macht über weite Strecken auch den Standard der Qualität von Schulen aus. Im Kontext von Steuerung muss beachtet werden, dass Unterricht auf Input-Steuerung abstellt und gelingender Unterricht auf Kooperation. Wenn beides zutrifft, liegt es nahe, auch im Bildungswesen auf eine Steuerungsperspektive zu setzen, die sich auf den Input (gute Rahmenbedingungen, Ausbildungsgänge der Lehrkräfte, Lehrpläne, Weiterbildung, Wissensmanagement, Kollegienstrukturen, Supportsysteme etc.) ausrichtet. Diese Form der Steuerung kann nochmals präzisiert werden: als eine, die auf Verhandlungen setzt und mit Fairness und Vertrauen arbeitet. Ziel innerhalb des Bildungswesens müsste es sein, dass der Unterricht in den Klassenzimmern auf einem hohen Standard laufen kann. Standardisierte Schulleistungstests und ihr Einsatz müssen unter dieser Zielvorgabe und im Rahmen der als günstig befundenen Steuerungsform beurteilt und geplant werden. Lediglich an der Schnittstelle zwischen Regierung und Parlament, also dort, wo sich ein gesamtes Bildungswesen ausweisen muss, macht die Form der OutputSteuerung Sinn. Insofern sind umfassende Informationen zu Leistungen und Wirkungen des Bildungswesens am Systemrand - beispielsweise an der Schnittstelle zur Legislative - richtig platziert. Mein Beitrag wird der bis jetzt skizzierten Problematik nachgehen und mit Leitgedanken für eine Entscheidungsfindung zum Einsatz standardisierter Testverfahren schließen.

\section{Ein Blick auf die US-amerikanische Standard-Debatte}

Staatliche Bildungsverwaltungen verfügen zunehmend über wissenschaftlich erzeugte Instrumente zur Messung fachlicher und fächerübergreifender Kompetenzen von Schülerinnen und Schülern. Von wissenschaftlicher Seite her werden diese Instrumente auf hohem Standard hergestellt und die Ergebnisse entsprechend analysiert.

Die Studie der National Commission on Excellence in Education umschrieb 1983 den Zustand des US-amerikanischen Bildungswesens mit „A Nation at Risk“. In der Folge der prekären Ergebnisse wurden u.a. regelrechte Testindustrien aufgebaut: Über strikte Kontrolle der Leistungen und Wirkungen aller Ebenen sollte der Systemzustand gebessert werden. Präsident Bush hat mit dem education act von 2001 den konsequenten Gebrauch 
von Leistungstests fort- und festgeschrieben (U.S. Department of Education 2001). Er ist Anhänger des high-stakes testing, eines Testeinsatzes also, in dem vom jeweiligen Abschneiden viel abhängig gemacht werden kann: der Lebenslauf von Schülerinnen und Schülern, die Qualifizierung von Lehrkräften, die Qualifizierung der Schule und der Schulleitung, die Qualifizierung der Schulaufsicht und die Qualifizierung der Bildungsverwaltung in den Gliedstaaten.

Diese Anstrengungen auf Bundesebene wurden vom New York City Department of Education noch übertroffen. Das City Department richtete große Anstrengungen darauf, im städtischen Bildungswesen ein computergestütztes Controlling einzurichten. Das Controlling sollte sich auf äußerst detaillierte, in kurzen Abständen aktualisierte Individualdaten von Leistungen von Schülerinnen und Schülern, Lehrkräften, Schulen stützen. Die Absicht der Bildungsverwaltung war, über sogenannte Compstat-meetings (Abkürzung für computer statistic meetings; New York Times, 23. Juli 2001) mit Bezirksverantwortlichen, mit Schulleitungen usf. wirkungsorientierte Steuerung auszuüben. Seit Sommer 2002 ist ein neuer Schulkanzler (Bildungsminister) im Amt. Er ist nicht nur dabei, Instrumente des Bildungsmonitoring und -controlling zu reduzieren, sondern plant einen strategischen Wechsel (New York Times, 3. Oktober 2002). Es geht darum, Curriculum und Unterrichten, Rekrutierung und Ausbildung von Lehrkräften, Schulleitungen und Verwaltungen sowie die lokale Schulentwicklung und deren gemeindliche Einbindung zu verbessern. In der US-amerikanischen Bildungsdebatte wird dies unterstützt durch Argumentationen, test-basierte Reformen müssten ergänzt, korrigiert, umfasst werden von standard-basierten Reformen. Gemeint sind damit Reformen, in denen sich alle Energien darauf richten, dass der Unterricht auf einem hohen Standard laufen kann und nicht - so die Kontroverse - der Unterricht mit hoch standardisierten Tests gemessen wird. Ein Dauerbrenner ist seit Jahren zudem die Frage „Who Puts the Standards Into Standardized Tests?“ (New York Times, 18. Juli 2001).

Festgehalten werden kann, dass es einen Trend gibt, den Anwendungsbereich der Testverfahren zu limitieren, um freiwerdende Mittel in (Aus-) Bildungsanstrengungen auf allen Ebenen zu investieren. Deutlich wird aber auch, dass Standard-Setzung sowohl mit Sachfragen (,Wie gelingt wirksamer Unterricht") als auch mit Machtfragen (,Wie gelingt wirksame Steuerung") verbunden werden kann. ${ }^{14}$ Letzteren gehe ich anschließend nach. Ich werde die Analyse außerhalb des Erziehungssystems beginnen und dann Schritt für Schritt bis zum Klassenzimmer vorstoßen. Dabei fällt auf,

14 Zum Zusammenhang von Testverfahren und Macht (Herrschaft) siehe auch Bourdieu (2001 [1997]: 107). Bourdieu analysiert, dass zum Herrschen ,immer mehr technische und rationale Ressourcen und Rechtfertigungen mobilisiert" werden müssen. Aus diesem Grunde würden sich ,völlig neue Herrschaftsstrategien“ entwickeln, die mithilfe der Sozialwissenschaften „hochgerüstet“ wurden. 
dass politische Macht und administrative Kontrolle im Schulsystem limitiert sind, gerade weil es darum geht, Wirkungen des Systems, d.h. fachliche und überfachliche Kompetenzen sowie das Wohlbefinden der Schülerinnen und Schüler auf ein hohes Niveau zu bringen.

\section{Testverfahren im Kontext von Steuerung}

\section{Können über standardisierte Testverfahren Erziehungssysteme gesteuert werden?}

Wer könnte das Erziehungssystem eines Staates steuern wollen? Gehen wir von außen nach innen: Vorstellbar wären Intentionen auf internationaler Ebene, von Organisationen wie der OECD oder der Weltbank. Über Testverfahren wie PISA könnte es dann gelingen, Strukturen in den Ländern zu verändern, lokal und kulturell verschiedene Bildungswesen stärker global zu vereinheitlichen. Innerhalb der Staaten könnten es Akteure und Organisationen des politischen Systems sein, die das Erziehungssystem steuern wollen: Eine direkte Beobachtung von Schülerleistungen könnte dann dem politischen System als Indikator für Erfolge bzw. Misserfolge des Erziehungssystems dienen.

Welche Probleme können auftauchen? Grundsätzlich einmal diejenigen, die immer dann entstehen, wenn ein Akteur einen anderen steuern will und dies in einem einseitigen Steuerungsmodus vorhat. Auf der Länderebene gibt es immerhin die Exit-Option ${ }^{15}$ : Länder müssen nicht teilnehmen, aber je nachdem kann eine Nicht-Teilnahme Auswirkungen im finanziellen Bereich haben. Innerhalb von Staaten lässt sich schlecht davonlaufen. Steuerungs-Intentionen unterlaufen kann man aber auch, indem man sie nur zum Schein befolgt.

\section{Können über standardisierte Testverfahren Lehrkräfte gesteuert werden?}

Wer könnte Lehrkräfte steuern wollen? Vorstellbar wären hier gezielte Intentionen der Bildungsverwaltungen als Staatsorganisationen oder ihrer Behördenformationen. Eine direkte Beobachtung von Schülerleistungen könnte dann der Bildungsverwaltung als Indikator für Erfolge bzw. Misserfolge des Schulsystems dienen, d.h. des handelnden Zusammenwirkens der Lehrpersonen und ihrer Aus- und Weiterbildungsinstitutionen. Welche Probleme können auftauchen? Auch hier wieder diejenigen, die aus einem einseitigen Steuerungsvorhaben entstehen. Die Exit-Option gibt es auch hier. Eine Lehrkraft kann den Schuldienst verlassen, wenn sie sich nicht steuern lassen will, aber es steht schnell der persönliche Lebenslauf auf

15 Exit-Option ist ein Begriff aus der Spieltheorie. Er bezeichnet die Option eines Spielers, das Spiel zu verlassen. 
dem Spiel. Die Steuerungs-Intentionen unterlaufen kann man auch, indem man sie scheinbar befolgt. Auf der Schul- und Unterrichtsebene kann es dann gezielte Vorbereitungen oder Engführungen geben.

\section{Können über standardisierte Testverfahren Schülerinnen und Schüler gesteuert werden?}

Das Klassenzimmer scheint der ideale Einsatzort zu sein. Es gibt für Schülerinnen und Schüler eigentlich keine Möglichkeit, den Steuerungs-Intentionen zu entkommen. Ihr Lebenslauf wird hier ausgerichtet. Wer dauerhaft nicht mitmacht, fällt aus der Gesellschaft. Allerdings sehen Schülerinnen und Schüler diese Gefahr kaum. Letztlich werden Lehrkräfte alles versuchen, ihre Schülerinnen und Schüler insgesamt zum Lernen zu bewegen. Motivieren ist hier der richtige Begriff, nicht steuern. Nur wenn Lernen gelingt, werden Schülerinnen und Schüler auch in standardisierten Testverfahren gut abschneiden. Gutes Abschneiden der Schülerinnen und Schüler kann aber von der Lehrkraft nicht befohlen werden. Die Machtausübung endet vor dem Lernen der Schüler. Ebenfalls würde es nicht viel bringen, wenn Administration und Politik Lehrkräfte mit einem testbasierten Controlling dazu bringen wollten, dass gut abgeschnitten wird. Welchen Weg gibt es dann?

\section{Wie erreicht man, dass in Tests gut abgeschnitten wird?}

Wenn man sich die Konstellation aus Schülern, Lehrkräften, Schulen, Behörden und Bildungsverwaltungen ansieht, dann bekommt man den Eindruck, dass es einen erfolgreichen Weg gibt, ein gutes Abschneiden von Schülerinnen und Schülern zu erreichen: Die Kooperation der Akteure auf den verschiedenen Ebenen. Kooperation von Schülerinnen und Schülern mit ihren Lehrkräften, Kooperationen von Lehrkräften auf der Schulebene, Kooperationen von Schulen, Behörden und Bildungsverwaltungen, Kooperation von Bildungsexekutive und Parlament. Jeder Akteur, jede Ebene müsste selber gut abschneiden wollen. Die Möglichkeiten dafür sind allerdings unterschiedlich gegeben.

Der kritische Punkt liegt ganz eindeutig auf der Ebene Schulklasse. Die Schulklasse ist keine Organisation, welche mit selbst rekrutiertem Personal arbeitet. Von Output-Steuerung im Zusammenhang mit Schulklassen reden, sollte man nicht einmal metaphorisch. Auf der Ebene Schulklasse müsste es starke Unterstützungen von Lehrkräften geben, starke Input-Unterstützungen in der Form von zusätzlichen Support-Lehrkräften, zusätzlichen Aus- und Weiterbildungsmöglichkeiten, zusätzlichen Kontextprogrammen für die Familiensysteme und zusätzlichen diagnostischen und förderdiagnostischen Instrumenten. Im Rahmen des gerade erwähnten diagnostischen Instrumentars könnten Leistungstests - allerdings in einer anderen Form - nun wieder auftauchen, als output-orientierte Inputstützen, oder, in 
einer weniger paradoxen Formulierung, als wirkungsorientierte InputSteuerung. Ich komme darauf zurück.

Spieltheoretisch wäre Kooperation zwischen Akteuren auf den verschiedenen Ebenen die erfolgreiche Variante. Kooperation setzt dabei Vertrauen voraus. Wo Vertrauen fehlt, muss Kontrolle her. Bildungsverwaltungen sind teilweise fasziniert von Kontrollinstrumenten, welche die Wissenschaft mittlerweile bietet und sinnieren über Kontrollkreisläufe: Uns kontrolliert das Parlament, wir kontrollieren die Schulen, die Klassen, die Lehrkräfte, wir kontrollieren Herkunft und Intelligenz der Kinder, verrechnen diese und erhalten dann objektive Kontrollaussagen zu den Leistungen von Lehrkräften. Wir erhalten objektive Daten und wir schalten auf OutputSteuerung, d.h. wir müssen uns nicht mehr beschäftigen mit dem Problem, wie denn bessere Leistungen bei Schülerinnen und Schülern möglich werden, sondern wir setzen Standards, die zu erreichen sind und schreiben Lehrkräften die Möglichkeit zu, dies zu erreichen.

Nur: Im Klassenzimmer endet die Output-Steuerung. Lehrkräfte haben keine Chance, die Output-Mentalität, die man Bildungsverwaltungen unterstellen kann, zu übernehmen. Lehrkräfte werden sich, in welcher Form auch immer, zusammen mit den Schülerinnen und Schülern auf den Weg der Wissens- und Verhaltens-Produktion machen. Sie werden sich nie einfach nur auf Kontrollieren, sprich: Prüfen von Leistungen beschränken können. Das Klassenzimmer ist der Ort der Input-Steuerung. Gleichzeitig ist es der Ort, an dem Schulqualität zu einem hohen Maße entsteht (vgl. Terhart 2002, Fend 1998).

Letztlich ist der Kontrollweg dysfunktional und nur bei einem Systemzustand zu empfehlen oder zu rechtfertigen, wo das System in sehr schlechtem Zustand ist und ein weniger schlechter Zustand schon ein Erfolg wäre. Terhart (2002: 103) meint dazu:

„Administrative Durchgriffsversuche auf die Ebene des Unterrichts gehen meistens ins Leere, da eine genaue Fern-Steuerung von Unterricht ... nicht möglich ist. Da aber Unterrichtsprozesse faktisch durch die gesetzten innerschulischen Rahmenbedingungen beeinflusst bzw. vorgesteuert werden, sollte die Schulaufsicht sich selbst im Hinblick auf die Frage überprüfen, wie sie durch eine sachgerechtere Organisation der Rahmenfaktoren zur Steigerung der Qualität des Unterrichts beitragen kann.“

Zusammenfassend lässt sich festhalten: Wenn Unterricht der Kernbereich von Qualität im Schulsystem ist und dort nur die Form der Input-Steuerung erfolgreich wird, liegt es nahe, innerhalb des Systems auf eine Steuerungsperspektive zu setzen, die sich auf den Input - zum Beispiel auf gute Rahmenbedingungen, Ausbildungsgänge der Lehrkräfte, Lehrpläne, Weiterbildung, Wissensmanagement, Kollegienstrukturen, Supportsysteme - ausrichtet. Diese Form der Steuerung kann präzisiert werden als eine, die auf Verhandlungen setzt, mit Fairness und Vertrauen arbeitet. In dieser Weise beschreiben sich mittlerweile Fortentwicklungen des New Public Managements, die sich von der Wirtschaftslastigkeit dieses Ansatzes (zumindest 
teilweise) befreien, und, was entscheidender ist, dessen Mangel an demokratischen Politikprozessen überwinden wollen. Die Rede ist von Ansätzen des Public Governance bzw. des Good Governance. ${ }^{16}$

Lediglich an der Schnittstelle zwischen Regierung und Parlament, also dort, wo sich sozusagen das ganze Bildungswesen ausweisen muss, macht die Form der Output-Steuerung Sinn. Das Parlament hat einerseits den Auftrag der Kontrolle der Regierung; andererseits wäre es sinnlos, wenn das Parlament sich auf eine die Ebenen des Bildungswesens durchgreifende Input-Steuerung kaprizieren würde. Insofern sind Informationen zu Leistungen und Wirkungen des Bildungswesens am Systemrand - an der Schnittstelle zur Legislative - richtig platziert. D.h. aber auch, dass diese Informationen repräsentativ sein müssen und nicht populations-genau sein dürfen. Die Daten der Schule Apfelbaum und der Lehrerin Müller, das sind Daten, die das Parlament nichts angehen. Untersuchungen wie PISA - oder auch die kantonalen Untersuchungen der 3., 6. und 8. Klassen (Moser/Rhyn 1999, 2000; Moser u.a. 2002) in Zürich - erzeugen den richtigen Datentyp zum Leistungs- und Wirkungsausweis von Bildungswesen dem Parlament und der Öffentlichkeit gegenüber. Output-Steuerung des Bildungswesens von außen, ist zu unterscheiden von der Output-Steuerung innerhalb der Ebenen des Bildungswesens. Die, wie vorstehend angemerkt, macht keinen Sinn.

Es gibt allerdings Formen der Input-Steuerung mit mehr oder weniger Realitätskontakt. Für die Ebene der Bildungsverwaltung sind anonymisierte Ergebnisse repräsentativer Erhebungen hinreichend für einen sensitiven Modus der Input-Steuerung, ich habe ihn als wirkungsorientierte InputSteuerung bezeichnet. Mit ihm lässt sich bedarfsgerechte Bildungsplanung machen, und es zeigt sich der Unterstützungsbedarf von Schulen und Klassenzimmern. Den Kooperationsgedanken aufnehmend, kann Planung aber kein einsames Vorgehen in einer Kommando-Stelle sein, sondern eines, das gemeinsam mit signifikanten Akteuren des Bildungswesens um Verbesserungen ringt.

\section{Ausblick auf den Einsatz von Testverfahren: Leitlinien zur Entscheidungsfindung}

Auf der PISA-Tagung der Schweizerischen Konferenz der kantonalen Erziehungsdirektoren (Kultusministerkonferenz) im Zürich arbeitete Fend (2002) in seinem Eröffnungsreferat zu PISA heraus, dass es ungemein schwierig sei, allgemein gültige Erfolgsmerkmale für die Effizienz von Bildungssystemen zu bezeichnen: Gleiche institutionelle Merkmale hätten

16 Dies kann an dieser Stelle nicht weiter verfolgt werden. Für einen Überblick siehe Online-Verwaltungslexikon, Begriff Good bzw. Public Governance. Instruktiv ist Forstmoser u.a. (2002). 
in verschiedenen Ländern ganz unterschiedliche Bedeutung. Er schlägt vor, günstige Konfigurationen zu analysieren.

Einige Leitlinien zum Aufbau einer günstigen Konfiguration für den Einsatz von Testverfahren sollen im Folgenden aufgestellt werden.

Ausgangspunkt meiner Überlegungen bildet ein Modell, welches im Bildungswesen drei Ebenen unterscheidet: die Systemebene, die Schulebene und die Ebene Schulklasse. Davon nochmals unterschieden wird die Ebene Politik. Eine günstige Konfiguration entsteht, wenn die Testverfahren innerhalb der Ebenen des Bildungswesens nicht im Kontext von Kontrolle und Beurteilung eingesetzt, sondern im Kontext der Optimierung von Lernen und Förderung situiert werden, im Sinne der genannten wirkungsorientierten Input-Steuerung. Innerhalb der Ebenen des Bildungswesens muss es darum gehen, einen Beitrag zu leisten, dass der Unterricht auf hohem Standard laufen kann. Nach außen stellt sich das Bildungswesen als Ganzes der Beurteilung durch die Öffentlichkeit und das Parlament. Auf der Systemebene werden deshalb Leistungen und Wirkungen des Bildungswesens nach außen ausgewiesen. Eine weitere Ausrichtung im Zusammenspiel der Ebenen betrifft das Verfügungsrecht über die Daten und das Einsichtsrecht in sie. Die allgemeinste Aussage wäre hier, dass jede Ebene über diejenigen diagnostischen Daten verfügt, die den eigenen Handlungsmöglichkeiten und dem eigenen Handlungsraum entsprechen, und, dass jeder Ebene grundsätzlich ein Eigentumsrecht der Daten (ownership) zugestanden wird. Dies ist keineswegs lapidar, denn es bedeutet beispielsweise, dass Behördenorganisationen keinen Zugriff auf Daten aus Schulklassen haben, wobei es aber durchaus denkbar ist, dass Lehrkräfte im Kontext einer Kooperationskonstellation die Daten ihren Behörden zur Kenntnis bringen. Ideal ist, wenn das Wissensmanagement zwischen den Ebenen des Bildungswesens und innerhalb der Ebenen auf Verhandlung, Fairness und Vertrauen abstellen kann (good governance).

Eine zweite Gruppe von Überlegungen soll sich abschließend der Ausgestaltung und Planung der Testinstrumente widmen. Bedeutsam ist, dass die diagnostischen Instrumente aller Ebenen hohen wissenschaftlichen und fachdidaktischen Standards entsprechen. Die in den Tests verwendeten Aufgaben sollen einen ausgezeichneten Aufgabentypus darstellen, da sich bekanntermaßen Lehrkräfte mit der Zeit an ihnen orientieren. Die Planung der Instrumente richtet sich idealerweise auf die Handlungsmöglichkeiten der Ebenen aus. Dies hat auch Auswirkungen auf die Weite des Einsatzbereichs: Stichprobenbasierte Erhebungen sind auf der Ebene System völlig ausreichend. Erhebungen auf der Ebene Schulklasse müssen jeden Schüler und jede Schülerin umfassen. Vorteilhaft ist auch, wenn die diagnostischen Instrumente regelmässig eingesetzt werden. Auf der Ebene System könnte man sich längsschnittig angelegte Untersuchungen am Ende der Schuleingangsstufe, Ende Unterstufe, Ende Mittelstufe und am Ende der obligatori- 
schen Schulzeit vorstellen. ${ }^{17}$ Auf der Ebene Schule sehe ich gegenwärtig weniger den Einsatz spezifischer Instrumente als vielmehr den Einsatz von Verfahren wie beispielsweise einen kontinuierlichen Qualitätsdiskurs, der sich auf Daten aus den Klassen stützen kann. Für die Ebene Schulklasse sind Instrumente günstig, die auch während des Schuljahres der Lehrkraft Rückmeldungen zum Lernstand der Schülerinnen und Schüler geben. Eine letzte Bemerkung: Alle diagnostischen Instrumente sollten Vergleiche erlauben. Je nach Ebene wäre dies ein statistischer Vergleich mit anderen Bildungssystemen - ich denke hier beispielsweise an Bildungssysteme anderer Länder - oder mit anderen Schulklassen.

Die dargestellte Form der Modellierung des Einsatzes von Instrumenten zur Messung fachlicher und fächerübergreifender Kompetenzen von Schülerinnen und Schülern ließ sich von der Prämisse leiten, dass Lernen in Schulklassen eine komplexe Interaktionsform ist.

\section{Literatur}

Bourdieu, Pierre (2001 [1997]). Meditationen. Zur Kritik der scholastischen Vernunft, Frankfurt am Main: Suhrkamp.

Fend, Helmut (1998). Qualität im Bildungswesen. Schulforschung zu Systembedingungen, Schulprofilen und Lehrerleistung, Weinheim; München: Juventa.

Fend, Helmut (2002). Beste Bildungspolitik oder bester Kontext für Lernen? - Über die Verantwortung von Bildungspolitik für pädagogische Wirkungen; EDK PISA Tagung vom 17./18. Oktober 2002, Universität Zürich.

Forstmoser, Peter u.a. (2002). Corporate Governance: Symposium zum 80. Geburtstag von Arthur Meier-Hayoz, Zürich: Schulthess.

Moser, Urs/Rhyn, Heinz (1999). Schulmodelle im Vergleich. Eine Evaluation der Leistungen in zwei Schulmodellen der Sekundarstufe I, Aarau: Sauerländer.

Moser, Urs/Rhyn, Heinz (2000). Lernerfolg in der Primarschule. Eine Evaluation der Leistungen am Ende der Primarschule, Aarau: Sauerländer.

Moser, Urs u.a. (2002). Evaluation der 3. Primarschulklassen. Schlussbericht zuhanden der Bildungsdirektion des Kantons Zürich, Zürich: Kompetenzzentrum für Bildungsevaluation und Leistungsmessung an der Universität Zürich (KBL).

Online-Verwaltungslexikon (2002; Version 10.2). In: URL: http://www.olev.de. Stichwort Good Governance bzw. Public Governance.

Terhart, Ewald (2002). Wie können die Ergebnisse von vergleichenden Leistungsstudien systematisch zur Qualitätsverbesserung in Schulen genutzt werden? In: Zeitschrift für Pädagogik, H. 1, S. 91-110.

U.S. Department of Education (2001). No Child Left Behind Act, In: URL: http://www.ed.gov/legislation/ESEA02/.

17 Dies entspricht der Stufenlogik des Zürcher Volksschulwesens: Schuleingangsstufe (bis anhin Kindergarten); Unterstufe (1. bis 3. Schulstufe); Mittelstufe (4. bis 6. Schulstufe); Oberstufe (6. bis 9. Schulstufe). 


\section{Organisationsentwicklung}

\section{Kommentar (Brüsemeister)}

Die ersten beiden Texte (Buschor, Kempfert/Rolff) stellen ausgearbeitete Konzepte der Organisations- und Schulmodernisierung vor. Auch wenn die Autoren beschreiben, dass und wie die Akteure der Schule zu einer Qualitätsarbeit kommen können, also eine bottom-up-Modernisierung machen - das gilt vor allem für den Beitrag von Guy Kempfert und HansGünter Rolff -, kann man sagen, dass die Konzepte bereits entwickelt sind und in diesem Sinne als top-down-Modernisierung an Schulakteure adressiert werden.

\section{Top-down}

Ernst Buschor, Bildungsdirektor - in unserer Terminologie: Kultusminister - des Kantons Zürich, gibt in seinem Artikel einen Überblick, inwieweit das Schulsystem im Kanton ${ }^{18}$ im Rahmen von NPM umgestaltet wurde. ${ }^{19}$

Kernelement von NPM ist eine Trennung zwischen der strategischen und der operativen Führung. Dies bedeutet, dass Politik und die Verwaltungsspitze „nur“ noch Rahmenbedingungen festlegen und die operative Leistungsumsetzung einzelnen Schulen freistellen. Die Schulmodernisierung im Kanton zeigt sich konkret in der Einführung eines Qualitätsmanagements zwischen der Bildungsverwaltung und der Einzelschule; in der Einführung der Schulleiterposition, die es zuvor nicht gab; in der Einführung einer professionellen Schulaufsicht, die die bisherige Laienaufsicht der Gemeinde- und Bezirkspflege ablösen soll, und in Projekten, die der Einzelschule operative Autonomie geben. Der Kanton Zürich befindet sich dabei ,Zwischen Projektphase und ,Generalisation““ (Maag Merki/Büeler 2002: 143), d.h. ein Teil der Schulen hat bereits ausgedehnte Projektphasen hinter sich, und die Bildungsverwaltung will die Ergebnisse für alle Schulen generalisieren. ${ }^{20}$ Insgesamt kann man davon sprechen, dass im Kanton

18 Buschor studierte Betriebswirtschaftslehre an der Hochschule St. Gallen. Im Jahr 1993 trat er das Amt des Gesundheitsdirektors des Kantons Zürich an und 1995 das Amt als dortiger Erziehungsdirektor. Das Gesundheits- sowie das Bildungswesen wurden unter seiner Leitung im Rahmen von New Public Management (NPM) umgestaltet.

19 In ihrer Übersicht zu den bis 1999 realisierten Schulreformen bei den 20 deutschschweizerischen Kantonen (von 26 Kantonen insgesamt) schreiben Maag Merki/Büeler (2002: 135f.) dem Kanton Zürich „das vielleicht prominenteste schweizerische Schulprojekt“" zu, das Schulprojekt 21. In diesem Projekt sollen unter anderem die Fächer Informatik und Englisch ab der 1. Klasse eingeführt werden.

20 Am 24. November 2002 lehnte jedoch die Mehrheit im Kanton Zürich einerseits die Einführung eines großen Reformvorhabens für die kantonale Volksschule bzw. das zu Grunde liegende Volksschulgesetz ab. Der Umbau der Volksschule hätte etappenweise zwischen 2004 und 2012 erfolgen sollen. Die Schulreform wäre, so die 
Zürich unter einer großflächigen Perspektive mit der Modernisierung der Schulen begonnen wurde.

Die anfängliche freiwillige Mitarbeit einzelner Schulen an Projekten der Schulautonomie stellt gleichzeitig ein strategisches Handeln der Bildungsdirektion dar. Dieses Handeln berücksichtigt explizit die Zeitlichkeit der Modernisierung, d.h. Ziele und Methoden müssen den Akteuren nicht nur kognitiv verständlich werden, sondern es muss vor allem eine neue evaluative Orientierung vermittelt werden, welche die Schule als eine Qualitätsorganisation für die Akteure erstrebenswert macht. Zudem wird die öffentliche Akzeptanz einer Modernisierung steigen, wenn zuerst Freiwillige in die Modernisierung einbezogen werden. Denn nicht nur von den Akteuren der Einzelschule, sondern auch von den Lehrerverbänden sowie der Öffentlichkeit insgesamt ist ein Umlernen in Richtung NPM verlangt, was nicht von allen Akteuren positiv gesehen wird. ${ }^{21}$

Die Akteurkonstellation zwischen Lehrkräften und der Bildungsverwaltung beinhaltet, dass beide Akteure lernen müssen, mit NPM umzugehen. Dies im Unterschied zu Deutschland, insofern dort Bildungsverwaltungen erst partiell in Richtung neuer Steuerungsmodelle gehen, aber mitunter von Schulakteuren erwarten, dass sie die Qualitätsverfahren bereits einsetzen. Im Kanton Zürich bedeutet die gemeinsame Lernsituation aber nicht, dass die beiden Hauptakteure, Bildungsverwaltung und Lehrkräfte, automatisch zusammenarbeiten oder das gleiche Verständnis von Modernisierung haben (vgl. zur Sichtweise von Lehrkräften des Kantons Zürich: Brüsemeister im letzten Buchabschnitt). Aber offensichtlich scheint im Schweizer Modernisierungspfad, der generell stärker auf Konsenskulturen in überschaubaren lokalen Kontexten gründet (vgl. Vatter 2002: 55), ein wechselseitiges Lernen der Akteure eher möglich.

Es darf aber nicht vergessen werden, dass Bildungsverwaltungen nach wie vor Agenturen des Staates sind und als solche mehr Macht als andere Akteure haben, was ihre Steuerungsmöglichkeiten qua legitimer Herrschaft angeht (vgl. Weber 1972). Trotz der Selbstbeschreibung des NPM, nach der der umgestaltete Staat wie eine Wirtschaftsorganisation aussehen würde, bleibt eine Bildungsverwaltung zunächst eine Bildungsverwaltung des Staates, die rechtlich verbindliche Entscheidungen durchsetzen kann - darauf verweisen insbesondere die Kritiker des NPM (vgl. Maeder 2002: 214). Der zweite Text, der sich schwerpunktmäßig der Organisationsentwicklung

Neue Zürcher Zeitung (vom 24. November 2002) „Buschors politische Krönung gewesen; er tritt im Frühjahr aus der Regierung zurück“. Andererseits wurde mit dem Volksentscheid der Änderung der Kantonsverfassung zugestimmt und die damit mögliche Abschaffung der Bezirksschulpflege gut geheißen - an die Stelle einer Laienschulaufsicht kann eine professionelle Schulaufsicht treten. Entsprechende Projekte für eine professionelle Schulaufsicht wurden zuvor erprobt; vgl. als externe Evaluation den Bericht von Binder/Trachsler (2002).

21 Darauf wirkt die Bildungsdirektion auch mit einer aktiven Öffentlichkeitspolitik hin. Vgl. allein die Präsentation im Internet: http://www.bildungsdirektion.ch. 
und -modernisierung widmet, stammt aus pädagogischer Feder. Guy Kempfert (Gymnasialdirektor in Liestal, Schweiz) und Hans-Günter Rolff (Leiter des Instituts für Schulentwicklungsforschung, Universität Dortmund) haben für Schule und Unterricht ein Arbeitsbuch entwickelt. Nach Ansicht der Autoren schlagen gegenwärtig Wirtschaft und Politik Qualitätsentwicklungskonzepte für Schulen vor, ohne dass klar sei, welche Konzepte „für die Schulpraxis wirklich tauglich sind“. Mit ihrem Buch schlagen Kempfert und Rolff den Schulen vor, mit der Entwicklung selbst zu beginnen, wobei die Autoren auf langjährige Erfahrungen mit schulischen Qualitätsmanagements zurückgreifen (vgl. auch Rolff 1995, 1998).

Als Kernpunkt legen die Autoren dar, dass die Modernisierung der Einzelschule als Dreiklang von Unterrichts-, Personal- und Organisationsentwicklung zu verstehen ist. Dies bedeutet, dass die einzelne Schule als operative Instanz auftritt, die über ihre Belange selbst entscheidet; ein Aspekt, der auch im Konzept des NPM formuliert wird. Die Autoren sehen als größeren Kontext ebenfalls, dass angesichts einer ,weltweiten ,Krise der Außensteuerung “" - gemeint ist eine Krise der bisherigen staatlichen Steuerung von Schulen - nach neuen Steuerungsmodellen gesucht werde.

Als Methode wird in der Qualitätsentwicklung die wechselseitige Beobachtung, d.h. Evaluierung der Schulpraxis durch die schulischen Akteure selbst zum wichtigsten Aspekt. Vorgesehen sind Schüler- und Lehrerselbstevaluation sowie Unterrichtsbeurteilungen durch die Schüler. Zudem sind externe Evaluationen vorgesehen.

Eine solch intensive wechselseitige Beobachtung der Akteure bedeutet einen gravierenden Wandel der Schulkultur. Beobachtungsverhältnisse zwischen Akteuren gibt es in der ,traditionell“" organisierten Schule zwar auch, dort aber oftmals nur als impliziter Teil einer Schulkultur. Unter den Prämissen des Qualitätsmanagements sollen die Beobachtungen dagegen systematisch in Teamarbeit, als Teil der Organisations-, Personal- und Unterrichtsentwicklung, entwickelt sowie (wie schon der Name sagt) ,gemanagt" werden. Dafür müssen in den Schulen neue organisatorische Instanzen geschaffen werden, die sich der Beobachtung, Datenerhebung und auswertung widmen. Ein Großteil der pädagogischen Qualitätsentwicklung besteht entsprechend darin, Arbeitsweisen von Qualitätskreisläufen darzulegen. Diese zeichnen sich durch systematisch verzahnte Feedbacks aus, d.h. verschiedene Organe der Schule (z.B. Jahresgespräche, Fachkonferenzen) stimmen ihre Funktionen aufeinander ab (vgl. zu den „Organen“ von Qualitätskreisläufen: Kempfert/Rolff 2000, Kap. III). Das Qualitätsmanagement beinhaltet die systematische Einführung von Beobachtungen zweiter Ordnung. Kommunikationen der Praxis von Schule sollen nicht nur vorkommen, sondern systematisch meta-kommuniziert werden, mit dem Ziel einer Organisation Schule, deren Organe viel stärker als bislang miteinander verzahnt sind. 
Lehrkräfte, an die sich das Qualitätsmanagement vor allem richtet, müssen in kognitiver Hinsicht kaum dazu lernen. ${ }^{22}$ Neu ist hingegen, dass sich die evaluative Orientierung ändert, insofern im Zentrum des Erstrebenswerten die Organisation Schule steht - so betonen Kempfert/Rolff. Das, was der Lehrer bisher beobachtet hat, soll gleichsam nicht mehr ihm allein ,gehören', sondern in Teams kommuniziert, von einer neu zu bildenden Organisation Schule kollektiv genutzt werden.

Durch die neuen Beobachtungsaufgaben - in dem Sinne neu, dass sie der Organisation Schule dienen sollen - wird die bestehende Konstellation zwischen den Akteuren an der Einzelschule grundlegend verändert. Allein die Tatsache, dass Schüler als Evaluierungsinstanzen vorgesehen sind, kann die bisherige Alleinzuständigkeit von Lehrkräften in pädagogischen Fragen erschüttern. Zudem sollen an der Einzelschule externe Evaluierer wirken. Auch dies stellt nach Kempfert/Rolff einen „Kulturbruch“ mit der bisherigen, von Lehrkräften dominierten Schulpraxis dar. Offen ist, ob dies von den Betreffenden als Angriff auf ihre Integrität als Professionelle erlebt wird. Generell sollten Modernisierungskonzepte darauf hin beurteilt werden, inwiefern sie mögliche Negativreaktionen, die bei der Implementation entstehen, von vornherein mit einrechnen. Dies tun die Autoren, insofern sie den Widerstand gegen ein Qualitätsmanagement offen ansprechen. ${ }^{23}$

\section{Bottom-up}

Während die bislang vorgestellten Texte eher eine top-down-Perspektive von Modernisierung einnehmen, insofern für Schulen bereits ausgearbeitete Konzepte der Qualitätsentwicklung angesprochen werden, gehen die beiden nachfolgend angeführten Autoren auf Entwicklungsprozesse ein, wie sie sich „bottom-up“ aus Sicht der Lehrkräfte abspielen. Thematisiert werden ,schwierige Beziehungen“ (bei Maritzen) sowie Chancen lokaler Entwicklungsprozesse (im Text von Maeder).

Norbert Maritzen bezieht sich in seinem zweiten Text, den wir ins Buch aufgenommen haben, auf ein Instrument der Schulmodernisierung: das Schulprogramm. Es dient der organisationalen Umgestaltung der Schule, ist ,gleichsam das Drehbuch, das die innere Entwicklung einer Schule steuert und orientiert". Schulprogramme sind in einigen Bundesländern zur Zeit insbesondere in Bremen und Hamburg - diejenigen Mittel, mit de-

22 Obwohl die Autoren in ihrem Buch auch einen Schnellkurs in empirischer Datenerfassung anbieten, insofern insbesondere der Unterricht mit Anleihen an Methoden der empirischen Sozialforschung beobachtet werden soll (vgl. Kempfert/Rolff 2000, Kap. II).

23 Es lässt sich davon ausgehen, dass im Modernisierungsgeschehen mikropolitische Aktivitäten zwischen schulischen Akteuren (vgl. Altrichter/Posch 1996), aus denen Konflikt- oder Konsenskulturen hervorgehen, noch wichtiger werden, als sie es ohnehin ,im Alltag' schon sind. Durch Modernisierungen entstehen bei den Akteuren der Einzelschule neue Selbst- und Fremdbeobachtungen. Dies kann verunsichern, hält aber auch Chancen für die Selbstvergewisserung eigener Leistungen bereit. 
nen schulische Akteure erstmals mit der Idee regelmäßiger Outputbeobachtungen in Berührung kommen. Dabei gilt: „Was im Schulprogramm festgeschrieben ist, kann mit offengelegten Kriterien überprüft werden“. Was aus einem Schulprogramm wird, ob es als bloßes Papier bei Behörden verstaubt, als Entwicklungschance gesehen wird oder zu ideologischen Kämpfen anregt, ist nach Maritzen offen. ${ }^{24}$ Er weist in diesem Zusammenhang auch auf mögliche Abwehrstrategien von Lehrerkollegien hin. So könnten diese zum Beispiel fordern, dass die neuen Organisations-, Personal- oder Unterrichtsmethoden ihre pädagogische Qualität ausweisen müssen. Oder es könnte betont werden, dass das Neue im Prinzip schon immer gemacht werde.

Darüber hinaus lässt sich eine grundlegende Problematik erkennen. Aus der Perspektive der Lehrkräfte müssen die Instrumente der dezentralen Selbststeuerung, die ihnen an die Hand gegeben werden, als eine Verstärkung der klassischen Schulaufsicht erscheinen - so lange die Betreffenden nicht den Eindruck haben, dass auch die Schulverwaltung ihre bisherigen Aufsichtsprinzipien ernsthaft in Richtung einer Qualitätsentwicklung umstellt. Ein Problem wird sein, dass die schulischen Akteure in einer Übergangszeit unterschiedliche Bewertungskontexte - alte und neue - heranziehen können: man lebt gewissermaßen in zwei ,Welten'. In der bisherigen Welt konnten Lehrkräfte die top-down-Bemühungen der Schulverwaltung als Mittel der Schulaufsicht entlarven, die dem Lehrerhandeln nur weitere Kontrollen auferlegt. In der neuen Welt der Qualitätsmanagements dagegen stellen diese Methoden jedoch nicht auf Kontrolle, sondern auf größere Beobachtungs- und Entscheidungsmöglichkeiten an der Einzelschule ab. Dabei halten die neuen Methoden selbst keine operativen Regeln bereit, wie diese zwei Welten aufeinander abzustimmen wären. Generell gewinnt man den Eindruck, dass Innovationen (wie Qualitätsverfahren oder andere Konzepte), blind“ für Übergangsphänomene, die sie mit ihrer Einführung selbst erzeugen, sind. Das von Maritzen angeführte widerständige Verhalten von Lehrkräften müsste also ergänzt werden mit der Frage an die Qualitätsverfahren, ob und wie sie solche Übergangsphänomene beobachten.

Ein weiterer Text, der die bottom-up-Perspektive von Modernisierung verstärkt in den Blick nimmt, stammt von dem Schweizer Soziologen Christoph Maeder (Universität St. Gallen). Sein Untersuchungsgegenstand, die Messung von Leistungen, die Pflegerinnen und Pfleger in Krankenhäusern erbringen, passt auf den ersten Blick nicht zu unserem Thema. Dennoch wurde der Text ausgewählt, insofern eine ganz andere Art der Outputmessung sichtbar wird, nämlich eine, die von den Akteuren selbst stammt. Ähnliches ließe sich für Lehrkräfte entwerfen.

Maeder hat zusammen mit den Pflegekräften in Schweizer Krankenhäusern ein Leistungsinstrument erarbeitet, die „LEP (Leistungserfassung in

24 Wie unterschiedlich Schulprogramme sein können, zeigt sehr gut eine Inhaltsanalyse verschiedener Aktivitäten von Hamburger Schulen (vgl. Holtappels u.a. 2002). 
der Pflege)“. Auf der Basis ethnographischer Beobachtungen und Gespräche wurde von Forschern ermittelt, wie Handlungen von Pflegenden beschaffen sind, die direkt am Patienten ansetzen. Dafür begleiteten die Forscher Pflegende bei ihrer Arbeit auf verschiedenen Stationen des Krankenhauses. Das Verfahren will zu weiten Teilen eines sein, welches erstens ohne vorgefertigte Konzepte arbeitet, um die bottom-up-Sicht der Akteure zu rekonstruieren. Zweitens beleuchtet das Konzept den ,Ist-Zustand“ in einem sozialen Feld. Im Gegensatz dazu handelt es sich bei den Konzepten des Qualitätsmanagements erstens um fertige Konzepte, die auf ein soziales Feld übertragen werden, und die zweitens einen künftigen Soll-Zustand herzustellen trachten.

In der LEP werden die Tätigkeiten kommunikativ validiert, d.h. die Feldforscher fragen Pflegende, ob die einzelnen Tätigkeiten richtig beschrieben wurden und welche Bedeutung sie im Verhältnis zu anderen Tätigkeiten haben. So entstand allmählich ein „Lexikon der Praxis“ (Maeder), welches in der Sprache der Pflegenden verfasst ist. Auf der Basis ethnographischer Beobachtungen ließen sich ca. 80 Tätigkeitsdimensionen festhalten, die das Feld der Pflege in der Sprache der Beteiligten wiedergeben. Die mittlerweile als Computerprogramm ausgearbeitete LEP bezieht Leistungen der Pflegenden auf die verfügbare Arbeitszeit und stellt die sich daraus ergebenden Quotienten optisch dar, wobei die Leistungskategorien selbst nach wie vor auf Beschreibungen der Pflegenden basieren, wie sie ethnographisch erfasst wurden. Mit der Darstellung von Leistungen in Zahlen, so Maeder, wurde ein äußerst brauchbares „Artefakt“" geschaffen, mit dem die Pflege an die beiden anderen zentralen Akteure eines Krankenhauses, Ärzte und die Verwaltung, die ihre Leistungen ebenfalls in Zahlen darstellen, anschließen kann. Das Konzept wurde auf andere Krankenhäuser übertragen, wobei die Leistungskategorien auch örtlichen Gegebenheiten angepasst wurden. Heute wird LEP in ungefähr einem Drittel aller Krankenhäuser in der Schweiz eingesetzt und ist auch in Deutschland stark angefragt.

Diese Erfolgsgeschichte lässt sich damit erklären, dass die Pflegenden froh darüber scheinen, mit dem Lexikon eine genauere Beschreibung ihrer Arbeit zu haben, was der Selbstvergewisserung der Profession zugute kommt. Pflegende können mit dem Lexikon ihrer Praxis auch eigene Interessen gegenüber der Klinikverwaltung und Ärzten besser durchsetzen, insofern sich die Pflegeleistungen nun an Daten belegen lassen. Bislang dominierten Ärzte und Krankenhausverwaltung als zentrale Akteure im Krankenhaus mit eigenen Zahlen- und Kriterienkatalogen, während die Pflegenden dem nichts Vergleichbares entgegenzusetzen hatten - sie litten an einem Dokumentationsproblem ihrer Leistungen. Maeders Liste ethnographischer Beobachtungen füllt diese Lücke. Wenn belegt werden konnte - so die Erfahrungen aus der Schweiz -, welche Arbeiten im Einzelnen verrichtet wurden, waren Krankenhausverwaltungen auch bereit, entsprechend bessere Arbeitsbedingungen zu schaffen und so den Output der Stationen 
zu erhöhen. Analoges würde sich erreichen lassen, würde man die von Maeder favorisierten „Ethnostatistiken“25 auf Schulen übertragen. Ein entscheidender Vorteil wäre, dass der Ansatz methodisch durchsichtig ist, da er auf den Praxiserfahrungen der Akteure basiert.

Überträgt man diese für die Profession „Pflege“ entworfene Perspektive auf das Schulsystem, ergibt sich eine neue Sicht auf die schulische Modernisierung: Man kann auch für die schulische Profession ein gravierendes Dokumentations- und Darstellungsproblem vermuten. Die bestehende Schule hat in enger struktureller Kopplung an den Staat keine eigene professionelle Leistungsdokumentation entfaltet. Sie hat unabhängig vom Staat weder für eigene qualitative, noch quantitative Leistungserfassungen gesorgt - und auch nicht dafür sorgen müssen, da sie bis vor kurzem nicht von nachgewiesenen Leistungsoutputs lebte, sondern von staatlichen Inputs. Diese Situation ist nun anders, insofern die Schulen ihre Leistungen darlegen sollen - was sie aus eigener Kraft niemals gelernt haben.

Maeders Text eröffnet zugleich eine Unterscheidungsmöglichkeit hinsichtlich der Instrumente, die ansetzen, Darstellungsprobleme von Professionen zu beheben. Auf der einen Seite ließe sich die Darstellungslücke mit von außen eingeführten Methoden der Qualitätsmanagements füllen. Damit hat man zwar das Darstellungsproblem beseitigt, aber zugleich die bestehende Struktur bestätigt, denn es sind wieder - wie zuvor der Staat - externe Instanzen, welche die Darstellung übernehmen. Diese Lösungsvariante bleibt also gleichsam auf halbem Weg stehen, weil sie zwar das Dokumentationsproblem der Lehrkräfte behebt, aber die Lösungskonzepte als solche immer noch von außen importiert. Daraus entstehen Akzeptanzprobleme im schulischen Feld (und so ist es nicht verwunderlich, dass Kempfert/ Rolff (2000) ein Kapitel über Widerstände gegen das Qualitätsmanagement schreiben müssen). Die zweite, von Maeder entwickelte Lösungsvariante würde ebenfalls das Darstellungsproblem der Lehrkräfte beheben, und dies auf der Basis ethnographischer Methoden. Diese sind zugleich so ,gebaut", dass Lehrkräfte mit ihnen eigene Konzepte, wie sie in der Arbeit mit Schülern und Schule relevant werden, wiedergeben können. Ein solches auf die bottom-up-Perspektive der Lehrkräfte zugeschnittenes Instrument liegt derzeit freilich noch nicht als Umarbeitung für das schulische Feld vor.26 In der Zwischenzeit haben die Konzepte des Qualitätsmanagements den entscheidenden Vorteil, dass es sie bereits gibt und in den verschiedensten

25 Wie sie von Maeder entlang der Methode der ethnographischen Semantik genannt werden, d.h. Zahlen und dahinterstehende ,native terms“, die durch Beobachtungsdaten generiert wurden.

26 Die seit langem bekannte Aktionsforschung (vgl. Altrichter 2002) arbeitet zwar ebenfalls mit ethnographischen Beobachtungsmethoden, aber es fehlt eine mit Zahlen verbundene Dokumentation qualitativer Kategorien, die, wie LEP zeigt, dem Instrument erst zum entscheidenden Durchbruch in denjenigen sozialen Feldern verhilft, in welchen die übrigen Akteure der sozialen Konstellation ebenfalls mit Zahlen operieren. 
Feldern sofort eingesetzt werden können. Aber die Methoden legen die Leistungen nicht in der Sprache von Lehrkräften dar, provozieren die schon angeführten Akzeptanzprobleme bei der Profession, und messen vor allem nicht gegebene Leistungen, sondern Leistungen qualitätsbasierter Organe, die erst hergestellt bzw. konstituiert werden müssen. Was vorhandene Akteure und Strukturen leisten, wird hingegen nicht evaluiert. Maeders Text verweist darauf, dass es durchaus möglich ist, bereits gegebene Leistungen einer Profession in deren eigener Sprache darzustellen.

\section{ERNST BUSCHOR \\ Schulen in erweiterter Verantwortung - Die Schweizer Anstrengungen und Erfahrungen}

\section{Erweiterte Schulverantwortung als Thema von wachsender Bedeutung in der Schweiz}

Die Schulentwicklungsdiskussion in der Schweiz folgt den internationalen Spuren der 1980er Jahre. Der Schulautonomiegedanke steht zunehmend im Zentrum und löst das Modell des „Einzelkämpfers“ Lehrkraft ab. Die Eigenverantwortung wird in die Gemeinschaftsverantwortung Schule eingebettet, das gemeinsame Entwickeln der extern unterstützten Schulqualitätsförderung rückt in den Mittelpunkt. [...]

Die Schweiz scheint in vielerlei Hinsicht für einmal kein Sonderfall zu sein. Auch hierzulande sind unter den Bezeichnungen „Schulen mit erweitertem Gestaltungsraum“, „teilautonome Schulen“ oder „geleitete Schulen“ vielfältige Schulformen mit erhöhter Schulhausautonomie entstanden. Für die meisten Anwendungsfälle ist eine gleichzeitige Integration von Elementen des New Public Management - eines für die Schulen durchaus geeigneten Führungsansatzes - typisch [...].

\section{Merkmale des New Public Management}

Mit New Public Management wird eine Ausprägungsform der Verwaltungsführung bezeichnet, die im anglo-amerikanischen Raum seit Mitte der 1980er Jahre entwickelt und in der Folge auch durch die Verwaltungswissenschaften aufgenommen und weiterentwickelt wurde ${ }^{27}$. Im deutschen Sprachraum gingen entscheidende Impulse von der Bertelsmann-Stiftung

27 Erste Standardwerke sind Osborne/Gaebler (1990). Vor allem die neuseeländische Entwicklung des NPM war durch eine gute Zusammenarbeit von Wissenschaft und Praxis begleitet. Vgl. Boston/Martin/Pallot/Walsh (1996). 
und der Kommunalen Gemeinschaftsstelle der Städte (KGST) aus. Die Bertelsmann-Stiftung baut ihre jährlichen Preisverleihungen weitgehend auf das New Public Management-Modell auf und trägt damit auch maßgeblich zu dessen Weiterentwicklung bei. ${ }^{28}$ Die KGST hat das NPM vor allem im Rahmen der Diskussion um das sogenannte „Neue Steuerungsmodell““ gefördert, das eine Übernahme wesentlicher Elemente des New Public Management enthält (vgl. Reichard/Banner 1993). Für die Schweiz wurde die Diskussion vor allem durch die Universität St. Gallen eingeleitet, was verschiedene Umsetzungen in der Schweiz auslöste (vgl. Buschor/Schedler 1995, Schedler 1995). Allgemein ist festzuhalten, daß es sich um ein relativ neues Modell handelt. Noch nie hat aber ein Verwaltungsführungsmodell in so kurzer Zeit einen weltweiten Einsatz, und eine so intensive globale wissenschaftliche Diskussion erfahren.

Für das NPM sind sieben Elemente charakteristisch, die im folgenden am Beispiel der Schule kurz dargelegt werden sollen; dabei ist zu unterstreichen, daß es ,die NPM-Schule“ an sich zwar nicht gibt, aber ,,idealtypische NPM-Schulen“ die erwähnten Merkmale aufweisen. In Europa kommen diesem Modell die holländischen Schulen am nächsten.

1. Wettbewerb statt Regelsteuerung: Wettbewerb schafft Innovation und Mobilität im Gegensatz zur herkömmlichen umfassenden Steuerung über Vorschriften; NPM lehnt Vorschriften nicht ab, begrenzt sie aber primär auf die zu erreichenden Wirkungen und Leistungsergebnisse wie Schulstufenabschlüsse (Abitur, Übertrittssprüfungen usw.). [...]

2. Möglichst weitgehende Deregulierung: Die Regulierung ist auf das für das Endziel der Wirkung Erforderliche zu begrenzen. Es sind dies insbesondere die Wirkungen und zu erreichenden Bildungsleistungen der einzelnen Schulstufen bei einer maximalen Freiheit der Gestaltung des Ressourceneinsatzes (Löhne, Klassengrößen, Lehrformen und Lehrmittelbeschaffung usw.).

3. Fokussierung auf Effektivität, Effizienz und Qualität der Aufgabenerfüllung: Effektivität ist das Verhältnis der Zielvorgabe zur Zielerreichung, Effizienz das Verhältnis der Leistungen zu den Leistungserstellungskosten, wobei in beiden Fällen qualitative Elemente einzubeziehen sind. Wesentlich ist auch hier, daß den (staatlichen und privaten) Anbietern von Leistungen ein bezüglich der Ressourcen möglichst umfassender, gleichartiger Freiheitsgrad gewährt wird.

4. Trennung der strategischen und operativen Führung: Die Gleichbehandlung privater und öffentlicher Anbieter erfordert eine klare Trennung der strategischen Führung (WAS getan bzw. erreicht werden muß und WIE es getan bzw. erreicht wird). Hier ist die Dezentralisierung mit Hilfe umfassender, in der Regel stark ressourcenorientierter Vorschriften wie Löh-

$28 \mathrm{Zu}$ erwähnen sind etwa die Preisverleihungen 1990 für die beste Universität (vgl. Bertelsmann-Stiftung 1990) und 1996 für das beste Schulsystem (vgl. BertelsmannStiftung 1996). 
ne, Arbeitsbedingungen der Lehrkräfte, Klassengrößen, Unterrichtsformen usw. zu unterscheiden von Delegationssystemen, die sich strikt auf die Umschreibung der zu erreichenden Ausbildungsergebnisse beschränken. New Public Mangement will - im Sinne eines marktwirtschaftlichen Ansatzes - über Ergebnisse steuern und den Formen des Faktoreinsatzes bewußt den „Produzenten“ der Leistungen überlassen (Delegation statt Dezentralisierung).

5. Globalbudget und Leistungsauftrag: Das Globalbudget muß auf einem Vollkostenansatz aufbauen, damit eine echte Gleichstellung staatlicher und privater Anbieter gegeben ist. Auch staatliche Anbieter werden aufgrund ihres Leistungs-/Kostenverhältnisses ausgewählt, was eine massive Deregulierung der Kostenelemente der einzelnen Schulen (Löhne, Unterhalt usw.) voraussetzt. [...]

6. Pflicht zur und Spielraum für Innovation: Im Mittelpunkt muß die Umschreibung und Prüfung des Endergebnisses für die Ausbildungszeit stehen. Es ist einzuräumen, daß die Umschreibung der zu erwerbenden Kenntnisse in einzelnen Fächern einfacher ist als die Umschreibung und Messung der Lernleistung in den Bereichen der schwer definierbaren „Sozialkompetenz". Auch dieses Meßproblem ist aber lösbar. [...]

7. Haushaltsgleichgewicht und -sanierung: Systemflexibilisierung der öffentlichen Aufgabenerfüllung, durch den Wettbewerb bedingte Wahlmöglichkeiten der „Kunden“ (Eltern oder Schülerschaft im Falle des Bildungswesens) und Einsatz von Benchmarking (Auswahl der Anbieter mit dem besten Leistungs-/Kostenverhältnis) erleichtern das Erreichen des Haushaltsgleichgewichts, was durch aktive Sanierungsmaßnahmen (gezielter Einsatz des Benchmarking) allenfalls unterstützt werden muß.

[...] Während der regulierende Staat die operative Kontrolle über die detaillierte Ressourcenzuweisung vornimmt (Stellenbewilligung und Kreditbewilligung detailliert nach Konten), werden im NPM Leistungen (Outputs) mit Qualitätsvorgaben kostendeckend ausgeschrieben und an die (internen oder externen) Bestbieter mit Leistungsaufträgen vergeben. Staatseigene Schulen werden damit gleichermaßen zu „Dienstleistungsunternehmen" wie allfällige Anbieter aus dem gemeinwirtschaftlichen Bereich (z.B. Kirchen) oder rein private, erwerbswirtschaftlich orientierte Anbieter. [...]

\section{Kriterien für „gute Schulen"}

Die teilautonome Schule ist keine Zürcher „Erfindung“, sondern sie geht zurück auf die mit Rutters (1980) wegweisenden Werkes Ende der 1970er Jahre eingeleitete Diskussion über die gute Schule. Der Begriff der teilautonomen Schule wurde Mitte der 1980er Jahre in Deutschland geprägt. Diese bis in die neuste Zeit außerhalb des New Public Management geführte pädagogische Diskussion ist im Zürcher Modell der teilautonomen Schule mit dem New Public Management systematisch vernetzt worden. Es 
würde im Rahmen dieses Beitrags zu weit führen, die Phasen der pädagogischen Diskussion dieses Modells umfassend aufzuzeigen. Die Diskussion umfaßt ohnehin alle Industriestaaten. Sie ist wegweisend im Rahmen der OECD in einem 1989 veröffentlichten Bericht „Quality of Schools“ zusammengefaßt worden. Ziel dieser Forschungen war es, die Rahmenbedingungen guter Schulen zu erfassen, wobei der Begriff der "guten Schule“ nicht immer völlig transparent ist. [...]

\section{Das Konzept der Zürcher teilautonomen Schulen}

1995 beschloß die Zürcher Regierung eine grundsätzliche Verwaltungsreform im Sinne des New Publik Management. Diese Reform verfolgt unter der Bezeichnung ,wif! “ (wirkungsgeführte Führung der Verwaltung) folgende Ziele:

1. stärkere Zielorientierung der Verwaltungsführung,

2. Erhöhung der Steuerungsfähigkeit der Aufgabenerfüllung,

3. höhere Effizienz und Wirtschaftlichkeit und

4. vermehrte Bürgerorientierung und -nähe.

Kurz: Der Staat soll wie ein modernes Dienstleistungsunternehmen geführt werden. Insgesamt laufen zur Zeit 37 sogenannte wif! - Projekte in der Zürcher Kantonsverwaltung, verteilt über alle „Ministerien“ (Direktionen). Im Bereich des Bildungswesens umfassen sie alle Schulstufen von der Volksschule über die Berufs- und Mittelschulen bis zu den Fachhochschulen und der Universität.

Die Zürcher Verwaltungs- und Schulreform hat eine grundsätzliche Debatte über das Verhältnis zwischen Schule und New Public Management (NPM) ausgelöst, die zuweilen ideologische Züge annimmt. Lehrkräfte befürchten, daß die pädagogischen Anliegen im New Public Management zu kurz kommen oder gar vernachlässigt werden.

[...] Ökonomie ist die Lehre vom Umgang mit knappen Ressourcen; New Public Management will die Ressourcen unter den neuen knapperen Verwendungsbedingungen nach dem Prinzip ,möglichst viel Wirkung für das verfügbare Geld oder möglichst wenig Geld für eine vorgegebene Wirkung" zuweisen.

Ausgangspunkt dieses Konzepts ist die Definition der Bedarfsziele. So ist es Ziel der Volksschule, den Jugendlichen die wesentlichen Kulturtechniken zu lehren, ihnen Sozialkompetenz als verantwortliche, mündige Personen zu vermitteln, Selbstkompetenz durch die richtige Selbsteinschätzung und den Willen zum lebenslangen Lernen zu fördern und die Leistungsbereitschaft für die globale Gesellschaft zu entwickeln. Ziel der Maturität oder des Abiturs ist die Hochschulreife, welche die Beherrschung der hochschulrelevanten Kulturtechniken und persönliche Reifemerkmale zum 
Ziel hat. Das Problem ist aber doppelter Natur: Diese Ziele müssen operationell definiert und nachher meßbar sein. Damit stehen wir mitten im Feld der schulischen Qualitätssicherung, einer vernachlässigten Dimension unserer Pädagogik. Zwar ist Ausbildungsqualität stets vielschichtig und komplex. Wir müssen uns aber auf Schlüsselqualifikationen konzentrieren, die empirisch gemessen werden. Eine „flächendeckende Qualitätsmessung“ wäre weder möglich noch ist sie nötig.

[...]

Im Rahmen der Schulreformen sind zwei Dinge zu unterscheiden: die Reformen der Schulorganisation und die Reform der Lehrinhalte. Zur Reform der Schulorganisation gehört die Einführung der teilautonomen Schule und die geplante Reform der Lehrerbildung. Zur Reform der Lehrinhalte gehört die Überarbeitung der Lehrinhalte des Gymnasiums aufgrund der neue Maturitätsordnung und die Evaluation des Volksschullehrplans. Der 1988 eingeführte Lehrplan soll evaluiert und gleichzeitig auf seine $\mathrm{Zu}$ kunftstauglichkeit überprüft werden. Erste Vorentscheide für die vermehrte Zukunftsorientierung des Zürcher Lehrplans sind getroffen mit dem Grundsatzentscheid zur obligatorischen Einführung von Englisch als zweite Fremdsprache an der Sekundarstufe (7.-9. Schuljahr), was auch im Sinne der EU-Bestrebungen liegt (vgl. Weißbuch der EU-Kommission 1996: 72ff.). Schulreformen müssen daher stets im Hinblick auf eine leistungsfähige und zukunftstaugliche Schule auf ein Gleichgewicht zwischen organistorischen und inhaltlichen Reformen achten.

Im Vergleich zu den Möglichkeiten des New Public Management ist die Ausschöpfung der Steuerungsformen in der Schuldiskussion des Kantons Zürich noch sehr eingeschränkt. Allgemein im Mittelpunkt steht der Einsatz des Globalbudgets und der in diesem Rahmen erteilten Leistungsaufträge. Die Option ist damit verengt auf die Qualitätssicherung (Evaluation und Benchmarking) unter öffentlichen Schulen. Wenigstens ,unter sich“zuweilen zum Ärger einzelner Betroffener - soll durch Benchmarking das System leistungs- und kostenmäßig optimiert werden. Dabei ergeben sich beispielsweise bei den Gymnasien bemerkenswerte Erkenntnisse (vgl. Erziehungsdirektion des Kantons Zürich 1996):

- Die pro Schüler erteilten Jahreslektionen variieren unter den Zürcher Gymnasien um knapp die Hälfte, was aus der Sicht der Chancengleichheit problematisch ist.

- Die Kosten pro Schüler variieren über 50 Prozent.

- Für vergleichbare Werte der Volksschule fehlen noch die Zahlen; die verfügbaren Daten deuten aber auf ähnliche Tatbestände hin.

- Vieles deutet darauf hin, daß weder Schulqualität noch Schülerzufriedenheit mit den Kosten pro Schüler korrelieren.

Im allgemeinen rufen heute jene Kreise der Lehrerschaft, die über Jahrzehnte die systematische Evaluation von Schulleistungen wohl bewußt un- 
terlassen haben, besonders laut nach wissenschaftlichen „Beweisen“ neuer Schulstrategien. Die Schule der Gegenwart und der Zukunft bedarf der Evaluation. Diesbezügliche Ansprüche dürfen aber nicht zu hoch angesetzt werden. Erfahrungen aus anderen Ländern sind ernst zu nehmen.

Die Zürcher Erziehungsdirektion hat im Frühjahr 1995 neben dem Benchmarking zwei Evaluationen über das 8. Schuljahr veranlaßt: eine Erfassung der Schulleistungen in den Kernfächern Deutsch und Mathematik über alle Schulstufen und eine Zufriedenheitsbefragung der ,ehemaligen“ Volksschülerinnen und -schüler und deren Eltern (vgl. Moser/Rhyn 1996). Bei der ersten Studie handelt es sich um eine methodisch anspruchsvolle Evaluation der Schulleistungen einer Stichprobe von Klassen mit insgesamt 3.000 Schülerinnen und Schülern. Sie umfaßt eine differenzierte Analyse der sozialen Herkunft, einen Intelligenztest, eine Schülerbefragung über die Zufriedenheit, eine Lehrkräftebefragung der die Fächer unterrichtenden Lehrkräfte und zunehmend schwere Aufgabenstellungen für Schüler der Oberschule, der Realschule, der Sekundarschule und des Untergymnasiums in den Fächern Deutsch und Mathematik.

Die Ergebnisse zeigen, daß das sozial-intellektuelle Milieu der Jugendlichen eine wichtige Erklärungsvariable der Leistungen ist. Die Jugendlichen aus intellektuell aktiven Familien sind entsprechend dominant im Untergymnasium vertreten. Als Gruppe weist das Untergymnasium auch den höchsten IQ-Wert auf. Die Sekundarschulen weisen eine stärkere Bandbreite der Schulleistungen auf, sie erreichen aber in der Spitzengruppe das Niveau des Untergymnasiums. Ein begrenzter Wettbewerb unter Schulen verstärkt die Qualität und Innovation. Wir haben es hier mit ähnlichen Phänomenen zu tun wie im Gesundheitswesen mit dem Managed Care-Modell, das ebenfalls mit kontrollierten, wettbewerbsgesteuerten Neuerungen arbeitet. Wir brauchen deshalb ein Managed School-Modell. Dies zeigt, daß auch gebietsübergreifende Innovationserfahrungen nützlich sind.

$[\ldots]$

Wichtig ist eine klare pädagogisch-organisatorische Führung. Die Führungs- und Moderatorfunktion müssen von der Schulleitung wahrgenommen werden. Die Teamkultur soll zwar zu einem erheblichen Teil auf dem „Primus inter pares-Prinzip“ aufbauen. Es gehört aber zu den wichtigen Führungseigenschaften, auch Entscheide zu fällen. In den Gymnasien ist diese Vorgesetztenrolle weniger bestritten. Zum Teil werden diese Schulen administrative Arbeiten übernehmen müssen, welche heute die Zentralverwaltung wahrnimmt (z.B. Personalverwaltung und Kreditverwaltung). Nun kann die Schulleitung die Ressourcenverantwortung voll übernehmen. Für Volksschulen müssen die konkreten Kompetenzmodelle noch zusammen mit den kommunalen Schulbehörden und der Lehrerschaft entwickelt werden.

$$
[\ldots]
$$




\section{Qualitätssicherung und Schulführung}

Die Ausrede, die Schulqualität sei nicht meßbar, weil es um die Vermittlung von Kultur schlechthin gehe und sich Bildung der Messung entziehe, ist aus zwei Gründen unhaltbar: Einmal wird damit eingeräumt, daß auch die heutige Schulqualität nicht meßbar sei. Damit könnte im Extremfall die Chancengleichheit durch die unterschiedliche Qualität der Schulen ernsthaft gefährdet und erheblicher sozialer Schaden angerichtet werden. Die pädagogische Forschung hat besonders in den letzten 15 Jahren viel zur Umschreibung und Messung guter Schulen beigetragen. Wenn gewisse Gymnasialkreise erklären, es sei Sache der Schule, „auszulesen aufgrund von Forderung" und nicht zu selektionieren (vgl. Herrmann 1996), so ist dies insofern unzutreffend, als gerade das Gymnasium zu Recht eine scharfe Eintrittsselektion vornimmt. Selbst ,gesamtgesellschaftliche Kulturvermittlung“ ist meßbar und wird keinesfalls ,automatisch“ in einem wettbewerbsorientierten Steuerungssystem ,demontiert". Wesentlich ist, daß die Maßstäbe der Outcomemessung interdisziplinär von Pädagogen und Verwaltungswissenschaftlern und „Kunden“ (Absolventen, Hochschulen als „Abnehmer“ usw.) erarbeitet und von der zuständigen Behörde (Erziehungsdepartement) festgelegt werden.

Wenn das hohe Qualitätsniveau der Zürcher Schulen gehalten werden soll - dieses Ziel steht außer Frage - müssen die Mechanismen der Qualitätssicherung tragfähig sein. Wenn heute aus einzelnen Klassen keine und aus anderen Klassen zwei Drittel der Schülerinnen und Schüler ins Untergymnasium eintreten, ist die Chancengleichheit nicht erfüllt. Mehr als eine Chancenfairne $\beta$, für welche die leistungsvergebenden Behörden verantwortlich sind, ist wohl nicht möglich. Hier sind noch vertiefte Untersuchungen und innovative Formen der interkulturellen Pädagogik auf der Volksschulstufe erforderlich. Als gut zu beurteilen ist jedoch die Quote von rund 20 Prozent der Jugendlichen, welche in das Gymnasium übertreten. Höhere Übertrittsquoten führen, wie die Untersuchung von Lambelet zeigt, nur zu erhöhter Akademikerarbeitslosigkeit und zum unerwünschten Niedergang der dualen Berufsausbildung (vgl. Lambelet/Natal 1995). Es ist daher wichtig, daß ein adäquates Lehrstellenangebot aufrechterhalten werden kann und daß die Berufsmaturität in Verbindung mit der Fachhochschulausbildung als zweiter Zugang zur tertiären Ausbildung zielstrebig gefördert wird. Im Kanton Zürich gehört der rasche Aufbau der Fachhochschulen zu den prioritären bildungspolitischen Zielen.

$$
[\ldots]
$$

\section{Das Verhältnis von New Public Management und Schule}

Wie schon R. Dubs (1995) in seiner Schrift „Schule, Schulentwicklung und New Public Management" festhält, droht diese Thematik zu Unrecht die 
Schulleitungsbehörden und die Lehrkräfte zu polarisieren. Dies entsteht vor allem dann, wenn man im Benchmarking ein Instrument des Kostendrucks und nicht der modernen Qualitätssicherung sieht oder das leistungsbezogene Lehrkräftelohnsystem nicht als Teil eines Förderungskonzepts betrachtet. Es ist dem Umstand Rechnung zu tragen, daß Lehrkräfte häufig primär intrinsisch motiviert sind (vgl. Dubs 1994, sowie die Literatur in Dubs 1995); allerdings reagieren sie heftiger als andere Personalgruppen auf individuelle Lohnunterschiede. Das Zürcher Modell läßt sowohl Einzel- als auch Gruppenzulagen in eigener Kompetenz der Schule zu, die aber entsprechend zu begründen und aus der Schülerpauschale zu finanzieren sind.

[...]

In allen Fällen braucht es leitende Lehrkräfte mit Leadership, den Willen zur Innovation, definierte Lernziele sowie klare Kompetenz- und Finanzierungsregelungen. Klar muß nicht einheitlich heißen. Das Zürcher Modell der teilautonomen Schule läßt bewußt verschiedene Kompetenzmodelle insbesondere bei der Kompetenzabgrenzung der kommunalen Behörden und den jeweiligen Schulen zu, was auch der unterschiedlichen Größe der Schulgemeinden Rechnung trägt. In allen Fällen sind aber ein Leitbild und ein Schulprogramm als Instrumente der internen pädagogischen Steuerung und Globalbudgets zu erstellen.

$[\ldots]$

Allerdings sind die Reformhürden nicht zu unterschätzen. Die Durchsetzung der Reformen erfordert - auch in kritischen Phasen - den klaren, glaubwürdigen Willen zur Realisierung. Dabei sind Sorgen und Ängste im Umgang mit dem ,neuen Steuerungsmodell“ ernst zu nehmen. Eine gute und umfassende Informationspolitik - hier gibt es noch Schwächen im Zürcher Modell - muß Mißverständnisse abbauen. Ein Erschwernis bildet die schlechte Datenlage bei den Outcome- und Kostendaten. Dem Aufbau entsprechender Führungsdaten kommt erste Priorität zu, wobei in einer ersten Phase nicht allzu hohe Perfektionsansprüche gestellt werden können. Der Perfektionismus und das Nullfehlersyndrom - vorab aus Angst vor Parlaments-, Öffentlichkeits- und Medienreaktionen - können den Fortschritt empfindlich hemmen. Der Ausbildungsbedarf auf allen Stufen ist allgemein groß. Die Reformen erfordern vor allem in der ersten Phase Pioniergeist und den Willen zur Innovation, die wohl nur bei freiwillig Beteiligten gegeben sind. Das Zürcher Modell arbeitet daher im Bereich der Volksschule in der ersten Phase mit dem Freiwiligkeitsprinzip. Schließlich gilt es zu vermeiden, daß es zu einer Überlagerung der heutigen bürokratischen Inputsteuerung durch die Wirkungssteuerung kommt, weil dadurch das System gefährlich übersteuert würde. Diese Gefahr muß von den Oberbehörden ernst genommen werden. So schaffen NPM und Pädagogik ein organisches Ganzes, das in ein übergeordnetes Verwaltungführungskonzept integriert sein muß.

$[\ldots]$ 


\section{Literatur}

Bertelsmann-Stiftung (1990): Award 1990. Gütersloh: Bertelsmann.

Bertelsmann-Stiftung (1996): Innovative Schulsysteme im internationalen Vergleich, Bd. I: Dokumentation zur internationalen Recherche. Gütersloh: Bertelsmann.

Boston/Martin/Pallot/Walsh (1996): Public Management. The New Zealand model. Auckland: Oxford University Press.

Buschor, E./Schedler, K. (Hg.) (1995): Perspectives on performance measurement and public sector accounting. Bern: Haupt.

Dubs, R. (1994): Die Führung einer Schule. Zürich: Kaufm. Verlag; sowie Dubs, R. (1995), Schule, Schulentwicklung und New Public Management. St. Gallen: Institut für Wirtschaftspädagogik der Universität St. Gallen.

Dubs, R. (1995): Schule, Schulentwicklung und New Public Management. St. Gallen: Institut für Wirtschaftspädagogik der Universität St. Gallen.

Erziehungsdirektion des Kantons Zürich: Teilautonome Mittelschulen, Benchmarking 11, Zürich 1996 (unveröffentlichte Analyse).

Herrmann U. (1996): Die Schule - eine Herausforderung für das New Public Management. Vervielfältigte Fassung eines Vortrags vom 2. Februar 1996 im Pestalozzianum. Zürich.

Lambelet. J./Natal. J. (1995): Chômages des jeunes, valeurs socio-économiques et systèmes éducatifs en Suisse, particulièrement en Suisse latine. Lausanne: CREA.

Moser, U./Rhyn, H. (1996): Schulsystemvergleich zwischen der dreiteiligen Oberstufe und der gegliederten Sekundarschule sowie dem Untergymnasium. 1. Bericht, Erziehungsdirektion des Kantons Zürich.

OECD (1989): Quality of schools. Paris.

Osborne/Gaebler (1990): Reinventing government. Reading: Addison Wesley.

Schedler, K. (1995): Ansätze einer wirkungsorientierten Verwaltungsführung. Bern: Haupt.

Reichard, C./Banner, G. (Hg.) (1993): Kommunale Managementkonzepte in Europa. Köln: Kohlhammer.

Rutter, M. (1980): 15000 Schulstunden. Weinheim: Beltz.

Weißbuch der EU-Kommission (1996): Lehren und Lernen auf dem Weg zur kognitiven Gesellschaft, Brüssel 1996.

\section{GUY KEMPFERT, HANS-GÜNTER ROLFF Qualitätsarbeit als Schulentwicklung: Praxisfelder und Methoden}

Was ist eigentlich Schulentwicklung? Um die Antwort vorwegzunehmen: Es handelt sich dabei um einen Systemzusammenhang von Organisations-, Unterrichts- und Personalentwicklung. [...]

Denkt man in Systemzusammenhängen [...], dann führt [jede Initiative der Schulentwicklung notwendig dazu, dass alle drei Aspekte berührt sind.] Eine Schule kann z.B. mit Unterrichtsentwicklung beginnen [...]. $\mathrm{Ob}$ es dabei um überfachliches Lernen oder um erweiterte Unterrichtsformen oder um Methodentraining geht, jeder dieser Ansätze überschreitet die konventionelle Orientierung an einem Fach oder einem Lehrer und führt mit Kon- 
sequenzen $\mathrm{zu}$ organisatorischen Veränderungen, die institutionell abgestützt werden müssen - also zu Organisationsentwicklung. Wer den Unterricht verändern will, muss mehr als den Unterricht verändern. Das kann auf mehr Kooperation hinauslaufen oder auf mehr Teamarbeit. Unterrichtsveränderung mag auch Kern des Schulprogramms werden. Auswirkungen auf das Lehrerhandeln sind unvermeidlich. Weshalb vermutlich immer ein Bedarf an Personalentwicklung entsteht - sei es in Form von Lehrerberatung, Kommunikationstraining oder Hospitation. [...]

\section{Qualitätsarbeit beruht auf Evaluation}

Qualitätsmanagement benötigt Daten als Grundlage für die Ist-Diagnose, für Steuerungswissen und für Bewertungen, also für Evaluation. Evaluation ist ein außerordentlich heikles Thema und eine hochdelikate Angelegenheit. Sie ist mit vielfältigen Widersprüchen und Ambivalenzen verbunden: Evaluation braucht Vertrauen und schafft gleichzeitig Misstrauen. [...] All das ist zu problematisieren, und gleichzeitig muss Evaluation vereinfacht und handhabbar werden. [...]

In letzter Konsequenz sind alle für die Entwicklung von Qualität verantwortlich: Die Schulleitung, das Kollegium, aber auch die Schülerinnen und Schüler sowie Eltern. [...] Wichtig ist, dass die Qualitätsstandards gemeinsam besprochen werden - zwischen Schülern und Lehrern, zwischen Leitungen und Kollegium, zwischen Behörden und Leitungen - und Ausdruck im Schulprogramm finden. [...]

\section{Schülerselbstevaluation}

Schülerinnen und Schüler sind der einzige Daseinsgrund von Schule. Ihr Lernfortschritt ist das ultimative Ziel des Qualitätsmanagements. Zugleich sind sie Subjekt der Qualitätsarbeit: Nur wenn sie selber etwas dazu beitragen, machen sie Lernfortschritte. Deshalb ist es kein Zufall, dass wir Methoden zur Schülerselbstevaluation an den Anfang dieses Kapitels stellen. Als zweiter, eher psychologischer Grund kommt hinzu, dass sich ein Lehrerkollegium eher an Selbstevaluation gewöhnt, wenn die Schüler damit anfangen; dann können Erfahrungen gesammelt und besprochen werden, die Versuche mit eigener Evaluation erleichtern. Ein dritter Grund könnte darin liegen, dass Schülerselbstevaluation vermutlich die wirkungsvollste Form der Qualitätsverbesserung von Unterricht ist. Es kommt noch hinzu, dass Schüler dabei lernen, ihren Lernprozess selbst zu steuern.

Carol Rolheiser hat zusammen mit Lehrkräften des Durham Board of Education (Kanada) ein Lernmodell entwickelt, welches Schülerinnen und Schülern hilft, das im Unterricht Gelernte für sich selbst einzuschätzen und eventuell - aber nicht immer und nicht notwendig - mit anderen zu besprechen. Es besteht aus vier Stadien: 
- Stadium 1: Einbezug von Schülern bei der Definition von Kriterien. [...]

- Stadium 2: Training der Schüler zur Anwendung der Kriterien. [...]

- Stadium 3: Die Schüler erhalten Feed-back zu ihren Selbstevaluationen. [...]

- Stadium 4: Die Schüler lernen, Handlungspläne aufzustellen. [...]

Schüler benötigen von Zeit zu Zeit (alle zwei bis vier Wochen) eine Fremdeinschätzung, damit blinde Flecke der eigenen Wahrnehmung aufgehellt werden und halbwegs realistische Maßstäbe heranwachsen. Im Übrigen sind nicht alle Ergebnisse von Selbstevaluation geeignet, Selbstvertrauen, Selbststeuerungskompetenz und Lernmotivation zu erzeugen. Schüler, die sich dauernd niedrig einstufen, benötigen eine Spiegelung durch Lehrer und auch Förderprogramme, die über die eigenen Ideen für Handlungspläne hinausgehen.

\section{Lehrerselbstevaluation}

Ohne Lehrer gibt es in der Schule keinen Unterricht und ohne qualifizierte Lehrer keinen qualifizierten Unterricht. Für die Weiterqualifikation von Lehrkräften ist die Lehrerselbstevaluation eine wichtige, vielleicht sogar entscheidende Grundlage.

Es gibt bisher wenig Instrumente zur und wenig Erfahrungen mit Lehrerselbstevaluation. Dennoch können wir einige Hinweise geben, die aus ganz unterschiedlichen Quellen stammen. So hat die schweizerische ,Zentralstelle für die Weiterbildung der Mittelschullehrerpersonen“ 1997 einen Fragebogen zum Thema „Welche Kompetenzen braucht eine Lehrperson?“ entwickelt. [...]

$\mathrm{Zu}$ diesen Kompetenzen wurden Skalen entwickelt, auf denen sich jede Lehrperson selbst einschätzen kann, und zwar sowohl den Ist- wie den Sollzustand. [...]

Schließlich weisen wir auf das Anlegen von Portfolios als Möglichkeit der Lehrerselbstevaluation hin. Mit Portfolios wird vor allem in den angelsächsischen Ländern gearbeitet. Ursprünglich meinte der Begriff Portfolio eine Mappe bzw. Tragetasche, in der Zeichnungen, Schriftstücke oder Dokumente gesammelt und aufbewahrt wurden. Portfolios wurden und werden vor allem von Malern, Zeichnern und Architekten benutzt. Analog dazu können Lehrerinnen und Lehrer eine Mappe anlegen und in dieser alle verfügbaren Dokumente zur Selbsteinschätzung ihres Unterrichts und ihrer Schulaktivitäten sammeln. Sie können damit ihre eigenen Stärken und Schwächen analysieren sowie ihre persönliche Entwicklung dokumentieren, aber auch Materialien sammeln, die sie bei Beurteilungen oder Bewertungen vorlegen. Zum Inhalt des Portfolios können gehören: Unterrichtsentwürfe, Video- oder Kassettenaufnahmen vom eigenen Unterricht, Beispiele von Schülerarbeiten, Selbsteinschätzungen, Zertifikate über Aus- 
und Fortbildung, Dokumente der Fremdeinschätzung, z.B. durch Schüler oder Kollegen. Ein Portfolio kann auch als Grundlage dienen, auf der die Behörde oder die Schulleitung der Lehrperson ein Zeugnis ausstellt, ohne die Lehrperson regelmäßig im Unterricht besuchen zu müssen.

\section{Unterrichtsbeurteilung durch Schüler}

[...] Es ist besonders naheliegend, wenn sich Lehrerinnen und Lehrer in erster Linie von ihren Schülern halbwegs regelmäßig Rückmeldungen (,Feed-backs“) über ihren Unterricht holen; denn Rückmeldungen, die qualitätsfördernd wirken sollen, müssen direkt vor Ort stattfinden, sich also unmittelbar auf das Unterrichtsgeschehen beziehen, dürfen keine nennenswerten Zeitabstände aufweisen und müssen in einer gewissen Regelmäßigkeit erfolgen. Dies ist gegeben, wenn Lehrerinnen oder Lehrer von Zeit zu Zeit Fragebögen [...] an ihre Schüler verteilen. Dieser Fragebogen lässt sich in wenigen Minuten ausfüllen, und auch die Auswertung ist nicht zeitaufwendig: Sie kann in der gleichen, zumindest aber der nächsten Stunde erfolgen. [...]

Allerdings erstreckt sich die Beurteilungskompetenz der Schüler nicht auf die Fachinhalte und auch kaum auf die Fachdidaktik. Dennoch können fächerbezogene Instrumente zur Unterrichtsbeurteilung durch Schüler sinnvoll zur Qualitätsentwicklung eingesetzt werden. [...] Es wird dabei im Wesentlichen um Auskunft nach allgemeindidaktischen Elementen des Unterrichts gebeten.

[...] Überhaupt sollten Fragebögen nicht mehr als zwei- bis dreimal pro Schuljahr ausgefüllt werden. Deshalb sollte eine gewisse Methodenvielfalt gepflegt werden, wenngleich es zu Zwecken der Evaluation nötig ist, etwa alle ein oder zwei Jahre dasselbe Instrument erneut zu gebrauchen, weil Entwicklungen und Veränderungen auf diese Weise am ehesten feststellbar sind. [...]

Bei der Methodenvielfalt spielt die Verwendung qualitativer Methoden eine besondere Rolle, weil qualitative Instrumente eine größere Datenvielfalt versprechen und auch eher unerwartete Ergebnisse erbringen als quantitative, die durchweg hochstandardisiert sind.

Bei qualitativen Methoden überwiegen offene Fragen. Für Zwecke der Unterrichtsbeurteilung durch Schüler empfehlen sich vor allem die folgenden: Was findet ihr an meinem Unterricht gut, was soll beibehalten werden? Was findet ihr an meinem Unterricht nicht so gut, was soll anders werden? Was vermisst ihr an meinem Unterricht?

$\mathrm{Zu}$ den qualitativen Verfahren zählen auch Gespräche über Unterricht, die durch Fragen - wie die eben genannten - gelenkt und fokussiert werden können.

Bei Gesprächen besteht das Problem, dass nicht alle zu Wort kommen und Kritiker befürchten, ihre Kritik würde die Lehrer vergällen. 
Auch bei schriftlichen Befragungen qualitativer Art besteht das Problem, dass Schüler fürchten, die Lehrer würden ihre Handschrift erkennen. Abhilfe kann hier ein kleiner Evaluationsausschuss der Klasse schaffen, der nur aus Schülern besteht, die Auswertung und die Ergebnisrückmeldung übernimmt und der sicherstellt, dass die Fragebögen unmittelbar nach der Auswertung vernichtet werden.

Unterrichtsbeurteilung durch Schüler ist indes nicht nur für Schüler heikel, sondern genauso oder erst recht für Lehrer. Denn Lehrer beurteilen zwar ständig Schüler und geben ihnen Noten, werden jedoch selber kaum beurteilt und benotet. Durch ihre eigene Beurteilungspraxis sind Lehrer dafür sensibilisiert, dass es Ungerechtigkeiten gibt und Objektivierung seine Grenzen hat; da sie es selber nicht gewohnt sind, beurteilt zu werden, sind mehr oder weniger unterschwellige Ängste und Befürchtungen vor Fremdbeurteilungen entstanden, vor allem, wenn sie mit Noten verbunden sind.

Qualitätsentwicklung, die auf diesem Gebiete wirksam sein will, muss es den Lehrern also leicht machen, d.h. sie muss Unerfahrenheit und Ängste der Lehrer erkennen, ernst nehmen und berücksichtigen. Die Möglichkeiten, die Psychodynamik der Unterrichtsbeurteilung durch Schüler für Lehrpersonen erträglich zu machen, sind vielfältig. Wichtig ist, zumindest zu Beginn auf den Unterricht der Lehrpersonen zu fokussieren und nicht auf die Person - und der Person schon gar keine Schulnote zu geben. [...]

Ein Fragebogen [...] könnte sowohl an alle Schüler der Schule etwa ab Klasse 8 verteilt werden und sich dann auf den Klassenlehrer beziehen, als auch klassenintern eingesetzt werden. Im ersten Fall könnten und sollten die Lehrpersonen anonym bleiben, was die Hemmschwelle enorm heruntersetzt. Im zweiten Fall sind sie von vornherein identifiziert, was die Hemmschwelle erhöht. Deshalb sollte hier Freiwilligkeit der Teilnahme gelten, solange der Gesetzgeber nichts anderes fordert, und den Lehrpersonen auch Datenhoheit zugebilligt wird.

Datenhoheit meint, dass die Lehrperson selbst entscheidet, was sie mit den Daten macht, wozu auch die Entscheidung gehört, sie ganz für sich zu behalten. Diese Entscheidung ist allerdings aus der Sicht von Qualitätsentwicklung ganz und gar nicht sinnvoll: Zumindest mit den Schülern sollten die Ergebnisse besprochen werden. Empfehlenswert ist auch ein Erfahrungsaustausch mit anderen Kollegen, deren Unterricht ebenfalls von Schülern eingeschätzt wurde. [...]

\section{Unterrichtsbeobachtung}

Ein Großteil des Unterrichts, wahrscheinlich sogar $90 \%$, besteht aus Phasen, in denen keine Klassenarbeiten oder Tests geschrieben werden. Es wird diskutiert, analysiert, geschrieben, in Gruppen gearbeitet, zugehört, vorgetragen oder ein Video angeschaut. Trotzdem erhalten Schülerinnen und Schüler Rückmeldungen über ihre Leistungen meistens nur über die scheinbar objektiv messbaren schriftlichen Noten. Genau wie Schüler er- 
halten auch Lehrkräfte nach jeder Lektion ein (unausgesprochenes) Feedback und sie spüren immer, ob die Stunde ein Erfolg war oder misslang.

Sie beobachten auch ständig das Unterrichtsgeschehen und ziehen meistens intuitive Schlüsse, seltener bewusst-reflektierte Konsequenzen. Die Beobachtungen sind in der Regel zufällige Einzelbeobachtungen, z.B. ein störender Schüler, eine originelle Antwort oder eine eigenständig gelöste Aufgabe. Unauffällige Schüler werden kaum registriert und Beobachtungen höchst selten systematisch analysiert. Oft werden die Eindrücke in der Hektik des Schulalltags vergessen und was bleibt sind diffuse Erinnerungen.

Für Lehrkräfte, die ihren Unterricht aber hin und wieder bewusst verbessern möchten, bietet sich die gezielte, systematische Unterrichtsbeobachtung als probates Instrument an. Solche Beobachtungen generieren die notwendigen Daten, ohne die Qualitätsverbesserungen nun einmal nicht zu Stande kommen. Unterrichtsbeobachtungen sollen Lehrkräfte anregen, ihren Unterricht nach eigenen Vorstellungen und mit vertretbarem Aufwand zu verbessern.

Dokumentierte Unterrichtsbeobachtungen können genutzt werden für erweiterte Beurteilungsformen, als Unterlagen für Besprechungen mit Eltern, Kollegen, Schülern, der Schulleitung. [...]

Instrumente sind als Anregung gedacht, den eigenen Unterricht zu reflektieren und vielleicht auf blinde Flecken aufmerksam zu werden. Sie sollen modifizierbar sein.

Die Beobachtungen können je nach Beobachtungsfokus und Intention von der Lehrkraft allein, von Schülern, Kollegen oder der Schulleitung durchgeführt werden. Sobald Außenstehende hinzugezogen werden, werden einerseits die Gütekriterien der Objektivität, Reliabilität und Validität eher erfüllt, andererseits ist der Aufwand größer und zu Beginn wohl auch die Angst der Lehrpersonen vor dem ungewohnten fremden Blick. Die Schultür für andere zu öffnen lohnt sich alle Mal. Schließlich können sowohl Schüler als auch Kollegen ebenfalls Beobachtungen mit anschließender Interpretation durchführen. Dass dabei der Zeitbedarf enorm hoch ist und insofern das Verhältnis von Aufwand und Ertrag in jeder Hinsicht ebenso hoch sein muss, versteht sich wohl von selbst.

\section{Voraussetzungen}

Um Unterrichtsbeobachtungen in Schulen nutzbringend anzuwenden, sollten sich Lehrkräfte (und Schulleitungen) einige wesentliche Bedingungen bewusst machen:

Beobachtungsmethoden müssen einfach handhabbar sein, weil Lehrkräfte sich in erster Linie auf den Unterricht, auf die Interaktion konzentrieren müssen und nicht ständig die Metaebene der Evaluation präsent haben können respektive dürfen. Einfache Methoden erschweren zwar eine differenzierte Beobachtung, aber zusätzliche Differenzierungen fallen oftmals statistisch eh weniger ins Gewicht. 
Beobachtungsmethoden müssen dem Beobachtungsfokus angepasst sein und dürfen das Ergebnis nicht durch eine Manipulation des Unterrichts verfälschen. So kann z.B. die Videoaufzeichnung einer Gruppenarbeit die Schüler bei der Arbeit stören und sie zu ,fernsehreifen“ Darstellungen bewegen, während diese Technik bei Rhetorikübungen vorteilhaft sein kann.

Lehrer sollten nur einen Beobachtungsfokus (eventuell den gleichen in mehreren Klassen) während einer bestimmten Zeit im Auge haben, damit sie sich nicht überlasten.

Methoden und Ergebnisse sollten den Schülern als Hauptbetroffene mitgeteilt werden, und je nach Bedarf können sie auch von Beginn an bei der Konzeption miteinbezogen werden. Schüler stehen Unterrichtsbeobachtungen im Allgemeinen eher positiv gegenüber, da sie die Anstrengungen der Lehrkräfte in Bezug auf deren Unterrichtsverbesserungen natürlich schätzen. Da es dabei immer um die Verbesserung der Unterrichtsqualität geht, müssen Schüler allerdings nicht immer vorher informiert werden, da sie sich - unbewusst - an den Beobachtungskriterien orientieren könnten.

$$
[\ldots]
$$

\section{Vorgehen}

Pädagogische Qualitätsverbesserung geschieht nicht einfach von allein, sondern bedarf einer systematischen Vorgehensweise. So sollte zunächst das Beobachtungskriterium festgelegt werden, und Lehrkräfte sollten sich Rechenschaft über ihre Beweggründe ablegen. Warum wollen sie gerade diesen Punkt beobachten, und was erwarten sie davon. Mögliche Beobachtungsgegenstände können sein:

- Schülerbeteiligung am Unterricht

- Reaktionen der Schüler auf Fehlerkorrekturen

- Gruppenarbeiten

- Sozialverhalten

- Verhalten von Mädchen gegenüber Jungen

- Körpersprache

- Wie und was schreiben Schüler im Unterricht mit

- Referate

- Aussprache. $[\ldots]$

Andere Methoden können sein:

- Tonband- oder Videoaufzeichnungen

- Strichlisten für diverse Beobachtungsraster

- Einsammeln der Hefte

- Gedächtnisprotokolle

- Fotografien 
- Beobachtung der Klasse bei einem anderen Lehrer.

[...] Sehr vorteilhaft ist es, die gleichen Instrumente mit Kollegen zusammen zu konzipieren und sich, wenn möglich, gegenseitig im Unterricht zu besuchen. $[\ldots]$

\section{Schüler- und Elternbefragungen}

Das IFS-Schulbarometer ist vom Dortmunder „Institut für Schulentwicklungsforschung“ (IFS) entwickelt worden. Es ist ein mehrperspektivisches Instrument zur Erfassung von Schulwirklichkeit. Es bietet der einzelnen Schule die Möglichkeit, eine innerschulische Bestandsaufnahme verschiedener schulischer Bereiche aus Schüler- und Elternsicht und auch aus Lehrersicht durchzuführen. Zusätzlich bietet es die Möglichkeit, diese Bestandsaufnahme mit Daten aus einem repräsentativen Bundesdurchschnitt zu vergleichen. Das IFS-Schulbarometer eignet sich zur Qualitätsevaluation von Schulen und als Impulsgeber für Schulentwicklung. [...]

Bei dem IFS-Schulbarometer handelt es sich um ein standardisiertes Befragungsinstrument, das flexibel benutzt werden kann. Es enthält einen Schülerteil mit 25 Fragenblöcken (S), einen Elternteil mit 17 Fragenblöcken (E) sowie einen Lehrerteil mit 23 Fragenblöcken (L). [...]

Man kann auf diese Weise alle Eltern einer Schule befragen oder - etwas weniger aufwändig - die Eltern einer Schulstufe oder Abteilung. Ein Vergleich mit Durchschnittswerten ist für deutsche Schulen möglich. [...]

Wichtig ist, dass die Befragungsdaten den Eltern zurückgespiegelt werden, z.B. auf Elternabenden. Das erhöht mit großer Wahrscheinlichkeit die Akzeptanz der Schule bei den Eltern und vermutlich auch die Bereitschaft der Eltern, die Schule bei der Qualitätsentwicklung zu unterstützen. Am förderlichsten für Qualitätsentwicklung ist allerdings, wenn die Ergebnisse von Schüler- und Elternbefragungen direkt in Maßnahmen umgesetzt werden nach dem Motto: Evaluation muss Konsequenzen haben.

Schließlich ist es auch möglich und sinnvoll, dieselben oder ähnliche Fragebögen der Lehrerschaft vorzulegen, weil dann die Einschätzungen von Schülern, Eltern und Lehrern miteinander verglichen werden können, was nicht nur deren Gültigkeit erhöht, sondern auch zusätzliche Impulse für Qualitätsentwicklung verspricht. [...]

\section{Literatur}

Rolheiser, C. (Ed.): Self-Evaluation. Helping Students Get Better At It. Toronto 1996 


\section{NORBERT MARITZEN \\ Schulprogramm und Rechenschaft - eine schwierige Beziehung}

Profil, Programm, Konzept, Leitbild, Corporate Identity ... Im Kontext der Debatte um Schulautonomie haben zunehmend Schlagwörter Konjunktur, die den Standort der Einzelschule, ihre Identität oder auch ihr pädagogischprogrammatisches Outfit auf den Begriff zu bringen trachten. Die Debatte ist zur Zeit bestimmt durch die übliche Unübersichtlichkeit: Die Begriffsverwendung geht durcheinander; bildungs- und schultheoretische Prämissen werden selten ausgewiesen; das Reden „über“ hat die Praxis „in“längst abgehängt; Politiker und Juristen gießen bereits in Gesetzessprache, wofür erfahrungsgesättigte und reflektierte Anschauung noch fehlt. Folge des inflationären Begriffsgeklimpers ist eine Desorientierung, die Schulpraktiker ebenso wie Berater, Fortbildner oder Bildungsplaner ratlos läßt.

Was tut not? Erstens konzeptionell nachvollziehbare begriffliche Klärung; zweitens eine Funktionsbestimmung dessen, was mit „Programm“ oder „Profil““ gemeint sein kann; drittens eine vorläufige inhaltliche Füllung der Begriffe, viertens die Verortung der neuen Konzeption im Kontext des sich verändernden Systemzusammenhangs (Bildungs- bzw. Schulpolitik, Behördenreform, Steuerungsmodelle), fünftens und vor allem die Veröffentlichung, Auswertung und Konzeptualisierung von exemplarischen Praxiserfahrungen. Für letzteres ist an dieser Stelle kein Platz (siehe z.B. Maritzen/Wassener 1977). Mit dem Mut zum Holzschnitt soll daher versucht werden, in aller Kürze ein paar Ordnungsvorschläge zu machen, die allenfalls heuristischen, d.h. problemstrukturierenden Wert beanspruchen können. Dies ist bereits ein schwieriges Unterfangen, da die Entwicklungskontexte in vielen Bundesländern weitgehend präjudiziert sind durch Gesetze und Verordnungen, die entscheidende Vorgaben in Sachen Schulprogramm und Schulprofil machen.

\section{Versuch einer Begriffsklärung}

Der Rede vom „Schulprofil “ unterliegen im wesentlichen drei semantische Konstrukte:

- Jede Schule hat ,irgendwie“ ein „Profil“. Damit kann der Ruf oder das Image einer Schule gemeint sein (,Elitegymnasium“, „Restschule“, „Leistungsschule“" usw.), oder man verweist mit dem Begriff auf einen traditionellen thematischen Schwerpunkt einer Schule (z.B. naturwissenschaftliches Gymnasium), der vielleicht nur noch wenig über die innerschulische Wirklichkeit aussagt, aber dennoch weiterlebt und wirksam ist.

- Eine Schule „profiliert“ sich durch besondere Schwerpunktmaßnahmen (z.B. bilingualer Zweig, Nachmittagsbetreuung usw.). „Profil“" heißt 
hier vor allem: sich unterscheidbar machen von den Schulen im Umfeld, sich in besonderer Weise positionieren zum Zwecke der Akquirierung einer bestimmten Schülerklientel. Dieser Profilbegriff wird bestimmt durch das Außenverhältnis der Schule, den Markt, auf dem sich Schulen (Wer in der Schule?) durch Profilgebung Vorteile im Konkurrenzkampf um Schüler erhoffen.

- Eine Schule entwickelt ein „Profil“, das die innere Entwicklung einer Schule in unterschiedlichen Bereichen koordiniert und auf einem Konsens in pädagogischen Zielen gründet. „Profil“" bezieht sich hier eher auf das Binnenverhältnis einer Schule: Alle für den Unterricht und das Schulleben Verantwortlichen erarbeiten eine pädagogische Grundorientierung als Ausweis ihrer Identität als Organisation Schule.

Diese letzte Bedeutung ist gemeint, wenn zum Beispiel im Bremischen Schulgesetz von Schulprofil die Rede ist (vgl. § 9 BremSchulG). Dort wird der Profilbegriff auch in spezifischer Weise mit dem Begriff des Schulprogramms verknüpft, indem es heißt: „,das ... zu entwickelnde Profil soll durch ein Schulprogramm gestaltet und fortgeschrieben werden."Während Profil also auf den von den Schulmitgliedern intendierten Sollzustand einer Schule verweist, ist Schulprogramm das Mittel, mit dem dieses Ziel, von der je gegebenen Ausgangslage startend, erreicht werden soll. Schulprogramm ist also ein Instrument, gleichsam das Drehbuch, das die innere Entwicklung einer Schule steuert und orientiert (siehe zur Begriffsbestimmung Fleischer-Bickmann/Maritzen 1996). Es ist ein schriftliches Dokument der Entwicklungsziele, -schritte und -maßnahmen einer Schule.

\section{Funktionen des Schulprogramms}

Aber auch das Schulprogramm, hier also als Schulentwicklungsinstrument verstanden, entkommt nicht dem Spannungsverhältnis, das sich in den widersprüchlichen Bedeutungsschichten des Profilbegriffs schon andeutete. Es lohnt sich deshalb, genauer nach möglichen Funktionen des Schulprogramms zu fragen. Es liegt nahe, drei Bereiche auszuweisen, in denen Schulprogrammen besondere Funktionen zukommen können:

a) Am naheliegendsten ist es, im innerschulischen Raum Funktionsbestimmungen für ein Schulprogramm vorzunehmen. Hier hat die Arbeit an einem Schulprogramm zu allererst eine Entwicklungsfunktion, indem die standortspezifische Herausbildung von zukunftsorientierten pädagogischen Schwerpunkten systematisch vorangetrieben wird. Weitere wesentliche Funktionen könnten in diesem Zusammenhang sein: interne kollegiale Orientierung und Konsensbildung, Anregung von Innovationsprozessen, Stimulierung und Planung von Kooperationszusammenhängen, das Verbindlich-Machen von Initiativen, Bereitstellung von partizipativen Gestaltungsmöglichkeiten usw. 
b) Im öffentlichen Raum kommen dem Schulprogramm Aufgaben im Hinblick auf außerschulische Partner und Institutionen zu. Schulen haben verstärkt ein Interesse daran, über ihre Angebote und Konzeptionen zu informieren, wobei dem Marketing-Aspekt ein zunehmend größerer Stellenwert beigemessen wird. Für Eltern hält das Schulprogramm wichtige Informationen bereit, die ihnen bei der gezielten Anwahl von Schulstandorten Entscheidungshilfen bereitstellen könnten. Auch für außerschulische Partner (z.B. Vereine, freie Träger im Sozialbereich usw.) können Schulprogramme Orientierung bieten, indem sie Kooperationsmöglichkeiten öffentlich machen. Dies gilt auch für die Zusammenarbeit mit Unterstützungssystemen (z.B. Fortbildungs- und Beratungseinrichtungen), da Schulprogramme die Möglichkeit eröffnen können, Unterstützungsbedarfe zu präzisieren und maßgeschneiderte Hilfsangebote zu erstellen.

c) Im Bezug zum administrativen Raum erhält das Schulprogramm eine wichtige Steuerungsfunktion, insofern es Grundlage für die interne und externe Evaluation der schulischen Arbeit wird. Was im Schulprogramm festgeschrieben ist, kann mit offengelegten Kriterien überprüft werden. Erfolg oder Mißerfolg der Umsetzung von Schulprogrammen werden beschreib- und vermittelbar, und zwar im Innern der Schule ebenso wie gegenüber vorgesetzten Dienststellen. Mit Schulprogrammen lösen Schulen wie noch genauer skizziert werden soll - auch ihre Rechenschaftspflicht ein. Darüber hinaus eröffnet der standortübergreifende Vergleich von Schulprogrammen Schulverwaltungen potentiell auch die Chance dezentraler Steuerung der Bildungsangebote, um regional vergleichbare Angebotsstandards zu halten und die regionale Angebotspalette insgesamt auszutarieren.

Alle drei Bezugsgrößen werden immer gleichzeitig präsent sein bei der Entwicklung von Schulprogrammen. Es liegt aber nahe zu vermuten, daß die Dominanz der einen oder anderen Funktionsbestimmung ganz wesentlich das Aussehen der Schulprogramme bestimmen wird, d.h. auf den Charakter der im Programm ausgewiesenen Zielsetzungen, die inner-schulischen Prozesse und die vereinbarten Maßnahmen (Produkte) durchschlagen wird. Auch höchstproblematische Entwicklungen sind in allen drei Funktionsbereichen denkbar. Ob Schulprogramme nun vornehmlich auf Werbewirkung durch Hochglanzbroschur bedacht sind, ob sie als trockene Rapporte ungelesen in Behördenregalen verstauben oder ob sie zum Zankapfel innerschulischer Ideologiekämpfe werden, es sind genug Szenarien denkbar, in denen die Entwicklungschancen, die Schulprogramme bereithalten können, verspielt werden.

\section{Struktur von Schulprogrammen}

Welches könnten nun Merkmale sein, die eine inhaltliche Füllung des hier entwickelten Programm-Begriffs versprechen? Wenn das Schulprogramm sich letztlich keinem der oben genannten Funktionsbereiche entziehen 
kann, dann liegt es nahe, sie in abgewogener Weise in der Struktur des Schulprogramms zu berücksichtigen, indem folgende Anforderungen an ein Schulprogramm formuliert werden:

- Im Schulprogramm drückt sich die pädagogische Grundorientierung einer Schule aus.

- Ein Schulprogramm enthält auf der Basis einer beschriebenen schulischen Ausgangslage klare Zielvorstellungen. Die Kriterien der Zielerreichung werden benannt.

- Das Schulprogramm nennt die Maßnahmen zur Zielerreichung, entwirft einen Zeitplan, benennt Verantwortliche für die Umsetzung und weist die notwendigen Ressourcen im Rahmen des Schulbudgets aus.

- Das Schulprogramm setzt Schwerpunkte im Unterricht und Schulleben und nimmt dabei Bezug auf curriculare und sonstige Rahmenvorgaben oder schulinterne Verabredungen.

- Das Schulprogramm enthält Aussagen über die Durchführung und die Referenzkriterien der internen Evaluation.

- Bei der Erarbeitung des Schulprogramms werden alle schulischen Gruppen (Lehrer/innen, Schulleitung, nichtunterrichtendes Personal, Schüler/innen, Eltern) angemessen einbezogen.

- Das Schulprogramm wird regional mit den benachbarten Schulen abgestimmt. $[\ldots]$

\section{Zwischen Rechtschaffenheit und Rechenschaft}

Es wurde implizit bereits angedeutet: Die Idee, Schulentwicklungsarbeit relativ umfassend in Schulprogrammen zu dokumentieren, bekommt ein problematisches Vorzeichen insofern, als sie derzeit in einem Kontext verschärften Rechtfertigungsdrucks propagiert wird, der von Lehrerinnen bzw. Lehrern und Schulleitungen als mehr oder weniger diffuser Kontrollanspruch erlebt wird. Das Schulprogramm wird in dieser Perspektive weniger als pragmatisches Entwicklungsinstrument oder Werkzeug der Selbstvergewisserung wahrgenommen denn als etwas, was „für Außenstehende“" oder „für die da oben“ aufgeschrieben werden soll. In der Tat legen auch Schulbehörden besonderen Wert auf die Schriftlichkeit von Schulprogrammen, eine Anforderung, die nicht nur dem schulischem Personal erhebliche Mühe und relativ ungewohnte Schreibarbeit bereitet, sondern vermutlich auch Rückwirkungen auf die Programme selbst haben wird: Im Programm steht - so ist zu befürchten - nur das, was sich (bequem) aufschreiben läßt, und Papier ist bekanntlich geduldig. Darin kommt die durchaus verständliche Abwehrhaltung derjenigen zum Ausdruck, die ihr rechtschaffenes Bemühen um die Gestaltung der schulischen Entwicklungsarbeit nicht durch von außen daherkommende Offenlegungszumutungen mit Mißtrauen belegt sehen wollen. 
Der Abwehrstrategien gibt es - so zeigen erste Erfahrungen mit Diskussionen in Lehrerkollegien - sehr viele. Sie kommen in einer Vielzahl argumentativer Figuren daher:

- Ohne besondere Stundenentlastung ist das nicht zu leisten.

- Jetzt sollen wir uns wohl selber kontrollieren. Ich säge mir doch nicht den Ast ab, auf dem ich sitze.

- Was geht denn die anderen an, wie ich meinen Unterricht mache. Es gibt ja wohl immer noch die pädagogische Freiheit.

- Schulprogramm, nein danke. Nichts als Leistungsverdichtung bei knapper werdenden Ressourcen.

- Na gut, wenn's sein muß, dann beauftragen wir halt zwei Kollegen.

- Schulprogramm wird uns schon wieder von oben aufgedrückt.

- Ständig deckt uns die Behörde mit Aufträgen ein, nun auch das noch.

- Wir denken doch immer über unseren Unterricht nach. Ist das keine Schulprogrammarbeit?

- Wenn die Abstimmung über die Schulprogrammentwicklung im Kollegium 50 zu 50 läuft, was dann?

- Wir haben so viele Alltagssorgen, laßt uns damit erst mal in Ruhe.

- Wir sind im Schnitt über 50. Da fällt es schwer, Neues zu beginnen.

- Schulprogrammarbeit und Elternbeteiligung? Die kennen uns doch oder interessieren sich immer weniger für unsere Arbeit.

Solche ernst gemeinten Einwände führen Bildungsplanern vor Augen, daß die frohe Botschaft vom Schulprogramm ein ähnliches Schicksal zu ereilen droht wie in der Vergangenheit schon andere zentral vorformulierten Innovationszumutungen, wenn nicht viel dezidierter am Gestaltungspotential, den Erfahrungen und Handlungsbedingungen der Schulen und dort vor allem der Lehrerinnen und Lehrer selbst angeknüpft wird. Von ermutigenden Beispielen, die es in großer Zahl gibt, müßte gelernt werden, um das Nützlichkeitsversprechen, das in der Idee vom Schulprogramm mittransportiert wird, anschaulich werden zu lassen.

Ein anderes wird ebenso deutlich: Im deutschsprachigen Raum mangelt es offensichtlich - anders als in Ländern, in denen die schulische Arbeit stärker und direkter an Anspruchshalter (Übersetzung des englischen Wortes stakeholders: z.B. Eltern, Schulgemeinden, Schulpflegen, school-boards usw.) rückgebunden ist - besonders an einem nicht-defensiven, d.h. konstruktiven Umgang mit legitimen internen und externen Informationsansprüchen. Die oftmals frustrierende Erfahrung, die Eltern mit der Durchsetzung ihres Anspruchs auf Unterrichtshospitation machen, ist dafür nur ein Beispiel. Als ähnlich schwierig erweist es sich nicht selten, die Arbeit an Schulprogrammen innerhalb der Schule plausibel erscheinen zu lassen, fällt diese Anforderung doch angesichts der angedeuteten Wahrnehmungsmuster sofort dem Kontrollverdacht anheim. Von außen an die Schule oder an einzelne Lehrerinnen und Lehrer herangetragene Ansprüche haben zu- 
nächst einmal ihre pädagogische Legitimation unter Beweis zu stellen. Der legalistische Hinweis auf die Rechtslage („Ihr müßt es aber tun!“) verfängt da zunächst wenig und wirkt sich vermutlich eher kontraproduktiv aus.

Was kann nun Rechenschaftslegung im Zusammenhang mit der Erarbeitung von Schulprogrammen bedeuten? In einem ersten Zugriff erscheint es sinnvoll, den Begriff der Rechenschaft, der in den angelsächsischen Ländern als accountability - obwohl semantisch leicht abweichend - über eine ältere Tradition verfügt (vgl. zum englischen Kontext Kogan 1986 und Wagner 1989), gegen den bürokratischen Kontroll-Begriff abzusetzen. Kontrolle meint in administrativen Kontexten gemeinhin Fremdbestimmung, oft einhergehend mit Vorstellungen von vertikalen Steuerungsmustern. Rechenschaft könnte demgegenüber allgemein als Bringschuld bezeichnet werden, die dadurch eingelöst wird, daß Anspruchshaltern professionelle Aufklärung und Information über geplante oder erbrachte Leistungen gegeben wird. Eine Rechenschaftspflicht besteht in diesem Sinne nicht nur - wie meist unterstellt - gegenüber einem „Außen“ und „Oben“ (z.B. Schulaufsicht), sondern ebenso gegenüber allen schulischen Interessengruppen.

Für das Schulprogramm heißt dies beispielsweise, daß im Prozeß seiner Entwicklung ebenso wie durch das schriftliche Dokument

- Schülerinnen und Schüler angemessen in die Gestaltung der schulischen Arbeit und die Darstellung ihrer Ergebnisse einbezogen werden;

- Eltern mit Informationen, die ihnen Entscheidungen zur Planung der konkreten Schullaufbahn ihrer Kinder erleichtern, versorgt werden;

- Lehrerinnen und Lehrer ihre Unterrichts- und Erziehungstätigkeit viel systematischer als bisher untereinander offenlegen und gemeinsam planen, sich regelmäßig ein professionelles Feedback geben und lernen, ihre individuelle Arbeit in einen Zusammenhang mit dem Organisationszweck ihrer besonderen Schule zu setzen;

- Schulbehörden über regionale schulische Bildungsangebote genauere qualitative Informationen erhalten, die sie zur strategischen Bildungsplanung und Sicherung einer ausgewogenen Angebotsstruktur benötigen.

Rechenschaftsbeziehungen ergeben sich also in allen Bereichen, in denen dem Schulprogramm Funktionen zukommen, innerhalb der Schule ebenso wie gegenüber der Öffentlichkeit und der Schulverwaltung.

$[\ldots]$

Schulprogramme werden also in vielfältiger Weise in einen Systemkontext eingebunden sein, der sich gegenwärtig radikal verändert, wofür die Autonomie-Debatte nur ein Ausdruck ist. Es ist keinesfalls Zufall, daß die Rede vom Schulprogramm derzeit en vogue ist. Vielmehr werden derartige Konzepte virulent, weil in einer Landschaft selbständiger werdender Schulen, in der auch das Handlungsrepertoire klassischer Schulaufsicht immer 
weniger wirksam ist, nach neuen Instrumenten dezentraler Selbststeuerung von Schulen gesucht werden muß.

$[\ldots]$

\section{Literatur}

Fleischer-Bickmann, W./Maritzen, N.: Schulprogramm. Anspruch und Wirklichkeit eines Instruments der Schulentwicklung. In: Pädagogik 48 (1996), H. 1, S. 12-17.

Kogan, M.: Educational Accountability. London: Hutchinson 1986.

Maritzen, N./Wassener, D.: Biographie eines Schulprogramms. Über die Innenseite eines Schulentwicklungsprozesses. In: Journal für Schulentwicklung 1 (1977), H. 2, S. 29-34.

Wagner, R.B.: Accountability in Education. A Philosophical Inquiry. New-York/London: Routledge 1989.

\section{CHRISTOPH MAEDER}

\section{Brauchbare Artefakte. Statistiksoftware für das Pflegemanagement im Spital als das Produkt ethnographischer Arbeit}

Im folgenden Text wird gezeigt, wie mit einer anwendungsorientierten ethnographischen Arbeit ein Darstellungsproblem der Arbeit einer Berufskategorie im Spital bearbeitet wurde und wie daraus ein Darstellungsproblem - oder möglicherweise eine erweiterte Form der Darstellung innerhalb der Ethnographie - entstanden ist.

$$
[\ldots]
$$

\section{Das Repräsentationsproblem von Arbeit in der Organisation}

Organisationen werden für ihre Mitglieder zu subjektiven und objektiven Phänomenen der Wirklichkeit, indem in alltäglichen, symbolisch codierten Handlungspraktiken immer wieder kommunikativ verdeutlicht wird, welche „Dinge“ für die Handelnden in diesen sozialen Ordnungen vorkommen und Gültigkeit haben. Das Fundament der Organisation wird dabei durch die Interaktionen der Mitglieder in einer ethnomethodologischen Sichtweise als ein ,doing organization' (Garfinkel und Sacks 1976) immer wieder hergestellt. Dabei gebrauchte Deutungsschemata und ihre kompetente Pragmatik in der Handlungssituation werden - in Anlehnung an Hall (1997: 15-47) - als kulturelle Repräsentationssysteme bezeichnet, die im Verlauf der Sozialisation zum Organisationsmitglied erlernt werden müssen. Doch so fundamental die interaktive Dimension des sozialen Handelns in Organisationen auch ist, so einsichtig ist es, dass sich die prinzipiell flüchtigen Interaktionen auf Interpretationsmaterial als kommunikative Ressourcen stützen müssen, die in objektivierter Form als Text, Bild und 
anderes mehr verfügbar sind. Im Rahmen dieses Aufsatzes beschränken wir uns auf diesen speziellen Aspekt der sozialen Repräsentation von Arbeit in der Organisation.

Dem sozialen Zwang der objektivierenden Repräsentationsarbeit in Organisationen unterliegen grundsätzlich alle Angehörigen einer Organisation. Je größer und arbeitsteiliger Organisationen sind und je mehr unterschiedliche Berufe und Professionen in ihnen auftauchen, umso wichtiger werden in der Regel die Praktiken der objektivierenden Repräsentation von Arbeit. Dies trifft insbesondere für die von uns untersuchte Organisation vom Typ „Spital“ zu. Nur durch die objektivierende Repräsentation von Arbeit sind längere Kooperations- und Koordinationsketten in solchen arbeitsteiligen Kontexten von personenbezogenen Dienstleistungen überhaupt herstellbar.

$$
\text { [...] }
$$

\section{Unterschiedliche Formen der professionellen Repräsentation der Arbeit im Spital}

Im Rahmen unserer Feldarbeiten [in Krankenhäusern] sind wir relativ rasch auf [...] von drei Berufsgruppen geordnete Repräsentationssysteme und [...] Objektivationsformen gestossen: die Ökonomie, die ärztliche Medizin und die Pflege. Wenn es auch für einen geregelten Spitalbetrieb noch vieler anderer Berufsgruppen bedarf, so bildet diese Dreiheit doch den definitorischen Kernbereich dieser Kultur [...]. Die Trias findet sich in der Schweizerischen Spitallandschaft fast immer als Führungsstruktur in der Aufbauorganisation in Form von Organigrammen und Funktionsbeschreibungen.

$$
[\ldots]
$$

Trotz formaler Gleichstellung der drei Disziplinen in der normativen Vorstellung über die Spitalführung fällt bei genauerer Betrachtung auf, wie die objektivierenden Repräsentationen und der Grad ihrer klaren Deutbarkeit stark zu Ungunsten der Krankenpflege ausfallen. Während - stark vereinfacht ausgedrückt - die Ärzteschaft die Codierung „krank“ und „gesund“, ,gelungen“" und „nicht gelungen“, „normal“ und ,abweichend“ konstant in ihre Dokumentationen und Unterlagen einarbeitet, verfügt die ökonomisch zuständige Verwaltung über den Apparat der Kostenrechnung und daraus abgeleiteter Systematiken der Darstellung von Erfolg oder Nichterfolg in der Arbeit. [...]

Die Krankenpflege verfügt - abgesehen von in die ärztlichen Dokumentationen integrierten, sogenannten Pflegedokumentationen - über keine tatsächlich ihrer eigenen und exklusiven Deutungsmacht unterstehende Form der Objektivation ihrer Arbeit. Und sie hat selber auch keine eigenen, für Dritte kommunizierbare, ja gar von wissenschaftlicher Expertise unterstützte Theorien darüber.

$$
\text { [...] }
$$


Im Vergleich zu den elaborierten Repräsentationspraktiken im ärztlichen Sektor (Diagnosecodierungen, bildgebende Verfahren aller Art, Beschreibungen von Eingriffsarten, Erfolgsquoten, Laborwerte usw.) und in der Verwaltung (die gesamten komplexen Darstellungsformen der Kostenrechnung, der Buchhaltung, der Personalführung usw.) konnte und kann die Pflege bis heute nicht mithalten. Sie war und ist deshalb als weiblich dominierte Halbprofession ständig in Gefahr, von der eigenen Führungsspitze, aber insbesondere von den anderen professionell organisierten Berufen im Spital als eine nicht-rationale Klagekultur typisiert zu werden. [...]

Zusammengefasst können wir festhalten, dass die Dokumentationspraktiken als Repräsentationsarbeit der Arbeit im Spital stark professionsgebunden und bei Ärzten und in der Verwaltung in erster Linie zahlenförmig sind. Die Pflege steht im offenen Gegensatz dazu. In der Regel verfügt sie über keine ausschliesslich in ihrer Definitionsmacht stehenden Konzepte der Repräsentation ihrer Arbeit. Diese Nichtrepräsentation der Pflegearbeit hat nun zweifellos Konsequenzen: die Pflege läuft konstant Gefahr, als nicht fassbar und somit auch nicht als eine rationale Handreichungspraxis zu gelten. [...] Damit einher geht eine geschlechtsgebundene Typisierung in männlich-wissenschaftliche Repräsentation im Zahlenformat und eine weiblich-klageartige im Schwatzformat. Diese unterschiedlichen Deutungskulturen der organisationellen Wirklichkeit führen - über hier nicht näher beschriebene Wirkungslinien - zu einer hierarchisch klaren Unterordnung der Pflege im Spital insgesamt. Das Regime der Wahrheit und des ärztlichen Blicks - um mit Foucault (1988) zu sprechen - lässt es bei der Selbstbeschreibung der Arbeit nicht zu, dass in diesem Kontext bei der Objektivierung der geleisteten Arbeit mit anderen Darstellungsformen als mit Zahlen operiert wird. [...] Es ist demnach folgerichtig zu erwarten, dass in einer solchen modernen, multiprofessionell bestückten Organisation mit den dominierenden Deutungskulturen der Ärzte und der Ökonomen Repräsentationsformen ohne Zahlenformat wenig Chancen haben.

\section{Angewandte Ethnographie: Geschichte und Konstruktion von LEP ${ }^{T M}$}

[...]

Die „Verrechnung“ der Pflegearbeit, d.h. deren zahlenmäßig sinnvolle Beschreibung, stösst tätigkeitsimmanent sehr schnell an Grenzen. Um Tätigkeiten messen zu können, müssen sie analytisch und empirisch klar voneinander trennbar sein. Das ist jedoch in der Pflegearbeit als einer personenbezogenen, interaktiv erbrachten Dienstleistung oft nicht der Fall. Da Produktion und Konsum solcher Dienstleistungen gemäß dem ,uno-actu Prinzip“ vielfach zusammenfallen, lässt sich auch bei genauer Beobachtung kaum feststellen, was wann und wo beginnt, was parallel ausgeführt wird, und wann etwas endet. Es ist nur analytisch und um den Preis einer groben, ja fast brachialen Vereinfachung möglich, sich für eine klare Zuschreibung zu entscheiden. 
$[\ldots]$

Sehenden Auges haben wir uns Anfang der Neunziger Jahre trotzdem entschlossen, ein quantifizierendes Managementinstrument für die Pflege zu entwerfen, um eine objektivierte Darstellung dieser Arbeit zu haben und sie so steuerbarer und für Dritte kommunikativ anschlussfähig zu machen. Die klassische Feldarbeit für diese Untersuchung wurde zwischen 1989 und 1992 im Kantonsspital St. Gallen und im Universitätsspital Zürich intensiv begonnen und seither sporadisch weitergeführt. [...] Die mit den Verfahren der ethnographischen Semantik (Maeder/Brosziewski 1997) gewonnenen Kategoriensysteme zur Arbeitspraxis in der Krankenpflege im Spital konnten jedoch vor dem Hintergrund der dominierenden Deutungskulturen naturwissenschaftlich-managerieller Art nie als ethnographische Befunde ausgewiesen und als eine Ethnographie dargestellt werden, da ja das explizite Ziel des Auftrags darin lag, ein Zahlensystem für die Pflegenden zu konstruieren. ${ }^{29}$ Die erste Modellierung der Pflegearbeit in dieser speziellen und ungewohnten Zahlenform erschien in Buchform (Güntert/Maeder 1994) und wurde anschliessend verfeinert und den sich in den Neunziger Jahren in Folge von diversen Reformprogrammen des Gesundheitswesens schnell wandelnden Gegebenheiten in der Spitalorganisation immer wieder angepasst (Maeder u.a. 1998; 1999a, b) ${ }^{30}$ In ethnographischer Selbstbeschreibung ausgedrückt, haben wir ein brauchbares Artefakt für die Auftraggeber hergestellt.

\section{[...]}

Das Kernstück von LEP besteht in der Anwendung aus einem Variablenkatalog von 80 Tätigkeitskategorien. Eine Variable steht für eine bestimmte pflegerische Tätigkeit, die einem Patienten oder einer Patientin direkt zugeordnet werden kann. Jede einzelne Pflegevariable umfasst eine Bezeichnung, eine Definition, illustrative Beispiele, eine Anwendungsanleitung und einen festen Zeitwert. Der Zeitwert ist so ausgelegt, dass eine ausgebildete und berufserfahrene Pflegeperson im Durchschnitt eine solche pflegerische Tätigkeit unter Einhaltung der qualitativen Standards des Berufes ausführen kann. Die Zeitwerte sind als normative Vorgaben konzipiert und absichtlich in der exklusiven Definitionsmacht der Pflege veran-

29 Für eine vollständige, theoretische und methodologische Fundierung der hier verfolgten Empirie wird verwiesen auf die beiden Bände zur Ethnographie in der Traditionslinie der ,Ethnoscience“ von Werner/Schoepfle (1986; 1987).

30 Für diese Konstruktionsarbeit war sicher hilfreich, dass der Autor dieses Textes von 1974-1977 die Berufsausbildung als diplomierter Krankenpfleger durchlief und zwischen 1978 und 1983 im Spital in dieser Funktion gearbeitet hat. Insbesondere die Vertrautheit mit den im Feld verwendeten Begriffen und deren Deutung machte es möglich, einen an den Relevanzen der tatsächlichen Berufspraxis ausgerichteten Katalog von pflegerelevanten Tätigkeitskategorien (mit)herzustellen. Diese Mitgliedschaft im Feld war insgesamt sicher von Vorteil, doch ist sie keine Voraussetzung, um solche Arbeiten durchführen zu können. 
kert. Sie wurden und werden von einem Expertengremium unter Zuhilfenahme von periodisch durchgeführten Arbeitszeitmessungen festgelegt.

Einmal täglich erhebt das Pflegepersonal pro Patient oder Patientin, welche Variablen wie häufig zugetroffen haben. Die Erfassung kann dabei mittels Barcode, optischem Belegleser, PDA (Personal Digital Assistant) oder auch „online“ erfolgen. Diese sogenannten „Patientendaten“ über die applizierte Pflege bilden die eine Seite des Instrumentes. Die andere Seite bilden die Arbeitszeiten des Personals, die ebenfalls berechnet werden. Diese zwei Datenkategorien stellen die Grundlage für zahlreiche Auswertungen dar, die nun möglich sind. Solche Auswertungen dienen den Vorgesetzten der Pflege für die kurzfristige Steuerung ihres Verantwortungsbereiches und den oberen Pflegekadern für die langfristige Planung. Das Produkt lässt sich auf den ersten Blick von einem traditionell hergestellten, quantitativen Messinstrument nicht unterscheiden. Einen Überblick über das Instrument findet die interessierte Leserschaft auf der Website „http://www.lep.ch“.

[...]

Das Außergewöhnliche des Instrumentes sehen wir nicht so sehr in seiner Endform, als vielmehr in seinem Konstruktionsprozess. Die Grundlage der Entwicklung dieses Instrumentes bilden Techniken der qualitativen Sozialforschung, und zwar die der teilnehmenden Beobachtung mit Pflegenden auf den Stationen und Gruppengespräche mit weiteren sachverständigen Personen aus der Pflege, wie z.B. Pflege-Expertinnen mit Höherer Fachausbildung, Oberschwestern, Leitungen Pflegedienst usw. Als besonders fruchtbar hat sich dabei die Form des Gruppengesprächs mit den Pflegenden herausgestellt. Unseres Erachtens dürfte ein Teil des Erfolges dieses Zugriffs auf die organisationelle Wirklichkeit damit zusammenhängen, dass diese Gesprächsformen auch sonst im kulturellen Bezeichnungsrepertoire der Organisation verankert sind, als Rapporte und Teamsitzungen. An Rapporten, denen Funktionen wie Arbeitsplanung, Arbeitsvergabe, Arbeitskoordination und Arbeitskontrolle zukommen, sind die Pflegenden konstant damit beschäftigt, Beschreibungen ihrer Arbeit zu kommunizieren. Die Pflege wird so gewissermaßen „,natürlich“ und für den Ethnographen zugänglich in Sprachkategorien gefasst, die auf die dazugehörigen beruflichen Wissensbestände verweisen. [...] Im ersten Zugriff wurde denn auch nichts anderes hergestellt als ein Lexikon der praktischen Tätigkeiten in der Sprache des Feldes. Dieses rekonstruierte Lexikon als lebensweltliches Konstrukt erster Ordnung (vgl. Eberle 1984: 81-147) besteht zumindest in der Schweiz - anderenorts mögen andere Arbeitskategorien in den Zuständigkeitsbereich der Pflegenden fallen - je nach Tätigkeitsbereich aus zwölf oder dreizehn Domänen in der Bezeichnung der Tradition der ethnographischen Semantik (vgl. Maeder/Brosziewski 1997). Diese Domänen sind alle mit der Relation „Ist eine Art Arbeit in der Pflege“ mit ihren semantischen Komplementen feinerer Abstufung verbunden. Die Komplemente ihrerseits tragen Attributdimensionen der Aufwendigkeit von „selb- 
ständig“ bis „,sehr aufwendig“ im Bereich der sogenannten „Grundpflege“ oder sind im Bereich von sogenannter Behandlungspflege nach den Anspruchsgraden aus Sicht der Pflegenden konnotiert. [...]

Diese Fachsprache wurde in einem Prozess teilnehmender Beobachtung systematisch erschlossen und in Anlehnung an Spradley (1980: 140-154) dem kulturellen Thema „Ist eine Art Arbeit der Pflegenden für den/die Patientin“" zugeführt. Dies wird in der Sprache des Feldes als „direkte Pflege“ bezeichnet, im Gegensatz zu den Arbeiten, die nicht an den Patienten und Patientinnen stattfinden. Ergänzt um jene Arbeiten, die zwar nicht face-toface mit zu versorgenden Menschen stattfinden, aber einer hospitalisierten Person dennoch zugerechnet werden können, erhielten wir so ein umfassendes und brauchbares Lexikon der Pflegearbeit in der berufseigenen Sprachlichkeit. Insgesamt konnten 13 Domänen der Arbeit in der Pflege rekonstruiert werden, die mit zwischen zwei und 15 Komplementen verbunden sind und so eine sehr präzise Beschreibung der Arbeiten ergeben, die sich direkt auf zu versorgende Personen beziehen. Diese Domänen ein Begriff zur kategorialen Taxonomisierung von Wissensbeständen innerhalb der kognitiven Anthropologie (vgl. D‘Andrade 1995) - kommt eine zentrale Stellung zu, da sie gewissermaßen so etwas wie eine berufsgebundene Kurzstenographie der Arbeit abgeben [...].

Die Konstruktionsarbeit des Variablenkatalogs erfolgte in zwei Schritten. Erstens mussten in einer umfassenden Liste die Begriffe für die im beruflichen Relevanzsystem bedeutsamen Tätigkeiten gefunden werden, und zweitens mussten diesen Begriffen normative Zeitwerte zugeordnet werden. Es hat sich herausgestellt, dass der erste Schritt immer der kritischere gewesen ist. In einem Gruppengespräch wird so unter Beteiligung eines Ethnographen (in diesem Kontext ,wissenschaftlicher Berater“ genannt) versucht, eine semantische Struktur von Selbstbeschreibungen der Pflegearbeit herauszuarbeiten. Einzelne Tätigkeiten, die unter Umständen aus mehreren Teilschritten bestehen, bilden die unterste Ebene. Diese Tätigkeiten werden zu Variablengruppen zusammengefasst, und schließlich bilden alle Gruppen zusammen die oberste Ebene der semantischen Struktur, nämlich der direkt einem Patienten zuordenbare Pflegeaufwand. ${ }^{31}$

Bei der Auswahl der Begriffe zur Konstruktion des Tätigkeitslexikons für die Pflegenden geht es nicht nur darum, eine im Feld geläufige und verständliche Bezeichnung zu finden, sondern auch das Bedeutungsfeld des Begriffes auszuloten und in Form einer Beschreibung und mit Beispielen festzuhalten. Fällt dies relativ einfach, dann dürfte es sich um einen Wissensbestand aus der allgemeinen Pflegekultur handeln. Gelingt dies nicht auf Anhieb, so handelt es sich vermutlich um organisationsspezifische Wissensbestände, die in relativ langwierigen Diskussionen verhandelt werden müssen. Im ersten Fall lässt sich in der Regel problemlos ein Zeitwert

31 Genau genommen werden nur die Tätigkeiten erfasst, die erstens zeitlich ins Gewicht fallen (also messbar sind) und zweitens auch bezeichnet werden können. 
zuordnen. Im zweiten Fall kann sich dies manchmal relativ schwierig gestalten und ein Begriff muss dann gewissermaßen ausgehandelt werden. Es zeigt sich somit klar, dass der Variablenkatalog des Systems eine eigene Aushandlungsordnung (,,negotiated order") darstellt. ${ }^{32}$

Entscheidend ist dabei nun, dass diese Ordnung von Insidern der Pflege und nicht von Managementberatern ökonomischer Provenienz hergestellt wird. Das Ziel des Prozesses, die Rekonstruktion und Objektivierung der semantischen Struktur der wichtigsten Tätigkeitskategorien der pflegerischen Arbeit, kann nämlich nur von in diesem Berufsfeld sozialisierten Personen stimmig geleistet werden. Berufsfremde verwenden nach unseren Erfahrungen regelmäßig und vorschnell analytische Kategorien aus der Arbeitswissenschaft, in denen die spezifischen Relevanzstrukturen der Handelnden im Feld übersehen werden.

Ein so gewonnener Variablenkatalog wird in einem nächsten Schritt in umfangreichen Validierungsstudien im Spital überprüft und revidiert, bevor er für die Ausprogrammierung an Computerfirmen freigegeben wird. ${ }^{33}$ Modulare Erweiterungen spezifizieren besondere Kontexte, wie beispielsweise die Intensivstation oder die Psychiatrie. Auch sie verfügen über unterschiedliche, aber ebenfalls standardisierte Variablensets. In allen Fällen hat man sich auf ein Total von maximal 80 Tätigkeitsvariablen für jeden Handlungskontext der Pflege beschränkt. Diese Beschränkung ist zwar willkürlich, aber aufgrund von mittlerweile rund 10 Jahren Erfahrung mit diesem „Pflegelexikon“ wissen wir, dass mit 80 Variablen der Pflegeaufwand eines Patienten als Pflegearbeit genügend genau beschreibbar ist für den vorgesehenen Zweck der Objektivierung und Repräsentation von Pflegearbeit. Außerdem gilt hier selbstverständlich auch eine Ökonomie der Daten, d.h. wenn mit mehr Messpunkten nur noch unwesentlich mehr verwertbare Information gewonnen wird, dann lohnt es sich nicht mehr genauer zu messen. Oder soziologischer formuliert sind diese Kategorien insgesamt genügend mit den ,folk theories' (Holland/Quinn 1987: 7-21) der Pflegekultur gesättigt im Sinne der Idee der begründeten Theoriebildung (Glaser/Strauss 1967). Das Instrument wird von den Pflegepersonen - unter

32 Dieser Punkt kann nicht genug hervorgehoben werden, denn in naiver Sicht bilden diese Variablen „,die objektive Wirklichkeit“ ab, doch aus sozialwissenschaftlicher Sicht wird diese gerade durch die Definition der Variablen hergestellt. In diesem Sinn sind auch andere Kategoriensysteme über Tätigkeiten - z.B. die Taxpunktkataloge der Ärzte - für sich genommen nicht objektiv, sondern sie erlangen ihre wirklichkeitskonstruierende Kraft erst durch die verhandelte Anerkennung darüber, dass sie eben objektiv seien.

33 Dabei werden quantitative und qualitative Verfahren kombiniert. Eine Art der Validierung besteht darin, dass Pflegende das Lexikon der Tätigkeiten kommentieren und allenfalls ergänzen oder vereinfachen, und die zweite Art der Validierung geschieht mittels der Diskussion von Ergebnissen des Instruments, bezogen auf eine noch vorhandene und gut bekannte Patientenpopulation. Im Hintergrund werden zudem Verfahren wie der, split half"-Test eingesetzt. 
Abzug der bereits erwähnten, nicht messbaren Dimensionen - denn auch als korrekte Beschreibung ihrer Arbeit anerkannt. Es wird in der organisatorischen Praxis vielerorts erfolgreich für die Steuerung und Optimierung der Pflegearbeit und auch für die Vertretung von Eigeninteressen des Berufs eingesetzt.

\section{Literatur}

D'Andrade, Roy (1995), The Development of Cognitive Anthropology, Cambridge: Cambridge University Press.

Eberle, Thomas S. (1984), Sinnkonstitution in Alltag und Wissenschaft. Der Beitrag der Phänomenologie an die Methodologie der Sozialwissenschaften, Bern: Paul Haupt.

Foucault, Michel (1988) Die Geburt der Klinik. Eine Archäologie des ärztlichen Blicks, Frankfurt am Main: Fischer.

Garfinkel, Harold, Harvey Sacks (1976), Über formale Strukturen praktischer Handlungen, in: Ethnomethodologie. Beiträge zu einer Soziologie des Alltagshandelns, Elmar Weingarten, Fritz Sack, Jim Schenkein, Hg., Frankfurt am Main: Suhrkamp, 130-176.

Glaser, Barney G., Anselm L. Strauss (1967), The Discovery of Grounded Theory: Strategies for Qualitative Research, Chicago: Aldine.

Güntert, Bernhard J., Maeder Christoph (1994), Ein System zur Erfassung des Pflegeaufwandes. Darstellung der Methode LEP des Universitätsspitals in Zürich, Muri: Schriftenreihe der SGGP Nr. 37.

Hall, Stuart (1997), Representation: Cultural Representations and Signifying Practices, London: Sage.

Holland, Dorothy, Naomi Quinn, Hg. (1987), Cultural Models in Language and Thought, Cambridge: Cambridge University Press.

Maeder, Christoph, Achim Brosziewski (1997), Ethnographische Semantik: Ein Weg zum Verstehen von Zugehörigkeit, in: Ronald Hitzler, Anne Honer, Hg., Sozialwissenschaftliche Hermeneutik, Opladen: Leske + Budrich, 335-362.

Maeder, Christoph, Urs Brügger, Ulrich Bamert (1998), Beschreibung der Methode LEP: Anwendungsbereich Intensivpflege, St. Gallen/Zürich: Kantonsspital St. Gallen und Universitätsspital Zürich.

Maeder, Christoph, Urs Brügger, Ulrich Bamert (1999a), Beschreibung der Methode LEP. Grundmodul Psychiatriebereich. St. Gallen/Zürich: Kantonsspital St. Gallen und Universitätsspital Zürich.

Maeder, Christoph, Urs Brügger, Ulrich Bamert (1999b), Beschreibung der Methode LEP. Anwendungsbereich Gesundheits- und Krankenpflege für Erwachsene und Kinder im Spital. St. Gallen/Zürich: Kantonsspital St. Gallen und Universitätsspital Zürich.

Spradley, James P. (1980), Participant Observation, New York: Holt, Rinehart \& Winston.

Werner, Oswald, Mark G. Schoepfle (1986), Systematic Fieldwork. Foundations of Ethnography and Interviewing, Newbury Park/London/New Dehli: Sage.

Werner, Oswald, Mark G. Schoepfle (1987), Systematic Fieldwork. Ethnographic Analysis and Data Management, Newbury Park/London/New Dehli: Sage. 


\section{Unterrichtsentwicklung}

\section{Kommentar (Eubel)}

In historischer Perspektive kann man für die Politik der Schulmodernisierung Phasen unterscheiden, die verstärkt auf äußere Schulreformen setzten, wie es etwa beim Versuch zur Einführung der Gesamtschule sichtbar war. ${ }^{34}$ In Abkehr davon stand anschließend die innere Seite der Schulreform im Vordergrund, z.B. durch Einführung neuer Unterrichtsmethoden und Modernisierung der Curricula. Gegenwärtig zentriert sich die Schulmodernisierung auf einen Bereich, der bei den beiden vorherigen „Modernisierungsschüben" mehr oder weniger ausgespart war, nämlich die Schule als Organisation. In der neuen Governance wollen die Entscheider auf den Ebenen der Politik und der Bildungsverwaltung mit Hilfe einer noch zu errichtenden Schule als Qualitätsorganisation auf das Unterrichtsgeschehen zugreifen. Die top-down-Reform zielt also auf den Hoheitsbereich der Lehrkräfte: den Unterricht. Hier wurde von den Lehrkräften in den letzten Jahrzehnten bottom-up bereits einiges verändert. Die Konzepte der schulischen Modernisierung stellen keine originäre Semantik für die Steuerung von Unterricht bereit ${ }^{35}$, vertrauen jedoch gleichsam darauf, dass sich durch die Veränderungen der organisatorischen Kontextbedingungen und durch Organisations- und Personalentwicklung auch der Unterricht verändern wird.

Implizit setzen alle ,Unterrichtsentwickler' voraus, dass ein modernisierter Unterricht nicht mehr allein aus der pädagogischen Intuition einzelner Lehrpersonen entsteht, sondern zumindest teilweise die Leistung eines teambasierten Kollegiums darstellt. ${ }^{36}$ Damit wird er notwendigerweise

34 Aus der Erfahrung der letzten Jahrzehnte lässt sich im Kontext der deutschen Bildungspolitik von einem weitgehenden Scheitern äußerer Schulreformen sprechen. An Daten über den relativen Erfolg oder Misserfolg von Initiativen der inneren Schulreform zu gelangen, ist relativ schwer, da im traditionellen Schulsystem Ereignisse, die sich schulintern abspielen, nicht nach außen kommuniziert wurden. Aus unterschiedlichen Befunden der empirischen Schulforschung lässt sich aber durchaus ableiten, dass innerschulische Veränderungen stattgefunden haben (siehe dazu z.B. auch den Beitrag von Schönknecht in diesem Band).

35 Obwohl sich mit PISA auch hier gravierende Veränderungen - hinsichtlich eines pragmatischen Verständnisses von Unterrichtsinhalten - andeuten (vgl. den Beitrag von Messner im vorliegenden Buch), die aber offensichtlich noch nicht den Alltag des Unterrichtens berühren.

36 An der konkreten Ausformung haben dann sicher auch die weiteren Akteure (Lehrer und Eltern) der autonomen Einzelschule ihren Anteil. Der Begriff ,Autonomie“ wird damit nicht nur semantisch umcodiert, sondern wirkt sich auf das Handeln aus: Nicht mehr die einzelne Lehrperson ist autonom, sondern das Lehrerteam, das seinerseits rückgekoppelt ist an die Adressaten der ,Dienstleistung' Unterricht. Vgl. auch die beiden Beiträge von Brüsemeister in diesem Band. 
stärker als bisher zu einem nach rationalen - oder zumindest nach intersubjektiv ausgehandelten - Kriterien gestalteten Geschehen. Diese „Enteignung" des autonomen Lehrers könnte zu Akzeptanzproblemen führen, gerade bei engagierten Lehrerinnen und Lehrern - die potentielle UnVerträglichkeit dieses Modells mit dem tradierten Ethos pädagogischer Theorie (,,Der Lehrer trägt die Verantwortung für seine Schüler") liegt auf der Hand. ${ }^{37}$

Die Gestaltung der alltäglich ablaufenden Interaktionsprozesse im Unterricht bildet für die Lehrerinnen und Lehrer den Kern ihrer Arbeit. Daher wundert es nicht, dass sie das Zusammenwirken von Personal-, Organisations- und Unterrichtsentwicklung (Bildungskommission NRW 1995: 162f.) oftmals vom Naheliegendsten her denken: der Unterrichtsentwicklung. Da Unterricht im tradierten Selbstverständnis der Lehrerschaft ein hochgradig individuelles, kaum formalisierbares Geschehen ist, für das jede Lehrperson einzeln Verantwortung trägt, birgt die Entscheidung, den Modernisierungsprozess mit der Unterrichtsentwicklung anzufangen, aber auch ein Problem. Die Zielperspektive der Schulentwicklung könnte auf der Strecke bleiben, wenn die Angebote zur Verbesserung des Unterrichts auf der personalen Ebene, hängen' bleiben und nicht mit der Organisationsperspektive verknüpft werden. ${ }^{38}$ Viele Erfahrungen sprechen aber dafür, dass es dennoch sinnvoll ist, den Startpunkt ,Unterricht' beizubehalten. Wegen des (noch) unzureichend entwickelten Denkens in Begriffen der Organisation dauert es bei anderen Zugängen wesentlich länger, bis sich Effekte einstellen, die von der Lehrerschaft als lohnenswert eingeschätzt werden könnten.

Generell empfiehlt sich ein Anknüpfen der neuen Qualitätsmanagements an tradierte und als erfolgreich erlebte Formen berufsbegleitender Qualifizierungsmaßnahmen. Eine Modellierung der Schulentwicklung nach dem Muster von schulintern organisierten Veranstaltungen der Lehrerfortbildung (SCHILF), mit denen viele Lehrerkollegien in den letzten Jahren positive Erfahrungen gemacht haben, bietet sich deshalb an. Diese Verknüpfung hat zudem den Vorteil, dass bei SCHILF-Angeboten die Organisationsebene strukturell schon , eingebaut' ist. ${ }^{39}$ Schulinterne Lehrerfortbildung wird auch deshalb positiver bewertet als andere Formen der früher oft

37 Vgl. dazu im Textblock „Wertediskussionen“ die Überlegungen Annemarie von der Groebens. Auch Hilbert Meyer macht das Festhalten an solchen Prinzipien zur Bedingung dafür, das „Neue“ zu akzeptieren. Er fordert, dass Schulentwicklung dazu führen sollte, „das Lehren und Lernen humaner und erfolgreicher zu machen.“ (Meyer/Ulrich 1996: 9)

38 Bei dem traditionell stark ausgeprägten pädagogischen Einzelkämpfertum der Lehrerinnen und Lehrer und dem kaum auf Organisation ausgerichteten professionellen Selbstverständnis ist eine solche Sorge sicher berechtigt.

39 Selbst wenn bei solchen Veranstaltungen nicht die Einzelschule als ganze Thema ist, so ist doch zumindest sichergestellt, dass das Kollegium oder Teilmengen desselben, die sich aus fachlichen oder thematischen Gründen gruppieren, an solchen Veranstaltungen partizipieren. 
sogar verordneten Lehrerfortbildung, weil sie besser zur Strategie der inneren Schulreform passt. Die Erfahrungen vom weitgehenden Scheitern struktureller Veränderungen und äußerer Schulreformen gehört zu den prägenden berufsbiographischen Erfahrungen aller Lehrergenerationen der Nachkriegszeit. Es ist deshalb mehr als verständlich, wenn die Lehrkräfte Felder und Strategien bevorzugen, von denen sie den Eindruck haben, etwas bewirken zu können. Und es ist kein Zufall, dass sich bei den aktuellen Qualitätsmanagements etwas ähnliches abzeichnet: Top-down-Strategien werden wesentlich kritischer wahrgenommen als bottom-up-Veränderungen.

Bemühungen um Unterrichtsentwicklung als Kernbereich der Reform zu wählen, empfiehlt sich also aus mehreren Gründen. Lassen sich bei den Lehrerinnen und Lehrern Akzeptanzen hierfür finden, so werden ihnen Mittel und Wege offeriert, Veränderungen zu realisieren und diese Veränderungen als Verbesserung der eigenen Praxis zu erfahren. Last but not least können sie sich als die ,Macher' dieser Veränderungen erleben.

Die nachfolgend abgedruckten Texte sind der hier skizzierten Argumentationslogik verpflichtet und nehmen ihren Ausgangspunkt bei den besonderen feldspezifischen Bedingungen des Handlungs-zusammenhangs ,schulischer Unterricht' ${ }^{\star}$. Der Beitrag von Johannes Bastian (Universität Hamburg) vertieft die angedeuteten Argumente, verknüpft sie mit theoretischen Konzepten der Schulpädagogik und reichert sie mit Erfahrungen aus der Reformpraxis an. ${ }^{40}$ Der Beitrag von Heinz Klippert ${ }^{41}$ (Dozent am Lehrerfortbildungsinstitut der evangelischen Kirchen in Rheinland-Pfalz, „EFWI“) stellt in Grundzügen sein Konzept der pädagogischen Schulentwicklung dar und setzt es in Bezug zu anderen Ansätzen. ${ }^{42}$ Wie Bastian setzt er sich kritisch mit der Vorgehensweise der Organisationsentwicklung $(\mathrm{OE})$ auseinander, wobei er vor allem die Langfristigkeit und den komplexen Zuschnitt dieses Ansatzes problematisiert. Bastian argumentiert ähnlich. Er betont besonders, dass die Semantiken und Denkweisen der Organisationsentwicklung der Institution Schule relativ fremd seien. ${ }^{43}$

40 Vgl. Bastian (1998). Dort werden Perspektiven der pädagogischen Schulentwicklung ausführlicher behandelt. Der von uns verwendete Aufsatz findet sich dort ebenfalls.

41 Der Autor hat eine Reihe von Publikationen vorgelegt, die als „Übungsbausteine für den Unterricht" praktische Arbeits- und Trainingshilfen für Lehrerinnen und Lehrer anbieten: Klippert (1994): Methoden-Training (inzwischen in der 13. Auflage); Kommunikations-Training (1995); Teamentwicklung im Klassenraum (1998); Eigenverantwortliches Arbeiten und Lernen (2001). Die überaus erfolgreichen Publikationen Heinz Klipperts sind ein Beleg dafür, dass bei Lehrerinnen und Lehrern ein großer Bedarf an praktischen Hilfen besteht, der bis vor kurzem von der universitären Erziehungswissenschaft so gut wie gar nicht bedient wurde.

42 Zur ausführlichen Begründung und Darstellung vgl. Klippert (2000).

43 Die Argumente, mit denen die beiden Autoren jeweils für ihre Sicht einer ,pädagogischen Schulentwicklung“" plädieren, sind äußerst plausibel. Zu fragen bliebe allerdings, ob die Zuordnung der verschiedenen derzeit auf dem Markt befindlichen 


\section{JOHANNES BASTIAN \\ Pädagogische Schulentwicklung \\ Von der Unterrichtsreform zur Entwicklung der Einzelschule}

\section{Schulentwicklung und Unterrichtsreform}

Alle Bemühungen um Schulentwicklung bleiben hohl, wenn sie den Unterricht nicht erreichen; denn: Unterrichtsgestaltung ist immer noch das Zentrum der Lehrer(innen)tätigkeit, auch wenn in den 90er Jahren die Entwicklung der Einzelschule ins Zentrum gerückt ist. [...] Hört man aber Debatten über Schulentwicklung, dann kann sich der Eindruck einstellen, daß dies mit den eigenen ,kleinen“"Veränderungsbemühungen nur wenig zu tun hat. Da geht es um lean management, top-down und bottom-up, um Implementation, Selbst- und Fremdevaluation, um Teil- oder Gestaltungs- oder um „mehr" Autonomie.

Dagegen steht die beruhigende Erfahrung, daß Schulen, in denen Ansätze einer neuen Unterrichts- und Schulkultur entwickelt wurden, diesen Jargon weder kennen und noch brauchen. Hier geht es um Schülerinnen und Schüler, die Förderung von Selbständigkeit, eine Erweiterung des Methodenrepertoires, um neue Unterrichtsformen, die Veränderung der Lehrer(innen)rolle, eine Öffnung der Schule in den Stadtteil, um die Zusammenarbeit von Lehrerinnen und Lehrern in Teams.

Meine erste These lautet deshalb:

Die Expert(inn)en für Schulentwicklung sitzen in den Schulen. Und: Wer Schulentwicklung befördern will, sollte zunächst einmal nachschauen, was sich dort tut. Dann wird er unter anderem feststellen, daß die neuen Fragen der Schulentwicklung nicht selten die alten Fragen Innerer Schulreform sind.

\section{Beobachtungen}

Schulentwicklung weckt Erwartungen und riskiert Enttäuschungen:

Lehrer(innen) verbinden mit Schulentwicklung häufig alte, meist uneingelöste Hoffnungen. Sie erwarten Unterstützung in einem Entwicklungsproze $\beta$, der vorhandene Reformansätze befördert, der Initiativen zur Unterrichtsreform stärkt und vernetzt, der aus Vereinzelung und Gegeneinander zu einem kooperativen Miteinander führt und aus verkrusteten LehrLern-Behörden lebendige pädagogische Einrichtungen werden läßt. Nicht

Programme und Handreichungen zur Unterrichtentwicklung, Schulentwicklung und Qualitätsentwicklung wirklich so eindeutig einem bestimmten Typus zuzuordnen sind (vgl. dazu vor allem Dalin/Rolff/Buchen 1995; Kempfert/Rolff 2000; Klippert 2000) oder ob die Diskussion darüber, von wo aus Qualitätsentwicklung zu starten hat, wenn sie letztendlich auf alle Bereiche der Schule ausstrahlen soll, faktisch doch nur eine Diskussion um das Henne-Ei-Problem darstellt. Vgl. dazu auch in systematischer Perspektive Messner (1998). 
zu übersehen ist aber auch, daß viele Schulen mit diesen Erwartungen überfordert sind, daß es Ängste, Widerstände und schlechte Erfahrungen gibt und dass das Wecken hoher Erwartungen zu Überforderung und Enttäuschung führen kann.

Schulentwicklung braucht den Kontakt zum Unterrichtsalltag der Normalschule:

Für Lehrer(innen) steht der Unterricht im Zentrum des Berufsalltags; hier konzentrieren sich die Probleme, hier liegt die sachliche und pädagogische Herausforderung, hier entsteht das Gefühl von Erfolg oder Mißerfolg und hier liegt auch das Zentrum der alltäglichen Belastung (vgl. Combe/Buchen 1996). Lehrer(innen) fragen deshalb, was es für die tägliche Unterrichtsarbeit bringt, wenn man sich für die Entwicklung der eigenen Schule engagiert.

Schulentwicklung braucht Verbindung zur Unterrichtsreform:

Erfahrungen der inneren Schulreform verweisen darauf, daß Veränderungen von Schulen ihren Ausgangspunkt meist in Bemühungen um Unterrichtsreform haben. [...] Nicht zu übersehen ist aber auch, daß Unterrichtsreform an Grenzen stößt, wenn sie auf individuelle Initiativen beschränkt bleibt, wenn die Perspektive des „Ich und meine Klasse“ nicht um ein „Wir und unsere Schule“ ergänzt wird.

Unterrichtsreform braucht Schulentwicklung:

Die individuelle Erprobung neuer Lernformen kann sehr befriedigend sein, wenn Erfolge in der eigenen Klasse sichtbar werden - sie stößt aber auch an Grenzen: an Grenzen des Stundenplans, des Zeittakts, der Kooperationsbereitschaft, der eigenen Fähigkeiten [...] an individuelle und institutionelle Grenzen. Unterrichtsreform braucht deshalb Rückhalt in der Zusammenarbeit mit anderen, Reflexion der Lernprozesse im Team, Unterstützung durch die Schulleitung und in der Regel auch gezielte schulinterne Fortbildung - sie braucht Schulentwicklung.

Meine zweite These lautet deshalb:

Interesse an Schulentwicklung kann sich in der "Normalschule "insbesondere dann entfalten, wenn sie klein anfängt, wenn sie Hilfen zur Bewältigung der Alltagsprobleme anbietet, wenn sie bei den Interessen an Unterrichtsreform ansetzt - kurz: wenn sie sich in die lebendige Tradition innerer Schulreform einreiht und diese mit Blick auf die ganze Schule weiterführt.

\section{Warum pädagogische Schulentwicklung?}

Pädagogische Schulentwicklung reagiert auf einen derzeit in der Praxis beobachtbaren Widerspruch:

Auf der einen Seite gibt es ein kontinuierliches Interesse von Lehrerinnen und Lehrern an der gemeinsamen Erprobung neuer Lehr- und Lern- 
formen; hier gibt es Erfahrungen, die im Sinne einer schulbezogenen Reformperspektive weiterentwickelt werden müssen.

Auf der anderen Seite stehen Verfahren zur Unterstützung von Schulentwicklungsprozessen - insbesondere Verfahren der Organisationsentwicklung - die das Interesse an einer Veränderung des Unterrichts oft nur am Rande berühren.

Diese und andere Erfahrungen sind in der Praxis inzwischen zu einem Konzept „Pädagogischer Schulentwicklung“ verdichtet worden, das im Spektrum des derzeitigen Angebots die Akzente neu setzt. Ein Konzept, das auch die Interessen derer aufgreift, die mit dem gegenwärtig dominierenden Ansatz der Organisationsentwicklung Schwierigkeiten haben (zur Kritik vgl. auch Schlee 1996).

Meine dritte These lautet deshalb:

Ausgangssituationen, Problemlagen und Interessen an Schulen sind unterschiedlich und verlangen nach unterschiedlichen Ansätzen. Welches Konzept der eigenen Ausgangssituation und der eigenen Perspektive angemessen ist, sollte jede Schule selbst prüfen und entscheiden.

\section{Pädagogische Schulentwicklung im Vergleich}

Zur Verdeutlichung der Differenzen will ich zunächst die unterschiedlichen Ansätze im Kontrast definieren:

Pädagogische Schulentwicklung definiere ich als einen Selbstbildungsprozeß der Institutionsmitglieder, in dem der Zusammenhang von gutem Unterricht, einer an Mündigkeit orientierten Subjektentwicklung und den dafür angemessenen institutionellen Bedingungen bearbeitet wird. Ausgangspunkt ist das Interesse an einer Erneuerung des Unterrichts und den daraus folgenden institutionellen und individuellen Veränderungen.

Organisationsentwicklung definiert sich als Verfahren zur Veränderung sozialer Systeme. Pädagogische Organisationsentwicklung - insbesondere der Institutionelle Schulentwicklungs-Prozeß (ISP; Dalin u.a. 1995) - versteht sich als Verfahren zur Veränderung der Schule als soziales System. Ausgangspunkt ist das Interesse an einer Veränderung der institutionellen Bedingungsfelder mit dem Ziel eines lernenden Systems.

Um die Unterschiede zu präzisieren, will ich diese Definitionsdifferenz in jeweils vier Thesen konkretisieren:

1. Pädagogische Schulentwicklung versteht sich als Entwicklungskonzept in der Tradition „Innerer Schulreform“. Ausgangspunkt sind Widerspruchserfahrungen von Lehrerinnen und Lehrern zwischen pädagogischen Veränderungsinteressen und schulischen Bedingungen. D.h. pädagogische Schulentwicklung hat ihren Ausgangspunkt entweder bei einem neu entdeckten oder einem bislang nur partiell realisierten Interesse an Unterrichtsreform. 
2. Pädagogische Schulentwicklung knüpft an diesen Interessen und (Widerspruchs-)Erfahrungen an, bietet unterrichtsbezogene Unterstützungssysteme an, aktiviert darüber die Binnenkräfte eines Kollegiums, involviert Lehrer(innen) und Schüler(innen) in Erprobungs- und Aushandlungsprozesse über veränderte Lehr-Lernformen, und erarbeitet in diesem Proze $ß$ die dafür notwendigen institutionellen und professionellen Bedingungen.

3. Pädagogische Schulentwicklung zielt auf eine langfristige Bearbeitung der Widersprüche zwischen Unterrichtsreform und schulischen Bedingungen. Unterrichtsformen, die Schülerinnen mehr Spielräume für eigenständiges handlungsorientiertes oder projektorientiertes Arbeiten geben, führen zu neuen Herausforderungen in der Lehrer-Schüler- und der LehrerLehrer-Interaktion: sie geraten z.B. in Widerspruch zur traditionellen Lehrer- und Schülerrolle, insbesondere zum Planungs-, Informations- und Kontrollmonopol der Lehrer(innen), aber auch zur traditionellen Rolle des Einzelkämpfers. Diese Erfahrungen fordern immer neue Aushandlungsprozesse über Unterricht, eine „Kultur der professionellen Kooperation“ (Terhart 1996: 463) und erweiterte Handlungsspielräume.

4. Pädagogische Schulentwicklung nutzt Angebote der schulinternen Lehrer(innen)fortbildung (SCHILF). Berater(innen) für pädagogische Schulentwicklungsprozesse sind Expert(inn)en in Unterrichtsreform, Supervision, pädagogischer Fallbesprechung und Prozeßmoderation. Sie schließen mit der Schule einen Kontrakt und bieten sowohl Unterstützung bei der Erarbeitung, Erprobung und Evaluation neuer Methoden und Unterrichtsformen, als auch Hilfen bei der Entwicklung entsprechender Kooperations- und Teamstrukturen an.

Zur Schulentwicklung als Organisationsentwicklung im Sinne des ISP ebenfalls vier Thesen:

1. Schulische Organisationsentwicklung versteht sich in der Tradition pädagogisch-sozialpsychologischer Konzepte (Rolff 1995: 18 mit Bezug auf Lewin 1953), die den einzelnen in einem untrennbaren Zusammenhang mit Organisationen und Institutionen begreifen. Ausgangspunkt ist deshalb das Interesse an Veränderungen der institutionellen Bedingungen, sind Verfahren, mit deren Hilfe Stärken und Schwächen der Institution diagnostiziert und bearbeitbar gemacht werden können.

2. Organisationsentwicklung (OE) setzt bei den Bedingungskonstellationen der Organisation an (Rolff 1995: 20). Sie unterstützt die Schule in der Einstiegsphase bei einer Skizzierung von Erwartungen, in der Diagnosephase bei einer ausführlichen Analyse von Stärken und Schwächen, in der Zielklärungsphase bei einer Klärung von Prioritäten und in der Implementationsphase bei einer Umsetzung und Evaluation der vereinbarten Ziele.

3. Organisationentwicklung zielt auf eine Optimierung der Bedingungskonstellationen insbesondere von Organisations- und Kommunikationsstrukturen. Sie bietet Verfahren an, die das Schulmanagement, die Lehrer(innen)kooperation und die gemeinsame Zielklärung und Planung unter- 
stützen. „OE erreicht den Unterricht nicht direkt, sondern nur indirekt ... Insgesamt jedoch wirkt $\mathrm{OE}$ weniger auf den Unterricht selbst ein als auf die Randbedingungen des Unterrichtens." (ebd.).

4. Organisationsentwicklung nutzt in der Regel ausgebildete OEModeratoren, entweder Lehrkräfte oder Leitungsmitglieder der Schule, die ein entsprechendes OE-Training absolviert haben, oder externe OE-Berater, die der Schule auf der Basis eines Kontrakts über eine vereinbarte Zeit zur Verfügung stehen. OE-Berater sind in der Regel keine Experten für Unterrichtsreform, sondern Prozeßberater, die insbesondere in der Einstiegs-, Diagnose- und Zielklärungsphase den Prozeß moderieren.

Die Kontrastierung fasse ich in These 4 zusammen:

Ausgangspunkte, Unterstützungssysteme und die jeweilige ,Schulentwicklungsphilosophie" von Organisationsentwicklung und pädagogischer Schulentwicklung unterscheiden sich deutlich. Beide Wege haben jedoch ein gemeinsames Ziel: Sie wollen allen an Schule Beteiligten helfen, ihren eigenen Entwicklungsprozeß reflektiert, so weit wie möglich aus eigener Kraft und in gemeinsamer Absprache zu gestalten.

Schon diese knappe Kontrastierung kann eine Orientierungs- und Entscheidungshilfe bieten.

Eine Analyse der Stärken und Schwächen soll diese noch ergänzen: Die Schwäche Pädagogischer Schulentwicklung liegt darin, daß dem Entwicklungsproze $ß$ keine ausführliche Diagnose und Zielklärungsphase vorausgeht. Pädagogische Schulentwicklung fragt, ob und welche Interessen die beteiligten Lehrer(innen) an der Reform von Unterricht haben. Der Prozeß kann sofort beginnen, wenn ein hinreichender Teil des Kollegiums dazu bereit ist. Pädagogische Schulentwicklung reduziert damit die Komplexität von möglicherweise differenzierteren Veränderungsinteressen zunächst auf einen zentralen Punkt - die Erneuerung des Unterrichts - und bearbeitet die damit verbundenen institutionellen Veränderungsperspektiven in einem zweiten Schritt. Sie läuft damit Gefahr, bei einer Erneuerung des Unterrichts stecken zu bleiben.

Diese Schwäche pädagogischer Schulentwicklung ist jedoch gleichzeitig ihre Stärke: Sie setzt im Zentrum von Schule und Lehrer(innen)tätigkeit an, braucht keine langen Entscheidungs- und Klärungsphasen, führt relativ schnell zu konkreten Erfolgserlebnissen und vermeidet die „Verzettelung“ in unterschiedliche Teilaktivitäten zur Veränderung des "ganzen Systems“. Sie setzt darauf, dass die hinderlichen bzw. förderlichen Bedingungskonstellationen von Unterrichtsreform (z.B. Lehrpläne, Zeittakte, Kooperationsdefizite) im Verlauf dieses Entwicklungsprozesses gemeinsam entdeckt und verändert werden.

Bezogen auf das Konzept der Organisationsentwicklung sieht die Stärken- und Schwächenanalyse wie folgt aus: 
Die Schwäche von Organisationsentwicklungsprozessen liegt in einem relativ abstrakten Verfahren, das neben dem Unterricht zu bewältigen ist. Nicht alle Schulen vertragen einen langandauernden Diagnose- und Zielklärungsprozeß. Auch die vielfältigen Aktivitäten in unterschiedlichen Teilgruppen des Kollegiums, die neben dem Unterricht bewältigt werden müssen, überfordern manchen, und nicht wenige Gruppen ,sterben“" auf diesem Weg. Der differenzierte und mit immer wieder neuen Entscheidungsprozeduren versehene Weg des institutionellen SchulentwicklungsProzesses hat einen hohen Preis.

Diese Schwäche der Organisationsentwicklung ist jedoch gleichzeitig ihre Stärke: Der institutionelle Schulentwicklungs-Prozeß geht von der Analyse aus, daß das Gelingen oder Nicht-Gelingen von Unterricht nicht nur von der Arbeit des Lehrers in der Klasse, sondern von zahlreichen Konstellationen in der Schule abhängt wie: Management der Schulleitung, Fähigkeiten zur Kooperation, gemeinsamer Planung und Abstimmung. [...]

Als Konsequenz der Kontrastierung formuliere ich das Selbstverständnis pädagogischer Schulentwicklung in These 5:

Pädagogische Schulentwicklung geht analytisch davon aus, daß das Hauptproblem und das Hauptinteresse von Lehrer(inne)n in einer schulinternen Verbesserung der Unterrichtskultur liegt. Sie knüpft deshalb an diesen Interessen und den daraus folgenden Interessen an Veränderungen der institutionellen Bedingungen der Einzelschule an. Sie setzt dabei auf einen selbstinitiierten und/oder von außen gestützten Bildungsprozeß, in dem die Mitglieder der Schule durch problemformulierendes und problemlösendes Handeln miteinander lernen. Pädagogische Schulentwicklungsprozesse, haben damit einen hohen Übereinstimmungsgrad mit Projektlernprozessen (Bastian/Schnack 1997). In diesem Verweisungsverhältnis von Unterrichtsreform, Institutionsentwicklung und Selbstbildung liegt der theoretische Kern pädagogischer Schulentwicklung.

\section{Pädagogische Schulentwicklung als Weiterentwicklung schulinterner Lehrerfortbildung}

Die pädagogische Diskussion in Kollegien kommt dann in Bewegung, wenn aufgrund des Problemdrucks - zumindest bei einem Teil des Kollegiums - die gemeinsame Ratlosigkeit positiv aufgenommen wird und das Klagen in eine Suche nach neuen Wegen umschlägt. Das Klima für derartige „Umschlagmomente“ ist in den 90er Jahren deshalb günstiger, weil sowohl die „Reformer“ als auch die „Traditionalisten“, vor allem aber die Kolleg(inn)en im sogenannten „Mittelfeld“ an die Grenzen individueller Problemlösungen gestoßen sind, weil der Beratungsbedarf ,fraktionsübergreifend" deutlich wird und weil die Hoffnungen auf Problemlösungen „Von oben“" gegen Null gehen. Aber auch, weil Schulleitungen, Schulaufsicht und Teile der Bildungspolitik erkannt haben, daß sie den wachsenden 
Herausforderungen an Schule nur im Bündnis mit Schulen gerecht werden können, die an Veränderungen interessiert sind.

Die Erfahrung der Grenzen individueller Problemlösungsstrategien im eigenen Unterricht und hinter verschlossenen Türen macht die einzelnen Kolleg(inn)en offener für den Versuch, Probleme gemeinsam anzugehen. Die „Reformer“ haben erfahren, daß weitergehende Veränderungen im Unterricht nur realisierbar sind, wenn sie in Absprache zumindest auf der Ebene von Klassenteams und gemeinsam mit der Schulleitung realisiert werden. Die „Traditionalisten“ geraten allmählich in die Zone der Lächerlichkeit, wenn sie behaupten, sie hätten immer noch ,alles im Griff“ und das breite „Mittelfeld“ erkennt immer deutlicher die Notwendigkeit, sich didaktisch neu zu orientieren, wenn sie die Schülerinnen und Schüler erreichen will.

Faßt man diese Veränderungstendenzen zusammen, dann eröffnet sich ein Spektrum von Fragen, das nicht neu ist, das aber in dieser Konzentration eine neue Qualität hat und die Fragen innerer Schulreform direkt in Fragen pädagogischer Schulentwicklung münden läßt:

Wie kann ich das, was mir bei meinen Bemühungen um einen veränderten Unterricht alleine nur in Ansätzen gelungen ist, gemeinsam mit anderen versuchen? Also: Wie kann ich von anderen und mit anderen lernen, meinen Unterricht zu verändern? Wie kommen wir zu einer gemeinsamen Erprobung von neuen Lehr- und Lernformen, zu einer Öffnung des Unterrichts, zu Projektunterricht, zu handlungsorientiertem Lernen, zu einer Öffnung unserer Schule in den Stadtteil und wie können wir die Schüler(innen) stärker in die Gestaltung von Unterricht und Schulleben einbeziehen? Aber auch:

Was muß sich an unserer Schule ändern, wenn sich der Unterricht ändert? Also: Wie müssen Stundenpläne, Lehrpläne, Zeittakte, Räume und Leistungskriterien bei einem veränderten Unterricht aussehen? Wie sehe ich meine Rolle als Lehrer, wie sehen die anderen ihre Rolle und wie muß sich diese Rolle langfristig ändern? Wie können wir die Reibungsverluste verringern, die im alltäglichen Neben- und Gegeneinander so viel Kraft kosten? [...]

Die neue Qualität der Fragen macht zwar die Probleme nicht kleiner, mit denen die konfrontiert werden, die sich auf einen gemeinsamen Weg begeben wollen; sie zeigt aber eine größere Bereitschaft, sich auf gemeinsame Entwicklungsprozesse einzulassen. $\mathrm{Zu}$ einem neuen Selbstbewusstsein in den Kollegien kann auch beitragen, daß auf absehbare Zeit kein Experte - weder in der Bildungspolitik, noch in der Erziehungswissenschaft die Lösung für den Modernitätsrückstand der heutigen Schule kennt. Auch die Diskussion über Schulentwicklung tastet sich erst langsam vor und wer heute behauptet, er kenne den „Königsweg“, auf dem die Schule von morgen erreichbar sei, der täuscht über die großen Probleme der kleinen Schritte hinweg. Wir wissen heute nur eins: Die Schulen von morgen werden an den Schulen von heute erfunden. Ob diese mit Hilfe der Organisationsent- 
wicklung oder Pädagogischer Schulentwicklung erfunden werden, ist weniger entscheidend als der Prozeß der Erfindung selbst. [...]

\section{Literatur}

Bastian, J./Schnack, J.: Projektunterricht und Schule. Zur schultheoretischen Begründung eines neuen Verhältnisses von Unterrichtsreform und Schulentwicklung. In: Bastian/Gudjons/Schnack/Speth (Hg.): Theorie des Projektunterrichts. Hamburg 1997.

Combe, A./Buchen, H.: Belastungen von Lehrerinnen und Lehrern. Weinheim und München 1996.

Dalin, P./Rolff, H.-G./Buchen, H.: Institutioneller Schulentwicklungsprozeß. Bönen 1995 (2. Veränd. Auflage).

Lewin, K.: Die Lösung sozialer Konflikte. Ausgewählte Abhandlungen über Gruppendynamik. Bad Nauheim 1953.

Rolff, H.-G.: Die Schule als Organisation erzieht. Organisationsentwicklung und pädagogische Arbeit. In Pädagogik, Heft 2/1995, S. 17 ff.

Schlee, J.: Kann ein nachlässiger Sprachgebrauch zu verantwortlichem Denken und Handeln bei Schulentwicklungsprozessen führen? In: Feind, A,/Mischke, W./Spindler, D. (Hg.). Schulentwicklung, Lehrerinnenbildung Studienreform. Oldenburger Vor-Drucke 305. Hg.: Carl von Ossietzky-Universität Oldenburg. Oldenburg 1996

Terhart, E.: Berufskultur und professionelles Handeln bei Lehrern. In: Combe, A./Helsper, W. (Hg.): Pädagogische Professionalität. Frankfurt 1996, S. 448 ff.

\section{HEINZ KLIPPERT \\ Schule entwickeln - Unterricht neu gestalten Plädoyer für ein konzentriertes Innovationsmanagement}

Schule muß sich entwickeln - keine Frage! Veränderte Schüler, ausgebrannte Lehrer, veränderte Anforderungen von Betrieben, Eltern und Bildungsverwaltungen - dieses und manches andere mehr verlangt nach Besinnung, Neuorientierung und tatkräftiger Problemlösung. Denn die Fülle der schulischen und unterrichtlichen Probleme, vor denen die Lehrkräfte heutzutage stehen, ist enorm. Entsprechend dringlich sind konstruktive Problemlösungsbemühungen, die Perspektiven aufzeigen, praktische Handlungsfelder eröffnen, Mut machen und pädagogischen Gestaltungswillen freisetzen. [...]

Die Frage ist nur, wie dieser Gestaltungswille zu entfachen ist. Fest steht, daß er in vielen Schulen (noch) unterentwickelt ist. Gestaltungswille setzt Gestaltungskompetenz voraus. Und diese Gestaltungskompetenz wiederum ist nicht nur eine Frage des „Dürfens“ und „Wollens“, sondern auch und besonders eine Frage des „Könnens“. Und genau da beginnt die Crux in unseren Schulen. Die meisten Kollegien wollen zwar neue Wege gehen und dürfen dieses auch. Nur fehlt es ihnen häufig am nötigen Innovations- 
Know-how sowie an dem Gefühl und der Gewißheit: „Das packe/n ich/wir!“ Zwar gibt es in jedem Kollegium einen gewissen Kreis energiegeladener Innovatoren, doch diese sind in aller Regel in der Minderheit. Die Mehrheit der Lehrkräfte steht den vielfältigen Herausforderungen und Innovationserfordernissen unserer Tage eher ängstlich, skeptisch und/oder resigniert gegenüber. J. Habermas spricht in diesem Kontext von der ,neuen Unübersichtlichkeit" und erklärt damit die lähmende Untätigkeit, die viele Verantwortliche in Politik, Wirtschaft und nicht zuletzt auch in der Schule befallen hat. Angesagt sind von daher Reduktion von Komplexität, expertengestützte Innovationsberatung sowie gezielte Qualifizierungsmaßnahmen zur Stärkung der Innovationskompetenz der Lehrkräfte. Das sind zugleich die Eckpfeiler des hier in Rede stehenden konzertierten „Innovationsmanagements". [...]

\section{Der Anspruch der Organisationsentwicklung (OE)}

Schulentwicklung wird in den letzten Jahren sehr stark in Verbindung gebracht mit dem aus der Wirtschaft stammenden Konzept der Organisationsentwicklung. OE meint die systematische Vitalisierung, Aktualisierung, Aktivierung und Erneuerung einer Organisation von innen heraus mit dem Ziel, die anstehenden Problemlösungsprozesse zu effektivieren. OE setzt somit auf Selbsterneuerung sowie auf sensibles und engagiertes Zusammenarbeiten der Organisationsmitglieder, damit die vorhandenen Problemlösungs- und Erneuerungspotentiale wirksam mobilisiert werden. OE ist grundsätzlich langfristig angelegt und hat einen relativ komplexen $\mathrm{Zu}-$ schnitt. [...] Entsprechend vielschichtig und langwierig sind die betreffenden Klärungs-, Abstimmungs- und Innovationsprozesse. [...] Kurzum, die Konferenz- und Arbeitsbelastung während dieser OE-Prozesse erreicht rasch ein Ausmaß, von dem viele gutwillige Lehrkräfte abgeschreckt werden, weil sie sich durch die vielschichtige "Sisyphusarbeit“ überfordert fühlen.

Unstrittig ist, daß der OE-Ansatz in sich stringent ist und auch von seinem Menschenbild her Zustimmung verdient. Ein mündiges Kollegium, das engagiert, kreativ und selbstbestimmt die Gestaltung der Einzelschule in die Hand nimmt, bestehende Probleme löst, die Schule zeitgemäß profiliert, für die nötige Qualitätssicherung sorgt und bei alledem eine tragfähige "Corporate Identity“ entwickelt, ist ein ehrenwertes Ziel und ganz sicher auch der Wunsch eines jeden Schulreformers. Nur ist die Zahl der Kollegien, die mehrheitlich bereit sind, derart umfängliche und belastende Schulentwicklungsprogramme anzugehen und durchzustehen, erfahrungsgemäß gering. Am ehesten zu gewinnen sind noch jene Kollegien, denen „das Wasser bis zum Hals steht" und die daher die Flucht nach vorne antreten. Das sind aber erfahrungsgemäß nicht mehr als 2-4 Prozent der Kollegien. Und was ist mit den anderen? Auch sie haben Innovationsbedarf! Nur wünschen sie in aller Regel, daß kleinere Brötchen gebacken und über- 
schaubare Innovationsschneisen geschlagen werden. [...] Man mag diesen Kleinmut bedauern oder auch kritisieren. An dem Faktum der begrenzten Belastbarkeit, Risikobereitschaft und der kurzfristigen Erfolgserwartung der meisten Lehrkräfte kommt man jedoch nicht vorbei. Das gilt keinesfalls nur für die erklärten Bremser und Skeptiker in den Kollegien, sondern auch und nicht zuletzt für die grundsätzlich gutwilligen Lehrkräfte des ,Mittelfeldes“, das leicht 50 Prozent eines Kollegiums umfaßt. Dieses „Mittelfeld“ läßt sich erfahrungsgemäß auf Innovationsprozesse nur dann ein, wenn sie überschaubar sind, nicht zuviel Arbeit machen und möglichst bald greifbare Erfolgserlebnisse versprechen. Mehrjährige OE-Vorhaben hingegen, die nachgerade uferlos erscheinen und häufig auch recht zeitaufwendige und abgehobene Diagnose-, Analyse-, Entscheidungs- und psycho-soziale Klärungsprozesse nach sich ziehen, stoßen schnell auf Vorbehalte und Ablehnung. [...]

\section{Weniger ist mehr - Ein Rezept wider die Überforderung}

Fleischer-Bickmann und Maritzen haben zweifellos recht, wenn sie in Anspielung auf die aktuelle Diskussion über Schulautonomie und Schulprogramme mehr Bescheidenheit und Pragmatismus anmahnen. „Man kann Schulen nur davor warnen“, so schreiben sie, ,sich zu überfordern und in Schulprogramme alles hineinzuschreiben, was pädagogisch wünschenswert ist. Es empfiehlt sich, daß Kollegien sehr kritisch bilanzieren, welche Probleme sie als vordringlich sehen, bearbeiten und lösen wollen, was sie sich zutrauen und was in absehbarer Zeit auch realisierbar ist. Eine Innovation in Schritten beugt einer Erwartungseuphorie vor, der allemal das Scheitern sicher ist." (Fleischer-Bickmann/Maritzen 1996: 14)

Bei der hier anvisierten Innovationsstrategie geht es aber nicht nur um die kleinen Schritte, sondern auch und zugleich um eine entschiedene Begrenzung des Innovationsbereichs und -anliegens. Ansonsten besteht die Gefahr, daß sich die Innovatoren verzetteln und ihre Potentiale an so unterschiedlichen Stellen einsetzen, daß letztlich wenig Gemeinsames herauskommt. Das Nebeneinander vieler Arbeitsgruppen in einem OE-Prozeß ist fragwürdig, da die Zentrifugalkräfte zwangsläufig groß und die Möglichkeiten der pädagogischen Verständigung und Konsensbildung entsprechend begrenzt sind. [...] Von daher ist eine entschiedene Bündelung und Focussierung der innerschulischen Innovationsarbeit geboten, damit die „Durchschnittslehrer“ das Gefühl bekommen: „Das packen wir!“”

Daraus folgen drei Konsequenzen:

1. die Reduzierung des Innovationsfeldes auf einen überschaubaren Kernbereich der Lehrertätigkeit, den Unterricht;

2. die Straffung der meist langwierigen Such-, Reflexions- und Entscheidungsprozesse im Vorfeld der eigentlichen Innovationsarbeit, sowie 
3. die Offerierung gezielter Qualifizierungsangebote für die betreffenden Lehrkräfte/Kollegien, damit diese - unterstützt durch erfahrene Innovatoren - möglichst rasch das nötige Know-how erwerben, um die intendierte Innovationsarbeit zügig und erfolgreich zu realisieren. [...]

\section{Innovationsfeld Unterricht - Ein profiliertes Wahlangebot}

Vieles spricht dafür, dem Innovationsfeld Unterricht besondere Aufmerksamkeit zu schenken. Unterricht ist nicht nur ein Kernbereich der Lehrertätigkeit, er stellt auch und zugleich ein äußerst virulentes Problemfeld dar, das von Lern- und Motivationsproblemen übersät ist und deshalb nach neuen Wegen des Lehrens und Lernens verlangt, die den betreffenden LehrerInnen wie SchülerInnen Entlastung und Erfolgserlebnisse versprechen. Wenn es gelingt, dieses Feld wirksam umzugestalten und in einem Kollegium einen entsprechenden unterrichtszentrierten Diskurs und Grundkonsens herzustellen, dann wäre gewiß ein gutes Stück Schulentwicklung erreicht. Die Frage ist nur, wo und wie mit der Unterrichtsreforrn anzusetzen ist. Fraglich ist ferner, ob das kollegiumsinterne Innovationspotential ausreicht, um mit vertretbarem Aufwand und in einem überschaubaren Zeitrahmen eine tragfähige neue Lernkultur auf den Weg zu bringen. Die Skepsis in den meisten Kollegien ist groß; die Hilflosigkeit und Ratlosigkeit ebenso. Zwar gibt es in jedem Kollegium eine Reihe von Lehrkräften, die über beträchtliches Innovations-Know-how verfügen. Nur sind diese in aller Regel weder in der Mehrheit, noch pädagogisch so akzeptiert und angefragt, daß sie als Helfer, Ratgeber und Weichensteller wirksam werden können. Vorherrschend sind vielmehr Skepsis und häufig auch bewußte Abgrenzung gerade gegenüber diesen potentiellen Meinungsführern und Innovationsberatern. Von daher verpuffen deren Potentiale vielerorts ungenutzt. Zwar wäre es möglich, diese kollegiumsinternen Kooperations- und Beziehungsstörungen zu thematisieren und gruppendynamisch auszuleuchten. Zweifelhaft ist nur, ob die betreffenden Kollegiumsmitglieder mehrheitlich bereit sind, einen derartigen Klärungs- und Gärungsprozeß mitzumachen. Die bisherigen Erfahrungen sprechen dagegen. Das Gros der Kollegien schreckt offenkundig davor zurück, die „Beziehungskiste“ zu öffnen und von einzelnen Kolleginnen und Kollegen Rat - und eventuell auch Kritik - entgegenzunehmen.

Was also tun? Die bisherige Innovationsarbeit zeigt, daß in den meisten Kollegien dann etwas zu bewegen ist, wenn vorrangig auf der instrumentellen Ebene angesetzt und mit Hilfe externer Experten möglichst überzeugend ausgelotet wird, wie der Unterricht ganz pragmatisch umgestaltet werden kann. Am besten ist es, wenn dieser Sensibilisierungs- und Klärungsprozeß im Wege des ,learning by doing“ erfolgt: durch praktische Übungen, durch offene Gespräche und durch konstruktive Transferüberlegungen. Dabei wird unter der Hand natürlich auch Kommunikation, Kooperation und pädagogische Kreativität praktiziert und gelernt. So gesehen 
ist die hier anvisierte Kultivierung neuer Lernformen nicht nur ein unterrichtszentrierter Innovationsproze $\beta$, sondern auch ein vielschichtiger Lernprozeß für die beteiligten Lehrkräfte, der ganz sicher zur Förderung der vielzitierten „Corporate Identity“ beiträgt. [...]

\section{Neue Formen des Lernens als Schulprogramm}

Konsens besteht in den meisten Kollegien darin, daß der Umgestaltung des Unterrichts besondere Priorität gebührt und ein zeit- und schülergemäßes Methodenrepertoire kultiviert werden muß. Auch die Zielrichtung ist mittlerweile den meisten klar. Gefragt sind offener Unterricht, Freiarbeit, Wochenplanarbeit, Stationenarbeit, Projektarbeit und andere Formen des „eigenverantwortlichen Arbeitens und Lernens" (EVA), und zwar unter besonderer Betonung von Partner- und Gruppenarbeit, da die meisten SchülerInnen zur angestrebten selbständigen Bewältigung komplexerer Aufgaben nur dann in der Lage sind, wenn sie dies in Kooperation mit anderen Schülern tun können. Diese Ausrichtung des Unterrichts verspricht nicht nur eine zeitgemäße Qualifizierung der SchülerInnen (Stichwort: Schlüsselqualifikationen), sondern sie eröffnet auch und zugleich deutliche Entlastungsperspektiven für die verantwortlichen Lehrkräfte. Denn wenn die SchülerInnen selbständig arbeiten und in aktiver und interaktiver Weise vorgegebene Aufgaben und Probleme lösen, dann wird es für die betreffenden Lehrkräfte beinahe zwangsläufig leichter und befriedigender. Voraussetzung ist allerdings, daß die SchülerInnen hinreichend bereit und in der Lage sind, die ihnen übertragenen Aufgaben selbständig und methodisch versiert anzugehen und zu lösen. Und genau das ist die Schwierigkeit in vielen Schulen und Klassen, die offenen, handlungsorientierten Unterricht praktizieren bzw. versuchen. Viele SchülerInnen sind eben nicht in der Lage, die gewährten Freiheitsgrade konstruktiv und methodisch versiert zu nutzen und auszugestalten. Sie beherrschen zumeist weder die nötigen Lern- und Arbeitstechniken, noch verfügen sie in hinreichendem Maße über die für offenen, handlungsorientierten Unterricht unerläßliche Kommunikationsund Teamfähigkeit. So gesehen ist die Öffnung des Unterrichts vielerorts eine ziemlich „,bodenlose Angelegenheit“. Diesen Grundüberlegungen trägt das „Neue Haus des Lernens“ Rechnung, das als mögliches Schulprogramm/Aktionsprogramm zur gezielten „Sanierung“ des traditionellen Unterrichts zu verstehen ist. Für die meisten Kollegien ist ein derartiges Programm nicht nur richtungsweisend und dringlich; es ist von seinem Anspruch und seinem Arbeitsanfall her auch gerade komplex genug, um von qualifizierten Mehrheiten in den betreffenden Kollegien wohlwollend akzeptiert und mitgetragen zu werden. Vorausgesetzt, es steht ein korrespondierendes Unterstützungsangebot in Aussicht.

Im Zentrum des angestrebten Lehr-/Lerngeschehens steht „EVA“, d.h. das eigenverantwortliche Arbeiten und Lernen der SchülerInnen. Denn wenn die Unterrichtsgestaltung zeit- und schülergemäß verändert werden 
soll, dann gilt es zunächst einmal, dieses eigenverantwortliche Arbeiten und Lernen möglichst vielschichtig zu intensivieren. Dementsprechend müssen die Lehrkräfte ihr Methodenrepertoire überprüfen, weiterentwickeln und eine möglichst breite Palette an handlungsorientierten Methoden kultivieren, die „EVA“ fordern und fördern. Dazu sind gegebenenfalls entsprechende Fortbildungen anzubieten. Gerichtet ist diese methoden- und handlungszentrierte Lehr-/Lernarbeit auf die Vermittlung zukunftsträchtiger „Schlüsselqualifikationen“, die das Lernen effektivieren, die Schülerpersönlichkeiten stärken, ihre Selbständigkeit fördern und ihr soziales Miteinander verbessern. Dieses Zielsystem wird mit den vier Qualifikationsbezeichnungen „Fachkompetenz“, „Methodenkompetenz“, „Kommunikationskompetenz" und „Teamkompetenz" umrissen.

Die Implementation des skizzierten Schul- bzw. Sanierungsprogramms ist allerdings nicht nur eine Frage der Unterrichtsmethodik und der Unterrichtsgestaltung, sondern sie ist auch und nicht zuletzt davon abhängig, daß innovationsfördernde Rahmenbedingungen geschaffen werden. [...] Innovationszentrierte Lehrerkooperation, Schulleiterfortbildung und Elternarbeit gehören ebenso dazu wie die Veränderung der Lehrpläne, der Stundentafeln und der Lehrereinsatzplanung sowie die Umgestaltung des Klassenraums und der Arbeitsbedingungen von Lehrern wie Schülern. [...]

\section{Konzertierte Qualifizierungs- und Implementationsmaßnahmen}

Unterstützt werden muß die Implementation des skizzierten Schulprogramms durch eine profilierte Qualifizierungsarbeit. Andernfalls besteht die Gefahr, daß der Prozeß bei hehren Vorsätzen und eher grundsätzlichen Diskussionen und Einsichten steckenbleibt, die praktische Methoden- und Gestaltungskompetenz der betreffenden Lehrkräfte aber unzureichend ist. Diese lähmende Diskrepanz zwischen Erkenntnis und Wollen auf der einen und praktischem Können und Tun auf der anderen Seite läßt sich in vielen Schulen beobachten. Soll sie wirksam überwunden werden, so müssen den interessierten Lehrkräften/Kollegien richtungsweisende, Mut machende und Praxiskompetenz vermittelnde Qualifizierungsmaßnahmen ermöglicht werden. [...].

Der Innovationsprozeß beginnt in der Regel mit einem einführenden Studientag (pädagogischer Tag) zur Sensibilisierung, Information und methodischen Grundorientierung des Gesamtkollegiums, d.h. das Gesamtkollegium wird mit den Grundzügen des handlungsorientierten Ansatzes vertraut gemacht, durch ausgewählte Beispiele und Übungen in bezug auf die praktische Umsetzung angeregt und ermutigt sowie in der Endphase des Studientages darüber informiert, wie der angelaufene Innovationsprozeß weitergehen und welche Unterstützung offeriert werden kann [...]. Alsdann liegt es an den Lehrkräften des jeweiligen Kollegiums, ein tatkräftiges „Innovationsteam" aufzubauen, das den festen Vorsatz hat, das handlungsund methodenzentrierte Arbeiten im Unterricht zu intensivieren. Dieses 
Innovationsteam sollte mindestens ein Drittel des jeweiligen Kollegiums umfassen, einschließlich Schulleiter und Stundenplanmacher. Eine solche Teamkonstellation begünstigt erfahrungsgemäß die Umsetzungsarbeit, stärkt das „Wir-Gefühl“, vergrößert das Problemlösungspotential und erhöht die Chance, daß die Teammitglieder die Lehr-/Lernkultur in der jeweiligen Schule entscheidend prägen können.

\section{Erfahrungen}

Das hier vorgestellte Schulentwicklungskonzept beruht auf Erfahrungen in vielen Schulen und mehreren Bundesländern. [...]. Geschätzt wird von den Lehrkräften/Kollegien nach den bisherigen Erfahrungen vor allem, daß ein überschaubares und erfolgversprechendes Programm vorliegt, dessen Realisierung - bei Bedarf - durch ein differenziertes Unterstützungssystem erleichtert und beschleunigt wird. „Warum muß denn jede Schule das Rad neu erfinden?", so fragte kürzlich ein Schulleiter sichtlich vorwurfsvoll und brachte damit sein Unbehagen angesichts der geradezu uferlosen Schulentwicklungsbemühungen an seiner Schule auf den Punkt. Recht hat er! Entscheidend ist freilich, daß die jeweiligen Lehrerfortbildungsinstitute gut ausgebildete Experten zur Verfügung stellen können, die zum jeweiligen Innovationsfeld und -pfad die entsprechenden schulinternen Angebote machen können.

\section{Literatur}

Fleischer-Bickmann, W.; Maritzen, N.: Schulprogramm. Anspruch und Wirklichkeit eines Instruments der Schulentwicklung. In: Pädagogik 1/1996, S.12 ff. 


\section{Beobachtung von}

\section{Akteurkonstellationen}

III. 



\section{Vorbemerkung}

Nachdem wir nun den relevanten Herkünften von Diskursen über Modernisierung, welche gleichsam die semantischen Bahnen abstecken, in denen eine Entwicklung verläuft, nachgegangen sind (siehe Textblock I), und ebenso methodische Konzepte wie z.B. Qualitätsmanagements erörtert haben, da diese die sachlichen Ressourcen der Modernisierung sind (vgl. Textblock II), trägt der folgende Buchabschnitt dem Umstand Rechnung, dass Diskurse und Konzepte für sich genommen noch nicht die Praxis von Modernisierungen ausmachen. Zusätzlich müssen die Akteure der Einzelschule als Träger und Interpreten der Diskurse und Konzepte des Modernisierungsprozesses angesprochen werden. Dabei geht es auf einer Mikroebene der Beobachtung zum einen um Interessen, um das Rollenhandeln einzelner Akteure und um ihre (vermuteten) Einstellungen zur Schulmodernisierung. Zum anderen beschäftigt sich dieser Themenblock mit Akteurkonstellationen, also dem handelnden Zusammenwirken mehrerer Akteure an der Einzelschule. Welche konkreten Akteurkonstellationen sich an der Einzelschule durch die Modernisierung einstellen, lässt sich dabei nur empirisch erforschen. Deshalb ziehen wir uns im Folgenden auf die generelle Beobachtung einzelner Akteure zurück. Zudem werden immerhin Hinweise auf Akteurkonstellationen gegeben, deren Ausprägung im Zuge des schulischen Modernisierungsprozesses denkbar erscheint. Wir beginnen mit einer methodischen Einführung von Helmut Fend, um die grundsätzliche Bedeutung von Akteuren und Konstellationen zwischen ihnen für das Schulsystem hervorzuheben.

\section{Methodisches}

\section{Kommentar (Brüsemeister)}

In seinen Forschungen zu verschiedensten Dimensionen schulischer Systeme hat Helmut Fend unter anderem Ende der 1980er Jahre einen Überblick zu Fallstudien gegeben, die sich mit dem Thema Schulqualität befassen (vgl. Fend 1987). Diese Fallstudien nahmen die inneren und äußeren Bedingungen von, guten' und ,schlechten' Schulen in den Blick. Fend ging hierbei nicht nur der Frage nach, welche Eigenarten gute bzw. schlechte Schulen jeweils auszeichnen, sondern suchte auch nach theoretischen Begriffen, mit denen man beide Arten von Schulen kennzeichnen kann. Er beantwortet die Frage, indem er zunächst auf verschiedene Akteure der Einzelschule und ihre Interessen verweist. Unterschieden werden die Schullei- 
tung, Lehrkräfte, Schüler und Eltern. ${ }^{1}$ Eltern seien zum Beispiel von einem „Sorge-Interesse getrieben, Schüler von einem Spaß-Interesse und Lehrer von einem Belastungsminimierungs-Interesse“. Fend denkt darüber hinaus die Schulkultur als eine Zusammensetzung der Teilkulturen der einzelnen schulischen Akteure. Er beobachtet, in welchem Verhältnis sich Teilkulturen einer Schule befinden, d.h. welche Konstellationen die Akteure an der Einzelschule ausbilden - z.B., ob die Akteure miteinander in Konflikt liegen oder aber zusammenarbeiten. „Schisma oder Partnerschaft“ sind nach Fend hinsichtlich der Kommunikationskultur zwischen den Akteuren der Einzelschule die zwei möglichen Pole.

Es kommt zwar sehr wohl darauf an, wie der einzelne Akteur gemäß seinen Interessen hinsichtlich der Modernisierung denkt und handelt, sich in seinem Wollen darauf einstellt oder nicht. Jedoch ist es ersichtlich, dass eine einzelne Gruppe, wenn sie eine Modernisierung befürworten würde, diese an ihrer Schule allein kaum umsetzen kann. Über das Gelingen der Modernisierung entscheidet vielmehr erst die die Akteurkonstellation. Sie ist neben dem „Wollen“ der Akteure eine soziale Strukturdimension eigener Art, mit Eigendynamiken und eigenen Mechanismen, die von einem einzigen Akteur nicht gesteuert werden kann. Akteurkonstellationen gehen aus dem handelnden Zusammenwirken der Akteure der Einzelschule hervor und entscheiden über das „Können“, Modernisierungsideen und -methoden umzusetzen. ${ }^{2}$ Gibt es z.B. an einer einzelnen Schule keine Ge-

1 Auch die Bedeutung des Kollegiums wird bei Fend, in unseren Kommentaren sowie in anderen Autorenbeiträgen immer wieder angesprochen. Das Fehlen eines gesonderten Kapitels in diesem Buch zu diesem entscheidenden kollektiven Akteur hat aber den systematischen Grund, dass es Kollegien als kollektiven Akteur noch nicht durchgängig gibt. Als Kommunikations- und Entscheidungseinheiten sind sie so vielfältig wie Einzelschulen selbst, d.h. manchmal sehr gut entwickelt und im Prinzip als eine Mitgliedschaftsorganisation der Lehrkräfte arbeitend, manchmal aber auch ,schismatisch“ gesteuert - sich selbst blockierend (vgl. auch Fend im Buchabschnitt „Schulkultur"). Es ist das Ziel der Modernisierung auf der Organisationsebene der Einzelschule, das Kollegium zu einer dauerhaften Kommunikations- und Entscheidungsinstanz auszubauen. Aus einem im Prinzip nur lockeren Interaktionszusammenhang, der überwiegend durch informelle Regeln strukturiert ist (vgl. grundlegend: Terhart 1986, 1987), soll eine Organisation werden. Dieses Schwanken zwischen Interaktion und Organisation scheint auch zu erklären, warum es wenig Literatur gibt, die - über lokal variantenreiche Fallbeispiele hinaus - das handelnde Zusammenwirken innerhalb von Kollegien auf ein allgemeineres Theorieniveau stellt.

2 In soziologischer Hinsicht ist das Wollen eines einzelnen Akteurs entscheidend für das erste Erklärungsproblem der Soziologie, nämlich die Erklärung der Handlungswahl. Diesbezüglich lassen sich vier analytische Akteurmodelle unterscheiden, die jeweils eine besondere Art der Handlungswahl und der Handlungsorientierung beschreiben (vgl. Schimank 2000). Damit wäre für unseren Zusammenhang gemeint, dass eine Modernisierungsbestrebung von einem Akteur prinzipiell entweder aus Gründen sozialer Normbefolgung, aus subjektiven Nutzengesichtspunkten, aus Gründen der Identitätsbehauptung oder aus Gründen des emotionalen Handelns ge- 
sprächskultur zwischen den Akteuren, wird das Wollen einer einzelnen Gruppe, das auf die Modernisierung zielt, allein wenig ausrichten - vielmehr muss auch die Konstellation selbst verändert werden.

Grundsätzlich werden die neue Governance sowie die zur Verfügung gestellten Qualitätsmanagements eine eingespielte Konstellation zwischen den Akteuren verändern. Im Kontext des Neuen könnte sich ein einzelner Akteur Hoffnungen machen, seine Interessen besser umsetzen zu können. Sobald er sich seinen Erwartungen entsprechend anders verhält, oder eine andere Gruppe nur erwarten könnte, dass er dies tut, wird die Gruppe ihrerseits anders handeln - die Konstellation verändert sich also schon auf Grund der Ankündigung (also auf der Ebene des „talk“), dass es eine Modernisierung geben werde. Handlungswahlen, Interessen und das Wollen einzelner Akteure als erste Erklärungsdimension sowie Konstellationen des handelnden Zusammenwirkens bzw. Akteurkonstellationen als zweite Erklärungsdimension bilden in der Pädagogik (in diesem Buch stellvertretend: Fend) sowie in der Soziologie einen möglichen, nämlich handlungstheoretischen Zugang, wenn man auf der Mikroebene der Einzelschule und des Rollenhandelns Umsetzungen von Modernisierungsideen erörtern will.

In lockerer Anlehnung an Fend lässt sich zudem angeben, in welche Richtung sich Akteurkonstellationen an der Einzelschule verändern werden. In der bislang vorherrschenden bürokratischen Governance sind eindeutig Lehrkräfte diejenigen Akteure, die alle anderen Akteure der Einzelschule strukturell dominieren. Auch wenn die einzelne Lehrkraft dies bisweilen vielleicht nicht so erlebt, so ist sie doch derjenige Akteur, der von den entsprechenden Gesetzen und Verordnungen mit ,Zugriffsrechten " auf die werdende Person des Schülers ausgestattet ist. Diesbezüglich kann man sagen, dass es aus Sicht der Lehrkraft zwar dichte Verhandlungs- oder Beeinflussungskonstellationen gegenüber Schülern geben soll, um Lernprozesse anzustoßen. $\mathrm{Zu}$ den übrigen Akteuren gibt es jedoch nur lockere Beobachtungskonstellationen. Schulleitung und Eltern greifen allenfalls unterstützend in den Lehr- und Lernprozess ein.

Anders in der neuen Governance. In ihr sollen Lehrkräfte ihre Zugriffsrechte mit den anderen Akteuren teilen. Grundsätzlich sehen Qualitätsmanagements Beeinflussungs- oder Verhandlungskonstellationen, d.h. dichtere Beziehungen zwischen allen (!) Akteuren der Einzelschule vor. Schulleitung, Eltern und auch die Schüler selbst arbeiten dann über Evaluierungen am Qualitätsmanagement mit, Verbindungen zwischen den Akteuren werden über Feedbackeinrichtungen verstetigt und bleiben weniger der (zufäl-

wählt werden kann. Das zweite Erklärungsproblem der Soziologie ist es, die aus den Handlungswahlen entstehenden Akteurkonstellationen zu erklären. Diese bilden soziale Strukturdynamiken aus. Prinzipiell lassen sich hierfür Konstellation der Beobachtung, der Beeinflussung oder der Verhandlung unterscheiden (vgl. ebd.). Die Konstellationen entscheiden über das Umsetzen-Können einzelner Motive der Handlungswahlen (vgl. zur Unterscheidung von Wollens-, Sollens- und KönnensOrientierungen: Schimank 1996: 243-246). 
ligen) Kultur einer Schule überlassen. Im Gegensatz zur bisher dominierenden bürokratischen Governance, in der die Lehrer dominierten, wird in der neuen Governance das Rollenhandeln der Schulleitung, der Eltern und der Schüler aufgewertet, weil es in Beeinflussungskonstellationen eingebunden werden soll und nicht mehr nur in gelegentlichen Konstellationen der Beobachtung vorkommt. Die Beziehungen zwischen den Akteuren werden also dynamisiert.

Als Ergebnisse lassen sich auf der einen Seite Negativentwicklungen und transintentionale Effekte vermuten. Vielleicht bestätigt eine Modernisierungsmaßnahme vorhandene ,Gräben', oder es bilden sich neue Lager der Modernisierungsbefürworter und -gegner. Auf der anderen Seite lassen sich Positiventwicklungen zumindest in dem Sinne vermuten, dass Akteure mehr ,zusammengebracht' werden. Dies meint eine intensivere Kommunikationskultur zwischen Lehrkräften und Schülern; die gemeinsame Festlegung unterrichtsbezogener Standards durch das Kollegium, die vielleicht auch zu einer Entlastung des einzelnen Lehrers führt; eine Verstetigung der Mitwirkung der Schulleitung durch Zielvorgaben oder auch die Verstetigung der Elterneinbindung. ${ }^{3}$

\section{HELMUT FEND \\ Schulkultur als Zusammenspiel der Teilkulturen von Lehrern, Schülern und Eltern - Schisma oder Partnerschaft}

Der obige Ansatz zur Bestimmung der Schulkultur [Fend meint hier sein vorangehendes Kapitel ,Schulkultur als Ausdruck unterschiedlicher Modalitäten der gemeinschaftlichen Bewältigung des Schulegebens heute“ - d. Hg.] war im Keim noch auf die Arbeit des Lehrers und auf die sozialen Beziehungen in Kollegien begrenzt. Den Ausgangspunkt bildeten Besonderheiten der Lehrerarbeit, die dazu führen, daß bestimmte Ängste und Abwehrprozesse entstehen, daß Lehrer in bestimmter Weise miteinander verkehren, daß sie bestimmte Weltbilder aufbauen und kollegiale Normen entwickeln. Das Kernproblem bestand in der ,weichen Technologie“ jeder Erziehung, in der schwachen Rationalisierbarkeit des Ziel-Mittel-Verhältnisses. Lehrer sind in hohem Maße auf die Mitarbeit der Schüler, auf ihre Zustimmung und Kooperation angewiesen. Lehrerarbeit ist somit auch im-

3 Darüber hinaus lässt sich davon ausgehen - auch wenn dies nicht von allen Beiträgen angesprochen wird -, dass sich jeder Akteur auch gleichsam selbst modernisieren kann, was dann angemessener mit Begriffen eines (längerfristigen) sozialen Wandels zu untersuchen wäre. Stellvertretend hierfür ist der Beitrag von Ziehe, der den Generationenwandel von Jugendlichen und Lehrkräften anspricht und einen solchen sozialen Wandel zugleich unter Gesichtspunkten der gegenwärtigen Modernisierung von Schule sieht. 
mer Beziehungsarbeit, gute Beziehungen sind ihr Kapital, um ihre Arbeit erfreulich zu gestalten (Wellendorf 1994: 109). Die Arbeit der „Menschengestaltung", die zum Kern der Schule gehört, aktiviert aber auch tiefliegende Ressentiments, unterdrückte Wünsche und Bedürfnisse, erlebte Wunden und unausgelebte Hoffnungen. Der Umgang der Lehrer untereinander, mit den Schülern und Eltern wird von Regeln geleitet, die diese Prozesse kanalisieren helfen. Es kann sich dadurch ein defensiver Modus des Umgangs untereinander entwickeln, in dem der Schutz der eigenen Sphäre im Vordergrund steht und viele Informationen und Erfahrungen schon im Vorfeld abgewehrt werden. Fürstenau $(1964,1974)$ hat auf diesem Gebiet Pionierarbeit geleistet, Wellendorf (1994) gehört heute zu den Theoretikern, die diesen Prozessen am sensibelsten auf der Spur sind. [...]

An der Gestaltung der Schule vor Ort sind zumindest zwei weitere Gruppen beteiligt: Schüler und Eltern. Schon die empirischen Studien haben gezeigt, daß deren Sichtweisen nicht identisch sein müssen, daß sie Schule von je eigenen Interessen her betrachten. Die kollegiumsinterne $\mathrm{Zu}-$ friedenheit ist z.B. von den Eltern und Schülern nicht wahrgenommen worden. Die Lernmotivation und das Leistungs-Selbstbild der Schüler waren von Kollegiums-Konstellationen ebenfalls weitgehend unabhängig. Aber auch „Brücken-Phänomene“ ließen sich beobachten, also Ausstrahlungen von internen Verhältnissen im Kollegium zu Außenbeziehungen mit Schülern und Eltern.

Können wir dann, so müßte man fragen, tatsächlich von einer „Schulkultur" sprechen, oder müssen wir nicht vielmehr auf die Besonderheiten dieser Interessengruppen eingehen und dann von einer Lehrerkultur, einer Schülerkultur und einer Elternkultur sprechen? Die Einzelschule wäre dann ein System von Teilkulturen, die vorerst nur wenig miteinander zu tun haben (vgl. Göhlich 1997). Göhlich betont diese Perspektive, indem er die Theorie von Bateson (1981) aufgreift. Auf phänomenologischer Ebene zeigen sich die Lehrerkulturen, Schülerkulturen und Elternkulturen in verschiedenen Gesprächsthemen und Redeweisen, in der Präferenz für bestimmte Treffpunkte und Aktivitäten. So sind für die Lehrerkultur Aktivitäten bezeichnend wie der Lehrersport, der pädagogische Tag und das Bier danach, die Grillfeste im Sommer und der Tee im Lehrerzimmer, die Kleidungsform und die Präferenz für Urlaub und Auto. Eine Schülerkultur hat ebenfalls vielfältige Ausdrucksformen, etwa bestimmte Redeweisen (Schülersprache), gemeinsame Entrüstungen über bestimmte Lehrer, Treffpunkte in der Schule und am Nachmittag, Demonstration von „cool“ oder von „angepaßt“, Hackordnungen und Solidaritätsdemonstrationen. Am wenigsten entfaltet erscheinen Elternkulturen, außer sie sind explizit inszeniert, etwa in Kaffee-Nachmittagen, in eigenen Kneipentreffs und Gesprächen nach den Elternabenden. Aber auch bei ihnen gibt es präferierte Themen und Gemeinsamkeit stiftende Gesprächsformen.

Göhlich spricht von je unterschiedlichen Interessenlagen, die diesen Kulturen zugrunde liegen: Eltern sind von einem Sorge-Interesse getrieben, 
Schüler von einem Spaß-Interesse und Lehrer von einem Belastungsminimierungs-Interesse. Jede Teilkultur bestimmt ihre Binnenkultur vom Verhältnis zu den anderen Teilkulturen, z.B. als Verhältnis der Opposition oder Kooperation, von Distanz oder Nähe. Innerhalb der einzelnen TeilKulturen können sich Fraktionen bilden, die sich ebenfalls wieder aus der Wahrnehmung des Verhältnisses einer anderen Fraktion zu den Teilkulturen ergeben: so haben wir extensiv Schülerkulturen untersucht und die zentrale Scheidelinie in schuloppositionellen oder schulkonformen Schülerkulturen gefunden (vgl. Specht 1974; Specht \& Fend 1979). In der Lehrerschaft können sich ebenso Trennlinien entwickeln: Lehrer, die Eltern und Schülern entgegenkommend und kooperativ gegenüberstehen oder die hier eher Feind-Verhältnisse unterstellen. Das gleiche gilt für die Elternschaft. Auch sie kann sich in solche Gruppen teilen, die mit der Schule arbeiten oder einen einsamen Kampf mit ihrem Kind um dessen Laufbahn führen, der von Opposition und Ablehnung großer Bereiche der Schule begleitet ist.

Die Beziehungen zwischen diesen Gruppen entwickeln sich jedoch nicht in einem gesetzesfreien Raum. Da die Qualität der Beziehung den Prozeß des Schulehaltens und Lernens so stark beeinflußt, ist er normativ über Gesetze und Verordnungen strukturiert. Die Mitwirkungsrechte und gegenseitigen „Zugriffsrechte“, etwa die Rechte der Lehrer über die Schüler, sind normativ verankert und machen Lehrerverhalten zu „Amtshandeln“, also zu regelgeleitetem Verhalten, und nicht zu spontanen Verhaltensmanifestationen.

[...]

Eine Analyse systematischer Variationen in den Entwicklungsprozessen und Zustandsmerkmalen der verschiedenen Teilkulturen ermöglicht die Theorie von Bateson über schismogene Prozesse (vgl. Bateson 1981). Mit ihr soll erklärt werden, wie es zu einem „Schisma“, also einer Spaltung innerhalb oder zwischen Gruppen, kommen kann, einer Spaltung, die unüberbrückbar erscheint, so daß bei einer Berührung dieser Gruppen eine Tendenz zur gegenseitigen Zerstörung (Liquidation) entsteht. [...]

Hier wird eine theoretische Interpretation des schulischen Geschehens angestoßen, der man in Zukunft mit Gewinn nachgehen könnte. Sie müßte von den Kernkonzepten der Schismogenese ausgehen. Diese bestehen in der Unterscheidung von zwei Typen von Interaktionen: komplementären und symmetrischen. Komplementäre Interaktionen tendieren dazu, daß ein Gleichgewicht durch die Ungleichheit der Beziehung der Interaktionspartner entsteht: ein Partner dominiert, der andere unterwirft sich, einer gibt großzügig, der andere nimmt dankbar an. Eine solche Komplementarität schafft dadurch Frieden, daß der eine das Komplementäre von dem tut, was der andere möchte (Angriff - Unterwerfung, Schenken - Empfangen, Befehlen - Gehorchen, Lehren - Lernen).

In symmetrischen Interaktionen herrscht Rivalität, ein Kampf um Ebenbürtigkeit, um gleichen Einfluß, um gleiche Erfolge, um gleich viel Besitz 
usw. Zwischen Gruppen führt zu dies zu einem Übertrumpfungsverhalten, wie es z.B. im Rüstungswettlauf zu beobachten war.

Ein schismogener Proze $\beta$ besteht in einer Eskalation entweder komplementärer oder symmetrischer Interaktionen. Dies kann sich zu explosiven sozialen Situationen steigern, zu einem Umkippen der komplementären in die symmetrische Interaktion bzw. zur Absorbierung oder Vernichtung der einen Kultur durch die andere.

In dieser theoretischen Perspektive können die Interaktionen der Teilkulturen von Schülern, Eltern und Lehrern als Kulturberührungen interpretiert werden, bei denen die obigen Tendenzen immer möglich sind. Zwischen diesen Teilkulturen bestehen klare Grenzen, die eine interne Homogenisierung und eine externe Abspaltung fördern. Das Verhältnis von Schülern und Lehrern ist eher das einer komplementären Interaktion, wenngleich Rivalitäten um Einfluß immer möglich sind. Die Beziehungen der Schüler untereinander wiederum sind eher solche symmetrischer Natur, es bestehen institutionsinduzierte und informell entstehende Konkurrenzund Rivalitätsverhältnisse. Dabei werden Koalitionen mit Außeninstanzen, z.B. mit Lehrern gesucht, die die Gruppe der Schüler spalten können: in solidarisch-oppositionelle und individualistisch-konformistische.

Das Verhältnis der Eltern zur Schule ist ebenfalls ein komplementäres. Die Macht liegt auf der Seite der Schule, Eltern wollen als KarriereStellvertreter der Kinder etwas von den Lehrern, das diese verweigern können. Dieses Verhältnis kann schismogen eskalieren. Eltern untereinander sind in eine Stellvertreter-Konkurrenz involviert, je nachdem, wie gut ihre Kinder in der Schule sind.

Lehrer sind von ihrem gesetzlichen Auftrag her klar die dominanten Spieler. Sie haben in den komplementären Interaktionen die übergeordneten Positionen. In diese soziale Situation können sie sich schismogen einleben und alle Kämpfe um symmetrische Interaktionen, um rivalisierenden Einfluß der Eltern oder Schüler solidarisch abblocken. Die Lehrerschaften können sich aber auch intern spalten, wenn die eine Gruppe eher zu Zusammenarbeit mit den anderen Teilkulturen neigt als die andere.

Solidarisierungsprozesse und Spaltungsprozesse werden nach diesem Analyseschema zu latenten Allgegenwärtigkeiten schulischen Lebens. Sie sind von Machtkalkülen durchzogen. Sie ergeben sich sowohl innerhalb der Teilkulturen der Lehrer, Eltern und Schüler als auch zwischen diesen Teilkulturen.

Wie sehr die Prozesse der Kulturberührung und der internen Auseinandersetzungen in die Ängste, Befürchtungen, Angriffe, gegenseitigen Vernichtungswünsche eingreifen, zeigt vor allem Wellendorf, der aus einem psychoanalytischen Ansatz her die Unstrukturiertheit der Erziehungsaufgabe von solchen latenten Illusionsbildungen durchzogen sieht (vgl. Wellendorf 1994). Damit verbindet er die Analyse der Besonderheiten von Erziehung (siehe oben) mit der Psychodynamik von sozialer Konfliktverarbeitung in großen Gruppen und Institutionen. Im folgenden Zitat kommt die 
tiefliegende Angst und ihre Bearbeitungsform zum Vorschein, die sich aus den latenten gegenseitigen Vernichtungsmöglichkeiten in der Schule ergibt:

„Für Schüler und Lehrer enthält die Arbeitssituation also einen Kern tiefer Angst und großer Spannung, der eng mit dem Zweifel an der Fähigkeit verbunden ist, die Lage zu verbessern. Die Struktur der Schule, ihre Rituale und alltäglichen Praktiken bilden ein komplexes soziales Abwehrsystem dagegen. Das Kernproblem wird aufgesplittert, so daß es als solches nicht länger erkennbar ist. Die entstehenden Fragmente - das NichtWissen, die Ohnmacht, die Verunsicherung der eigenen Identität, die magischen Wünsche, die Aggressivität, die Abhängigkeit - können in den Gruppenprozessen der Institution leicht auf andere - Individuen und Gruppen - projiziert werden. Es sind jeweils , die da', denen die aufgespaltene Verantwortung projektiv zugeschrieben wird: ,die Schulverwaltung', ,die heutigen Schüler', ,die mangelhafte Ausstattung', ,die Eltern', , die Drogen', , die alten Lehrer'. Derartige defensive Antworten auf institutionelle Probleme bedeuten auch, daß die Institution selbst nicht wirklich lernen kann. Das heißt: Es gibt keine institutionelle Veränderung, die das Kernproblem und den Umgang mit ihm berühren würde" (Wellendorf 1994: 120).

Die Kulturberührungen nehmen hier die Form von Phantasien an, was wohl die anderen tun werden, sie führen zu ,imaginary institutions“, die Spaltungsprozesse verfestigen können.

Vor diesem Hintergrund wird der Sachverhalt erklärungsbedürftig, daß es in Schulen vor Ort nicht zum Kampf aller gegen alle, nicht zu kriegsähnlichen Zuständen eines gegenseitigen Vernichtungswillens kommt. Eskalationsprozesse sind überall $\mathrm{zu}$ beobachten, sie führen jedoch selten $\mathrm{zu}$ schismogenen Gesamtkonstellationen.

Mehrere Prozesse verhindern dies, insbesondere Regeln der Bearbeitung von Grenzen. Einmal können Übereinkünfte formuliert werden, die die Interaktion der verschiedenen Gruppen regulieren und Rechte der einen und der anderen festschreiben. Schulkulturen entstehen so auf dem Hintergrund von Mitwirkungsregelungen, die regulierte Grenzüberschreitungen, also Ankoppelungen an die Rechte der anderen, ermöglichen.

Der zweite wichtige Weg besteht darin, möglichst viele Anlässe zu erzeugen, die metakommunikative Räume für die Diskussion der Probleme von jeweiligen Außengruppen schaffen und damit Empathie der Gruppen füreinander fördern.

Auf einem dritten Weg werden in komplementäre Interaktionen Inseln symmetrischer Interaktion eingesprengt, die einen dämpfenden Ausgleich zur Folge haben können. Wenn z.B. Lehrer in einem Fußballspiel gegen eine Schüler- oder Elternmannschaft unterliegen, dann geben sie damit freiwillig ihre dominante Position auf und lassen sich in symmetrische Interaktionen ein.

Vor diesem Hintergrund wird wieder sichtbar, daß es differentielle Ausprägungen der schismogenen Potentiale einer Schule gibt. Wenn wir auf die am stärksten differenzierenden Merkmale ,guter" und ,schlechter“ Schulen zurückblicken, dann fällt auf, daß gerade gruppenübergreifende Anlässe in der Schule (s. die verschiedenen Ausgestaltungen des Schulle- 
bens) am stärksten mit einer kooperativen Gesamtsituation verbunden waren. Innerhalb des Kollegiums war eine ausgeprägte Kontaktintensität auch außerhalb der Schule -, waren fachliche Austauschprozesse eng mit internen Verhältnissen im Kollegium verbunden, die frei von Fraktionierungen und damit von schismogenen Prozessen waren. In den Beziehungen zwischen Schülern und Lehrern schuf ebenfalls das Durchbrechen rein komplementärer Interaktionen, also eines reinen Dominanzverhältnisses mit symmetrischen Interaktionen, also mit Ebenbürtigkeiten, eine positive emotionale Rezeption. Auch die Zufriedenheit der Eltern mit der Schule stieg durch grenzüberschreitende Aktivitäten und durch die Übernahme der Elterninteressen in die Bemühungen der Lehrer.

Grenzüberschreitung und Solidarisierung werden jedoch nicht immer mit „lauteren“ Mitteln erreicht. Häufig werden geheime Koalitionen geschaffen, oder es werden zum Zwecke der Solidarisierung Personen der anderen oder der eigenen Gruppe stigmatisiert, also auf dem Altar der Solidarität und der Koalitionswünsche geopfert. Je stärker die internen Fraktionierungen zu werden drohen, um so größer ist die Versuchung, solche Bauernopfer in bezug auf isolierbare Außenpersonen zu bringen (vgl. Göhlich 1997). Diese Ausgrenzungen dienen zumindest der kurzfristigen innersystemischen Stabilisierung, ohne dadurch aber rechtfertigbar zu werden. Sie bedürfen eines klaren institutionellen Gegengewichts, das langfristig alle zu ihrem Recht kommen läßt und die Rechte der Einzelperson gewährleistet.

\section{Gesamtkonfiguration von Teilkulturen zwischen Partnerschaft und Schisma}

Die obige theoretische Perspektive legt typologische Beschreibungen der lokalen Schulkultur nahe, die aus dem jeweiligen Verhältnis von Teilkulturen und nicht allein aus den Merkmalen der Lehrerkultur resultieren. Ich möchte vorschlagen, von Relationierungen der Teilkulturen von Eltern, Schülern und Lehrern zu sprechen, die eher auf starre Grenzziehung, auf Aufhebung der Grenzen oder auf Flexibilisierungen der Grenzen verweisen. Die erste gesamtkulturelle Konfiguration tendiert auf Liquidation der anderen, die zweite auf Verschmelzung und die dritte auf einen professionellen Umgang mit Binnenstrukturen, Außenperspektiven und Grenzüberschreitungen.

Es gibt Lehrerkollegien bzw. einzelne Lehrer, die eine starke Tendenz zeigen, starre Grenzen zwischen sich und den anderen Kollegen, zwischen sich und den Schülern, zwischen von ihnen vertretenen Inhalten und Positionen und denen anderer zu ziehen. Anklänge zum beschriebenen defensiven Modus der Problemlösung im Umkreis des „Schulegebens“ sind hier unvermeidbar. Präziser erscheint mir aber das Konzept der Grenzbearbeitung oder die Terminologie von ,framing“ und „classification“, die Bernstein entwickelt hat (Bernstein 1973). Danach neigen Kollegien in unterschiedlichem Maße dazu, Interaktionsformen, Begegnungsmöglichkeiten, 
professionelle Profilierungen innerhalb von exakt gezogenen Grenzen zu halten und sich weder zu ,verbrüdern“ noch die eigenen inhaltlichen Ausrichtungen mit denen anderer zu amalgamieren. Wird eine solche Tendenz in einem Kollegium dominant, dann fühlen sich Schüler und Eltern - also die anderen Teilkulturen - ,ausgegrenzt“. Im Falle einer konflikthaften Kulturberührung entstehen bei einer solchen schismogenen Entwicklung in den betroffenen Parteien „Liquidations-Neigungen“, also Tendenzen, den anderen ,zu vernichten“, ihn zumindest auszuschalten.

Im Kontext der antiautoritären Erziehungsbewegung waren in Schulen Tendenzen zu beobachten, nicht nur schwache Grenzen zu ziehen, sondern diese teilweise ganz aufzuheben. Lehrer wollten Schülern keine Autoritäten sein, sie wollten nicht mehr einseitig lehren, sie gingen eher von einer grundsätzlichen Gleichheit aus. Auch die Interessen der Eltern und der Lehrer wurden als gleichartig definiert. Diese Konstellationen wurden rasch pathologisch, da sie den realen, institutionell vorstrukturierten Interessenlagen widersprachen und zu problematischen Ausbeutungsverhältnissen führten. Insbesondere Lehrer mußten diese Erfahrung häufig machen (s. die Fallberichte in: Fend 1984). Eine starre Grenzziehung erwies sich als ebenso problematisch wie die Verschmelzungstendenz. Dies war eines der wichtigsten Ergebnisse zur Erklärung unterschiedlicher Schulkulturen.

Damit ergibt sich als dritter Weg die flexible Grenzziehung bzw. die geregelte Grenzüberschreitung. Es wird dabei durchaus Gelegenheit geboten, Teilkulturen auszubilden. Sie wird nicht durch ein falsches Harmoniestreben beeinträchtigt (vgl. Göhlich 1997). Die institutionalisierten Grenzüberschreitungen in der Form geregelter Mitwirkungsrechte werden aktiv genutzt. Ferner bestehen viele Anlässe des gegenseitigen Kontaktes, die den jeweils anderen in einer neuen Rolle präsentieren, die Empathie, Metakommunikationsmöglichkeit und rationales Aushandeln von konfligierenden Themen ermöglicht.

Zum Umgang mit schismogenen Tendenzen würde auch ihre reflexive Bearbeitung gehören. Über sie wäre explizit zu reden, Fehlentwicklungen wären experimentell durchzuspielen, um die Versuchungen zu entdecken, die in Bauernopfern liegen, und um die Sensibilität für die Rechte aller Beteiligten zu schärfen.

Im Mittelpunkt hätte jedoch das dissensoffene Gespräch zu stehen, was die beste Art und Weise der Erfüllung des Schulauftrages im konkreten lokalen Fall ist. Um die bestmögliche Aufgabenerfüllung geht es schließlich. Da Schulen „selbstreflexive Systeme“ sind, da dies auch für alle Teilkulturen und deren Beziehungen zueinander gilt, dürfte die Aufrechterhaltung der Gesprächsfähigkeit ein Kernindikator für eine produktive Gesamtgestalt einer Schulkultur sein. Sie mündet nicht in absolute Harmonie, in völligen Konsens oder gar in den Stillstand der Perfektion. Ihr wünschenswertes Nebenergebnis ist die Aufrechterhaltung der Lernfähigkeit und der Entwicklungsfähigkeit. Der „Mechanismus“, der dies ermöglicht, besteht in der Entwicklung anschlußfähiger Codes aus den Teilkulturen heraus. Es 
gibt danach Übersetzungsmöglichkeiten des je internen Selbstverständnisses der verschiedenen Teilkulturen in die jeweils andere.

Für die Analyse der realen Prozesse vor Ort halte ich Weiterentwicklungen so heterogener Konzepte wie jener von Bateson (Systemtheorie und Kulturtheorie), von Bernstein (Wissenssoziologie) und von Wellendorf (Psychoanalyse und Institutionstheorie) für besonders fruchtbar. Bateson macht auf die Problematik der Grenzen zwischen Teilkulturen aufmerksam und läßt Situationen der Grenzüberschreitung ins Bewußtsein treten. Bernstein läßt einerseits die Verankerung der Grenzziehungsstrategien, von „classification“ und „framing“, in Prozessen von Macht und Kontrolle sichtbar werden. Andererseits verweist er auf Typologien der Bearbeitung der Machtfrage, etwa in der Form der harten und klaren bzw. der flexiblen und integrierten Grenzbearbeitungen. Wellendorf wiederum bindet die Lösung dieser Machtfragen an die Ängste und Phantasien zurück, die sich mit der Erfüllung einer so wenig objektiv strukturierbaren, aber lebenslaufentscheidenden Arbeit wie der des Lehrens und Beurteilens von Schülern verbinden.

Welches Erscheinungsbild lokaler Schulkulturen als Konfigurationen der genannten Teilkulturen jeweils entsteht, ist von außen schwer vorherzusagen. Es ergibt sich immer auf dem Hintergrund der institutionellen Regelungen, wie die jeweiligen Gruppen miteinander umzugehen haben, was ihre Rechte und Pflichten, ihre gegenseitigen Schutzzonen und Kooperationsnotwendigkeiten sind (s. die Mitbestimmungsgesetze). In unseren Studien hat sich auf diesem Hintergrund gezeigt, daß die pädagogischen Deutungsmuster sehr entscheidend sind, in welcher Weise der jeweilige Umgang gestaltet wird. Sie erweisen sich im nachhinein auch als Legitimationen verschiedener Strategien der Grenzbearbeitung. Sie rechtfertigen und verstärken gleichzeitig mehr oder weniger starre Grenzziehungen und erwecken das Erscheinungsbild von eher autoritär-abgrenzenden oder antiautoritär-verschmelzenden Kollegien. Schließlich dürfte jedoch jede Schule ihre Geschichte haben, die sich nicht zuletzt durch das eher zufällige Zusammentreffen verschiedener Lehrerpersönlichkeiten und verschiedener Schülerschaften und Elternschaften ergibt. Es sind damit auch viele historisch zufällige Prozesse am Werk, wenn eine Schulkultur als Gesamtkonfiguration gelingt. Man muß auch Glück haben.

Damit sind lediglich Perspektiven der weiteren Forschung zu Schulkulturen aufgezeigt, die teils bisherige Ergebnisse integrieren helfen, teils auf weitere Untersuchungsaufgaben verweisen. Bei einer Analyse der Schulebene bleibt jedoch das mehrfach angesprochene Desiderat, sie im Kontext aller Ebenen der Gestaltung des Bildungswesens zu sehen, also im Kontext der Makroebene des Bildungssystems und der Mikroebene des Unterrichts. Sie repräsentiert gewissermaßen ein Bindeglied zwischen diesen Ebenen, ohne daß bereits ausreichend klar wäre, wie sie durch die übergeordnete Makroebene mitgestaltet wird bzw. in welcher Weise sie regulierend auf die Mikroebene einwirkt. [...] 
Eines ist aber auch klar, wenn man die konkreten Gestalten der Schulkulturen vor Ort an sich vorüberziehen läßt. Alle Versuche der Außenregulierung des Bildungssystems, erfolge sie durch Wissenschaft oder durch Politik, müssen mit den Binnenkulturen in Schulen rechnen, die einen Kulturkonflikt mit „Reformmaßnahmen“ mit allen Konsequenzen schismogener Prozesse provozieren können. Punktuelle Eingriffe können somit „schismogen“ wirken, sie können das feine Gefüge kultureller Lebensformen in Schulen in einer Weise in Gefahr bringen, daß ähnlich wie bei Kolonialisierungsprozessen Kulturen absorbiert und neutralisiert oder liquidiert werden. Die bestehenden Kulturen können so stark sein, daß Außenregulierungen folgenlos neutralisiert werden. Sie können aber auch assimiliert werden, wenn sie an die inneren Kulturen anschlußfähig sind und wenn diese Anschlußfähigkeit bewußt gepflegt und die Außenregulierung eingeplant wird. Es besteht somit auch immer die Chance, daß induzierte Konflikte ein höheres und besseres Niveau der Wirklichkeit schaffen, daß auf einem höheren Niveau ein neues Fließgleichgewicht entsteht.

$[\ldots]$

\section{Literatur}

Bateson, G. (1981): Ökologie des Geistes. Frankfurt a.M.

Bernstein, B. (1973): On the Classification and Framing of Educational Knowledge. In: R. Brown (Hg.): Knowledge, Education, and Cultural Change. London, 363-392

Fend, H. (1984): Die Pädagogik des Neokonservatismus. Frankfurt a.M.

Fürstenau, P. (1964): Zur Psychoanalyse der Schule als Institution. In: Das Argument, $6,65-78$

Fürstenau, P. (1974): Der psychoanalytische Beitrag zur Erziehungswissenschaft. Darmstadt

Göhlich, M. (1997): Schule als schismogene Kulturgemeinschaft. In: Zeitschrift für Sozialisationsforschung und Erziehungssoziologie, 17 (4), 356-367

Specht, W., u.a. (1974): Erfahrungen mit der Schule. Weinheim

Specht, W., Fend, H. (1979): Der „Klassengeist“ als Sozialisationsfaktor. In: Unterrichtswissenschaft, 2, 128-141

Wellendorf, F. (1994): Grenzen der Erziehung - Überlegungen zur Schule als Institution. In: G. E. Schäfer (Hg.): Soziale Erziehung in der Grundschule. Weinheim, 107124 


\section{Schulleitung}

\section{Kommentar (Brüsemeister)}

Es ist kein Zufall, dass als erste Akteurgruppe im Konstellationsgefüge der Einzelschule die Schulleiter genannt werden. In den aufkommenden Modellen der Modernisierung (also NPM und Qualitätsverfahren), die auf ein stärkeres Management der Schule zielen, spielt die Schulleitung eine zentrale Rolle. Dies stellt exemplarisch Jochen Wissinger (Universität Gießen) in seinem Beitrag heraus.

Nach dem neuen Governance-Modell des NPM sollen die Leitungspositionen in der Schule gestärkt werden. ${ }^{4}$ Führung und operative Autonomie der Einzelschule bilden einen engen Zusammenhang im Modell des NPM. Im Kontext der ,organisatorischen Neuordnung des Steuerungs- und Verantwortungssystems für die Qualitätssicherung in den Schulen' spricht der Autor die (neuen) Funktionsaufgaben von Schulleitern an. Bislang fühlten sich die Schulleiter im deutschen Sprachraum neben organisatorischen Aufgaben vor allem für den Unterricht zuständig, z.B. indem sie über die Unterrichtszeit mit Hilfe von Lehrplänen wachten. Weitere Verantwortlichkeiten lagen z.B. in der Weiterbildung der Lehrkräfte sowie die Einbindung der Eltern in das Schulleben. Durch das NPM-Modell wird dagegen die Balance zwischen den pädagogischen und den organisatorischen Funktionen der Schulleitung zugunsten Letzterer verschoben. Die Schulleitung gibt Zielorientierungen bezüglich pädagogischer Projekte, Schulorganisation, Personal und Finanzen aus und kontrolliert die Einhaltung der Ziele. Es geht ihr darum, Anreize zu geben, Leitlinien zu entwerfen und die Akteure der Einzelschule darauf zu verpflichten. Zwar ist dies vom Grundsatz her auch schon vorher Aufgabe von Schulleitern gewesen, aber es ist neu, dass dies nicht mehr nur informell im Rahmen einer Schulkultur geschehen soll, sondern in der neuen Governance zu einer ausformulierten Rollenposition in einer neuen Qualitätsorganisation Schule wird. Die Schulleitung steht dabei in enger Verbindung zur Bildungsverwaltung, mit der sie die strategischen Ziele abstimmt.

Mit dem Beitrag von Wissinger lässt sich fragen, ob Schulleiter in Modernisierungen stärker belastet sind, insofern sie einerseits in engem Kontakt zur Schulbehörde stehen, welche die Implementation bestimmter Modelle vorschlägt, andererseits auch ,das Neue' gegenüber dem Kollegium darstellen müssen. Eine weitere Frage, die sich aus dem Beitrag ergibt, ist, ob der Schulleiter, wenn er zunehmend Manager-Aufgaben übernimmt, noch aus dem pädagogischen Bereich kommen muss bzw. in ihm soziali-

4 Dies ist auch in Modernisierungsmodellen für Universitäten so - im Rahmen von NPM wird die Position von Rektoren und Dekanen aufgewertet (vgl. Brinckmann 1998). 
siert sein sollte. In US-amerikanischen Universitäten sind die Dekane als zentrale Entscheidungsträger zum Teil keine Akademiker mehr (vgl. Braun 2001). Für eine wesentliche Aufgabe von Hochschulen, nämlich das Akquirieren von Drittmitteln, zeigen sich Manager aus der Industrie ebenso kompetent. Die - für unser Thema formulierte - gegenteilige Forderung, dass nämlich Schulleiter nicht nur gute Manager, sondern auch gute Pädagogen sein müssen, wird durch Sach- und Zeitbelastungen, die sich aus beiden Rollen ergeben, vermutlich an Grenzen stoßen. Die pädagogische Disziplin hat - so weit wir sehen können - für dieses Problem noch keinen eigenen Vorschlag entwickelt, der darauf zielen würde, Manager aus der eigenen Profession heraus auszubilden.

\section{JOCHEN WISSINGER \\ Rolle und Aufgaben der Schulleitung bei der Qualitätssicherung und -entwicklung von Schulen}

\section{Einleitung}

Die Beschäftigung mit Rolle und Aufgaben der Schulleitung ist, was die Forschung in Deutschland angeht, erst am Anfang und orientiert sich dort, wo sie um Systematisierung und empirischen Zugang bemüht ist, an schulbezogener Forschung des anglo-amerikanischen Sprachraumes. Spezifische Zugänge eröffnet zum einen die Schulentwicklungsforschung, die ihre Wurzeln in der Forschung zu school effectiveness und school improvement hat (vgl. Stoll/Fink 1992: 19ff.), zum anderen als ein spezifischer Zweig von school administration research die Schulleiterforschung (vgl. Hultman 1989; für die deutsche Diskussion Baumert/Leschinsky 1986; Baumert 1989; Wissinger 1994, 1996).

Bildungs- sowie berufs- bzw. verbandspolitisch angetrieben ist die Beschäftigung mit Rolle und Aufgaben der Schulleitung durch die Diskussion um Schulreform und Schulentwicklung sowie die Frage der Rekrutierung und Qualifizierung von Schulleiterinnen und Schulleitern (vgl. Wissinger 1996; Winterhager-Schmid 1998; Wissinger/Huber 2002), die den Blick auf Schule in den vergangenen zehn Jahren auch in Deutschland beherrscht (für die USA vgl. z.B. Bacharach 1990). Einen mehr oder weniger systematisierten Zugang zur Diskussion eröffnen zwei Diskurse - der Schulqualitätsdiskurs und der Autonomiediskurs.

Die Beantwortung der Frage nach Rolle und Aufgaben der Schulleitung bei der Qualitätssicherung und -entwicklung ist in zweierlei Weise zu bearbeiten. Zum einen ist das Schulrecht, sind Verordnungen und Erlasse eines Bundeslandes zu sichten, da Rolle und Aufgaben der Schulleitung in Deutschland durch den rechtlichen Rahmen bestimmt sind (vgl. Wissinger 
1996). Auf diesen Zugang wird hier aus Platzgründen verzichtet. Zum anderen eröffnet neben dem normativ-rechtlichen Zugang die empirische Schulforschung in ihrer ganzen Breite Zugänge zu Antworten auf die gestellte Frage, die nur dadurch gefunden werden können, daß die Schulleitungsfunktion in ein Verhältnis gesetzt wird zu den definierten Aufgaben und Verantwortlichkeiten der Institution Schule generell sowie zu den Strukturen, Ressourcen und Anforderungen einer konkreten Schule. Denn woher sonst kommen die Kriterien, die darüber zu entscheiden erlauben, daß Rolle und Aufgaben der Schulleitung bei der Qualitätssicherung und Qualitätsentwicklung so und nicht anders zu bestimmen sind, und die die Notwendigkeit und Wirksamkeit schulischen Leitungshandelns überprüfbar machen? Auch sind Schulleiterinnen und Schulleiter selbst daraufhin zu befragen, worin sie ihre Rolle sehen, wird ihnen doch auf der Basis der Annahme, daß sie selbst im Hinblick auf die Bildungsqualität der Schule die entscheidende Einflußgröße darstellen, erhöhte Verantwortung zugesprochen (Murphy/Beck 1994).

\section{Pädagogische Führung: Rolle und Aufgaben der Schulleitung im Kontext des Schulqualitätsdiskurses}

Rolle und Aufgaben der Schulleitung bei der Qualitätssicherung und Qualitätsentwicklung von Schulen sind in Deutschland bislang nicht systematisch untersucht worden, wenn man einmal von den Studien zur Schulqualität absieht, die Fend (1998) jüngst dokumentiert hat. Zu großen Teilen sind diese Studien in den 70er Jahren durchgeführt worden und arbeiten mit zwei Konzepten, dem Schulklima- und dem Schulkultur-Konzept - eine Herangehensweise, die, wenn man sich die Entwicklung der internationalen Forschung anschaut, als ihrer Zeit voraus angesehen werden muß. Im Rahmen dieser Konzepte richtet sich die Aufmerksamkeit auch auf die Rolle der Schulleitung, insbesondere aus der Wahrnehmung der Lehrer.

Wenn man auf die Schulleitung als Untersuchungsgegenstand fokussiert (vgl. Wissinger 1994, 1996), dann kommt man nicht umhin, sich der entsprechenden Forschungstradition des anglo-amerikanischen Sprachraums zuzuwenden (vgl. Lenz 1991; Steffens 1991) ${ }^{5}$, d.h. der Schulentwicklungsforschung einerseits (vgl. im Überblick Reynolds u.a. 1996; Scheerens/Creemers 1996; Stringfield/Herman 1996; Townsend 1996) und dem school administration research andererseits (vgl. Ogawa 1995; Leithwood u.a. 1996). [...]

Rekurriert man auf anglo-amerikanische Forschung, so muß zunächst an den entsprechenden forschungsgeschichtlichen Kontext erinnert werden,

5 Ich folge anglo-amerikanischen Zugängen zur Fragestellung in dem Bewußtsein, daß Forschungsergebnisse aufgrund kultureller Unterschiede nicht einfach übertragbar sind. 
der für die Beantwortung auch der Frage nach Rolle und Aufgaben der Schulleitung von nicht hintergehbarer Bedeutung ist. Denn es war der Coleman-Report, der Anfang der 60er Jahre in den USA ein Bildungsdefizit in den Kulturtechniken bei Kindern und Jugendlichen feststellte und mit der berühmt gewordenen, provokanten Schlußfolgerung, ,schools don't make a difference" den Impuls gab für die Ausdifferenzierung des school effectiveness research, dessen Ergebnisse klar ausweisen, daß sehr wohl ein Unterschied zwischen Schulen derselben Schulart besteht (Creemers 1994). ${ }^{6}$ Diese Gegenbewegung zum Coleman-Report, die die Schulforschung des anglo-amerikanischen Sprachraums kennzeichnet, ist in Deutschland lange Zeit vor allem mit den Studien von Brookover/Lezotte (1979) sowie von Rutter u.a. (1979) identifiziert worden. Sie hat bis zum heutigen Tage eine mittlerweile unüberschaubare Vielzahl nicht nur US-amerikanischer, sondern internationaler Untersuchungen zur Wirksamkeit der Schule, d.h. zu den Bedingungen für eine erfolgreiche schulische Arbeit und ihrer Entwicklung nach sich gezogen, ohne daß, wie die alljährlichen Tagungen des „International Congress for School Effectiveness and School Improvement (ICSEI)" nebst gleichnamiger Fachzeitschrift überzeugend dokumentieren, ein Ende abzusehen wäre.

[...]

Wie auch immer die theoretische Fundierung, die methodische Arbeitsweise oder die Ergebnisse zu beurteilen sind, die anglo-amerikanische Schulwirkungsforschung hilft dabei, angesichts vielschichtiger öffentlicher wie fachöffentlicher Kritik an der Bildungsqualität nachwachsender Generationen wie an der Schule, ihrer Organisation, Professionalität und pädagogischen Wirksamkeit die Aufmerksamkeit zu schärfen. Unter dem Druck der school improvement-Bewegung - Schulwirkungsforschung und Praxis der Schulentwicklung gehen, was die Wissenbasis betrifft, nicht unbedingt Hand in Hand (vgl. dazu Reynolds u.a. 1996: 143) - hat sie sich zum Teil zur Schulentwicklungsforschung gewandelt. Vom Zugriff her beschäftigt sie sich mit der Lehr- und Lernqualität im Unterricht. Dabei verfolgt sie einen praxisbezogenen, optimistischen Ansatz, was die Möglichkeiten intentionaler Erziehung im Unterschied zu funktionaler Erziehung oder unbewußten und ungeplanten Prozessen (Sozialisation) betrifft. Im Unter-

6 Siehe den gegenüber der Rezeption der anglo-amerikanischen Schulwirkungsforschung kritischen Beitrag von Ditton/Krecker (1995). Auf der Grundlage einer Analyse von Daten aus Schuluntersuchungen in Rheinland-Pfalz aus dem Jahre 1980 arbeiten sie die Schulart als durchgängig relevanten und überwiegend hochbedeutsamen Faktor, hinsichtlich insbesondere der Schülerleistungen heraus (ebd., 513). „Dieses bundesdeutsche Spezifikum wird bei der Rezeption der prominenten ausländischen (amerikanischen und britischen) Untersuchungen gern übersehen“" (ebd.). Statt einer Orientierung auf die Schule fordern sie die Schulklasse als Untersuchungseinheit.

7 Zur deutschen Diskussion um Schulqualität vgl. Aurin (1991); Steffens/Bargel (1993); Tillmann (1994); Ditton/Krecker (1995). 
schied zur Unterrichtsforschung, die ihr Augenmerk auf die Untersuchung von Lehr- und Lernprozessen konzentriert, nimmt sie die Schule als Ganzes in Augenschein, wobei die Schule als Ganzes durch den Schulleiter, dessen Rolle und Aufgabe repräsentiert ist.

[...] In ihrer fünfzehn Jahre und länger währenden Tradition hat die Schulwirkungsforschung relativ stabile Faktoren herausgearbeitet, die effektive Schulen kennzeichnen. Sie weisen einen Zusammenhang zwischen Faktoren auf der Lenkungsebene und der Klassenebene nach. Auf der Grundlage von Studien aus verschiedenen Ländern kann eine Auswahl von acht Merkmalen genannt werden (Mortimore 1993: 300ff. ${ }^{8}$ ):

1. Starke, positive Schulleitung

2. Hohe Leistungserwartungen und angemessene Anforderungen an alle Schüler

3. Überprüfung des Lernfortschritts des Schülers

4. Einbindung des Schülers in die Verantwortung für das Schulleben

5. Anreize und Belohnungen

6. Einbeziehung der Eltern in das Schulleben

7. Klare Zielabsprachen unter den Lehrern

8. Berücksichtigung neuester Erkenntnisse der Unterrichts- und Lernforschung

[...] Im Hinblick auf die Frage, wie Schulleiterinnen bzw. Schulleiter eine einflußreiche Rolle bei der Entwicklung und Sicherung der Wirksamkeit ihrer Schule spielen könnten, nennen frühe Studien der Wirksamkeitsforschung mehrere Merkmale pädagogisch einflußreicher Schulleiter bzw. Schulleiterinnen. Effektive Schulleiter sind demzufolge Leistungszielen verpflichtet, sie schaffen ein Klima hoher Erwartungen in die Lernfortschritte der Schüler, sie verteilen notwendige Ressourcen, sie sind charakterstark und dynamisch, sie schaffen eine stabile Lernumgebung mit klarem Akzent auf Disziplin, sie betonen die Anleitung der Schüler als eine wichtige Zielvorstellung pädagogischen Handelns, sie bevorzugen unterrichtsbezogene Aktivitäten gegenüber solchen des täglichen Ablaufmanagements bzw. der Verwaltung (Glasman/Heck 1992: 7f.). Dieses Bild vor Augen wird die Schulleiterin bzw. der Schulleiter als die mit Leitungs- und Verwaltungsaufgaben befaßte Person verantwortlich gesehen für die Kommunikation von Zielen wie auch einer Vision, sie wird verantwortlich gesehen für die Gestaltung des Schulklimas und der Schulkultur und schließlich für die Organisation und Gewährleistung des Unterrichts.

Erst vor dem Hintergrund einer Schulwirkungsforschung ${ }^{9}$, die in dieser Weise die Funktion und Bedeutung der Schulleitung betont, ist ein in der

8 Übersetzung - J.W.

9 Interessant ist in diesem Zusammenhang, daß die Herausstellung der Schulleitung und die Betonung der Führung kein Resultat der Schulleitungsforschung im engen 
Diskussion zentrales Konzept zu verstehen, das sich als instructional leadership role etabliert hat. Dieses Konzept betont den Aspekt der Führung im schulischen Geschehen und macht Aussagen zur Rolle und zu Aufgaben der Schulleitung (vgl. z.B. Edmonds 1979, 1982; Bossert u.a. 1982; Leithwood/Montgomery 1982; Hallinger/Murphy 1985, 1987; Greenfield 1987; Heck u.a. 1991).

Was der frühen Schulwirkungsforschung klar zu sein schien - daß nämlich die Schulleitung qua Funktion, insbesondere durch eine auf Unterrichtssteuerung (und nicht auf Verwaltung) bezogene Interpretation und Ausgestaltung der Vorgesetztenrolle einen unübersehbaren und unverzichtbaren Beitrag zur Qualitätssicherung und Qualitätsentwicklung einer Schule leistet - wird dort, wo sie sich zur Schulentwicklungsforschung wandelt, zum Untersuchungsgegenstand. Ausgangspunkt ist die Frage, wie Schulleiterinnen bzw. Schulleiter die ihnen angetragene Führungsrolle ausgestalten und dadurch zur Entwicklung und Sicherung der Bildungsqualität beitragen. Führung heißt , pädagogische Führung ${ }^{60}$; sie ,umfaßt solche Politiken und Praktiken des Schulleiters oder anderer Führungskräfte in der Schule, die das pädagogische Programm und die schulische Lernumgebung für Schüler und Lehrer gestalten“ (Hallinger u.a. 1994: 326). Im Rahmen dieses Konzeptes fallen der Schulleitung zwei Aufgaben zu: erstens die Verbesserung der Schülerleistungen als Zielpunkt schulischen Handelns und als Antwort auf spezifische soziale und ethnische Kontexte des Lehrens und Lernens, zweitens die Implementation bildungspolitischer und/oder mikropolitischer Reformen in der Schule als Antwort auf Anforderungen einer sich tiefgreifend verändernden schulischen Umwelt einerseits, als Antwort auf eine als neuordnungsbedürftig angesehene schulische Organisation andererseits.

[...] Dahinter stand gerade zu Anfang die Vorstellung, daß der Schulleiter bzw. die Schulleiterin als Inkarnation der Schule als Ganzes direkt in den Unterricht wirken würde und damit auf die Lernergebnisse der Schüler Einfluß nehmen könnte. Es entstand ein Bild von der Rolle und den Aufgaben der Schulleitung, das bei Lenz (1991: 55f.) sehr plastisch beschrieben ist:

„Die Schulleiterposition entwickelt sich aus der ,head teacher' Rolle: der Schulleiter als ,instructional leader', als pädagogisch Führender. Die Forderung an den Schulleiter, als ,instructional leader' den Unterricht und die Erziehung zu prägen und zu gestalten, ist bis heute das wichtigste Element in der Rolle des Schulleiters.“ ... „Der Schulleiter als ,instructional leader' verbringt den größten Teil seines Tages mit Anweisungen zur Verbesserung des Unterrichts, Überwachung seiner Anweisungen einschl. Klassen-

Sinne ist, sondern Untersuchungen zuzuschreiben ist, die sich mit der Wirksamkeit von Schule, mit der Implementation von Veränderung sowie mit Programmverbesserung beschäftigen (Hallinger u.a. 1994: 329).

10 Vgl. dazu kritisch Wissinger (1997). Ich übersetze hier ,instructional leadership mit pädagogischer Führung. 
beobachtungen, Bewertung und Weiterbildung der Lehrer. Der Schulleiter hilft jedem Lehrer bei der Festlegung der Lernziele und Planung von Aktivitäten. Einmal im Jahr wird mit jedem Lehrer über seine Stärken und Schwächen gesprochen, um den Lehrer optimal zu fördern und zu beruflicher Weiterbildung zu ermutigen. Außerdem hilft der Schulleiter dem Lehrer, Material zum Curriculum auszuwählen, Tests zu entwickeln, Bewertungsinstrumente einzusetzen, Kontakt zu den Eltern zu finden und Ordnung und Disziplin in der Schule herzustellen“.

Interessant ist, daß sich Schulleiterinnen und Schulleiter lange Zeit selbst vornehmlich in dieser Teilrolle sahen (Cohen 1983: 31, zit. n. Steffens 1991: 59), also in einer Rolle, die auf die Qualität des Unterrichts unmittelbar und damit auf die Lernleistungen der Schüler positiv Einfluß nimmt. Dies galt bislang auch und gerade für deutsche Schulleiterinnen und Schulleiter, gedeckt durch die formalrechtliche Funktion, die ihnen z.B. die Organisation des Unterrichts (Unterrichtsverteilung und Stundenplanerstellung) zuschreibt oder das Recht einräumt, den Unterricht der Kolleginnen bzw. Kollegen zu besuchen, sowie durch die rechtlich fixierte Rollenvorstellung, aufgrund derer ,die Schulleiterfunktion primär eine pädagogische Tätigkeit ist“ und „,er Schulleiter als Initiator pädagogischer Prozesse“" gilt (Holtappels 1989: 82f.).

$\mathrm{Da} ß$ sich mittlerweile diese einseitige Akzentuierung im Bild von der Rolle und den Aufgaben der Schulleitung (nur für die Forschung gesprochen) relativiert, hat wenigstens drei Gründe:

1. Seit Ende der 80er Jahre zeichnet sich ein Trend in der Forschung ab, der die Annahme eines kausalen Zusammenhangs zwischen instructional leadership und school achievement theorie- und methodenkritisch sieht und eine Abkehr von univariaten Analysen fordert (Heck u.a. 1991: 116). Zur Gruppe der Kritiker gehört z.B. van de Grift, der in einer Sekundäranalyse der Frage einer kausalen Beziehung zwischen pädagogischer Führung und Schülerleistung in der Elementarerziehung nachgeht, also die Annahme überprüft, daß sich pädagogische Führung durch das Lehrerverhalten hindurch auf die Lernleistung des Schülers auswirkt (van de Grift 1990: 31). Er kommt zu dem Ergebnis, daß eine Kausalbeziehung nicht nachgewiesen werden kann, ein indirekter Zusammenhang gleichwohl unterstellt werden darf (ebd., 38ff.).

2. Es bestand und besteht im anglo-amerikanischen Raum wie auch in Deutschland ein Widerspruch zwischen Anspruch und Wirklichkeit. Tätigkeitsanalysen der Schulleiterforschung konnten z.B. zeigen, daß die Unterrichtsbeobachtung und Unterrichtsbeurteilung als denkbares, in Deutschland rechtlich vorgesehenes Instrument der Einflußnahme auf die Qualität des Unterrichts des einzelnen Lehrers nur geringen Anteil an der geleisteten Arbeit und an der Arbeitszeit von Schulleiterinnen und Schulleitern hat (Morris u.a. 1984: 74; vgl. auch Krüger 1983). [...]

3. Eine Relativierung der auf eine kausale Beziehung zwischen Schulleitungshandeln und Schülerleistung orientierenden Vorstellung von Instructional Leadership geht von den Impulsen der Improvement- oder 
Implementationsforschung aus, die sich mit der Durchsetzung und Ausführung bildungspolitischer Reformen oder der Einführung von Innovationen beschäftigt. Erst die Implementationsforschung fragt angesichts des grundlegenden Problems der Schulwirkungsforschung, daß sie über Charakteristika guter Schulen mehr weiß als darüber, wie man Schulen zu wirksamen Einheiten macht (Townsend 1993: 3; vgl. auch Reynolds u.a. 1996), in welcher Weise die Schulleitung auf Inhalt und Entwicklung eines pädagogischen Programms sowie auf die Gestaltung einer Lernumgebung für Schüler und Lehrer Einfluß nimmt (vgl. Hallinger u.a. 1994: 326). Die Erkenntnis, daß eine Schulleitung immer nur indirekt Wirkung ausüben kann, führt zu der Konsequenz, daß die Beziehung zwischen Schulleitung und Kollegium (wie auch zwischen Schulleitung und einzelnen Lehrkräften) unter dem Gesichtspunkt von Arbeitszufriedenheit und Arbeitsplatzgestaltung thematisiert wird (vgl. z.B. Rosenblum u.a. 1994).

Eine in diesem Sinne kulturvergleichend arbeitende Richtung in der Schulentwicklungsforschung, die beide Dimensionen der Instructional Leadership Role berücksichtigt, ja im Zusammenhang sieht und der Frage nachgeht, wie SchulleiterInnen die Rolle des pädagogischen Führers ausgestalten, hat drei Dimensionen der Instructional Leadership Role - im Sinne von Beschreibungskategorien - generiert, die verschiedene, die beiden Aspekte der Rolle konkretisierende Aufgaben zu unterscheiden und zu organisieren erlauben (Hallinger u.a. 1994: $310^{11}$ ):

1. Definition des selbstgestellten schulischen Auftrags:

- Formulieren der schulischen Ziele

- Kommunizieren der schulischen Ziele

2. Management des schulischen Unterrichts

- Aufsicht über und Evaluation des Lehrens und Lernens

- Koordination des Lehrplans

- Kontrolle der Schülerleistungen

3. Förderung eines positiven schulischen Lernklimas

- Sicherung der Unterrichtszeit

- Förderung der beruflichen Weiterentwicklung

- Unterstützung durch Präsenz

- Anreize für Lehrer

- Ansporn zum Lernen.

Eine amerikanische Untersuchung von Bradley, die mit diesen Beschreibungskategorien arbeitet und auf einer Befragung von Lehrerinnen und Lehrern beruht, kommt zu dem Ergebnis, daß amerikanische Schulleiterinnen bzw. Schulleiter dazu tendieren, die dritte Dimension zu betonen, d.h. ihrer Rolle dadurch Ausdruck verleihen, daß sie ein positives Lernklima für Lehrer wie Schüler zu fördern suchen. Interessanterweise geht diese Ak-

11 Übersetzung - J.W. 
zentuierung auf Kosten der Bedeutung der zweiten Dimension: des Unterrichtsmanagements (Hallinger u.a. 1994).

Im Rahmen eines kulturellen Vergleichs wäre zu untersuchen, wohin deutsche Schulleiter und Schulleiterinnen heute tendieren, vermittelt doch z.B. die Politik der Arbeitsgemeinschaft der Schulleiterverbände Deutschlands (ASD 1999) den Eindruck, daß sie dabei sind, einen Wandel im Rollenverständnis zu vollziehen, ein Aspekt, der unter dem Gesichtspunkt der Entwicklung und Sicherung von Schulqualität neben der Beteiligung der Lehrer bzw. Lehrerinnen an der Entscheidungsfindung, neben der Gestaltung der Beziehung zu den Lehrern sowie neben Selbstmanagement (Wissen und Umgang mit Zeit) als conditio sine qua non angesehen wird (vgl. Rosenblum u.a. 1994).

\section{Vom Lehrer zum Transformational Leader: Zum Rollenwandel von Schulleitung im Kontext des Schulautonomiediskurses}

[...] Neue, das Verständnis von Rolle und Aufgaben der Schulleitung bei der Qualitätsentwicklung und Qualitätssicherung tiefgreifend verändernde Impulse kommen aus der Forderung nach Schulentwicklung, wie sie im Rahmen des sog. Schulautonomiediskurses national wie international diskutiert werden (vgl. Altrichter 1992; de Lorent/Zimdahl 1993; Daschner u.a. 1995; Ahrens 1996; Döbert/Geißler 1997; Avenarius u.a. 1998) und seit Mitte der neunziger Jahre ihren Niederschlag in mehr oder weniger weitreichenden Vorstellungen wie Maßnahmen zur Reform der Bildungsverwaltungen in Deutschland haben.

$$
[\ldots]
$$

Wie [...] zu sehen ist, verbindet sich im Autonomiediskurs die Forderung nach Schulentwicklung mit der Forderung nach einer Neuordnung des Verhältnisses zwischen Staat und Schule. Im Mittelpunkt stehen Maßnahmen, die Hierarchieabbau, Dezentralisierung und Kundenorientierung beinhalten mit dem Ziel, die Steuerung des Schulwesens zu optimieren und die Einzelschule zu stärken (vgl. Brockmeyer 1998: 125ff.). Denn es wird davon ausgegangen, daß Qualitätsentwicklung und Qualitätssicherung als zentraler Gegenstand von Steuerung auch im Bildungswesen nur vor Ort geleistet (vgl. z.B. Robertson/Briggs 1998) und damit ein Wechsel von der Inputsteuerung zur Produktsteuerung, wie sie international bereits Praxis ist oder Praxis wird (vgl. Hutmacher 1998), durch Programmentwicklung und Evaluation vorgenommen werden kann (vgl. Rolff 1995).

[...] [Die] an „Autonomie“ orientierte Restrukturierung des Schulwesens [rückt] ins Zentrum bildungspolitischer Reformen. ${ }^{12}$ Dabei handelt es sich um eine Verwaltungsreform, die die Schulleitungsfunktion von einer

12 Im anglo-amerikanischen Sprachraum heißt das Stichwort „School-Based Management" oder „Site-Based Management“. 
reduzierten Verwaltungs- und Kontrollfunktion hin zu einer „Managementund Führungsfunktion“ (vgl. Brockmeyer 1998: 130f.) verändert und damit der Vorstellung von Rolle und Aufgaben der Schulleitung bei der Qualitätssicherung und Qualitätsentwicklung der Institution Schule eine qualitativ neue Richtung gibt - nämlich eine Umorientierung zielbezogenen Denkens und Handelns von der Ebene des Unterrichts auf die Ebene der Schule, von der Ebene personbezogener Führung und Intervention auf die Ebene systembezogener Führung und Prozeßsteuerung.

Die Aufgabe der Programmentwicklung und Evaluation, im Sinne von Ziel und Weg einer vor Ort ansetzenden, die Bildungsqualität sichernden und entwickelnden Steuerung, impliziert eine Restrukturierung nicht nur der Bildungsverwaltung, sondern auch der Einzelschule. Dies ist ein mikropolitischer Prozeß (vgl. Altrichter/Salzgeber 1995), der in seinen Anforderungen an alle Beteiligten, insbesondere an die Schulleitung weit über das hinausgeht, was mit der instructional leadership role eher naiv gedacht worden war und noch immer gedacht wird - sei es als Restrukturierung auf der Interaktionsebene der Organisation Schule, die sich auf das Rollenverständnis der Schulleitung, auf die inner-schulische Entscheidungsfindung, auf die Beziehung zu den Lehrern sowie auf das Selbstmanagement der SchulleiterInnen (Wissen und Zeit) bezieht (vgl. Rosenblum u.a. 1994), sei es in der Ratgeberliteratur reduziert auf einen Führungsstil, der als Transformational Leadership kommuniziert wird. Denn im Prozeß der Restrukturierung der Organisation Schule geht es um nichts geringeres als um die innere Neugliederung der Schule, um die Veränderung der Aufbau- und Ablauforganisation im Rahmen einer historisch gewachsenen Organisationskultur.

Die transformational leadership role, der Komplementärbegriff $\mathrm{zu}$ transformational change - hier fällt die Sicherung von Bildung und die Verbesserung der Schülerleistungen mit der Implementation bildungspolitischer Reformen sowie der Reform der inner-schulischen Selbstorganisation zusammen - ist das Konzept für eine Schlüsselrolle, deren Zentralität im Prozeß der Reform wie in der Frage von Erfolg und Mißerfolg einer Schule in der Vermittlungsaufgabe zwischen Anforderungen der außerschulischen und der innen-schulischen Umwelt begründet liegt. Die Transformational Leadership Role ist durch Komplexität, Unsicherheit und Risiko gekennzeichnet; sie stellt höchste Anforderungen an Motivation und Engagement sowie an Lern- und Leistungsfähigkeit von Schulleiterinnen und Schulleitern; sie kann zu einer psychischen Belastung werden (Murphy 1994: 22f. u. 25).

Um es zusammenzufassen: Die Verkoppelung von Schul- und Verwaltungsreform drängt Schulleiterinnen bzw. Schulleiter im Prozeß der Restrukturierung in eine Schlüsselfunktion, die theoretisch der der Schule übergeordneten Verwaltungs- und Entscheidungsebene zufiele und in der undankbaren Rolle des Schulrats eine Vorläufer-Rolle hat. In der Kultur der Semi-Professionals, die keine Managementstruktur kennt, sind Schul- 
leiterinnen bzw. Schulleiter allein auf Methoden indirekter, das soziale Klima und die individuelle Befindlichkeit stimulierender Führung angewiesen, um Lehrerinnen und Lehrer eines Kollegiums gegen die Erfahrung und Mechanismen einer in Denken und Handeln egozentrisch und individualisiert strukturierten Organisations- und Arbeitskultur eine Einsicht in die unmittelbare Verantwortung für Qualitätsentwicklung und -sicherung zu vermitteln. Die Forschung wird erst noch zeigen müssen, ob und in welchen Hinsichten School Based Management die Erwartungen zu erfüllen vermag (vgl. Leithwood/Menzies 1998).

Bei kritischer Sicht auf die Möglichkeiten der Schulleitung, in dieser Hinsicht zu wirken, bleiben für die Untersuchung der Frage, welche Rolle und welche Aufgaben SchulleiterInnen bei der Qualitätssicherung und entwicklung der Einzelschule haben, vor allem zwei Zugänge - die Schulklima- und Schulkulturforschung (vgl. z.B. Hoy 1990; Hargreaves/Hopkins 1991; Heck/Markoulides 1996). Während mit dem ersten Konzept die subjektiven Strukturbedingungen in der Beziehung zwischen Schulleitung, Lehrer-, Schüler- und Elternschaft zugänglich werden, erlaubt das zweite Konzept die Beschreibung und Analyse sozialer Strukturen und deren Veränderung in der Schule.

Die methodologische Umorientierung hin zu einer prozeßorientierten Forschung, die mit dem Übergang von der Schulwirkungs- zur Schulentwicklungsforschung einhergeht, beinhaltet in der Analyse wie in Konzepten zur Entwicklung des Leistungspotentials und der Wirksamkeit einer Schule die Abkehr von konkreten Einzelpersonen oder Gruppen als Grundeinheit des Denkens hin zum System, so daß sich die ursprüngliche, traditionelle, die Einzelperson betonende Vorstellung hinsichtlich der Rolle von Schulleiterinnen und Schulleitern relativiert. Schulen und deren Qualität werden vielmehr unter dem Gesichtspunkt betrachtet, in welcher Weise als relevant erkannte Dimensionen miteinander interagieren. Neben der Dimension der Führung werden sechs weitere Dimensionen als relevant erachtet, und es wird davon ausgegangen, daß sie sich alle wechselseitig beeinflussen. Es handelt sich um die Dimensionen ${ }^{13}$ Führung, Entscheidungsfindung, Einbeziehung der professionellen Mitglieder der Organisation Schule, Ressourcenverteilung, Ausführung des Lehrplans, Schulumgebung, -klima, -kultur sowie Kommunikation (Townsend 1993: 25ff.). Veränderungen in der einen Dimension einer Schule ziehen Veränderungen in den anderen Dimensionen nach sich. Schulqualität wird als eine Kombination aus Prozessen, Ressourcen und Zielen in Abhängigkeit vom Kontext gesehen, d.h. von den objektiven Bedingungen wie von den subjektiv wahrgenommenen Möglichkeiten, auf die Schulleitungen allerdings nur bedingt Einfluß haben.

$$
\text { [...] }
$$

13 Übersetzung - J. W. 


\section{Literatur}

Ahrens, J.-R.: Schulautonomie. Zwischenbilanz und Ausblick. In: Die Deutsche Schule 88 (1996), S. 10-21

Altrichter, H.: Autonomie der Schule als Chance zukunftsorientierter Schulentwicklung. In: Erziehung und Unterricht 142 (1992), S. 558-568.

Altrichter, H./Salzgeber, St: Mikropolitik der Schule. In: H.-G. Rolff (Hg.): Zukunftsfelder von Schulforschung. Weinheim 1995, S. 9-40.

ASD (Arbeitsgemeinschaft der Schulleiterverbände Deutschlands): Schulleitung in Deutschland. Ein Berufsbild in Entwicklung. Stuttgart 1999.

Aurin, K. (Hg.): Gute Schulen - worauf beruht ihre Wirksamkeit? 2. Auflage. Bad Heilbrunn/Obb. 1991.

Avenarius, H./Baumert, J./Döbert, H./Füssel, H.-P. (Hg.): Schule in erweiterter Verantwortung. Positionsbestimmungen aus erziehungswissenschaftlicher, bildungspolitischer und verfassungsrechtlicher Sicht. Neuwied 1998.

Bacharach, S. B. (Hg.): Education reform: Making sense of it all. Boston 1990.

Baumert, J.: Schulleitung in empirischer Forschung. In: H.S. Rosenbusch/J. Wissinger (Hg.): Schulleiter zwischen Administration und Innovation. Schulleiter-Handbuch Band 50. Braunschweig 1989, S. 52-63.

Baumert, J./Leschinsky, A.: Zur Rolle des Schulleiters. In: schulmanagement 17 (1986) 6, S. 18-24

Bossert, S.T./Dwyer, D.C./Rowan, B./Lee, G.V.: The Instructional Management Role of the Principal. In: Educational Administration Quarterly 18 (1982), S. 34-64.

Brockmeyer, R.: Länderbericht Deutschland. In: Schulleitung und Schulaufsicht. Neue Rollen und Aufgaben im Schulwesen einer dynamischen und offenen Gesellschaft. Herausgegeben vom Bundesministerium für Unterricht und kulturelle Angelegenheiten, Innsbruck 1998, S. 119-161.

Brookover, W. B./Lezotte, L. W.: Changes In School Characteristics Coincident With Changes In Student Achievement. ERIC Document Reproduction Service No. ED 181005, East Lansing: Institute for Research on Teaching, Michigan University 1979.

Creemers, B. P. M.: The History, Value and Purpose of School Effectiveness Studies. In: D. Reynolds/B.P.M. Creemers/P. Nesselrodt/E.C. Schaffer/S. Stringfield/C. Teddlie (Eds): Advances in School Effectiveness Research and Practice. Oxford 1994, S. 9-23.

Daschner, P./Rolff, H.-G./Stryck, T. (Hg.): Schulautonomie - Chancen und Grenzen. Impulse für die Schulentwicklung. Weinheim 1995.

De Lorent, H.-P./Zimdahl, G. (Hg.): Autonomie der Schule. Hamburg 1993.

Ditton, H./Krecker, L.: Qualität von Schule und Unterricht. Empirische Befunde zu Fragestellungen und Aufgaben der Forschung. In: Zeitschrift für Pädagogik 41 (1995), S. 507-529.

Döbert, H./Geißler, G. (Hg.): Schulautonomie in Europa. Baden-Baden 1997.

Edmonds, R.: Effective schools for the urban poor. In: Educational Leadership 37 (1979), S. 15-24.

Edmonds, R.: Programs of school improvement: An overview. In:. Educational Leadership 40 (1982), S. 4-11.

Fend, H.: Qualität im Bildungswesen. Schulforschung zu Systembedingungen, Schulprofilen und Lehrerleistung. Weinheim 1998

Glasman, N. S./Heck, R.H.: The Changing Leadership Role of the Principal: Implications for Principal Assessment. In: Peabody Journal of Education 68 (1992), S. 5-24.

Greenfield, W. (Hg.): Instructional Leadership: Concepts, Issues, and Controversies. Boston 1987. 
Hallinger, Ph./Murphy, J.: Assessing the instructional leadership behavior of principals. In: Elementary School Journal 86 (1985), S. 217-248.

Hallinger, Ph./Murphy, J.: Assessing and developing principal instructional leadership. In: Educational Leadership Journal 45 (1987), S. 54-61.

Hallinger, Ph./Taraseina, P./Miller, J.: Assessing the Instructional Leadership of Secondary School Principals in Thailand. In: School Effectiveness and School Improvement 5 (1994), S. 321-348.

Hargreaves, D.H./Hopkins, D.: The Empowered School: The Management and Practice of Development Planning. London 1991.

Heck, R.H./Markoulides, G.A./Lang, P.: Principal Instructional Leadership and School Achievement: The Application of Discriminant Techniques. In: School Effectiveness and School Improvement 2 (1991), S. 115-135.

Heck, R.H./Markoulides, G.A.: School Culture and Performance: Testing the Invariance of an Organizational Model. In: School Effectiveness and School Improvement 7 (1996), S. 76-95.

Holtappels, H.-J.: Der Schulleiter - zwischen Anspruch und Wirklichkeit. Essen 1989.

Hoy, W. K.: Organizational Climate and Culture: A Conceptual Analysis of the School Workplace. In: Journal Of Educational And Psychological Consultation 1 (1990), S. 149-168.

Hultman, G.: The State of the Art of School Administration: A review of facts and theory. In: Scandinavian Journal of Educational Research 33 (1989), S. 123-162.

Hutmacher, W.: Strategien der Systemsteuerung. Von der Systemexpansion zum Systemumbau. In: Schulleitung und Schulaufsicht. Neue Rollen und Aufgaben im Schulwesen einer dynamischen und offenen Gesellschaft. Herausgegeben vom Bundesministerium für Unterricht und kulturelle Angelegenheiten. Innsbruck 1998, S. 49-92.

Krüger, R.: Was tut der Rektor? Zum Berufsbild und Selbstverständnis des Schulleiters. In: Schulmanagement 14 (1983) 4, S. 32-36.

Leithwood, K./Chapman, J./Corson, D./Hallinger, Ph./Hart, A. (Hg.): International Handbook of Educational Leadership and Administration. Dordrecht 1996.

Leithwood, K./Montgomery, D.: The role of the elementary principal in program improvement. In: Review of Educational Research 52 (1982), S. 309-339.

Leithwood, K./Menzies, T.: A Review of Research Concerning the Implementation of Site-Based Management. In: School Effectiveness and School Improvement 9 (1998), S. 233-285.

Lenz, J.: Die Effective School Forschung der USA - ihre Bedeutung für die Führung und Lenkung von Schulen. Frankfurt am Main 1991.

Morris, V. C./Crowson, R. L./Porter-Gehrie, C./Hurwitz Jr., E.: Principals in Action. The Reality of Managing Schools. Columbus/Ohio 1984.

Mortimore, P.: School Effectiveness and the Management of Effective Learning and Teaching. In: School Effectiveness and School Improvement 4 (1993), S. 290-310.

Murphy, J.: Transformational Change and the Evolving Role of Principal: Early Empirical Evidence. In: J. Murphy/K. S. Louis (Hg.): Reshaping the Principalship. Insights from Transformational Reform Efforts. Thousand Oaks, California 1994, S. $20-53$

Murphy, J./Beck, L. G.: Reconstructing the Principalship: Challenges and Possibilities. In: J. Murphy/K. S. Louis (Hg.): Reshaping the Principalship. Insights from Transformational Reform Efforts. Thousand Oaks, California 1994, S. 3-19.

Ogawa, R. T. (Hg.): Advances in Research and Theories of School Management and Educational Policy. Vol. 3. Greenwich/Connecticut 1995. 
Reynolds, D./Sammons, P./Stoll, L./Barber, M./Hillman, J.: School Effectiveness and School Improvement in the United Kingdom. In: School Effectiveness and School Improvement 7 (1996), S. 133-158.

Robertson, P.J./Briggs, K.L.: Improving Schools Through School-Based Management: An Examination of the Process of Change. In: School Effectiveness and School Improvement 9 (1998), S. 28-57.

Rolff, H.-G.: Steuerung, Entwicklung und Qualitätssicherung von Schulen durch Evaluation. In: H.-G. Rolff (Hg.): Zukunftsfelder von Schulforschung. Weinheim 1995, S. 375-392.

Rosenblum, S./Louis, K.S./Rossmiller, R.A.: School Leadership and Teacher Quality of Work Life in Restructuring Schools. In: J. Murphy/K. S. Louis (Hg.): Reshaping the Principalship. Insights from Transformational Reform Efforts. Thousand Oaks, California 1994, S. 99-122.

Rutter, M./Maughan, B./Mortimore, P./Ouston, J.: Fifteen Thousand Hours. Secondary Schools and their Effects on Children. London 1979.

Scheerens, J./Creemers, B. P. M.: School Effectiveness in the Netherlands: The Modest Influence of a Research Programme. In: School Effectiveness and School Improvement 7 (1996), S. 181-195.

Steffens, U.: Empirische Erkundungen zur Effektivität und Qualität von Schule. In: Ch. Berg/U. Steffens (Hg.): Schulqualität und Schulvielfalt. Das Saarbrücker Schulgütesymposion '88. Wiesbaden/ Konstanz 1991, S. 51-71.

Steffens, U./Bargel, T.: Erkundungen zur Qualität von Schule. Neuwied 1993.

Stoll, L./Fink, D.: Effecting School Change: The Halton Approach. In: School Effectiveness and School Improvement 3 (1992), S. 19-41.

Stringfield, S./Herman, R.: Assessment of the State of School Effectiveness Research in the United States of America. In: School Effectiveness and School Improvement 7 (1996), S. 159-180.

Tillmann, K.-J. (Hg.): Was ist eine gute Schule? 2. Auflage, Hamburg 1994.

Townsend, T.: School Effectiveness: Identifying the Complexities. Paper presented at the International Congress for School Effectiveness and Improvement 1993, Norköping/ Sweden, January 3-6.

Townsend, T.: School Effectiveness and Improvement Initiatives and the Restructuring of Education in Australia. In: School Effectiveness and School Improvement 7 (1996), S. 114-132.

Van De Grift, W.: Educational Leadership and Academic Achievement in Elementary Education. In: School Effectiveness and School Improvement 1 (1990), S. 26-40.

Winterhager-Schmid, L.: Berufsziel Schulleiterin. Professionalität und weibliche Ambition. Weinheim 1997.

Wissinger, J.: Schulleiter-Beruf und Lehreridentität - zum Rollenkonflikt von Schulleiterinnen und Schulleitern. Ein Beitrag zur Schulentwicklungsforschung. In: Zeitschrift für Sozialisationsforschung und Erziehungssoziologie 14 (1994), S. 38-57.

Wissinger, J.: Perspektiven schulischen Führungshandelns. Eine Untersuchung über das Selbstverständnis von SchulleiterInnen. Weinheim 1996.

Wissinger, J.: Führung - eine pädagogische Funktion? In: J. Wissinger (Hg.): Schulleitung als pädagogisches Handeln. Schulleiter-Handbuch, Band 83. Braunschweig 1997, S. 21-33.

Wissinger, J./Huber, S.G. (Hrsg.): Schulleitung - Forschung und Qualifizierung. Opladen 2002. 


\section{Lehrkräfte}

\section{Kommentar (Brüsemeister/Eubel)}

Neben Schulleiterinnen und Schulleitern sind in den Diskussionen um eine Schulmodernisierung vor allem die Lehrkräfte angesprochen. Sie sollen an ihrer Schule eine Modernisierung in Unterrichtsform sowie generell für die Organisation Schule realisieren. Dies wird in Konzepten der pädagogischen Qualitätsentwicklung formuliert (siehe Textblock II). Zur Position der Lehrkräfte in Schulentwicklungsprozessen liegt mittlerweile eine Vielzahl von Fallstudien vor, ${ }^{14}$ die sich jedoch als schwer generalisierbar erweisen. Mit anderen Worten: es gibt derzeit keine Literatur, die das Umgehen von Lehrkräften mit Schulmodernisierungen in den einzelnen Bundesländern überblickt und vergleichend vorstellt, und es gibt gegenwärtig keine Theorie, die in der Lage wäre, auf einem allgemeineren Niveau die Reaktionen von Lehrkräften im Kontext der schulischen Modernisierung zu erörtern oder gar zu prognostizieren. Angesichts dessen konzentrieren wir uns zunächst auf zwei kontrastive Grundlagentexte. Mit Gudrun Schönknecht (Universität Eichstätt) lässt sich die Innovationsfähigkeit von Lehrkräften betonen, mit Fritz Bohnsack (Emeritus, Universität Essen) das Gegenteil nämlich Widerstand gegen Innovationen. Beides gehört offensichtlich im Hinblick auf Lehrkräfte zur Realität der Schulmodernisierung. In einem weiteren Beitrag (von Thomas Brüsemeister) wird die Kopplung von Lehrkräften und Schulorganisation problematisiert.

In dem unseren Textauszügen zu Grunde liegenden Buch „Innovative Lehrerinnen und Lehrer" (1997) stellt Gudrun Schönknecht dar, dass Konzepte, die den Lehrberuf klassischerweise als eine Semi-Profession kennzeichnen - mit Kriterien wie z.B. einem spezifischen Berufsethos und einem kodifizierten Wissen - zu kurz greifen. Professionalität gibt es im Berufsfeld der Lehrer, aber sie verdankt sich nach Schönknecht ,nicht in erster Linie der institutionalisierten Aus- und Fortbildung“, sondern individuellen beruflichen und biographischen Entwicklungen der einzelnen Lehrkraft. Nach Ansicht der Autorin lassen sich Generationen von Lehrkräften ausmachen, die sich „inneren Reformen“ zuwenden, z.B. nachdem in den 1970er Jahren ,äußere Bildungsreformen“ scheiterten. Diese Lehrkräfte setzten nicht am System Schule an, sondern am eigenen „Selbst“. Vor allem Grundschullehrerinnen und -lehrer hätten sich aus eigenem Antrieb mit neuen Unterrichtsmethoden beschäftigt.

14 Vgl. exemplarisch Arnold u.a. (1999); zu biographischen Fallstudien vgl. den Überblick mit weiterer Literatur bei Reh/Schelle (1999); vgl. generell den von Combe u.a. (1999) herausgegebenen Sammelband zur Schulmodernisierung, unter anderem mit Fallstudien zu Ostdeutschland. 
Die Autorin will also die Entstehung von Innovationen auf die Lehrkräfte zurückführen. Wenn auch die Innovationsfähigkeit der einzelnen Lehrkraft nicht unabhängig von der Gesellschaft gesehen wird, so erschreckt doch der Befund, Innovation und Modernisierung würden von Lehrkräften gerade durch eine Selbstqualifizierung neben dem Beruf - also informell - erreicht. Denn dies bedeutet, dass die Betreffenden zum Teil indifferent gegenüber institutionalisierten Berufsaufgaben sind. Es ist die grundsätzliche Frage aufgeworfen, inwieweit individuelle biographische Perspektiven in einem Beruf aufgehen sollen oder können. Und dies hängt wiederum mit der Frage zusammen, welchen Typus der Organisation Schule und welchen Typ von Beruflichkeit man Lehrkräften zuschreibt. Geht man von einer bürokratischen Arbeitsorganisation aus, ist die Lehrkraft relativ indifferent gegenüber der Organisation Schule, da sie (Arbeits-) Leistungen gegen Geld tauscht. Man ist nur über die ,schmale Brücke‘ eines Tauschgeschäfts mit der Schule verbunden, was aber gerade viele Freiheiten lässt, außerhalb der Schule informelle Kompetenzen zu erwerben und in das Berufsfeld einfließen zu lassen. Indem Lehrkräfte beständig gleichsam ,über ihren Tellerrand' schauen, nichtberufliche Sinnfelder in die Schule hineinholen, werden sie zu ,Motoren' der Modernisierung. In dieser Lesart wird die relative Indifferenz zwischen der Arbeitsorganisation Schule und der Berufsbiographie zum zentralen Faktor schulischer Veränderungen. Oder noch einfacher: Nur der (einzelnen) Lehrkraft, nicht der Organisation Schule wird noch Veränderungskraft zugetraut. ${ }^{15}$

Umgekehrt wird von Fritz Bohnsack betont, dass von Lehrkräften Widerstände gegen Innovationen ausgehen können. Die Gegensätzlichkeit dieser beiden Positionen zeigt, dass das bestehende Arrangement der beruflichen Arbeitsorganisation offensichtlich zweischneidig ist, in dem Sinne, dass auf der lokalen Ebene der Einzelschule Innovationen sehr wohl vorkommen - nach Schönknecht vor allem in Grundschulen und bei Lehrerinnen -, dass sie aber an anderen Einzelschulen wiederum kaum denkbar sind.

In seinem Beitrag listet Bohnsack, gute Gründe' von Lehrkräften auf, gegen Innovation zu sein. Er führt Untersuchungen an, die zeigen, dass Lehrkräfte Bedenken gegen Neuerungen - wie z.B. Gruppenarbeit - haben. Einen wesentlichen Grund dafür sieht der Autor darin, dass Lehrkräfte auf einem ,schmalen Grat zwischen Überlastung und Unzufriedenheit mit

15 Man kann hierbei fragen, ob nicht Schönknecht eine besondere historische Situation, nämlich die Frustration von Lehrkräften der 1980er Jahre über ausgebliebene institutionelle Schulreformen der 1970er Jahre, zu stark verallgemeinert und das Innovationspotential nur noch individuellen Lehrkräften und nicht mehr schulischen Organisationen zuschreibt. Erinnert man sich dagegen an die in Textblock II vorgestellten Qualitätsmanagements, haben wir heute offensichtlich eine genau umgekehrte Situation. Die Organisation Schule steht im Zentrum der Innovation und nicht mehr die Person des Lehrers. Offensichtlich hat sich in der Zwischenzeit eine gravierende Änderung der Verhältnisse ergeben. 
ihren Unterrichtsergebnissen“"balancieren. ${ }^{16}$ Diese Belastungen lassen sich damit in Zusammenhang bringen, dass der Lehrberuf historisch gesehen auf Profession und weniger auf Organisation festgelegt ist. ${ }^{17}$

\section{Folgerungen}

Die Perspektive der einzelnen Lehrkraft ist relevant, wenn es um die Frage geht, unter welchen Umständen Neuerungen wie ein Qualitätsmanagement aufgegriffen werden. Wenn die neue Schule im Wesentlichen auf kollektiver Teamarbeit basieren soll, stößt dies zunächst einmal gegen die bisherige individualistische Berufskultur von Lehrkräften, innerhalb derer es die Betreffenden nicht gewohnt sind, Rückmeldungen zu erhalten (Terhart 2002: 83) - genau darauf soll aber die neue, an einem Qualitätsmanagement ausgerichtete Schule basieren. Terhart (ebd.) verweist darauf, dass sich die Zusammenarbeit zwischen Lehrkräften nicht verordnen lässt. Ansetzen lässt sich nach seiner Meinung am ehesten,

„wenn fachunterrichtsbezogene Kooperationen in Fachgruppen von Lehrern jedem Beteiligten erfahrbar machen, dass Zusammenarbeit sich lohnt, weil sie mittelfristig Arbeitserleichterungen bringt; wenn starke Konkurrenz/Ängste gerade in einer Fachgruppe auftreten: stattdessen versuchen, fächerübergreifende Kooperationsgruppen zu bilden; wenn zunächst Lehrer-Tandems gebildet werden, bei denen bereits persönliches Vertrauen vorhanden ist; wenn neu hinzukommende Kollegen unmittelbar in fach-oder aufgabenbezogene Kooperationen eingebunden werden; und wenn es gelingt, die Rückmeldungen über die Lernleistungen/Lernfortschritte verschiedener Klassen an einer Schule nicht als Instrumente der Diskriminierung, sondern als Anlässe für Ursachenanalyse und Weiterentwicklung zu nehmen.“

In all diesen Punkten wären überschaubare Erfahrungen möglich, die es der einzelnen Lehrkraft erlauben, individuelle Vorteile in der neuen Zusammenarbeit zu sehen, die weg von der individualistischen Berufskultur, hin zu einer Zusammenarbeit im Kollegium führen. Dabei müssen vor allem individuelle Empfindlichkeiten, oder neutraler gesagt: die Selbstzuschrei-

16 Hier ließen sich weitere Befunde aus der Lehrerforschung anführen, die von einem belastenden Lehrerindividualismus sprechen. Vgl. Terhart 2001b: 50. Zur Erforschung beruflicher und berufsbiographischer Verläufe von LehrerInnen vgl. zur Übersicht: ebd., 13-114.

17 Ausbildung und Berufspraxis des Lehrers sind darauf gerichtet, dass die einzelne Lehrkraft Lernsituationen mit einem einzelnen Schüler bewältigt. Demgegenüber zielen die neuen Qualitätsmanagements darauf, dass jeweils Teams von Organisationsmitgliedern, die intern sowie über die Organisationsabteilung hinweg kommunizieren, Probleme des Berufsfeldes gemeinsam angehen. Im Kontext der (in Textblock II vorgestellten) Qualitätsmanagements wird die organisationale Seite des Lehrerhandelns aufgewertet. Und durch die (dem Modell nach) einsetzende horizontale Kommunikation zwischen den Lehrkräften könnte sich der einzelne Lehrer entlastet sehen. Es würde dann nicht mehr, wie von Schönknecht explizit formuliert sowie von Bohnsack streckenweise unterstellt (Bohnsack geht freilich auch auf das Kollegium ein), das einzelne Selbst Ausgangspunkt für die Innovation sein. 
bung und Zurechnung von Fehlern auf die eigene Person umgestellt werden auf eine langfristige Entwicklungsperspektive des Kollegiums oder des Teams. Fehler sind in dieser Perspektive eine Chance, die vom Team aufgegriffen werden können, um es im nächsten Schritt besser zu machen. Diesbezüglich wird die neue Schulorganisation nicht nur fehlertolerant, sondern sieht gerade in "Fehlern“ Ansätze zum Organisationslernen. ${ }^{18}$ Gleichzeitig muss dem Umstand Rechnung getragen werden, dass sich die qualitätsbasierte Schulorganisation nur schrittweise etabliert, dass sich bestimmte Lehrkräfte von der Teamarbeit weniger schnell überzeugen lassen. Es sind Implementationsprobleme aufgeworfen, die - akteurtheoretisch gesehen - darauf basieren, dass unterschiedliche Aufnahmebereitschaften bei Vorreitern, Nachzüglern und ,konservativen' Lehrkräften entstehen, die am scheinbar Bewährten zunächst festhalten.

Hinsichtlich solcher Akteurkonstellationen wäre über die Perspektive des individuellen Wollens der einzelnen Lehrkraft, wie sie Schönknecht und Bohnsack einnehmen, hinauszugehen: die Akteurkonstellation selbst kommt hinsichtlich der Akzeptanz einer Modernisierung ins Spiel. Wie bereits einleitend zu diesem Buchabschnitt angedeutet, hängt die Modernisierung nicht nur vom Wollen der Einzelnen und dem institutionellen Sollen (informellen Erwartungen und rechtlichen Normen), sondern auch vom Können, d.h. dem Zusammenwirken aller Akteure an der Schule ab. ${ }^{19}$ Eine Konstellation lässt sich weder durch den „besten Willen“ einzelner Lehrer, noch durch ein „Sollen“ (man habe nun ein bestimmtes Modernisierungsprogramm durchzuführen) einfach verändern. Die für die Übernahme einer Modernisierung aufnahmebereite Akteurkonstellation - bzw. das „Können“ - entwickelt sich zum Teil erst im Prozessgeschehen der Modernisierung.

In der Perspektive von Schönknecht agieren Lehrkräfte gleichsam an der Organisation Schule vorbei. Innovationen sind durch die Person der Lehrkraft von Lebenswelten motiviert, die es außerhalb der Schule gibt. Eine Organisation Schule spielt in dieser Perspektive kaum eine Rolle. Diese Perspektive wird von Bohnsack fortgesetzt; hier erzeugt die Organisation allenfalls Widerstand bei Lehrkräften. Mit einem weiteren Text (von Thomas Brüsemeister) wird das Verhalten von Lehrkräften innerhalb der schulischen Organisation angesprochen. Es geht um mögliche Verzahnungen zwischen der Perspektive von Lehrkräften und der Perspektive der Organisation. Solche Verzahnungen werden vom neuen Governance-Modell auf der Makroebene sowie von Qualitätsmanagements auf der Mesoebene des Schulsystems propagiert. Eine Annäherung der Perspektiven von Orga-

18 In einer Zwischenphase der Modernisierung, in der die alte ,Welt ${ }^{\star}$ auf der Ebene des ,talk“ delegitimiert wurde, aber auch die neue qualitätsbasierte ,Welt' auf der Ebene der ,action“ noch nicht durchgehend verankert ist, können sich die Lehrkräfte wahrscheinlich Fehler innerhalb der bisherigen individualistischen Berufskultur selbst zuschreiben.

19 Vgl. zur Unterscheidung von Wollens-, Sollens- und Könnens-Orientierungen erneut Schimank (1996: 243-246). 
nisation und Lehrerperson ist in solchen Standorten erkennbar, in denen sich eine qualitätsbasierte Schulorganisation zu entwickeln beginnt. ${ }^{20}$ In der neuen schulischen Organisation werden die operativen Fähigkeiten von Lehrkräften, wie sie jetzt schon in der Berufspraxis vorkommen, aber bislang wenig systematisch beobachtet sind, aufgegriffen. Dies nimmt Brüsemeister zum Anlass, ein grundsätzliches Umschwenken von der bisherigen Orientierung der Lehrkraft an einer individualistischen Berufskultur der Profession hin zu einer Orientierung an Organisation zu diskutieren. AuBerdem verknüpft er seine Sicht der ,organisationsbasierten Schule " mit dem Konzept des „Wissensmanagements“. Auch daraus ergeben sich neue Orientierungen für das Praxisfeld des Lehrberufs - und auch für eine reformierte Lehrerbildung.

\section{GUDRUN SCHÖNKNECHT Lehrkräfte und Innovation}

\section{Ein neues Verständnis von Professionalisierung}

Professionalisierung bezeichnet einen historischen Prozeß der Entwicklung von Berufsständen zu sog. Professionen. Damit ein Beruf professionellen Status erreicht, müssen bestimmte Merkmale vorhanden sein wie Autonomie, ein spezifisches Berufsethos, systematisches und kodifiziertes Wissen, eine wissenschaftliche Ausbildung sowie eine gesellschaftIich zentrale Dienstleistung (Schwänke 1988: 31). Als klassische Professionen gelten z.B. Medizin und Jura. Mit dem Begriff Professionalisierung wird aber auch der Prozeß bezeichnet, den die Individuen eines Berufs(standes) durchlaufen müssen, um berufsspezifische Fähigkeiten und Fertigkeiten sowie die Berufsethik zu erwerben. [...]

Wird der Lehrerberuf innerhalb dieses Ansatzes von Professionalisierung [...] betrachtet, können LehrerInnen nur den Status von SemiProfessionellen erreichen. Allerdings hat die Diskussion der Professionalisierung des Lehrerberufs, die schon seit über 20 Jahren geführt wird, gezeigt, dass die professionelle Entwicklung von LehrerInnen nicht diesen Professionalisierungsmodellen entspricht [...] und deshalb das klassische Professionalisierungskonzept für den Lehrerberuf ergänzt und modifiziert werden muß.

[...]

Als Dimensionen pädagogischer Professionalität und Kriterien der Professionalität, die für den Lehrerberuf geeignet sind, führen Bauer/Burkhard (1992) Autonomie und Berufsethos, Reflexivität und Supervision sowie

20 Vgl. dazu Brüsemeister (in einem weiteren Beitrag in Textblock IV). 
Kollegialität (unter dem Gesichtspunkt LehrerInnen lernen von KollegInnen) an. [...]

Diese [...] Bestimmung des Begriffs ,pädagogische Professionalität“ ist auch für die vorliegende Untersuchung zentral. In dem Begriff, ,innovative LehrerInnen", der häufig für die Befragten verwendet wird, sind mit die o.g. Kennzeichen pädagogischer Professionalität eingeschlossen. „Professionell“ und „innovativ“" werden als normative, wertende Begriffe verwendet, sie deuten an, daß die LehrerInnen als qualifizierte ExpertInnen in ihrem beruflichen Handeln gesehen werden.

Aus dem bisherigen Stand der Untersuchung [...] zieht Bauer die Schlußfolgerung, daß es zwar pädagogische Professionelle im Lehrerberuf gibt, die allerdings nur Einzelfälle und zudem meist Autodidakten sind, d.h. daß sie ihr erweitertes pädagogisch-professionelles Handlungsrepertoire und ihre berufsbiographische Entwicklung nicht in erster Linie der institutionalisierten Aus- oder Fortbildung verdanken. Ihre Entwicklung zum pädagogischen Profi hat sich nach seinen Ergebnissen teilweise außerhalb des Lehrerberufs vollzogen.

[...] [Die] ,pädagogischen Profis“, auf die Bauer u.a. in ihrer Untersuchung immer wieder gestoßen sind, bezeichnen sie in einer jüngeren Darstellung als „Pioniertypen“ (Bauer/Kopka 1994: 287, 305). Sie zeichnen sich auch dadurch aus, daß sie nicht dem üblichen Denkmuster folgen, das vielen LehrerInnen und ErziehungswissenschaftlerInnen eigen ist und beinhaltet, daß Theorie und Praxis in den seltensten Fällen aufeinander bezogen werden können. Diese Pioniertypen verwenden in ihrem Denken und Handeln Kategorien, die ,aus einer praxisnahen pädagogischen, psychologischen und sozialpsychologischen Forschung und Theoriebildung stammen" (ebd., 287f.). Sie setzen sich intensiv mit erziehungswissenschaftlichen Theorien auseinander. Bauer/Kupka sehen in ihnen ,einen Prototyp des professionellen Lehrers", der auch dem in der Forschungsliteratur zur Schulentwicklung skizzierten Wunschbild entspricht durch seine Schlüsselqualifikation, Theorie und Praxis im Unterrichtsalltag aufeinander zu beziehen und verbinden zu können. [...]

\section{Innovation}

Innovieren ist ein Bestandteil des Aufgabenfeldes von LehrerInnen und wurde schon vom Deutschen Bildungsrat als eine der Grundqualifikationen von LehrerInnen neben Lehren, Erziehen, Beurteilen und Beraten beschrieben:

„Innovationen sind zu einem besonderen Aspekt seines Berufs geworden. ... Mit dieser Aufgabenstellung wird er zum ersten und wichtigsten Träger fortschreitender Schulund Bildungsreform." (Deutscher Bildungsrat 1972: 220)

Die den LehrerInnen damals schon zugesprochene zentrale Rolle in Innovationsprozessen wird heute angesichts der veränderten und neuen Aufga- 
ben der Schule, $[\ldots]$ insbesondere der Grundschule, immer wichtiger und bestätigt sich heute, 20 Jahre später, in neueren empirischen Untersuchungen. [...]

Nach dem Modell von Edelfelt (1983) müssen vier Bereiche für Innovationen beachtet werden: Die professionelle Entwicklung der LehrerInnen selbst, Entwicklungen im Kollegium, Verbesserungen an der Schule und Verbesserungen im Bereich des Erziehungswesens. Der zentrale Faktor für die Innovation an Schulen bleibt die professionelle Entwicklung der LehrerInnen selbst, auf die sich auch das Interesse der vorliegenden Arbeit konzentriert.

\section{Innovation und innere Schulreform}

Nach der Ernüchterung über die geringe Wirksamkeit der großen Schulund Bildungsreform der 70er Jahre in einigen Bereichen wurde in den 80er Jahren die innere Schulreform immer wichtiger. Damit wurden die Lehrerpersönlichkeit und eine ganzheitliche Lehrerbildung ins Zentrum gerückt. Die innere Schulreform kann auch als Reaktion der LehrerInnen selbst auf das Scheitern vor allem äußerer Reformen der 70er Jahre gesehen werden.

$[\ldots]$

Als sog. ,innere Schulreform“ wird eine Weiterentwicklung des pädagogischen Konzepts der Schule bezeichnet, die nicht strukturell in das Bildungssystem eingreift, sondern sich im Rahmen gültiger Richtlinien, Verordnungen und Gesetze abspielt und von einzelnen oder Gruppen von LehrerInnen als logische Konsequenz aus sich verändernden Lebensbedingungen gestaltet wird (Krichbaum 1991: 32). Mit einem Verständnis von Innovation und Schulreform als innere Reform stehen die LehrerInnen als Agierende im Zentrum, wie schon bei der Professionalisierungsdiskussion deutlich wurde. Dieser „Aufbruch der Grundschule“ [...] wird auch als „Reform von unten" bezeichnet, was eine zweifache Bedeutung beinhaltet: eine „von unten“ gewachsene im Gegensatz zur „,von oben“ verordneten Reform sowie „von unten“ ausgehend im Sinne einer Basis des Schulsystems, als Grundschule, die Grundlage des gesamten Schulwesens ist. [...] Die innere Reform der Schule findet vor allem an Grundschulen statt: Ein Teil der GrundschullehrerInnen hat erkannt, da $\beta$ sie den neuen Anforderungen an die Schule mit herkömmlichen Unterrichtsmethoden nicht gewachsen sind, daß Qualifikationen wie Kreativität, Offenheit, Kooperationsfähigkeit und Selbständigkeit nicht hinreichend ausgebildet werden können, daß die Schule von einer Belehrungsschule zu einer offenen Schule werden muß.

$[\ldots]$

Für Innovationsprozesse in der Grundschule sind zwei Bereiche zentral: das System „Schule“ und das System „Selbst" (Schley/Wallrabenstein 1994: 11). Auch Krichbaum (1991: 32) nennt als Bedingung für innere Schulreform den Bereich des Kollegiums und der ganzen Schule, das Selbstverständnis der Schulaufsicht sowie die LehrerInnen selbst. 
Für Entwicklungen im System Schule wird als zentrale Strategie die Autonomie der Einzelschule gefordert [...], Autonomie in pädagogischer, organisatorischer, personeller, finanzieller und evaluativer Hinsicht (Büchel u.a. 1994). Diese soll die Innovationskraft der einzelnen Grundschule stützen. [...]

Bei der Forderung nach Autonomie der Einzelschule muß allerdings beachtet werden, daß als Voraussetzung für diese Freiräume ein Kollegium bereit sein muß, diese Gestaltungsfreiräume mit Inhalten zu füllen. [...] Auch die Untersuchung von Little (1982: 85ff.) verweist auf den Zusammenhang der Normen „Kollegialität“ und „Reformbereitschaft“, die zentral für Arbeitsbedingungen an sog. ,guten Schulen“ (Aurin 1991) sind. Schulinterne Lehrerfortbildung, also Innovationsbestrebungen der einzelnen Schule, hat „dort die besten Einflußmöglichkeiten, wo eine entwickelte Kollegialität herrscht“" (Little 1982: 97).

Ramseger sieht in den bei den Prinzipien Integration und Autonomie zukunftsträchtige Ideen für die Strukturveränderungen an Grundschulen (Ramseger 1994: 10f.). Am Beispiel von LehrerInnen in Integrationsklassen von behinderten und nichtbehinderten Kindern wird bei ihnen deutlich, welche Folgen dieses Prinzip der Integration für die Schulentwicklung hat. Unterrichten in solchen Klassen zwingt die LehrerInnen zu konsequenter Differenzierung, die Fiktion eines homogenen Leistungsniveaus, gleicher Lernzeiten und -ziele für alle kann hier nicht mehr aufrechterhalten werden. Integration wird in der Regel in Teamarbeit verwirklicht. Mit diesen Veränderungen in Integrationsklassen ist ein Professionalisierungsschub bei den LehrerInnen verbunden, der auch durch vermehrte Fortbildung gestützt wird. Sieht man die Aufgaben, vor die die Grundschule in den letzten 20 Jahren gestellt wurde, aus diesem Blickwinkel, so wird deutlich, daß auch die Integration von Kindern ausländischer ArbeitnehmerInnen, die veränderte Lebenswelt von Kindern, der Wandel in der Familienstruktur und die multikulturelle Gesellschaft als wichtige Entwicklungsimpulse für die Arbeit von LehrerInnen gesehen werden können. Sie mußten auf diese neuen Anforderungen reagieren und begegneten ihnen, indem sie ihren Unterricht öffneten und damit eine innere Reform der Grundschule voranbrachten.

Auch die zweite Idee, die Ramseger anführt, die Autonomiebestrebungen, bewirkt wie das Prinzip Integration eine Selbstprofessionalisierung der LehrerInnen und damit auch eine gesteigerte Professionalisierung der Schule als Ganzes, die sich in erhöhter didaktischer und sozialer Kompetenz aller Beteiligten, auch z.B. der Eltern, auswirkt. Sie führt schließlich auch zu einer Politisierung im Bereich der Grundschule, die auch in ihrer ursprüngliche Aufgabe, nämlich der Erziehung von Kindern unabhängig von gesellschaftlicher Stellung, Herkunft, Religion und Begabung, bereits angelegt ist.

Ein wichtiger Punkt, der in Veröffentlichungen zu diesem Bereich selten erwähnt wird, aber doch zentral erscheint für die Möglichkeiten der 
Öffnung des Unterrichts in der Grundschule, ist das Klassenlehrersystem. Die Aussetzung des 45-Minuten Rhythmus, die Rhythmisierung des Schultages und der Schulwoche nach Prinzipien des offenen Unterrichts ist für GrundschullehrerInnen, die den größten Teil des Schultages mit ,ihrer“ Klasse verbringen, ohne größere Probleme realisierbar. [...] Auch wenn der Lehrerberuf grundsätzlich mit großer Autonomie und Gestaltungsfreiheit im inhaltlichen Bereich ausgestattet ist, ist doch diese strukturelle Besonderheit an Grundschulen eine wichtige Voraussetzung für Reformen. Das Klassenlehrersystem erhöht die Gestaltungsfreiheit und Autonomie von GrundschullehrerInnen erheblich und erleichtert somit die Öffnung des Unterrichts. [...]

Neben der Einzelschule sind aber und vor allem die LehrerInnen selbst für die Innovation an Schulen zentral, um die es auch in der vorliegenden Untersuchung geht, ihre Entwicklungsprozesse, subjektiven Theorien und Handlungsstrategien stehen im Mittelpunkt, aus ihrer Sicht muß zunächst auch das System Schule gesehen und erforscht werden.

Ein Grund für das Scheitern einiger positiver Reformansätze des Deutschen Bildungsrates war, daß diese Reform von oben durchgeführt und nicht mit der Bereitschaft der LehrerInnen, diese Reform zu tragen, verbunden werden konnte. Flitner (1990) kritisiert dies und weist auf eine andere Art von Reformarbeit hin, die in Großbritannien üblich ist und dort sehr erfolgreich ist, weil sie das Reformpotiential der LehrerInnen beachtet und einbezieht. [...] Das Reformpotential, die subjektiven Theorien und Handlungsstrategien innovativer LehrerInnen werden untersucht und analysiert, um daraus Hinweise für die innere Reform der Schule und der Lehrerbildung zu erhalten.

$$
[\ldots]
$$

\section{Innovation und pädagogische Frauenforschung}

Im Zusammenhang mit den Bereichen Innovation und innere Schulreform müssen Forschungsergebnisse und die Diskussion in der pädagogischen Frauenforschung beachtet werden. Grundlage feministischer Schulforschung sind die emanzipative Erziehungswissenschaft und die Frauenforschung, die sich beide in den 70er Jahren etabliert haben. [...]

Zentrale Aspekte aus der pädagogischen Frauenforschung [...] sind neben Subjektorientierung und Theorie-Praxis-Verbindung die Doppelbelastung von Frauen durch Beruf und Familie, die als Chance zur Doppelqualifikation für die pädagogische Arbeit in der Schule gesehen wird, die Feminisierung des Lehrberufs und dessen Auswirkungen sowie empirische Forschungsergebnisse im Bereich innere Schulreform.

Die doppelte Sozialisation Erwachsener als Sozialisation durch den Berufsalltag und das private Leben ist bei erwerbstätigen Frauen besonders sichtbar, betrifft aber alle Erwachsenen (vgl. Hoff 1990). Sie ist allerdings als „doppelte Vergesellschaftung“ oder „doppelte Sozialisation“ zunächst 
von Frauenforscherinnen in die soziologische Diskussion eingebracht worden (vgl. Becker-Schmidt 1987).

Frauen eignen sich in ihrer Sozialisation ein sog. ,weibliches Arbeitsvermögen" an, auf das sie in ihrer beruflichen Qualifizierung und im Berufsalltag zurückgreifen können und das im Fall einer Berufstätigkeit als Lehrerin, die auch Erziehung umfaßt, zu ihrem Berufserfolg beiträgt (Händle 1989b: 109). Berufliche und familiale Tätigkeit sind zwei ganz unterschiedliche Bereiche mit divergierenden Anforderungen, Strukturen und Logiken. Daß vor allem berufstätige Frauen in beiden Bereichen stark gefordert sind, läßt sie ihr spezifisch weibliches Arbeitsvermögen ausbilden. Die Tätigkeit von Frauen in beiden Lebensbereichen kann so nicht mehr als Doppelbelastung, sondern auch als Entlastung betrachtet werden. Beide Bereiche können sich stützen, in beiden Bereichen können Frauen ihre Bedürfnisse befriedigen und damit ausgeglichener sein als bei NurBerufstätigkeit oder Nur-Hausfrauendasein (Metz-Göckel 1993: 13). [...]

Händle untersucht die Auswirkungen dieses weiblichen Arbeitsvermögens für Lehrerinnen und auch den Einfluß der Doppelqualifikation für Lehrer, die auch, wenn auch in geringerem Maße, gegeben ist, mit Fallstudien in der Berufseingansphase (Händle 1989a, 1989b). Durch Erfahrungen aus ihrer Herkunftsfamilie, aber auch durch die Erziehung eigener Kinder haben Lehrerinnen vor allem soziale und kooperative Handlungsprioritäten [...]. Deshalb sind ihnen offene und reformorientierte Unterrichtsformen sehr wichtig, sie stimmen mit ihren Zielsetzungen überein. In offenen Situationen und als Klassenlehrerin können sie ihre sozialen und kooperativen Handlungsprioritäten eher verwirklichen als im Fachlehrerprinzip bei äußerer Leistungsdifferenzierung (Händle 1989b: 109). „Weiblicher Stil“ läßt sich von Frauen in der Grundschule deshalb leichter verwirklichen.

[...]

Eigene biographische Erfahrungen mit Kindern als Vater und Mutter kann zur Qualifikation für pädagogisches Arbeiten führen, kann aber auch in ungünstigen Situationen eine Festlegung sein, die Job-Orientierung im Beruf fördert. Wie sich die Lebenspraxis als Vater und Mutter auf das Engagement im Beruf auswirkt, hängt eng von der individuellen Konstellation und den biographischen Erfahrungen in der eigenen und der Herkunftsfamilie ab (Händle 1989a: 222). Händle kommt zu dem Ergebnis, daß egalitäre Ansprüche und Erfahrungen in der Biographie und der aktuellen Lebenssituation schülerorientiertes Unterrichten stützen, hierarchische Erfahrungen dagegen lehrerzentrierten Unterricht (vgl. ebd.).

Die Feminisierung des Lehrberufs, die ursprünglich als Hindernis für seine Professionalisierung gesehen wurde (vgl. Nyssen 1994: 349), erweist sich damit als ein wichtiges Innovationspotential für die innere Reform der Schule. An Grundschulen unterrichten zu 70-90 \% Lehrerinnen, sie bringen ihr spezifisch weibliches Arbeitsvermögen in die Berufsarbeit dort mit ein und haben damit entscheidend zu einer Reform der Grundschule von unten beigetragen. Ihre Sichtweisen, Werte, Orientierungen und ihr Engagement 
für pädagogische Ideen befördert die Humanisierung der Grundschule und die Integration ausländischer und behinderter Kinder. [...]

\section{Literatur}

Aurin, Kurt (1991) (Hg.): Gute Schulen - worauf beruht ihre Wirksamkeit? Bad Heilbrunn

Bauer, Karl-Oswald, Andreas Kopka (1994): Vom Unterrichtsbeamten zum pädagogischen Profi - Lehrerarbeit auf neuen Wegen. In: Hans-Günter Rolff, u.a. (Hg.): Jahrbuch der Schulentwicklung, Band 8. Weinheim, 267-307

Bauer, Karl-Oswald, Christoph Burkhard (1992): Der Lehrer - ein pädagogischer Profi? In: Hans-Günter Rolff, u.a. (Hg.): Jahrbuch der Schulentwicklung, Band 7. Weinheim, 193-226

Becker-Schmidt, Regina: Die doppelte Vergesellschaftung - die doppelte Unterdrückung: Besonderheiten der Frauenforschung in den Sozialwissenschaften. In: Lilo Unterkirchner/Ina Wagner (Hg.): Die andere Hälfte der Gesellschaft. Österreichischer Soziologentag. Wien, 11-25

Büchel, Helga, Horst Ewald, Hadmut Scholz, Herrmann Schwarz (1994): Schulautonomie - ein Weg zur besseren Grundschule? In: Die Grundschulzeitschrift, H. 71, 4045

Deutscher Bildungsrat (1972): Empfehlungen der Bildungskommission. Strukturplan für das Bildungswesen. Stuttgart

Edelfelt, Roy A. (1983): In-service education: Moving from professional development to school improvement. In: Urban Educator, 7 (1), 100-113

Flitner, Andreas (1990): Wirklichkeitssinn und Möglichkeitssinn über Lehrerarbeit und Schulreform. In: Peter E. Kalb, u.a. (Hg.): Unterrichten - und was sonst? Zum Berufsverständnis von Lehrerinnen und Lehrern. Weinheim, 13-32

Händle, Christa (1989a): Lebenspraxis als Mutter und Vater. Doppelbelastung oder Qualifizierung für den Lehrberuf? In: Bärbel Schön (Hg.): Emanzipation und Mutterschaft. München, 203-225

Händle, Christa (1989b): Soziale Handlungsprioritäten im Beruf. Befunde aus Fallstudien von Lehrerinnen in der Berufseinstiegsphase. In: Hannelore Faulstich-Wieland (Hg.): Weibliche Identität. Dokumentation der Fachtagung der AG Frauenforschung in der DGfE. Bielefeld, 93-111

Hoff, Ernst-H. (1990) (Hg.): Die doppelte Sozialisation Erwachsener. Zum Verhältnis von beruflichem und privatem Lebensstrang. München

Krichbaum, Gabriele (1994): Mit Konflikten leben - aber wie? Zum Fragebogen über Lehreraus- und Lehrerfortbildung (2. Teil). In: Grundschule, H. 1, 34-36

Little, Judith Warren (1982): Norms of collegiality and experimentation: Worplace conditions of school success. In: American Educational Research, 19, 325-340

Metz-Göckel, Sigrid (1993): Die Macht der Lehrerinnen. In: Maria-Anna Kreienbaum, u.a. (Hg.): Was ist eine gute Schule? Weinheim, 9-23

Nyssen, Elke (1994): Einführung (zum Symposion 13: PrimarstufenlehrerInnen in Europa). In: Zeitschrift für Pädagogik, Beiheft 32: Bildung und Erziehung in Europa. Weinheim, 349-351

Ramseger, Jörg (1994): Was wird aus der Grundschule? In: Die Grundschulzeitschrift, H. 71, 7-11

Schley, Wilfried, Wulf Wallrabenstein (1994): Grundschule im Aufbruch: Lernen im Widerstand? In: Die Grundschulzeitschrift, H. 76, 6-13

Schwänke, Ulf (1988): Der Beruf des Lehrers. Professionalisierung und Autonomie im historischen Prozeß. Weinheim und München 


\section{FRITZ BOHNSACK \\ Widerstand von Lehrern gegen Innovationen in der Schule}

$[\ldots]$

\section{Die Abwehr des Ungewohnten}

Zunächst gilt ganz generell, daß Menschen sich in ihrem Leben mit Gewohnheiten gleichsam eine Wohnung, ein Haus bauen, welches sie endgültig nur verlassen, wenn es abbrennt oder bleibend überflutet wird. Ohne dieses Bild gesprochen: Gewohnheiten, auch Routinen, sind das Ergebnis von Erfahrungen. Sie machen das Leben einfacher, weil sie von selbst ablaufen, so daß nicht jeder weitere Schritt dieselben Grundüberlegungen und neue Entscheidungen erfordert. Gewohnheiten sind also notwendig aus Kräfteersparnis. Das gilt auch für die Arbeit von LehrerInnen.

Doch Gewohnheiten verleiten auch, als eingefahrene Geleise, zur Unflexibilität und Erstarrung, wenn neue Situationen neue Reaktionen und Antworten erfordern. Und je erwachsener wir werden, um so eher empfinden wir es als eine Zumutung oder gar Bedrohung, wenn wir unser Sicherheit gebendes Gehäuse verlassen und Neues wagen sollen. Das ist ein allgemeines menschliches Charakteristikum - mit Ausnahme von den Typen, die eine Lust am Experimentieren oder gar an ein wenig Abenteuer haben.

[...] Die LehrerInnen haben in oft mühsamem Ringen eine Art Gleichgewicht gefunden zwischen der eigenen Arbeitskraft und andererseits den Anforderungen von innen aus dem pädagogischen Über-Ich (wie ich den Unterricht eigentlich machen sollte) und von außen, also von Kollegen, Schulleiter, Schulaufsicht, Eltern, SchülerInnen etc. Und dieses Gleichgewicht ist stets gefährdet, so daß jede Bedrohung abgewehrt wird. Denn viele LehrerInnen balancieren auf dem schmalen Grat zwischen Überlastung und Unzufriedenheit mit ihren Unterrichtsergebnissen. Das Fatale heute ist, daß beides zugleich, die Unzufriedenheit und die Belastung, zunimmt, weil manche gesellschaftlichen, z.B. normativen Gratisvoraussetzungen für leichteres Schule-halten entfallen (vgl. Ziehe 1984) und die veränderten SchülerInnen schwieriger geworden sind (vgl. Bohnsack 1991). LehrerInnen sehen sich daher gezwungen, nach neuen Wegen zu suchen, und tun dies auch, teilweise mit Erfolg. Diese Versuche gehen generell in Richtung stärkerer Offenheit, Schülerorientierung und Individualisierung im Unterricht.

\section{Widerstand gegen Schülerorientierung}

Hans Haenisch (1992) hat die Ergebnisse der deutschsprachigen Forschung zu stärker schülerorientierten Unterrichtsformen zusammengefaßt und festgestellt, daß Schülerorientierung Motivation, Lernfreude und Lernleistung erhöht und Schulmüdigkeit, Disziplinprobleme und Unterrichtsstörungen reduziert. $[. .$. 
Doch angesichts der positiven Ergebnisse stärkerer Schülerorientierung bleibt die Frage nach den Gründen der bisherigen Dominanz des lehrerzentrierten Frontalunterrichts. Die von Haenisch herangezogenen administrativen, Lehrplan- und Leistungsvorgaben und die Mängel der Lehrerausbildung lassen auch für ihn durchaus Spielräume offen. Ein mehrjähriges eigenes Forschungsprojekt eines Essener Teams (Bohnsack 1984) kam aufgrund ganz konkreter Unterrichtsarbeit mit LehrerInnen u.a. zu dem Ergebnis, daß Innovationen im bestehenden System zwar angesichts vielfältiger Widerstände Energie und Kreativität erfordern, aber kein Lehrer, keine Lehrergruppe und keine Schule ihre Spielräume wirklich ausschöpft.

Die äußeren Barrieren liefern also keine ausreichende Erklärung. Und selbst Vorgaben durch Erlaß und Gesetz lassen sich ja unterlaufen. Empirische Untersuchungen in den USA haben ergeben, daß SchulleiterInnen (und LehrerInnen) an effektiven Schulen gesetzlich vorgeschriebene Ziele flexibel angehen und im Blick auf die Möglichkeiten ihrer Schule variieren. Das heißt, sie lassen sich leiten durch ,the wisdom of knowing where and how to disobey [!], in order to protect the integrity and operation of the local [=their] school" (Lenz 1991: 111f.). Dem steht allerdings der sprichwörtliche „vorauseilende Gehorsam“ des deutschen Beamten entgegen! Doch vielleicht dürfen wir darauf hoffen, daß in einer Zeit der Stärkung der Autonomie der Einzelschule durch neue Schulgesetze in Hessen und Rheinland-Pfalz und ähnliche Bestrebungen in Hamburg und Bremen nun auch die LehrerInnen danach streben, diese größere Autonomie auszufüllen, d.h. daß sie im Gegensatz zur Tradition mehr Mut zur Erprobung von Neuerungen und d.h. auch: mehr Zivilcourage und ,aufrechten Gang“ im Blick auf die Durchsetzung des von ihnen als pädagogisch notwendig Erkannten entwickeln. Das setzt allerdings voraus, daß LehrerInnen wirklich an einer Veränderung interessiert sind. Bloße Appelle an ihr pädagogisches ÜberIch bringen keine Veränderungen. Da die traditionelle Lehrerrolle das Genießen der eigenen Dominanz in der lehrerzentrierten Frontalstellung nicht ausschließt, müßte ein solcher „Genuß“ relativiert bzw. überwunden und Geschmack am Zurücktreten zugunsten von Schüleraktivität gefunden werden. Und das bedeutet die Veränderung von Gewohnheiten und Traditionen.

$[\ldots]$

\section{Widerstand gegen Gruppenunterricht}

Zur Gruppenarbeit liegen, ähnlich wie zur Schülerorientierung nach Haenisch, seit langem Untersuchungen vor, welche für manche Lernaufgaben die Überlegenheit dieser Unterrichtsform über traditionelle Arbeitsweisen im Frontalunterricht belegen - allerdings erneut unter der Voraussetzung, daß der Gruppenunterricht wirklich gelingt.

Georg Dietrich (1971: 85-87, 104, 114-119, 146-150, 185f.) fand schon 1969 eine ,hochsignifikante Überlegenheit“ in Kenntnisumfang, -präzision, 
-ordnung und Behaltensdauer, aber natürlich auch in Kooperationsfähigkeit, gegenseitiger Hilfe und Disziplin. Neuere Publikationen betonen die Anregung durch kontroverse Positionen in der Gruppe und die daraus resultierende Vielfalt der Ideen, die in der Gruppe zusammenkommen können, oder die bessere Anwendung des Gelernten auf neue Probleme (Huber 1985: 19). R. E. Slavin (1983) hat die Ergebnisse zahlreicher amerikanischer Untersuchungen zusammengefaßt, die gleichfalls mehrheitlich zu eindeutig positiven Resultaten kamen. [...]

Damit fragt sich erneut, weshalb diese Unterrichtsform relativ wenig angewandt wird. Sicher spielt die Gewohnheit auch hier eine Rolle. Heutige Lehrer haben als Schüler, als Hochschüler, Referendare und im vollen Schuldienst vorwiegend traditionellere Unterrichtsformen kennengelernt. Norbert Vorsmann (1986: 197) trägt Bedenken gegen den Gruppenunterricht vor, die als faktisch von LehrerInnen so erlebt durchaus ernst zu nehmen sind:

„Selbstherrliche oder herrische Dominanz einzelner Schüler, Zurückdrängen und Ausschließen der Schwachen von der Mitarbeit, Verweigerung der Zusammenarbeit, Ausweichen vor dem Sachanspruch, verkappte Einzelarbeit, die durch pseudo-demokratische Abstimmungsprozesse zum Gruppenergebnis umfunktioniert wird, ein rüder Umgangston begegnen dem aufmerksamen Beobachter leider recht häufig unter dem Etikett eines modernen und zeitgemäßen Unterrichts.“

\section{$[\ldots]$}

Heinz S. Rosenbusch u.a. (1991: 131) stellen fest, daß viele LehrerInnen mit Gruppenunterricht Schwierigkeiten haben, weil sie ihn 1) nicht fachgerecht einsetzen, 2) ihre eigenen Interventionen in der Wirkung nicht richtig einschätzen, 3) das wirkliche Gruppengeschehen nicht angemessen wahrnehmen und überhaupt die Arbeit mit Gruppen ihnen eine ,terra incognita“ ist, d. h. ihnen die nötige Kompetenz fehlt, diese ,störanfälligste Sozialform von allen" gekonnt zu leiten. Denn der Erfolg setze im Grunde Selbständigkeit, Selbst- und Gruppenverantwortlichkeit, Solidarität und Regelbeherrschung schon voraus (ebd., 119; Herv. i.O.). Und diese Sozialkompetenzen erfordern eben eine ,anspruchsvolle und langdauernde erzieherische Arbeit“ (Kasper 1991: 249) - auch eine Fortbildung und Selbsterziehung des Lehrers.

Der Eindruck, in der „Lehrerferne“ der Gruppe kämen gestörte Beziehungen, Rivalitäten und Konflikte zwischen den Schülern und Cliquen erst recht zum Ausbruch, so daß auch manche Schüler Gruppenarbeit ablehnen, erklärt weitere Bedenken. Hinzu kommt die psychische Belastung bzw. Ängste durch die begrenztere Berechenbarkeit. Oft werden Zeitmangel, Ineffektivität und übergroße Vorbereitung angegeben. Doch dahinter verbirgt sich vielfach eben ein Mangel an didaktisch-methodischer und sozialer Kompetenz, zu deren Erwerb Fortbildung und „Trainingsprogramme“ nötig sind (Denecke/Ritz 1991: 293f.).

$$
[\ldots]
$$




\section{Überwindung von Widerstand durch Eingehen auf die Personen: Der kommunikative Gesprächsstil}

Im Blick auf Widerstand ist es sinnlos, ja kontraproduktiv, von LehrerInnen etwa einen schülerorientierten Unterricht oder Gruppenarbeit zu verlangen, solange sie keine Chance hatten, diese Unterrichtsformen zu lernen. Solche Lernprozesse aber setzen eine Lernbereitschaft voraus, und die zu eröffnen ist eine Aufgabe von Schulentwicklung bzw. Fortbildung. Die Methoden reichen vom persönlichen Gespräch zwischen KollegInnen bis zu organisatorischen Maßnahmen. Bei den Hinweisen auf solche Ansätze soll uns erneut die Frage leiten, wieweit eine positive Wertung von Widerstand, also das Bemühen um Verständnis der abwehrenden Gegenposition, trägt und sinnvoll ist. Bei meinem Ausgang vom kommunikativen Ansatz heißt dessen Prämisse, daß die vielfach geübte falsche Kollegialität i.S. von kollektiver Verdrängung bzw. Tabuisierung von eigenen Problemen, gegenseitiger Kritik und Differenzen die Auseinandersetzung, Kommunikation, Kooperation und einen wachsenden Konsens, damit Voraussetzungen einer Weiterentwicklung blockieren und daß eine kritische Analyse solcher Beziehungsstrukturen Ängste auslöst, den Schutz durch Scheingemeinsamkeiten zu verlieren.

$$
[\ldots]
$$

Wenn ich eine Schule will, welche stärker an der „Bildung“ von autonomen Schülerpersonen orientiert ist, muß ich erst einmal die KollegInnen, die ich dafür gewinnen möchte, als autonome Personen akzeptieren und behandeln und sie nicht als Objekte meiner vorgefaßten oder verabsolutierten Zielsetzungen über den Tisch zu ziehen suchen. In solcher Kommunikation geht es also nicht um Politik, Taktik, Manipulation, um Gewinner und Verlierer, sondern um einen gemeinsamen Weg, der nur aus diesem offenen Austausch der zunächst differierenden Interessen, Ansichten und Ziele resultieren kann. In Bindungen an institutionelle Vorgaben oder Gesetze, auch an grundlegende Normen, findet solche Offenheit allerdings ihre Grenze: dann muß eventuell angeordnet oder mit Mehrheitsabstimmungen durchgesetzt werden.

\section{$[\ldots]$}

Der angeführte kommunikative Gesprächsstil gilt für Schulentwicklung auch unter dem Aspekt der kollegialen Beratung. Da außer- und innerschulisch der Umgang zwischen Personen, hier also zwischen Lehrenden und Lernenden und zwischen den KollegInnen, weitgehend der Charakter der Belehrung bzw. Behandlung von Objekten statt der Kommunikation mit Subjekten angenommen hat, entwickelte die Schulung von Beratern Formen des "Kommunikationstrainings" mit dem grundlegenden Stil des nichtdirektiven Beratungsgesprächs, welches allerdings in der Notwendigkeit von Anordnungen seine Grenzen findet (Miller 1990: 175-178).

$$
\text { [...] }
$$


Mit dem Phänomen der „Reaktanz“ greife ich einen bereits angesprochenen Aspekt des Widerstands gesondert heraus. Zwar wenden Jochen Grell und Waldemar Pallasch (1978) die Reaktanztheorie J. W. Brehms vor allem auf Schülerverhalten im Unterricht an; doch eine Übertragung auf Lehrerverhalten bei Reformversuchen ist nicht unergiebig. Dann zeigen nämlich nunmehr LehrerInnen die „,Sperrigkeit“ des ,Menschenmaterials“ gegenüber Beeinflussungsversuchen mit Erziehungsabsicht" und reagieren auf die gegen den Widerstand gerichteten Versuche, durch Verfeinerung und „Intensivierung der Fremdsteuerung“ (Grell/Pallasch 1978: 94f.) das Reformziel dennoch durchzusetzen, mit noch mehr „Sperrigkeit“, welche sich äußert in offener Kritik an Inhalten, Verfahren oder am Leiter oder auch verschlüsselter in Lustlosigkeit, Passivität und dysfunktionalem Rollenverhalten (Brocher 1971: 140f.): dabei fehlt oft die Erkenntnis, daß solcher Widerstand gerade aus zu starker Fremdsteuerung resultiert und durch größere Freigabe zur Selbststeuerung abgebaut werden könnte (Grell/Pallasch 1978: 95).

\section{[...]}

Nach Thomas Fleischer (1990: 325, 330f., 339f.) ist die Organisationsstruktur unserer Schulen und vor allem Schulbehörden auf „Vollzug und Durchführungsabschluß angelegt“, mit den Nachteilen eines dem „,funktionalistischen Schulverständnis nahestehenden abwicklungsorientierten Lernens und Schullebens“. Statt Schule als „verwaltungs-bürokratische Anstalt" brauchten wir heute die Schule als ,sich selbst evaluierendes, beratendes, entwickelndes Arbeits- und Dienstleistungssystem“. Helmut Fend (1987) nannte eine solche Schule eine relativ autonome „pädagogische Handlungseinheit", welche in der Lage ist, ihre jeweils neu auftretenden Probleme weitgehend selbständig kollegial zu lösen. [...]

Doch gegen die von Fend geforderte Autonomie regt sich auch individuell Widerstand: nicht nur, weil manche LehrerInnen glauben, sie werde aus Gründen der Kostenersparnis und nicht aus pädagogischen eingeführt; sondern weil manche Machtpositionen um ihre Privilegien fürchten und weil Selbstverantwortung und Selbstentscheidung neue Belastungen bringen und auch verunsichern (vgl. Langmaack/Braune-Krickau 1993: 2). Und weil für Fends relative Autonomie der ,pädagogischen Handlungseinheit“ neue Formen der Kommunikation und Kooperation als Voraussetzung zum Konsens nötig sind, die die bisherige „Erfolgsideologie“ (Verbergen von Schwächen und Mißerfolgen) und Konventionen des unkontrollierten Einzelkämpfertums hinter der geschlossenen Klassentür genauso in Frage ziehen (Schulz-Wensky 1992: 112f.) wie manche der gewohnten bzw. erstarrten Handlungsmuster und Rituale (vgl. Wellendorf 1973). Damit schließt sich der Kreis zur Notwendigkeit stärker kommunikativ bzw. gruppendynamisch bestimmter Ansätze der Bearbeitung von Widerständen. 


\section{Abschließende Bemerkungen zum Umgang mit Widerständen}

Der Tenor der vorausgehenden Abschnitte geht dahin, daß Widerstand nicht vorschnell abqualifiziert werden darf, sondern auch als positive Kraft ernst zu nehmen ist. Widerstand könnte vom Reformer übersehene, erhaltenswerte Praktiken und d.h. empfehlenswerte Modifikationen der Reform anzeigen. Er könnte auch darauf hinweisen, daß durch die intendierten Innovationen die bisherige Arbeit und Rolle der LehrerInnen und die Traditionen der Schule in Frage gezogen bzw. entwertet werden, so daß eine respektvolle Behandlung dieser bisherigen Praxis ebenso angezeigt ist wie die ausführliche Begründung der (neuen) Notwendigkeit von Veränderungen, z.B. angesichts gesellschaftlicher Wandlungen (vgl. Horster 1991: 95f.). [...]

$\mathrm{Zu}$ vermeiden ist jede Überheblichkeit oder Arroganz der Reformkräfte im Kollegium und d.h. die Ausgrenzung der Abwartenden oder Widerständler.

[...]

Eine der wichtigsten Motivationen, sich aus eingefahrenen Gleisen hinauszubewegen, ist das Leiden an ihnen. Das Leiden an einer schwierigen Unterrichtssituation - wenn es nicht gar zu stark ist: das könnte als Verzweiflung wiederum lähmen - hat heute schon manchen Lehrer über traditionelle Unterrichtsformen hinaus zu alternativen Praktiken geführt, zur vorsichtigen Aufgabe liebgewonnener oder in ein mühsam errungenes Gleichgewicht zwischen Arbeitskraft und Zielen geronnener Verhaltensweisen, und liefert insofern eine Hoffnung auf Veränderung. Der Weg des Lehrers (und in mancher Weise: des Schülers) zur „Sozialkompetenz“ und (beim Lehrer) zur pädagogischen „Identität“ und „Persönlichkeit“, zum „Profi““, führt über Veränderungen, über langjährige Erfahrungen, Irrtümer, auch Scheitern und dessen Aufarbeitung (Oelkers/Prior 1982: 120). Dazu sind Ermutigungen nötig, innerhalb der Schule oder von außen, etwa durch Moderatoren im Rahmen von schulinterner Fortbildung, damit die gängige Praxis der Abschiebung von Initiativen auf andere (Schulleitung, Kollegen, Schüler etc.) reduziert werden kann.

\section{[...]}

Aus alledem wird deutlich, daß die an Reformen Interessierten - als Moderatoren - nicht mit Zwängen arbeiten dürfen: sie müssen die gleichsam besseren Interessen der abwartenden und abwehrenden Kollegen zu wecken suchen, was z.B. Echtheit, also offene Vertretung und Begründung der eigenen pädagogischen Ideen und Wünsche, aber auch, wie erwähnt, eine spezifische Kunst des Gesprächs erfordert.

Das Ernstnehmen der gegenwärtigen Verfassung der KollegInnen bezieht sich etwa auf die subjektiv erlebte Stoffülle und die Belastung oder Überlastung (Burnout; vgl. Meyer 1994) und Angst vor Mehrarbeit, auf ihre negativen Erfahrungen mit früheren Neuerungen oder inkompetenter Fortbildung, ihr Einzelkämpfertum bzw. ihre begrenzte Kommunikations- 
und Kooperationsfähigkeit, auf bestehende Beziehungsgeflechte, Konkurrenz und fehlendes Vertrauen, auf Kompetenzmängel, auf die Angst vor einem Verlust von Autorität oder Kontrolle der Klasse, auf (überholte) fachdidaktische Vorstellungen, ja selbst auf Jobmentalität und deren (z.B. familiale) Hintergründe. Auch LehrerInnen müssen zu Lernprozessen - und Innovationen implizieren Lernprozesse - dort abgeholt werden, wo sie heute wirklich stehen, dort aber nicht stehen gelassen werden.

Leonhard Horster (1991: 96) erinnert an den psychoanalytischen Gesichtspunkt, daß in bestehenden Gewohnheiten und eingespielten Formen des Umgehens mit Schwierigkeiten und Konflikten Ängste kanalisiert sein können, die bei Veränderungen neu aufbrechen und sich intensivieren. Auch bei der Bearbeitung von ,subjektiven Theorien “ von LehrerInnen, die ja aus deren Erfahrungen stammen, ist Behutsamkeit angeraten: von „grundlegenden impliziten pädagogischen Theorien“ der LehrerInnen abweichende Neuerungen stürzen diese in Widersprüche (Brody 1993: 116f.). Einseitigkeiten und Unzulänglichkeiten des eigenen Standpunktes werden oft nicht durch Argumente, sondern erst durch alternative Erfahrungen überwunden (vgl. Schlee/Wahl 1987). Als Verfahren zur Bearbeitung von Widerstand empfiehlt Horster die ,Kräftefeldanalyse“ (Sammlung und Aufzeichnung von Pro- und Contrakräften) und Vervollständigung von Sätzen wie „Um Unterrichtsstörungen zu beseitigen, sollte man ...“ (ebd., 105, 156f.), so daß die Gründe für unterschiedliche Standpunkte sichtbar werden.

\section{Literatur}

Bohnsack, Fritz: Veränderte Jugend - veränderte Schule? In: Bohnsack, Fritz/Nipkow, Karl Ernst: Verfehlt die Schule die Jugendlichen und die allgemeine Bildung? Münster (Comenius-Institut) 1991, S. 9-55

Bohnsack, Fritz u.a.: Schüleraktiver Unterricht. Möglichkeiten und Grenzen der Überwindung von „Schulmüdigkeit“ im Alltagsunterricht. Weinheim/Basel 1984

Brocher, Tobias: Gruppendynamik und Erwachsenenbildung. Zum Problem der Entwicklung von Konformismus oder Autonomie in Arbeitsgruppen. Neuaufl. Braunschweig 1971

Brody, Celeste M.: Kooperatives Lernen und implizite Theorien der Lehrer aus konstruktivistischer Sicht. In: Huber, Günter L. (Hg.): Neue Perspektiven der Kooperation. Hohengehren 1993, S.105-117

Denecke, Wulf/Ritz, Eberhard: Gruppenarbeit im Netz pädagogischer Ansprüche. Wann kann der Lehrer sich auf Gruppenarbeit einlassen? In: Meyer, Ernst/Winkel, Rainer (Hg.): Unser Konzept: Lernen in Gruppen. Hohengehren 1991, S. 271-299

Dietrich, Georg: Bildungswirkungen des Gruppenunterrichts. Persönlichkeitsformende Bedeutung des gruppenunterrichtlichen Verfahrens. 2. Aufl. München 1971

Fend, Helmut: „Gute Schulen - schlechte Schulen“ - Die einzelne Schule als pädagogische Handlungseinheit. In: Steffens, Ulrich/Bargel, Tino (Hg.): Beiträge aus dem Arbeitskreis „Qualität von Schule“ Heft 1. Hessisches Institut für Bildungsplanung und Schulentwicklung. Wiesbaden/Konstanz 1987, S. 55-79 
Fleischer, Thomas: Zur Verbesserung der Sozialen Kompetenz von Lehrern und Schulleitern. Kommunikationskompetenz und Interaktionskultur als Systemanforderung in der Schule. Hohengehren 1990

Grell, Jochen/Pallasch, Waldemar: Selbstgesteuertes Lernen in einer Kultur der Fremdsteuerung. In: Neber, Heinz u.a. (Hg.): Selbstgesteuertes Lernen. Psychologische und pädagogische Aspekte eines handlungsorientierten Lernens. Weinheim/Basel 1978, S. 88-108

Haenisch, Hans: Erfolgreich unterrichten - Wege zu mehr Schülerorientierung. Forschungsergebnisse und Empfehlungen für die Praxis. In: Landesinstitut für Schule und Weiterbildung: Schularbeiten Heft 4, April 1992, S. 1-8 (Soest)

Horster, Leonhard: Wie Schulen sich entwickeln können. Schulleitungsseminar. Der Beitrag der Organisationsentwicklung für schulinterne Projekte. Soest 1991

Huber, Günter L. (Hg.): Pädagogisch-psychologische Grundlagen für das Lernen in Gruppen. Studienbrief I A. Lernen in Schülergruppen - Grundlagen. Deutsches Institut für Fernstudien an der Universität Tübingen. Tübingen 1985

Kasper, Hildegard: Praxis des Gruppenlernens in der Grundschule - Wie sich Schulen auf den Weg machen können. In: Meyer, Ernst/Winkel, Rainer (Hg.): Unser Konzept: Lernen in Gruppen. Hohengehren 1991, S. 249-270

Langmaack, Barbara/Braune-Krickau, Michael: Wie die Gruppe laufen lernt. Anregungen zum Planen und Leiten von Gruppen. 4. Aufl. Weinheim 1993

Lenz, Jutta: Die Effective School Forschung der USA - ihre Bedeutung für die Führung und Lenkung von Schulen. Frankfurt/M. u.a.1991

Meyer, Ernst (Hg.): Burnout und Streß. 2. Aufl. Hohengehren 1994

Miller, Reinhold: Schilf-Wanderung. Wegweiser für die praktische Arbeit in der schulinternen Lehrerfortbildung. Weinheim, Basel 1990

Oelkers, Jürgen/Prior, Harm: Soziales Lernen in der Schule. Königstein 1982

Rosenbusch, Heinz S. u.a. : Neuere Untersuchungen zum Gruppenunterricht: Subjektive Theorien von Lehrern zum Gruppenunterricht und die beobachtbare Unterrichtsrealität. In: Meyer, Ernst/Winkel, Rainer (Hg.): Unser Konzept: Lernen in Gruppen. Hohengehren 1991, S. 118-132

Schlee, Jörg/Wahl, Diethelm (Hg.): Veränderung subjektiver Theorien von Lehrern. Oldenburg 1987

Slavin, Robert E.: Cooperative Learning. New York 1983

Vorsmann, Norbert: Frontalunterricht - vergessene Chancen in der Sozialerziehung. In: Biermann, Rudolf/Wittenbruch, Wilhelm (Hg.): Soziale Erziehung. Orientierung für pädagogische Handlungsfelder. Heinsberg 1986, S.196-207

Wellendorf, Franz: Schulische Sozialisation und Identität. Zur Sozialpsychologie der Schule als Institution. Weinheim/Basel 1973

Ziehe, Thomas: „Ich bin heute wohl wieder unmotiviert ...“- Zum heutigen Selbstbild von Schülern und Lehrern. In: Bohnsack, Fritz (Hg.): Sinnlosigkeit und Sinnperspektive. Die Bedeutung gewandelter Lebens- und Sinnstrukturen für die Schulkrise. Frankfurt/M. u.a. 1984, S. 116-133 


\section{THOMAS BRÜSEMEISTER Zur Kopplung von Lehrkräften und Schulorganisation}

In der Gegenwart sieht sich das Schulsystem einer Modernisierungsoffensive gegenüber, die auf eine neue „qualitätsbasierte“ Organisation Schule zielt. Schulen sollen sich nun selbst mehr führen und die staatliche Verwaltung auf strategische Rahmensetzungen reduziert sein. Ein eigenes Management soll die Schule von der staatlichen Bürokratie ablösen. Qualitätsmanagements, die von den Bildungsverwaltungen aufgegriffen werden (Kempfert/Rolff 2000; zum „Quality Movement“ vgl. Cole/Scott 2000), würden Lehrkräften stärkere Selbstbeobachtungen, Teamarbeit sowie eine verstärkte horizontale Kommunikation zwischen den Organisationsmitgliedern ermöglichen. Dies würde die bisherige „Isolation der Lehrkräfte untereinander (Lehrerindividualismus) “ verringern sowie schließlich auch eine „personenneutrale Fach- oder Berufssprache“ ermöglichen (Terhart 2001: 50).

Eine Durchsetzung dieses Modells würde die Schulen völlig umgestalten. Die Organisation Schule würde gestärkt, die Schule als Ort der LehrerProfession hingegen geschwächt. Während im Professionalisierungsdiskurs unmarkiert mehrere Tätigkeitsbereiche der Lehrkraft zusammen fallen, sind in einer qualitätsbasierten Schule verschiedene Spezialrollen ausdifferenziert. Die mit den Rollen einhergehenden Aufgaben sind jedoch zum Teil jetzt schon im Berufsfeld präsent, z.B.:

- bei der Technikexpertin, die sich um die Computerausstattung der Schule kümmert;

- beim Teamcoach, der bei Abstimmungsproblemen in und zwischen verschiedenen Gruppen des Kollegiums einspringt;

- bei der Schulforscherin, die sich um die wissenschaftliche Einbindung von Schulprojekten und Begleitstudien, die es an ihrer Schule gibt, kümmert;

- bei der Verhandlungsführerin, die mit der Schulbehörde kommuniziert;

- bei den Unterrichtsexperten verschiedener Fächer und Schulstufen, die sich auch um Koordinatoren bemühen, wenn es um Schulstandards geht;

- beim biographischen Coacher und Karriereberater;

- bei den Profis, die die Einstellung neuer Lehrkräfte beraten;

- bei Lehrern, die für die interne Mittelverteilung zuständig sind;

- bei Lehrern, die Profilbilder für Schulen erarbeiten;

- bei Lehrkräften, die ihre Schule in der Öffentlichkeit vertreten;

- bei denjenigen, die bei der Stadt, Vereinen, Betrieben und Verbänden Mittel für ihre Schule akquirieren;

- bei denjenigen, die über Projekte für eine Verzahnung der Schule mit dem gesellschaftlichen Umfeld sorgen;

- bei denjenigen, die sich mit anderen Schulen austauschen. 


\section{Wissensmanagement}

Welche Funktion hat der Begriff ,Wissensmanagement“" in diesem Zusammenhang? Mit diesem Begriff würden die faktisch jetzt schon in der Schulpraxis vorkommenden, aber nicht systematisch beobachteten Funktionsrollen aufgegriffen werden können. Der Lehrberuf würde dann weniger mit Begriffen aus dem Professionalisierungsdiskurs beschrieben, der für die prinzipielle Unendlichkeit der Tätigkeiten des Lehrers steht, sondern mit abgrenzbaren operativen Aufgaben eines Wissensmanagements. Ein ,Wissensmanagement" würde Funktionsaufgaben von Lehrkräften zudem mit kollektiv verbindlichen Entscheidungen in einer Organisation Schule verbinden. Damit ließe eine solche Beschreibungssprache den Lehrberuf insgesamt näher an eine Organisation Schule heranrücken.

Es gibt einen sachlichen Grund für eine solche Annäherung von individuellen Wissensmanagements und dem Wissensmanagement von Organisationen. Der Begriff ,Wissensmanagement" kommt aus der Organisationssprache (vgl. Schütt 2000) ${ }^{21}$ und impliziert ganz klar ein instrumentelles Interesse der Organisation an einer starken Einbeziehung der Individuen (Lehrkräfte). Der Begriff macht jedoch auch den Faktor des Individuums in der Organisation stark - und stellt Lehrerarbeit begrifflich von individuellen Entscheidungen eines Einzelnen innerhalb einer Profession auf kollektiv verbindliche Entscheidungen eines Kollegiums und einer Organisation Schule um, die in Teams arbeitet. Dabei erfährt auch der Begriff des Kollegiums eine gravierende Aufwertung: von einer bloß das einzelne professionelle Handeln rahmenden Instanz zur zentralen Entscheidungseinheit einer Organisation.

Für die Berufsarbeit der Lehrer würde ein entscheidender Vorteil sein, dass in einer Organisation Schule der Lehrer einerseits stärker über die Teamarbeit eingebunden ist, was dem Lehrerindividualismus entgegengesetzt wäre. Andererseits würde die Lehrkraft weniger eingebunden sein, weil nicht mehr professionelle Allzuständigkeit dominiert, sondern abgrenzbare Rollenaufgaben in einer Organisation. Dies schützt vor dem ungesteuerten ,Raubbau' an der Ressource Person, die es bislang innerhalb des Professionalisierungsdiskurses nach dem Muster „Ich bin immer ansprechbar" (Buchen 1991) gab.

\section{Verzahnungen}

Was Organisationen vor allem interessiert, und worin das individualisierte Individuum (vgl. Beck 1986) einen Vorsprung gegenüber Organisationen

21 Im Rahmen der Organisation werden mit dieser Sprache drei Problemfelder bearbeitet: (1) beim Wissensmanagement geht es um aktuelle Probleme und Problemlösungsaufgaben einer Organisation; (2) Wissensmanagement zielt darauf, individuelles Wissen in kollektives Wissen der Organisation zu überführen; (3) Organisationen haben ein Interesse daran, wie neues Wissen von Individuen generiert wird und künftig für die Organisation genutzt werden kann. 
zu haben scheint, sind die operativen Fähigkeiten, mit Wissen umzugehen und verschiedene Wissensbereiche zu integrieren (vgl. aus Sicht von Organisationen: Weber 2000). Dabei erlaubt der Begriff des Wissensmanagements eine grundsätzlich andere Beobachtung solcher Fähigkeiten, als es in Diskursen über Profession und Professionalisierung der Fall ist. In letzteren geht es im Prinzip darum, eine selbstreferentielle Exklusivität inhaltlicher Wissensbestände, ein bestimmtes sachliches Wissen gegenüber anderen Professionen bzw. Umwelten fortlaufend im Berufsfeld zu erkennen und zu behaupten. Ein großer Teil des pädagogischen Diskurses ist darauf gerichtet, „nichtpädagogisches“ Wissen in der inneren und äußeren Umwelt zu identifizieren, um es vom professionellen Wissen abzugrenzen.

Die Perspektive des Wissensmanagements ist demgegenüber auf ,Verzahnung" ausgerichtet. Da es zunächst nicht um Inhalte - also was verzahnt wird -, sondern um das „Wie“ des Organisierens geht, besteht kein Konkurrenzanspruch zwischen Akteuren oder Einrichtungen, die andere Wissensinhalte vertreten. Es geht darum, das Umgehen mit Wissen - eine operative Fähigkeit - in der gesamten Umwelt zu beobachten und zu übernehmen. Dies soll der Lernentwicklung der Schule als qualitätsbasierter Organisation zu Gute kommen.

Was wird verzahnt? Hier lassen sich zunächst biographische Wissenselemente erkennen, die dazu dienen, dass sich das Individuum in der funktional differenzierten Gesellschaft selbst prozessiert, sein Leben ,in die Hand nimmt ${ }^{\star}$. Diese operativen Fähigkeiten wirken sich auch auf das Ergreifen eines Berufes (des Lehrberufes) aus. Es kommt darauf an, wie sich die Lehrkraft biographisch in den Beruf , einsozialisiert', welche CopingFähigkeiten sie in ihrem Beruf entwickelt, ob es Belastungen durch kritische Lebensereignisse gibt und wie sie verarbeitet werden, wie insgesamt die Stationen des berufsbiographischen Verlaufs aussehen und integriert werden. Im Professionalisierungsdiskurs wird dabei die (lebensweltliche) „Umwelt“ für die Lehrkraft generell als eine Belastung gesehen, die es von Berufsthemen freizuhalten gilt. In operativer Hinsicht lässt sich dagegen sagen, dass es gerade Belastungen - oder allgemeiner formuliert: Umwelten - sind, an denen sich operative Fähigkeiten entfalten, sich zeigt, wie Fremd- und Eigenerwartungen organisiert werden. In diesem Kontext fallen eine Reihe von Befunden zur beruflichen Sozialisation von Lehrkräften auf, die, unter der ,Brille' eines operativen Wissensmanagements gesehen, eher positiv geprägt sind. Ich nenne exemplarisch: Erfahrungen im Umgang mit eigenen Kindern mit dem Beruf zu verbinden, oder genereller gesagt, informelle Qualifizierungen für den Beruf zu nutzen (vgl. Händle 1997); berufliche Ausstiege mit anschließenden Wiedereinstiegen zu organisieren; Stellenreduktion oder Teilzeitbeschäftigungen zu organisieren; biographische Wechsel von Unterricht zu Fachvertretungen zu organisieren; Wechsel von höheren zu niederen Schulformen zu organisieren, um damit die berufsbiographische Zufriedenheit zu erhöhen. Während innerhalb des Professionsdiskurses hier leicht Misstrauen gegenüber den fachli- 
chen Ambitionen einer Lehrkraft wach wird, bedeuten die gleichen Handlungen unter der Perspektive des Wissensmanagements gesehen operative Kompetenz - die sich bei der Lehrkraft, so die These, auf den Unterricht positiv auswirken wird. ${ }^{22}$

Wendet man sich vom biographischen Wissensmanagement ab und dem Wissensmanagement der Lehrkraft im Unterricht zu, so lassen sich mit dem Begriff Wissensmanagement weitere Fähigkeiten beschreiben, die zum Alltag der Berufspraxis gehören. Ich nenne wiederum exemplarisch: das ,Umswitchen' zwischen Lehrplanvorgaben und situativen Unterrichtserfordernissen; Unterrichtsmaterialien aus der eigenen privaten Umwelt werden in den Unterricht einbezogen; es werden Grenzen überschritten, um Schüler (und deren Eltern) wegen bestimmter Schulschwierigkeiten auch außerhalb der Schule anzusprechen; es kommt zum Zurückweisen von überhöhten Unterrichtsansprüchen (die von Eltern ausgehen); Lehrer fühlen sich für situative Ereignisse (Konflikte) in der Klasse zuständig und grenzen andere Ereignisse aus; es werden Entscheidungen ohne Letztbegründungen getroffen. Beispiele solcher operativer Entscheidungen ließen sich auch (was ich hier nicht weiter fortsetzen will) für Bereiche der Berufspraxis formulieren, in denen Lehrer untereinander Beziehungen im Kollegium organisieren, oder in denen sie Organisationsbelange der Schule verhandeln (z.B. Stundenpläne, Neueinstellungen). Es ist zu vermuten, dass diese operativen Fähigkeiten ganz wesentlich einen reibungslosen Ablauf von Schule gewährleisten. Wissensmanagement basiert dabei nicht nur auf explizitem, sondern auch auf implizitem Wissen (Polanyi 1958). Dieses, stille Wissen " wird gerade in Situationen relevant, in denen unter Zeitdruck entschieden werden muss (Schütt 2000: 79) - die Personen können in diesen Drucksituationen entscheiden, (müssen) ihr Handeln aber nicht erklären. Diese Wissensart nutzt auch ein Kind, das Rad fahren, die Abläufe aber kaum wiedergeben kann (so das Beispiel von Willke 1998: 13). Für den Lehrberuf ist dieses stille Wissen auch bedeutsam, insofern die Kernaufgabe darin besteht, in hochvariablen Interaktionsbereichen - dem Unterricht unter Druck laufend pädagogisch angemessen zu entscheiden. In diesen

22 Man könnte im Anschluss daran auch für die Einstellungspraxis von Lehrkräften überlegen, ob nicht gerade diejenigen Aspiranten für den Lehrberuf interessant sind, die in Sinnfeldern außerhalb des Berufes operative Fähigkeiten entwickelt haben. Es ergäbe sich eine Umcodierung von Kriterien, wenn man operative Fähigkeiten in den Blick nimmt. Eine solche Fähigkeit wäre z.B., wenn sich Lehrkräfte eine Zeit lang vom Beruf abwenden, um anschließend, mit einem „Mehr“ an operativen Erfahrungen ausgestattet, wiederzukommen. Während von Schulbehörden diese Praxis z.B. durch „Sabbatjahre“ zwar gewährt, aber kaum positiv sanktioniert wird, und während gleichzeitig in der informellen Beurteilungspraxis die zurückkehrenden Lehrkräfte sehr wohl anerkannt werden, eben weil sie sich durch ein Mehr an operativen Fähigkeiten auszeichnen, fehlt der Schulverwaltung offensichtlich noch eine Beschreibungssprache, wie sie das operative Wissensmanagement nun bereitstellt. 
Situationen wird das Konzept des Wissensmanagements relevant. Es geht hierbei um Kombinationen von stillem und explizitem Wissen, die nicht nur unter dem Einfluss der Situation stehen, sondern gleichzeitig durch biographische Erfahrungen gesteuert sind. Die daraus erwachsenden operativen Fähigkeiten, Unterricht sowie Schulabläufe insgesamt zu handhaben, werden vom Professionsdiskurs nur zum kleinen Teil beobachtet. Selbst bzw. gerade in den „Ablaufsprachen“ der Unterrichtsorganisation, wie sie in der universitären Lehrerbildung vermittelt werden, werden verwissenschaftlichte Sollensforderungen eingeführt, die die freie Beobachtung operativer Praxisabläufe beschneiden. Das biographische Können, ,etwas` zu organisieren, wird aus der Ausbildung radikal ausgegrenzt - um dann ungesteuert spätestens nach dem ersten Praxisschock, nachdem auf eine Klasse mit stillem Wissen reagiert werden musste, wieder eingeführt zu werden. ${ }^{23}$

Organisationen haben ein Interesse daran, die hier nur angedeuteten operativen Fähigkeiten von Individuen zu nutzen. Dies lässt sich zum Beispiel in der Reform der Lehrerbildung erkennen (vgl. für Hamburg: Keuffer/Oelkers 2000). Man will bei den Individuen gleichsam ,abgucken', wie sie verschiedene Erfahrungen und Wissenselemente diachron miteinander verzahnen. Die Lehrerbildung in Deutschland hat hier noch erhebliche organisatorische Defizite. Der werdende Lehrer wird durch AusbildungsPassagen , geschleust ${ }^{6}$, die organisational so gut wie nicht miteinander zusammenhängen (Berufswahl, Studienbeginn, Praxiselemente, Referendariat, Berufseinstieg und Erstplatzierung, berufliche Etablierung, Fort- und Weiterbildung). Derzeit ist die Verzahnung der verschiedenen Bereiche der einzelnen Lehrkraft überantwortet, die dafür ihre personalen Ressourcen einsetzen muss - es gibt kaum eine organisationale Unterstützung. Folge ist, dass die berufsbiographischen Verläufe der Kontingenz ausgeliefert sind, d.h. manchmal gut, manchmal schlecht integriert sind. ${ }^{24}$

Im Praxisfeld des Lehrberufs gibt es ein ähnliches Manko. Hier sind die Wissensbereiche ebenfalls extrem unterschiedlich organisiert und vor allem institutionell nicht miteinander verbunden. Es gibt Unterschiede im Hinblick auf das Verhalten einzelner Lehrer in Organisations-, Personal- und Unterrichtsfragen. Auf der Sachebene sind diese Unterschiede im Lehrerverhalten nicht das eigentliche Problem, sondern vielmehr die Tatsache, dass diese Unterschiede einzig als Unterschiede von Personen markiert werden und nicht einer Organisation Schule als bearbeitbare Unterschiede zufließen. ${ }^{25}$ Im Diskurs des Wissensmanagements werden dagegen die (he-

23 Altrichter (2000: 155) notiert dazu: „Dem Lehrberuf ist es bisher nicht gelungen, überindividuelle Fassungen des verwendeten beruflichen Wissens zu entwickeln.“

24 Die Kontingenz ist mit einer Liste seit langem bekannter Strukturschwächen des Lehrberufs verbunden, ich nenne nur den Praxisschock, Unsicherheiten bei der beruflichen Erstplatzierung, Fehlplatzierungen an Schulen, unsystematische Nutzung von Weiterbildungsangeboten. 
terogenen) operativen Kompetenzen einzelner Lehrer zu bearbeitbaren Unterschieden einer Organisation. Von dieser Bearbeitung würden alle Mitglieder der Organisation profitieren können. Und in der Einzelschule könnten nacheinander kollektive Probleme, die das Kollegium hinsichtlich Unterricht, Personal und Organisation ausgemacht hat, bearbeitet werden.

\section{Literatur}

Altrichter, Herbert (2000): Schulentwicklung und Professionalität. In: Johannes Bastian, Werner Helsper, Sabine Reh, Carla Schelle (Hg.): Professionalisierung im Lehrberuf. Opladen, 145-163.

Beck, Ulrich (1986): Risikogesellschaft. Frankfurt a.M.

Buchen, Sylvia (1991): „Ich bin immer ansprechbar“. Gesamtschulpädagogik und Weiblichkeit. Weinheim.

Cole, Robert E.; W. Richard Scott (2000): The Quality Movement and Organization Theory. Thousand Oaks.

Händle, Christa (1997): Qualifizierung für den Beruf in formeller Lehrerbildung und anderen Handlungsfeldern. In: Manfred Bayer, Ursula Carle, Johannes Wildt (Hg.): Brennpunkt Lehrerbildung. Opladen, 93-120.

Kempfert, Guy; Hans-Günter Rolff (2000): Pädagogische Qualitätsentwicklung. Ein Arbeitsbuch für Schule und Unterricht. Weinheim, Basel.

Keuffer, Josef; Jürgen Oelkers (2000). Reform der Lehrerbildung in Hamburg. Weinheim, Basel.

Polanyi, Michael (1958): Personal Knowledge. Chicago.

Schütt, Peter (2000): Wissensmanagement. Niedernhausen/Ts.

Terhart, Ewald (2001): Lehrerberuf und Lehrerbildung. Forschungsbefunde, Problemanalysen, Reformkonzepte. Weinheim, Basel.

Weber, Susanne (2000): Fördern und Entwickeln. Institutionelle Veränderungsstrategien und normalisierendes Wissen. In: Zeitschrift für Erziehungswissenschaft, Heft 3, 411-428.

Willke, Helmut (1998): Systemisches Wissensmanagement. Stuttgart.

25 In diesem Zusammenhang kann man auch davon sprechen, dass - bildlich gesehen - die Sach- und Situationskompetenz, das Wissensmanagement der Lehrkräfte, zusammen mit ihren Trägern stirbt, da die Fähigkeiten an biographisches Kapital gebunden sind. Während der Berufspraxis werden diese Fähigkeiten nicht systematisch von einer Organisation aufgegriffen und anderen Organisationsmitgliedern zugeführt; und es wird nicht institutionell dafür gesorgt, dass das individuelle Wissensmanagement in der Berufspraxis ans Kollektiv ,vererbt' wird. 


\section{Eltern}

\section{Kommentar (Eubel)}

Um die Rolle der Eltern in dem nach ,neuen Spielregeln“ funktionierenden System der modernisierten Schule näher zu bestimmen, sind einige Vorbemerkungen zu den spezifischen Relationen dieser Akteurgruppe zu den anderen Akteuren erforderlich. (1) Im herkömmlichen Schulsystem hatte die ,Verbindung ' zwischen Eltern und Schule etwas Schicksalhaftes: Da es in Deutschland eine gesetzliche Schulpflicht ${ }^{26}$ mit sehr eingeschränkten Wahlmöglichkeiten gibt, sind die Eltern - aber auch die aufnehmende Schule - gezwungen, miteinander , auszukommen ${ }^{6}$ - oder eben auch nicht. ${ }^{27}$ (2) Die Akteurkonstellation ,Schule'-Eltern ist eine mittelbare. Sie kommt zustande, weil Eltern Kinder haben, die durch die Inklusion ins Schulsystem zu Schülern werden. Nach Rolf-Torsten Kramer und Werner Helsper, die den ersten Beitrag in diesem Abschnitt liefern, ist also eine „komplexe Vernetzung der Ebene der Familie mit der Ebene der Schule auf der Ebene der Schülerbiographie“ gegeben. ${ }^{28}$ Durch die funktionale Ausdifferenzierung von Schule und Familie fallen den beiden Bereichen spezifische Funktionen und Umgangsmodi zu. Die Schule ist stärker universalistisch, von affektiver Neutralität, einer professionellen Einstellung geprägt, die Familie dagegen eher partikularistisch. Überwiegend bestimmen Intimität und Emotionalität die Beziehungen zwischen den Familienmitgliedern (vgl. Parsons 1968, 1972).

Im Schulsystem haben sich spezifische Umgangsformen zwischen Eltern und Schule eingeschliffen: Eltern haben gegenüber der Schule nichts zu fordern, sondern eine Bringschuld. Partizipationswünsche der Eltern werden von der Lehrerschaft gerne mit Verweis auf die eigene Professionalität abgewehrt (vgl. Krumm 1996). Da Eltern aber über praktische Erfahrungen im ,Erziehungsgeschäft ${ }^{\star}$ verfügen, kommt es durchaus vor, dass sie die exklusive Verortung pädagogischen Sachverstands bei der Lehrerschaft in Zweifel ziehen. Außerdem interessiert die Eltern an der Schule gemeinhin nicht unbedingt, das große Ganze', sondern eher das spezifische

26 Im Unterschied zur „Unterrichtspflicht“, die es in vielen anderen Ländern gibt, wodurch das Lehr-Monopol der staatlichen Schule zumindest auf der gesetzlichen Ebene eingeschränkt wird.

27 So kommt es zu durchaus unterschiedlichen Konstellationen, die von der Abgrenzung und Ablehnung der Schule durch die Eltern über Indifferenz und eher harmonische Koppelungen bis zur Überanpassung und auch Vereinnahmung reichen können (vgl. Tyrell 1987).

28 Das Zitat stammt aus dem vierten, hier nicht abgedruckten Kapitel des Beitrags von Kramer/Helsper. Die Lektüre des Gesamttextes ist empfehlenswert, weil die Erforschung der Beziehung zwischen Eltern (respektive Familie) und Schule nicht als Dyade, sondern als komplexer systemischer Zusammenhang zwischen drei Akteuren (Schule, Schüler, Familie) gesehen wird. 
Wohl und die möglichst erfolgreiche Schulkarriere des eigenen Kindes. Diese Sicht muss in Konflikt geraten mit der professionellen, auf pädagogischer Qualität und prinzipieller Gerechtigkeit gegenüber allen Schülern aufbauenden Attitüde des Lehrpersonals.

An der einseitigen Verlagerung von Verantwortung und Macht zugunsten der Schule hat sich trotz der in demokratischen Gesellschaften erforderlichen Installierung partizipativer Strukturen bisher nicht viel geändert (vgl. Melzer 1997), obwohl es formalisierte und auch informelle Formen der Elternpartizipation gibt. All dies steht in krassem Widerspruch zu den neuen Reformprogrammen, denn die modernisierte Schule soll innere Transparenz herstellen, ihr eigenes Profil entwickeln, um sich mit anderen Schulen vergleichen und sich letztlich von diesen unterscheiden zu können. Sie soll Qualität entwickeln und sichern. Wenn aber ihr tradiertes Verhältnis zu ihrer Klientel, zu ihren ,Kunden', so bliebe wie es ist, dann machte das wenig Sinn. Wozu Schulen, die sich profilieren, die sich voneinander unterscheiden, wenn sie für das Publikum nicht wählbar sind? Konkurrenz und Wettbewerb um Schüler, beziehungsweise um Eltern, die dann ihre Kinder einer Schule ihrer Wahl anbieten, sind die logische Folge. Das bewirkt zugleich, dass sich die Machtbalance zwischen Eltern und den Professionellen verschiebt. Die Schule ,gehört" dann nicht mehr nur den Lehrerinnen und Lehrern (vgl. Lange 2000), sondern die Klientel wird zum Teilhaber. Über Teilhaber kann die Institution dann nicht mehr verfügen, sondern ist zur Kooperation aufgerufen.

Es sollte nicht in Vergessenheit geraten, dass es sich hierbei um Szenarien handelt, die in der deutschen Bildungswirklichkeit weitgehend noch nicht realisiert wurden. Dennoch sind Veränderungen beobachtbar. Der Wandel der familialen Situationen in der deutschen Gegenwartsgesellschaft, erhöhte Anspruchshaltungen der Eltern gegenüber der Institution Schule, Veränderungen im Umgang mit partizipativen Instrumenten und Strategien eines politisch versierteren Publikums dürften an vielen Stellen dazu geführt haben, dass der Status quo, den vor allem einige Lehrer verteidigen, gar nicht mehr der ist, für den sie zu kämpfen glauben. Im zweiten und dritten Text dieses Textblocks finden sich Indizien, die diese Vermutung stützen. ${ }^{29}$

29 Ein aktuelles Beispiel mag dies illustrieren. Die Bertelsmann-Stiftung bietet interessierten Eltern eine Checkliste, anhand der diese besser darüber entscheiden können, was eine gute Schule für ihr Kind ist. Zehn Fragen werden vorgeschlagen (z.B.: Was lernen Schülerinnen und Schüler? Wie lernen sie? Arbeiten die Lehrer im Team? Fördert die Schule aktive Elternarbeit?) und es werden Ratschläge gegeben, wie man an solche Informationen gelangen kann (vgl. Bertelsmann-Stiftung 2002). In den Niederlanden veröffentlicht eine Verbraucherschutzzeitschrift solche Listen übrigens schon seit Jahrzehnten. In der deutschen Bildungsarena ist eine (private, aber selbstverständlich gemeinnützige) Stiftung als Akteur aber neu und beachtenswert! Andernorts haben solche Akteure eine lange Tradition und auch viel Ein- 
Den Auftakt dieses Buchabschnitts macht ein Aufsatz von Rolf-Torsten Kramer und Werner Helsper (Universität Halle), die mit ihrer Untersuchung systematische Bestimmungen der Situation von Schülern zwischen Familie und Schule liefern. ${ }^{30}$ Sie arbeiten die grundlegenden strukturellen Aspekte heraus und beschreiben die Forschungslage, die sich auf die Wandlungen der Beziehungen zwischen den drei Akteuren Schule, Schüler und Familie bezieht. Die theoretischen und empirischen Ausführungen sehen sie als notwendige Grundlage für einen ,reflexiven Umgang mit der Differenz von Schule und Familie“. Die Autoren bieten damit ein solides Fundament für die weitere Beschäftigung mit konzeptionellen und analytischen Fragen aus diesem Feld.

Im zweiten Text geht Heike Ackermann (Universität Marburg) der Frage nach, welche Rolle den Eltern in einer modernisierten Schule bei der Herstellung und Sicherung von Schulqualität zukommt. Auch sie charakterisiert den bisherigen Zustand als einen systematischen Ausschluss der Eltern von allen substantiellen Entscheidungen in schulischen Angelegenheiten, zeigt aber auch, dass dort, wo Eltern Einfluss haben, sie sich nach nachvollziehbaren Kriterien entscheiden (zum Beispiel beim Schulwahlverhalten) und damit längst schon Veränderungsprozesse in Gang setzen, die völlig kompatibel mit der Logik einer modernisierten Schule sind (weil zum Beispiel das Schulwahlverhalten den Faktor Konkurrenz ins Spiel bringt). Sie benennt weitere Reformtendenzen, die für eine verstärkte Elternpartizipation günstig sind (zum Beispiel die zunehmende Offenheit von Schullaufbahnen), weist aber auch auf die Gefahr der verstärkten sozialen Segregation hin, die sich aus gestärkten Elternrechten ergeben könnte. ${ }^{31}$ Sie sieht Chancen dafür, dass die Lehrerschaft ihre Skepsis gegenüber verstärkter Mitwirkung der Eltern aufgibt und erkennt, welche Ressource zur Verbesserung der Schulqualität sich aus kooperativem Handeln ergeben könnte.

fluss. Nationale Tests in den USA werden z.B. von Stiftungen wie der Carnegie Foundation entwickelt.

30 Mit dem expliziten Einbezug der SchülerInnen in das ,Spiel ${ }^{\star}$ zwischen Eltern und Schule schlägt dieser Text auch schon eine Brücke zu den nachfolgenden Texten von Ziehe und Melzer/Al-Diban, wo diese Akteurgruppe dann im Zentrum des Interesses stehen wird.

31 Vgl. dazu die Studie zu den segregativen Tendenzen in der niederländischen Schule von Katrin Dörner (im Textblock IV dieses Bandes). 


\section{ROLF-TORSTEN KRAMER, WERnER HELSPER \\ Schülerlnnen zwischen Familie und Schule - systematische Bestimmungen}

Das Verhältnis von Familie und Schule ist durch Spannungen, gegenseitige Anspruchshaltungen, Anforderungen sowie Grenzziehungen bestimmt. So löst die Schule die Kinder aus ihren Familien heraus, bricht damit tendenziell die umfassende Sozialisationswirkung von Familie und Milieu. In unterschiedlichen, besonders deutlich in erziehungsstaatlichen, aber auch teilweise in reformpädagogischen Konzepten, verbindet sich die Schule mit weitreichenden, auf die Gesamtformung der Person zielenden Erziehungsoder Bildungsvorstellungen. Diese weitreichenden schulischen Erziehungsansprüche führen, sofern es nicht eine enge Verkopplung von Schul- und Familienmilieu gibt, zu Abgrenzungskämpfen oder -strategien auf seiten der Familien, die dies als unzulässigen Übergriff verstehen. Andererseits stellen Familien durchaus umfassende Ansprüche an die schulische Versorgung ihrer Kinder und versuchen gezielt auf die Schule Einfluß zu nehmen. Diese gegenseitigen Vereinnahmungsversuche dürfen aber nicht darüber hinweg täuschen, daß das Verhältnis der beiden Teilsysteme zueinander nicht als Einheit, sondern als Differenz zu bestimmen ist, die aber auch Anspruchs- und Vereinnahmungshaltungen antreibt (vgl. Tyrell 1985, 1987).

Im Spannungsfeld dieser Differenz sind nun die Diskussionen zum Verhältnis von Familie und Schule anzusiedeln, wie sie sich [...] in den letzten Jahrzehnten verstärkt ausformen. [...] Die Lebensferne, die Künstlichkeit, die Trennung der Schule von alltäglicher Erfahrung, von lebensweltlichen und familiären Hintergründen, Sinnlosigkeitsgefühle, Disziplinund Motivationsprobleme sowie Schulunlustphänomene auf seiten der SchülerInnen, diese Krisendiagnosen lassen sich wie eine Negativbilanz der Differenzierung lesen. [...] Der Appell, die Familie möge sich doch an ihre emotional stabilisierende Haltung erinnern und damit die „kriselnde“ Schule entlasten, erfolgt allerdings gegenüber einer Familie, die nicht weniger als die Schule mit Krisendiagnosen belegt wird. [...] Gerade diese Einschätzungen führen nun dazu, daß von der Schule „Familienersatzleistungen“ erwartet werden und die Schule quasi als „Familienersatzversorgungseinheit" konzipiert wird (vgl. Struck 1995, 1997; Böhnisch 1999: 25). $[\ldots]$

\section{Perspektiven zum Verhältnis von Familie und Schule}

Das Verhältnis von Familie und Schule ist u.E. bislang vor allem unter den fünf folgenden Perspektiven betrachtet, analysiert und teilweise auch empirisch erforscht worden:

1) Soziale Reproduktion bzw. Transformation durch Bildungszertifikate: Schule ist aus der Sicht der Eltern bzw. der Familie zu einer unerläßli- 
chen Instanz der Statusreproduktion bzw. -transformation geworden. Familien vermögen aufgrund ihrer Ressourcen alleine nicht mehr die zukünftige soziale Plazierung der nachfolgenden Generation zu sichern. [...] Auf der anderen Seite ist es gerade die zu große Distanz der Eltern gegenüber der Schule, die Gleichgültigkeit gegenüber der schulischen Bildungslaufbahn, die mangelnde Unterstützung ihrer Kinder in schulischen Belangen, die langfristig die Biographie der Heranwachsenden belasten kann (vgl. Hurrelmann/Wolf 1986, Nittel 1992). Auch wenn die Selektionshärte infolge des „Bildungs-Fahrstuhleffekts“ nachgelassen hat (vgl. Meulemann 1999) und geschlechtsspezifische Bildungsungleichheiten abgebaut sind, zeigen sich, $[\ldots]$ entlang neuer soziokultureller und ethnischer Exklusionen, nach wie vor deutliche soziale Benachteiligungen, auch wenn die einfache These einer zirkulären sozialen Reproduktion ausdifferenziert worden ist (vgl. Meulemann 1995; Ditton 1992, 1995; Brendel 1998).

2) Kulturelles und habituelles „Passungsverhältnis “: Daneben ist aber auch die kulturelle Passung für das Verhältnis von Schule und Familie bedeutsam. Zwar bricht die Schule mit ihrer universalistischen Orientierung jede inhaltlich spezifische Lebensform, aber für die generative Transformation und Reproduktion ist es entscheidend, wie Schulen mit ihren Werten, pädagogischen Prinzipien und Schulmythen an familiäre Lebensformen anknüpfen, also in welches Verhältnis die kulturelle Form der Familie und der Schule zueinander gesetzt werden. [...] Was in bildungsambitionierten familiären Milieus den Charakter der Auswahl annimmt, zeigt sich in anderen Familienmilieus oder in sozialen und regionalen Räumen ohne Schulwahlmöglichkeiten eher als erzwungene Anschlußfähigkeit oder AbstoBung zwischen schulischer und familiärer habitueller Ausformung. [...]

3) Schule und Familie unter der Perspektive von sozialer Integration und Individuation: Einerseits integriert die Schule alle Heranwachsenden zum gleichen biographischen Zeitpunkt homogenisierend in die Schülerrolle. Alle können und müssen damit an schulischen Bildungsprozessen, Leistungsstatuszuweisungen und Selektionsvorgängen partizipieren. [...] Dies [wird] einmal positiv als Sozialisations- oder als Integrations- und Legitimationsfunktion der Schule thematisiert, die damit zum Erhalt der gesellschaftlichen Ordnung beiträgt. Zum anderen wird dies negativ als Unterwerfung und ideologische Einordnung in bestehende Herrschafts- und Ungleichheitsverhältnisse kritisiert. Andererseits wird [...] auch die Bedeutung der Schule für die Individuation der Jugendlichen hervorgehoben. Die Schule setzt in dieser Sicht die familiären Separationsprozesse auf einem erweiterten Niveau fort, indem die Heranwachsenden aus der Familie herausgelöst werden und in transfamiliären Zusammenhängen angesichts neuer Anforderungen mit anderen interagieren müssen, die nicht mehr durch Verwandtschaft oder Freundschaft als nahe Andere charakterisiert sind [...].

Schließlich wird das Verhältnis von Familie und Schule aus der Perspektive der 4) Beziehung zwischen zwei sozialisatorischen Teilsystemen 
bestimmt, die füreinander Leistungen erbringen und Ressourcen bereitstellen. Beide Teilsysteme beziehen sich dabei über das „Kind“ aufeinander, einmal, auf der Seite der Familie, in Form des unauswechselbaren, einzigartigen Familienkindes im Code der Liebe, zum anderen, auf Seite der Schule, in Form des austauschbaren Kindes „Schüler“ über den Code vermittelbar/nicht-vermittelbar und der - nicht genuin pädagogischen - Selektionscodierung „,besser-schlechter“ (Kade 1997) [...].

5) Das Verhältnis von Familie und Schule unter der Perspektive der Elternpartizipation und der Einflußnahme von LehrerInnen auf die Familie: Damit geht die Frage einher, inwieweit die Schule legitim in familiäre Belange eingreifen darf und umgekehrt, inwiefern Eltern legitim auf schulische Entscheidungen Einfluß nehmen dürfen. [...]

\section{Schule und Familie unter der Perspektive der Differenz}

Die Ausdifferenzierung von Familie und Schule hat spezifische Funktionen der Familie an die Schule übergehen lassen. Gleichzeitig vollzog sich, lebenslagespezifisch allerdings sehr unterschiedlich, eine Funktionsverschiebung innerhalb der Familie, die zunehmend um reproduktive, emotionale und Erziehungsleistungen zentriert wurde. Im Rahmen der Durchsetzung der Schulpflicht und der schulischen Systembildung (vgl. Herrlitz u.a. 1984, Kolbe 1994) wurden Kindheit und Jugend als Phasen von Bildungsprozessen und disziplinarischer Erziehungskontrolle etabliert. Mit der sukzessiven Durchsetzung des Berechtigungswesens [...] wurde es für Familien zwingend, die generative Statusreproduktion über die Instanz der Schule zu sichern. Die soziale Plazierung, die Vermeidung von Abstieg bzw. der soziale Aufstieg ist für Eltern nur noch über den schulischen „Umweg“ ihrer Kinder gestaltbar. Das heißt aber auch, daß die Sicherung privilegierter Positionen zunehmend weniger direkt dem elterlichen Einfluß unterliegt und dies zweifach: Zum einen können Eltern nicht direkt ihre Ambitionen auf ihre Kinder übertragen. Aber gerade die Leistungsbereitschaft und die Schul- und Statusaspirationen sind für langfristigen beruflichen Erfolg hoch bedeutsam (vgl. Meulemann 1995, 1999). Zum zweiten kann sich der soziale Ort der Herkunftsfamilie nur über den für alle gleichermaßen homogenisierten Leistungswettbewerb der Schule reproduzieren. [...] Im Rahmen dieser schulischen Systembildung wird es für Familien erforderlich, in ihre Kinder als einem „schulischem Bildungsprojekt“ zu ,investieren", ihnen Bildungsatmosphäre zuteil werden zu lassen, sie durch häusliche Bildungs- und Erziehungsarbeit (vor allem, auch heute noch, eine Arbeit der Frauen) zu stützen, schulisch zu flankieren und zu ambitionieren. Schule wird - als das Andere der Familie - dadurch immer mehr auch zu einem familiären „Innen“.

Parallel dazu entwickelt sich [...] eine um Emotionalität, Liebe, Intimität, das Kind und seine Erziehung zentrierte Lebensform, die auf geschlechtsspezifischer Arbeitsteilung, einer Polarisierung der Geschlechts- 
charaktere und einer Trennung von Öffentlichkeit und Privatheit beruht. [...]

Im Sinne einer „funktionalen Ausdifferenzierung“ lassen sich Schule und Familie somit idealtypisch kontrastieren: [...] Die Familie [ist] gekennzeichnet durch exklusive Intimität und Emotionalität, eine sinnlichleibliche Basis, durch Unauswechselbarkeit und Exklusivität der gegenseitigen Bindungen und Bindungsansprüche. [...] Das Kernelement dieser modernisierten Familienform ist die mit weitreichenden Ansprüchen versehene primäre dyadische und schließlich als erster Individuierungsschritt „triadische“ Beziehung zwischen dem Kind und den signifikanten Anderen, eine dezentrierende Separation, die die Schule weiterführen kann.

Die Schule ist demgegenüber auf affektiv neutrale Haltungen eingespielt, auf eher spezifische und universalistische Haltungen der LehrerInnen gegenüber SchülerInnen. Diese sind daher in aller Regel keine signifikanten Anderen mit einer exklusiven Bedeutung für die Heranwachsenden. [...] Der Zugang zu den Jugendlichen ist damit „spezifisch“ beschränkt, zielt in aller Regel nicht auf die ganze Person der Heranwachsenden, sondern auf ein eingegrenztes Segment des Selbst, was im übrigen auch als Schutz gegenüber weitreichenden institutionellen Übergriffen zu verstehen ist. $[\ldots]$

In dieser Perspektive ergibt sich durch die Trennung von Familie und Schule gerade eine gelingende Ergänzung: Was als Funktionsverlust der Familie gegenüber der Schule erscheint, kann auch als Entlastung der Familie durch die Schule verstanden werden. Und umgekehrt entlastet die Familie die Schule von dem, was sie aufgrund ihrer rollenförmigen, organisatorischen Struktur nicht zu leisten vermag. Die Familie wird zum Stützsystem der Schule und umgekehrt kann sich die Familie auf schulische Leistungen stützen, nicht zuletzt auf die Freiräume und Möglichkeiten, die daraus resultieren, daß sich die Kinder die Hälfte des Tages außerhalb der Familie aufhalten. Daraus könnte nun die These einer Harmonie durch Differenz abgeleitet werden, in der Annahme, daß sich die beiden sozialisatorischen Instanzen gegenseitig stützen und ergänzen.

Diese idealtypische Konstruktion setzt allerdings die prototypisch konstruierte bürgerliche Kernfamilie voraus, die als Stützsystem der Schule in der familiären Erziehung ,zuarbeitet“: In Form der Erzeugung schulischer Lernmotivation, Betreuung von Schularbeiten und Hausaufgaben, emotionaler Stützung bei Belastungen, Mißerfolgen, bei der zeitlichen Strukturierung des kindlich/jugendlichen Tagesablaufes nach schulischen Zeitvorgaben etc. Hier sind Relativierungen angebracht: Erstens trifft diese idealtypische familiär-bildungsorientierte Haltung längst nicht auf alle familiären Lebensformen zu. Zweitens unterschlägt diese idealtypische Konstruktion Problematiken und Krisen der idealtypischen bürgerlichen Kernfamilie in ihrer modernisierten Form. Drittens läßt sich [...] eine Erosion und Deinstitutionalisierung dieser Familienform feststellen. Vor diesem Hintergrund gestaltet sich das Verhältnis von Familie und Schule - ohne daß die These 
der strukturellen Differenz zu revidieren wäre, vielmehr gerade aufgrund dieser konstitutiven Differenz - weit spannungsträchtiger. Spannungsreicher zum ersten deswegen, weil

a) im Rahmen der Bildungsexpansion zusehends mehr „Familien“ immer länger mit der Schulbildung ihrer Kinder, der Planung und Organisation der schulischen Laufbahn und Karriere beschäftigt sind;

b) mit der „Inflationierung“ schulischer Zertifikate Familien zusätzliche Anstrengungen unternehmen müssen, um ihre Kinder möglichst optimal auf Schulen und Leistungsrängen zu plazieren, und vor allem darüber hinaus für ergänzende und erweiternde Bildungsmöglichkeiten Sorge tragen müssen;

c) die „Entauratisierung“ der Schule (vgl. Ziehe/Stubenrauch 1982, Helsper 1990, Bois-Reymond 1998) [...] und die Entwicklung vom Bildungsprivileg zum Bildungszwang für die Familien bedeutet, daß sie verstärkt familiäre Stützungs-, Motivierungs- und Sinnstiftungsarbeit gegenüber ihren Kindern erbringen müssen;

d) das Anwachsen der biographischen Optionen bei erweiterten biographischen Unsicherheiten es erforderlich macht, daß Familien die Bildungsbiographie ihrer Kinder verstärkt flankieren und beratend begleiten müssen;

e) weil die Schule damit auch zunehmend zu einem konflikthaften Familienthema wird, auch wenn die von Tyrell skizzierte „Überanpassung der Familie an die Schule“ (vgl. Tyrell 1987) sicherlich nur eine, allerdings bedeutsame, Strukturvariante darstellt.

Neben diesen, aus der gesteigerten Ansprüchlichkeit und Riskanz von Bildungsverläufen resultierenden, Spannungsmomenten wird das Verhältnis zwischen Schule und Familie zweitens auch dadurch spannungsreicher, daß die Diagnosen zur Gegenwart und Zukunft der modernisierten Kernfamilie darauf hindeuten, daß die Voraussetzung der familiären Stützungsarbeit in Gestalt der geschlechtsspezifisch differenzierten Haus- und Erziehungsarbeit sich ambivalenter gestaltet. [...] Fraglos läßt sich [...] eine Erosion und „Deinstitutionalisierung“ der bürgerlichen Kernfamilie konstatieren (vgl. Tyrell 1988, Sieder 1997), die zentral durch die steigende Verberuflichung, die berufliche Ambitionierung und die Individualisierung im weiblichen Lebenszusammenhang gekennzeichnet ist. Die hohen Ansprüche an Liebe, Intimität, Glück, Geborgenheit steigern sich eher noch, ebenso wie die Kindzentrierung. Zugleich aber ergeben sich Spannungen hinsichtlich eigener Lebensziele, individualisierter Lebenswerte, werden die familiären Beziehungen fragiler und störanfälliger und tendieren die kommunikativen Aushandlungsprozesse dazu, auch anstrengend und aufreibend zu werden. Damit bewegt sich die von Deinstitutionalisierungen betroffene modernisierte Kernfamilie in den Ambivalenzen der Bilder des Kindes als Sinnstifter und Glücksbringer, des Kindes als Projekt hoher elterlicher Ambitionen 
und des Kindes als Last angesichts eigener Individualisierungsansprüche (vgl. Helsper 1989) gegenüber den gestiegenen Anforderungen an die Begleitung der Schullaufbahn und Bildungsbiographie.

Drittens schließlich gestaltet sich die Differenz von Schule und Familie aus der Perspektive der Schule ambivalenter. Denn die LehrerInnen werden mit einer Relativierung der Selbstverständlichkeit von Bildungsinhalten, der verstärkten Konkurrenz gegenüber alternativen Informationsmöglichkeiten, den Veränderungen jugendlichen Aufwachsens und den daraus resultierenden verstärkten Infragestellungen schulischer Regeln konfrontiert. Dies erfolgt im Rahmen einer Globalisierung schulischer Leistungsvergleiche und steigender Ansprüche an die Selbststeuerung der Einzelschule bei knapper werdenden Ressourcen. In diesem Zusammenhang führen dann steigende Erwartungen von Eltern an die schulische Betreuung ihrer Kinder, an die Leistungsfähigkeit von Schulen, an die optimale Vorbereitung für weitere Bildungsprozesse und an die stützende Entlastung der Familie von Erziehungsaufgaben, die sich zu den insgesamt steigenden Erwartungen an die Leistungsfähigkeit der Schulen hinzu addieren, zu einer weiteren Anspruchssteigerung.

\section{Familie und Schule - zwischen Entdifferenzierung, distanzierter Fremdheit und reflexiver Differenz}

Aus den bisherigen Ausführungen wird deutlich, erstens daß die Differenz von Familie und Schule als konstitutiv und strukturell gegeben begriffen wird; zweitens daß jede Form einer Überanpassung der Familie an die Schule bzw. einer Überanpassung der Schule an die Familie zu problematischen Formen der Entdifferenzierung führt; drittens daß die Spannungsund Krisenmomente im Verhältnis von Schule und Familie nicht übergangen werden und mit Differenzargumenten negiert werden können; und daraus resultiert viertens, daß es um einen reflexiven Umgang mit der Differenz von Schule und Familie gehen muß, die sowohl eine distanzierte $\mathrm{Zu}$ sammenhanglosigkeit zwischen Familie und Schule als auch eine inkonsistente Vermischung vermeidet.

Dabei entsteht in den Diskursen der letzten Jahre verstärkt der Eindruck, daß sich die Blickrichtung von der Familie als Stützsystem der Schule zur Schule als Stützsystem der Familie verlagert. Zumindest auf der Ebene der Forderungen und Reformprogrammatik sind Züge einer „Überanpassung der Schule an die Familie" nicht zu übersehen, also die Aufforderung an Schule und LehrerInnen, daß sie kompensatorisch Elemente der Familie in sich aufnehmen sollen. Die "sozialpädagogische Schule" (vgl. schon Homfeldt 1977) gewinnt familialistische Züge mit problematischen Konsequenzen vor allem für die Individuationspotentiale der Jugendlichen (vgl. Helsper 1990, Terhart 1996).

Aus professionstheoretischer Perspektive ist festzuhalten, daß das LehrerInnenhandeln in der antinomischen Spannung von diffusen und spezifi- 
schen Haltungen, von Nähe und Distanz situiert ist (vgl. Oevermann 1996, Helsper 1996, 2000) und damit gerade eine Zwischenstellung zwischen formal-organisatorischen und familialen Handlungsmustern aufweist. Von da aus lassen sich sowohl völlig distanzförmige Entfremdungen als auch entdifferenzierende Formen des Verhältnisses von Familie und Schule kritisieren und zurückweisen. Wenn das Handeln von LehrerInnen um die Vermittlung von Inhalten zentriert ist und darin Bildungsstrukturen auf seiten der Schülerinnen aufgebaut und lebenspraktische Autonomie befördert werden soll, dann bedarf es hier notwendigerweise diffuser Orientierungen gegenüber den Ausgangslagen der SchülerInnen, den Lernkrisen und lebensweltlichen Hintergründen, die in einem vertrauensvollen Arbeitsbündnis fundiert sein müssen. Der Versuch von LehrerInnen, als Elternersatz zu fungieren, führt gerade in deprofessionalisierende, inkonsistente und für paradoxe Verstrickungen prädisponierte Haltungen, die im Rahmen einer entsprechenden schulischen Programmatik nochmals gesteigert werden (vgl. Helsper 2000). Das gleiche gilt für formal-rationale, vergleichgültigte Haltungen, die als Pendant einer deprofessionalisierenden Familialisierung erscheinen und im Sinne einer deprofessionalisierenden Bürokratisierung verstanden werden können. Die reflexive Differenz beinhaltet nun genau die Fähigkeit, den professionellen Kern des Lehrerhandelns nicht familialistisch und nicht vergleichgültigt bürokratisch zu interpretieren, sondern auf der Grundlage von Distanz diffuse Beziehungen zu ermöglichen, die aber keine Familienersatzbeziehungen sein können. Zeigen sich hier systematisch Wünsche und Ansprüche von SchülerInnen nach umfassender psychosozialer Stützung und Stabilisierung, dann muß [...] über professionelle Ergänzung des Lehrerhandelns durch Sozialpädagogen, Psychotherapeuten etc. nachgedacht werden. In diesem Sinne kann die Schule durchaus ein Ort des Zusammenwirkens unterschiedlicher Professionen sein, wie etwa Kraft sie skizzenhaft hinsichtlich der „Sozialpädagogisierung der Schule“ entwirft:

„In dem Maße, wie familiale Sozialisationsprozesse defizitär verlaufen, muß das System dafür sorgen, diese Defizite zu kompensieren. [...] Derzeit sieht es so aus, als ob sich diese Entwicklung hauptsächlich zu Lasten des Unterrichts vollzieht. Man kann sich aber eine Schule denken, in der Pädagogen arbeiten und nicht ,nur' Lehrer [...]. Innerhalb der Lehrerrolle erscheint die Grenze möglicher Ausdifferenzierung offensichtlich erreicht, nicht jedoch die Grenze der Differenzierung pädagogischer Rollen innerhalb der Schule als Institution.“ (Kraft 1999: 544)

$[\ldots]$

\section{Literatur}

Böhnisch, L.: Abweichendes Verhalten. Weinheim/München 1999.

Bois-Reymond, M. du: Aura und Modernisierung der Schule. In: Keuffer, J. u.a. (Hg.):

Schulkultur als Gestaltungsaufgabe. Weinheim 1998, S. 326-337

Brendel, S.: Arbeitertöchter beißen sich durch. Weinheim/München 1998 
Combe, A./Helsper, W.: Was geschieht im Klassenzimmer? Perspektiven einer hermeneutischen Schul- und Unterrichtsforschung. Weinheim 1994

Ditton, H.: Ungleichheit und Mobilität durch Bildung. Weinheim/München 1992

Ditton, H.: Ungleichheitsforschung. In: Rolff, H. G. (Hg.): Zukunftsfelder der Schulforschung. Weinheim 1995, S. 89-125

Helsper, W.: Selbstkrise und Individuationsprozeß. Subjekt- und sozialisationstheoretische Entwürfe zum imaginären Selbst der Moderne. Opladen 1989

Helsper, W.: Schule in den Antinomien der Moderne. In: Krüger, H.-H. (Hg.): Abschied von der Aufklärung? Opladen 1990, S. 175-195

Helsper, W.: Antinomien des Lehrerhandelns in modernisierten pädagogischen Kulturen: Paradoxe Verwendungsweisen von Autonomie und Selbstverantwortlichkeit. In: Combe, A./Helsper, W. (Hg.): Pädagogische Professionalität. Frankfurt a. M. 1996, S. 521-569

Helsper, W.: Antinomien des Lehrerhandelns und die Bedeutung der Fallrekonstruktion - Überlegungen zu einer Professionalisierung im Rahmen universitärer Lehrerausbildung. In: Cloer, E. u.a.: Lehrerbildung. Weinheim/München 2000

Herrlitz, H. G./Hopf, W./Titze, H.: Institutionalisierung des öffentlichen Schulsystems. In: Baethge, M./Nevermann, K. (Hg.): Enzyklopädie Erziehungswissenschaft. Band 5. Stuttgart 1984, S. 55-71

Holtappels, H. G.: Ganztagsschule und Schulöffnung. Weinheim/München 1994

Homfeldt, H.: Die sozialpädagogische Schule. München 1977

Hurrelmann, K./Wolf, H. K.: Schulerfolg und Schulversagen im Jugendalter. Fallanalysen von Bildungslaufbahnen. Weinheim/München 1986

Kade, J.: Vermittelbar/nicht-vermittelbar: Vermitteln: Aneignen. Im Prozeß der Systembildung des Pädagogischen. In: Lenzen, D./Luhmann, N. (Hg.): Bildung und Weiterbildung im Erziehungssystem. Frankfurt a. M. 1997, S. 30-70

Kalthoff, H.: Wohlerzogenheit. Frankfurt/New York 1997

Kolbe, U.: Strukturwandel schulischen Handelns. Weinheim 1994

Kraft, V.: Erziehung im Schnittpunkt von Allgemeiner Pädagogik und Sozialpädagogik. In: Zeitschrift für Pädagogik 45, H. 4, 1999, S. 531-548

Lüscher, K.: Familienrhetorik, Familienwirklichkeit, Familienforschung. In: Vaskovics, L. A. (Hg.): Familienleitbilder und Familienrealitäten. Opladen 1997, S. 50-68

Lüscher, K.: Familie und Familienpolitik im Übergang zur Postmoderne. In: Lüscher K. u.a. (Hg.): Die ,postmoderne' Familie. Konstanz 1988, S. 15-39 (1990)

Meulemann, H.: Die Geschichte einer Jugend. Opladen 1995

Meulemann, H.: Stichwort: Lebenslauf, Biographie und Bildung. In: Zeitschrift für Erziehungswissenschaft 2, H. 3, 1999, S. 305-325

Nittel, D.: Gymnasiale Schullaufbahn und Identitätsentwicklung. Weinheim 1992

Oevermann, U.: Theoretische Skizze einer revidierten Theorie professionellen Handelns. In: Combe, A./Helsper, W. (Hg.): Pädagogische Professionalität. Frankfurt a. M. 1996, S. 70-182

Sieder, R.: Besitz und Begehren, Erbe und Elternglück. Familien in Deutschland und Österreich. In: Berguière, A. u.a. (Hrsg.): Geschichte der Familie. 20. Jahrhundert. Darmstadt 1997, S. 211-285.

Struck, P.: Schulreport. Reinbek 1995

Struck, P.: Neue Lehrer braucht das Land. Darmstadt 1997.

Terhart, E.: Zur Neuorientierung des Lehrens und Lernens - Kultureller Wandel als Herausforderung für die Professionalisierung des Lehrerberufs. In: Helsper, W./Krüger, H.-H./Wenzel, H. (Hg.): Schule und Gesellschaft im Umbruch. Band 1. Theoretische und internationale Perspektiven. Weinheim 1996, S. 319-332

Tyrell, H.: Gesichtspunkte zur institutionellen Trennung von Familie und Schule. In: Melzer, W. (Hg.): Eltern, Schüler, Lehrer. Weinheim/München 1985, S. 81-102 
Tyrell, H.: Die „Anpassung“ der Familie an die Schule. In: Oelkers, J./Tenorth, H. E. (Hg.): Erziehungswissenschaft und Systemtheorie. Weinheim 1987, S. 102-125

Tyrell, H.: Ehe und Familie - Institutionalisierung und Deinstitutionalisierung. In. Lüscher, K. u.a. (Hg.): Die ,postmoderne' Familie. Konstanz 1988, S. 145-157 (1990)

Ziehe, T./Stubenrauch, H.: Plädoyer für ungewöhnliches Lernen. Reinbek 1982

\section{HEIKE ACKERMANN}

Eltern - Ratgeber für Schulqualität?

Über die Rolle der Eltern im Prozeß der Schulentwicklung

$[\ldots]$

Elternrechte grenzen Eltern aus

Die schulische Perzeption der Eltern beruht vornehmlich auf deren staatlich fixierter Rolle als Erziehungsberechtigte (Art. 6,2 GG), mit denen sich die Schule den Einflußbereich der Erziehungsaufgaben teilt, nicht aber auf einem pädagogischen Verständnis der Eltern als Erziehenden. Während den Eltern in den Angelegenheiten der Schule nur eine eher subalterne Rolle zukommt, bestehen umgekehrt seitens der Schule massive Erwartungen an familiale Unterstützungsleistungen zur Erfüllung schulischer Leistungsanforderungen. [...]

Im Bereich der Schule sind den Eltern kollektiv in den Länderschulgesetzen formalisierte Rechte eingeräumt worden. Als ,echte“ Mitwirkungsrechte beziehen sie sich vorwiegend auf Fragen der Schul- und Hausordnung und der Schulwegsicherung. Bezüglich der Unterrichtsplanung und gestaltung sind ihnen Anhörungs- und Beratungsrechte eingeräumt worden (vgl. Jach 1992: 138). Diese bloß formalen Kollektivrechte der Eltern, so die Forschung, begünstigen höhere Sozialschichten dieser heterogenen Gruppe, und sie haben eine umgreifende Demokratisierung und Erneuerung der Schule verhindert (vgl. Melzer 1987).

Seit der juristischen Aufhebung des obrigkeitsstaatlichen Schulverständnisses als einer nicht grundrechtsfähigen Lehranstalt32, die sich einem gesellschaftlich umgreifenden Modernisierungsprozeß verdankt, wird es zwar verstärkt für erforderlich erachtet, Konflikte, die aus der Funktion der Schule als Instanz sozialer Plazierung entstehen, mit elterlichen Ansprüchen an Bildung und Qualifizierung ihrer Kinder kommunikativ zu vermitteln. Bislang bedeutete diese Aushandlung von Interessen jedoch nur, daß die Eltern - unbeschadet ihrer erwünschten Hilfsdienste bei Klassenfahrten, Festen oder Feiern - aus pädagogischen Entscheidungen und Belangen der Schule „rausgehalten“ worden sind. Eine inhaltliche Mitwirkung und Teil-

32 Dieses begriff die Schule als „besonderes Gewaltverhältnis“, in dem die Rechte des einzelnen durch innerschulische Maßnahmen nicht berührt werden konnten (vgl. Lenhardt 1993). 
habe der Eltern an der pädagogischen Schulgestaltung, die seit langem als unabdingbar für den Erfolg pädagogischer Verbesserungen gilt (vgl. Deutscher Bildungsrat 1973), und die die unterschiedlichen Lebensweltbezüge der Schüler in Elternhaus und Schule miteinander zu vermitteln strebt, kam aufgrund eines vornehmlich auf die Wissensvermittlung im Unterricht und weniger auf die Erziehungsaufgabe gerichteten Schulverständnisses kaum ins Blickfeld.

\section{Das Schulwahlverhalten von Eltern orientiert sich an den Zukunftsperspektiven}

[...] Als individuelle Akteure der Schulwahlentscheidungen bescherten die Eltern den Schularten eine Konkurrenzsituation, indem sie aufgrund der gewachsenen gesellschaftlichen Bedeutung einer höherwertigen Schulbildung für ihre Kinder einen mittleren Schulabschluß oder das Abitur anstreben. Die Hauptschule wurde zur Schulart mit der geringsten Nachfrage. [...]

Die Schulwahlentscheidungen zeigen denn auch die wesentliche Orientierung von Eltern an, die auf der Hierarchie der Schularten beruht. Qualitative Unterschiede der Schulen spielen offenbar für sie vorerst nur eine geringe Rolle. Selbst die in ihrem curricularem Bildungsprogramm freieren Privatschulen werben gegenüber den Eltern mit der Vergabe von höherwertigen Abschlüssen, zu denen sie auch Schüler mit Lernschwierigkeiten führen würden. [...]

Die Bildungsaspirationen der Eltern sind mit dem vielzitierten gesellschaftlichen „Wertewandel“ verkoppelt, der auch die Erziehungsnormen und -ziele der Schule tangiert. Eltern drücken in ihren veränderten Wertorientierungen ,die objektiv notwendige Anpassung der Sozialpsyche an die Herausforderungen eines übergreifenden sozioökonomischen Modernisierungsprozesses" aus (Hepp 1996: 23). Beeinflußt vom Wandel in der Arbeitswelt sind in diversen Lebenssphären der Individuen ,die Selbständigkeitserwartungen an die einzelne Person gewachsen“ (ebd., 21). Ausgehend von dieser gesellschaftlich vermittelten Erfahrung wünschen sich Eltern von der heutigen Schule, daß ihre Kinder dabei unterstützt werden, frühzeitig selbständig und entscheidungsfähig zu werden, um künftigen, in ihren Dimensionen und Perspektiven weitgehend unklaren beruflichen und sozialen Anforderungen gerecht werden zu können. Die Rationalität der elterlichen Bildungsentscheidungen besteht darin, möglichst lange die Bildungswege und damit die Entwicklungs- und Zukunftschancen für ihre Kinder offen zu halten. [...]

\section{Die Offenheit der Bildungslaufbahn als strukturelle Bedingung der Elternpartizipation}

Die Offenheit der Bildungswege hat sich als wichtige Voraussetzung der Bereitschaft von Eltern erwiesen, in der Schule aktiv mitzuwirken. [...] So 
ist das Interesse der Eltern an der Schule zu Beginn der Schullaufbahn ihres Kindes hoch, ebenso wenn Übergangsentscheidungen anstehen oder wenn der Schüler die Schulart gewechselt hat, oder die Einmündung in eine berufliche Ausbildung bevorsteht. In Schularten, wo der Abschluß klar vorgezeichnet scheint, geht die Elternbeteiligung vergleichsweise zurück. [...]

\section{Neue Verantwortlichkeiten durch Einbindung in die pädagogische Schulgestaltung}

[...] Im Rahmen neu geschaffener schulischer Mitwirkungsorgane wie der Schulkonferenz in Hessen, Niedersachsen, Bremen und Hamburg werden Eltern in die Verantwortung für das Schulprogramm eingebunden. [...] Die verstärkte In-Pflichtnahme der Eltern entspricht einer vorhandenen gesellschaftlichen Tendenz zur Übertragung von Verantwortung im Rahmen der „Bürgergesellschaft“ und der Verlagerung von Entscheidungen an untere Instanzen in der Hierarchiestruktur von Organisationen. Kritisiert wird, daß das individuelle Elternrecht durch die Stärkung des kollektiven Rechts beschnitten wird (vgl. Wollenweber 1997: 126).

[...] Die Einbeziehung von Eltern, die Kooperation der Schule mit ihrer Umwelt gelten ebenso als moderierende Variablen „guter"Schulen wie das Schulklima, die Qualität des Unterrichts und die Qualität der Schulleitung (vgl. Thonhauser 1996: 399). Gravierend ist, daß die Individuen auf ihre neuen Aufgaben der Alltagsarbeit in sozialen Kontexten, die auf sie zukommen, noch nicht vorbereitet sind. Es gilt, die nahezu ausschließlich auf Klassenebene sich beziehende Elternarbeit der Lehrer, für deren pädagogische Gestaltung diese bereits im herkömmlichen Rahmen kaum ausgebildet sind, in ein pädagogisches Gesamtkonzept der Schule einzubinden und weiterzuentwickeln. Hierbei sind künftig Initiativen der Schulleitung gefordert.

\section{Die Mitwirkung der Eltern am Schulprogramm}

Eltern sollen beispielsweise bei Fragen der pädagogischen Zielsetzung der einzelnen Schule im Rahmen eines Schulprogramms mitwirken, bei der Entscheidung über die Organisation eines flexibilisierten Stundenplans im Rahmen einer Jahresstundentafel, der Zusammenfassung von Fächern zu Lernbereichen, bei Entscheidungen über freiwillige Unterrichtsveranstaltungen, über Samstagunterricht, bei der Frage, ob bis zur dritten Jahrgangsstufe auf Ziffernoten zugunsten anderer Beurteilungsformen verzichtet werden soll, über Grundsätze der Zusammenarbeit mit anderen Schulen bis hin zur Verwendung von Haushaltsmitteln oder der Wahl der Schulleitung - Aufgaben also, die bisher hoheitlich der Bildungsadministration vorbehalten waren und nun der ,Schulgemeinde“ überantwortet werden.

Die Schule bekommt in diesen Mitentscheidungen für Eltern einen komplexeren Charakter, der den Rahmen der einzelnen Schulkasse ihres 
Schulkindes übersteigt. Auf der Klassenebene konnten Eltern bereits ein Korrektiv zu Lehrerentscheidungen darstellen, wenn sie beispielsweise monierten, daß soziale Lernprozesse in der Klasse zu kurz kämen oder die Kinder mit der Fülle oder dem Anforderungsniveau der Hausaufgaben überfordert seien. In einer Perspektive der gesamten Schule werden Lernoder Integrationsprobleme verschiedener Schülergenerationen oder Altersstufen thematisiert werden, Stärken oder Schwächen des schulischen Bildungsangebotes, Vergleichbarkeiten schulischer Abschlüsse, die Offenheit von Bildungswegen, die berufliche Vorbereitung durch die Schule, die Notwendigkeit der Kooperation mit anderen Schulen, um Übergänge zu erleichtern, oder mit außerschulischen Bildungsträgern, die Probleme von Schülerinnen und Schülern mit bestimmten Fächern oder die Art und Weise der Leistungsbeurteilung.

Wenn seitens der Lehrer aber auch über das mangelnde pädagogische Verständnis der Eltern geklagt wird, weil diese in der Perspektive auf den Übergang zu anderen Schularten oder von Abschlüssen pädagogische Zielsetzungen gering schätzten und nach ihrem jeweiligen Leistungsverständnis pädagogische Maßnahmen beurteilten, so machen diese ganz normalen Schwierigkeiten in der Lehrer-Eltern-Beziehung deutlich, welche komplexe Entwicklungs- und Bildungsarbeit im Hinblick auf die Schule geleistet werden müßte. [...]

Im Kontext dieser Mitwirkung an der Schulgestaltung sollen Eltern auch im Rahmen einer kooperativen Organisationsentwicklung in die Entwicklungsprozesse der einzelnen Schule einbezogen werden (vgl. Ackermann 1997). Indem das Schulprogramm mit allen am schulischen Geschehen beteiligten Gruppen diskutiert wird, und Kontroversen über Ziele, Inhalte und Wege des pädagogischen Programms zum produktiven Moment der Schulentwicklung werden, soll die Gefahr einer rein verfahrensmäßigen formalen Beteiligung und deren „Overruling" vermieden sowie die Expertise der an der Schulgestaltung Beteiligten gestärkt werden. Von Lehrern und Schulleitungen wird bisher viel zu wenig gesehen, daß gerade die Eltern als Schulöffentlichkeit bei aller Unterschiedenheit in Milieus und Lebensstilen als politische Kraft ein Reservoir für die Unterstützung der pädagogischen Ziele einer Schule darstellen. [...]

\section{Eltern als Einflußgrößen für schulisches Lernen}

Die Überlegungen einer inhaltlich umgreifenden Form der Elternbeteiligung werden nicht nur durch zahlreiche Arbeiten zur schulischen Elternpartizipation befürwortet. Untersuchungen im Umkreis der Kindheits-, Jugend- und Familienforschung zu differenzierten Erziehungsmilieus der Kinder und Jugendlichen, die sich wechselseitig beeinflussen, thematisieren die Eltern als wichtige soziale Umwelt (vgl. Zinnecker 1997). Eine intensive elterliche Anteilnahme am Leben der Kinder gilt als positive Bedingung für die schulische Motivation (vgl. Wild/Wild 1997). [...] Die er- 
zieherischen Milieus des Elternhauses beeinflussen die Eingangsvoraussetzungen und die weiteren Schulleistungen der Kinder (vgl. Krumm 1996). Allerdings gilt es als Vorurteil, daß allein Eltern mit höherer Bildung „durchweg bessere Partner oder Eltern sind“ (Grundmann u.a. 1994: 71). Vor allem wenn Eltern ,sich für die Bedürfnisse und Aktivitäten ihres Kindes interessieren und dessen Selbständigkeit unterstützen, ein ausgeprägtes Engagement in schulischen Belangen aufweisen und hohe Erwartungen an ihr Kind in bezug auf den von diesem zu erreichenden Schulabschluß richten" (Wild/Wild 1997: 69), scheint dieses Erziehungsverhalten eine wichtige Rolle für die Intensität zu spielen, mit der sich Schüler mit schulischen Lerninhalten auseinandersetzen.

Im Gefolge des sozialen Öffnungsprozesses der Schule nach außen wandelt sich langsam das Verständnis von Eltern als den wesentlichen auBerschulischen Miterziehern, die die Ablaufprozesse und Einwirkungsmöglichkeiten der Schule entweder erschweren oder die ignoriert werden können, zu nunmehr wichtigen schulischen Kooperationspartnern, denen sich die Schule öffnen soll (vgl. Risse 1994). [...]

\section{Schulen als Bildungsghettos?}

Eine weitere Problemstellung deutet sich mit der veränderten Rolle der Eltern jedoch bereits an: Infolge der in Gang kommenden Pluralisierung der Schulen durch eine Schulprofilbildung (vgl. Maritzen 1998) ${ }^{33}$ wird anhand der Ergebnisse der angloamerikanischen Schulforschung diskutiert, inwiefern sich durch einen quasi „naturwüchsig“ entstehenden Bildungsmarkt die soziale Zusammensetzung sowie die Erziehungsmilieus der Eltern- und Schülerschaft ändern und die Schulen vor neue Herausforderungen stellen werden (vgl. Osterwalder 1998; Preuss-Lausitz 1997; Oelkers 1995) ${ }^{34}$. Denn wenn es richtig ist, daß auf Grundlage von Wahlmöglichkeiten eine Homogenisierung der sozialen Zusammensetzung und der Erziehungsmilieus der Schülerschaft eintritt, wie dies bei Privatschulen der Fall zu sein scheint (vgl. Preuss-Lausitz 1997), könnten sich die schulischen Erfahrungsprozesse in ihrer lebensweltlichen Dimension einander angleichen und damit Bildungsghettos entstehen. Neue Ungleichheiten werden aufgrund einer öffentlich wenig beachteten Umakzentuierung der staatlichen Sozialverantwortung durch Deregulierung und Dezentralisierung auch im Bildungsbereich befürchtet (Friedeburg 1996, Ahlheim/Bender 1996). [...]

33 [Vgl. in Textblock II: Norbert Maritzen: Schulprogramm und Rechenschaft - eine schwierige Beziehung.]

34 [Vgl. dazu in Textblock IV: Katrin Dörner: Ethnische Minderheiten.] 


\section{Die Elternkooperation im Kontext von Programm und Situation einer Schule}

Eltern sind eine sozial heterogene Gruppe, für deren spezifische Bildungsaspirationen und das damit verknüpfte Schulengagement soziale Milieus und Lebensstile ausschlaggebend scheinen (Lüders 1997). [...] Generelle Vorschläge einer Elternkooperation, die die besonderen Probleme der diversen Schularten in der Schulhierarchie und die jeweilige Erziehungswirklichkeit einer Schule unberücksichtigt lassen, [scheinen nicht sinnvoll]. Für die Schulen in Deutschland sind nach wie vor strukturelle Probleme bedeutsam, die auf dieser Hierarchie und den unterschiedlichen Abschlußberechtigungen basieren. Mit Recht ist vor der Illusion zu warnen, Profilbildung, pädagogische Gestaltungsautonomie oder verstärkte Partizipation könnten das Strukturproblem bannen, ,das darin besteht, daß die Schulpolitik des Landes überhaupt Schulformselektion als soziale und ethnische Selektion zuläßt" (Preuss-Lausitz 1997: 591).

Für jede Schulart und für jede Schule liegen aufgrund der regionalen Situierung, aufgrund ihres Einzugsbereichs, der jeweiligen Eltern- und Schülerschaft, ihrer Ausstattung und den Unterstützungsleistungen durch Schulträger und Gemeinde und ihrem Schulprogramm andere Bedingungen für eine Elternkooperation vor. Die Elternkooperation ist sowohl in die gesellschaftliche Situation der Verwertungsperspektiven von Bildungszertifikaten, die damit verbundenen subjektiven Ansprüche und Erwartungen an Bildung und Qualifizierung als auch in die jeweilige Erziehungswirklichkeit der Schule eingebunden. So wird z.B. eine Kooperation mit Eltern ethnischer Minderheiten anders aussehen und andere Wege einschlagen müssen (vgl. NIACE 1997) als eine Kooperation mit Eltern, die dem Ziel dienen soll, das naturwissenschaftliche Lernen von Mädchen zu befördern.

Einer Schulleitung, die das Gespräch mit den Eltern optimieren möchte, die sich zunächst eine Bestandsaufnahme der in der Schule vorherrschenden Elternarbeit vornimmt, auf die sich weitere Überlegungen gründen, in welcher Art und Weise die Eltern in das Schulgeschehen eingebunden werden sollen und können, könnte die Beantwortung der folgenden Fragen hilfreich sein:

- Wie engagieren sich Eltern gegenwärtig im Schulalltag? Geht das Engagement über die Teilnahme an Elternabenden und Elternsprechtagen hinaus?

- Welche Berührungspunkte gibt es zwischen Elternhaus und Schule? Was erfahren die Eltern über das Schulgeschehen? Welche Kommunikationswege gibt es? Wie häufig und worüber werden Eltern informiert? Gehen diese Informationen über die Klassenebene hinaus? Wünschen Eltern mehr und öfter Informationen? 
- Wie können die Berührungspunkte zwischen Elternhaus und Schule erweitert werden? Wie kann die Kommunikation weiter verbessert werden?

- Welche gesellschaftlichen Erfahrungsbereiche repräsentieren Eltern durch Herkunft, Beruf und Engagement in der Gemeinde? Welche Brücken könnten zur schulischen Lebenswelt geschlagen werden?

- Welche Elterngruppen werden mit der schulischen Informationspolitik nicht erreicht? Wie könnte z.B. das Engagement von Eltern ethnischer Minderheiten und sozial benachteiligter Eltern gefördert werden? Wieviel Eltern sind alleinerziehend? Welche Eltern benötigen welche Unterstützungsleistungen? Welche Angebote und Hilfsdienste im regionalen Umfeld könnten angesprochen werden?

- Wie werden Eltern gefördert, die sich im Schulleben besonders engagieren?

- In welchem Maße haben Eltern Einfluß auf das Schulgeschehen? Wie wird dieser Einfluß von allen Gruppen in der Schule bewertet: als ausreichend, zu gering, zu stark? In welche Entscheidungsprozesse sollten Eltern verstärkt eingebunden werden? Was soll und muß vom Kollegium und der Schulleitung allein entschieden werden?

- Wird langfristig eine Elternmitwirkung im Bereich von Arbeitsgemeinschaften, Lernfördergruppen, Mittagstisch und Betreuung oder bei Unterrichtsgängen gewünscht? Was muß getan werden, um dies zu realisieren?

- Welche pädagogischen Fragen tangieren sowohl Elternhaus als auch Schule? In welcher Form könnten diese aufgegriffen und behandelt werden?

- Soll eine Elternbildung zusammen mit anderen Instanzen, z.B. der Volkshochschule betrieben werden? Gibt es eine schulische Kooperation mit organisierten Elternvereinen?

\section{Eltern für die Schulerfahrungen ihrer Kinder öffnen - Die Schule für die Lebenswirklichkeit der Kinder sensibilisieren}

Gerade die Befürchtung, Elternwünsche könnten schulferne Gesichtspunkte in die Schule tragen oder durch ihre Wertmaßstäbe die Universalität von Allgemeinbildung untergraben, hat eine Auseinandersetzung mit Vorstellungen der Eltern bisher behindert. Es wird jedoch zunehmend notwendig sein, die unterschiedlichen Perspektiven der beiden pädagogischen Realitäten Elternhaus und Schule miteinander zu vermitteln. Die Zusammenarbeit von Elternhaus und Schule ist im Interesse an der Förderung von schulischen Lehr-/Lernprozessen und den Entwicklungs- und Entfaltungsmöglichkeiten von Kindern und Jugendlichen unerläßlich.

Die selbstverständliche Unterstellung der Elternkooperation sollte sein, daß Eltern selbständige Erzieher ihrer Kinder sind und diesen basale Fertigkeiten, Fähigkeiten und Kenntnisse vermittelt haben, auf denen die 
Schule aufbaut (Krumm 1996; Grundmann u.a. 1994). Pädagogische Kompetenzen der Eltern sind ebenso weiter zu entwickeln wie die von Lehrpersonen und Schulleitungen. Während eine Pädagogisierung sozialer Umwelten längst vorangeschritten ist, scheut sich die Schule, ihr Erziehungs- und Bildungsverständnis zu thematisieren und eine Verständigung über pädagogische Ziele anzustreben. Die Einbeziehung von Eltern in die Schule und das Schulleben soll dem doppelten Ziel dienen, Eltern für die Schulerfahrungen ihrer Kinder zu öffnen, ebenso wie sich die Schule der Lebenswirklichkeit der Kinder öffnen muß [...]. Die verschiedenen sozialen Umwelten Elternhaus und Schule gilt es unter Berücksichtigung von pädagogischen Qualitätsmaßstäben miteinander ins Gespräch über gemeinsam interessierende pädagogische Fragen zu bringen, um nach Lösungen für die Lebensund Lernprobleme der Kinder und Jugendlichen zu suchen, die diesen aus der Erwachsenenwelt erwachsen.

Es ist eine Binsenweisheit, daß eine Kooperation, die sich von der bisherigen unbefriedigenden Elternpartizipation unterscheidet, nicht verordnet werden kann. Sie kann der Schule ebensowenig oktroyiert werden wie den Eltern, die bisher diese Gelegenheiten nur - erzwungenermaßen durch ihr Interesse am Fortkommen ihres Kindes - als eine sie eben nicht persönlich bereichernde Angelegenheit wahrgenommen haben. Die Zustimmungswürdigkeit des in der wissenschaftlichen Literatur verbreiteten Postulats der Elternkooperation hat oftmals die gesellschaftlichen Ursachen der Distanz beider Erziehungswirklichkeiten aus den Blick geraten lassen. Von einer Interessenidentität von Elternhaus und Schule kann nicht ausgegangen werden (vgl. Ulich 1989), da die Erziehungsaufgabe von Elternhaus und Schule durch den Gegensatz überformt wird, der in den gesellschaftlichen Funktionen der Schule, Selektion, Allokation und Legitimation, begründet liegt. Seitens der Schule ist es unfruchtbar, Eltern den Vorwurf zu machen, häufig zu ehrgeizig am Fortkommen ihrer Kinder interessiert zu sein und diese durch Leistungsansprüche zu überfordern, da der Vorwurf an die Schulen zurückzuwenden wäre, Defizite im Lernstand bis in Bildungskarrieren hinein festzuschreiben, anstatt sie als Herausforderungen für pädagogische Hilfen zu verstehen (vgl. Heid 1989, 1986).

Es handelt sich insofern vorerst nur um ein Postulat, daß das gemeinsame Anliegen von Eltern und Schule in der Förderung schulischer und häuslicher Lehr-/Lernprozesse besteht. [...]

\section{Literatur}

Ackermann, H.: Wie nehmen Schüler und Eltern Schule wahr? Neue Ansatzpunkte für die Qualitätsdiskussion. In: schul-management (1997), H. 4, S. 9-16.

Ahlheim, K./Bender, W. (Hg.): Lernziel Konkurrenz? Erwachsenenbildung im „Standort Deutschland“". Eine Streitschrift. Opladen 1996.

Deutscher Bildungsrat. Empfehlungen der Bildungskommission: Zur Reform von Organisation und Verwaltung im Bildungswesen. Teil 1 Verstärkte Selbständigkeit der Schule und Partizipation der Lehrer, Schüler und Eltern. Stuttgart 1973. 
Friedeburg von, L.: Schulentwicklung zur Ungleichheit. In: Jahrbuch Bildung und Arbeit 96. Opladen 1996, S. 36-50.

Grundmann, M./Huinink, J./Krappmann, L.: Familie und Bildung. Empirische Ergebnisse und Überlegungen zur Frage der Beziehung von Bildungsbeteiligung, Familienentwicklung und Sozialisation. In: Büchner, P. u.a. (Hg.) Kindliche Lebenswelten, Bildung und innerfamiliale Beziehungen. Materialien zum 5. Familienbericht. Bd. 4, München 1994, S. 41-104.

Heid, H.: Lernerfolg von Schülern - ein Indikator für die Qualität des Lehrers? In: Bäuerle, S. (Hg.): Der gute Lehrer. Empfehlungen für den Umgang mit Schülern, Eltern und Kollegen. Stuttgart 1989, S. 8-19.

Heid, H.: Kritische Anmerkungen zur pädagogischen Rechtfertigung ontogenetisch früher Auslese. In: Heim, H./Ipfling, H.-J. (Hg.): Pädagogik in geschichtlicher Erfahrung und gegenwärtiger Verantwortung. Frankfurt/M. 1986, S. 184-199.

Hepp, G.: Wertewandel und Schulpolitik. In: Informationsschrift Nr. 50 zur Lehrerbildung, Lehrerfortbildung und pädagogischen Weiterbildung der Pädagogischen Hochschule Heidelberg 1996, S. 21-37.

Jach, F.-R.: Mitwirkungsrechte von Eltern und Schülern. Partizipation zwischen Gesetzesvorbehalt und Schulaufsicht. In: Pädagogische Führung 3 (1992), H. 3, S. 137140.

Krumm, V.: Über die Vernachlässigung der Eltern durch Lehrer und Erziehungswissenschaft. Plädoyer für eine veränderte Rolle der Lehrer bei der Erziehung der Kinder. In: Die Institutionalisierung von Lehren und Lernen. 34. Beiheft der Zeitschrift für Pädagogik (1996), S. 119-137.

Lenhardt, G.: Schulpflicht. Vom ständischen Gewaltverhältnis zu Grundrechten im Klassenzimmer. In: Deutsches Jugendinstitut (Hg.): Was für Kinder. Aufwachsen in Deutschland. München 1993, S. 252-260.

Lüders, M.: Von Klassen und Schichten zu Lebensstilen und Milieus. Zur Bedeutung der neueren Ungleichheitsforschung für die Bildungssoziologie. In: Zeitschrift für Pädagogik 43 (1997), H. 2, S.301-320.

Maritzen, N.: Schulprogramm und Rechenschaft - eine schwierige Beziehung. In: Ackermann, H./Wissinger, J. (Hg.): Schulqualität managen. Von der Verwaltung der Schule zur Entwicklung von Schulqualität. Neuwied 1998, S. 135-145.

Melzer, W.: Familie und Schule als Lebenswelt. Zur Innovation von Schule durch Elternpartizipation. München (DJI-Forschungsbericht) 1987.

National Institute of Adult Continuing Education (NIACE): Lernen, in einer multikulturellen Gesellschaft zu leben: Der Bezug Elternhaus-Schule. Leicester 1997.

Oelkers, J.: Schulreform und Schulkritik. Würzburg 1995.

Osterwalder, F.: Profilbildung und Öffentlichkeit als Problem schulischen Managements. In: Ackermann, H./Wissinger, J. (Hg.): Schulqualität managen. Von der Verwaltung der Schule zur Entwicklung von Schulqualität. Neuwied 1998, S. 239250.

Preuss-Lausitz, U.: Soziale Ungleichheit, Integration und Schulentwicklung. In: Zeitschrift für Pädagogik 43 (1997), H.4, S. 583-596

Risse, E.: Öffnung von Schule als Programm und Handlungsfeld. Eine wichtige Aufgabe für Schulleitungen. In: Buchen, H./Horster, L./Rolff, H.-G. (Hg.): Schulleitung und Schulentwicklung. Erfahrungen, Konzepte, Strategien. Stuttgart (LoseblattSammlung) 1994, K 4.1, S. 1-21.

Thonhauser, J.: Neuere Zugänge der Forschung zur Erfassung von Schulqualität. In: Specht, W./Thonhauser, J. (Hg.): Schulqualität. Entwicklungen, Befunde, Perspektiven. Innsbruck 1996, S. 394-425.

Ulich, K.: Schule als Familienproblem? Konfliktfelder zwischen Schülern, Eltern und Lehrern. Frankfurt a.M. 1989. 
Wild, E./Wild, K.-P.: Familiale Sozialisation und schulische Lernmotivation. In: Zeitschrift für Pädagogik 43 (1997), H. 1, S.55-77.

Wollenweber, H.: „Autonomie der Schule?“ Zur Problematik einer schulpolitischen Forderung. In: Aurin, K./Wollenweber, H. (Hg.): Schulpolitik im Widerstreit. Brauchen wir eine ,andere Schule“? Bad Heilbrunn 1997, S. 113-128.

Zinnecker, J.: Streßkinder und Glückskinder. Eltern als soziale Umwelt von Kindern. In: Zeitschrift für Pädagogik 43 (1997), H. 1, S. 7-34. 


\section{Schüler}

\section{Kommentar (Eubel)}

Die Beobachtung von Akteurkonstellationen dient dazu, mögliche Haltungen einzelner Akteurgruppen zu schulischen Modernisierungen zu analysieren. Es geht dabei um Fragen wie: „Was versprechen sich schulische Akteure von Modernisierungen?" Und vor allem: „Welche Interessen lassen sich in neuen Konstellationen durchsetzen?" Für die bis hierher vorgestellten Akteure konnte dies im Ansatz erörtert werden. Wie verhält es sich im Fall von Kindern und Jugendlichen respektive Schülern? Erwarten sie von der Modernisierung viel? Wollen und können sie ihre Interessen in der Modernisierung durchsetzen? ${ }^{35}$ Diese Fragen sind schwer zu beantworten, weil sich in der Literatur überwiegend Formulierungen von Interessen für die Schülerschaft und nicht von ihnen finden. Es gibt nur wenige empirisch gehaltvolle Beschreibungen zur Akteursgruppe der Schüler in der gegenwärtigen Modernisierung (vgl. aber exemplarisch Müller 1996). Dabei wird aus Sicht der ,qualitätsbasierten Schule' das Schülerhandeln immer wichtiger. Schülerinnen und Schüler werden in der Akteurkonstellation der Einzelschule, gegenüber Schulleitung, Lehrkräften und Eltern aufgewertet; in Qualitätsdiskursen sind sie verstärkt „Objekt“ der Beobachtung - aber auch "Subjekt", da sie selbst evaluieren sollen bzw. Beobachtungsrechte haben. Welchen Part jedoch Schüler in der modernisierten Einzelschule faktisch spielen, ist damit noch nicht geklärt. Leichter fällt es zu eruieren, welchen Part Schülerinnen und Schüler spielen sollen.

In der Pädagogik hatte diese Perspektive Tradition. Ein Bild vom Kinde wurde normativ gesetzt und daraus eine Pädagogik abgeleitet. Die Bilder können wechseln. Sieht man im Kind den noch nicht, fertigen 'Erwachsenen, dann gilt es, gegebenenfalls auch seinen Eigenwillen zu brechen, damit aus ihm ein ,ordentlicher' Mensch wird. Dieses Bild war lange Zeit stark aus der Mode gekommen. ${ }^{36}$ Gängiger war die Weiterentwicklung des von der Reformpädagogik entworfenen Bildes, dass mit Rousseau davon ausgeht, dass das Kind von Natur aus gut sei und es in erster Linie gelte, sein ,Eigenrecht' ${ }^{\star}$ zu schützen, weil es nur so davor bewahrt werden kann,

35 Fend wagt eine Zuschreibung von Interessen: Eltern haben ein ,Sorge-Interesse‘, Lehrer ein ,Belastungsminimierungs-Interesse‘. Und die Schüler? Für diese macht Fend ein ,Spaß-Interesse' aus (vgl. auch den Kommentar zum Text zu Beginn dieses Textblocks).

36 Manche Kritiker der modernisierten Schule, die mit Begriffen wie Basiskompetenzen, Kerncurricula, Standards etc. operiert, unterstellen ihr, dass sie diesem Bild vom Kinde zu einer ,Renaissance v verhilft und halten das für einen Rückfall in die ,pädagogische Steinzeit‘. 
dass seine Persönlichkeit ausgelöscht oder deformiert wird. ${ }^{37}$ Jürgen Oelkers hat diese Form der „Mythisierung des Kindes“ (1989: 74) präzise beschrieben und nachgewiesen, dass solche Mythen unabhängig von aller empirischen Evidenz entstehen können. Viel schlimmer: er kann zeigen, dass die Wissenschaften, die sich in der Epoche der Reformpädagogik mit der Erforschung der Kindheit befassten, also etwa die Kinder- und Jugendpsychologie, in steter Gefahr waren, solche idealisierten Bilder in ihre Vorannahmen zu integrieren.

Es kann aber als gesichert gelten, dass die aktuelle Forschung von realistischeren Vorannahmen ausgeht und somit prinzipiell in der Lage ist, den an Schule beteiligten Akteuren valide Daten und Deutungen über die Schüler von heute zu liefern. ${ }^{38} \mathrm{Ob}$ solche Daten von der Lehrerschaft genutzt werden, um daraus adressatenspezifische unterrichtliche Handlungsweisen abzuleiten, darf bezweifelt werden. Zwar gehört die Feststellung, dass die Kinder von heute ganz anders seien als die Generation von vor ein paar Jahren, zu den häufigst kommunizierten Feststellungen von Lehrern, was jedoch eher die Funktion hat, die Nichterreichung gesetzter Unterrichtsund Erziehungsziele dem Interaktionspartner Schüler zuzuschreiben.

Thomas Ziehe (Universität Hannover) demonstriert in seinem Text exemplarisch den Wandel der Kindheit von den 1970er Jahren bis heute. Er beschreibt dramatische Veränderungen der Alltagskultur von Kindern und konfrontiert diese mit den Wahrnehmungsformen der Lehrer. Er stellt fest, dass viele von ihnen an den Realitätskonstruktionen und an den pädagogischen Programmen von damals festzuhalten scheinen. Letzteres tun sie unter anderem deshalb, weil sie feststellen, dass die Reformen ,stecken geblieben' sind oder aber abgebrochen wurden. Das Problem scheint aber darin zu bestehen, dass es die Jugend, für die diese entwickelt wurden, nicht mehr gibt. Die Anstrengungen laufen also unweigerlich ins Leere. Ziehe konstatiert, dass sich der alltagskulturelle Kontext von Schule trotz

37 So lässt sich Rilke nach der Lektüre des Buches von Ellen Kay (Das Jahrhundert des Kindes) zu folgender dramatischen Situationsschilderung hinreißen: „Freie Kinder zu schaffen, wird die vornehmste Aufgabe dieses Jahrhundert sein. Ihr Sklaventum ist schrecklich und schwer" (zitiert nach Oelkers 1989: 83).

38 Die Forschung nimmt dabei Kinder und Jugendliche nicht nur in ihrer Rolle als ,Schüler' ins Blickfeld. Gerade die intensive Auseinandersetzung mit ihrer Lebenswelt in einem umfassenderen Sinn hat sich als fruchtbar erwiesen, denn diese Erfahrung legen die jungen Leute von heute ja nicht an der Schulgarderobe ab, wie Ziehe in seinem hier abgedruckten Text eindrucksvoll schildert. Andererseits ist sich die Forschung durchaus der Tatsache bewusst, welchen Anteil die Schule an dieser Lebenswelt hat, egal ob man die tägliche Verweildauer oder die zunehmende Verlängerung der durch Schule belegten Lebensspanne zum Maßstab nimmt: Die ,Pädagogisierung' beziehungsweise ,Verschulung' der Kindheit und Jugend ist Fakt. Schüler zu sein ist zunehmend der ,Hauptjob“ der nachwachsenden Generation. Es würde zu weit führen, hier einen einigermaßen systematischen Überblick über die konkrete Publikationslage der an solchen Forschungsprogrammen beteiligten Disziplinen zu geben. 
des Versandens der damaligen Reformen gravierend verändert hat: „Wo der programmatisch orientierte Pädagoge Stillstand diagnostiziert, sieht der Kultursoziologe markanten Wandel.“ Diesen Wandel zu beobachten und auf ihn zu reagieren, ist zentrale Aufgabe der Lehrer. ${ }^{39}$ Lassen sie sich hingegen von abstrakt und normativ begründeten pädagogischen Prinzipien leiten (z.B.: „Der Unterricht muss so ganzheitlich wie möglich sein!“), besteht die Gefahr, dass sie in eine Falle laufen, so wie die romantisierenden Reformpädagogen, die sich ihre Kinder, erfinden' mussten, damit diese zu den Konzepten passten. Pädagogische Prinzipien haben aber keine garantierten Effekte, die sich unabhängig von konkreten Kontexten automatisch einstellen. Erfolgreicher scheint die Strategie, sich Ziele zu setzen (das kann durchaus auch die Chancengleichheit sein, an der festzuhalten sich lohnt) und auszuprobieren, welche Wege mit höherer Wahrscheinlichkeit als andere zum Erfolg führen. Damit sind die Grundprinzipien professionellen Lehrerhandelns beschrieben, zu denen auch die Fähigkeit des handelnden Zusammenwirkens mit anderen Akteurgruppen, hier also den Schülern, gehört.

An genau dieser Thematik arbeiten Wolfgang Melzer und Sabine AlDiban (Technische Universität Dresden), welche über zwei von ihnen durchgeführte empirische Untersuchungen von Schülerkompetenzen berichten.

Melzer und Al-Diban gehen davon aus, dass heute auch Schüler vermehrt „,Individualisierungsansprüche“ an Schule stellen“, die nicht immer kompatibel sind mit den Erwartungen der Institution. Dies macht deutlich, "dass es sich bei der Funktionsbestimmung von Schule in modernen demokratischen Gesellschaften um einen sehr komplexen Prozess handelt." Da derzeit im Kontext einer sich modernisierenden Schule vermehrt auf Evaluationen und Effizienz geachtet wird, stellen sich die Autoren die Frage, „ob und inwieweit bislang konsensuale Vorstellungen von Bildung als umfassendes Konzept der Kompetenzaneignung und Persönlichkeitsentwicklung tatsächlich im Unterricht verwirklicht werden. ${ }^{“ 40}$ Ein Befund der Un-

39 Vor seiner Zeit an der Universität war Thomas Ziehe als Forscher und Lehrer an der Glocksee-Schule in Hannover tätig, die sich besonders stark für die Selbstregulierung der Schüler engagierte (vgl. Negt 1997) und somit neben Alexander S. Neills Schule Summerhill als eine besonders konsequente Reformschule angesehen werden kann, die hervorragend in das damalige pädagogische Reformklima passte. Anders als viele andere Reformschulen, die häufig dazu neigen, an ihrem Programm festzuhalten, bis hin zu seiner Orthodoxierung, scheint diese Schule lernend auf Veränderungen ihrer Klientel reagiert zu haben. Das könnte unter anderem darauf zurückzuführen sein, dass sie sich durch die Begleitforschung ständig selbst beobachtete. In anderen Worten: Selbstevaluation verändert die ,Datenlage' und erweitert die Handlungsoptionen.

40 Modernisierungsskeptiker bezweifeln, dass dies unter den Bedingungen der ,neuen Schule überhaupt möglich sei. Sie postulieren, dass die Persönlichkeitsentwicklung auf dem ,Altar der Effizienz' zugunsten der Kompetenzaneignung geopfert wird 
tersuchungen ist folgender: Den Schüler gibt es nicht, sondern vielfältige Gruppen von Schülern, die sich in zentralen Merkmalen voneinander unterscheiden, insbesondere hinsichtlich ihres ,Erfolgs' beim Bildungs- und Erziehungsauftrag der Schule. Dabei lassen sich Risikogruppen von Schülern genauer beschreiben. Außerdem können die Autoren nachweisen, dass der Bildungs- und der Erziehungsauftrag der Schule miteinander vereinbar sind und dass sich „Fachleistungsstatus, Selbst- und Sozialkompetenzen der Schüler wechselseitig bedingen". Daraus leiten sie die Forderung nach Verbesserung der Lehrerfort- und -weiterbildung ab. Sie fordern verstärkte Kooperation zwischen Elternhaus und Schule sowie Konzepte der differenzierten Förderung der unterschiedlichen Schüler im Unterricht. Damit ist die Frage der Qualität angesprochen: „Die Qualität der Institution Schule und die individuelle Erfolgsbilanz der Schüler bedingen sich wechselseitig."

Mit dem Neuen Steuerungsmodell und mit den sich daraus ergebenden Spielregeln, nach denen die unterschiedlichen Akteure sich wechselseitig aufeinander beziehen müssen (sei es neutral, konsensual oder im Widerspruch), müsste sich eine neue „Verhandlungskultur“ entwickeln. Möglicherweise ist sie die Voraussetzung dafür, dass Schüler erstmals eine ,Bühne' haben, auf der sie ihre Akteurinteressen artikulieren können, die vermutlich bislang einfach deshalb wenig wahrgenommen wurden, weil sie nicht in die ,legitimen' Muster derer ,passen', die fast ausschließlich die Definitionsgewalt in ihren Händen hielten. ${ }^{41} \mathrm{Zu}$ diesen Spekulationen können wir keinen Text bieten. Aber möglicherweise gibt es eine Vielzahl von Schülern, die unsere Vermutungen durch ihr Akteurverhalten bereits leben.

\section{THOMAS ZIEHE}

\section{Adieu, 70er Jahre! Jugendliche und Schule in der zweiten Modernisierung}

\section{Alltagskultur - Nach der ersten Modernisierung}

All die Tinas und Svens, Mirkos, Olivers, Tanjas und Saschas, die heute die Schulhöfe bevölkern, wachsen in einer Alltagskultur auf, die in ihren Augen, seit sie überhaupt wahrnehmen und denken können, immer schon durchmodernisiert gewesen ist. Das ist für sie so selbstverständlich, daß all

(vgl. z.B. den Beitrag von von der Groeben im vorliegenden Band; zur gegenteiligen Position siehe Böttcher 2002).

41 Vgl. dazu den Aphorismus von Arnfried Astel: „Berechtigte Frage eines lernwilligen Schülers an seinen Lehrer: Wie kann ich lernen, was Sie wissen, ohne zu werden, wie Sie sind“ (zit. nach Negt 1997: 7). 
die Tinas, Svens und die anderen es nicht einmal bemerkenswert finden. Diese durchmodernisierte Alltagskultur - ein lockeres Gewebe aus Themen, Bildern, Orientierungsmustern, Wahrnehmungsgewohnheiten, Moden, Gegenstandsbedeutungen - hat selbst Sozialisationswirkung. Sie integriert dabei u.a. Kinder und Jugendliche in deren Lebenswelten. Eine Zeitschrift wie „Bravo“ vermittelt ihren Lesern ein erhebliches Maß an subjektiv bedeutsamen Verhaltens- und Bewertungsstandards, gerade in den umfänglichen Leserbriefteilen. Diese Alltagskultur ist sozialisatorisch hochwirksam, sie dringt in die Poren der Lebensstile und Mentalitäten ein und läßt sich gar nicht auf einen „Bereich“, wie etwa Freizeit, eingrenzen. Und diese Sozialisationswirkung ist keineswegs restlos in eine Erziehungsaufgabe umzudefinieren. Die Alltagskultur wirkt unterhalb und neben den Erziehungsintentionen - und natürlich nicht selten auch gegen diese. Zwei Charakteristika dieser Alltagskultur möchte ich hier herausgreifen:

\section{Die Entmächtigung der Hochkultur}

Die Alltagskultur steht „für sich“, sie ist keineswegs mehr die niedere Teilwelt, der eine hehre Hochkultur gegenübergestellt wird. Nein, die Alltagskultur selbst ist zur dominanten Kultur geworden. Und die Hochkultur - ob Lyrik, Konzert oder Ausstellung, ob Krolow, Ligeti oder Vermeer fungiert nicht mehr als normatives Dach „über“ der Alltagskultur. Die Hochkultur ist offenkundig weiterhin existent, aber sie hat nicht mehr die unbefragte normative Leitfunktion, die ihr früher zugeschrieben wurde und die mehr oder weniger von allen hingenommen worden ist. (Damit will ich die empirische Rezeption der Hochkultur-Produkte in der Vergangenheit nicht überschätzen. Kurz gesagt: Nicht daß ganz viele Menschen „,den Goethe“ wirklich gelesen hätten, ist mein Argument. Sondern daß „Goethe“ als idealisierte Niveauvorgabe auch dort eine kulturelle Funktion besaß, wo man ihn gar nicht las.)

Heute ist die Hochkultur selbst zu einer Teilkultur geworden, nicht auf einer höheren, sondern auf gleicher Ebene mit den anderen kulturellen Produktionen - und wenn ich heute Vermeer anschaue, dann eben eine Woche später die Comics von Carl Barks. Bis in die gesellschaftlichen Machteliten hinein kann man sich heute einen beträchtlichen Abstand zur Hochkultur leisten, ohne daß das der Karriere der Betreffenden ernsthaft schaden würde. Ich möchte diese Funktionsverlagerung der Hochkultur hier überhaupt nicht bewerten, sondern lediglich festhalten, daß die selbstverständliche normative Plausibilität, die ihr früher zukam, durchlöchert ist. Und das macht den Begründungsaufwand, den als Kulturvermittelnde im weiten Sinne des Wortes nunmehr die Pädagogen leisten müssen, höher und anstrengender.

Die Kluft zwischen der alltagskulturell vermittelten Mentalität der Kinder und Jugendlichen einerseits und den Bildungsintentionen der Pädagogen andererseits wird immer größer. Diese Kluft zeitweise zu überbrücken 
wird für beide Seiten motivational aufwendiger. Lehrarbeit wird Überbrückungsarbeit, ohne daß man sich dabei noch auf die Selbstverständlichkeit eines gemeinsamen hochkulturellen Daches verlassen könnte.

\section{Zweite Modernisierungsphase, das Lebensgefühl}

Das weitere Charakteristikum der heutigen Alltagskultur: sie ist uns - in ihrer Enttraditionalisierung - zu etwas Selbstverständlichem geworden. Sie ist nicht mehr neu, der Kontrast zum Früher verblaßt, wir gewöhnen uns ab, sie zu bewundern oder uns zu wundern. Dieser eigentümliche Effekt - daß die Alltagskultur nicht mehr als Ablösung der vorgängigen „traditionellen“ Zeiten gefeiert wird, daß Modernität nicht mehr Gefühle des Staunens, des Schwindels, der rauschhaften Dynamik mit sich bringt - dieser Effekt läßt es begrifflich plausibel erscheinen, unsere gegenwärtige gesellschaftliche Entwicklungsphase als eine zweite Modernisierung zu fassen. (Und andere Autoren sprechen vergleichbar von später Moderne, Postmoderne oder reflexiver Modernisierung.)

Die erste Modernisierung besteht, pauschal gesprochen, aus gesellschaftlichen Effizienzsteigerungen und kulturellen Rationalisierungsprozessen. In der zweiten Modernisierung sind diese Entwicklungen bereits selbstverständlich geworden, entzaubert und trivialisiert. Die Begleitfolgen für das Lebensgefühl sind erheblich: Im Kontext der ersten Modernisierung wird bespielsweise ein rundum verglaster Schulneubau als Wirkursache für fröhliche, aufgeweckte, gesunde Schülerseelen und -körper gefeiert. Das ist sozusagen der „Kennedyeffekt" zuzeiten der Modernisierungsaufge-schlossenheit - sagen wir um 1961. Im Kontext der zweiten Modernisierung, also heute, blättert am nämlichen Schulbau nicht nur ganz wörtlich der Putz ab; nein, auch die Erlebnisweise hat sich verändert. Kein Mensch erwartet mehr, daß ein Neubau bleibende Fröhlichkeit seiner Insassen hervorrufen könnte.

Im Kontext erster Modernisierung, sagen wir z.B. 1967, schwärmen in Jungenbüchern Zukunftsgeschichten davon, daß es irgendwann Hubschrauberlandeplätzen in jeder Innenstadt geben würde: Im Kontext zweiter Modernisierung, also heute, denken wir an die bestialischen Lärmwellen, die mit einem solchen Projekt unvermeidlich verbunden wären. Im Kontext erster Modernisierung, sagen wir um 1971, sind ganze Scharen von Jugendlichen begeistert, Schottenrock oder Konfirmationsanzug vermeintlich lebenslang hinter sich lassen zu können. Im Kontext zweiter Modernisierung wird die Informalisierung des Alltagslebens von jungen Leuten gar nicht mehr als biografischer Gewinn erlebt, weil sie es anders sowieso nie kennengelernt haben.

Ich will mit all dem sagen: Das Lebensgefühl der zweiten Modernisierungsphase ist erheblich weniger vom Neuen verzaubert, ist gebrochener, folgenbewußter und desillusionierter. Die Modernisierungsphänomene 
selbst setzen keine euphorischen Erwartungen mehr frei und werden auch nicht mehr überwiegend als biografischer Gewinn erfahren.

Auch dies hat erhebliche Folgen für die Alltagsarbeit in pädagogischen Institutionen, zum Beispiel in der Schule. Erste Modernisierungsphase hieß hier: Kampf um Enttraditionalisierungen, Auseinandersetzung mit den Autoritäten, in Form der heute fast rührend erscheinenden „Streiche“, später aber auch als affektiv hochbesetzte „Aktionen“.

Jugendliches Lebensgefühl, Schülerdasein, war ein Dauerleiden daran, „was alles verboten ist“. Der biografische Hauptkonflikt war vom Typus der Repression. Älterwerden hieß im geglückten Falle, herauskommen aus beengenden Traditionskorsetten. In der zweiten Modernisierungsphase hat sich dieser Kontext beträchtlich verlagert. Die Eltern und Lehrer der heutigen Jugendlichen sind ja selbst bereits in hohem Maße enttraditionalisiert. Der Kernkonflikt für die Heranwachsenden erwächst nicht aus dem Leiden, was alles verboten sei, sondern daraus, was alles sie in ihrem Leben zustande bringen sollen. Die Repressionsfrage verschiebt sich zur Sinn- und Motivierungsfrage. Es ist heute kaum mehr identitätsstützend, sich darüber zu definieren, „wogegen“ sie sind, vielmehr gilt es, eigene Anschlußpunkte zu finden, ,wofür" sie sein möchten und sein können.

Nunmehr als Angehörige der mittleren Generation sind viele Lehrerinnen und Lehrer biografisch durch die erste Modernisierungsphase geprägt. Und sie unterstellen den heutigen Schülern vielfach einen ähnlich gelagerten Erwartungshorizont. Die Schüler sollen Alliierte der Schul- und Unterrichtsreform sein. Sie sollen sich freuen, daß die Traditionen abgebaut sind, daß sich die Schule öffnet, daß soziale Prozesse wichtiger genommen werden, daß die Lehrer sich bemühen, authentisch zu sein, daß die Themen lebensnäher werden, daß sie mitbestimmen können. Und was machen die Kinder der zweiten Modernisierung? Sie fragen die Lehrerin: Müssen wir heute wieder machen, was wir wollen?

Alltagskultur, zurückgestufte Hochkultur und zweite Modernisierung ergeben einen Kontext, der die Schulerfahrung symbolisch und mental verändert. Pädagogen, die weiterhin in Kategorien der ersten Modernisierung denken, fühlen und wahrnehmen, dürften dazu neigen, die biografische und kulturelle Semantik der 70er Jahre festschreiben zu wollen. Und damit jedenfalls in meiner Diagnose - liegen die Betreffenden meines Erachtens „,voll daneben“. Sie schließen von dem empirisch zutreffenden Faktum, daß die Schul- und Bildungsreformansätze der 70er-Jahre steckengeblieben sind oder gestoppt wurden, auf eine weiterbestehende pädagogisch-normative Gültigkeit der damaligen Ideen. Meine These ist hingegen: trotz vieler Stagnationen bei den Reformen hat sich der alltagskulturelle Kontext von Schule dessen ungeachtet gravierend verändert. Die alltagskulturellen Kontextveränderungen von Schule haben eben (verglichen mit der Geschichte der Reformhaben) eine eigene Dynamik, und wo der programmatisch orientierte Pädagoge Stillstand diagnostiziert, sieht der Kultursoziologe markanten Wandel. Aus der Nichtrealisierung der 70er-Jahre-Programmatik 
sollten wir jedenfalls nicht schließen, die traditionelle Schule hätte ,deswegen" unverändert überdauert. Betrachte ich Schule unter dem Gesichtspunkt der Mentalitäten, Verhaltensstile und Selbstdeutungen der Beteiligten, so hat sich diese „Software“ der Schulrealität ganz beträchtlich gewandelt. Und hierauf müssen die Entwicklungsfragen an Schule und Unterricht Antworten finden, die auf den Kontext der zweiten Modernisierung zugeschnitten sind.

\section{Die Normalschwierigkeiten von Schule heute}

\section{Auraverzicht}

Die Schule hat sich im Zuge der Modernisierungen radikal verweltlicht, auch die letzten Reste einer sakralen Aura sind hinweggeschmolzen. Sie ist eine ganz normale gesellschaftliche Funktionseinrichtung geworden, stark verrechtlicht und administrativ verregelt, aber keineswegs mehr alltagsenthoben. Es gibt sozusagen keine Hinterbühne, kein Geheimnis der Erwachsenen, mehr. (Es gibt natürlich Nichtwissen von Jugendlichen, aber das ist ein Informationsproblem, also etwas grundlegend anderes, als, an ein kulturell gehütetes Geheimnis noch nicht herangelassen zu werden.)

Während meiner eigenen Schulzeit in den 50er- und 60er- Jahren bin ich nicht ein einziges Mal in das Lehrerzimmer vorgelassen worden; man wurde grundsätzlich schon an der Tür abgefangen. In meiner Phantasie hatte diese Zone dadurch etwas vom Allerheiligsten, es mußte das verborgene Sinnzentrum der ganzen Institution sein. Nach dem Abitur, als ich diese Räume einmal betrat, war ich verwundert und enttäuscht, dort auch nur Stühle, Tische, Postfächer und ein Anschlagsbrett vorzufinden.

Heute ist die Schule ebenso verweltlicht wie profaniert. Ohne „Geheimnis" löst sie einerseits nicht mehr jene anlaßfreie Grundangst aus, die seinerzeit Generationen um Generationen von Schülern schon beim bloßen Anblick jener düsteren Backsteinfassaden mit langen Fensterreihen befiel. Das ist zweifellos ein Gewinn. Die Schüler heute erwarten nicht nur kein Geheimnis hinter dem Ganzen mehr, sie können sich sogar in die Erwachsenenseite hineindenken. Sie fragen zum Beispiel die Lehrerin: „Warum haben Sie eigentlich diesen Beruf gewählt?" Oder in den oberen Jahrgängen beteiligen sie sich hin und wieder am Unterrichtsgespräch, damit die Lehrperson da vorne es nicht ganz so schwer hat.

Es gibt aber auch einen Preis für diese Normalisierung, nämlich eine eigentümlichen Zuwachs an Anstrengung: Die Schule im Kontext der ersten Modernisierung hatte nämlich noch einen zwar zeitlich ,auslaufenden“, aber gleichwohl noch recht lange weiterwirkenden autoritativen Überhang an Erwachsenen-,,Geheimnis“. Dies gab dem Lehrerhabitus Rückendeckung. Die Lehrer waren Repräsentanten einer kulturellen Tradition, die sie rollengerecht weiterzuvermitteln hatten, die sie aber keineswegs selbst 
legitimieren oder subjektiv plausibel machen mußten. Nicht der Lehrer mußte die kulturelle Tradition rechtfertigen, sondern ggf. die Schülerin ihre mangelnde „Reife“ oder „Eignung“. Wenn diese Lehrkräfte überdies noch sympathisch waren, was nur hin und wieder vorkam - um so besser; am beliebtesten waren liberale Lehrer an konservativen Schulen. Aber solche Sympathie war immer nur ein Zusatz, das Grundverhältnis beruhte auf dem Repräsentantenstatus - der Lehrer als Torwächter zur Erwachsenenwelt.

Ohne diese Rückendeckung kommt die Lehrerin, ob sie will oder nicht, in die Rolle einer Produzentin. Sie muß nun die Plausibilität des Lehrstoffs herstellen, eine personale Beziehung zwischen sich und den Schülern aufbauen, zur Selbstmotivation anregen und Lernsituationen arrangieren. In dieser Weise die symbolischen, intersubjektiven und empirischen Voraussetzungen für Unterricht allererst herstellen und immer erneut sichern zu müssen macht die Lehrtätigkeit heute so komplex, so verletzlich und so anstrengend. Dieses Grundverhältnis basiert nicht mehr auf einer kulturellen Selbstverständlichkeit, sondern auf einem angestrebten intersubjektiven Anerkennungsverhältnis. Die Lernsituation muß im Grunde ausgehandelt werden, und die Verhandlungen laufen am ehesten, wenn eine wechselseitige Sympathiebasis vorhanden ist bzw. aufgebaut werden kann. Im gelingenden Falle ermöglicht diese Konstellation eine gegenseitige Akzeptanz, wie sie in der früheren Schule kaum denkbar gewesen wäre. Im mißlingenden Falle allerdings, wenn etwa die Schüler ihre Sympathie entziehen und sich in vollkommenes Desinteresse hüllen, steht die Lehrerin (fast) ohne pädagogische Durchsetzungsmittel da.

Nimmt man nun die hier aufgeführten Phänomene zusammen - die Sozialisationskraft der Alltagskultur, die normative Entmächtigung der Hochkultur, der Erlebnishorizont einer zweiten Modernisierung und die restlose Entauratisierung der Schule - dann wird die Tiefendimension der heutigen Arbeitssituation verständlicher. Ich nenne dies die Normalschwierigkeit von Schule. Diese Bezeichnung soll die gleichsam stumme, alltägliche Anstrengung beim Namen nennen, aber sie soll die Situation keineswegs überdramatisieren. Nicht alles, was anders ist als in früherer Zeit, ist deshalb schon Symptom von Krise oder Verfall. Aber der Gesichtspunkt einer Normalschwierigkeit soll festhalten, daß es in Schule heute eine hohe interne Irritierbarkeit gibt.

Vermittelt über die Medienberichterstattung, richtet sich die öffentliche Aufmerksamkeit dagegen mit Vorliebe auf skandalöse externe Faktoren, wie Dealer auf dem Schulgelände, Waffendrohungen in der Pause und Jackenklau auf dem Heimweg. Diese Vorfälle gibt es in der Tat, und sie häufen sich in den sogenannten sozialen Brennpunkten. Es gibt Schulen, in denen man im Grunde gar nicht mehr "Schule“ machen kann - das stimmt. Diese Beispiele taugen aber nicht dafür, daraus ein paradigmatisches Modell für die Schulsituation heute zu machen. Auch wenn man sich Dealer, Gewalt und Vandalismus fortdenkt - der Schulalltag wäre damit noch längst nicht störungs- und irritationsfrei. 
Ich neige sogar zu der Vermutung, daß die Affinität des öffentlichen Schuldiskurses $\mathrm{zu}$ den „Katastrophenthemen“ Verdeckungsfunktion hat: bei diesen Themen sind nämlich, bei allem Erschrecken, die moralischen Gewichte noch übersichtlich verteilt, man weiß, wer böse und wer gut ist, und die viel subtileren Leiden am Normalalltag in Schule und Unterricht brauchen nicht näher thematisiert zu werden.

\section{Normalschwierigkeit und Normalunbehagen}

Eben dies möchte ich aber thematisieren, wenn ich von Normalschwierigkeit spreche. Sie zu bezeichnen heißt auch, normativ bescheidener sein zu wollen: nicht daß Schule, wenn wir erst pädagogisch hinreichend gut geworden sind, „Spaß“ machen wird, ist meine Botschaft, sondern da 3 wir mit der Normalschwierigkeit werden rechnen müssen. Und die Normalschwierigkeit bringt für beide Seiten ein Normalunbehagen an Schule mit sich, mit dem wir leben müssen, das wohl ertragbar ist, aber eben auch irritierend, und dies vermutlich bleibend.

Für die Schülerinnen und Schüler dürfte dieses Normalunbehagen darin kulminieren, mehrere Jahre lang der Gleichaltrigengruppe, ihren Mentalitäten, Weltdeutungen, Identitätsmustern und Verhaltensstilen, die oberste Relevanz zuzusprechen und sich doch mit den Forderungen der Erwachsenenseite einigermaßen arrangieren zu müssen. Schule ist, von den subjektiven Präferenzen her, zunächst einmal ein Ort, an dem sich massenhaft die Gleichaltrigen treffen können. „Schule ist echt geil“", stellt ein Siebzehnjähriger fest, ,nur der Unterricht stört.“

Und für die Lehrerinnen und Lehrer kulminiert deren Normalunbehagen wohl in folgendem Ärgernis, das in die Berufsrolle eingebaut ist: Immer von den Schülern etwas wollen, was diese wollen sollen; immer von den Schülern etwas wollen, wobei ich sicher sein kann, daß ein Teil gerade das, was ich will, nicht will und dies auch deutlich zeigt. Hierin steckt ein Moment des Sich-anbieten-Müssen, das durchaus die eigene persönliche Würde berührt, vermutlich gerade mit steigendem Lebensalter des Lehrers.

Den konservativen Kulturpessimismus teile ich nicht. Die hier skizzierten Phänomene sind keineswegs einfach nur Symptome von Wertezerfall und gesellschaftlicher Desintegration. Nein, die Entraditionalisierungen beinhalten durchaus verteidigungswerte Modernisierungsgewinne. Und die fraglosen autoritativer Selbstverständlichkeiten der Vergangenheit sollten nicht und können auch nicht wiederhergestellt werden. Kultureller Konsens ist nicht, und schon gar nicht mit heutigen Jugendlichen, durch den Dauerappell an Tugenden oder durch Sanktionshärte zu erreichen.

Ich teile aber auch nicht die Affinität vieler Linker zu einer Entfremdungsdiagnose, wenn sie an Schule denken. Für diese Position ist der Abstand des Schulbetriebs zu den Schülern, zum Leben, zum Alltag gerade die Crux. Ich hingegen meine: im Kontext der zweiten Modernisierung ist das Vorhaben einer gesteigerten Annäherung des Unterrichts an die Schü- 
lerhorizonte oder an die Alltagskultur überhaupt nicht mehr produktiv. (Was es in den 70er-Jahren durchaus gewesen ist.) Eine Pragmatisierung der Inhalte, eine Informalisierung der Umgangsweisen, eine Subjektivierung der Selbstwahrnehmung - dies alles wäre heutzutage nichts anderes als eine Fortsetzung von jugendlichen Lebenswelten und von üblicher Alltagskultur auf schulischem Terrain. Wer Öffnung von Schule so versteht, der ist geradezu in Gefahr, etwas zu verschließen, nämlich die Möglichkeit, aus der Differenz zu den Schülern und aus der Differenz zur Alltagskultur neue und auch subjektiv bedeutsame Gegenerfahrungen er-öffnen zu können.

\section{Wohldosierte Fremdheiten}

Die Kritik an der Schule ist längst auch Routine geworden und folgt recht geläufigen Mustern. „Heilige Kühe“ der landläufigen Schulkritik sind: die Forderung nach größerer Lebensnähe der Lerngegenstände, nach freieren Sozialformen des Unterrichts; und nach Ausweitung der pädagogischen Zuständigkeit von Schule und Lehrern. - Ich will diese drei Forderungen hier kurz und kritisch betrachten, weil auch sie sich meines Erachtens im Lichte einer zweiter Modernisierung anders darstellen.

\section{Lerngegenstände}

$\mathrm{Da}$ die Schüler vom Leben, von der Gesellschaft, von den wichtigen Themen zu sehr abgekapselt seien, ist eher eine Beobachtung der 60er- und 70er-Jahre gegenüber der damals modernisierungsrückständigen Schule. Heute sind die Thematisierungen und Wahrnehmungsmuster der alltäglichen Welt ,immer schon da“, und keine Macht der Welt - und schon gar nicht die Schule - könnte sie den Schülern prohibitiv vorenthalten. Nicht mangelnde Lebensnähe ist heute das Problem, sondern die Gewöhnung an die andauernde Alltagsnähe von allem und jedem. Nicht die Verhinderung von Selbstbetroffenheit ist das Problem, sondern die subjektive Neigung der Jugendlichen, möglichst alle Themen und Situationen sogleich an die eigene Sichtweise anschließen zu wollen.

„Öffnung von Schule“? - Ja, aber wie gesagt als Er-öffnung. Nicht als Verdoppelung der Alltagsgewohnheiten, sondern als Eröffnung von Möglichkeiten zu ungewohntem Lernen. Nicht Veralltäglichung, sondern Entselbstverständlichung.

So gesehen sind die Lerngegenstände im Idealfalle nicht etwa eine Kopie der Wirklichkeit, sondern symbolische Bestandteile einer zweiten, kognitiv konstruierten, Welt in den Köpfen. Der Wert von Lerngegenständen bemißt sich dann nicht an ihrem lebensrealistischen Stellenwert, sondern an ihrem Neuheitsgehalt für die „kognitive Landkarte“ in den Köpfen der Schüler; er bemißt sich daran, ob sie Themenbereiche „neu“ zu denken ler- 
nen und im Kopf Ordnungen anlegen können. Die Denunziationsrede von der „Verkopfung“ halte ich für einen ärgerlichen Fehlgriff. Kognition ist in weiten Teilen der Reformöffentlichkeit zu einem Zwangsbegriff geworden, und Abstraktionsfähigkeit erscheint manchen fast schon als eine Form von Charaktermangel. Wenn Schule aber ein eröffnendes Angebot für Ungewohntes bieten will, dann gehört Erfahrung mit kognitiver Sorgfalt und mit der gedanklichen Sportivität eines Detektivs allemal hierzu!

\section{Sozialformen des Unterrichts}

Hier geht es um die Annahme, eine Informalisierung der Sozialformen brächte einen erheblichen Schub an primärer Produktivität der Schüler mit sich. Aber auch auf dieser Ebene hat sich der kulturelle Kontext verändert: Eine weitere Steigerung von Informalisierung und Wahrnehmungszerstreuung ist keinesfalls mehr anzustreben. Die Wahrnehmungszerstreuung, die Öffnung, Vermischung, der Situations-Mix, ist längst Normalfall. Wie oft machen wir im Alltag alles gleichzeitig: Gehen, Essen, Reden, Schauen. Ungewohnt ist das Gegenteil: Einer Situation ihre Spezifik zu belassen. Eine Wegnahme von Regeln, Kleinstritualen und symbolischen Strukturierungen bedeutet im veränderten Kontext nicht Entlastung, Befreiung oder Ermutigung zur Eigenproduktivität, sondern bloß eine weitere Stufe der bereits habituell gewordenen Informalisierung. Von daher hat dies für Schüler nicht unterstützende, sondern trivialisierende Effekte.

„Freiere Sozialformen“? - Ja, aber nur zusammen mit neu zu stiftenden Regeln, Kleinstritualen und symbolischen Strukturierungen. Und das heißt für die Lehrer auch: Freieres Arbeiten erfordert einen höheren Aufwand an Regie- und Moderationsarbeit, wenn es nicht einfach im Eintopf der Alltagsgewohnheiten enden soll. Eine Schule für das Ungewohnte müßte unterschiedliche Situationstypen ermöglichen, stabilisieren und kultivieren: lockere und konzentrierte Situationen, anstrengende und entspannte, quasihandwerkliche und abstrakte - auf ihre jeweilige Eigenart hin zugespitzte und deutlich voneinander unterscheidbare Situationen.

Also: Ich möchte mich auf dieser Ebene der Sozialformen für eine „Kunst der Trennungen“ (M. Walzer) stark machen. Ich bin dagegen, Situationen in entstrukturierender Absicht zu veralltäglichen, und stattdessen dafür, sie in strukturierender Absicht zu spezifizieren und zuzuspitzen.

\section{Pädagogische Zuständigkeit}

Hier dürfte das Schlüsselwort die vielberufene „Ganzheitlichkeit“ sein (deren partielle Erblast als antimoderner Kampfbegriff meistens ausgeblendet bleibt). Im normativen Fluchtpunkt von Ganzheitlichkeit arbeiten „ganze“ Lehrer-Menschen an der Formung ,ganzer" Schüler-Menschen. Die Ausrichtung dieses Bildes an einer vormodernen Tugendgemeinschaft ist kaum zu übersehen. Als reformorientiert gilt es, wenn die Lehrer andere, bislang außen vor gebliebene Aspekte der Persönlichkeitsentwicklung im Auge 
haben, intentional formen und pädagogisch bewerten wollen. Statt bloßer Benotung von Fachkenntnissen sollen dann Lernberichte über die Schüler erstellt werden, die unter ganzheitlichen Aspekten die Gesamtentwicklung einer Schülerin beschreiben und beurteilen. Das pädagogische Kalkül wird auf die soziale Gesamtwirklichkeit der Schule und der Schüler ausgedehnt. In dem Maße, in dem die Pädagogen sich zum ,richtigen“ Selbstverständnis haben reformieren lassen, werden sie im Gegenzug therapeutischmoralisch ermächtigt, den pädagogischen Zugriff nun, da sie ja „,das Richtige wollen“" zu totalisieren.

Ich plädiere für eine umgekehrte Aufmerksamkeit. Die Schüler haben ein Recht auf Schutz vor Ausweitung des pädagogischen Kalküls, auch eines gut gemeinten. Die Schüler haben das Recht auf eine gewissen Intransparenz ihrer Schüler-Welt. Und die Schüler haben das Recht auf bewertungsfreie Zonen innerhalb des Schulalltags. Gerade nicht der ganze Mensch sollte zur Formungsdisposition gestellt sein. Schüler haben demokratische Beteiligungsrechte, sie haben aber auch zivilitäre Enthaltungsrechte.

Für die Seite der Lehrer gilt Analoges. Lehrer füllen eine institutionelle Berufsrolle aus; sie sollten sich insoweit als Professionelle verstehen. Aber auch diese Professionalität sollte nicht totalisiert werden. Nicht um die grenzenlose Ausdehnung des professionellen Habitus auf alle Situationen und Bereiche kann es gehen. Eine Nur-Pädagogin ist schwer ertragbar, auch und gerade wenn sie ständig besten Willens ist. Ich plädiere für das Bild eines professionellen Lehrers, der gleichwohl die Fähigkeit hat, Ausnahmesituationen anzuerkennen und zu erfinden. Der also auch außerprofessionelle Person sein kann - und möglicherweise in dieser Eigenschaft für die Schüler interessant ist. (Ein faszinierndes Beispiel dieser Fähigkeit veranschaulicht Peter Weirs Kultfilm „Club der toten Dichter“.)

Soweit mein Kommentar zur Stereotypie der Schulkritik. Lebensnähe, freiere Sozialformen, Ganzheitlichkeit sind ironischerweise im Kontext einer zweiten Modernisierung keine erfrischenden Gegenprinzipien mehr, die man emphatisch auch heute noch einfordern sollte. Sondern sie sind selbst mittlerweile insoweit kalter Kaffee, als sie von kulturellen Modernisierungstendenzen längst eingeholt, überholt und damit trivialisiert worden sind.

Das Neue, das die Schule der zweiten Modernisierung benötigt, wird anders aussehen und in andere Richtung gehen, als es uns die routinierten Muster der Schulkritik vormachen. Das bedeutet, daß Schule - zumindest in einigen Raum- und Zeitzonen ihres Normalbetriebs - Kontrasterfahrungen anbietet und entsprechende Situationstypen hierfür institutionell und symbolisch stützt. Es wären dies dann hoch spezifizierte Lern- und Erfahrungssituationen und gerade nicht Situationsmix und Eintopf. Es wäre gerade Lernen durch Entselbstverständlichung und nicht durch Veralltäglichung. Im Grunde wäre solche Schülerzentrierung ein Angebot an Dezentrierungen, die für die Schülerinnen und Schüler Abstand vom Gewohn- 
ten, d.h. Erfahrungen von Fremdheit darstellen könnten - allerdings von wohldosierter Fremdheit, die nicht überwältigt, sondern anregt.

Schulpädagogische Reformimpulse sollten sich mithin nicht mehr auf die Motive, Deutungen und Semantiken der 70er-Jahre verlassen. Sonst ist es, als spielte eine Kapelle die längst bekannten Melodien unerschütterlich weiter und weiter, ohne gewahr zu werden, daß das Publikum längst den Saal gewechselt hat. Es wird Zeit, Neues zu spielen, man sollte einen Neuanfang wagen. Adieu, 70er-Jahre!

\section{WolfGang MeLZER, SABine Al-Diban \\ Vermittlung von Fachleistungs-, Sozial- und Selbstkompetenzen als zentrale Bildungsaufgabe von Schule}

$[\ldots]$

Der sich gegenwärtig vollziehende Umbau der Gesellschaft im Kontext von Modernisierungsprozessen [führt] dazu, dass man alle Sektoren und Institutionen - so auch die Schulen - evaluiert und auf ihre Effizienz hin überprüft. Dabei wird nicht nur die Frage gestellt, ob und inwieweit bislang konsensuale Vorstellungen von Bildung als umfassendes Konzept der Kompetenzaneignung und Persönlichkeitsentwicklung tatsächlich im Unterricht verwirklicht werden.

Im Hinblick auf diesen notwendigen gesellschaftlichen Diskurs bieten wir in unserem Beitrag eine Argumentationshilfe dahingehend an, den Bildungs- und Erziehungsauftrag der Schule als ein integratives Konzept zu begreifen. Es sind nicht nur reformpädagogische Postulate, sondern es lässt sich auch empirisch belegen, dass sich Fachleistungs-, Sozial- und Selbstkompetenzen wechselseitig bedingen (vgl. u.a. Fend 1997, Fend/Stöckli 1997, 1995, Weinert/Helmke 1996, Melzer 1999). [...] Für die Schüler ergibt sich [daraus], dass Schul- und Lebenserfolg mit einer komplexen Anforderungsstruktur verbunden sind, die fachliche und soziale Aspekte sowie Persönlichkeitskomponenten beinhaltet.

[...] In den Begriffen der Evaluationsforschung ausgedrückt stellt die Fachleistung - gemessen durch Noten und Abschlüsse - den „Output“ dar und steht allenfalls für kurz- und mittelfristige Erfolge, während Bildung als „Outcome“ eine umfassendere Kompetenz und Prädisposition für eine langfristig erfolgreiche biographische Bewältigung von Entwicklungs- und Lebensaufgaben beinhaltet. [...] 


\section{Die Bedeutung von Erziehungsmilieu und Schulkultur fuir den Bildungserfolg}

[...]

Zusammenfassend bleibt festzuhalten, dass in unseren beiden Studien folgende Befunde erhärtet werden konnten: Der Bildungserfolg von Heranwachsenden wird [...] zunächst von den außerschulischen Sozialisationsbedingungen (Familie, Peers, Medien-/Freizeitverhalten), in denen die Kinder und Jugendlichen aufwachsen, beeinflusst. Das Herkunftsmilieu der sozialen Schicht spielt insofern eine Rolle, da es durch Selektionsprozesse in den verschiedenen Schulformen zu einer Verstärkung und Aggregation schichttypischer Verhaltensmodi kommt [...] (vgl. Forschungsgruppe Schulevaluation 1998: 218 ff.). Die Daten haben darüber hinaus gezeigt, dass die Schulkultur einen ebenfalls relevanten Einflussfaktor darstellt, wobei den Lehrerkompetenzen die größte Bedeutung für den Bildungserfolg der Schüler zukommt. Die didaktische und Förderkompetenz der Lehrer wirkt sich nach unseren beiden Befragungen (1996/1998) überraschenderweise sogar stärker auf die Sozialkompetenz und das allgemeine Selbstkonzept als auf die Fachleistungen aus. [...] Wesentliche Bausteine einer umfassenden Lehrerqualifikation sind daher nicht allein hervorragende Fachkenntnisse und das Wissen, dass es unterschiedliche Lehrmethoden gibt. Entscheidend für die Lehrerprofessionalität im Berufsalltag ist vielmehr die Handlungskompetenz, unterschiedliche Lehrmethoden auch angemessen und souverän einzusetzen, sowie die Fähigkeit, Schüler zu integrieren und individuell zu fördern. [...] Außerdem sollten Lehrerinnen und Lehrer über die Fähigkeit verfügen, immer wieder sinnstiftende Bezüge zwischen dem Unterrichtsstoff und der gesellschaftlichen Realität herstellen zu können. [...]

Unsere Grundannahme dabei ist, dass Maßnahmen zur Förderung der Motivation, zum Aggressionsabbau oder zur Stabilisierung des Selbstvertrauens auch dem Fachleistungsstatus zugute kommen können, während umgekehrt durch eine fachspezifische Förderung auch Sozialverhalten und Selbstkonzept positiv beeinflusst werden können. [...]

In der Biographie eines Schülers fließen die unterschiedlichen Einflussfaktoren und Kompetenzen zusammen und bilden mit ihren individuellen Spezifika eine Einheit in der Persönlichkeitsstruktur. Gleichwohl gibt es Gruppen von Schülern, die unter ähnlichen Lebensbedingungen unterschiedliche Kompetenz- und Erfolgsprofile entwickeln. Nicht jeder nutzt seine guten Chancen und manchen gelingt es, die schlechten Startbedingungen auszugleichen. Im Folgenden wird daher der Versuch einer Ausdifferenzierung und Typisierung der Schülerschaft unter dem Gesichtspunkt der drei Dimensionen des Bildungserfolgs vorgenommen. 


\section{Typologie von Schülergruppen mit unterschiedlichem Bildungserfolg}

[Es lassen] sich empirisch unterschiedliche Schülergruppen ermitteln, die sich hinsichtlich der drei Dimensionen von Erfolg unterscheiden. Es treten also verschiedene Konfigurationen von Fachleistungsstatus, Sozialverhalten und Selbstkonzept auf. [...]

Die Gruppe $1[\ldots]$ ist eine der zwei Hauptproblemgruppen. Hier treten die gravierendsten Unterschiede in den einzelnen Dimensionen des Bildungserfolges auf. Diese Schüler erreichen zwar durchschnittliche Fachleistungen und haben ein leicht überdurchschnittliches Selbstkonzept, aber ihre Sozialkompetenz ist ausgesprochen schlecht. [...]

In der Gruppe 2 [...] haben die betreffenden Schüler trotz durchschnittlicher Noten und einer guten Sozialkompetenz nur ein gering entwickeltes Selbstvertrauen. [...]

Die Gruppe $3[\ldots]$ ist die zweite Hauptproblemgruppe, die dazugehörigen Schüler haben Misserfolge auf allen, für den Bildungserfolg zentralen Gebieten. [...]

Die Gruppe 4 [...] charakterisiert Erfolge in allen drei Kompetenzbereichen. Damit stellt diese Gruppe einen Idealtyp des umfassenden Bildungserfolges dar. [...]

Schließlich [haben] die Schüler der Gruppe 5 [...] leicht unterdurchschnittliche Fachleistungen, können aber im Sozialverhalten und in Bezug auf das Selbstkonzept etwas über dem Mittel liegende Werte erreichen.

$[\ldots]$

Unter dem Gesichtspunkt eines allgemeinen Bildungserfolges ist die Gruppe 4 und unter dem eines allgemeinen Bildungsmisserfolges ist die Gruppe 3 idealtypisch. [...] Es sind dieselben Einflussfaktoren - nur mit umgekehrten Vorzeichen -, die Schüler in einer Erfolgs- bzw. Misserfolgsposition aufweisen. Mit Ausnahme einiger für Gewalthandeln besonders relevanter Variablen (Konsum von Gewaltsendungen, TV-Vielseher, Aggressivität im Freundeskreis), bei denen die Gruppe 1 noch etwas schlechter als die Gruppe 3 abschneidet, stellen die Erfolgreichen bzw. Erfolglosen auch die Extremgruppen dar, wenn man die außerschulischen Sozialisationsbedingungen und die Einflüsse der Schulkultur im Allgemeinen und der Lehrerprofessionalität im Besonderen betrachtet.

Dieses Interpretationsmuster setzt sich bei der Betrachtung der Individualdaten fort. Erfolgreiche Schüler (Gruppe 4) stehen beim Vergleich aller fünf Gruppen an erster Stelle bei der sozialen Integration in den Klassenverband, sie empfinden den geringsten Leistungsdruck, sind am wenigsten ängstlich, geben der Sinnhaftigkeit schulischen Lernens erste Priorität, äußern die höchste Schulfreude und sind am wenigsten aggressionsbereit und nationalistisch eingestellt. [...] $\mathrm{Zu}$ all dem stellt die Gruppe 3 der erfolglosen Schüler das Gegenstück dar. In ihr ist der Anteil derjenigen, die nicht in Gleichaltrigengruppen eingebunden sind, keinen festen Freundeskreis haben und nach eigenen Angaben meistens allein sind, überproportional groß. 
Unter den Erfolgreichen der Gruppe 4 sind vor allem die Mädchen und auch die Gymnasiasten deutlich überrepräsentiert. Schüler der Erfolgsgruppe kommen häufiger aus Familien der oberen, Schüler der Misserfolgsgruppe eher aus Familien der unteren Sozialschichten, wobei die soziale Herkunft erst durch Verstärkungsprozesse des Familienklimas und des elterlichen Erziehungsstiles richtig zum Tragen kommt.

Aufgrund der extremen Unterschiede zwischen den einzelnen Dimensionen verdient die Gruppe 1 eine genauere Betrachtung. [...] Diese Gruppe kann dadurch beschrieben werden, dass zwar durchschnittliche Noten erreicht werden, aber das Sozialverhalten sehr problematisch ist. Die entsprechenden Schüler sind meist in die Peers und in den Klassenverband integriert, verüben ihre Taten z.T. gemeinschaftlich und stärken dadurch ihr Selbstbewusstsein. Die Gruppe 1 [...] umfasst dreimal, in der Studie von 1996 waren es sogar fünfmal mehr Jungen als Mädchen und ist mit Jugendlichen aus allen Sozialschichten besetzt, wobei sogar mittlere und obere Schichten überwiegen. Nach eigenem Bekunden gehören ihre Mitglieder überdurchschnittlich häufig Peergruppen an, deren Mitglieder sich gut kennen, verstehen und vieles gemeinsam machen.

Eine weitere, oben bereits aufgeworfene Frage ist die, warum Schüler mit guten Noten und positivem Sozialverhalten sich hinsichtlich ihres Selbstvertrauens unterscheiden. Ein Vergleich der Gruppen 2 und 4 kann diesbezüglich Hinweise geben. Die Gruppe 4 ist idealtypisch für den Bildungserfolg, in dieser Gruppe befinden sich die auf ganzer Linie erfolgreichen Schüler, während die Schüler der Gruppe 2 in zwei Dimensionen ebenfalls erfolgreich sind, aber bei dem allgemeinen Selbstkonzept zeigen sie deutlich geringere Werte. Der Vergleich offenbart einen überproportionalen Anteil von Mädchen in der Gruppe 2 mit einem deutlich unterdurchschnittlichen allgemeinen Selbstkonzept. In ihrer Verteilung auf die Schulformen unterscheiden sich beide Gruppen nicht wesentlich voneinander. Unterschiede werden dagegen bei den Sozialisationsbedingungen ersichtlich. Während diese in der Regel für die Gruppe 4 als sehr positiv eingeschätzt werden können, liegen die Werte der Gruppe 2 meist im Mittelfeld (z.B. Erziehungsmilieu der Familie, Einflüsse der Schulkultur, Leistungsdruck, Schulfreude) und nur zum Teil im positiven Bereich (z.B. reflektiertes Medienverhalten, geringe Aggressivität des Freundeskreises, keine nationalistisch-rechtsextremistische Einstellung). Markante Differenzen zeigen sich hingegen bei den Variablen der psychischen Disposition: Schüler der Gruppe 2 sind ängstlicher und fühlen sich hilfloser bei ungerechter Behandlung als alle anderen Schüler mit der Folge, dass sie sich als Außenseiter empfinden und damit weniger in die Klasse und in Gleichaltrigengruppen integriert sind. Sie haben keinen festen Freundeskreis und sind daher häufiger als andere allein. [...] 


\section{Bildungserfolg unter Berücksichtigung des bereichsspezifischen Selbstkonzeptes}

[...] Im Folgenden wird versucht, die Identitätsfindung der Schülergruppen mit unterschiedlichem Bildungserfolg näher zu charakterisieren [...].

Tabelle: Charakteristika des Selbstkonzeptes der unterschiedlichen Schülergruppen*

\begin{tabular}{|l|c|c|c|c|}
\hline & $\begin{array}{c}\text { Soziales } \\
\text { Selbstkonzept }\end{array}$ & $\begin{array}{c}\text { Individualistisches } \\
\text { Selbstkonzept }\end{array}$ & $\begin{array}{c}\text { Akademisches } \\
\text { Selbstkonzept }\end{array}$ & $\begin{array}{c}\text { Transparente } \\
\text { Chancenstruktur }\end{array}$ \\
\hline Gruppe 1 & -- & ++ & - & $\emptyset$ - \\
\hline Gruppe 2 & - & -- & $\varnothing$ & $\emptyset-$ \\
\hline Gruppe 3 & - & $\emptyset$ & $\varnothing$ & - \\
\hline Gruppe 4 & + & + & + & + \\
\hline Gruppe 5 & - & $\emptyset$ &.- & $\varnothing$ \\
\hline
\end{tabular}

Ø: Mittelwert; + : geringfügig über dem Mittel liegend; ++ : überdurchschnittlich hoch;

- : geringfügig unter dem Mittel liegend; -- : überdurchschnittlich niedrig.

* Nach den Daten des Originalbeitrags (Abbildung 4, S. 56) von den Herausgebern erstellt.

Zu Gruppe 1, einer der beiden Hauptproblemgruppen, gehören ca. ein Zehntel aller Schüler und drei- bis fünfmal mehr Jungen wie Mädchen. Mitglieder dieser Gruppe sind als Schüler mit durchschnittlichen Fachleistungen und sehr schlechten Sozialkompetenzen zu charakterisieren. Die Schüler dieser Gruppe gehören zu den Hauptakteuren schulischer Gewaltausübung. [...] Diese Jugendlichen scheinen ihr negatives Sozialverhalten nicht im Widerspruch zu ihrer Persönlichkeit zu verarbeiten, da das Soziale Selbstkonzept konform dazu ebenfalls stark negativ ausgeprägt ist. Ein unterdurchschnittlich geringes Soziales Selbstkonzept bedeutet, dass die sozialen Beziehungen als sehr negativ eingeschätzt und gleichzeitig auch abgewertet werden (z.B.: „Die Schüler meiner Klasse sind mir völlig gleichgültig“). Die geringe soziale Integration in der Klasse bis hin zu einer verstärkt wahrgenommenen Etikettierung durch Lehrer und Mitschüler wirkt sich defizitär auf das sozial bezogene Selbstwertgefühl dieser Jugendlichen aus. Aber es scheint so, als ob eine Kompensation dieses negativen Selbstwertgefühles durch das als überdurchschnittlich eingeschätzte Individualistische Selbstkonzept stattfindet. Das bei diesen Schülern auftretende, stark positive Selbstwertgefühl speist sich allerdings vorrangig aus individuellen Motiven (z.B.: „Im Großen und Ganzen halte ich mich für erfolgreich“). Das negative Sozialverhalten und das überdurchschnittlich negative Soziale Selbstkonzept dieser Jugendlichen verstärken sich also möglicherweise gegenseitig. Außerdem nehmen diese Schüler trotz durchschnittlicher Leis- 
tungen eine schulische „Überforderung“ wahr, sie sind durch „Schulängste“ und der „Wahrnehmung eines hohen Leistungsdrucks“ charakterisiert und neigen zu einer mittelmäßigen Bewertung der Transparenz der Chancenstruktur.

Die Schüler der Gruppe 2 befinden sich allem Anschein nach auf der für die Pubertätsphase kennzeichnenden Identitätssuche. Die psychische Instabilität der Schüler dieser Gruppe bleibt von den Lehrern in der Regel unentdeckt, da diese keine besonderen „Auffälligkeiten“ hinsichtlich ihrer Fachleistungen oder ihres sozialen Verhaltens aufweisen. Zu dieser Schülergruppe mit einem niedrigen Selbstkonzept zählen mehr als ein Fünftel aller Schüler und etwa ein Drittel aller befragten Mädchen. Die psychische Instabilität, die vielleicht mit einer noch „diffusen Identität“ (vgl. Erikson 1976) zu erklären sein dürfte, zeigt sich an dem stark unterdurchschnittlich ausgeprägten Individualistischen Selbstkonzept, einem tendenziell negativen Sozialen Selbstkonzept bei gleichzeitig durchschnittlichem Akademischen Selbstkonzept und einer ebenfalls durchschnittlichen Leistungsattribuierung. Diese Schülergruppe kennzeichnet vor allem eine deutlich negativ gefärbte emotionale Stimmungslage, vorrangig negativ eingeschätzte und bewertete soziale Beziehungen zu Mitschülern und Lehrern, sowie eine ablehnende Einstellung zur eigenen Körperlichkeit. Die schulischen Anforderungen sind weniger bedeutsam für das Selbstkonzept dieser Schülergruppe.

Die Schüler der Gruppe 3, der zweiten Hauptproblemgruppe, mit einem Bildungsmisserfolg in allen drei Kompetenzdimensionen, haben die vergleichsweise schlechtesten Noten und eine geringe Sozialkompetenz. Ihr Selbstbewusstsein ist nicht ganz so instabil wie bei den Schülern der Gruppe 2, da ihr Individualistisches und Akademisches Selbstkonzept durchschnittlich ausgeprägt sind. Jedoch weisen diese Schüler einen tendenziell geringen Wert des Sozialen Selbstkonzeptes auf und betrachten die schulische Chancenstruktur durchaus skeptisch, d.h. sie haben wie keine andere Gruppe Zweifel daran, dass Schule gerecht sei und sie Erfolg durch Anstrengung erreichen könnten. Die sozialen Beziehungen werden von diesen Schülern ebenfalls als eher negativ wahrgenommen. Das Akademische Selbstkonzept liegt auf mittlerem Niveau, was angesichts der schlechten Schulnoten eher als unrealistisch eingeschätzt werden muss. Das bedeutet aber, dass diese Schüler trotz schlechter Noten nur einen geringen Leistungsdruck und kaum Schulangst verspüren. Diese Schüler sind normalerweise allgemein bekannt, da ihre Probleme in Bezug auf unser Modell des Bildungserfolges genereller Art sind und damit für Lehrer augenfällig werden.

$\mathrm{Zu}$ der Gruppe 4 mit reichlich einem Viertel der Befragten gehören Schüler mit einem umfassenden Bildungserfolg; für diese ist ein sehr ausgeglichenes und generell leicht positives Selbstkonzept in allen Bereichen besonders charakteristisch. Das heißt, diese Schüler weisen sowohl ein positives Soziales, ein positives Individualistisches und ein positives Akade- 
misches Selbstkonzept auf. Außerdem sind sie der Auffassung, dass sie ihren Erfolg im Rahmen einer gerechten Ordnung dem eigenen Bedürfnisverzicht und ihrer Anstrengungsbereitschaft verdanken. Für diese Schüler sind keinerlei zusätzliche Kompensationsmechanismen im Hinblick auf ihre Identitätsfindung notwendig.

Die Schüler der Gruppe 5, mit ebenfalls etwa einem Viertel aller Schüler, unterscheiden sich von denen der Gruppe 4 vor allem durch ihre deutlich schlechteren Fachleistungen. Betrachtet man ihr Selbstkonzept detaillierter, so fällt zunächst ein überdurchschnittlich negatives Akademisches Selbstkonzept auf. Das bedeutet, diese Schüler leiden stark unter ihren tendenziell schlechteren schulischen Leistungen, obwohl sie nicht zu der in Bezug auf die Fachleistungen tatsächlich schwächsten Gruppe 3 gehören. Ihr Individualistisches Selbstkonzept und ihre Bewertung der Transparenz schulischer Chancenstruktur sind durchschnittlich ausgeprägt. Hinzu kommt ein tendenziell negatives Soziales Selbstkonzept. Es wird deutlich, dass auch diese Schülergruppe bezüglich ihrer Identität eher Probleme und kaum Kompensationsmöglichkeiten hat. [...]

\section{Fazit}

Scheitern oder erfolgreich sein in der Schule gilt in unserer Gesellschaft als wichtige Voraussetzung für die soziale Statuspositionierung [...]. Zumindest werden durch die Vergabe von Abschlüssen und Berechtigungen die Weichenstellungen für oder gegen bestimmte Laufbahnen und Positionen getroffen, die später nur mit einem sehr viel höheren Aufwand zu korrigieren sind. [...]

In Folge dieser Entwicklungen haben sich die Minimalstandards formaler Bildungsabschlüsse sowie der diesbezügliche gesellschaftliche und familiale Erwartungsdruck, der auf den Heranwachsenden lastet, erhöht es ist auf allen Ebenen zu einer Einengung der Lernziele durch eine Intensivierung der Qualifikations- und Selektionsfunktion von Schule gekommen. [...] Es ist zu einer Fokussierung auf den Fachleistungsstatus und die Selektions- und Allokationsfunktion von Schule gekommen, die bei einem erheblichen Teil der Schüler zu Lasten der Sozial- und Persönlichkeitsentwicklung geht.

Dass der Bildungs- und Erziehungsauftrag der Schule durchaus miteinander vereinbar sind, Fachleistungsstatus, Selbst- und Sozialkompetenzen der Schüler sich wechselseitig bedingen, ist das Hauptergebnis unserer beiden repräsentativen Befragungen aus den Jahren 1996 und 1998.

Prinzipiell muss konstatiert werden, dass der Fachleistungsstatus zwar ein wesentlicher, aber niemals der alleinige Gradmesser für den Bildungserfolg der heranwachsenden Generation sein kann. Insbesondere das mit einem negativen Sozialverhalten eng verbundene Soziale Selbstkonzept scheint vor dem Hintergrund eines allgemeinen gesellschaftlichen Wertewandels bei Gruppen von Jugendlichen in relevanter Größenordnung zu 
einer stärkeren Selbstbezogenheit beizutragen. Konstellationen des Bildungserfolges, bei denen ein äußerst negatives Sozialverhalten bei gleichzeitigem Erfolg in Bezug auf die Fachleistungen und einem damit verbundenen Statusgewinn auftritt, dürften in unserer Gesellschaft, die letztlich ohne Solidarität, Teamfähigkeit und Kooperation nicht auskommen wird, langfristig individuell und auch gesellschaftlich zu größeren Problemen führen. [...]

Alle Dimensionen von Bildungserfolg werden durch dieselben Sozialisationsbedingungen beeinflusst, über die sich zu informieren für eine professionelle Lehrertätigkeit damit unabdingbar ist. Dies spricht ebenso für die Verbesserung der Lehrerfort- und -weiterbildung wie für eine verstärkte Zusammenarbeit von Schule und Elternhaus und dafür, die sonstigen Ressourcen im Umfeld der Schule pädagogisch zu nutzen. Unsere Ergebnisse zeigen, dass die Schulkultur und vor allem die Kompetenz der Lehrer ein entscheidender Faktor für den Erfolg der Schüler sind. Damit sind auch Strategien zur Entwicklung der Qualität von Schule angesprochen, deren Konsequenz für den Erfolg der Schüler deutlich geworden ist. Die Qualität der Institution Schule und die individuelle Erfolgsbilanz der Schüler bedingen sich somit gegenseitig.

Aus dem Nebeneinander und Miteinander verschiedener Erfolgs- und Misserfolgstypen und der Unterschiedlichkeit der Gruppen, die zu einem Klassenverband gehören, ist als pädagogische Konsequenz abzuleiten, dass die Schüler der einzelnen Gruppen ihren Voraussetzungen entsprechend im fachlichen bzw. psychisch-sozialen Kompetenzbereich differenziert gefördert und unterstützt werden müssen. [...]

Die empirischen Befunde sprechen für einen umfassenden Bildungsund Förderauftrag von Schule. [...] Historisch lässt sich dagegen eine Entwicklung von der „Unterrichtsanstalt" zur „Offenen Schule“ ablesen (Terhart 1994: 152). Die Mehrzahl der Schulpädagogen und Bildungsforscher, die sich mit dieser Thematik beschäftigen, treten ganz in diesem Sinne für eine größere Breite der Funktionen und Aufgaben von Schule ein.

[...]

Die Notwendigkeit und Sinnhaftigkeit eines umfassenden Bildungsauftrages für die Schule der Gegenwart und Zukunft lässt sich [...] empirisch belegen. $[\ldots]$

\section{Literatur}

Erikson, E. H.: Identität und Lebenszyklus. Frankfurt 1976.

Fend, H./Stöckli, G.: Der Einfluss des Bildungssystems auf die Humanentwicklung: Entwicklungspsychologie der Schulzeit. In: Weinert, F. E. (Hg.): Enzyklopädie der Psychologie Band I.3.: Psychologie des Unterrichts und der Schule. Göttingen 1997.

Fend, H.: Der Umgang mit Schule in der Adoleszenz. Bern, Göttingen, Toronto, Seattle 1997. 
Forschungsgruppe Schulevaluation: Gewalt als soziales Problem in Schulen. Opladen 1998.

Melzer, W.: Erfolg oder Misserfolg von Heranwachsenden in der Schule - Reflexionen und empirische Untersuchungsergebnisse. In: Päd Forum H. 1/1999, S. 23-28.

Terhart, E.: Unterricht. In: Lenzen, D. (Hg.): Erziehungswissenschaft. Ein Grundkurs. Reinbek 1994, S. 133-158.

Weinert, F. E./Helmke, A.: Der gute Lehrer: Person, Funktion oder Fiktion? In: Leschinsky, A. (Hg.): Die Institutionalisierung von Lehren und Lernen. 34 Beiheft der Zeitschrift für Pädagogik. Weinheim und Basel 1996. 


\section{Mögliche Effekte}

schulischer Modernisierung

IV. 



\section{Vorbemerkung}

In diesem Textblock sollen die möglichen Konsequenzen von Schulmodernisierung thematisiert werden. Die konkreten Folgen sind von den spezifischen Randbedingungen der Schulsysteme abhängig - hierzu zählen die Modernisierungspfade und Akteurkonstellationen auf der nationalen Ebene sowie lokale Settings. Die Frage, ob es sich dabei um eher positive oder eher negative Effekte handelt, kann nur durch empirische Untersuchungen beantwortet werden. Nach unserem Kenntnisstand gibt es nur wenige solcher Forschungsprojekte - im deutschen Kontext so gut wie keine.

Um uns der Problematik der Modernisierungsfolgen nähern zu können, blicken wir deshalb zunächst ins Ausland. In drei Texten werden exemplarische Erfahrungen mit Entwicklungen im französischen, im US-amerikanischen sowie im niederländischen Schulsystem mitgeteilt. Der vierte Text schließlich entwickelt, ausgehend von Forschungsdaten aus Deutschland und der Schweiz, konzeptionelle Überlegungen für eine Steuerung des Schulsystems, welche die Eigenarten der Profession der schulischen Akteure berücksichtigt.

\section{Kommentar (Eubel)}

In dem Text „Das Räderwerk“, veröffentlicht in dem von Bourdieu herausgegebenen Werk „Das Elend der Welt“, skizzieren Sylvain Broccholichi (Forscherin beim CNRS, Paris) und Françoise Euvrard (Forscherin beim Ministerium für Erziehungswesen, Paris) ein ,worst-case-Szenario'. Gäbe es zwischen Schulen mehr Wettbewerb und Konkurrenz, würden diese zu einem „Räderwerk“, denn „gute“ Schulen, hätten sie die Möglichkeit, würden sich vornehmlich ,gute“ Schüler aussuchen, so dass sich die übrigen an „schlechten“ Schulen konzentrierten. Solche (Rest-)Schulen würden aus Sicht der Autorinnen damit gleichsam zu ,Orten der Verbannung', weil sich die durch Praktiken selektiver Orientierungen' einstellenden Segregationsprozesse innerhalb des Schulsystems verschärfen. Von den Autorinnen wird dabei - wie auch von Bourdieu selbst (siehe seinen Text in diesem Band) - unterstellt, dass sich der Staat mehr oder weniger vollständig aus dem Schulsystem zurückzieht. Nach all dem, was wir in diesem Buch hinsichtlich der neuen Governance erörtert haben, die sogar verstärkt auf Steuerung setzt, ist das Szenario einer vollständig Marktkräften überantworteten Schullandschaft unseres Erachtens wenig plausibel. Dennoch erfüllt der Beitrag eine grundsätzliche Funktion darin, auf „unkontrollierte Wirkungen" von Modernisierungen, wie sie schreiben, zu achten. So war es z.B. explizites Ziel der französischen Bildungspolitik seit Mitte der 1980er Jahre, den Anteil der Schüler, die ihre Schulzeit mit dem ,baccalaureat' abschließen, dem Äquivalent des deutschen Abiturs, auf 80 Prozent zu erhö- 
hen. Die Schulen erhielten mehr Spielraum in schulorganisatorischer Hinsicht (Gestaltung der Stundentafel, Fächerangebot etc.). Trotz der guten Absichten und trotz der wertvollen und auf der Ebene der Einzelschule auch erfolgreichen pädagogischen Arbeit verstärkten sich aber segregative Tendenzen im Gesamtsystem. ${ }^{1}$

Soziale Ungleichheit und die Reaktionen der Akteure des Schulsystems darauf untersucht $S$. Karin Amos (Universität Frankfurt) am Beispiel der Vereinigten Staaten. Die Autorin konstatiert zunächst, dass derzeit im USamerikanischen Schulsystem die Umsteuerung von Chancengleichheit auf Ökonomie besonders extreme Formen angenommen habe. Sie weist auch darauf hin, dass im Fokus des amerikanischen „talk“ über Reformen seit der Etablierung eines öffentlichen Schulsystems nur immer ein besonderer Schultyp im Zentrum stand, nämlich benachteiligte Schulen in großen Städten. In den ,inner city schools“ konzentrierten und konzentrieren sich auch heute noch Schüler, deren ,Beschulung' mit besonderen Problemen belastet war und ist. Daraus ergibt sich für das amerikanische Bildungswesen als Ganzes, dass Modernisierung als Thema selektiv konzipiert ist. Sichtbar wird aber ebenso, dass gerade durch die Schulen, die besonders an Folgen der sozialen Segregation leiden, das Problem der Chancengleichheit als Dauerproblem für das gesamte Schulsystem wachgehalten wird. Im Text von Amos deutet sich damit an, dass die Orientierung der Schulsysteme an Chancengleichheit vielleicht aktueller denn je ist, weil die Umstellung auf Effizienz und Wettbewerb eben immer auch die entscheidende Frage aufwirft, an welchem Maßstab sich die neuen Regelungsstrukturen der Governance denn bemessen sollen. Wie von der Systemtheorie formuliert: Exklusion und Inklusion verweisen unauflösbar aufeinander. Daran gehen die derzeitigen nur negativen Debatten über , mehr Markt' im Schulsystem deutlich vorbei. Aber man muss natürlich die Hinweise auf die positiven Effekte von Marktorientierungen für die Chancengleichheit auch empirisch nachweisen - dies bleibt eine künftige Forschungsaufgabe. Dabei müssten, so die Autorin am Ende ihres Beitrages, ,inklusive“ und „exklusive" Prozesse lokaler Schulpolitiken aufgegriffen und theoretisch ausgearbeitet werden.

Genau umgekehrt zu Broccholichi und Euvrard und im Anschluss an Lesarten wie bei Amos, lässt sich an Hand des Beitrags von Katrin Dörner (FernUniversität Hagen) darauf verweisen, dass in einer Schullandschaft mit wenig Staat und viel Markt - wie in den Niederlanden - das Gesamtergebnis der Schulwahlen von Eltern und der Schulpolitiken der Einzelschulen nicht automatisch eine Intensivierung von Segregation nach sich zieht. Die Autorin zeigt, dass die Schulsysteme ihre Integrationsleistungen gerade in Bezug auf sozial benachteiligte Schichten sogar noch steigern können, wenn sich diese Schulsysteme gleichsam ungesteuert selbst organisieren

1 Mit anderen Worten: es stellen sich transintentionale Effekte ein; vgl. erneut Schimank (in diesem Band). 
dürfen. In einer Schullandschaft, in der die einzelne Schule eine hohe Autonomie hat, können sich auch Eltern mit ,Migrationshintergrund" eine Schule aussuchen, die ihren Interessen entspricht. Gerade ein Teil der Bevölkerung islamischen Glaubens zieht es vor, die Kinder an eigenen Schulen unterrichten zu lassen, was Dörner als Möglichkeit der schulischen Emanzipation für diese Teile der Bevölkerung deutet. Gleichzeitig verweist die Autorin darauf, dass dieser Befund nicht verallgemeinert werden kann vielmehr müssen für jede einzelne Gruppe der Migranten die Modernisierungseffekte gesondert untersucht werden. Denn es sind nach wie vor Faktoren der institutionellen Diskriminierung wirksam, die nicht originär auf Schulen zurückgehen, sondern auf eine staatlicherseits formulierte und über Rechte verankerte Inklusionspolitik gegenüber bestimmten Gruppen von Migranten, denen Exklusionspolitiken gegenüber anderen Gruppen von Migranten gegenüberstehen. ${ }^{2}$ Damit wird von Dörner wie von Amos darauf verwiesen, dass nach wie vor Untersuchungen zu lokalen Schulen notwendig sind. Zudem sind die Governance-Mechanismen gegenwärtiger Schulsysteme nicht nur auf der Mesoebene lokaler Schulen und auf der Ebene des Rollenhandelns von Lehrkräften und Schulleitern zu betrachten, sondern auch auf der Ebene des schulischen Gesamtsystems mitsamt den rechtlichen Möglichkeiten bzw. Unmöglichkeiten für Inklusion.

Trotz dieser analytisch wichtigen Berücksichtigung einer institutionellen Diskriminierung durch Staat und Recht kann man mit Dörner festhalten, dass es bezüglich der Integration neben einer Perspektive des Könnens, die eben aus institutionellen Faktoren des Staates, der Politik und des Rechts resultiert, auch die Dimension des Wollens auf der Akteurebene des Schulsystems geben muss. Dies betrifft nicht nur Entscheider in Politik, Bildungsverwaltung und Schulrecht, sondern auch Eltern - in diesem Fall jene mit Migrationshintergrund. Jedes Schulsystem lebt , an seiner Basis ${ }^{6}$ von Interpretationen und Interaktionen der Eltern, Schüler und Lehrer. Diese Interaktionen machen wesentlich - so betont unter anderem auch Fend (hier im Buch) - die Schulkultur, die Berufspraxis und die Unterrichtsbedingungen von Schule aus. Integration wird auf der Ebene der Interaktion durch das Wollen der verschiedenen Akteure erreicht; keine noch so gute Konstellation des Könnens kann dies ersetzen. Und dies bedeutet, dass keine Schullandschaft, sei sie auch noch so integrativ, Migranten-Eltern davon abhalten könnte, ihre Kinder an eigenen Schulen unterrichten zu wollen. ${ }^{3}$

2 Vgl. zur institutionellen Diskriminierung des Staates: Mackert (1998); zur institutionellen Diskriminierung von Schule: Gomolla/Radtke (2002). In welch unterschiedlicher Weise verschiedene Gruppen von Migranten durch Ausländergesetze, angewandtes EU-Recht sowie Einbürgerungsgesetze in Deutschland positiv und negativ diskriminiert werden, zeigen u.a. (mit neueren Daten aus der PISA-Studie versehen) Karakasoglu/Nieke (2002).

3 In der Diskussion darüber, dass und in welcher Weise Migranten die jeweiligen Werte des Gastlandes teilen sollen oder können, wird oft übersehen, dass die Werte zwar sehr wohl kognitiv bekannt sein können, aber abgelehnt, d.h. nicht gewollt 
Allerdings - und damit kommen wir zu einer weiteren möglichen Folge der Schulmodernisierung - ist weder das Wollen noch die staatliche und bildungspolitische Sanktionierung allein hinreichend für die gegenwärtige Umstellung von Schule. Was hinzu kommt, ist auf der Mesoebene des Schulsystems geradezu eine Flut von operativen Hilfen für das Organisations-, Personal- und Unterrichtsmanagement der Einzelschule. In welcher Weise diese Instrumente vom Personal aufgegriffen werden, beleuchtet der Beitrag von Thomas Brüsemeister. Auf der Basis von qualitativen Interviewdaten mit Lehrkräften in Hamburg und im Kanton Zürich zeichnet der Autor die heterogenen Modernisierungspfade nach. In Hamburg scheint eine Organisationsentwicklung zu beginnen, die das Kollegium und verschiedene Mitgliedschaftsrollen von Lehrkräften einer qualitätsbasierten Schulorganisation ins Zentrum rücken, so dass es der Hamburger Bildungsverwaltung heute relativ leicht fällt, ihre eigenen Modernisierungsüberlegungen damit zu verzahnen. Im Kanton Zürich dagegen sind einzelne Lehrkräfte engagiert - es gibt kein Kollegium, dass sich kollektiv wie in Hamburg auf bestimmte Qualitätsstandards zu bewegt. Ein Grund dafür ist die Orientierung der Lehrkräfte am Modell der Profession. In diesem Zusammenhang ist auch zu beobachten, dass die Qualitäts- und Organisationssprache der Zürcher Bildungsverwaltung die Lehrkräfte nicht erreicht. Auf Grund der unterschiedlichen Kommunikationsmedien, die es in den Professionen sowie in Organisationen gibt, ist eine kommunikative Verständigung zwischen Bildungsverwaltung und Lehrkräften schwierig. Brüsemeister fragt in seinem Beitrag, wie ein Steuerungsmodell aussehen müsste, in welchem die ,Profis' im Organisationsbereich, die Bildungsverwaltung, mit den ,Profis' im Interaktionsbereich, den Lehrkräften, miteinander besser kommunizieren könnten. Hier zeichnen sich Steuerungsmodelle der ,good governance“ ab (vgl. auch Bähr in diesem Band), in denen Eigenverantwortung und Vertrauen zwischen den Bildungsakteuren dominiert. Im Zuge dieser Steuerungssemantik könnte sich die Profession des Schulsystems stärker einbringen - zumal ihre Stärke genau in der Herstellung von (vertrauensvollen) Kommunikationen zwischen Lehrern und Schülern besteht. Ein solches Vertrauen würde die derzeitigen ,nackten“ Mechanismen des Controlling ablösen. Vieles am Modell der good governance muss in seinen praktischen Dimensionen erst noch entwickelt werden, und sicher lässt sich an jedem Detail Kritik üben. Aber es ist nicht zu übersehen, dass solche Modelle der Governance (jenseits von Controlling) erstmals in der Geschichte von Schulsystemen ein (stärkeres) Zusammenführen der Makro-, Meso- und Mikroebene des Schulsystems wagen.

werden. Diese Dimension des Wollens (einer Integration) lässt sich nicht durch noch so gut gemeinte „kognitive“ Aufklärung und inklusive Programme erreichen. 


\section{SYLVAIN BROCCOLICHI, FRANÇOISE OEUVRARD Das Räderwerk}

Seit ungefähr dreißig Jahren weisen die sichtbarsten Transformationen des Raums der schulischen Einrichtungen in die Richtung einer formalen Vereinheitlichung (dafür steht im wesentlichen die Einführung des einheitlichen Collège ${ }^{4}$ sowie des allgemeinbildenden und technischen Gymnasiums), welche jedoch einen tiefgründigen Differenzierungsprozeß verdeckt hat. Nicht nur, daß alte, an beamtenrechtliche Stellung und Dienstalter geknüpfte Unterschiede zwischen Lehrern im Sekundarschulbereich alles andere als verschwunden sind. $\mathrm{Zu}$ diesen trat auch noch ein Ensemble damit einhergehender Transformationen, welche die Unterschiede zwischen einzelnen Schulen noch weiter verschärften, insbesondere was die ungleiche Häufung der bildungsmäßig am meisten benachteiligten Schüler anbelangt, also der Schüler, von denen anzunehmen ist, daß sie der Schule die größten „Probleme bereiten“. Die Bedingungen, unter denen Lehrer heute ihren Beruf ausüben, werden zunehmend heterogener und unterscheiden sich von Schule zu Schule stark. [...]

Die Lehrer, und unter ihnen besonders diejenigen, die an den am stärksten betroffenen Schulen unterrichten, tun sich um so schwerer mit den Problemen, auf die sie in ihrer beruflichen Praxis stoßen, als die Ursachen dieser Schwierigkeiten zu wenig bekannt sind, und somit die Möglichkeit besteht, daß man ihnen die Verantwortung dafür anlastet und ihnen die Schuld zuweist. Die Schule, deren Auftrag es eigentlich ist, Wissen unter möglichst gerechten Bedingungen zu vermitteln, scheint selbst kaum darüber aufgeklärt, was sie von der Erfüllung ihrer Aufgaben abhält, und dies geht so weit, daß das, was die Berufsausübung an einigen Schulen bereits heute ,verunmöglicht“, im Dunkeln bleibt.

\section{Nachfragedruck und demagogische Entscheidung}

Dieser sich ab Mitte der achtziger Jahre intensivierende Differenzierungsprozeß hatte zur Folge, daß sich die Schwierigkeiten zunehmend in einigen Schulen konzentrierten. [...] Die Verlängerung der Dauer des Schulbesuchs, die seit Mitte der achtziger Jahre zu beobachten ist, folgt auf ein Jahrzehnt, in dem nur geringe Veränderungen der Schülerströme auf der Sekundarschulstufe zu verzeichnen sind, und dies insbesondere in bezug auf den Übergang in die gymnasiale Oberstufe und das Erlangen der allgemeinen Hochschulreife. Mittels eines Vergleichs der Schulverläufe von Schülerkohorten, die 1973 und 1980 von der Grundschule zum Collège wechselten, konstatiert die Schulverwaltung, daß von einer ,reellen Ver-

4 Im Anschluss an die Schulpflichtverlängerung auf 16 Jahre 1963 eingeführte, als Gesamtschule organisierte allgemeinbildende oder technische Ganztagsschule für alle 11-16jährigen (Sekundarstufe I). [Aus dem Glossar von Bourdieu u.a. 1997; die Hg.] 
besserung der schulischen Laufbahnen für jede der in Betracht gezogenen Kategorien" nicht gesprochen werden kann (sofern man die soziale Herkunft und das Alter beim Übergang ins Collège berücksichtigt). „Und wenn die Übergangsrate (von der Sekundarstufe I zur Sekundarstufe II) in sieben Jahren von $41 \%$ auf $46 \%$ anstieg, so ist dies darauf zurückzuführen, daß die herkunftsmäßig bevorteilten Schülerkategorien, die im Alter von elf Jahren ins Collège wechseln, häufig Kinder von Cadres und Freiberuflern, 1980 stärker vertreten sind als 1973“. [...] Daraus folgt, daß die Funktionsweise des Schulsystems auch dann noch, als die Nachfrage nach höheren Schulabschlüssen schon stark und allgemein verbreitet war, weiterhin dieselben sozialen Ungleichheiten hinsichtlich des Schulerfolgs erzeugte, und diese ungleichen Schulerfolge weiterhin von denselben Praktiken selektiver Orientierung sanktioniert wurden.

Angesichts dessen kann man die politische Zielbestimmung, ,im Jahr 200080 \% eines Jahrgangs zum Abitur zu führen“, und die ab 1985 betriebene „Politik der $80 \%$ “ als Ausdruck des Wunsches verstehen, die starke soziale Nachfrage nach Zugang zu höheren Schulabschlüssen auf offenkundige Weise zu befriedigen, wobei man allerdings dem Urteil der Lehrer ein immer geringeres Gewicht beimaß. Die Entscheidungen hinsichtlich anstehender Versetzungen sind in immer stärkerem Maße von den Beurteilungen des Lehrerkollegiums entkoppelt, während zugleich der Druck seitens der Eltern zunimmt, die nun die Versetzung ihrer Kinder in die nächste Klasse auch gegen der Empfehlung der Klassenlehrer durchzusetzen in der Lage sind. Und so ist es auch zu erklären, daß der Anteil der Schüler, die das zwölfte Jahr (sei es des allgemeinbildenden, technischen oder berufsbildenden Gymnasialtyps) erreicht haben, von $36 \%$ im Jahr 1985 auf 58 \% im Jahr 1991 angewachsen ist, was einer Zunahme um 22 Prozentpunkte im Zeitraum von sechs Jahren, gegenüber einer Zunahme um 10 Prozentpunkte im Lauf der vorausgegangenen 15 Jahre, entspricht.

\section{Unordnung und Spannungen}

Das frühere System hatte trotz der mit ihm verbundenen brutalen Diskriminierung zumindest noch eine gewisse Kohärenz besessen. Bestehende Unterschiede (im Kenntnisstand der Schüler und in deren schulischer Motivation) wurden von diesem System verstärkt und sanktioniert, indem schon zu einem recht frühen Zeitpunkt die Schüler, denen man die Befähigung zu einer „längeren Bildungslaufbahn“ bescheinigte, von den Schülern getrennt wurden, deren schulische Leistungen und deren Verhalten in den Augen der Lehrer den „Beweis erbrachten“, daß sie auf dem Collège oder dem Gymnasium fehl am Platze sind: Jene Schüler wurden ab Vollendung des 16. Lebensjahrs auf „die technischen Abschlüsse“ oder auf „das Berufsleben" hin orientiert.

Mit dem neuen Modell zur Steuerung der Schülerströme wird aber zugleich das gesamte Gleichgewicht zwischen Unterrichts- und Orientie- 
rungspraxis gestört. Um die Wirkungen dieses neuen Modells auf die Schüler und die Reaktionen, die jenes bei Lehrern oft hervorruft, verstehen zu können, muß man einen entscheidenden Sachverhalt in die Überlegungen mit einbeziehen: Die gegenwärtige Organisation des Schulsystems macht es den Lehrern unmöglich, den Schülern intensive und individuell angepaßte Hilfestellungen zu geben; diese jedoch werden in dem Maße unverzichtbarer, als der Anteil der Schüler mit nur geringem kulturellem Kapital zunimmt, welche es aus diesem Grund auch nötig haben, mehr als andere in der Schule zu lernen. Wenn man also diejenigen auf der Schule beläßt, die früher von ihr ,,ausgeschlossen“ geblieben wären, ohne zugleich die Bedingungen für eine effiziente pädagogische Intervention zugunsten der Schüler zu schaffen, die in höherem Maße von der Schule abhängig sind, um all das zu erlernen, was die Schule an Fähigkeiten verlangt, so führt dies zu all den Schwierigkeiten, die die Arbeitsbedingungen der Lehrer verschlechtern, ohne jedoch damit das Los der Schüler wirklich zu verbessern. So wird auch verständlich, warum die unkontrollierten Wirkungen der, wenn man es genau betrachtet, demagogischen „Politik der $80 \%$ “ zahlreiche Lehrer dazu verführt, den alten Verhältnissen nachzutrauern. Äußerungen wie: „Ich tue meine Arbeit, aber ich bin doch nicht dazu da, mich mit Schülern abzuplagen, die eigentlich gar nicht hier sein dürften", sind in den Lehrerzimmern der Gymnasien und Collèges immer häufiger zu hören.

Daß diese „schwierigen“ Schüler bis zur neunten Klasse auf dem Collège verbleiben konnten - unter Bedingungen, die die Regulierung der Schwierigkeiten um so weniger gelingen läßt, als diese vermehrt auftreten - konnte sowieso nur erreicht werden, indem den Schulleitern von höherer Stelle entsprechende Anweisungen gegeben sowie die Klassen, die zu CAP, CPPN und CPA führten ${ }^{5}$, nach und nach abgeschafft wurden. Was die Lehrer die Fassung, den Mut und die Hoffnung verlieren läßt, ist nicht alleine der Zwang, die Schüler bis in ein Alter hinein ertragen zu müssen, in dem diese sehr viel gefährlicher erscheinen können - in ihren Augen sind diese Schüler wegen ihres „,katastrophalen Benehmens“, Ihres „,völligen Mangels an Motivation“ und ihrer ,kompletten Verständnislosigkeit“ dem Schulbetrieb gegenüber als ,unerträglich“, ,zum Verzweifeln“, ja sogar als ,hoffnungslose Fälle“ einzustufen. Dies hängt auch mit den geringeren Befugnissen der Lehrer zusammen, die Arbeit der Schüler sanktionieren zu können, sie zur Mitarbeit zu bewegen sowie sich und ihren Vorgaben, selbst bei den Widerspenstigsten, ein Minimum an Respekt verschaffen zu können. Da die Versetzung in die nächste Klasse deutlich weniger von den Bemühungen und Leistungen der Schüler abhängt, ist den

5 CAP: Berufsabschluss, der zur Ausübung einer qualifizierten Berufstätigkeit in technischen oder administrativen Sektoren berechtigt. CPPN: Zweijährige VollzeitKlassen an Collèges. CPA: Zweijährige Teilzeit-Klassen mit alternierender Ausbildung, u.a. an Collèges, zur Vorbereitung auf das Berufsleben oder eine Lehre. [Aus dem Glossar von Bourdieu u.a. 1997; die Hg.] 
Lehrenden, als seien sie eines wesentlichen Fundaments ihrer Autorität bestimmten Schülern gegenüber beraubt, und sie fühlen sich zunehmend „ohnmächtig“ angesichts von Schülern, die wenig Neigung zeigen, sich für den Lernstoff zu interessieren, und das zu einem Zeitpunkt, zu dem das relative Gewicht dieses Schülertyps an vielen Collèges wächst.

\section{Von der schulischen Prüfung zur schulischen Kraftprobe}

Die Konsequenzen dieser Transformationen sind zweifelsohne in den berufsbildenden Gymnasien am stärksten zu spüren. Der Großteil der Schüler, die unter den früheren Bedingungen des Systems ein $\mathrm{BEP}^{6}$ anstrebten, geht heute aufs Gymnasium; während das Zugangsalter früher bei 14 oder 15 Jahren lag, kommen Schüler heutzutage im Alter von 17 oder 18 Jahren aufs berufsbildende Gymnasium, und das mit einer belasteteren schulischen Vergangenheit und mit „offenen Rechnungen“, die sie mit der Schule zu begleichen haben, im Gepäck. Diese Schüler, die man über einen längeren Zeitraum hinweg in einer Position des Mißerfolgs, einer Quelle von Passivität und Gewalt, auf dem Collège belassen hat, haben Eigenschaften angenommen, die die Arbeit der Lehrer auf dem berufsbildenden Gymnasium um vieles schwieriger und belastender machen. [...] Da die Unterrichtsbedingungen nicht wirklich die Umsetzung erzieherischer Ansprüche erlauben, hat es die Schule immer häufiger mit „Bandenführern“ zu tun, die die Lehrer offen herausfordern. Die Kraftproben zwischen Lehrer und Schüler nehmen immer mehr zu, und diese dienen den Schülern, die von der Schule als Versager gestempelt wurden, als Gelegenheit, an der Schule Rache zu nehmen.

$$
[\ldots]
$$

\section{Das Gesetz des Marktes}

Dieser Prozeß der zunehmenden Differenzierung der schulischen Einrichtungen, der auch einen Prozeß der Konzentration von Schwierigkeiten darstellt, was mit dem verlängerten Verbleib der Schüler zuerst auf den Collèges und dann auf den Gymnasien zusammenhängt, wurde freilich durch Maßnahmen der „Dezentralisierung“ und der Einführung von Konkurrenzbeziehungen zwischen Schulen, welche neue Teufelskreise in Gang setzten, noch weiter verstärkt. Die einzelnen Schulen verfügen seither in der Tat über einen vergrößerten Spielraum in der Verwendung ihrer finanziellen Mittel. Und wenn sie gezwungen sind, sich auf ihre Klientel einzustellen, so heißt das auch, daß sie ihrem Ruf auf dem lokalen Markt und dessen potentieller Wirkung auf Interessenten, die durch ihn angezogen oder abgestoßen werden könnten, Sorge tragen müssen. Da die Mittel, über die sie „freie“ Verfügung haben, begrenzt sind, müssen sie sich entscheiden: Bei-

6 Facharbeiter- und ähnliche Berufsbildungsabschlüsse. [Aus dem Glossar von Bourdieu u.a. 1997; die Hg.] 
spielsweise zwischen einer prestigereichen Option, etwa einem Unterrichtsangebot in Griechisch, um damit Abgänge guter Schüler zugunsten konkurrierender Schulen zu verhindern, oder der Option, Stützkurse für Schüler mit Lernschwierigkeiten anzubieten. Auf diese Weise bilden oder verstärken sich Hierarchien zwischen Schulen, denen es am einen Ende der Skala gelingt, sich als „Leistungsspitze“ zu präsentieren, und jenen am anderen Ende der Skala, denen keine andere Möglichkeit der Spezialisierung bleibt als die, die (geringbewertete und nur wenig beneidete) Betreuung von Schülern mit Schwierigkeiten zu übernehmen.

Während die größere Autonomie der Schulen eigentlich eine bessere Anpassung an die Bedürfnisse ihrer Klientel bewirken sollte, sorgt der Konkurrenzdruck für den gegenteiligen Anreiz, nämlich daß sich die Schulen dadurch auf die Nachfrage einzustellen suchen, indem sie vordringlich das „Abwandern der guten Schüler“ zu verhindern trachten, da dies in der Regel mit einer Erhöhung des Anteils der in diesen Zeiten abgeschwächter Selektion ohnehin schon als zu zahlreich angesehenen ,schwierigen Schülern" einhergeht. Und da die Eltern von Schülern mit den besten sozialen und schulischen Voraussetzungen zugleich auch am ehesten in der Lage sind, nach Maßgabe der Kenntnis der Ursachen zu entscheiden und ihren Willen durchgesetzt zu bekommen, hat die Notwendigkeit, die am stärksten von Abwanderung betroffenen Schulen wieder ,,aufzufüllen“, [...] mit noch größerer Sicherheit als in der Vergangenheit zur Folge, daß sich Orte der Verbannung herausbilden, in denen sich die Probleme konzentrieren.

Selbst in Departements, die [...] noch in Schulbezirke unterteilt sind, ist an den Collèges in der Mehrzahl der Städte eine durch solche Abwanderungsbewegungen ausgelöste, verstärkte Differenzierung der Schülerpopulationen zu beobachten. Insbesondere aber in den städtischen Gebieten, in denen man die Schulbezirke aufgelöst hat, sind die Differenzierungs- und Wanderungsbewegungen am intensivsten und in starkem Maße abhängig von „öffentlichkeitswirksamen“ Argumenten oder unsicheren Vergleichen zwischen engen Konkurrenten, an welche sich die Eltern der Schüler klammern. [...] Die Qualität eines Schulzeugnisses, die, wie man weiß, eng mit der sozialen Herkunft zusammenhängt, ist ein entscheidender Faktor bei der Bestimmung der Chancen, von einer öffentlichen oder privaten Schule aufgenommen zu werden. In Gegenden, in denen die an Schulbezirke gekoppelten Beschränkungen der freien Schulwahl aufgegeben worden waren, bestimmt die Qualität des Zeugnisses die reelle oder fiktive Freiheit, sich eine Schule auswählen zu können (die Freiheit ist dann fiktiv, wenn sie sich darauf beschränkt, Aufnahmeanträge zu stellen, die abgelehnt werden, um dann anschließend zwangsweise einer der am wenigsten gefragten Schulen zugewiesen zu werden).

Dieser zirkuläre Prozeß, der nach und nach Verdachtsmomente in Beweise überführt, indem sich in stigmatisierten Schulen die von den begehrtesten Schulen abgewiesenen „Problemschüler“ sammeln, bringt in der Tat das Äquivalent dessen hervor, was in bezug auf Stadtlandschaften gemein- 
hin als „Ghettoisierung“ angeprangert wird. Auf diese Weise fielen in Paris zahlreiche Collèges, ja sogar selbst drei Gymnasien mit altehrwürdiger Vergangenheit panikartigen Fluchtbewegungen zum Opfer - wobei die Folgen der Panik oftmals tödlicher sind, als die der Panik ursprünglich zugrunde liegenden verschwommenen Beweggründe. Diese wurden im Anschluß daran, angesichts des „Verlusts der besten Schüler“ und des darauf folgenden Absinkens der Prüfungsresultate, beinahe amtlich zum „Katastrophengebiet" [...] erklärt, was wiederum den Abgang weiterer Schüler als gerechtfertigt erscheinen ließ.

\section{Schuldzuweisung und Demoralisierung}

Die räumliche Konzentrierung der Schüler, die den schulischen Anforderungen nicht entsprechen, ist für die Lehrer um so belastender, als sie ihre Arbeit undankbar werden läßt: „Es nimmt kein Ende mit den Stellen-Austritten ..., da gibt man sich solche Mühe, oft für nichts und wieder nichts, daß man sich sagt: ,Bei denen kann ich eh nichts machen'. Bei einigen weiß ich von vornherein, daß ich die aufgeben werde." Und anstatt sich $\mathrm{zu}$ fragen, warum die Schule so funktioniert, daß man den Lehrberuf nicht mehr auf befriedigende Weise auszuüben imstande ist, neigt man im Gegenteil dazu, den Lehrern die Schwierigkeiten der Schüler anzulasten, die um so größer werden, je geringer die vorgängige Selektion der Schüler und, folglich, je seltener Schüler die sozialen Eigenschaften aufweisen, die den Lehrern früher die Arbeit „erleichterten“. Die (kurz nach der allgemeinen Öffnung der Collèges erfolgte) öffentliche Beteuerung, daß ,,alle Schüler zum Erfolg aufgerufen sind“", fiel, zunächst auf der Ebene der Schulerlasse, zeitlich mit der an die Lehrer gerichteten dienstlichen Aufforderung zusammen (besonders deutlich im 1985 verkündeten Diensterlaß an die Lehrer der Collèges), daß ,für eine Diversifizierung und Individualisierung des Unterrichts zu sorgen ist“, wobei diese Aufforderung freilich von den Voraussetzungen einer solchen Neuorientierung absieht. Desgleichen ermahnt man die örtlichen Lehrer-Gruppen mit dem Hinweis auf die „Autonomie der Schule" dazu, die Probleme zu lösen, die größtenteils von der zentralstaatlichen „Politik der $80 \%$ “ verursacht sind. Ob es nun so ist, daß die Lehrer, die mit weit größeren Schwierigkeiten zu kämpfen haben als die verschiedenen „Schulerlasse“ legitimerweise vorsehen, sich selbst die Verantwortung dafür zuschreiben, oder, daß sie in diesen Erlassen eine wirkliche oder vorgetäuschte Unkenntnis seitens derer erblicken, die sie eigentlich aufklären sollten, in jedem Fall führen ihnen diese Texte auf schmerzliche Weise „die große Entfernung vom Ideal“ vor Augen.

Und obgleich die Schule und die berufliche Ausbildung regelmäßig als Prioritäten nationaler Politik präsentiert werden, bestehen doch die Widersprüche zwischen der offiziellen Sichtweise eines Schulsystems, welches für „den erfolgreichen Schulbesuch eines jeden Einzelnen“ (sprich: für "Chancengleichheit") Sorge tragen sollte, und dessen realer Funktionswei- 
se um so leichter fort, als sie zum großen Teil unerkannt bleiben. Neben statistischen Untersuchungen, die sich darauf spezialisiert haben, Schulverläufe zu erfassen sowie Unterschiede zwischen Schulbezirken oder Schulen aufzudecken, existieren pseudo-ethnologische Untersuchungen (beide Forschungsrichtungen kommunizieren nicht miteinander), die es jedoch versäumen, die Bedingungen, die mit der Emergenz eines bestimmten Problemtyps regelmäßig verknüpft sind, zu objektivieren. Wenn man aber eine solche Objektivierung unterläßt, führt dies unweigerlich dazu, den Opfern die Schuld zuzuweisen, beispielsweise dadurch, daß man „die Befähigung und die Beteiligung“ der betroffenen Akteure besonders herausstreicht. ${ }^{7}$ In diesen Studien werden auf manichäistische Weise Schulen, bei denen „der Wille, nach vorne zu schauen“ zu spüren sei und Veränderungen ,,als Chance zur Weiterentwicklung aufgefaßt" würden (,die Akteure zeigen keine Neigungen, in der Vergangenheit zu verharren"), anderen Schulen gegenübergestellt, in denen „Lehrpersonal und Schulleitung eine negative Sicht ihrer Schüler haben sowie zugleich unterschiedliche Standpunkte bezüglich der anzustrebenden Lösungen vertreten“. Die Probleme kleinzureden oder sie denen anzulasten, die ihnen ausgesetzt sind, bedeutet im Endeffekt nichts anderes, als sich einer genauen Erkenntnis der Probleme der schulischen Einrichtungen zu verweigern. Es bedeutet auch, zur Entmutigung derjenigen beizutragen, deren Bedingungen der Berufsausübung sich am stärksten verschlechtert haben. Daß man einseitig den Schulbesuch verlängert, ohne dies auf der Ebene der Unterrichtsbedingungen zu berücksichtigen, sowie unüberlegt Konkurrenzbeziehungen zwischen Schulen einführt, die auf höchst ungleiche Weise mit Schwierigkeiten zu kämpfen haben, scheint in starkem Maße dazu beigetragen $\mathrm{zu}$ haben, daß sich die Probleme dort konzentrieren und zuspitzen, wohin man die am stärksten Benachteiligten zunehmend verbannt. Der Verzicht auf Maßnahmen, die den Folgen dieser demagogischen und unkontrollierten Politik entgegenwirken könnten, hat das Unterrichtssystem in eine schwere Krise gestürzt, wobei die Demoralisierung der Lehrer zugleich Folge und Teil der Krise ist.

7 Dieses wie die folgenden Zitate sind Auszüge eines Artikels von Olivier Cousin und Jean Philippe Guillemet (erschienen 1992 unter dem Titel „Variations des performances scolaires et effets d'établissements" in der Nummer 31 der Zeitschrift É $d u$ cation et Formations), der auf einer allzu groben Gegenüberstellung von Schulen „Im Aufwind“ und Schulen „Im Abwind“ beruht. 


\section{S. KARIN AMOS \\ Schulentwicklung und soziale Ungleichheit - Was lässt sich am amerikanischen Beispiel beobachten?}

Wenn in den folgenden Überlegungen zu „Schulentwicklung und soziale Ungleichheit" auf das amerikanische Beispiel zurückgegriffen wird, so geschieht dies nicht zur Stützung oder Abwehr eines bestimmten Wahrnehmungsmusters oder einer bereits aufgestellten These nach dem Motto: das Ausland als Argument (Zymek 1975). Anliegen ist hier vielmehr, Aspekte von Praktiken und Semantiken im Blick auf ihre relationale Kontextuierung $\mathrm{zu}$ beachten, Irritationen zuzulassen, um so den Horizont der Betrachtung zu erweitern und die Argumentation zu differenzieren. Damit ist angedeutet, dass es sich hier noch nicht um eine vergleichende Untersuchung handelt, aber immerhin um Vorüberlegungen, die, so die Absicht, ausbau- und anschlussfähig sind.

Im Vergleich der gegenwärtigen Modernisierung mit den historischen Reformperioden ist ein Unterschied darin zu sehen, dass die internationale Dimension heute von vornherein expliziter mitgeführt und als zentrale Referenz genutzt wird (vgl. Adick 2002, Schriewer 1994 und Steiner-Khamsi 2000): „Kampf um Standorte“, „durch Globalisierung verschärfter Wettbewerbsdruck" sind zwei der zentralen Topoi, die die Umsteuerungen antreiben. Gleichzeitig scheint aber auch klar, dass die aktuellen Reformen in radikaler Abwendung von den Anliegen und Zielen der früheren - unter dem Leitwort „Chancengleichheit“ stehenden - Bildungsreform diskutiert und implementiert werden; mit Martin Carnoys Unterscheidung gesprochen, von „equity driven“ auf „finance driven“ umgestellt wird (Carnoy 1995). ${ }^{8}$

\section{Aspekte der amerikanischen Schulentwicklungsdebatte}

Nirgends scheint dieser Befund besser bestätigt als am Beispiel USA. Es fällt auf, dass die Wellen amerikanischer Reformen (zu den großen Entwicklungslinien und allgemeinen Tendenzen vgl. Oelkers 2000, Sünker 1999, Weiß 1991) immer einen spezifischen Fokus hatten und haben: die metropolitanen Schulsysteme. Bereits die erste große Expansions- und Mo-

8 Vorausgesetzt ist dabei der Befund, dass, trotz aller nationaler Besonder- und Eigenheiten, moderne Bildungssysteme in nationalstaatlich verfassten Gesellschaften in strukturähnlicher Weise in den gesellschaftlichen Gesamtkontext eingelassen sind; die Stanford Group um John W. Meyer verwendet hierfür den Begriff der Isomorphie (vgl. Meyer/Rowan 1977). Dies bedeutet freilich nicht, dass überall und zur selben Zeit die gleichen gesellschaftlichen Fragen an das Bildungssystem gerichtet werden; aber es bedeutet, dass große Schulreformbewegungen international konstituiert sind. Dies gilt für die um die vorletzte Jahrhundertwende einsetzende Reformbewegung ebenso wie für die Bildungsreform der sechziger und siebziger Jahre. 
dernisierungsphase des Bildungssystems wurde von Akteuren befördert, die in der Integration der Einwandererkinder und in den Anpassungen des Bildungssystems an die gesellschaftlichen Erfordernisse industrialisierter Nationen die zentrale Aufgabe sahen. David Tyack und Elisabeth Hansot (1982) haben diese am industriellen Paradigma orientierte Modernisierung personalisiert und die Protagonisten als „Managers of Virtue“ bezeichnet. Chancengleichheit war damals nicht Thema, sondern „Amerikanisierung“ sowie Überarbeitung des Lehrkanons bei gleichzeitiger Effizienzsteigerung des Schulsystems. Der gemeinsame Nenner zwischen „Amerikanisierung“ und "Chancengleichheit" als zwei zentralen Leitzielen ist im Erhalt oder der Wiederherstellung von gesellschaftlicher Kohärenz oder zumindest Kohäsion zu sehen. Durch die schwarze Bürgerrechtsbewegung wurde in den sechziger Jahren die Forderung nach unblockierten gesellschaftlichen Partizipationsmöglichkeiten auf die nationale Agenda gesetzt. Dieses komplexe Anliegen wurde, soweit es den zentralen Bereich von Bildung und Erziehung betraf, vom Bildungssystem so bearbeitet, dass der Fokus auf frühkindliche Förderung gerichtet war. Das „,culturally deprived“, „disadvantaged child", an dessen Konstruktion die Pädagogen in entscheidender Weise beteiligt waren (Popkewitz 2000), war vor allem ein Stadtkind. In den Metropolen wurde die durch ethnisch markierte und hierarchisierte Raumaufteilung bedingte soziale Isolation vom gesellschaftlichen mainstream zu einem besonderen Problem. „Kompensatorische Erziehung“ lautete das Zauberwort; durch Gewährung eines Vorsprungs, eines „head starts" sollten die gefährdeten Kinder von Anfang an so gefördert werden, dass sie den Anschluss nicht verpassten. Präsident Johnson hatte noch von Gleichheit der Resultate, ,equality of outcomes“ gesprochen, schnell setzte sich aber die Interpretation von Chancengleichheit im Sinne einer Gewährung von gleichen Startchancen durch. Nun zeigt eine genaue Betrachtung der vielstimmigen und hitzigen Diskussionen, dass bereits damals die erst mit der konservativen und neo-liberalen Wende der Achtziger in Zusammenhang gebrachten Leit- und Kampfworte in die Debatte gebracht wurden. Thesenartig zusammengefasst ist die Position wie folgt markiert (vgl. Campbell 1974):

1. Es hat eine technologische Revolution stattgefunden, die unqualifizierte Arbeit weitgehend überflüssig macht. Deshalb ist der einzige gangbare Weg aus dem Ghetto mit der Erlangung von Bildungszertifikaten verbunden.

2. Die Schulbürokratie der großen urbanen Schulsysteme ist nicht auf die Bedürfnisse von Ghettokindern ausgerichtet. Sie ist zu einem großen Anteil Teil des Problems und nicht dessen Lösung.

3. Die mit dem Lehrerzertifikat bescheinigte Kompetenz wird bestritten. Lehrer sind rechenschaftspflichtig: so wie man einen Chirurgen für eine misslungene Operation verantwortlich macht, so sollten auch die Lehrer für Versagen haftbar gemacht werden. Das Versagen der bürokratisch 
reglementierten Schulsysteme legt nahe, den Gemeinden (communities) größere Kontrolle zu gewähren.

Der zentrale Punkt, von dem alle Programme und Umstrukturierungen ihren Ausgang nahmen und nehmen, ist die Beschreibung, dass ohne Bildungsabschlüsse - aus der Sicht des Individuums keine soziale Mobilität und aus der Sicht des Staates kein nationaler Fortschritt und damit keine Wettbewerbsfähigkeit möglich sind. Das tiefsitzende Misstrauen gegen schwerfällige Bürokratien, unfähige Lehrer, unangemessenes und schlechtes Material bilden den Kern der Kritik und einen zentralen Bezugspunkt für alle folgenden Reformen. Und es ist auch kein Zufall, wenn die Idee der charter schools $^{9}$ ausgerechnet von Al Shanker in die Diskussion gebracht wurden. In seiner Funktion als Vorsitzender der New Yorker Lehrergewerkschaft war Shanker einer der zentralen Protagonisten in der von Campbell beschriebenen Krise. In dieser frühen Phase von ,community control" und Deregulierung war der Auslöser des erbitterten Zusammenpralls von community und Gewerkschaft die Entlassung von als unfähig befundenen Lehrern im Rahmen des Versuchsprogrammes.

Nicht nur die Schulbürokratien, auch die Lehrerbildung geriet ins Kreuzfeuer der Kritik: Streit um Lehrerzertifizierung, leistungsbezogene Entlohnung, unterschiedliche Modi der Evaluation und Kontrolle der Lehrqualität sind seitdem Dauerthema des amerikanischen Reformdiskurses, häufig stehen sich hier auch gewerkschaftlich organisierte Lehrer solchen gegenüber, die nicht Mitglieder einer Lehrergewerkschaft sind. Kritik wird von Eltern, community leaders, Experten aus unterschiedlichen Wissenschaftsbereichen, Bildungspolitikern aber auch von auf Profit ausgerichteten Bildungsunternehmern geübt.

Nicht nur die seit der Reformpädagogik geübte Kritik an Schulverwaltung und Lehrerbildung, auch Wettbewerb, Effizienz und Effektivität sind weitere Markierungen des semantischen Feldes, die nicht nur mit konservativen oder neo-liberalen Interessen zu identifizieren sind. Hier ist an Milton Friedmans berühmten Aufsatz aus dem Jahre 1955 zur Einführung von Bildungsgutscheinen (school vouchers) zu erinnern. Und Joseph P. Vitteriti (2003) hat aktuell nochmals unterstrichen, dass für Friedman die Abschaffung des Bildungsmonopols nicht nur ökonomische Effizienzsteigerung bedeutete, sondern auch mit dem Argument eingeführt wurde, benachteiligten Gruppen zugute zu kommen.

Die Frage der Chancengleichheit hat sich nicht erledigt. Dokumente wie der Bericht der National Commission of Excellence in Education, A Nation at Risk, aus dem Jahre 1983, lassen unter der in allgemeinen Formulierungen gehaltenen Oberfläche leicht erkennen, dass es eigentlich nach wie vor

9 Weitgehend deregulierte öffentliche Schulen, die sich einem bestimmten Programm und Bildungsziel verpflichten und für die Erfüllung auch einstehen müssen; Schulen, die die Lehrerkompetenzen und Entscheidungsfreiheit betonen. 
um die großen metropolitanen Schulsysteme geht, die vor allem von ,at risk“ Schülern besucht werden. „At risk“ ist das aktualisierte Etikett zur Bezeichnung der Kinder von gesellschaftlich marginalisierten Minderheiten - die vormals als culturally deprived oder disadvantaged bezeichnet wurden. Die von der Kommission reklamierten Mängel des amerikanischen Schulsystems: schlechtes Abschneiden in den basics, zu große Wahlfreiheit, Spezialisierung in Fächern, die bestenfalls in die Sackgassen der untersten Ebenen des Arbeitsmarkts führen, hohe Analphabetismusrate usw. sind ja keine Probleme der Schulen in den wohlhabenden Vorstädten und sind es nie gewesen; es sind auch keine Probleme, die in besonderer Weise die ländlichen Regionen Amerikas beträfen - es sind eindeutig und vor allem Probleme der Großstädte. Chancengleichheit muss aus staatlicher Perspektive auch bei knappen öffentlichen Kassen Thema bleiben. a) Sie ist zentral für die gesellschaftliche Kohärenz, für die Aufrechterhaltung der Nation als vorgestellte Gemeinschaft. b) Trotz Entkopplung von Wirtschaftsentwicklung und Beschäftigungsmarkt gilt der Erwerb von hochwertigen Bildungszertifikaten im Kontext internationaler Wettbewerbsfähigkeit als unerlässlich für eine gute nationale Positionierung. Aus der Sicht des Individuums wird dies bestätigt. Die meritokratische, leistungsbezogene Semantik beinhaltet die Anerkennung der Notwendigkeit des Erwerbs immer anspruchsvollerer und höherwertigerer Bildungsabschlüsse. ${ }^{10}$

Die Einsicht, dass Bildungsmärkte keine reinen Märkte sind, aber bereits die Einführung marktförmiger Strukturen in den öffentlichen Bildungsbereich aus Sicht des Steuerzahlers sehr unangenehme Folgen haben kann, zeigt das Beispiel Charter Schools. Bereits jetzt gibt es ernsthafte Kritik an dieser als Quadratur des Kreises versprochene Innovation. Die Fragen, die in diesem Zusammenhang aufgeworfen werden, sind auch für die deutsche Diskussion von Interesse. Eine grundsätzliche Schwierigkeit neben monetären Debakeln, die aus Unterfinanzierung resultieren - besteht in der Evaluation der Programme und der Beurteilung, ob die Bildungsziele erreicht wurden. Die öffentlichen Institutionen, die die charter vergeben, seien es Schulbehörden, Universitäten oder andere, sehen sich häufig überfordert in der Bestimmung und Durchsetzung von Bewertungskriterien, Indikatoren und Parametern.

10 Einerseits gilt in modernen Gesellschaften das in der Normalbiographie dokumentierte zielbestimmte und zügige Durchlaufen von Bildungsinstitutionen als zentraler Bestandteil für erfolgreiche Lebensgestaltung; andererseits legt das ausdifferenzierte Bildungssystem mit seiner Vielzahl von formalen und informellen Angeboten nahe, eine abgebrochene Bildungskarriere sei lediglich als unterbrochene aufzufassen, die jederzeit wieder aufgenommen und fortgesetzt werden könne (vgl. Fine 1991). Gleich ob die Bildungsexpansion staatlich zentral-bürokratisch geregelt ist wie in Frankreich oder dereguliert und umgesteuert wie in den USA - in jedem Falle haben marginalisierte Jugendliche verinnerlicht, Schulversagen mit persönlichem Versagen gleichzusetzen. Bourdieu hat das Funktionieren dieses gleichzeitigen Durchschauens und Leugnens eindringlich dokumentiert (Bourdieu 1997). 
Empirische Untersuchungen (vgl. Hess 2003) beleuchten weitere Reaktionsmodi öffentlicher Schulen auf Wahlfreiheit und Wettbewerb. Auch hier gilt die Unterstellung, dass aus der Einführung von Umsteuerung wünschenswerte Veränderungen in den großen städtischen Schulsystemen resultieren. Wie genau aber die Schulen reagierten, blieb lange Zeit ununtersucht. ${ }^{11}$ Im Kontext öffentlicher Schulsysteme werden durch freie Wahl induzierte Veränderungen offensichtlich nicht nur geprägt durch die öffentliche Steuerung, sondern auch durch den lokalen Markt, innerhalb dessen sie operiert.

\section{Die deutsche Diskussion}

Im Fokus auf spezifische Bedürfnisse einzelner Schulen und lokaler Schulsysteme finden die deutsche und die amerikanische Diskussion eine Gemeinsamkeit. ${ }^{12}$ Beiderseits des Atlantiks birgt dieser Fokus Chancen und Gefahren. Einigen Implikationen möchte ich anhand von Joachim Schroeders „Bildung im geteilten Raum“ nachgehen. $\mathrm{Zu}$ den Koordinaten der Schulentwicklung im städtischen Raum schreibt Schroeder, dass die „Organisation von Bildungssystemen nicht nur zu strukturfunktional ausdifferenzierten Bildungsräumen führt, sondern zumindest in urbanen Kontexten Ordnungsmuster der sozialräumlichen Zuteilung und Reproduktion sozialer Positionierungen und gesellschaftlicher Teilhabe erzeugt" (Schroeder 2002: 307). Die von Schroeder durchgeführte synchrone und diachrone Untersuchung des Hamburger Stadtteils Wilhelmsburg zeigt hinsichtlich zentraler Strukturen und Mechanismen basale Übereinstimmungen mit den amerikanischen Bildungsforschungen in urbanen Kontexten. Mit Schroeder gesagt versprechen genaue Untersuchungen von „Raumordnungsproblemen der Bildung“ und diesen „Konzepten hinterlegten Steuerungs- und Wirkungskräften“ die Voraussetzung für eine auf „Abbau von Bildungsbenachteiligung zielende Gestaltung der Schullandschaften“. Aus den USA bekannt und bezüglich der genauen Wirkungsweise hierzulande noch eingehender und vollständiger zu untersuchen, sind die ethnischen Hierarchisierungen,

11 Hess fokussiert in seiner Studie die drei Schuldistrikte, die während der neunziger Jahre im Zentrum der Schulwahl-Diskussion waren: Milwaukee im Bundesstaat Wisconsin, Cleveland in Ohio und Edgewood, Texas. Der Befund konstatiert, dass die Schuldistrikte nicht durch Betonung von Produktivität und Effizienz auf die Wettbewerbssituation geantwortet haben. Stattdessen wurde die Öffentlichkeitsarbeit verstärkt und die Chance genutzt, mehr regulatorische und prozedurale Freiräume zu eröffnen. Ineffiziente Praktiken wurden damit nicht beseitigt.

12 In den USA wie in Deutschland scheint grundsätzlich ein Charakteristikum der aktuellen Schulreformbewegung - im Unterschied zur großen Reformwelle der sechziger und siebziger Jahre - zu sein, dass nicht mehr große Entwürfe im Mittelpunkt der Anstrengungen stehen, nicht länger ,rational begründeten, technologisch brauchbaren Modellkonstruktionen“ (Gudjons 1995: 36) das Interesse gilt, sondern zeitlich und örtlich eng begrenzte Kleinvorhaben (Hiller 1994: 175, vgl. auch Rolff 1995, Dalin 1999). 
die sich auch sozialräumlich abbilden. In Bezug auf die Schulentwicklungsdebatte wird dem auch von Schroeder erwähnten ,tipping point“ größere Aufmerksamkeit zu zollen sein:

„Auf der Elbinsel werden immer wieder Überlegungen angestellt, um nach quantitativen Kriterien einen tipping point zu bestimmen, an dem, so dieser erreicht ist, ein ,normaler Unterricht" angeblich nicht mehr möglich sei und regulierende Eingriffe der Schulentwicklung erforderlich würden. In dieser Diskussion um die ,Mischungsverhältnisse" der Schülerschaft in einer Klasse oder in einer Schule erfolgt eine auf numerische Kriterien bezogene Konstruktion von Problemlagen, die sodann zur Legitimierung von Schulentwicklungsmaßnahmen Verwendung findet" (Schroeder 2002: 150).

Ob und inwieweit hier eine Parallele zu US-amerikanischen Verhältnissen vorliegt und ob diese Diskussion eine Rolle im Rahmen einer möglichen Polarisierung des Bildungssystems aufgrund von Schulwahlfreiheit führen könnte, sind weiter zu analysierende Probleme. Zwar wäre es sicher voreilig, einige der von Schroeder genannten Befunde mit ,white flight“ zu etikettieren; aber auch in Deutschland wird die Wahl des Wohnortes verstärkt durch das örtliche Schulangebot bestimmt. Wer in welcher Weise Wahlfreiheiten nutzen kann, ist in allen Ländern Frage der sozialen Positionierung und auch in Deutschland ist diese zunehmend durch ethnisch definierte Hierarchien überformt. Argument-items wie der ,tipping point" verweisen auf einen übergreifenden gesellschaftlichen Kontext, denn entweder ist ein solches Argument als allgemeine Ressource verfügbar oder es ist wirkungslos.

\section{Literatur}

Adick, Christel (2002): Demanded and Feared: Transnational Convergencies in National Educational Systems and Their (Expectable) Effects. In: Amos, S. Karin u.a. (Hg.): Globalisation: Autonomy of Education under Siege? Shifting Boundaries between Politics, Economy, and Education. European Educational Research Journal, Volume 1, Number 2, S. 214-233.

Bourdieu, Pierre, u.a. (1997): Das Elend der Welt: Zeugnisse und Diagnosen alltäglichen Leidens an der Gesellschaft. Konstanz: UVK.

Campbell, Robert (1974): The Chasm: The Life and Feath of an Experiment in Ghetto Education. Boston: Houghton Mifflin Company.

Carnoy, Martin (1995): Structural adjustment and the changing face of education. In: International Labour Review, Vol. 134, No. 6, S. 653-673.

Dalin, Per (1999): Theorie und Praxis der Schulentwicklung. Neuwied.

Fine, Michelle (1991): Framing Dropouts. Notes on the Politics of an Urban Public High School. Albany.

Friedman, Milton (1982): The Role of Government in Education. In: Robert A. Solo, (Hg.): Economics and the Public Interest. New Brunswick.

Gudjons, Herbert (1995): Pädagogisches Grundwissen. Bad Heilbrunn.

Hess, Frederick M. (2003) Revolution at the Margins. The Impact of Competition on Urban School Systems. Washington, D.C.

Hiller, Gotthilf Gerhard (1994): Schule zwischen allen Stühlen? Chancen pädagogischer Verständigung in einer pluralen Gesellschaft. In: Die Deutsche Schule, Heft 2, S. 
160-176.

Meyer, John W.; Brian Rowan (1977): Institutionalized Organizations. Formal Structures as Myth and Ceremony. In: American Journal of Sociology 83, 340-363.

Oelkers, Jürgen (2000): The Futures of Education. Bern.

National Commission on Excellence in Education (1983): A Nation at Risk. The Imperative for Educational Reform. Washington, D.C.

Popkewitz, Thomas S. (2000): Globalization/Regionalization, Knowledge, and the Educational Practices. Some Notes on Comparative Strategies for Educational Research. In: ders. (Hg.): Educational Knowledge: Changing Relationships between the State, Civil Society, and the Educational Community. Albany, S. 3-27.

Radtke, Frank-Olaf; Manfred Weiß (Hg.) (2000): Schulautonomie, Wohlfahrtsstaat und Chancengleichheit. Opladen.

Rolff, Hans-Günter (1995): Zukunftsfelder der Schulforschung. Weinheim.

Schriewer, Jürgen (1994): Welt-System und Interrelations-Gefüge. Die Internationalisierung der Pädagogik als Problem vergleichender Erziehungswissenschaft. Berlin.

Schroeder, Joachim (2002): Bildung im geteilten Raum. Schulentwicklung unter Bedingungen von Einwanderung und Verarmung. New York u.a.

Steiner-Khamsi, Gita (2000): De-Regulierung und Schulwahl in den USA. Gewinner und Verlierer. In: Radtke, Frank-Olaf; Weiß, Manfred (Hg.): Schulautonomie, Wohlfahrtsstaat und Chancengleichheit. Opladen, S. 117-135.

Sünker, Heinz (1999): Kritische Erziehungswissenschaft am Neubeginn?! Frankfurt a.M.

Tyack, David; Elisabeth Hansot (1982): Managers of Virtue. Public School Leadership in America 1820-1980. New York.

Viteritti, Joseph P. (2003): Defining Equity: Politics, Markets, and Public Policy. In: Alan Wolfe (Hg.): School Choice. The Moral Debate. Princeton, S. 13-30.

Weiß, Manfred (1991): Schulreform in den USA. In: Die Deutsche Schule, Heft 3, S. 360-372.

Wolfe, Alan (Hg.) (2003): School Choice. The Moral Debate. Princeton.

Zymek, Bernd (1975): Das Ausland als Argument in der pädagogischen Reformdiskussion. Schulpolitische Selbstrechtfertigung, Auslandspropaganda und Ansätze zu einer vergleichenden Erziehungswissenschaft in der internationalen Berichterstattung deutscher pädagogischer Zeitschriften 1871-1952. Ratingen, Kastellaun. 


\section{KATRIN DÖRNER \\ Ethnische Minderheiten im niederländischen Schulwesen}

\section{Strukturen und Bedingungen des niederländischen Bildungswesens}

Das wesentliche Charakteristikum des niederländischen Schulwesens ist die Freiheit des Unterrichts und beinhaltet die ,vrijheid in stichting, richting und inrichting“ (Gründung, Richtung und Einrichtung) von Schulen. Sie wurde 1917 in Artikel 23 der niederländischen Verfassung festgeschrieben und beendete einen seit Mitte des 19. Jahrhunderts währenden Streit zwischen den verschiedenen Konfessionen und dem Staat um das Recht auf Gründung und Unterhaltung eigener Schulen. Diese, aus den historischen Bedingungen des Ausgleichs zwischen widerstreitenden Kräften gewachsene Situation hat als Ergebnis eine Bildungslandschaft, die zu zwei Dritteln aus privaten (bijzonderen) und nur einem Drittel öffentlichen Schulen besteht (vgl. Skiera 1991). Dabei kommt der Staat gleichmäßig für die Finanzierung aller Schulen auf. Das ist einzigartig in Europa (vgl. Dronkers 1995). Obwohl das niederländische Schulwesen zu 100 Prozent vom Staat finanziert wird, hat dieser nicht die Befugnis, sich in Inhalte, pädagogische oder organisatorische Formen der privaten Schulen einzumischen. So gibt es neben den katholischen und protestantischen Privatschulen z.B. auch Basisschulen in jüdischer, muslimischer oder hinduistischer Trägerschaft. Fase (1993) beurteilt daher die niederländische als die radikalste Lösung für Pluralismus in der Erziehung.

Wegen dieses ausgeprägten Privatschulwesens kann die niederländische Regierung nur unter großen Schwierigkeiten Bildungsreformen in die Wege leiten und eine konstruktive Schulpolitik durchführen. So muß der Staat bei gewünschten Erneuerungen vor allem gegenüber den Privatschulen in Fragen der Inhalte und Methoden im Unterricht äußerste Zurückhaltung üben und die Balance zwischen Anregung und Eingriff in die Schulfreiheit wahren (vgl. Kroon/Sturm 1994). Weitreichende Änderungen können nur unter Beteiligung der verschiedenen Schulträger und einem unter diesen ausgehandelten Konsens erreicht werden. So gab es 1994 alleine 6300 verschiedene Schulträger (vgl. Karsten 1994). Schon die Reform der Basisschule hat aus diesem Grund mehr als zehn Jahre bis zu ihrer gesetzlichen Umsetzung gebraucht (vgl. Lumer-Henneböhle/Nyssen 1988). Reformen werden deshalb zunächst häufig an einzelnen öffentlichen Schulen als Pilotprojekte eingeführt und ,ausprobiert“. Aufgrund dieser eingeschränkten zentralen Realisierungsmöglichkeiten besteht zwischen bildungspolitischen Programmen und der Umsetzung an den Schulen daher oft eine beträchtliche Kluft, sie sind eigentlich eher als Anregungen zu verstehen.

Eine Folge dieser gesetzlich verankerten Zurückhaltung des Staates ist aber auch, daß die Lösung inhaltlicher und organisatorischer Probleme zum Beispiel im Zusammenhang mit der Aufnahme von Kindern nicht-nieder- 
ländischer Herkunft weitgehend den Schulen selbst überlassen ist. Dafür stehen diesen bei entsprechender Schülerpopulation allerdings zusätzliche personelle Mittel zur Verfügung (vgl. Mulder/Vierke 1998). Insgesamt kann man also finanziell von einer verstärkten Förderung, wenn nicht sogar positiver Diskriminierung von Kindern ethnischer Minderheiten sprechen, wenngleich die Verwendung der Mittel durch die einzelne Schule nicht staatlich vorgegeben ist.

Daneben können Schulen in den Niederlanden, auch zur Umsetzung pädagogischer Reformen, auf ein Netzwerk von Einrichtungen zurückgreifen, wie die Schulbegleitungsdienste, pädagogische Zentren, Institute zur Weiterbildung von Lehrern und für Curriculum- und Testentwicklung (CITO). Auch diese sollen die Reformfähigkeit des Schulwesens verbessern. Gerade letzteren kommt trotz freier Schulmittelwahl besondere Bedeutung für die Vereinheitlichung schulischer Inhalte und Anforderungsniveaus zu.

Aufgrund der nur groben staatlichen Vorgaben bezüglich der Fächer und Stundenanteile und der fehlenden Bestimmungen über Lehrpläne und Unterrichtsmaterialien hat jede Schule unabhängig von ihrer Trägerschaft das Recht und die Pflicht, ein eigenes Profil zu entwickeln. Unterschieden werden muß dabei zwischen Basis- und Sekundarschulen.

Die Basisschule ist angehalten, ihr gewähltes Profil mit seinen Zielen, Inhalten und pädagogischen Methoden im sogenannten „Schularbeitsplan“ (schoolwerkplan) detailliert zu dokumentieren. Auf dieser Grundlage kann intern und extern evaluiert werden (vgl. Lumer-Henneböhle/Nyssen 1988). Dies bietet der Schule die Möglichkeit, ihre eigene Qualität zu überprüfen und dementsprechende Veränderungen vorzunehmen. So kann das Schulprogramm auf die besonderen Bedürfnisse der Klientel abgestimmt werden. Der Schularbeitsplan stellt also ein indirektes Mittel staatlicher Steuerung und öffentlicher Transparenz dar, reicht als Mittel der Innovation und Kontrolle offenbar aber nicht aus (vgl. Kroon/Sturm 1994). Die inhaltliche Freiheit wird in der Basisschule bisher nur durch national entwickelte (CITO-)Tests im letzten Schuljahr eingeschränkt. Die Teilnahme daran ist für die Grundschulen zwar nicht verpflichtend, jedoch benötigen Kinder für den Zugang zu einer höheren Sekundarschule neben einer entsprechenden Empfehlung auch ein durch den Test nachgewiesenes Leistungsniveau in Sprache, Rechnen und Informationsverarbeitung. Der Test gibt daher implizit ein Anforderungsniveau für Kenntnisse in den getesteten Fächern vor. Manche Basisschulen, vor allem solche mit einem hohen Anteil an allochthonen und Arbeiterkindern, nehmen allerdings nicht an dem CITOTest teil. Man kann daraus schließen, daß sie die dafür notwendigen Inhalte gar nicht anbieten (vgl. Jungbluth 1994a).

In der Sekundarschule ist dagegen seit 1993 mit Einführung der „basisvorming“, einer Art „allgemeinen Grundbildung“, die aus einem Kerncurriculum aus 15 Fächern mit festgelegten Kernzielen besteht und $80 \%$ der Unterrichtsstunden in den ersten Jahren der Sekundarstufe für alle Schulen 
umfaßt, eine inhaltliche Vereinheitlichung verwirklicht worden (vgl. Meijer 1994). Allerdings können die Schulen selbst entscheiden, ob sie die basisvorming auf 2, 3 oder 4 Jahre ausrichten wollen (vgl. MOCW 1993: 4). Zudem kann sie auf zwei verschiedenen Niveaus abgeschlossen werden. Auch die staatlichen Abschlußprüfungen am Ende der Sekundarschule, die neben der schuleigenen Prüfung abgenommen werden, stellen eine Form der Lenkung und Qualitätskontrolle dar.

Das Profil der Schulen ist der Öffentlichkeit zugänglich und bildet die Basis für Vergleiche zwischen Schulen und die letztendliche Wahl der gewünschten Schule für das eigene Kind. Die Schulen sind verpflichtet, einen Schulführer herauszugeben, aus dem für die Eltern u.a. die Wahl der Lehrmittel sowie die erzielten Unterrichtsergebnisse ersichtlich sind (vgl. MOCW 1998a: 2). Inzwischen werden sogenannte „Qualitätskarten“ der Schulen erstellt, die deren diesbezüglichen Resultate beinhalten. Sie sind in einem von der Schulinspektion erstellten Qualitätsleitfaden veröffentlicht und auch im Internet (http://www.owinsp.nl) zugänglich. Den Eltern ermöglichen sie einen Qualitätsvergleich zwischen den für ihre Kinder geeigneten weiterführenden Schulen (vgl. MOCW 1998c: 3). Allerdings kann sich durch die Veröffentlichung der Schülerleistungen die Position von benachteiligten Kindern, dazu zählen auch die Minderheiten, verschlechtern und diese Praxis die ethnische Segregation (s.u.) fördern (vgl. Driessen 2000). Die Verantwortung für die Qualität der Leistungen liegt somit sehr stark bei der einzelnen Schule, sie muß sich mit ihren Ergebnissen dem Markt stellen. Aus der vielfältigen Bildungslandschaft können sich Eltern dann eine Schule für ihr Kind aussuchen. Sie sind nicht verpflichtet, die Schule in ihrem Wohnbezirk zu wählen.

Die Freiheit der Schulwahl wird im Hinblick auf ihre Konsequenzen für ethnische Minderheiten nicht nur negativ bewertet. Sie wird dagegen gerade als Möglichkeit einer Verbesserung der Schulqualität gesehen (vgl. Ritzen u.a. 1997), die in der Folge auch das Ausbildungsniveau von Migrantenkindern erhöhen kann. Weiterhin bleibt der Zugang zu gleichen Bildungschancen durch die freie Schulwahl gewährleistet (vgl. Rutten 1996).

\section{Ethnische Segregation im niederländischen Schulalltag}

Für die segregativen Tendenzen im niederländischen Bildungswesen wird häufig die Möglichkeit der freien Schulwahl und der damit verbundene sogenannte „white flight“, worunter die Meidung von Schulen mit vielen allochthonen Kindern durch autochthone niederländische Eltern ${ }^{13}$ verstanden wird, verantwortlich gemacht. Nach Angabe vieler Schulleitungen geschieht dies vor allem dann, wenn der Anteil an Minderheitenkindern die 50-60 Prozentmarke überschreitet (vgl. Karsten 1994). Diese Tendenz ver-

13 Als authochthon wird in der Migrationsforschung der Teil der Bevölkerung bezeichnet, der ,alteingesessen' ist, als allochthon derjenige Teil, der nicht aus dem Land selbst stammt [die Hg.]. 
stärkt die ethnische Segregation der Schüler unterschiedlicher Herkunft und mündet, vor allem in den großen Städten, im Entstehen von sogenannteo „schwarzen“ und „weißen“ Schulen. Die Hälfte der Kinder und Jugendlichen in Amsterdam beispielsweise gehört heute schon zu den ethnischen Minderheiten (vgl. Tesser u.a. 1999). $90 \%$ der Segregation nach ethnischer Herkunft in den Grundschulen Amsterdams ist allerdings der Wohnsegregation zuzuschreiben (vgl. Teunissen 1996). An $40 \%$ der Basisschulen in den großen Städten kommen die Kinder zu mehr als der Hälfte aus Migrantenfamilien, allerdings gibt es dort auch noch 4-8 \% rein „weiße“ Basisschulen (vgl. Rutten 1996).

Neben ethnischen bestimmen jedoch vorwiegend soziale Präferenzen die Schulwahl der Eltern (vgl. Fase 1993). Wegen des meist niedrigen Sozialstatus ethnischer Minderheiten läßt sich hieraus ein Grund für ihre Konzentration an bestimmten Schulen ablesen und erklärt, warum die niederländischen Kinder auf ,schwarzen“ S Schulen größtenteils auch aus sozial benachteiligten Verhältnissen kommen.

Obwohl bereits seit 1977 Schulen mit einem Prozentsatz von 60 bis $90 \%$ allochthoner Kinder bestehen (vgl. Teunissen 1988), hat das Problem der Segregation im Schulwesen erst seit einer Fülle von Presseberichten über „Apartheid in der Schule“ im Jahre 1986 und sich daran anschließenden Diskussionen breite öffentliche Aufmerksamkeit erlangt.

Der Zusammenhang zwischen einer hohen Konzentration allochthoner Schüler und schlechten Schulleistungen, eine Befürchtung vieler Eltern, die für den ,white flight“" mitverantwortlich gemacht wird, ist jedoch uneindeutig (vgl. Leiprecht/Lutz 1996), zumal auch der Anteil autochthoner Schüler auf Konzentrationsschulen nicht repräsentativ ist und diese häufig ebenfalls aus schwachen sozio-ökonomischen Verhältnissen stammen (s.o.) (vgl. Karsten 1994).

Auch Schulen in islamischer oder hinduistischer Trägerschaft sind von ihrer Schülerpopulation her ,schwarze“ Schulen. Sie beruhen auf der bewußten Entscheidung allochthoner Eltern, ihre Kinder auf einer Schule entsprechend ihres religiösen und kulturellen Hintergrunds unterrichten zu lassen. Dabei wird die Trennung von niederländischen Schülern bewußt in Kauf genommen, verbunden mit der Hoffnung, das dortige Angebot sei besser auf die Bedürfnisse der eigenen Kinder zugeschnitten. Sie nutzen die Möglichkeit, die das niederländische Schulsystem bietet, nämlich eigene Schulen nach eigenen weltanschaulichen Vorstellungen zu gründen. Insgesamt gibt es heute 28 islamische Schulen, die ca. 6800 der Migrantenkinder versammeln (vgl. Inspectie van het Onderwijs 1999). Man könnte hier von Emanzipation einzelner Migranten in und durch eine segregierte Situation sprechen. Dabei existiert, so wie im übrigen Schulwesen auch, nicht eine islamische „Musterschule“, sondern die einzelnen Schulen unterscheiden sich in ihrer religiösen Orthodoxie und Unterrichtsweise stark voneinander. Allgemein verfolgen die islamischen Schulen das Ziel, eine Verbesserung der Schülerleistungen bis zum Niveau des durchschnittlichen autochthonen 
Altersgenossen zu erreichen. Dies soll besonders durch Abstimmung auf den eigenen kulturellen Hintergrund erzielt werden. Auch die Integration in die niederländische Gesellschaft unter Erhalt der eigenen islamischreligiösen Identität wird von diesen Schulen angestrebt (ebd.). Bedenken muß man jedoch, daß auch auf islamischen Schulen die Lehrerschaft zum überwiegenden Teil aus autochthonen „weißen“ niederländischen Lehrern besteht. Durchschnittlich $70 \%$ des Kollegiums haben nach Angaben von Driessen (1996) keinen islamischen Hintergrund und sprechen ausschließlich Niederländisch.

Das niederländische Bildungsministerium beurteilt den dortigen Unterricht nicht schlechter als an anderen Schulen mit mehr als $70 \%$ Zuwandererkindern. Die Qualität des Lehrangebotes und die Zahl der Unterrichtsstunden seien sogar höher. Allerdings würden die Kinder an islamischen Schulen weniger zu Selbständigkeit und Eigenverantwortlichkeit angeregt (MOCW 1999: 2). Auch die Schulaufsicht kommt zu dem Ergebnis, daß die Schüler dort nicht schlechter abschneiden als an Schulen mit einer ähnlichen Zusammensetzung der Schülerschaft, also anderen „schwarzen“ Schulen. Die Rechenleistungen waren im Durchschnitt sogar höher (Inspectie van het Onderwijs 1999).

Von offizieller Seite werden daher islamische und andere „schwarze“ Schulen nicht als bildungspolitisches Problem gesehen. Es wird allerdings auf die qualitativen Unterschiede zwischen verschiedenen Basisschulen, die Migrantenkinder unterrichten, hingewiesen (Inspectie van het Onderwijs 1997). Schon 1988 hat Teunissen in seiner Studie über „witte“ (weiße) en „Zwarte“ (schwarze) basisscholen festgestellt, daß dies erst bei einem Anteil von unter $20 \%$ der niederländischen Schüler nachteilig für diese ist, wohingegen die Migrantenkinder von einem höheren Anteil an Schülern der gleichen Herkunft durch Prozesse der ethnischen Gruppenbildung profitieren. In „weißen“ Schulen würden sie hingegen sozial ausgeschlossen und kulturell marginalisiert. Es war generell kein oder nur ein geringer statistischer Zusammenhang zwischen der ethnischen Zusammenstellung und den Schulleistungen von Grundschülern feststellbar. Dieser verschwand völlig, wenn auch Faktoren des Ausbildungsniveaus der Eltern miteinbezogen wurden (vgl. Teunissen 1996). Auch zahlreiche andere statistische Daten weisen per se keine schlechteren Unterrichtsresultate für Schüler mit vergleichbarem Hintergrund an ,schwarzen“ Schulen auf, es scheint ebenso gute wie schlechte Basisschulen unabhängig von der Zusammensetzung der Schülerschaft zu geben (vgl. Driessen 1990; Tesser/Mulder 1990).

\section{Resümee}

Das niederländische Bildungsministerium beurteilt die deutlich unter dem Durchschnitt liegenden Leistungen von Schülern aus Migrantengruppen als besorgniserregend (vgl. MOCW 1998b: 2). Ob dies allerdings als Folge der segregativen Tendenzen im niederländischen Bildungswesen zu sehen ist, 
bleibt umstritten. Schon Jungbluth (1994b) sah gerade in der freien Schulwahl der Eltern zwischen unterschiedlich effizienten Schulen die Möglichkeit, die Bildungschancen auch von Migrantenkindern zu erhöhen, die aufgrund ihrer Schichtzugehörigkeit seiner Meinung nach durch die bisherige ständische Orientierung des Bildungswesens benachteiligt sind. Dazu müssen Eltern ausreichend über die Schule und deren Qualität u.a. anhand der Leistungen ihrer Schüler im Verhältnis zu denen vergleichbarer Schüler auf anderen Schulen informiert sein. Inzwischen wurde diese Möglichkeit über sogenannte Qualitätskarten (s.o.), eine Art Schulqualitätskontrolle, realisiert. Die Schule befindet sich durch diese Entwicklung generell verstärkt unter (Konkurrenz-)Druck, ihre Angebote auch auf die Bedürfnisse von Migrantenkindern abzustimmen. Jungbluth (1994b) sieht darin die Chance einer emanzipatorischen Bewegung der Migranten. Aber auch andere niederländische Autoren bewerten die freie Schulwahl gerade im Hinblick auf die Bildungsposition der Minderheiten eher positiv (vgl. Karsten 1994). Sie ermöglicht den Eltern, am Schulleben zu partizipieren und ihren erzieherischen Vorstellungen Ausdruck zu verleihen. Daraus könne eine Qualitätsverbesserung resultieren. Fraglich ist, ob die ethnischen Minderheiten in den Niederlanden bereits solchen Einfluß haben, um eine Veränderung der Schulen zu bewirken. Vielleicht muß die Lage aber auch so bewertet werden, daß die Emanzipation der ethnischen Minderheiten auch in einer segregierten Situation eine Vorbedingung für eine gleichberechtigtere Partizipation in der niederländischen Gesellschaft darstellt.

Die finanzielle Basis und Ausstattung von Schulen zur Bekämpfung von Bildungsrückständen auch bei Kindern allochthoner Herkunft ist in den Niederlanden jedenfalls günstig. Umso erstaunlicher ist für den ausländischen Betrachter, daß dies nicht auf breiter Basis zu entsprechenden Bildungserfolgen von ethnischen Minderheiten geführt hat. Besonders die Situation von Türken und Marokkanern ist trotz des langen Aufenthaltes dieser Bevölkerungsgruppen in den Niederlanden noch immer bescheiden. Unverständlich ist auch die im Vergleich zu den autochthonen Niederländern schlechtere Bildungsposition der in der niederländischen Sprache aufgewachsenen Surinamer, Antillianer und Molukker. Dagegen haben die ehemaligen Arbeitsmigranten aus Italien, Spanien und Portugal trotz der ursprünglich ähnlichen Migrationsbedingungen und einer mit den Migranten aus der Türkei und Marokko vergleichbaren sozio-ökonomischen Lage und Sprachproblematik in ihrem Bildungsniveau Anschluß an die autochthone niederländische Bevölkerung gefunden.

Dies wirft die Frage auf, ob Status und Ansehen der Migranten nicht in stärkerem Maße über Bildungserfolge entscheiden als familiäre und schulische Bedingungen. Auch wenn manche ethnische Minderheiten unter einer Kumulation ungünstiger sozio-ökonomischer und sprachlicher Voraussetzungen zu leiden haben, ist damit ihre nachteilige Bildungssituation nicht abschließend erklärt. 
Ein Grund für den scheinbar geringen Einfluß der finanziell verstärkten Zuwendungen für Migrantenkinder mag darin liegen, daß die Schulen über die Art der Verwendung der Mittel selbst entscheiden dürfen und diese nicht immer effektiv für die Belange allochthoner Schüler ist. Auf der anderen Seite kann diese Finanzautonomie der Schulen aber auch von Vorteil sein, da die besonderen Bedürfnisse vor Ort eine angepaßte Strategie erfordern. So konnten auf der Basis der liberalen niederländischen Schulverfassung interessante unterschiedliche (Pilot-)Projekte verwirklicht werden, die zu zahlreichen praktischen Erkenntnissen geführt und Eingang in die Empfehlungen und neuesten Maßnahmen der Regierung gefunden haben. Diese werden nun in großem Maßstab an den betreffenden Schulen eingeführt und durch ein Netzwerk von Einrichtungen und Experten begleitet (siehe MOCW 2000).

Es scheint also, daß die niederländische Regierung ihre zurückhaltende Rolle als Financier und Verbreiter von Empfehlungen aufgibt und sich aktiver auch in das Schulleben vor Ort einmischt. Dies ist bei dem sonst vor allem von den privaten Schulträgern betonten Recht auf Unterrichtsfreiheit verwunderlich. Denn die Übernahme gemeinsamer Verantwortung von Staat, Gemeinde und Schulträgern für die Verbesserung der Schulleistungen von ,achterstandsleerlingen“ (das sind Schüler, die von Leistungsrückständen betroffen sind), die sich auch in gegenseitigen Verpflichtungen ausdrückt, beschneidet dieses niederländische Verfassungsrecht erheblich.

\section{Literatur}

Driessen, Geert (1990). De onderwijspositie van allochtone leerlingen: de rol van sociaal-economische en etnisch-culturele factoren, met speciale andacht voor het Onderwijs in Eigen Taal en Cultuur. Nijmegen: ITS.

Driessen, Geert (1996). Prestaties, gedrag en houding van leerlingen op islamitische basisscholen. In: Migrantenstudies, 12, S. 136-151.

Driessen, Geert (2000). The limits of educational policy and practice? The case of ethnic minorities in the Netherlands. In: Comparative education, 36, 1, S. 55-72.

Dronkers, Jaap (1995). The existence of parental choice in the Netherlands. In: Educational Policy, 9, 3, S. 227-243.

Fase, Willem (1993). Ethnic claims in the debate of public versus private education in the Netherlands. In: International Perspectives on Education and Society, 3, S. 227240.

Inspectie van het Onderwijs (1997). Zicht op resultaat. De kwaliteit van het onderwijs aan achterstandsleerlingen. Utrecht.

Inspectie van het Onderwijs (1999). Islamitische Basisscholen in Nederland. In: URL: http://www.owinsp.nl/producten/ibin/index.html.

Jungbluth, Paul (1994a). An den Grenzen der schulischen und schulpolitischen Kompetenz: Migrantenbildungspolitik in den Niederlanden. In: Ingrid Gogolin (Hg.): Das nationale Selbstverständnis der Bildung. Münster, New York, S. 235-254.

Jungbluth, Paul (1994b). Lehrererwartungen und Ethnizität. Innerschulische Chancendeterminanten bei Migrantenschülern in den Niederlanden. In: Zeitschrift für Pädagogik, 40, 1, S. 113-125. 
Karsten, Sjoerd (1994). Policy on ethnic segregation in a system of choice: the case of the Netherlands. In: Journal of Education Policy, 9, 3, 1994, S. 211-225.

Kroon, Sjaak \& Sturm, Jan (1994). Eine Schule in den Niederlanden. In: Pädagogik, 78, S. 70-75.

Leiprecht, Rudolf; Helma Lutz (1996). The Dutch Way: Mythos und Realität der interkulturellen Pädagogik in den Niederlanden. In: Georg Auernheimer; Peter Gstettner (Hg.): Jahrbuch für Pädagogik 1996. Pädagogik in multikulturellen Gesellschaften, Frankfurt a.M., S. 239-262.

Lumer-Henneböhle, Beatrix; Elke Nyssen (1988). Basisschulen in den Niederlanden. Köln, Wien: Böhlau.

Meijer, Wilna A. J. (1994). Allgemeine Bildung: Balance zwischen Gemeinsamkeit und Diversität. In: Rudolf Lassahn; Birgit Ofenbach (Hg.): Bildung in Europa. Frankfurt a.M.: Lang, S. 87-96.

MOCW (1993, 4). Mitteilung des niederländischen Ministeriums für Unterricht und Wissenschaft, April 1993, Nr. 50-D.

MOCW (1998a). Informationsblatt des Ministeriums für Bildung, Kultur und Wissenschaft über Niederländische Bildungspolitik, Februar 1998, Nr. 1-D.

MOCW (1998b). Informationsblatt des Ministeriums für Bildung, Kultur und Wissenschaft über Niederländische Bildungspolitik, Juni 1998, Nr. 4-D.

MOCW (1998c). Informationsblatt des Ministeriums für Bildung, Kultur und Wissenschaft über Niederländische Bildungspolitik, Oktober 1998, Nr. 6-D.

MOCW (1999). Informationsblatt des Ministeriums für Bildung, Kultur und Wissenschaft über Niederländische Bildungspolitik, Mai 1999, Nr. 3-D.

MOCW (2000). Aan de slag met onderwijskansen. Gerichte aanpak onderwijsachterstanden. Zoetermeer: Ministerie van Onderwijs, Cultuur en Wetenschappen.

Mulder, L.; H. Vierke (1998). Onderwijsachterstanden in het basisonderwijs. De gewichtenregeling en mono-etnische scholen nader bekeken. Nijmegen: ITS.

Ritzen, Jozef M. M.; Jan van Dommelen; Frans J. de Vijlder (1997). School Finance and School Choice in the Netherlands. In: Economics of Education Review, 16, 3, S. 329-335.

Rutten, J. J. G. M. (1996). Kleurrijke scholen, kleurenblind beleid. Het beleid ten aanzien van witte en zwarte scholen. In: C. A. Tazelaar, u.a. (Hg.): Kleur van de school. Etnische segregatie in het onderwijs. Houten, S. 44-72.

Skiera, Ehrenhard (1991). Das Bildungswesen der Niederlande. Geschichte, Struktur und Reform. 2. Aufl., Gießen.

Tesser, P.; L. Mulder (1990). Concentratie en prestaties van allochtone leerlingen in het basisonderwijs. In: Migrantenstudies, 6, 2, S. 31-45.

Tesser, P.; J.G.F. Merens; C.S. van Praag (1999). Rapportage minderheden 1999: positie in het onderwijs en op de arbeidsmarkt. Sociaal en Cultureel Planbureau.

Teunissen, Joop (1988). Etnische relaties in het basisonderwijs. „Witte“ en „zwarte“ scholen in de grote steden. Wageningen.

Teunissen, J. (1996). Etnische segregatie in het basisonderwijs: een onderwijskundige benadering. In: C. A. Tazelaar u.a. (Hg.): Kleur van de school. Etnische segregatie in het onderwijs, Houten, S. 23-43. 


\section{THOMAS BRÜSEMEISTER \\ Lehrerbiographien in der Schulmodernisierung - Modernisierungspfade - Steuerungsschwierigkeiten}

In diesem Beitrag gehe ich davon aus, dass in einer künftigen qualitätsbasierten Organisation Schule Lehrkräfte voneinander abgegrenzte organisationale Mitgliedschaftsrollen haben werden. Die horizontale Kommunikation zwischen den Lehrkräften würde intensiviert, weil Funktionsaufgaben im Team bearbeitet werden (vgl. Kempfert/Rolff 2000). Und dabei würde das Kollegium neu konzipiert - es wandelt sich von einer nur locker assoziierten Einheit von Lehrerindividualismen $\mathrm{zu}$ der zentralen Organisationseinrichtung, die kollektiv über Belange ihrer Schule entscheidet.

Lehrkräfte würden in einer solchen qualitätsbasierten Schulorganisation auf der einen Seite mehr Aufgaben haben. Während sich die Profession bislang vor allem auf Unterrichtsentwicklung konzentrierte und Organisations- und Personalfragen der staatlichen Bürokratie überließ, fällt nun die Unterrichts-, Personal- und Organisationsentwicklung in den Entscheidungsbereich schulischer Teams. Auf der anderen Seite wären die Aufgaben jedoch für den einzelnen Lehrer begrenzter und schärfer konturiert. Jeder würde nur noch arbeitsteilig im Rahmen überschaubarer Mitgliedschaftsrollen an der Schule mitwirken. ${ }^{14}$

\section{Kollegium und Organisation: Empirische Befunde}

Wie steht es nun in empirischer Hinsicht um eine Organisationsentwicklung mit dem Kollegium im Zentrum? Dazu nachfolgend eine knappe Zusammenfassung eines kürzlich abgeschlossenen explorativen Forschungsprojekts, in dem je 20 narrative Interviews mit Lehrkräften aus Hamburg, Bayern und dem Kanton Zürich geführt wurden. ${ }^{15}$ Es wurde untersucht, in welcher Weise Lehrkräfte an den drei Standorten auf die gegenwärtige Schulmodernisierung reagieren, und in welcher Weise dafür ein biographisches Kapital eine Rolle spielt (vgl. Bourdieu 1987; Heinz 2000: 177f.). ${ }^{16}$

14 Dies bedeutet, dass Lehrer neben dem Unterricht nur noch einige wenige Funktionen ausüben, oder sogar, dass nicht mehr alle Lehrer unterrichten, sondern einige für besondere Funktionsaufgaben freigestellt sind.

15 Mittels eines Schneeballverfahrens wurden an den drei Erhebungsorten jeweils 10 jüngere und 10 ältere Lehrkräfte (ab 44 Jahren) befragt. Qualitative Erhebungsmethode war das narrative Interview (vgl. Schütze 1983), Auswertungsmethode die Grounded Theory (vgl. Strauss/Corbin 1996). Zur Konzeption und zu den Methoden siehe meinen Schlussbericht „Biographische Modernisierungsreaktionen von Lehrkräften in Deutschland und der Schweiz“ (http://www.fernuni-hagen.de/soz/ preprints).

16 Unter schulischer Modernisierung wurde dabei eine Modernisierung der Schulverwaltung verstanden, die, so die Anfangshypothese, im Kanton Zürich relativ hoch (im Sinne von New Public Management) und in Bayern schwach ist und sich in Hamburg auf einem mittleren Niveau bewegt. 
Für den vorliegenden Zusammenhang greife ich vor allem einen Aspekt aus den Ergebnissen heraus: ob sich in den Interviews Evidenzen für die oben skizzierte Entwicklung von Schule in Richtung einer (auf Qualitätsmanagement basierenden) Organisation zeigen lassen.

Zentrales Ergebnis der Untersuchung ist, dass Lehrkräfte drei unterschiedliche Aufmerksamkeitsreichweiten in ihrer Berufspraxis haben ${ }^{17}$ :

1) eine Aufmerksamkeitsreichweite, die sich auf eingesetzte Didaktiken des einzelnen Lehrers bezieht und den einzelnen Schüler über den Unterricht anspricht;

2) eine, die sich auf die Klasse als Ganze bezieht und verschiedene kommunikative Unterscheidungen der Lehrkraft bezüglich Schülergruppen und deren unterstellte Lernfähigkeiten berücksichtigt;

3) eine, die sich auf die Schule als Ganze bezieht. Diese Perspektive musste sich zugleich auf Unterricht beziehen. ${ }^{18}$

In der Auswertung wurden diejenigen Lehrkräfte, die Unterricht, Klasse und die Schule als Ganze beobachten, einer Gruppe mit großer Aufmerksamkeitsreichweite zugerechnet. Diejenigen Lehrkräfte, die neben dem Unterricht auch noch gelegentlich die Perspektive der Schulklasse oder aber gelegentlich die Schule als Ganze als Perspektive für ihren Unterricht relevant machen, wurden einer zweiten Gruppe zugeordnet (Lehrkräfte mit mittlerer Aufmerksamkeitsreichweite). Schließlich wurden Lehrkräfte, die überwiegend nur eine einzige der drei Perspektiven in ihrer Schulpraxis zeigen (,Unterricht' oder ,Klasse' oder ,Schule als Ganze'), einer dritten Gruppe zugerechnet (Lehrkräfte mit geringer Aufmerksamkeitsreichweite). Diese drei Gruppen wurden nochmals in Untergruppen differenziert, so dass sich letztendlich eine Typologie mit 7 Ausprägungen ergab (vgl. Übersicht 1):

17 Aufmerksamkeitsreichweiten wurden hinsichtlich der zentralen Aufgaben von Lehrkräften, Inklusion zu bewerkstelligen, in der Untersuchung auch ,Inklusionsstile“ genannt. Der Inklusionsbegriff der Soziologie wurde zuerst von Parsons (1972) geprägt und meint Rollenmitgliedschaften in ausgewählten Teilsystemen (Recht, Politik, Ökonomie, Soziales). Die neuere Differenzierungstheorie versteht unter Inklusion kommunikative Adressierungen von Leistungsrollenträgern und dem jeweiligen Publikum eines Teilsystems (z.B. Arzt/Patient, Lehrer/Schüler; vgl. Stichweh 1988).

18 Dies hieß z.B., dass biographische Übergänge von Schülern antizipiert werden, insofern die Lehrperson mit ihren Schülern Verhaltenstrainings macht, damit sie vor dem örtlichen Handwerk aufzutreten wissen; oder es werden mit Schülern Projekte und kulturelle Ereignisse organisiert; oder es wird an Schulprogrammen und Leitbildern der Schule mitgewirkt, die Unterrichtsveränderungen zum Ziel haben. 


\section{Übersicht 1:}

\begin{tabular}{|c|c|c|c|c|c|c|c|}
\hline \multirow{2}{*}{$\begin{array}{l}\text { Lehr- } \\
\text { kräfte }\end{array}$} & \multicolumn{2}{|c|}{$\begin{array}{l}\text { Typengruppe 1: } \\
\text { mit großer } \\
\text { Aufmerksamkeits- } \\
\text { reichweite }\end{array}$} & \multicolumn{3}{|c|}{$\begin{array}{l}\text { Typengruppe 2: } \\
\text { mit mittlerer } \\
\text { Aufmerksamkeits- } \\
\text { reichweite }\end{array}$} & \multicolumn{2}{|c|}{$\begin{array}{c}\text { Typengruppe 3: } \\
\text { mit schwacher } \\
\text { Aufmerksamkeits- } \\
\text { reichweite }\end{array}$} \\
\hline & 1 & 2 & 3 & 4 & 5 & 6 & 7 \\
\hline
\end{tabular}

Bei der Verteilung der 60 Interviews aus den drei Erhebungsorten auf die 7-stufige Typologie fallen drei Schwerpunkte auf.

1) Ein Teil der Interviews konzentriert sich auf die Typennummern 1 und 2. $\mathrm{Zu}$ diesen Lehrkräften mit großer Aufmerksamkeitsreichweite gehören in unserem Sample ausschließlich ältere Lehrkräfte aus dem Kanton Zürich sowie ältere Lehrkräfte aus Hamburg. Die Anfangshypothese, in Bayern gäbe es von allen drei Erhebungsorten die schwächste Schulmodernisierung, bestätigte sich; nur ältere Zürcher und Hamburger Interviewpartner sind mit jeweils großen Aufmerksamkeitsreichweiten aktiv an Schulmodernisierungen beteiligt. Die Interviewpartner richten ihre Aufmerksamkeit auf Unterricht, Klasse und die Schule als Ganze, was flexible Beobachtungen beinhaltet. Dies bedeutet auch ein aktives Engagement für schulische Modernisierungen. Aufmerksamkeiten sind nicht, fest gestellt", sondern situationsoffen, beziehen insbesondere die Umwelt von Schule in den Unterricht mit ein. ${ }^{19}$

Im Einzelnen betrachtet ist der Umgang mit der Schulmodernisierung im Kanton Zürich und in Hamburg verschieden. Während im Kanton Zürich überwiegend einzelne Personen Netzwerkaktivitäten entfalten, das heißt zum Beispiel durch Projekte und Beobachtungen von biographischen Übergängen der Schüler die Umwelt von Schule für den Unterricht relevant machen, sind die Hamburger Gesprächspartner als ein qualitätsorientiertes Kollegium aktiv. Darauf gehe ich unten detaillierter ein.

2) In der Verteilung der 60 Interviews gibt es einen zweiten Schwerpunkt, den Lehrkräfte mit mittlerer Aufmerksamkeitsreichweite (Typennummern 3, 4, 5) bilden. Hier finden sich fast ausnahmslos die bayrischen Interviewpartner wieder. Die Aufmerksamkeiten der Lehrkräfte richten sich

19 Dies bedeutet zum einen, dass die Grenzen der Schule gleichsam in Umwelten hinein erweitert werden können - konkret: Unterrichtsmaterialien aus der Umwelt und eigenen Erfahrungen werden in den Unterricht eingebaut. Zum anderen lässt sich bei den Lehrkräften mit entwickelten Aufmerksamkeitsreichweiten ein Setzen von Grenzen beobachten, was z.B. heißt, dass etwas entschieden werden kann, ohne dass es begründet werden muss. Solche Fähigkeiten lassen sich unter dem Begriff des biographischen Wissensmanagements erörtern, siehe meinen Beitrag in Textblock III. 
nur noch gelegentlich auf weiter gefasste Unterrichtsdimensionen. In den Interviews kommen ,klassische“ Mängel der staatlichen Schulorganisation zum Ausdruck, z.B. eine gelegentlich gute Einbindung in das Kollegium gelegentlich aber auch keine; oder gelegentlich gute Beziehungen zur Schulleitung und zu Eltern - gelegentlich aber auch keine. Im Prinzip dominiert in den mittleren Typennummern der bisherige Lehrerindividualismus, der bei den Typennummern 1 und 2 durch das Kollegium ersetzt wurde. Schulische Modernisierung ist den bayrischen Befragten zwar als Thema bekannt (talk), berührt aber kaum eine Ebene ihres Handelns (action; vgl. Brunsson 1989).

3) Einen dritten Schwerpunkt in der Verteilung bilden Lehrkräfte der Typennummern 6 und 7. Bei ihnen sind die Aufmerksamkeiten noch weiter abgeschwächt bzw. in gewisser Weise noch starrer gehandhabt als bei ihren Kollegen in mittleren Typennummern. Während die o.g. Lehrer Unterricht, Klasse und die Schulumwelt beobachten, sind Lehrer unterer Typennummern selektiver. Operative Fähigkeiten der Beobachtung sind schwach ausgeprägt, weil das, was beobachtet wird, in einer starren Weise fixiert wird. Der Grund dafür liegt in einer besonderen biographischen Situation: In den Typennummern 6 und 7 finden sich überwiegend junge Lehrer aus dem Kanton Zürich, die gerade ihren Beruf beginnen. Die Betreffenden fixieren eigene Unterrichtsprobleme und sind überwiegend mit Problemen der Identitätssuche beschäftigt.

\section{Gründe für die Unterschiede}

Was sind nun die Gründe für die heterogene Lehrerschaft bzw. die unterschiedlichen Aufmerksamkeitsreichweiten? Ich greife nachfolgend nur die ,engagierten' älteren Hamburger und die ,engagierten' älteren Zürcher Lehrkräfte heraus, da sie sich innerhalb ihres Engagements (1) einmal an Organisation und dem Kollegium (Hamburg), das andere Mal (2) an Profession und implizit am Lehrerindividualismus (Kanton Zürich) orientieren.

(1) Wie ist der Prozess aus Sicht der InterviewpartnerInnen aus Hamburg abgelaufen? ${ }^{20}$ Etwa Mitte der 1980er Jahren bringen einzelne Hamburger Lehrkräfte aus privaten Interessen heraus erste Computer mit in die Schule. Darüber kamen einzelne Kollegen miteinander in intensiveren Kontakt, wobei es um die Frage ging, wie der Computer im Unterricht eingesetzt werden kann. Dabei wurde darüber gesprochen, a) welche Sachthemen beim Thema Computer für bestimme Schülerstufen geeignet sind; b) wie andere Kollegen an den Erfahrungen teilhaben können. In der ,Sprache' des Qualitätsmanagements ist dies der Beginn von Teambildung, als Teil einer sich entwickelnden Schule als Organisation.

Die interne Kommunikation wurde also auf mehreren Ebenen gleichzeitig verändert - gegenüber Schülern und Kollegen. Gleichzeitig war die

20 Zur Modernisierung aus Sicht der Hamburger Schulbehörde und begleitender Wissenschaftler vgl. Tillmann/Vollstädt (2001). 
Kommunikation nur auf das Thema Computer begrenzt. Dies stellt Unterschiede zu herkömmlichen Modernisierungsoffensiven via Qualitätsdiskursen dar. Denn diese zielen darauf, Kommunikationen über Unterrichts-, Personal- und Organisationsentwicklung gleichzeitig in Gang zu bringen. Die offerierten Qualitätsverfahren beantworten nicht die Frage, wie umfangreich die neue Kommunikation sein soll, damit das Kollegium nicht überfordert wird. In Hamburg dagegen wird die Kommunikation über das Medium Computer verzahnt und gleichzeitig begrenzt.

Zudem ist der Computer ein Medium, das auch in der Schulumwelt sinnfällig ist. Man ,versteht ${ }^{\star}$ - so lässt sich in Anlehnung an Luhmanns (1997: 302ff.) Begriff von Verbreitungsmedien sagen -, dass sich Lehrkräfte damit beschäftigen. Der pädagogische Sinn des Computereinsatzes trifft sich mit außerhalb der Schule vorhandenen Leitmedien, die den Computer zum Inbegriff der technischen und sozialen Modernisierung auserkoren haben (vgl. generell: Degele 2000). Deshalb ist es Mitte der 1990er Jahre leicht möglich, dass Bildungsbehörde und Politik in Hamburg die Bemühungen einzelner Schulen, deren Kollegien mittlerweile stärker Computertechnik in den Unterricht integriert hatten, unterstützten. Die Kollegien sprechen mittlerweile im Sinne einer ,pädagogischen Qualitätsentwicklung“" verstärkt, angestoßen durch die Arbeit mit Computern, über Unterrichts-, Personal- und Organisationsbelange, d.h. zum Beispiel über Leistungsstandards für einzelne Schülerjahrgänge. Offensichtlich hat in Hamburg eher beiläufig eine bottom-up-Modernisierung stattgefunden, die beinhaltet, dass sich Lehrkräfte an einer Organisationsarbeit ausrichten. Diese wird nicht vornehmlich als zusätzliche Arbeit erlebt, sondern verschafft auch schon Entlastungen, insofern der einzelnen Lehrer nicht mehr für alles, sondern nur noch für begrenzte Funktionsaufgaben verantwortlich ist.

(2) Unsere Interviews mit engagierten Lehrkräften aus dem Kanton Zürich zeigen, dass die Entwicklung auch anders verlaufen kann. Hier stand nicht wie in Hamburg ,zufällig“ das Verbreitungsmedium Computer im Zentrum. Stattdessen haben sich einzelne Lehrkräfte vor Ort zum Teil sehr stark engagiert, im Sinne eines Erlebens von professioneller Zuständigkeit, das weit über ein irgend geartetes $\mathrm{Ma} ß$ einer standardisierten Berufsausübung hinausgeht. Eine institutionelle Kontextbedingung dafür sind offensichtlich die überschaubaren lokalen Schulkulturen. Es wird nicht systematisch durch fachliche Einrichtungen und organisationale Feedbacks unterstützt, aber doch wohlwollend von der Ortsgesellschaft honoriert, wenn sich die einzelne Lehrerin an ihrer Schule engagiert zeigt. Man kann sagen, dass sich das professionelle Engagement im Rahmen von individuellen Verhandlungen in lokalen Schulkulturen in sozialer Hinsicht verankert. In fachlicher Hinsicht stehen der einzelnen Lehrkraft dabei nach wie vor nur traditionelle Institutionen zu Verfügung (Schul- und Bezirkspflegschaft). Diese Institutionen wurden als solche nicht - wie in Hamburg das Kollegium - modernisiert. An Stelle organisationaler Maßnahmen der gesamten 
Schule werden von den engagierten älteren Lehrkräften aus dem Kanton Zürich in den Interviews individuelle Projekte beschrieben, die darauf zielen, eigene Feedbackeinrichtungen zu schaffen, die die Laienaufsicht der Schulpflege nicht bieten. Die engagierten Befragten tun dies zum Beispiel, indem sie sich auf eigene Faust regelmäßig mit anderen Kolleginnen und Kollegen austauschen, oder indem sie ein „Lehrstellenforum“ ins Leben rufen. Es gibt hier jedoch kein einheitliches Leitmedium, wie es in Hamburg der Computer darstellt, über das die Kollegien beiläufig miteinander ins Gespräch kommen. Statt eines solchen organisationalen Mediums dominiert „nur“ die Verhandlungsfähigkeit der einzelnen Lehrkraft. Zudem müssen in den individuellen Projekten auch die jeweiligen spezifischen Umsetzungsschwierigkeiten individuell von der einzelnen Lehrkraft bearbeitet werden; dafür steht nicht wie in Hamburg das Kollegium zur Verfügung.

Schwierigkeiten sind darüber hinaus entstanden, als die individuellen bottom-up-Modernisierungen der engagierten Lehrer mit der top-downModernisierung der Zürcher Bildungsverwaltung konfrontiert wurden. Die Bildungsdirektion startete insbesondere mit dem Projekt „Teilautonome Volksschule“ (vgl. Bildungsdirektion des Kantons Zürich 1999), orientiert an einer Verwaltungsmodernisierung nach dem Modell des New Public Management, eine organisatorische Umgestaltung von Schule. Da es kein einheitliches Leitmedium wie in Hamburg gab, wurden diese Bemühungen von den engagierten Lehrkräften überwiegend als Konkurrenz zu den eigenen Verhandlungsstrukturen gesehen, die vor Ort aufgebaut worden waren. Von der Konstellation her haben wir es also mit einer Konfrontation zwischen „denen da oben“ und ,ich hier unten“ zu tun, d.h. ein Kollegium als organisationales Objekt und Vehikel der Modernisierung, welches Konflikte würde abpuffern können, ist kaum vorhanden. Die Bildungsdirektion kann ihre Modernisierungsabsichten also nicht an Schulorganisationen (Kollegien) adressieren (vgl. Luhmann 1997: 834), sondern muss gleichsam jeden Einzelnen überzeugen, dass ihre Vorschläge der Reorganisation sinnhaft sind. Es ist in diesem Zusammenhang verständlich, dass die engagierten Lehrkräfte Energie aufbringen, die von oben kommende Modernisierung zu unterlaufen, um den lokal verhandelten Status und die eigenen Projekte zu bewahren.

Damit deutet sich an, dass sich in Hamburg das Kollegium als zentrales Element einer neuen Schule als Organisation zu entwickeln beginnt, während sich die Lehrkräfte im Kanton Zürich nach wie vor am Modell der Profession orientieren.

\section{Ausblick}

Wenn man die Situation der Lehrkräfte im Kanton Zürich und der dortigen Bildungsverwaltung abschließend allgemeiner kommentiert, fallen Steuerungsprobleme auf. Die älteren Lehrkräfte sind offensichtlich autonom und 
engagiert. Und es gibt ein grundsätzlicheres Problem dahingehend, dass die Bildungsverwaltung eine Organisation ist, die in Kategorien von Mitgliedschaft und Entscheidung denkt. Lehrkräfte sind dagegen nicht als Organisation, sondern als Profession gefasst, die sich über Autonomie, Selbstorganisation und thematische Reflexivität definiert.

Lehrkräfte achten darauf - weil sie von Berufs wegen für Stile von Kommunikationen geschult sind, um mit ganz unterschiedlichen SchülerInteraktionen zurecht zu kommen -, wie die Modernisierung öffentlich ,daher kommt ‘. Neu ist für die Lehrer vor allem, dass ihre professionelle Autonomie, über Schülerinteraktionen bislang allein entscheiden zu können, beschnitten wird. Es geht dabei nicht um neue Programme selbst, sondern dass ein wesentlicher Identitätsaspekt der Profession in Frage steht, nämlich: allein entscheiden zu können.

Offensichtlich muss die Bildungsverwaltung nicht nur in sich stimmige Programme vorlegen, sondern auch die Eigenart der Lehrerprofession sowie deren Medien, über die sie sich organisiert, berücksichtigen: Autonomie und Selbststeuerung. Für die Bildungsdirektion würde diese Anerkenntnis keinen Verzicht auf Steuerung bedeuten, sondern ein besonderes Modell von Steuerung: nämlich eine, die die Selbstorganisation der Lehrkräfte als deren Strukturprinzip aufgreift. Das heißt, die Bildungsverwaltung könnte im Rahmen einer Steuerung via Auslösekausalität Anregungen geben, die indirekt bewirken, dass sich die Lehrkräfte selbst organisieren. Der Verzicht auf Durchgriffskausalität bedeutet automatisch, dass auf beiden Seiten der Akteurbeziehung statt Kontrolle nun Verantwortung und Vertrauen wachsen kann - und auch muss. Dies sind zentrale Elemente des sog. „good governance“-Modells (vgl. dazu grundsätzlich König 2001: 287f.).

Die Autonomie und Fähigkeit der Profession zur Selbstorganisation kann zum Beispiel forciert werden, indem die Schulen bei der Beschaffung und Auswertung eigener Daten unterstützt werden, wobei die Daten nur der Schule gehören; oder indem man Plattformen für die Weiterbildung anbietet; oder vor allem, indem die Bildungsverwaltung aus ihren spezialisierten Abteilungen heraus jeweils Spezialthemen mit Professionellen der Einzelschule dauerhaft bespricht. Dadurch würden sich korrespondierend in der Profession ebenfalls besondere Zuständigkeiten für Forschungsfragen, Fragen des Fachunterrichts, Schulung des Kollegiums, Partizipation mit Eltern etc. herausbilden, d.h. voneinander abgegrenzte Mitgliedschaftsrollen einer Organisation Schule. Diese Funktionsrollen kommen in der Berufspraxis jetzt schon vor, werden aber überwiegend nur im Rahmen von Personen und nicht von Organisationen kommuniziert. Würde die Bildungsverwaltung spezielle Sachthemen dauerhaft besprechen, würde sie damit stillschweigend voneinander abgegrenzte Rollenzuständigkeiten auf der korrespondierenden Seite der Lehrkräfte befördern. Und damit würde sie sich einen gleichsam natürlichen Prozess gesellschaftlicher Differenzierung zu Nutze machen, der sich in der Gesellschaft seit 150 Jahren bewährt hat, und 
eben in der allmählichen Ausdifferenzierung korrespondierender Rollengefüge besteht (vgl. Stichweh 1988).

\section{Literatur}

Bildungsdirektion des Kantons Zürich (1999): Unsere Schule - unsere Zukunft. Die Zürcher Volksschulreform: Die solide Basis erneuern. Ms. Zürich.

Bourdieu, Pierre (1987): Die feinen Unterschiede. Kritik der gesellschaftlichen Urteilskraft. Frankfurt a.M.

Degele, Nina (2000): Informiertes Wissen. Eine Wissenssoziologie der computerisierten Gesellschaft. Frankfurt a.M., New York.

Heinz, Walter R. (2000): Selbstsozialisation im Lebenslauf. Umrisse einer Theorie biographischen Handelns. In: Erika M. Hoerning (Hg.) (2000): Biographische Sozialisation. Stuttgart, 165-186.

Kempfert, Guy; Hans-Günter Rolff (2000): Pädagogische Qualitätsentwicklung. Ein Arbeitsbuch für Schule und Unterricht. Weinheim, Basel.

König, Klaus (2001): Institutionelle Aspekte der Modernisierung - die Sphäre der öffentlichen Verwaltung. In: Hermann Hill (Hg.): Modernisierung - Prozess oder Entwicklungsstrategie? Frankfurt a.M., 263-290.

Luhmann, Niklas (1997): Die Gesellschaft der Gesellschaft. Frankfurt a.M.

Parsons, Talcott (1972): Das System moderner Gesellschaften. München.

Schütze, Fritz (1983): Biographieforschung und narratives Interview. In: Neue Praxis 3, 283-293.

Stichweh, Rudolf (1988): Inklusion in Funktionssysteme der modernen Gesellschaft. In: Renate Mayntz u.a. (Hg.): Differenzierung und Verselbständigung. Frankfurt a.M., 261-293.

Strauss, Anselm; Juliet Corbin (1996): Grounded Theory. Grundlagen Qualitativer Sozialforschung. Weinheim.

Tillmann, Klaus Jürgen; Witlof Vollstädt (Hg.) (2001): Politikberatung durch Bildungsforschung. Das Beispiel Schulentwicklung in Hamburg. Opladen. 
Anhang 



\section{Von den Herausgebern zitierte Literatur}

Achtenhagen, Frank; Ingrid Gogolin (Hg.) (2002): Bildung und Erziehung in Übergangsgesellschaften. Beiträge zum 17. Kongress der Deutschen Gesellschaft für Erziehungswissenschaft. Opladen.

Adam, Konrad (2002): Die deutsche Bildungsmisere. PISA und die Folgen. Berlin, München.

Adick, Christel (1992): Die Universalisierung der modernen Schule. Eine theoretische Problemskizze zur Erklärung der weltweiten Verbreitung der modernen Schule in den letzten 200 Jahren mit Fallstudien aus Westafrika. Paderborn.

Altrichter, Herbert (2002): Aktionsforschung als Strategie zur Förderung professionellen Lernens. In: Georg Breidenstein u.a. (Hg.): Forum Qualitative Schulforschung 2. Interpretative Unterrichts- und Schulbegleitforschung. Opladen, 195-220.

Altrichter, Herbert; Peter Posch (1996): Mikropolitik der Schulentwicklung. Förderliche und hemmenden Bedingungen für Innovationen in der Schule. Innsbruck, Wien.

Amos, Karin u.a. (Hg.) (2002): Globalisation: Autonomy of education under siege? Shifting Boundaries between Politics, Economy and Education. European Educational Research Journal 2.

Apel, Hans Jürgen (1995): Theorie der Schule. Historische und systematische Grundlinien. Donauwörth.

Arbeitsgemeinschaft Freier Schulen (Hg.) (1999): Handbuch Freie Schulen. Reinbek.

Archer, Margaret S. (Hg.) (1982a): The Sociology of Educational Expansion. Beverly Hills.

Archer, Margaret S. (1982b): Sociology of Educational Systems. In: Tom Bottomore; Stefan Nowak; Magdalena Sokolowska (Hg.): Sociology - The State of the Art. London, Beverly Hills, 233-261.

Archer, Margaret S. (1984): Social Origins of Educational Systems. Beverly Hills.

Arnold, Eva u.a. (1999): Schulentwicklung und Wandel der pädagogischen Arbeit. Arbeitssituation, Belastung und Professionalisierung von Lehrerinnen und Lehrern in Schulentwicklungsprozessen. In: Ursula Carle; Sylvia Buchen (Hg.): Jahrbuch für Lehrerforschung. Bd. 2. Weinheim, München, 97-122.

Bastian, Johannes (Hg.) (1998): Pädagogische Schulentwicklung. Schulprogramm und Evaluation. Hamburg.

Baumert, Jürgen; Wilfried Bos; Rainer Lehmann (Hg.) (2000): TIMSS/III. Dritte internationale Mathematik- und Naturwissenschaftsstudie. Opladen.

Baumgart, Franzjörg; Ute Lange (Hg.) (1999): Theorien der Schule. Erläuterungen Texte - Arbeitsaufgaben. Bad Heilbrunn.

von Below, Susanne (2002): Bildungssysteme und soziale Ungleichheit. Das Beispiel der neuen Bundesländer. Opladen.

Benner, Dietrich (2002): Die Struktur der Allgemeinbildung im Kerncurriculum moderner Bildungssysteme. In: Zeitschrift für Pädagogik 1, 68-90.

Benner, Dietrich, u.a. (Hg.) (1992): Erziehungswissenschaft zwischen Modernisierung und Modernitätskrise. Zeitschrift für Pädagogik, 29. Beiheft. Weinheim, Basel.

Benner, Dietrich; Herwart Kemper (2002): Theorie und Geschichte der Reformpädagogik. Teil 2: Die pädagogische Bewegung von der Jahrhundertwende bis zum Ende der Weimarer Republik. Stuttgart.

Bertelsmann-Stiftung (2002): Was ist eine gute Schule für mein Kind? In: URL: http://www.bertelsmann-stiftung.de.

Bildungsdirektion des Kantons Zürich (1999): Unsere Schule - unsere Zukunft. Die Zürcher Volksschulreform: Die solide Basis erneuern. Ms. Zürich. 
Bildungskommission NRW (1995): Zukunft der Bildung - Schule der Zukunft. Denkschrift der Kommission „Zukunft der Bildung - Schule der Zukunft“ beim Ministerpräsidenten des Landes Nordrhein-Westfalen. Neuwied.

Binder, Hans-Martin; Ernst Trachsler (2002): wif! - Projekt „Neue Schulaufsicht an der Volksschule“. Externe Evaluation. Ms. Luzern.

Birnbaum, Robert (2000): The Life Cycle of Academic Management Fads. In: The Journal of Higher Education 1, 1-16.

Blossfeld, Hans-Peter; Yossi Shavit (1993): Dauerhafte Ungleichheiten. Zur Veränderung des Einflusses der sozialen Herkunft auf die Bildungschancen in dreizehn industrialisierten Ländern. In: Zeitschrift für Pädagogik 1, 25-52.

Bogumil, Jörg (2000): Modernisierung der Landesverwaltung - Institutionelle Ausgangslage, Implementationsstand und Forschungsperspektiven. In: Leo Kißler; Hans-Jürgen Lange; Norbert Kersting (Hg.): Politische Steuerung und Reform der Landesverwaltung. Baden-Baden, 123-134.

Bogumil, Jörg (2002): Verwaltungsmodernisierung und aktivierender Staat. In: Perspektiven des demokratischen Sozialismus 1, 43-65.

Bogumil, Jörg (Hg.) (1999): Modernisierung der Landesverwaltung. Polis Nr. 42, Arbeitspapiere aus der FernUniversität Hagen.

Bogumil, Jörg; Lars Holtkamp (2002): Liberalisierung und Privatisierung kommunaler Aufgaben - Auswirkungen auf das kommunale Entscheidungssystem. In: Jens Libbe; Stephan Tomerius; Jan-Hendrick Trapp (Hg.): Liberalisierung und Privatisierung öffentlicher Aufgabenerfüllung - Soziale und umweltpolitische Perspektiven im Zeichen des Wettbewerbs. Berlin, 71-91.

Bogumil, Jörg; Leo Kißler (1998): Die Beschäftigten im Modernisierungsprozess - Akteure oder Agierende? In: Industrielle Beziehungen 3, 298-321.

Borchert, Jens (1995): Die konservative Transformation des Wohlfahrtsstaates. Frankfurt a.M., New York.

Böttcher, Manfred; Horst Weishaupt; Manfred Weiß (Hg.) (1997): Wege zu einer neuen Bildungsökonomie. Pädagogik und Ökonomie auf der Suche nach Ressourcen und Finanzierungskonzepten. Weinheim, München.

Böttcher, Wolfgang (2002): Kann eine ökonomische Schule auch eine pädagogische sein? Schulentwicklung zwischen Neuer Steuerung, Organisation, Leistungsevaluation und Bildung. Weinheim, München.

Boudon, Raymond (1983): Individual Action and Social Change: A No-Theory of Social Change. In: The British Journal of Sociology 1, 1-18.

Bourdieu, Pierre; Jean-Claude Passeron (1971): Die Illusion der Chancengleichheit. Untersuchungen zur Soziologie des Bildungswesens am Beispiel Frankreichs. Stuttgart.

Bourdieu, Pierre, u.a. (1997) : Das Elend der Welt. Zeugnisse und Diagnosen alltäglichen Leidens an der Gesellschaft. Konstanz.

Braun, Dietmar (2001): Regulierungsmodelle und Machtstrukturen an Universitäten. In: Erhard Stölting; Uwe Schimank (Hg.): Die Krise der Universitäten. Leviathan Sonderheft 20. Wiesbaden, 243-262.

Brinckmann, Hans (1998): Die neue Freiheit der Universität. Operative Autonomie für Lehre und Forschung an Hochschulen. Berlin.

Brunsson, Nils (1989): The Organization of Hypocrisy. Talk, Decisions and Actions in Organizations. Chichester.

Brüsemeister, Thomas (2002a): Transintentionalität im Bildungssystem. Bourdieus Gegenwartsdiagnose zu LehrerInnen im Neoliberalismus. In: Matthias Wingens; Reinhold Sackmann (Hg.): Bildung und Beruf. Ausbildung und berufsstruktureller Wandel in der Wissensgesellschaft. Weinheim, München, 241-254. 
Brüsemeister, Thomas (2002b): Myths of Efficiency and the School System - observed at the levels of interaction, organisation and society. In: Karin Amos u.a. (Hg.): Globalisation: Autonomy of education under siege? Shifting Boundaries between Politics, Economy and Education. European Educational Research Journal 2, 234255.

Bundesverband der Freien Alternativschulen in der BRD (o.J.): Freie Alternativschulen in Deutschland. In: URL: http//www.paritaet.org/bfas/adressen.htm.

Chubb, John E.; Terry M. Moe (1990): Politics, markets, and Americas Schools. Washington D.C.

Colomy, Paul (1990): Strategic Groups and Political Differentiation in the Antebellum United States. In: Jeffrey Alexander; Paul Colomy (Hg.): Differentiation Theory and Social Change. Comparative and Historical Perspectives. New York, 222-264.

Combe, Arno; Werner Helsper; Bernhard Stelmaszyk (Hg.) (1999): Forum Qualitative Schulforschung 1. Schulentwicklung - Partizipation - Biographie. Weinheim.

Cuban, Larry; David Tyack (1995): Tinkering Towards Utopia. Cambridge.

Dahrendorf, Ralf (1979): Lebenschancen. Anläufe zur sozialen und politischen Theorie. Frankfurt a.M.

Dalin, Peer; Hans-Günter Rolff; H. Buchen (1995): Institutionelles Schulentwicklungsprogramm. Bönen.

Deutsches PISA-Konsortium (Hg.) (2001): PISA 2000 - Basiskompetenzen von Schülerinnen und Schülern im internationalen Vergleich. Opladen.

Deutsches PISA-Konsortium (Hg.) (2002): PISA 2000 - Die Länder der Bundesrepublik Deutschland im Vergleich. Opladen.

Diederich, Jürgen; Heinz-Elmar Tenorth (1997): Theorie der Schule. Ein Studienbuch zu Geschichte, Funktionen und Gestaltung. Berlin.

Dronkers, Jaap (1996): Dutch public and religious schools between state and market. In: Dietrich Benner u.a. (Hg.): Bildung zwischen Staat und Markt. Beiträge zum 15. Kongreß der Deutschen Gesellschaft für Erziehungswissenschaft. Zeitschrift für Pädagogik, 35. Beiheft. Weinheim, Basel, 51-66.

Durkheim, Emile (1984): Erziehung, Moral und Gesellschaft. Frankfurt.

Esser, Hartmut (2000): Soziologie - Spezielle Grundlagen, Bd. 5: Institutionen. Frankfurt a.M., New York.

Eurydice (2000): Private education in the European Union. Organisation, administration and the public authorities' role. In: URL: http://www.eurydice.org/Documents/ private/de/privatDE.htm.

Faust, Michael (2000): Warum boomt die Managementberatung? Und warum nicht zu allen Zeiten und überall? In: Sofi-Mitteilungen 28, 59-85.

Faust, Michael (2002): Der „Arbeitskraftunternehmer“ - eine Leitidee auf dem ungewissen Weg der Verwirklichung. In: Eva Kuda; Jürgen Strauß (Hg.): Arbeitnehmer als Unternehmer? Herausforderungen für Gewerkschaften und berufliche Bildung. Hamburg, 56-80.

Fend, Helmut (1980): Theorie der Schule. München, Wien, Baltimore.

Fend, Helmut (1987): „Gute Schulen - schlechte Schulen“. Die einzelne Schule als Pädagogische Handlungseinheit. In: U. Steffens; T. Bargel (Hg.): Erkundungen zur Wirksamkeit und Qualität von Schule (Beiträge aus dem Arbeitskreis Qualität von Schule, Hessisches Institut für Bildungsplanung und Schulentwicklung, Heft 1), 5579.

Fend, Helmut (2001): Bildungspolitische Optionen für die Zukunft des Bildungswesens. Erfahrungen aus der Qualitätsforschung. In: Zeitschrift für Pädagogik, 43. Beiheft. Weinheim, Basel, 37-48.

Flitner, Andreas (1985): Gerechtigkeit als Problem der Schule und als Thema der Bildungsreform. In: Zeitschrift für Pädagogik 1, S. 1-26. 
Friedman, Milton (1955): Die Rolle des Staates im Erziehungswesen. In: A. Hegelheimer (Hg.) (1975): Texte zur Bildungsökonomie. Frankfurt, Berlin, Wien, 180206.

Friedman, Milton (1995): Public Schools - Make them Private. Cato Institute Briefing Paper No. 23. In: URL: http://www.cato.org/pubs/briefs/bp-023.html.

Geißler, Rainer (1996): Die Sozialstruktur Deutschlands. Zur gesellschaftlichen Entwicklung mit einer Zwischenbilanz zur Vereinigung. Opladen.

Gerhards, Jürgen (2001): Der Aufstand des Publikums. Eine systemtheoretische Interpretation des Kulturwandels in Deutschland. In: Zeitschrift für Soziologie 3, 163184

Gomolla, Mechthild; Frank-Olaf Radtke (2002): Institutionelle Diskriminierung. Die Herstellung ethnischer Differenz in der Schule. Opladen.

Greshoff, Rainer; Georg Kneer; Uwe Schimank (Hg.) (2002): Die Transintentionalität des Sozialen. Studienbrief der FernUniversität Hagen.

Gruber, Karl Heinz (2002): Die OECD - Anatomie eines pädagogischen ,global player“. In: Frank Achtenhagen; Ingrid Gogolin (2002): Bildung und Erziehung in Übergangsgesellschaften. Beiträge zum 17. Kongress der Deutschen Gesellschaft für Erziehungswissenschaft. Opladen, 65-76.

Grunder, Hans-Ulrich; Friedrich Schweitzer (Hg.) (1999): Texte zur Theorie der Schule. Historische und aktuelle Ansätze zur Planung und Gestaltung von Schule. Weinheim, München.

Hentig, Hartmut von (1994): Die Schule neu denken. München.

Herrlitz, Hans-Georg; Wulf Hopf; Hartmut Titze (1998): Deutsche Schulgeschichte von 1800 bis zur Gegenwart. Eine Einführung. Weinheim, München.

Holtappels, Heinz Günter; Sabine Müller; Frank Simon (2002): Schulprogramm als Instrument der Schulentwicklung. Inhaltsanalyse aller Hamburger Programmtexte. In: Die Deutsche Schule 2, 217-233.

Hurrelmann, Klaus (1996): Das deutsche Schulsystem privatisiert sich. In: Pädagogik 9, 35-39.

Inkeles, A. (1979): National Differences in Scholastic Performance. In: Comparative Education Review 23, 386-407.

Kaboolian, Linda (2000): Quality Comes to the Public Sector. In: Robert E. Cole; W. Richard Scott (Hg.): The Quality Movement und Organization Theory. Thousand Oaks, 131-153.

Kade, Jochen (1997): Vermittelbar/nicht-vermittelbar. Vermitteln: Aneignen. Im Prozeß der Systembildung des Pädagogischen. In: Dieter Lenzen; Niklas Luhmann (Hg.): Bildung und Weiterbildung im Erziehungssystem. Frankfurt a.M., 30-70.

Karakasoglo, Yasemin; Wolfgang Nieke (2002): Benachteiligung durch kulturelle Zugehörigkeit? In: Michael Weegen u.a. (Hg.): Bildungsforschung durch Politikberatung. Schule, Hochschule und Berufsbildung an der Schnittstelle von Erziehungswissenschaft und Politik. Weinheim, München, 199-235.

Keiner, Edwin u.a. (2000): Discourses on Education Governance and/or Social Exclusion and Inclusion in Political Parties in Germany. In: Sverker Lindblad; Thomas S. Popkewitz (Hg.): Public Discourses on Education Governance and Social Integration and Exclusion. Analyses of Policy Texts in European Contexts. Uppsala Reports on Education 36, 55-79.

Kempfert, Guy; Hans-Günter Rolff (2000): Pädagogische Qualitätsentwicklung. Ein Arbeitsbuch für Schule und Unterricht. Weinheim, Basel.

Klemm, Klaus (1997): Geld - Macht - Zeit. In: Manfred Böttcher; Horst Weishaupt; Manfred Weiß (Hg.): Wege zu einer neuen Bildungsökonomie. Pädagogik und Ökonomie auf der Suche nach Ressourcen und Finanzierungskonzepten. Weinheim, München, 98-104. 
Klippert, Heinz (1994): Methoden-Training. Übungsbausteine für den Unterricht. Weinheim, Basel.

Klippert, Heinz (1995): Kommunikations-Training. Übungsbausteine für den Unterricht. Weinheim, Basel.

Klippert, Heinz (1998): Teamentwicklung im Klassenraum. Übungsbausteine für den Unterricht. Weinheim, Basel.

Klippert, Heinz (2000): Pädagogische Schulentwicklung. Planungs- und Arbeitshilfen zur Förderung einer neuen Schulkultur. Weinheim, Basel.

Klippert, Heinz (2001): Eigenverantwortliches Arbeiten und Lernen. Bausteine für den Fachunterricht. Weinheim, Basel.

Köller, Olaf; Jürgen Baumert; Wilfried Bos (2001): TIMSS - Third International Mathematics and Science Study. In: Franz E. Weinert (Hg.): Leistungsmessungen in Schulen. Weinheim, Basel, 269-284.

König, Klaus (2001): „Public Sector Management“ oder Governance. Steuerungs- und Strukturierungsprobleme öffentlicher Verwaltung. In: Hans-Peter Burth; Axel Görlitz (Hg.): Politische Steuerung in Theorie und Praxis. Baden-Baden, 293-314.

Konzendorf, Götz (1998): Verwaltungsmodernisierung in den Ländern. Überblick und Einblicke. Speyerer Forschungsberichte Nr. 187. Speyer.

Krüger, Heinz-Hermann; Jan-Hendrik Olbertz (Hg.) (1997): Bildung zwischen Staat und Markt. Opladen.

Krumm, Volker (1996): Über die Vernachlässigung der Eltern durch Lehrer und Erziehungswissenschaft. Plädoyer für eine veränderte Rolle der Lehrer bei der Erziehung der Kinder. In: Achim Leschinsky u.a. (Hg.): Die Institutionalisierung von Lehren und Lernen. Zeitschrift für Pädagogik, 34. Beiheft, 119-137.

Kuper, Harm (2003): Das Thema ,Organisation“ in den Arbeiten Luhmanns über das Erziehungssystem. Ms. Berlin.

Lange, Hermann (2000): Die Schule gehört den Lehrerinnen und Lehrern! - Wirklich nur ihnen? Eine Antwort auf Annemarie von der Groeben. In. Die Deutsche Schule 4, 407-413.

Lenhardt, Gero (1984): Schule und bürokratische Rationalität. Frankfurt a.M.

Lepsius, M. Rainer (1997): Institutionalisierung und Deinstitutionalisierung von Rationalitätskriterien. In: Gerhard Göhler (Hg.): Institutionenwandel. Leviathan, Sonderheft. Opladen, 57-69.

Leschinsky, Achim; Peter-Martin Roeder (1976): Schule im historischen Prozeß. Zum Wechselverhältnis von institutioneller Erziehung und gesellschaftlicher Entwicklung. Frankfurt a.M.

Link, Jörg-W.; Axel Nath; Heinz-Elmar Tenorth (2003) : Bildungssystem im Wandel. Zwischen Eigendynamik, Politik und Pädagogik. In: Zeitschrift für Pädagogik 1, 17.

Lockwood, David (1979): Soziale Integration und Systemintegration. In: Wolfgang Zapf (Hg.): Theorien des sozialen Wandels. Regensburg, 124-137.

Lohmann, Ingrid; Rainer Rilling (Hg.) (2002): Die verkaufte Bildung. Kritik und Kontroversen zur Kommerzialisierung von Schule, Weiterbildung, Erziehung und Wissenschaft. Opladen.

Lorenzen, Michael (2002): Charter Schools: Are They Needed? Looking at Both Sides of the Debate. In: URL: http://www.libraryreference.org/charter.html.

Lowe, Roy (1997): Schooling and Social Change 1964-1990. London, New York.

Luhmann, Niklas (1987): Soziale Systeme. Grundriß einer allgemeinen Theorie. Frankfurt a.M.

Luhmann, Niklas (1993): Das Recht der Gesellschaft. Frankfurt a.M.

Luhmann, Niklas (2002): Das Erziehungssystem der Gesellschaft. Frankfurt a.M. 
Luhmann, Niklas; Karl Eberhard Schorr (1979): Reflexionsprobleme im Erziehungssystem. Frankfurt a.M.

Luhmann, Niklas; Karl Eberhard Schorr (1982): Das Technologiedefizit der Erziehung und die Pädagogik. In: dies. (Hg.): Zwischen Technologie und Selbstreferenz. Fragen an die Pädagogik. Frankfurt a.M., 11-40.

Lundgreen, Peter (2003): ,Bildungspolitik' und ,Eigendynamik' in den Wachstumsschüben des deutschen Bildungssystems seit dem 19. Jahrhundert. In: Zeitschrift für Pädagogik 1, 34-41.

Maag Merki, Katharina; Xaver Büeler (2002): Schulautonomie in der Schweiz. Eine Bilanz auf empirischer Basis. In: Hans-Günter Rolff u.a. (Hg.): Jahrbuch der Schulentwicklung. Daten, Beispiele und Perspektiven. Band 12. Weinheim, München, 131-161.

Maas, Michael (1998): Geschichte, Mythen und Erfolge der Alternativschulbewegung. Versuch einer selbstkritischen Zwischenbilanz. In: Manfred Borchert; Michael Maas (Hg.) (1998): Freie Alternativschulen. Die Zukunft der Schule hat schon begonnen. Bad Heilbrunn, 15-35.

Mackert, Jürgen (1998): Kampf um Zugehörigkeit. Nationale Staatsbürgerschaft als Modus sozialer Schließung. Opladen, Wiesbaden.

Maeder, Christoph (2002): ,New Public Management“ in der Schweiz. Zur Dramaturgie und Pragmatik eines moralischen Kreuzzugs. In: Hans-Georg Soeffner; Dirk Tänzler (Hg.): Figurative Politik. Zur Performanz der Macht in der modernen Gesellschaft. Opladen, 211-224.

Magotsiu-Schweizerhof, Eumorfia (2000): Zur deutschen Debatte um die Schulautonomie und die Folgen für die Chancengleichheit von Migrantenkindern. In: FrankOlaf Radtke; Manfred Weiß (Hg.): Schulautonomie, Wohlfahrtsstaat und Chancengleichheit. Ein Studienbuch. Opladen, 225-255.

Maritzen, Norbert (2001): Schulforschung und Bildungspolitik in Hamburg: Mühen einer Schulverwaltung, wissenschaftlich aufgeklärt zu handeln. In: Klaus Jürgen Tillmann; Witlof Vollstädt (Hg.) : Politikberatung durch Bildungsforschung. Das Beispiel Schulentwicklung in Hamburg. Opladen, S. 33-58.

Melzer, Werner (1997): Elternhaus und Schule - ein Beispiel misslingender und gelingender gesellschaftlicher Partizipation von Familien. In: Lothar Böhnisch; K. Lenz (Hg.): Familien. Weinheim, München, 299-310.

Merton, Robert K. (1967): On Sociological Theories of the Middle Range. In: ders.: On Theoretical Sociology. New York, 39-72.

Merton, Robert K. (1968): The Matthew Effect in Science. In: Science 159, 56-63.

Messner, Rudolf (1998): Pädagogische Schulentwicklung zwischen neuer Lernkultur und wachsendem Modernisierungsdruck. In: Schweizer Beiträge zur Lehrerbildung 1, 81-110.

Messner, Rudolf (2002): Das Bildungskonzept von PISA als Teil einer globalen gesellschaftlichen Neuorientierung. In: Erziehung und Unterricht. Österreichische Pädagogische Zeitschrift 7-8, 841-848.

Meyer, Hilbert; G. Ulrich (1996): Was ist eine lernende Schule? Oldenburger VorDrucke 276. Oldenburg: Carl von Ossietzky-Universität.

Meyer, J.W. u.a. (1977): The World Education Revolution, 1950-1970. In: Sociology of Education 50, 242-258.

Mitter, Wolfgang (1996): Staat und Markt im internationalen Bildungswesen aus historisch-vergleichender Sicht - Gegner, Konkurrenten, Partner? In: Dietrich Benner u.a. (Hg.): Bildung zwischen Staat und Markt. Beiträge zum 15. Kongreß der Deutschen Gesellschaft für Erziehungswissenschaft. Zeitschrift für Pädagogik, 35. Beiheft. Weinheim, Basel, 125-142. 
Molnar, Alex (1996): Giving Kids the Business. The Commercialisation of America's Schools. Boulder, Colorado.

Müller, Sabine (1996): Schulentwicklung und Schülerpartizipation. Möglichkeiten der Beteiligung von Schülerinnen und Schülern an innerschulischen Innovationsprozessen. Neuwied.

Münch, Richard (1992): Die Struktur der Moderne. Frankfurt a.M.

Nath, Axel (2003): Bildungswachstum und äußere Schulreform im 19. und 20. Jahrhundert. Individualisierung der Bildungsentscheidung und Integration der Schulstruktur. In: Zeitschrift für Pädagogik 1, 8-25.

Negt, Oskar (1997): Kindheit und Schule in einer Welt der Umbrüche. Göttingen.

Oelkers, Jürgen (1989): Reformpädagogik. Eine kritische Dogmengeschichte. Weinheim, München.

Oelkers, Jürgen (2000a): Schule und Bildung im Prozess der Globalisierung. Vortrag Zürich, 22. März 2000.

Oelkers, Jürgen (2000b): Schulreform und Schulkritik. Würzburg.

Ozouf, Jacques (1967): Nous, les maîtres d'école. Autobiographies d'instituteurs de la Belle Époque. Paris.

Parsons, Talcott (1968): Die Schulklasse als soziales System. In: ders: Sozialstruktur und Persönlichkeit. Frankfurt a.M.

Parsons, Talcott (1972): Das System moderner Gesellschaften. Weinheim, München.

Paulsen, Friedrich $\left({ }^{3} 1906\right)$ : Das deutsche Bildungswesen in seiner geschichtlichen Entwicklung. Berlin.

Picht, Georg (1964): Die deutsche Bildungskatastrophe. Analyse und Dokumentation. Olten.

Preuss-Lausitz, Ulf (1995): Private und Freie Schulen - Besser als die öffentliche Schule? Zur Privatisierung des Bildungswesens in den Neunziger Jahren. In: Die Deutsche Schule 4, 447-462.

Preuss-Lausitz, Ulf (1997): Soziale Ungleichheit, Integration und Schulentwicklung. Zu den Qualitätskriterien bei der „Entstaatlichung“ von Schule. In: Zeitschrift für Pädagogik 4, 583-596.

Radtke, Frank-Olaf (2000): Einleitung. In: Frank-Olaf Radtke; Manfred Weiß (Hg.): Schulautonomie, Wohlfahrtsstaat und Chancengleichheit. Ein Studienbuch. Opladen, 13-31.

Radtke, Frank-Olaf; Manfred Weiß (Hg.) (2000): Schulautonomie, Wohlfahrtsstaat und Chancengleichheit. Ein Studienbuch, Opladen.

Ravitch, Diane (1983): The Troubled Crusade - American Education 1945-1980. New York.

Ravitch, Diane (2000): Left Back. A Century of Failed School Reforms. New York.

Reh, Sabine; Carla Schelle (1999): Biographieforschung in der Schulpädagogik. Aspekte biographisch orientierter Lehrerforschung. In: Heinz-Hermann Krüger; Winfried Marotzki (Hg.): Handbuch erziehungswissenschaftliche Biographieforschung. Opladen, 373-390.

Richter, Ingo (1999): Die sieben Todsünden der Bildungspolitik. München, Wien.

Ringer, Fritz K. (1979): Education and Society in Modern Europe. Bloomington.

Rolff, Hans-Günter (1995): Wandel durch Selbstorganisation. Theoretische Grundlagen und praktische Hinweise für eine bessere Schule. Weinheim, München.

Rolff, Hans-Günter (1998): Entwicklung von Einzelschulen - viel Praxis, wenig Theorie und kaum Forschung. Ein Versuch, Schulentwicklung zu systematisieren. In: Hans-Günter Rolff u.a. (Hg.): Jahrbuch der Schulentwicklung. Daten, Beispiele und Perspektiven. 10. Band. Weinheim, München, 295-326.

Sarason, Seymour B. (1998): Charter Schools - Another Flawed Educational Reform? New York. 
Schedler, Kuno; Isabella Proeller (2000): New Public Management. Bern u.a.

Schimank, Uwe (1995): Hochschulforschung im Schatten der Lehre. Frankfurt a.M., New York.

Schimank, Uwe (1996): Theorien gesellschaftlicher Differenzierung. Opladen.

Schimank, Uwe (1998): Funktionale Differenzierung und soziale Ungleichheit. In: Hans-Joachim Giegel (Hg.): Konflikt in modernen Gesellschaften. Frankfurt a.M., 61-88.

Schimank, Uwe (2000): Handeln und Strukturen. Einführung in die akteurtheoretische Soziologie. Weinheim, München.

Schimank, Uwe (2001): Teilsysteminterdependenzen und Inklusionsverhältnisse. Ein differenzierungstheoretisches Forschungsprogramm zur System- und Sozialintegration der modernen Gesellschaft. In: Eva Barlösius; Hans-Peter Müller; Steffen Sigmund (Hg.): Gesellschaftsbilder im Umbruch. Soziologische Perspektiven in Deutschland. Opladen, 109-113.

Schimank, Uwe (2002a): Neue Steuerungssysteme an den Hochschulen. Förderinitiative des BMBF: Science Policy Studies. Abschlussbericht, 31. 5. 2002. Ms. Hagen.

Schimank, Uwe (2002b): Theoretische Modelle sozialer Strukturdynamiken: Ein Gefüge von Generalisierungsniveaus. In: Renate Mayntz (Hg.): Akteure - Mechanismen - Modelle. Zur Theoriefähigkeit makro-sozialer Analysen. Frankfurt a.M., New York, 151-178.

Schimank, Uwe; Ute Volkmann (1999): Gesellschaftliche Differenzierung. Bielefeld.

Schlömerkemper, Jörg (1986): Bildung für alle. Über das Verhältnis von Egalität und Bildung. In: Die Deutsche Schule 78, 405-416.

Stichweh, Rudolf (1988): Inklusion in Funktionssysteme der modernen Gesellschaft. In: Renate Mayntz u.a. (Hg.): Differenzierung und Verselbständigung. Frankfurt a.M., 261-293.

Stichweh, Rudolf (1994): Soziologische Differenzierungstheorie als Theorie des sozialen Wandels. In: Jürgen Miethke; Klaus Schreiner (Hg.): Sozialer Wandel im Mittelalter. Sigmaringen, 29-43.

Strauss, Anselm; Juliet Corbin (1996): Grounded Theory. Grundlagen Qualitativer Sozialforschung. Weinheim.

Tenorth, Heinz-Elmar (2003): Wachstumsschübe des Bildungssystems und Konjunkturen seiner Thematisierung. Über Kontinuität und Variation pädagogischer Reflexion. In: Zeitschrift für Pädagogik 1, 69-85.

Terhart, Ewald (1986): Organisation und Erziehung. Neue Zugangsweisen zu einem alten Dilemma. In: Zeitschrift für Pädagogik 2, 205-223.

Terhart, Ewald (1987): Kommunikation im Kollegium. In: Die Deutsche Schule 79, 440-450.

Terhart, Ewald (2001a): Bildungsforschung, Bildungsadministration, Bildungswirklichkeit: eine systematische Annäherung. In: Klaus Jürgen Tillmann; Witlof Vollstädt (Hg.): Politikberatung durch Bildungsforschung. Das Beispiel Schulentwicklung in Hamburg. Opladen, 17-32.

Terhart, Ewald (2001b): Lehrerberuf und Lehrerbildung. Forschungsbefunde, Problemanalysen, Reformkonzepte. Weinheim, Basel.

Terhart, Ewald (2001c): Schule und Selektion: Die Perspektive der Lehrer. In: Wolfgang Melzer; Uwe Sandfuchs (Hg.): Was Schule leistet. Funktionen und Aufgabe von Schule. Weinheim, München, 87-110.

Terhart, Ewald (2002): Nach PISA. Bildungsqualität entwickeln. Hamburg.

Tillmann, Klaus Jürgen; Witlof Vollstädt (Hg.) (2001): Politikberatung durch Bildungsforschung. Das Beispiel Schulentwicklung in Hamburg. Opladen.

Tillmann, Klaus-Jürgen (Hg.) (1987): Schultheorien. Hamburg. 
Timmermann, Dieter (1987): Bildungsmärkte oder Bildungsplanung. Eine kritische Auseinandersetzung mit zwei alternativen Steuerungssystemen mit ihren Implikationen für das Bildungssystem. Mannheim.

Tyrell, Hartmann (1987): Die „Anpassung“ der Familie an die Schule. In: Jürgen Oelkers; Heinz-Elmar Tenorth (Hg.): Erziehungswissenschaft und Systemtheorie. Weinheim, Basel, 102-125.

Vatter, Adrian (2002): Kantonale Demokratien im Vergleich. Entstehungshintergründe, Interaktionen und Wirkungen politischer Institutionen in den Schweizer Kantonen. Opladen.

Vogel, Johann Peter (1991): Schulen in freier Trägerschaft als Beispiel der Balance von Autonomie und öffentlicher Verantwortung. In. Bildung und Erziehung 4, 427-435.

Vogel, Johann Peter (1995): Verfassungsrechtliche Bemerkungen zur Verselbständigung der Schule. In. Zeitschrift für Pädagogik 1, 39-48.

Wagner, Peter (1995): Soziologie der Moderne. Frankfurt a.M., New York.

Watzlawick, Paul u.a. (2000): Menschliche Kommunikation. Formen, Störungen, Paradoxien. Bern (10. unveränderte Auflage).

Weber, Max (1972): Wirtschaft und Gesellschaft. Grundriß der verstehenden Soziologie. Tübingen.

Weegen, Michael u.a. (Hg.) (2002): Bildungsforschung durch Politikberatung. Schule, Hochschule und Berufsbildung an der Schnittstelle von Erziehungswissenschaft und Politik. Weinheim, München.

Weiß, Manfred (1993): Der Markt als Steuerungssystem im Schulwesen? In: Zeitschrift für Pädagogik, 71-84.

Weiß, Manfred (2000): Entwicklung und Evaluation von Quasi-Märkten. In: Jürgen Oelkers (Hg.): Futures of Education. Bern.

Weiß, Manfred (2002): Quasi-Märkte als Steuerungsregime im Schulbereich. Vortrag auf dem Kongress der Deutschen Gesellschaft für Soziologie, Sektion Bildung und Erziehung, am 11. Oktober 2002 in Leipzig. In: URL: http://www.soziologie.de/sektionen/b01/beitraege1.pdf.

Weiß, Manfred; Brigitte Steinert (1994): Privatisierungstendenzen im Bildungsbereich. Internationale Perspektiven. In: Die Deutsche Schule 4, 439-456.

Wenning, Norbert (1999): Vereinheitlichung und Differenzierung. Zu den „wirklichen“ gesellschaftlichen Funktionen des Bildungswesens im Umgang mit Gleichheit und Verschiedenheit. Opladen.

Zapf, Wolfgang (2001): Modernisierung - Dimensionen eines Begriffs. In: Hermann Hill (Hg.): Modernisierung - Prozess oder Entwicklungsstrategie? Frankfurt a.M., 13-22. 


\section{Quellennachweis}

\section{Heike Ackermann}

Eltern - Ratgeber für Schulqualität?

Über die Rolle der Eltern im Prozeß der Schulentwicklung

Aus: Heike Ackermann; Jochen Wissinger (Hg.) (1998): Schulqualität managen.

Von der Verwaltung der Schule zur Entwicklung von Schulqualität. Neuwied:

Luchterhand, 120-134.

\section{S. Karin Amos}

Schulentwicklung und soziale Ungleichheit -

Was lässt sich am amerikanischen Beispiel beobachten?

Originalbeitrag.

\section{Konstantin Bähr}

Die Rolle von Schulleistungstests für das Qualitätsmanagement im Bildungswesen, in Schulen und Klassenzimmern

Referat an der Plenarversammlung der CODICRE- $\mathrm{CH}^{1}$, Institut de recherche et de documentation pédagogique (IRDP). Neuchâtel, 21. November 2002.

\section{Johannes Bastian}

Pädagogische Schulentwicklung -

Von der Unterrichtsreform zur Entwicklung der Einzelschule

Aus: Pädagogik, Heft 2, 1997, 6-11.

\section{Thomas Bethge}

Zum Umgang mit den Ergebnissen von TIMSS

Aus: Die Deutsche Schule, Heft 2, 1999, 178-181.

\section{Fritz Bohnsack}

Widerstand von Lehrern gegen Innovationen in der Schule

Aus: Die Deutsche Schule, Heft 1, 1995, 21-37.

\section{Pierre Bourdieu}

Die rechte und die linke Hand des Staates

Aus: ders. (1998): Gegenfeuer. Wortmeldungen im Dienste des Widerstands gegen die neoliberale Invasion. Konstanz: UVK Universitätsverlag, 12-21.

„Conférence suisse des directeurs/directrices de centres de développement scolaire et de recherche en éducation". 


\section{William Lowe Boyd}

Die Politik der freien Schulwahl und marktorientierte Schulreform in Großbritannien und den Vereinigten Staaten. Wie erklären sich die Unterschiede?

Aus: Zeitschrift für Pädagogik, Heft 1, 1993, 53-69 (übersetzt von Annette Roeder).

\section{Sylvain Broccolichi, Françoise CEuvrard}

Das Räderwerk

Aus: Pierre Bourdieu u.a. (Hg.) (1997): Das Elend der Welt. Zeugnisse und Diagnosen alltäglichen Leidens an der Gesellschaft. Konstanz: UVK Universitätsverlag, 575-585.

\section{Thomas Brüsemeister}

Lehrerbiographien in der Schulmodernisierung - Modernisierungspfade Steuerungsschwierigkeiten

Orginalbeitrag.

Zur Kopplung von Lehrkräften und Schulorganisation

Orginalbeitrag.

\section{Ernst Buschor}

Schulen in erweiterter Verantwortung -

Die Schweizer Anstrengungen und Erfahrungen

Aus: Herman Avenarius u.a. (Hg.) (1998): Schule in erweiterter Verantwortung. Positionsbestimmungen aus erziehungswissenschaftlicher, bildungspolitischer und verfassungsrechtlicher Sicht. Beiträge zur Schulentwicklung. Neuwied: Luchterhand, 67-88.

\section{Katrin Dörner}

Ethnische Minderheiten im niederländischen Schulwesen

Von der Autorin überarbeiteter Auszug aus der unveröffentlichten gleichnamigen Magisterarbeit, 2000. Ms. Hagen.

\section{Helmut Fend}

\section{Schulkultur und Schulqualität}

Aus: Achim Leschinsky (Hg.) (1996): Die Institutionalisierung von Lehren und Lernen. Beiträge zu einer Theorie der Schule. Zeitschrift für Pädagogik, 34. Beiheft. Weinheim, Basel: Beltz, 85-97.

Schulkultur als Zusammenspiel der Teilkulturen von Lehrern, Schülern und Eltern - Schisma oder Partnerschaft Aus: ders. (1998): Qualität im Bildungswesen. Schulforschung zu Systembedingungen, Schulprofilen und Lehrerleistung. Weinheim, München: Juventa, 187195. 
Annemarie von der Groeben

Wo liegen die Wurzeln von Schulqualität? Eine Antwort auf Hermann Lange Aus: Die Deutsche Schule, Heft 3, 2000, 339-354.

\section{Helmut Heid}

Chancengleichheit unter den Bedingungen sozialstruktureller Ungleichheit.

Zur gesellschaftlichen Funktion eines Legitimationsmusters

Aus: Die Deutsche Schule, Beiheft 6, 2000, 87-92.

\section{Wulf Hopf}

Chancengleichheit und Individualisierung.

Zur Revision eines bildungspolitischen Ziels

Aus: Die Deutsche Schule, Beiheft 6, 2000, 93-112.

\section{Guy Kempfert, Hans-Günter Rolff}

Qualitätsarbeit als Schulentwicklung: Praxisfelder und Methoden

Aus: dies. (2000): Pädagogische Qualitätsentwicklung. Ein Arbeitsbuch für Schule und Unterricht. Weinheim, Basel: Beltz, 19-72.

\section{Heinz Klippert}

Schule entwickeln - Unterricht neu gestalten.

Plädoyer für ein konzentriertes Innovationsmanagement

Aus: Pädagogik, Heft 2, 1997, 12-17.

\section{Rolf-Torsten Kramer, Werner Helsper}

SchülerInnen zwischen Familie und Schule - systematische Bestimmungen

Aus: dies. (2000): SchülerInnen zwischen Familie und Schule - Systematische Bestimmungen, methodische Überlegungen und biographische Rekonstruktionen. In: Heinz-Herrman Krüger; Hartmut Wenzel (Hg.): Schule zwischen Effektivität und sozialer Verantwortung. Opladen: Leske + Budrich, 201-234.

\section{Hermann Lange}

Qualitätssicherung in Schulen

Aus: Die Deutsche Schule, Heft 2, 1999, 144-159.

\section{Christoph Maeder}

Brauchbare Artefakte. Statistiksoftware für das Pflegemanagement im Spital als das Produkt ethnographischer Arbeit

Aus: Thomas S. Eberle; Jean Widmer (Hg.) (2000): Interpretative Soziologien. Sonderband der Schweizerischen Zeitschrift für Soziologie, 637-662.

\section{Norbert Maritzen}

Schule zwischen Staat und Markt? Für kritische Genauigkeit beim Reden über Schulautonomie - eine Antwort auf Frank-Olaf Radtke Aus: Die Deutsche Schule, Heft 3, 1997, 292-305. 
Schulprogramm und Rechenschaft - eine schwierige Beziehung

Aus: Heike Ackermann; Jochen Wissinger (Hg.) (1998): Schulqualität managen. Von der Verwaltung der Schule zur Entwicklung von Schulqualität. Neuwied: Luchterhand, 135-145.

\section{Wolfgang Melzer, Sabine Al-Diban}

Vermittlung von Fachleistungs-, Sozial- und Selbstkompetenzen

als zentrale Bildungsaufgabe von Schule

Aus: Wolfgang Melzer; Uwe Sandfuchs (Hg.) (2001): Was Schule leistet. Funktionen und Aufgaben von Schule. Weinheim, München: Juventa, 37-64.

\section{Rudolf Messner}

Das Bildungskonzept von PISA als Teil einer globalen gesellschaftlichen Neuorientierung

Aus: Die Deutsche Schule, Heft 3, 2002, 290-294.

\section{Jürgen Oelkers}

Wie lernt ein Bildungssystem?

Aus: Die Deutsche Schule, Heft 1, 1995, 4-20.

\section{Schulen in erweiterter Verantwortung -}

Eine Positionsbestimmung aus erziehungswissenschaftlicher Sicht

Aus: Hermann Avenarius u.a. (Hg.) (1998): Schule in erweiterter Verantwortung. Positionsbestimmungen aus erziehungswissenschaftlicher, bildungspolitischer und verfassungsrechtlicher Sicht. Beiträge zur Schulentwicklung. Neuwied: Luchterhand, 23-35.

Unterricht und Effizienz: Probleme der Schulentwicklung Vortrag auf dem 11. Schweizerischen Tag für Mathematik und Unterricht am 16. Mai 2000 in der Kantonsschule Wohlen.

\section{Frank-Olaf Radtke}

Schulautonomie: Bildungspolitisches Ringen um Definitionsmacht

Aus: ders.: Schulautonomie, Sozialstaat und Chancengleichheit. Wofür ist Bildungspolitik (noch) verantwortlich? In: Die Deutsche Schule, Heft 3, 1997, 278-291.

\section{Ingo Richter}

Entscheidungsstrukturen für Bildungsfragen in offenen Gesellschaften

Aus: Zeitschrift für Pädagogik, Heft 2, 1994, 181-191.

Die Öffentliche Schule im Umbau des Sozialstaates

Aus: Achim Leschinsky u.a. (Hg.) (1996): Die Institutionalisierung von Lehren und Lernen. Zeitschrift für Pädagogik, 34. Beiheft. Weinheim, Basel: Beltz, 107-118. 


\section{Uwe Schimank}

Teilsysteminterdependenzen und Inklusionsverhältnisse.

Ein differenzierungstheoretisches Forschungsprogramm zur System- und Sozialintegration der modernen Gesellschaft

Aus: Eva Barlösius; Hans-Peter Müller; Steffen Sigmund (Hg.) (2001): Gesellschaftsbilder im Umbruch. Soziologische Perspektiven in Deutschland. Opladen: Leske + Budrich, 109-113.

\section{Gudrun Schönknecht}

Lehrkräfte und Innovation

Aus: dies. (1997): Innovative Lehrerinnen und Lehrer. Berufliche Entwicklung und Berufsalltag. Weinheim: Beltz, 42-57.

\section{Ewald Terhart}

Qualität und Qualitätssicherung im Schulsystem:

Hintergründe - Konzepte - Probleme

Aus: Zeitschrift für Pädagogik, Heft 6, 2000, 809-829.

\section{Horst Weishaupt}

Die Situation des Schulwesens im Kontext der veränderten Wahrnehmung öfentlicher Aufgaben durch den Staat

Aus: Heike Ackermann; Jochen Wissinger (Hg.) (1998): Schulqualität managen. Von der Verwaltung der Schule zur Entwicklung von Schulqualität. Neuwied: Luchterhand, 23-33.

\section{Jochen Wissinger}

Rolle und Aufgaben der Schulleitung bei der Qualitätssicherung und -entwicklung von Schulen

Aus: Zeitschrift für Pädagogik, Heft 6, 2000, 851-865.

\section{Thomas Ziehe}

Adieu, 70er Jahre! Jugendliche und Schule in der zweiten Modernisierung Aus: Pädagogik, Heft 7-8, 1996, 35-39. 


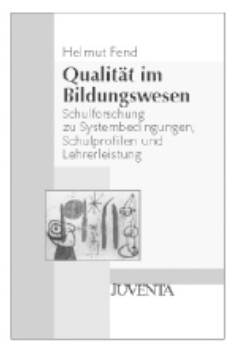

\section{Helmut Fend}

\section{Qualität im}

Bildungswesen

Schulforschung $z u$

Systembedingungen, Schulprofilen

und Lehrerleistung

2. Auflage 2001, 398 S., br.

$€ 25,-; \operatorname{sFr} 45,00$ (1048 9)

Der Autor nutzt die Grundlage von 25 Jahren eigener Schulforschung, um die Konturen von Qualität im Bildungswesen zu schärfen. Über die Beschreibung von Schulen in verschiedenen Ländern wird plastisch sichtbar, wo Schulen Lebensräume des Lernens und Lebens sind.

\section{Wolfgang Böttcher \\ Kann eine ökonomi- sche Schule auch eine pädagogische sein?}

Schulentwicklung zwischen Neuer Steuerung, Organisation,

Leistungsevaluation und Bildung

Juventa Materialien. 2002, $336 \mathrm{~S}$., br. $€ 24,50 ; s F r 44,50(1090 X)$

Sowohl einer Analyse der Schule als Organisation als auch der aktuellen Qualitätsdiskussion liegen betriebswirtschaftliche Überlegungen $\mathrm{zu}$ grunde. Die ökonomische Analyse einiger paradigmatischer Anwendungsfelder zeigt, dass ein Dialog zwischen ökonomischer Organisation und Pädagogik möglich wird.

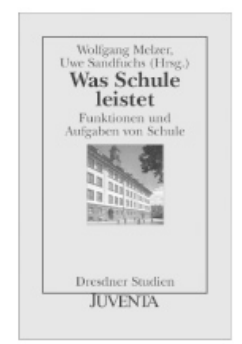

Wolfgang Melzer, Uwe Sandfuchs (Hrsg.)

\section{Was Schule leistet}

Funktionen und Aufgaben von Schule

Dresdner Studien, hrsg. von der Fakultät Erziehungswissenschaften der TU Dresden. 2001, $272 \mathrm{~S}$., br. $€ 20,50 ; s F r 37,50(13100)$

Das mittelmäßige Abschneiden bei einer großen internationalen Vergleichsstudie im Fach Mathematik hat in der Bundesrepublik zu einem bildungspolitischen Schock geführt und eine Debatte über die Schule der Zukunft ausgelöst. Angesichts dieser Situation wird in diesem Band der Versuch unternommen, die Funktionen und Aufgaben von Schule des 21. Jahrhunderts neu zu umreißen.

OlafKöller, Ulrich Trautwein (Hrsg.)

\section{Schulqualität und Schülerleistung}

Evaluationsstudie über innovative Schulentwicklung an fünf hessischen Gesamtschulen

Juventa Materialien, 2003, 240 S., br. $€ 19,50 ; \operatorname{sFr} 33,90$ (1658 4)

Fünf hessische Gesamtschulen, die zuvor an keiner Schulleistungsstudie teilgenommen hatten, wollten in Form einer empirischen Untersuchung Rechenschaft über die Erträge ihrer pädagogischen Programme ablegen.

Juventa Verlag, Ehretstraße 3, D-69469 Weinheim

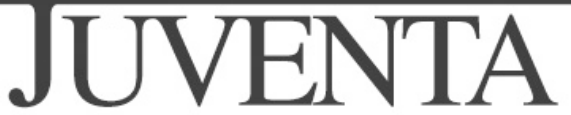

